UNIVERSIDADE DE SÃO PAULO

FACULDADE DE ECONOMIA, ADMINISTRAÇÃO E CONTABILIDADE DEPARTAMENTO DE ADMINISTRAÇÃO

PROGRAMA DE PÓS-GRADUAÇÃO EM ADMINISTRAÇÃo

\title{
O TORCEDOR COMO VANTAGEM COMPETITIVA: UMA ANÁLISE SOB A ÓTICA DA TRANSFERÊNCIA DA LEALDADE
}

Fernando De Andrade Franco Malagrino

Orientador: Professor. Dr. Paulo Roberto Feldmann

SÃO PAULO 
Prof. Dr. Marco Antonio Zago

Reitor da Universidade de São Paulo

Prof. Dr. Adalberto Américo Fischmann

Diretor da Faculdade de Economia, Administração e Contabilidade

Prof. Dr. Roberto Sbragia

Chefe do Departamento de Administração

Prof. Dr. Moacir de Miranda Oliveira Júnior

Coordenador do Programa de Pós-Graduação em Administração 


\section{O TORCEDOR COMO VANTAGEM COMPETITIVA: UMA ANÁLISE SOB A ÓTICA DA TRANSFERÊNCIA DA LEALDADE}

Tese apresentada ao Programa de Pós-Graduação em Administração do Departamento de Administração da Faculdade de Economia, Administração e Contabilidade da Universidade de São Paulo, como requisito parcial para a obtenção do título de Doutor em Ciências.

Orientador: Prof. Dr. Paulo Roberto Feldmann

Versão Original

SÃO PAULO 
FICHA CATALOGRÁFICA

Elaborada pela Seção de Processamento Técnico do SBD/FEA/USP

Malagrino, Fernando de Andrade Franco

O torcedor como vantagem competitiva: uma análise sob a ótica da transferência da lealdade / Fernando de Andrade Franco Malagrino. -- São Paulo, 2017.

290 p.

Tese(Doutorado) - Universidade de São Paulo, 2017.

Orientador: Paulo Roberto Feldmann.

1. Marketing esportivo 2. Economia do esporte 3. Gestão do esporte 4. Vantagem competitiva 5. Comportamento do consumidor 6. Transferência de lealdade I. Universidade de São Paulo.

Faculdade de Economia, Administração e Contabilidade. II. Título.

CDD - 338.43796 


\section{AGRADECIMENTOS}

Os agradecimentos de um trabalho de quatro anos são, para mim, uma das partes mais interessante deste tipo de trabalho. Por isso, sempre me interessei por ler os agradecimentos dos trabalhos de outros. Escrever uma tese é, na maioria dos momentos, um processo solitário. Mas, por mais estranho que possa parecer, impossível de ser realizado sem a ajuda de muitas pessoas.

De verdade, espero não esquecer ninguém, mas se alguém, ao ler os agradecimentos, sentir-se esquecido, fica aqui registrado, desde já, meu pedido de desculpas. É descaso da memória, não do coração.

Desde 2012, quando as primeiras ideias em torno deste trabalho começaram a ser formuladas, muita coisa mudou. A vida pessoal me trouxe uma série de amigos novos, além do crescimento da família. A vida profissional, com seus altos e baixos, foi como uma longa valsa. Enfim, impossível dizer que hoje, em 2017, sou a mesma pessoa.

Se tudo isso mudou, dá para imaginar o quanto esse trabalho "sofreu" ao longo destes 4 anos. Ao ter contato com mentes brilhantes, entre professores, colegas, alunos e amigos, o fluxo do conhecimento aumenta e as ideias se misturam. Cada informação nova vinha com uma interjeição de surpresa, sobretudo quando percebia que aquilo se encaixava no meu tema.

Mas chega um momento em que você tem que colocar um ponto final às reflexões mais gerais e traçar uma rota definitiva. E esse é um momento essencial no desenvolvimento do trabalho. Assim, as primeiras pessoas que agradeço são os professores que me ajudaram a definir esse caminho.

Primeiramente, obrigado ao meu orientador, o professor Paulo Roberto Feldman. Agradeço por, ainda em 2012, no processo seletivo, ter aceitado meu pré-projeto. Verdade que mudamos bastante coisa (para melhor), mas mantivemos sempre o mesmo objeto de estudo: esporte. Obrigado por acreditar nas minhas ideias e, principalmente, por direcioná-las de forma a poder concretizá-las. Obrigado pela autonomia dada. Essa confiança, desde o primeiro dia que sentamos para discutir meu projeto, foi fundamental para que eu pudesse escrever esse trabalho.

Tenho certeza de que esse trabalho também não teria acontecido sem a coorientação (mesmo que extraoficial) de dois professores: José Afonso Mazzon e. Thomas Brashear.

Prof. Mazzon, obrigado por me apresentar o "mundo encantado" dos métodos qualitativos. Por sua parceria nos momentos de loucura e por sua lucidez na hora de apontar meus equívocos. 
Prof. Thomas, até hoje não entendo o que passou pela sua cabeça para aceitar me orientar por um ano, mas o período em Amherst foi fundamental para que eu pudesse entender como a ciência funciona. Obrigado pela ajuda, incentivo, críticas, empurrões e xingamentos. Hoje sei que a ciência e as pesquisas devem ser universais.

Diversos outros professores também contribuíram, em maior ou menor grau, para colocar de pé (quase que literalmente) este projeto, e fica aqui meu muito obrigado a Roberto Sbragia e Nuno Fouto, pelos constantes empurrões; Diógenes Bido, pela paciência e pelas ideias; Roberto Palmero, pelas contribuições nos momentos difíceis; Elizabeth Miller, pelos valorosos ensinamentos a respeito do comportamento do consumidor; Janet Fink, pela ideia de utilizar a teoria do equilíbrio; Guy Masterman, pelas aulas a respeito de patrocínio esportivo e pelas "caipirinhas"; e Prof. Daniel Funk, pelo aprendizado a respeito das questões sobre lealdade do consumidor esportivo.

Aos amigos (e de certo modo professores) Thilo Kunkel e Kevin Snyder, agradeço pelo convívio, contribuições e ensinamento a respeito do esporte norte-americano. Obrigado por me abrirem as portas das casas vocês na hora do desespero. Ah, claro, não posso deixar de agradecer a Van, que na hora do aperto me possibilitou comer coxinha e pão na chapa.

As contribuições de uma turma de professores, que são grandes amigos, também merece reconhecimento: André Fagundes, Claudio Rocha, Elcio Santana, Filipe Quevedo, Patrícia Vance e Wagner Ladeira (o uso do sobrenome é para que todos reconheçam vocês). Saibam que as conversas, bate-papos, cafés e cervejas foram fundamentais para que as ideias pudessem sair da cabeça e ir para o papel.

Diversos alunos tornaram meu dia a dia mais divertido (às vezes, mais complicado). Citar todos seria impossível. Então citarei apenas aqueles que, diretamente ou indiretamente, acabei orientado e, com certeza, sendo orientado: Rui Marques, Geraldo Guimarães, Luana Hilário, Pedro Corat e Solange Pukaro. Valeu, de verdade.

Alguns amigos de curso também contribuíram bastante para me manter focado: David Rodrigues, Luis Eduardo Pilli e Rodolfo Ribeiro. Valeu pelas dicas, que não foram poucas.

Giuliana Isabella, quem diria que um email enviado pedindo a senha do Qualtrics daria nisso tudo, hein? Giu, de coração, meu muito obrigado pelo apoio incondicional, pelas ideias brilhantes e pelo ouvido amigo.

Izabelle Quezado, ou Isa (a piada é inevitável), obrigado demais por sua valiosa ajuda. Por me apresentar novas ideais, teorias e conceitos.

Aos amigos Ary Rocco, pé frio, mas parceiro; João Malaia (vulgo Joca), palmeirense, mas a gente não escolhe amigos pelo time (ou escolhe?); Alex Bourgeois, francês, mas gente 
boa (podia ser pior, podia ser argentino); Gustavo Calatrava, argentino, melhor não dizer mais nada, César Grafietti, pensei seriamente se incluía você aqui ou não; e Paulo Calçade, sem bullying por aqui. A vocês, meu obrigado pela amizade e pelos valorosos ensinamentos. Se essa turma ler até o fim essa tese, eles irão ver que absorvi muito do conhecimento de vocês. Valeu pelas discussões sobre gestão, governança e consumidor no esporte.

Ao amigo, sócio e parceiro Marcos Cardoso. Obrigado pelas horas "gastas". Nos bons e nos maus momentos. Na mesa da sala de aula e na mesa do bar.

A Anne Walton, Mario DePillis Jr. e Mario DePillis Sênior, por abrirem a porta da casa de vocês e me aceitarem em sua maravilhosa família. Os ensinamentos de vocês foram essências para minha sobrevivência em Amherst.

Reza Rajabi e Felipe Assef, saibam que vocês também foram incríveis. A vida ficou mais tranquilo em Amherst com a ajuda e amizade de vocês.

Aos irmãos que a vida me deu, ou melhor, deixou-me escolher: Alexandre Modonezzi, Educardo Calbucci e Rodrigo Benitez. Literalmente sem vocês eu não teria chegado até aqui. Obrigado por ajudar a segurar a barra quando a coisa apertou. Não existe forma de retribuir o que fizeram e fazem por mim, mas prometo tentar sempre.

Se a vida me deixou escolher alguns irmãos, ela também me presenteou com irmãs. Comecei a tese com uma irmã e termino com três (eu falei que a família aumentou). Arianne, obrigado pelo carinho. Paulinha, a caçula, muita coisa ainda para acontecer, não é?

Sem querer causar ciúmes, mas em especial a você, Laura. Lalá, obrigado por todos esses anos ao meu lado. Por me dar um suporte incrível nos momentos difíceis e por estar sempre pronta a ajudar. Logo mais vem a sua. Ah, fico na dúvida se a gente tem que agradecer a cunhado. Mas acho que o Marquinhos merece. Valeu pela ajuda, não só pessoal, mas acadêmica.

Obviamente não posso esquecer de agradecer à minha mãe. Pelo amor, carinho e compreensão dedicados em todos esses anos. Amo você, mãe.

Aqui, espero que os amigos entendam, mas seriam muitos nomes para citar. Então, obrigado aos pais dos "amiguinhos" da Bruna.

À Bia, amiga e parceira. Presente nos bons e maus momentos. Sempre incentivando e compreendendo (eu tentando compreender) os caminhos que decidir trilhar. Mesmo que eu, muitas vezes não demonstre, saiba que agradeço enormemente tudo que fez.

Por fim, a minha princesa. Antes de um muito obrigado, um pedido de desculpas. Foi duro ficar longe, mas a causa foi boa e logo mais será a sua vez de ir. Obrigado, Bruna, pelo 
carinho, abraços, beijos e cócegas. Que nossas segundas-feiras de pai e filha possam se repetir ao longo de nossas vidas. Papai te ama muito.

Ah, não posso esquecer de agradecer aos mais de 1.500 respondentes que me auxiliaram nessa pesquisa. Se não fosse por vocês, isso aqui não seria possível mesmo! Obrigado.

À banca de defesa deixarei para agradecer após a defesa.

Ufa, agora acabou. Divirtam-se lendo, pois eu me diverti muito (de verdade) pesquisando e escrevendo. Que essa tese possa ser um raio de sol na vida de vocês, como os raios de sol que foram na minha... 


\section{RESUMO}

A indústria do esporte tem despertado cada vez mais o interesse de acadêmicos e profissionais das mais diversas áreas. Não só pela importância social que o esporte sempre teve no mundo, mas agora, também, pela importância econômica que essa indústria vem alcançado. O esporte deixou, há tempos, de ser apenas uma atividade de lazer. Se, para o público, ele ainda o é, para aqueles que trabalham nele, é claramente uma atividade de negócios. E, para disputar o jogo dentro das quatros linhas é necessário ter um time competitivo fora delas. Neste trabalho, consideramos as equipes esportivas como organizações e analisamo-las como firmas, com sua estrutura organizacional estreitamente relacionada à sua forma de apresentação ao público consumidor. Assumimos como premissa que essas organizações (times) não devem ser apenas organizadas como um win-maximizer, mas como um profit-maximizing. Neste sentido, o patrocínio vem ganhando cada vez mais importância na indústria do esporte. É difícil imaginar um grande time ou evento esportivo sem patrocínio. De um lado, os eventos e equipes participantes dependem dos recursos financeiros oriundos dos patrocinadores. Do outro lado, os patrocinadores utilizam de forma significativa o patrocínio como uma ferramenta estratégica de marketing. Assim, da mesma forma que os gastos globais com patrocínio vêm aumentando ano a ano, os esforços acadêmicos para medir o efeito do patrocínio vêm acompanhando este crescimento. No entanto, grande parte da literatura sobre patrocínio considera a influência do patrocínio na perspectiva do negócio. Estudos que analisem uma estrutura mais completa, desde a identificação do torcedor com o time até a compra final de produtos dos patrocinadores são raros. E é aqui que essa pesquisa se encaixa. Entendemos que o consumidor passa por constantes mudanças, que afetam os hábitos de consumo das pessoas e, por consequência, afetam as organizações. Um exemplo está na crescente demanda dos consumidores esportivos por produtos e serviços melhores. Além disso, a utilização cada vez maior de dispositivos móveis com internet e acesso às mídias sociais exige que as empresas repensem seu ambiente de negócios. Essa mudança no comportamento dos consumidores vem proporcionando a eles um novo papel. Os times e equipes esportivas devem assumir uma visão na qual o torcedor seja visto como alguém que contribui significativamente para o valor do produto e do serviço e que, ao mesmo tempo, direciona as estratégias da organização. Assim, os times devem buscar estratégias para aumentar o envolvimento ativo dos torcedores com o time e com as empresas patrocinadoras, incentivando-os a ser embaixadores da marca. Neste contexto, o trabalho teve como objetivo verificar se a lealdade do torcedor com seu clube pode ser 
transferida para as organizações patrocinadoras. Para alcançar esse objetivo, propusemos e testamos um modelo teórico multidimensional que permitisse mensurar desde a concepção da identificação com o time até a etapa de compra dos produtos dos patrocinadores. Assim, a partir da análise crítica de modelos propostos por diferentes autores, de diferentes áreas do conhecimento, foram desenvolvidos o modelo teórico e seus respectivos itens de mensuração. Os construtos principais desta tese foram: identificação com o time, lealdade ao time e lealdade ao patrocinador. A aplicação da escala desenvolvida para este trabalho se deu em duas amostras distintas e em momentos diferentes (amostra pré-teste: $\mathrm{n}=263$; amostra teste: $\mathrm{n}=787$ ). Para teste e refinamento da escala e do modelo, utilizamos a técnica de modelagem de equação estrutural PLS-SEM, por meio da qual os dados foram analisados em termos de validade convergente, validade discriminante e confiabilidade. Para tal, adotamos o uso da análise fatorial confirmatória. $\mathrm{O}$ modelo estrutural também foi testado e retestado por meio dos coeficientes de caminho, R2, Q2 e f2. Os resultados deste estudo mostram haver impacto considerável das variáveis antecedentes, benefícios sociais/não financeiros propostos neste trabalho, na identificação com o time. Ao mesmo tempo, a identificação com o time afeta positivamente e de forma significativa à lealdade ao time, que neste trabalho é analisada como um construto multidimensional formado por lealdade atitudinal, conativa e comportamental. Os testes realizados confiram o objetivo principal deste trabalho e permite inferir que a lealdade do torcedor ao time pode, sim, ser transferida para as empresas patrocinadoras. Em termos gerenciais, o conhecimento de novos antecedentes da identificação do torcedor com o time, bem como a clara distinção entre identificação, fanatismo e lealdade, permitirá às equipes formular estratégias mais assertivas para gerenciamento de suas marcas e o direcionar esforços de comunicação de marketing de forma mais eficaz. Para as empresas patrocinadoras, apresentamos um caminho alternativo para mensurar a eficiência e a eficácia do patrocínio e rentabilizar melhor os altos investimentos nesta área. Por fim, os resultados contribuem para a ampliação do conhecimento e do corpo teórico nos estudos da vantagem competitiva, comportamento do consumidor, lealdade e patrocínio.

Palavra-chave: Marketing Esportivo; Economia do Esporte; Gestão do Esporte; Vantagem Competitiva; Comportamento do Consumidor; Transferência de Lealdade; teoria da identidade social; teoria do equilíbrio; teoria da transferência. 


\section{ACKNOWLEDGMENTS}

Writing the acknowledgments to a four-year study is, for me, one of the most interesting parts of this kind of work. That is why I have always been interested in reading this part is other studies.

Writing a thesis is, for the most part, a lonely process. But, strange as it may seem, it is something impossible to be accomplished without the help of various people.

In fact, I hope I don't leave anyone out, but, if when reading the acknowledgments, someone feels forgotten, I record here my most sincere apology. It is a neglect of the memory, not the heart.

Much has changed since 2012 when the first ideas around this work began to be formulated. My personal life has brought me a lot of new friends as well as family growth. My professional life, with its ups and downs, has been like a long waltz. In anyways, it is impossible to say that today, in 2017, I am the same person.

If all this has changed, one can imagine how much this study was impacted over the course of these four years. By having contact with bright minds, among professors, colleagues, students and friends, the flow of knowledge increases and ideas mingle. Every new information came with a surprise interjection, especially when I realized that it fit my topic.

But there comes a time when you have to put an end to the more general reflections and draw a final route. And this is an essential moment in the development of the study. So, the first people I thank are the professor who helped me define this path.

First of all, thank you to my study advisor, Professor Paulo Roberto Feldman. Thank you for accepting my pre-project in 2012, in the selection process. It is true that we have changed a lot -- for the better, but we have always kept the same object of study: sports. Thank you for believing in my ideas and, above all, for directing them so that I could realize them. Thanks for the autonomy. This trust that you've had since the first day we sat down to discuss my project has been crucial for me to write this study.

I am sure that this work would not have happened without the co-advisory, even if unofficial, of two professors: José Afonso Mazzon and Thomas Brashear.

Professor Mazzon, thank you for introducing me to the "enchanted world" of qualitative methods. For your partnership in moments of madness and for your lucidity in pointing out my mistakes. 
Professor Thomas, to this day I don't understand what went through your head to agree to advise me for a year, but the period I spent in Amherst was instrumental so that I could understand how science works. Thanks for the help, encouragement, criticism, shoving and cursing. Today I know that science and research must be universal.

Several other professors have also contributed, to a greater or lesser extent, to make this project happen, and I record here my gratitude to Roberto Sbragia and Nuno Fouto for the constant shoving; Diógenes Bido, for his patience and his ideas; Roberto Palmero, for his contributions in difficult times; Elizabeth Miller, for the valuable teachings about consumer behavior; Janet Fink, for the idea of using the balance theory; Guy Masterman, for his classes on sports sponsorship and for our "caipirinhas"; and Professor Daniel Funk, for teaching me about the sports fan consumer loyalty.

To my friends -- and to some extent, teacher -- Thilo Kunkel and Kevin Snyder, I thank you for the conviviality, contributions, and the teachings about North American sports. Thank you for opening the doors of your homes to me in times of despair. Ah, and Van, of course, who, when things got tough, made it possible for me to eat coxinha and grilled French bread!

The contributions of a group of professors, who are great friends, also deserve recognition: André Fagundes, Claudio Rocha, Elcio Santana, Filipe Quevedo, Patrícia Vance, and Wagner Ladeira (the use of the surname is for everyone to recognize you). Know that our conversations, chats, coffees, and beers were key to getting the ideas out of my head and onto the paper.

Several students have made my days more fun and, sometimes, more complicated. Naming everyone would be impossible. So, I will name only those who, directly or indirectly, I ended up advising or being advised by them: Rui Marques, Geraldo Guimarães, Luana Hilário, Pedro Corat, and Solange Pukaro. Seriously, thank you!

Some college course also contributed a lot to keep me focused: David Rodrigues, Luis Eduardo Pilli, and Rodolfo Ribeiro. Thanks for the tips, which were not few.

Giuliana Isabella, who would say that an email sent asking for the Qualtrics password would end up in all of this, eh? Giu, from the bottom of my heart, thank you very much for your unconditional support, for your brilliant ideas and your friendly shoulder.

Izabelle Quezado, or Isa (the joke is inevitable), thank you very much for your valuable help. For introducing me to new ideas, theories, and concepts.

To my friends Ary Rocco, who's a bit of an unlucky fellow but a great brother; João Malaia (aka Joca), Palmeirense, but we don't choose friends based on the team they support 
(or do we?); Alex Bourgeois, French, but a good person -- it could be worse; he could be Argentinian; Gustavo Calatrava, Argentinean -- I'm not gonna say anything else! --; César Grafietti -- I seriously thought long and hard whether to included you here or not; and Paulo Calçade -- no bullying here, please! Thank you all for the friendship and the valuable teachings. If these people read this thesis to the end, they will see that I have absorbed much of their knowledge. Thanks for the discussions on management, governance, and consumer in sports.

To my friend, business partner, and brother, Marcos Cardoso. Thanks for the "exhausted" hours, in good times and bad times. By the classroom desk and at the bar table.

To Anne Walton, Mario DePillis Jr., and Mario DePillis Senior, for opening the door of your home and accepting me into your wonderful family. Your teachings were essential to my survival at Amherst.

Reza Rajabi and Felipe Assef, know that you too were incredible. Life became more peaceful in Amherst with your help and friendship.

To the brothers that life gave me, or rather, let me choose: Alexandre Modonezzi, Educardo Calbucci, and Rodrigo Benitez. Without you I would, literally, not have come this far. Thanks for helping me "hang in there" when the things got hard. There is no way to repay what you did and do for me, but I promise always to try.

If life has allowed me to choose some brothers, it has also presented me with sisters. I started the thesis with one sister and finished it with three -- I said earlier that the family had increased! Arianne, thanks for caring. Paulinha, the youngest one! There's still a lot to happen, isn't there?

Without trying to cause any jealousy, but especially you, Laura. Lala, thank you for all these years by my side. For providing me with an incredible support in difficult times and for always being ready to help. Soon comes your thesis. Oh, and, I wonder if we have to thank brothers-in-law. But I think Marquinhos deserves it. Thanks for the help, not only the personal one the but academic one as well.

Obviously, I cannot forget to thank my mother. For the love, affection, and understanding dedicated all these years. I love you, mom.

At this point, I hope that my friends understand that it would be too many names to mention. So thank you to the parents of Bruna's "little friends".

To Bia, friend and partner. Present in good and bad times. Always encouraging me and understanding (or trying to understand) the paths I decided to take. Even though I often do not show it, know that I greatly appreciate everything you've done. 
Finally, my princess. Before I thank you, I must apologize. It was hard being away, but the cause was good and soon will be your turn to go. Thank you, Bruna, for the affection, hugs, kisses and tickles. May our father-daughter Mondays can be repeated throughout our lives. Daddy loves you very much.

Oh, I can't forget to thank Melissa Harkin, for saving me, always at the last minute, with her knowledge of the English language, and the more than 1,500 respondents who assisted me in this research. If not for you, this study would not have been possible! Thank you.

I will thank the Examination Board after presenting my thesis.

Whew! TThat's it! Have fun reading this study, because I sure had a lot of fun -- for real! -- researching and writing it. May this thesis be a ray of sunshine in your life, as it was in mine. 


\begin{abstract}
The sports industry has attracted increasing interest from academics and professionals from various fields. Not only because of the social importance that sport has always had in the world but now, also because of the economic importance that this industry has achieved. For some time now, sport hasn't been just a leisure activity. If, for the public, it still is, for those who work in it, it is clearly a business activity, and to play the game within the four lines, it is necessary to have a competitive team outside of them. In this paper, we considered sports teams as organizations and analyzed them as companies, with their organizational structure closely related to their presentation to the consumer. We assumed the premise that these organizations (teams) should not only be organized as win-maximizer but as a profitmaximizing. In this sense, sponsorship is gaining more importance in the sports industry. It is hard to imagine a great team or sporting event without sponsorship. On the one hand, the events and participating teams rely on financial resources from sponsors. On the other hand, sponsors significantly utilize sponsorship as a strategic marketing tool. Thus, just as global spending on sponsorship is increasing on a yearly basis, the academic efforts to measure the effect of sponsorship have accompanied this growth. However, much of the literature on sponsorship considers the influence of sponsorship on the business perspective. Studies analyzing a more complete structure, from the fan's identification with the team to the final purchase of the sponsors' products, are rare, and this is the point of this research. We understand that the consumer goes through constant changes that affect the consumption habits of people and, consequently, affect organizations. An example is an increasing demand from consumers for sporting goods and better services. In addition, the increasing use of mobile devices with Internet and access to social media requires companies to rethink their business environment. This change in consumer behavior is giving them a new role. Teams and their staff must embrace the vision in which fans are seen as people who significantly contribute to the value of the product and service and, at the same time, direct the organization's strategies. Thus, teams must seek strategies to increase the active involvement of the fans with the team and with the sponsoring companies, encouraging them to be brand ambassadors. In this context, this study aimed to verify that the fan's loyalty to his club can be transferred to the sponsoring organizations. To achieve this goal, we proposed and tested a multidimensional theoretical model that allowed us to measure all the stages of the process that we call loyalty transfer, starting with the identification with the team and ending with the purchase phase of the sponsors' products. Thus, from the critical analysis of models proposed
\end{abstract}


by different authors from different areas of knowledge, the theoretical model was developed, and its respective items were measured. The main constructs of this thesis were identification with the team, loyalty to the team, and loyalty to the sponsor. The application of the scale developed for this study took place in two different samples at different times (pre-test sample: $n=267$; test sample: $n=787$ ). For testing and refinement of scale and model, we used the PLS-SEM structural equation modeling technique, whereby the data was analyzed regarding convergent validity, discriminant validity, and reliability. To this end, we have adopted the use of confirmatory factor analysis. The structural model was also tested and retested by the R2, Q2 e f2 coeficients. The results of this study show that there is a significant impact of background variables and the social/non-financial benefits proposed in this study in identifying with the team. At the same time, identification with the team affects positively and significantly the loyalty to the team, which, in this study, is considered as a multidimensional construct composed of attitudinal, conative and behavioral loyalty. The executed tests confirm the primary objective of this study and allow us to infer that fan loyalty to the team can indeed be transferred to the sponsoring companies. In management terms, the knowledge of new background of fan identification with the team, as well as the clear distinction between identification, fanaticism, and loyalty, will enable teams to formulate more assertive strategies for managing their brands and direct marketing communication efforts more efficiently. For sponsors, we present an alternative way to measure the efficiency and effectiveness of sponsorship and better monetize high investments in this area. Finally, the results contribute to the expansion of knowledge and theoretical background in the study of competitive advantage, consumer behavior, loyalty, and sponsorship.

Keywords: Sports Marketing; Economics of Sports; Sports Management; Competitive Advantage; Consumer Behavior; Loyalty Transfer; Social Identity Theory; Balance Theory; Theory of Transfer. 


\section{SUMÁRIO}

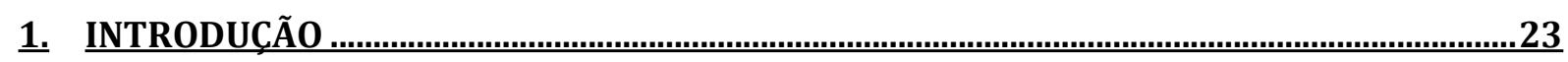

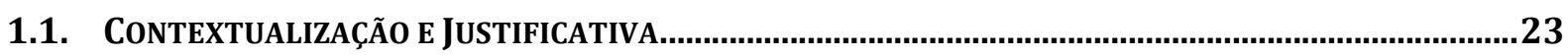

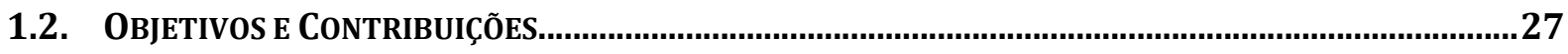

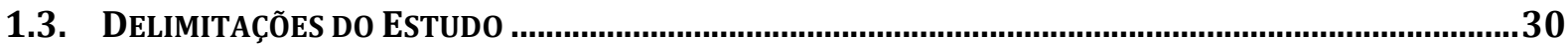

1.4. ESTRUTURA DA PESQUISA...............................................................................................

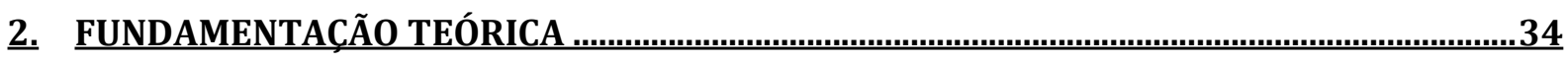

2.1. VANTAGEM COMPETITIVA..............................................................................................34

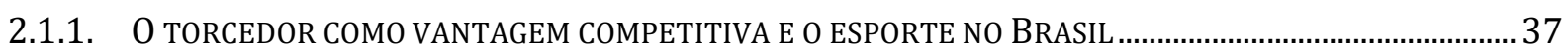

2.2. TEORIA DA IDENTIDADE SOCIAL .....................................................................................39

2.3. IDENTIFICAÇÃO COM O TIME ..............................................................................................

2.4. ANTECEDENTES DA IDENTIFICAÇ̃̃o COM 0 TIME.......................................................................47

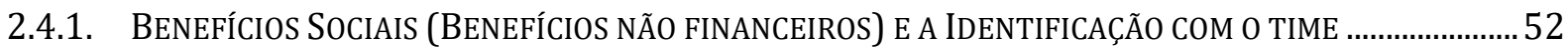

2.4.2. ENVOLVIMENTO COM o ESPORTE E A IDENTIFICAÇ̃̃o COM o TIME.........................................................6

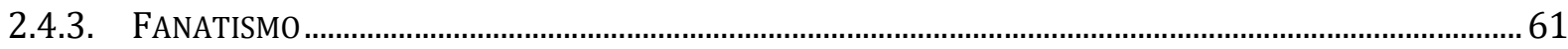

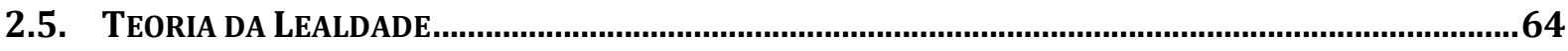

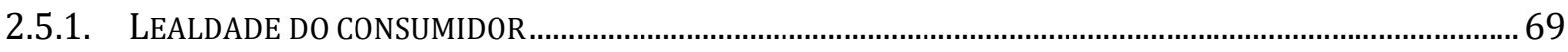

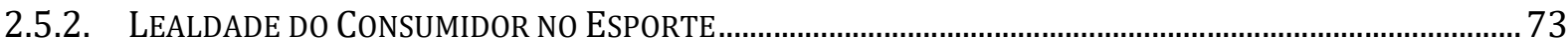

2.6. PATRocínIo ESPORTIVO.......................................................................................................85

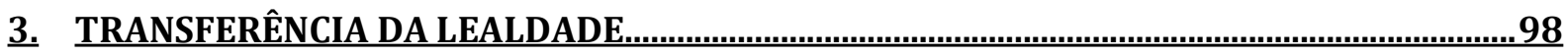

3.1. TEORIA DA TRANSFERÊNCIA.............................................................................................. 100

3.2. TeORIA do EQUILÍbRIo (BALANCE THEORY) _..................................................................... 109

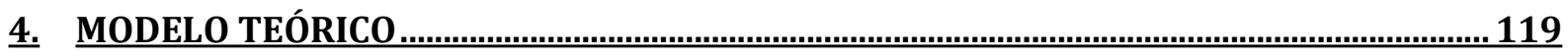

5. DESENVOLVIMENTO DA ESCALA _........

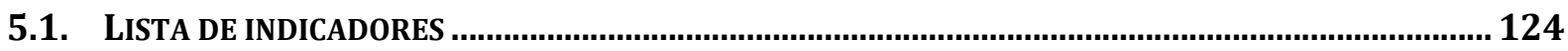

5.1.1. OPERACIONALIZAÇÃ̃o DA VARIÁVEL IDENTIFICAÇÃo COM O TIME...................................................... 126

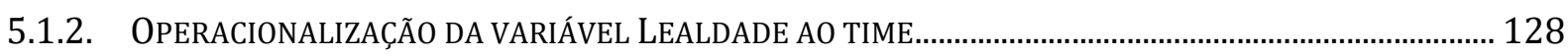

5.1.3. OPERaCionalizaçÃo do constructo LEaldade ao Patrocínio..................................................... 130

5.1.4. OPERACIONALIZAÇÃ̃o DOS OUTPUTS DA LEALDADE......................................................................... 133

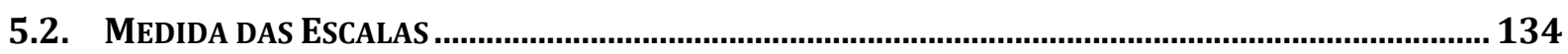

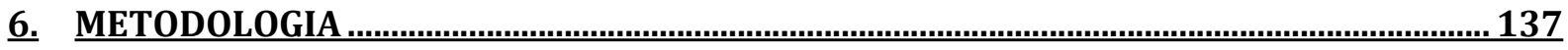




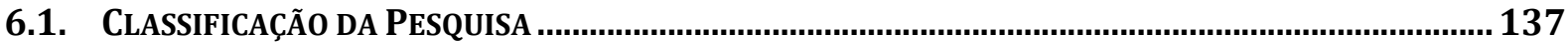

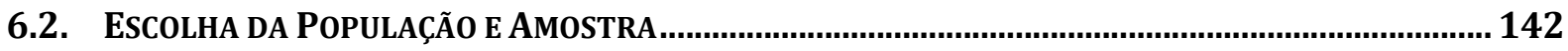

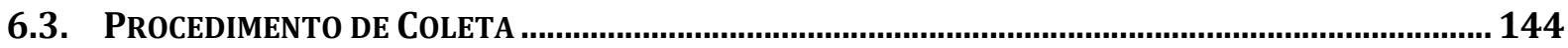

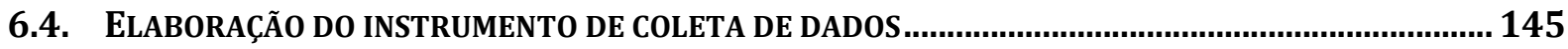

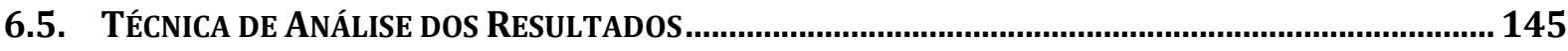

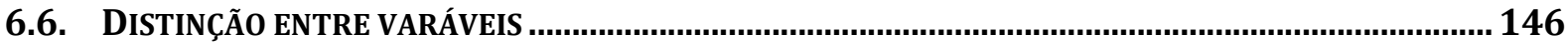

7. MODELAGEM DE EQUAÇÕES ESTRUTURAIS (MEE) ……......................................... 147

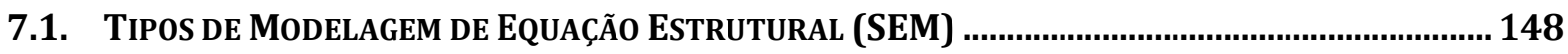

7.2. AVALIAÇão do ModElo de MENSURAÇÃo (MEASUREMENT MODEL ASSESSMENT)..........................151

7.2.1. ANÁLISE FATORIAL CONFIRMATÓRIA (AFC) ….............................................................................. 154

7.3. AVALIAÇÃo do Modelo ESTRUTURAL (STRUCTURAL MODEL ASSESSMENT) ................................... 157

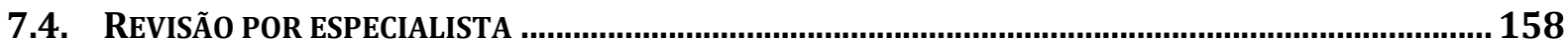

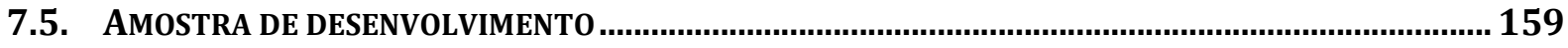

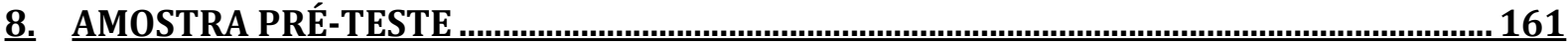

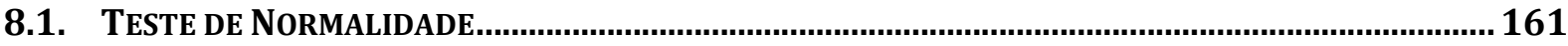

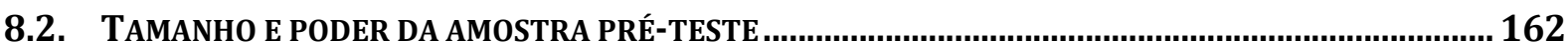

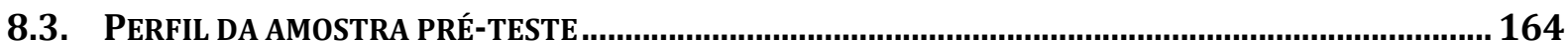

8.4. AVAliação do Modelo de MenSURAÇão (MEASUREMENT Model ASSESSMENT) - AMOSTRA PRÉ-

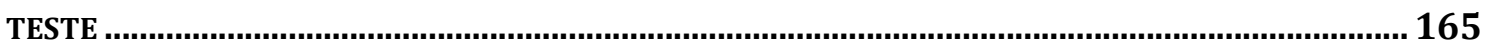

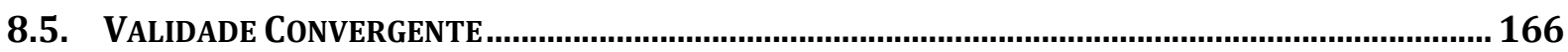

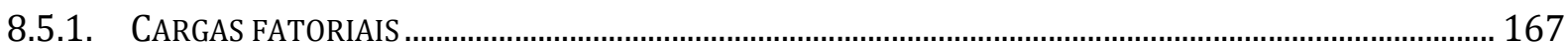

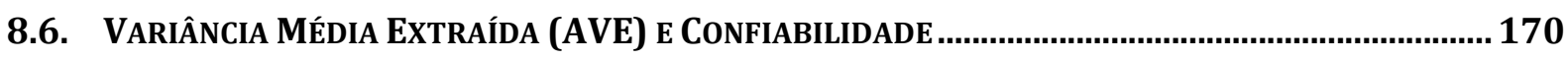

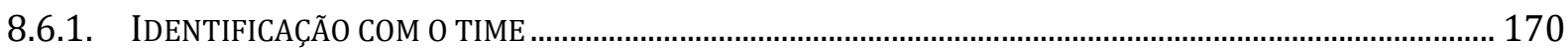

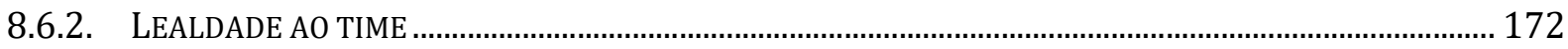

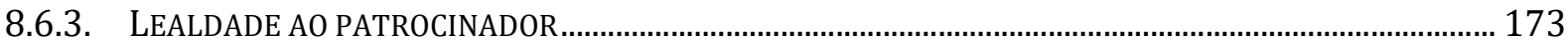

8.6.4. OUTPUTS DA LEALDADE AO PATROCINADOR ……............................................................................. 174

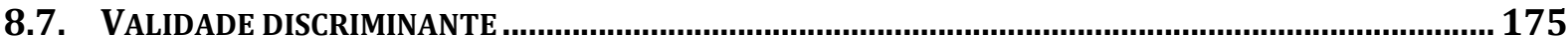

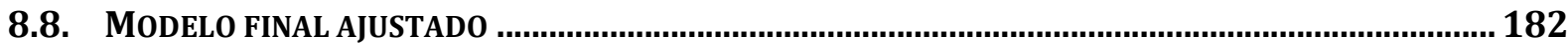

8.9. AVAliaÇÃo do MOdelo de ESTRUTRAl (STRUCTURAL MOdEL ASSESSMENT) - AMOSTRA PRÉ-TESTE

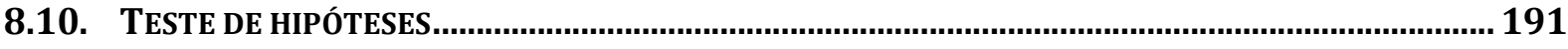

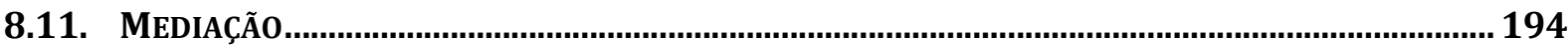

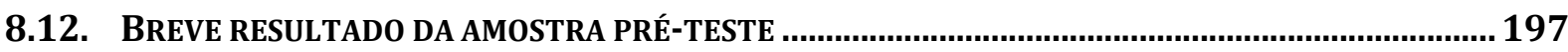

9. AMOSTRA TESTE 


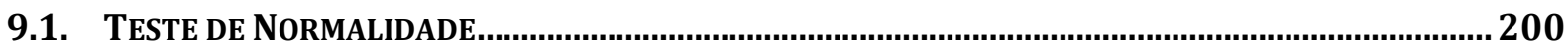

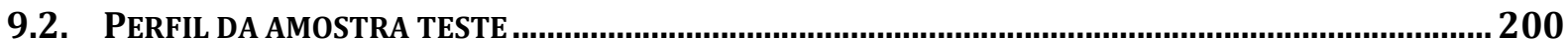

9.3. AVAliaÇão do Modelo de MENSURAÇão (MEASUREMENT MOdEl ASSESSMENT) - AMOSTRA TESTE

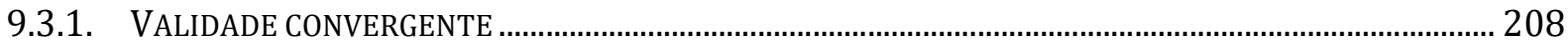

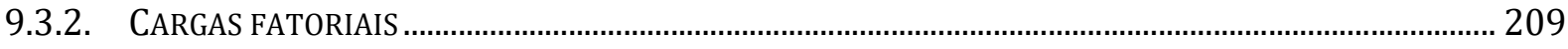

9.3.3. VARIÂNCIA MÉDIA EXTRAídA (AVE) E CONFIABILIDADE ……........................................................... 211

9.3.4. VALIDADE DISCRIMINANTE................................................................................................... 214

9.4. Avaliação do Modelo estrutural (STRUCtURAl model aSSESSMENT) - AMostra teSTE... 221

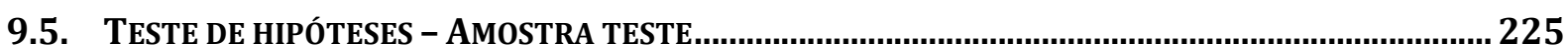

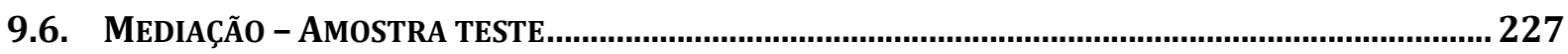

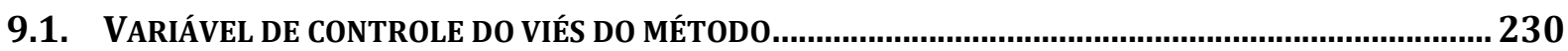

10. ANÁLISE DOS RESULTADOS NA COMPARAC̣ÃO ENTRE AS AMOSTRAS ……………......233

10.1. MODELO DE MENSURAÇÃO

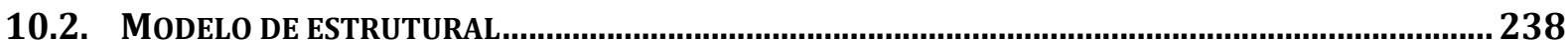

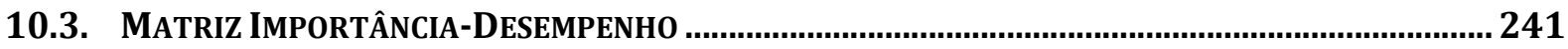

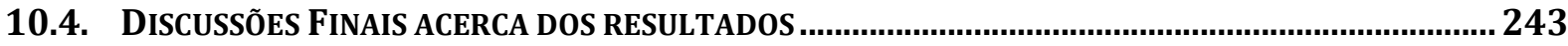

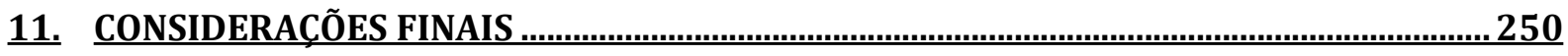

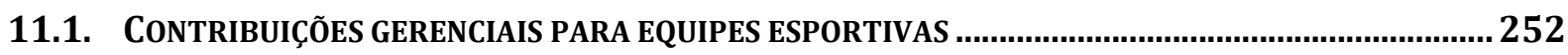

11.2. CONTRIBUIÇõES GERENCIAIS PARA ORGANIZAÇõES PATROCINADORAS .................................... 255

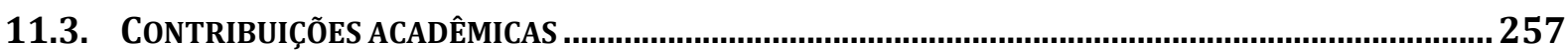

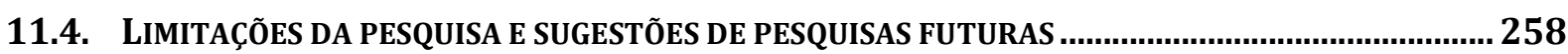

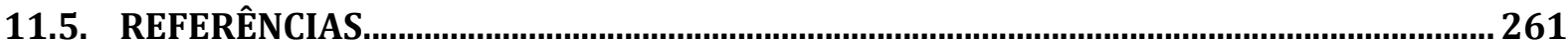

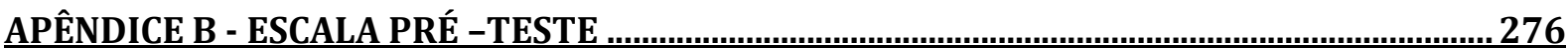

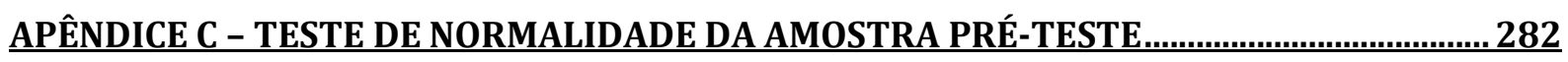

APÊNDICE D - CARGAS CRUZADO ……………

APÊNDICE E - TESTE DE NORMALIDADE DA AMOSTRA TESTE 


\section{LISTA DE FIGURAS}

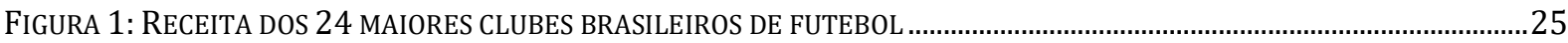

FigURA 2: PARTICIPAÇÃO DAS FonTES DE RECEITAS DOS 24 MAIORES CLUBES DE FUTEBOL DO BRASIL.................................30

Figura 3: Modelo PropostA dA RELAÇÃo ENTRE IDENTIFICAÇÃO, FANATISMO E LEALDADE ...........................................47

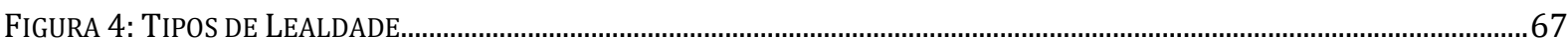

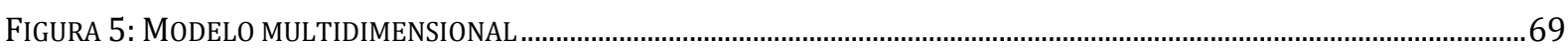

FIGURA 6: PSYCHOLOGICAL COMMITMENT TO TEAM (PCT) ….........................................................................................8

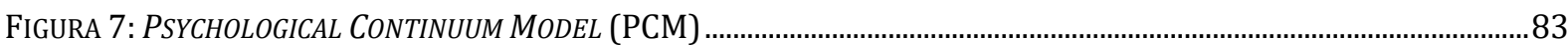

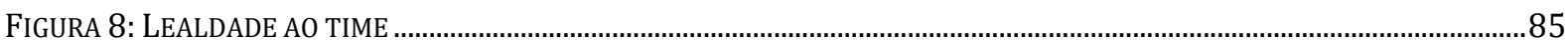

FIGURA 9: PATROCÍNIO POR REGĨ̃o DO GLOBO (BILHÕES DE DÓLARES) ……...................................................................86

FiguRA 10: PATRocínIO POR TIPO DE ATIVIDADE NA AMÉRICA DO NORTE (BILHÕES DE DólaRES) ....................................87

FigURA 11: SPONSOR OF CONSUMER-FOCUSED SPONSORSHIP-LINKED MARKETING COMMUNICATIONS..............................93

FigURA 12: MOVIMENTO DO SIGNIFICADO E O PROCESSO DE ENDOSSO.............................................................................. 101

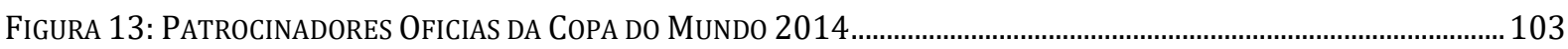

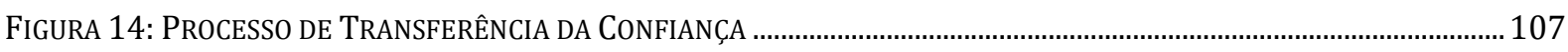

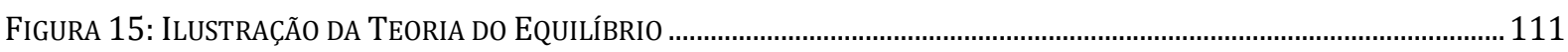

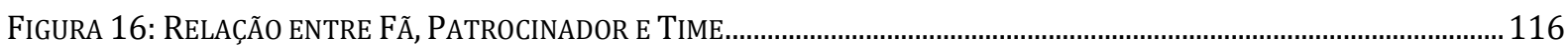

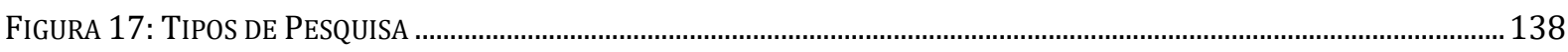

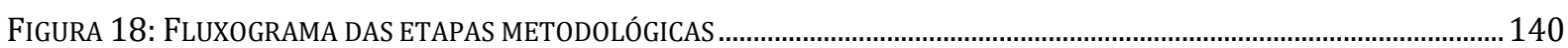

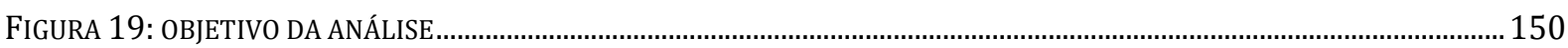

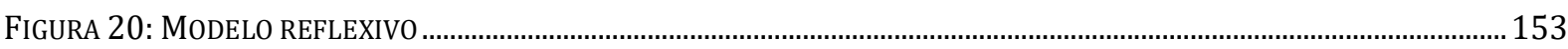

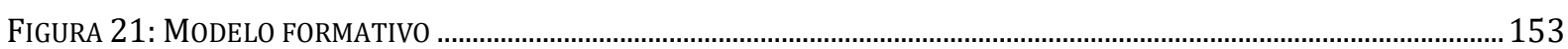

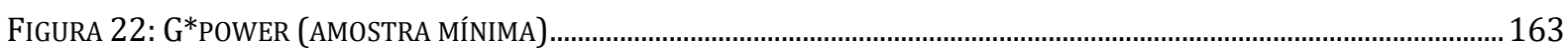

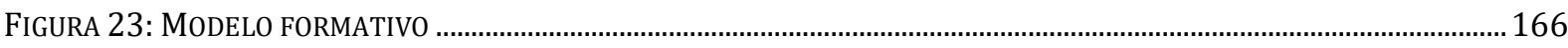

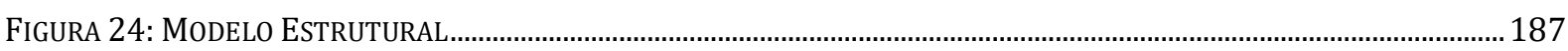

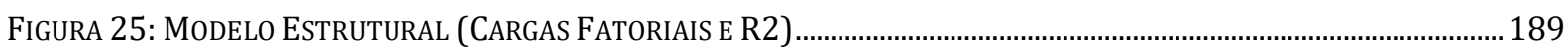

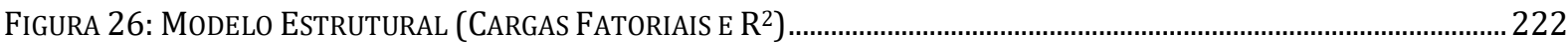

FiguRA 27: Modelo eSTRUTURAL DAS DUAS AMOSTRAS (PRÉ-TESTE / TESTE - RESPECTIVAMENTE) ..............................238

FIGURA 28: MATRIZ IMPORTÂNCIA-DESEMPENHO (AMOSTRA PRÉ-TESTE) ......................................................................242

FIGURA 29 MATRIZ IMPORTÂNCIA-DESEMPENHO (AMOSTRA TESTE) ............................................................................242 


\section{LISTA DE TABELAS}

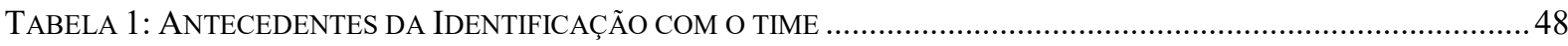

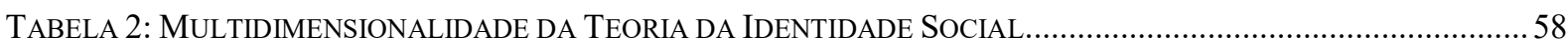

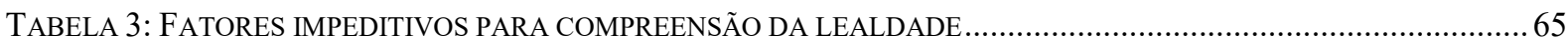

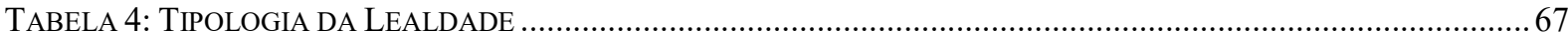

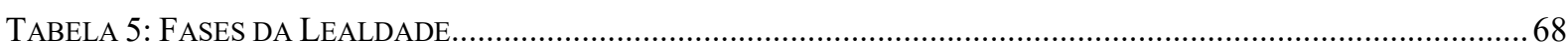

TABELA 6: MEIOS PELO QUAIS A LEALDADE DO TORCEDOR BENEFICIA SEU TIME …........................................74

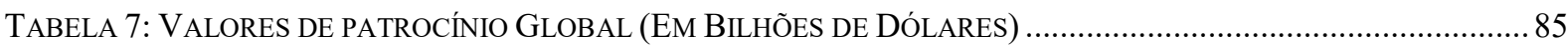

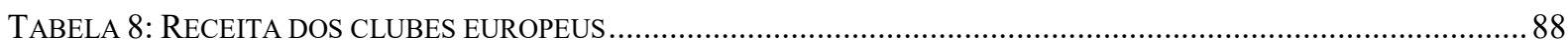

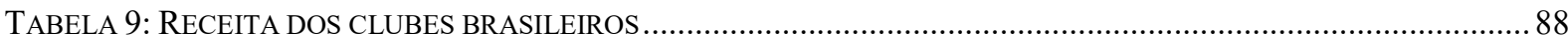

TABELA 10: DiVISÃo DOS INVESTIMENTO EM MARKETING NO MUNDO (\% DE CRESCIMENTO)............................89

TABEla 11: DiVisão dOS INVESTIMENTOS DE MARKETING NA AMÉRICA DO NORTE (\% DE CRESCIMENTO) ......... 89

TABELA 12: QUADRO RESUMO DE HIPÓTESES E CONTRIBUIÇÕES DA TESE........................................................ 119

TABELA 13: PROCEDIMENTOS METODOLÓGICOS PARA DESENVOLVIMENTO DA ESCALA DE MENSURAÇÃO DO

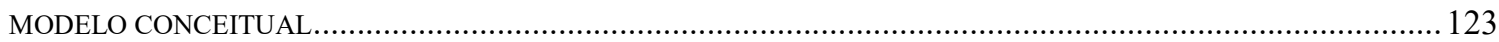

TABELA 14: PASSOS PARA ESCOLHA DOS INDICADORES DE CADA VARIÁVEL .................................................. 124

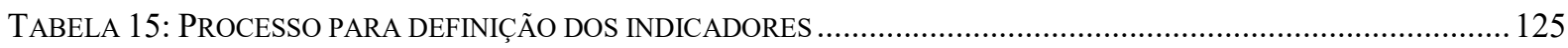

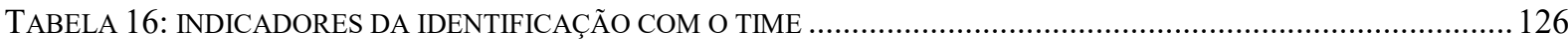

TABELA 17: INDICADORES DOS ANTECEDENTES DA IDENTIFICAÇÃO COM O TIME............................................... 127

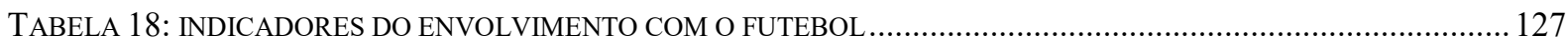

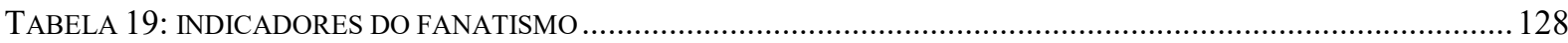

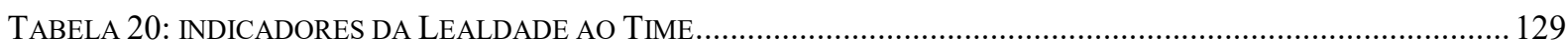

TABELA 21: INDICADORES DOS ANTECEDENTES DA LEALDADE AO PATROCINADOR ....................................... 131

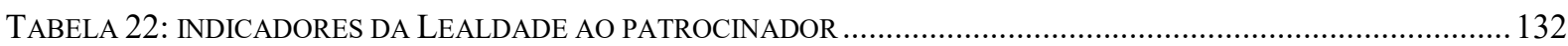

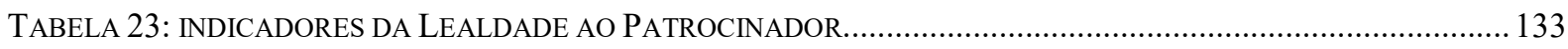

TABELA 24: FoRMATO DAS MEDIDAS DE MENSURAÇÃO DA ESCALA …...................................................... 136

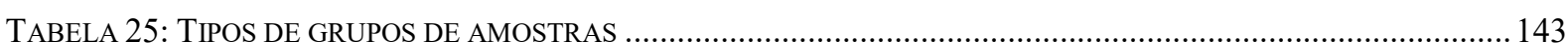

TABELA 26: QUESTÃO PARA APLICAÇÃO DO MÉTODO PLS-SEM .................................................................... 150

TABELA 27: PRINCÍPIOS DA AFC APLICADOS NA ANÁLISE DE MENSURAÇÃO DO MODELO POR MEIO DA PLS-SEM 156

TABELA 28: INDICADORES UTILIZADOS PARA AVALIAR O MODELO ESTRUTURAL …....................................... 157

TABELA 29: INDICADORES UTILIZADOS PARA AVALIAR O MODELO ESTRUTURAL ............................................. 158

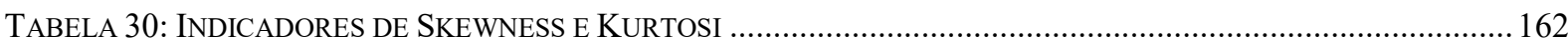

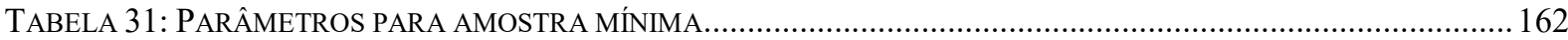

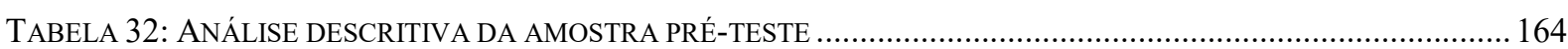

TABELA 33: AVALIAÇÃO DO NÍVEL DE SIGNIFICÂNCIA DOS INDICADORES - AMOSTRA PRÉ-TESTE....................... 167

TABELA 34: MODELO DE MENSURAÇÃO - IDENTIFICAÇÃO COM O TIME - AMOSTRA PRÉ-TESTE ............................ 170

TABELA 35: MODELO DE MENSURAÇÃO - LEALDADE AO TIME - AMOSTRA PRÉ-TESTE .......................................172

TABELA 36: MODELO DE MENSURAÇÃO - LEALDADE AO PATROCINADOR - AMOSTRA PRÉ-TESTE ....................... 173

TABELA 37: MODELO DE MENSURAÇ̃̃O - OUTPUTS DA LEALDADE AO PATROCINADOR - AMOSTRA PRÉ-TESTE .. 174 
TABELA 38: ESTATÍSTICA DESCRITIVA E CORRELAÇÕES - AMOSTRA PRÉ-TESTE 177

TABELA 39: MATRIZ DE CARGA CRUZADA - AMOSTRA PRÉ-TESTE.................................................................... 178

TABELA 40: MODELO DE MENSURAÇÃO FINAL: AVALIAÇ̃̃O DOS ITENS UTILIZADOS .......................................... 182

TABELA 41: ESTATÍSTICA DESCRITIVA E CORRELAÇÕES - AMOSTRA PRÉ-TESTE AJUSTE FINAL ............................ 185

TABEla 42: VAlidade Preditiva $\left(Q^{2}\right)$ - INDICADOR DE STONE-GEISSER - MODELO PRÉ-TESTE ........................ 188

TABELA 43: ANALiSE DA MultiCOLINEARIDAdE (VIF) MODELO PRÉ-TESTE.................................................... 190

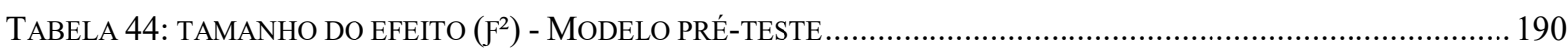

TABELA 45: COEFICIENTES DO MODELO ESTRUTURAL - AMOSTRA PRÉ-TESTE ................................................. 193

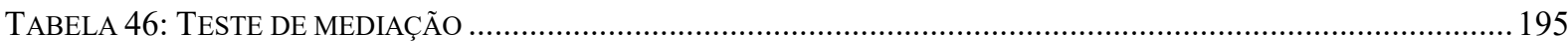

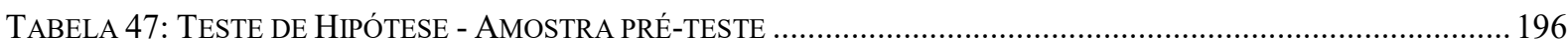

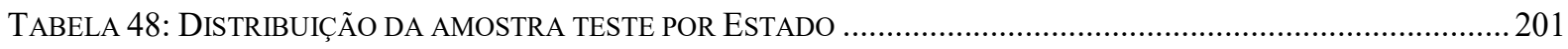

TABELA 49: DiSTRIBUIÇÃO DA AMOSTRA TESTE POR TIME DE FUTEBOL ........................................................... 202

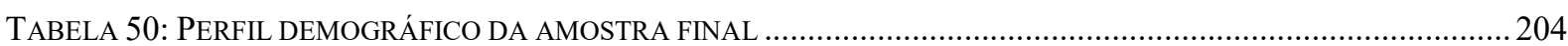

TABELA 51: DistribuiçÃo DA AMOSTRA TESTE ENTRE RESPONDENTES DE PATROCINADOR E FORNECEDOR DE

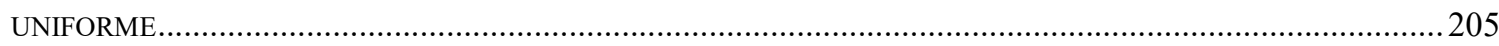

TABELA 52: PERFIL AMOSTRA FINAL POR ACERTO DO PATROCINADOR/FORNECEDOR ........................................206

TABELA 53: PERFIL AMOSTRA FINAL - COMPRA OU NÃo PRODUTOS ..........................................................207

TABELA 54: PERFIL AMOSTRA FINAL - MARCA ESPORTIVA PREFERIDA ……....................................................2 208

TABELA 55: AVALIAÇÃO DO NÍVEL DE SIGNIFICÂNCIA DOS INDICADORES - AMOSTRA TESTE .............................209

TABELA 56: MODELO DE MENSURAÇÃO - AMOSTRA TESTE .............................................................................. 211

TABELA 57: ESTATÍSTICA DESCRITIVA E CORRELAÇÕES - AMOSTRA TESTE ……............................................2 216

TABELA 58: MATRIZ DE CARGA CRUZADA - AMOSTRA PRÉ-TESTE MODELO AJUSTADO......................................217

TABEla 59: VALIDADE PREDITIVA $\left(Q^{2}\right)$ - INDICADOR DE STONE-GEISSER - AMOSTRA TESTE.............................223

TABELA 60: ANALISE DA MUltiCOLINEARIDAdE (VIF) AMOSTRA TESTE ........................................................222

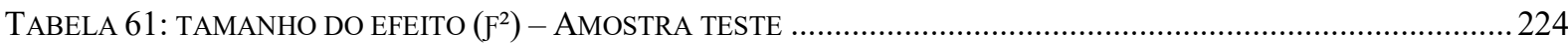

TABELA 62: COEFICIENTES DO MODELO ESTRUTURAL -AMOSTRA TESTE ….....................................................226

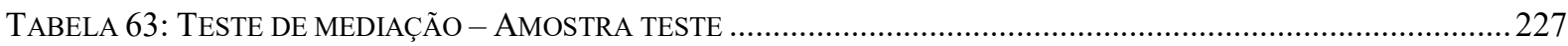

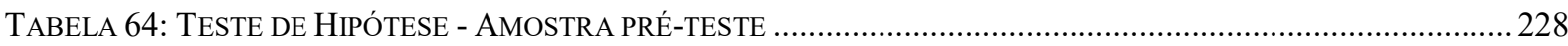

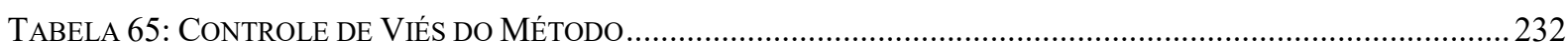

TABELA 66: AVALIAÇÃO DO NÍVEL DE SIGNIFICÂNCIA DOS INDICADORES - AMOSTRA TESTE.............................2234

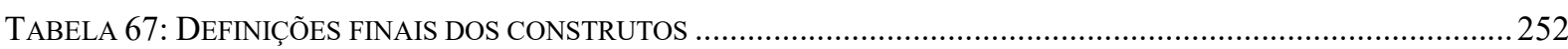




\section{INTRODUÇÃO}

Incialmente, apresentaremos o contexto mais amplo em que se insere essa pesquisa, com o intuito de facilitar a compreensão acerca da importância do tema, bem como justificar os fatores que motivam este pesquisador a estudar o problema. Abordaremos ainda a questão central da pesquisa e os objetivos. Buscaremos também delinear as principais contribuições teóricas e práticas deste trabalho, o escopo deste estudo e os conceitos teóricos que o delimitam. Por fim, mostraremos a estrutura total da pesquisa.

\subsection{Contextualização e Justificativa}

Em março de 2012, com o fechamento do PIB brasileiro de 2011 em US\$ 2,469 trilhões, 2\% acima do registrado pelo Reino Unido, o Brasil se tornou a $6^{\mathrm{a}}$ economia do mundo (Fellet, 2012). Tal dado mostra que o país, apesar da recente desaceleração econômica, vem ganhando maior destaque na economia mundial nos últimos anos. Porém, para aqueles que trabalham com o esporte, seja do ponto de vista acadêmico ou profissional, uma questão sempre se faz importante no meio de tudo isso: quanto representa o esporte em nossa economia?

Devido aos grandes eventos esportivos sediados no Brasil nos últimos anos (Copa do Mundo e Jogos Olímpicos do Rio de Janeiro), a indústria do esporte vem ganhando cada vez mais atenção. Grandes grupos de comunicação abriram agências especializadas em esporte e as que já existiam se reforçaram. Estudo realizado pela Ernst \& Young (2011) estimava que:

"Além dos gastos de $R \$ 22,46$ bilhões no Brasil relacionados à Copa para garantir a infraestrutura, e a organização, a competição deverá injetar, adicionalmente, $R \$ 112,79$ bilhões na economia brasileira, com a produção em cadeia de efeitos indiretos e induzidos. No total, o País movimentará $R \$ 142,39$ bilhões adicionais no período 2010-2014, gerando 3,63 milhões de empregos-ano e $R \$ 63,48$ bilhões de renda para a população, o que vai impactar, inevitavelmente, o mercado de consumo interno". (Ernst \& Young, 2011, p. 5).

Apesar do elevado crescimento do PIB da indústria do esporte e de boas expectativas para o futuro, podemos perceber que ainda existe um grande caminho a ser percorrido pelo Brasil quando nos comparamos a outros mercados: o PIB do esporte nos EUA, a maior economia mundial (PIB nominal de US\$15 trilhões), é estimado em 3\% (Hambrecht, 
Hambrecht, Morrissey, \& Taylor, 2012), sendo que quase $70 \%$ pode ser considerado vinculado às ligas esportivas norte-americanas (Wolfers, 2002).

Olhando para o setor esportivo brasileiro, como era de esperar, a proeminência do futebol é notável. O futebol destaca-se com 53\% do PIB esportivo, o que equivale a $\mathrm{R} \$ 36$ bilhões, cerca de $0,8 \%$ do PIB (Pluri Consultoria, 2012). No entanto os 40 maiores clubes do país, que representam $80 \%$ do faturamento total, são responsáveis por apenas $6,9 \%$ do PIB do futebol e menos de 4\% do PIB do setor esportivo. Essa informação levanta questionamentos sobre o papel dos clubes na adição de valor ao esporte. Segundo o diretor de Futebol Profissional do Ministério dos Esportes, Ricardo Gomyde ${ }^{1}$, são necessárias ações para proteger a cadeia produtiva do futebol. Para alavancar o crescimento do setor, é necessária a elaboração de mensurações sociais e econômicas dos clubes, assim como um plano de soluções para as dívidas dos times, que hoje atingem mais de R \$ 5,6 bilhões (BDO Brasil, , 2014).

Embora a parcela dos clubes no valor adicionado à economia brasileira seja pequena, analisando as receitas dos 24 maiores clubes (Figura 1), nota-se que ela cresceu 98\% entre 2009 e 2013, alcançando a casa dos R \$ 3,2 bilhões (BDO Brasil, , 2014). O Clube de Regatas do Flamengo, com maior receita entre os times brasileiros em 2014 (sem considerar a transferência de atletas), teve faturamento de R\$ 272,9 milhões em 2014. Um crescimento de 159,4\% em relação a 2009 (BDO Brasil, , 2014). Porém, comparado com outras empresas do setor esportivo, o faturamento ainda pode ser considerado pequeno. A Netshoes, que vende artigos esportivos pela internet, teve faturamento na casa dos $\mathrm{R} \$ 600$ milhões em 2011 (Sobral, 2011) e a Centauro (Grupo SBF), de R\$ 1,7 bilhões (Casado, 2012).

Enquanto os clubes brasileiros geraram receitas totais de R\$ 3,2 bilhões (BDO, 2014), a Major League Baseball (MLB) arrecadou, apenas com a venda de produtos licenciados, US\$ 3,3 bilhões; a National Football League (NFL), US\$ 3,25 bilhões; e a National Basketball Association (NBA), US\$ 2,15 bilhões ${ }^{2}$. As diferenças em relação aos direitos de TV são ainda maiores. É verdade que os clubes estão recebendo mais, desde o novo contrato assinado com a TV Globo em 2011, num total de R\$ 1 bilhão (Betting, 2011), mas esse valor

\footnotetext{
${ }^{1}$ Palestra ministrada no seminário “O futuro dos clubes brasileiro", no dia 17/09/2012.

${ }^{2}$ Números apresentados no Summer Program - Umass Amherst. Agosto de 2012
} 
é próximo ao que recebe a National Collegiate Athletic Association (NCAA), liga do basquete universitário norte-americano masculino, que vendeu, em 2010, os direitos para a CBS/Turner pelos próximos 14 anos por US\$ 11 bilhões $^{3}$.

Figura 1: Receita dos 24 maiores clubes brasileiros de futebol

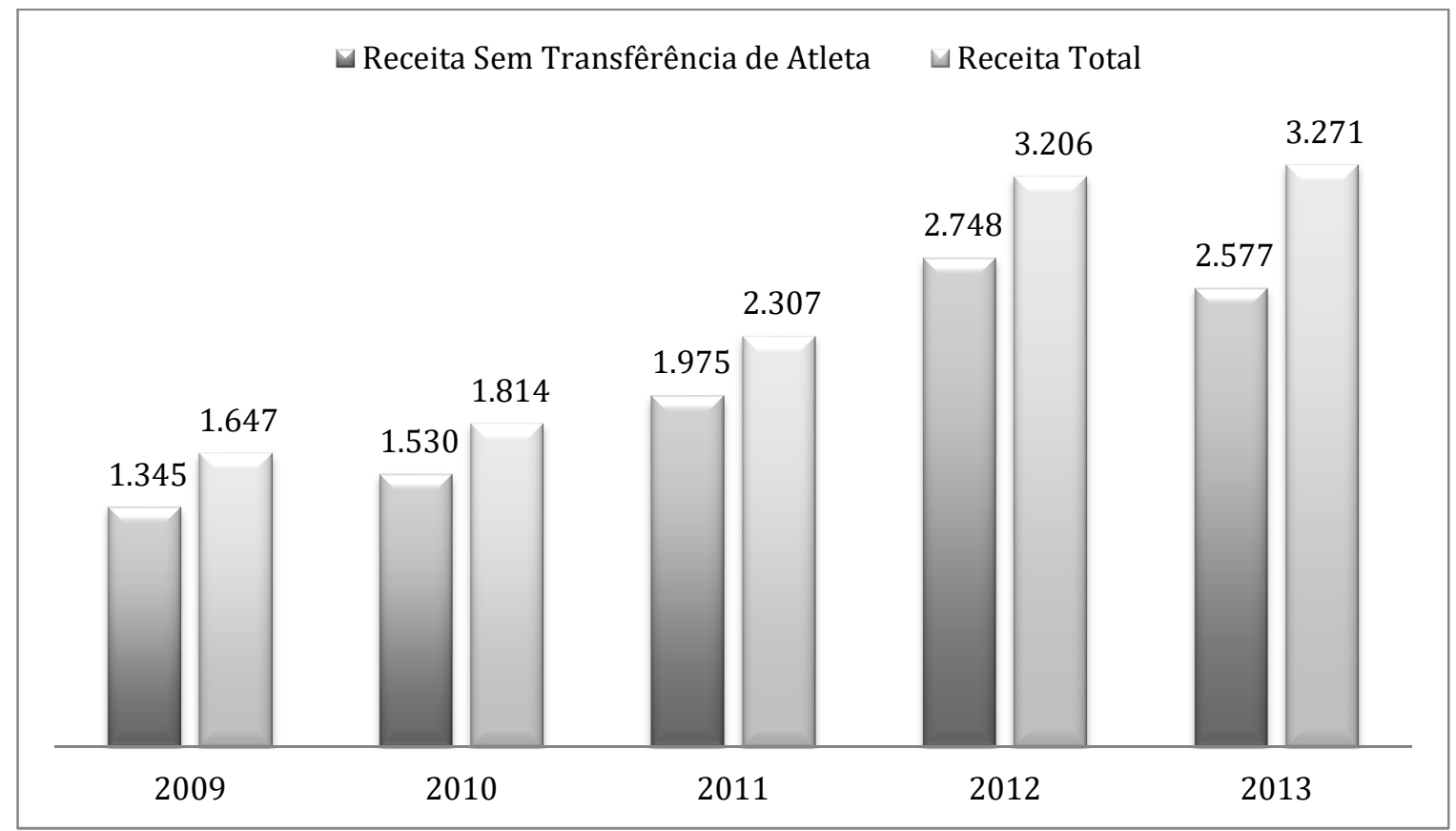

Fonte: Criado pelo autor baseado em BDO (2014)

A baixa participação dos clubes brasileiros no PIB do esporte vis-à-vis à importância deste esporte para o país - em termos tanto econômicos como comportamentais - levanta a necessidade de uma reflexão sobre a forma de atuação das equipes fora das quatro linhas.

As peculiaridades da indústria do esporte implicam processos produtivos diferentes, que abrangem duas etapas distintas, mas que se relacionam fortemente (Dietl, Franck, Hasan, \& Lang, 2009). Uma etapa está relacionada à esfera competitiva do esporte, na qual o clube busca maximizar suas chances de vencer campeonatos, que se tornam mais atraentes quanto maior é a competição. O problema, porém, é que este objetivo não gera, necessariamente, sucesso econômico para o clube. Como o esporte profissional é monopolista por definição ${ }^{4}$ visto que a entrada no mercado é restrita -, os donos dos clubes encaram um problema de

${ }^{3}$ Números apresentados no Summer Program - Umass Amherst. Agosto de 2012

${ }^{4}$ Analisando sob a ótica das grandes ligas americanas ou dos campeonatos de futebol em diversos países 
investimento específico (hold-up problem). A solução apresentada na teoria econômica para este problema - a integração vertical - não se aplica aqui, pois esta estrutura geraria efeitos negativos para a competição.

A outra etapa está relacionada à questão de os clubes atenderem necessidades específicas de seu mercado (vencer competições) e ainda garantirem a lucratividade para continuar suas atividades e seus investimentos. Num ambiente competitivo, mesmo fora das quatro linhas, as organizações esportivas devem buscar destacar-se dentre seus principais concorrentes, almejando alcançar um lugar de destaque nas preferências de seus consumidores. Mesmo dentro dos clubes esportivos, tal objetivo também deve ser colocado em prática e, para tanto, essas organizações precisam estar atentas ao que ocorre à sua volta.

A geração de informação de mercado, sua divulgação por toda a organização e a resposta de maneira satisfatória (Kohli \& Jaworski, 1990) podem garantir que as empresas acompanharão as mudanças em seus ambientes de negócios. Desta forma, as decisões empresarias ou, no caso dos clubes brasileiros, as decisões das diretorias devem ser tomadas tendo como norte os desejos e anseios dos consumidores (Shapiro, 1988), orientando-se para o mercado.

Sabe-se que os times hoje não podem mais sobreviver sem o aporte financeiro dos patrocinadores (Nufer \& Bühler, 2010). São estes que injetam bilhões no esporte mundial (IEG, 2014), garantindo que as equipes entrem em campo e possam executar sua principal atividade. Porém, se até pouco tempo atrás a principal questão que envolvia o retorno para os patrocinadores era do ponto de vista da imagem (Lachowetz, McDonald, Sutton, \& Hedrick, 2003; Smith, Graetz \& Westerbeek, 2008), hoje talvez esta resposta não seja mais suficiente.

Desse modo, entender a relação criada entre as três partes importantes do esporte (time/torcedor/patrocinador), dentro de um arcabouço econômico, torna-se fundamental. Os números financeiros, o baixo papel econômico dos clubes brasileiros e o percentual de participação do torcedor nestes números, em comparação ao sucesso das ligas norteamericanas e de seus times, precisam ser estudados.

Assim, a questão que esta tese visa a responder é:

O torcedor pode ser considerado uma vantagem competitiva para o clube pelo qual ele torce? 


\subsection{Objetivos e Contribuições}

A expansão latente da indústria esportiva no Brasil cria no mercado um fator que até então estava presente apenas dentro das quatro linhas do campo: a rivalidade. Esta rivalidade extracampo resulta na disputa entre os clubes pela melhor fatia do mercado. Em um mercado em que cerca de $80 \%$ dos potenciais consumidores se identificam como torcedores de algum clube (Pluri \& Stochos, 2013), não basta aos clubes saber o tamanho de sua torcida, é preciso também conhecer a capacidade desta torcida em incrementar suas receitas.

$\mathrm{Na}$ busca por melhores receitas, os times devem encontrar os melhores consumidores, que irão possibilitar aumento de receita. A receita pode ser direta, com a compra de produtos dos clubes, ou indireta, que será derivada da capacidade do clube em demonstrar aos seus patrocinadores o grau de transferência da fidelidade do torcedor ao clube para o patrocinador. Essa transferência possibilitará aumentos das receitas dos clubes, oriundas do aumento ou do valor da cota do patrocínio ou da venda dos direitos de TV.

A lealdade do consumidor vem sendo fortemente analisada como um componente vital para o sucesso das organizações (Yuksel, Yuksel, \& Bilim, 2010). A importância da lealdade nos estudos de marketing pode ser notada pelo volume substancial de pesquisas publicadas em jornais acadêmicos importantes (Pan, 2012). Não à toa, grande parte dos estudos se preocupam em compreender melhor que tipo de recompensas e caraterísticas são mais eficientes no processo de fidelização do consumidor (Reczek, Haws, \& Summers, 2014)).

Criar e manter consumidores leais ajuda as empresas a desenvolver relacionamentos de longo prazo, que podem ser mutuamente benéficos (Pan, Sheng, \& Xie, 2012). Acontece que a relação entre time e torcedor é mais complicada e imprevisível. Torcedor pode ser leal, pode ser identificado, mas será que ele mantém essa disposição quando os concorrentes dos times deixam de ser os times adversários e começam a ser outras empresas da indústria do entretenimento? Essa questão força as equipes a desenvolver estratégias eficazes para motivar os espectadores a participar de jogos, a se associar e a, comprar produtos e serviços dos times (Theodorakis, Koustelios, Robinson, \& Barlas, 2009).

A lealdade do torcedor ao seu time é algo que não se discute no Brasil, de maneira que é inimaginável pensar num torcedor, já formado como tal, trocar de time e passar a torcer por 
uma equipe rival. Porém essa lealdade ao time pode garantir ao patrocinador este potencial consumidor?

O futebol se situa numa indústria orientada para resultados (Brady, Voorhees, Cronin Jr, \& Bourdeau, 2006). A experiência dos torcedores é, em grande parte, determinada pelo produto central, o jogo em si (Theodorakis \& Alexandris, 2008). É isso o que ocorre no futebol brasileiro.

Neste contexto, e com o intuito de ampliar o entendimento sobre identificação do torcedor e sobre lealdade no comportamento do consumidor, entendido em um novo contexto de esporte, o que pode contribuir para a evolução da área de estudos sobre organizações, comportamento do consumidor e marketing esportivo, além de tomar como base as teorias de transferência de imagem, de transferência de confiança e a teoria do equilíbrio, essa tese possui como objetivo:

Analisar se a lealdade do torcedor com seu clube pode ser transferida para as organizações patrocinadoras.

Para o desenvolvimento do objetivo central do trabalho, foram definidos ainda os seguintes objetivos específicos:

a) Desenvolver uma escala de identificação com o time, alternativa aos modelos já existentes;

b) Mensurar identificação com o time, fanatismo e lealdade ao time como variáveis distintas;

c) Evidenciar a distinção entre os construtos identificação, fanatismo e lealdade ao time;

d) Desenvolver modelo para analisar a transferência da lealdade do torcedor para as marcas patrocinadoras;

e) Propor alternativas gerenciais para os clubes e patrocinadores que auxiliem a atingir melhores resultados.

Com a questão de pesquisa definida e com os objetivos traçados este estudo, pretende contribuir com o avanço do conhecimento da seguinte maneira:

a) A mística brasileira existente que afirma que não existe nada mais leal que o sentimento do torcedor para com seu time é um ponto de reflexão deste 
trabalho. Não se tem dúvida desta lealdade, mas se questiona o que esta lealdade significa. Assim, este trabalho visa a contribuir para o avanço do conhecimento do significado da lealdade do torcedor, desenvolvendo um novo modelo que permita medir o grau de lealdade e o impacto da transferência desta lealdade aos patrocinadores;

b) Se a lealdade ao clube pode ser medida e é possível derivar dela uma tipologia dos torcedores, torna-se fundamental analisar a capacidade que o clube tem em transferir a lealdade do torcedor ao time para impulsionar o consumo de produtos. Assim, este trabalho busca contribuir com a ciência por meio do desenvolvimento de uma escala que permita medir a capacidade de transferência da lealdade ao clube para o ato de consumo. Será analisada a capacidade do clube em impulsionar a venda de produto ligados ao time e ao patrocinador por meio dos torcedores, apresentando assim o torcedor como vantagem competitiva;

c) Na questão profissional, ou seja, do ponto de vista da prática de mercado, esta pesquisa irá contribuir com a proposição de alternativas gerencias para as organizações esportivas de forma a melhorar o desempenho extracampo e o relacionamento com patrocinadores;

d) Contribuirá para que os patrocinadores possam buscar novas formas de mensurar a eficiência e a eficácia dos investimentos realizados por meio de patrocínio esportivo;

e) O trabalho apresentará, de maneira concisa, soluções para melhorar a cesta de ofertas das entidades esportivas e dos patrocinadores para seus fãs. Assim, do ponto de vista da prática gerencial, os clubes poderão aumentar a participação dos torcedores na receita finnal, de forma a diminuir a dependência em relação aos direitos de TV e aumentar a participação das receitas diretas e indiretas derivadas dos torcedores. No caso específico do mercado brasileiro, isso poderia diminuir a dependência com relação à venda de atletas. Já os patrocinadores poderão diversificar os objetivos do patrocínio. Diminuindo a dependência por exposição de mídia e aumentando o engajamento com possíveis consumidores. 


\subsection{Delimitações do Estudo}

Já mostramos a importância, a complexidade e a amplitude do tema que apresentaremos. Querer tratá-lo em toda sua extensão seria impraticável. Assim, cabe aqui estabelecer algumas delimitações deste estudo.

Apesar do reconhecimento mundial com relação à capacidade do Brasil em montar grandes times e fabricar craques, os números financeiros dos clubes brasileiros mostram que o espaço do torcedor dentro do espetáculo futebol ainda é limitado no que diz respeito à sua participação nas fontes de receitas dos principais clubes nacionais (Figura 2).

As receitas oriundas dos torcedores (bilheteria, patrocínio e publicidade) representam apenas $24 \%$ das receitas dos clubes em 2014. A venda de atletas (22\%) e cotas de TV (33\%) que em 2009 representavam 34\% da receita total - atingiram sua representação máxima nos últimos cinco anos em 2012 e 2103 (54\% e 55\%), mostrando que os times brasileiros ainda estão longe de fazer do torcedor uma real fonte de receita.

Figura 2: Participação das Fontes de Receitas dos 24 maiores clubes de futebol do Brasil

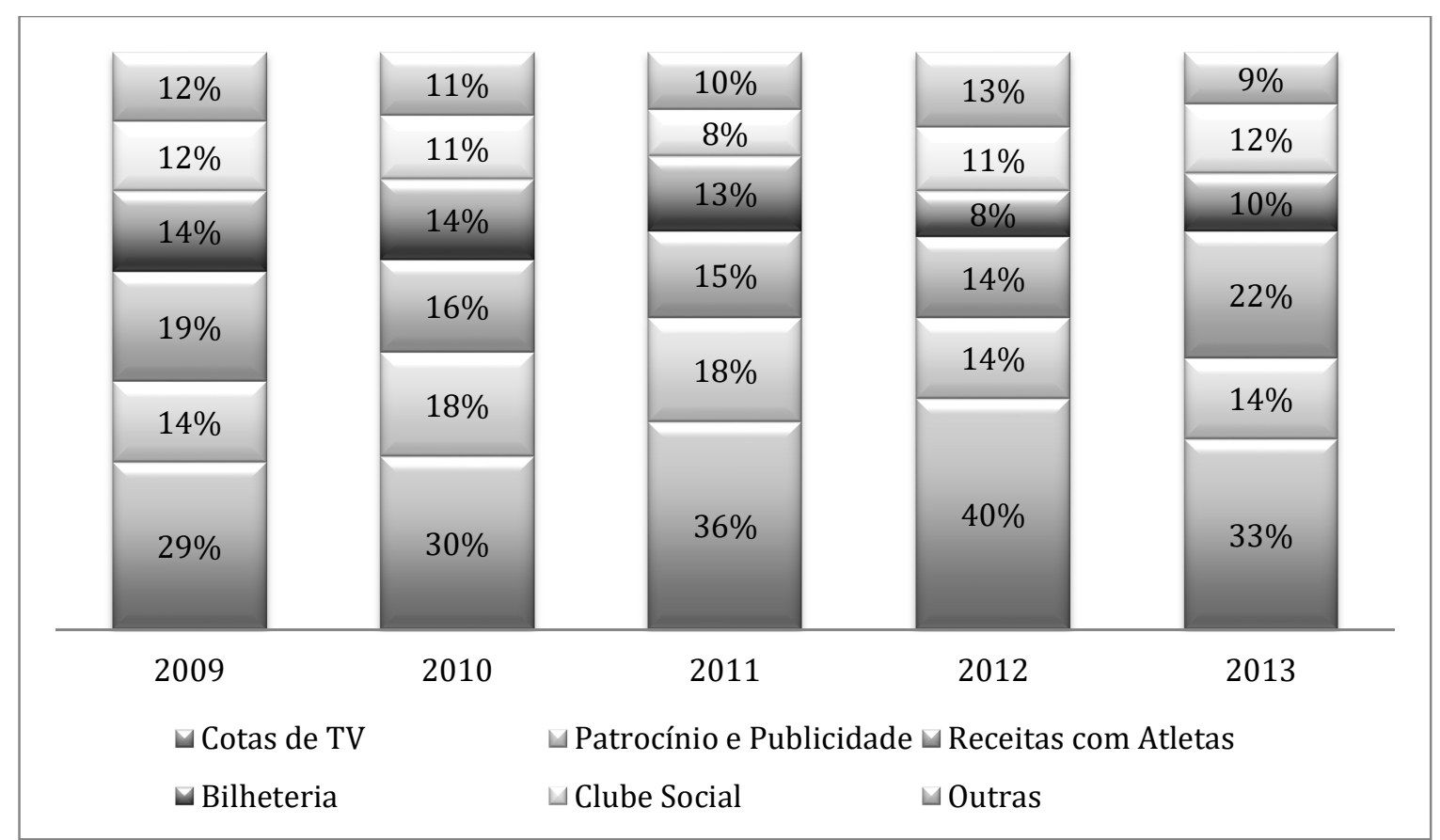

Fonte: Criado pelo autor baseado em BDO Brasil (2014)

As receitas oriundas de cotas de TV crescem vertiginosamente desde 2009, ocupando o espaço de receitas com patrocínio, publicidade e bilheteria. Essa dependência cada vez maior do futebol brasileiro em relação à TV pode se mostrar prejudicial para os clubes a 
longo prazo, pois isso afeta as estratégias de relacionamento com o torcedor, como demonstram as reclamações por causa dos horários das partidas.

Mas é possível identificar a importância do torcedor nas mais diversas fontes de receita, mesmo que não eles não sejam realmente considerados pelos clubes. A distribuição, no modelo atual, das cotas de TV é feita tendo como base a capacidade do time em gerar audiência. Os valores dos patrocínios, bilheterias, souvenirs e merchandising também são frutos do tamanho da torcida e do potencial de consumo da mesma. Neste sentido, a ampliação da torcida se mostra necessária, não só para melhorar a distribuição das fontes de receitas, mas para também aumentar os valores das já existentes. Assim, este trabalho assume a premissa de que, conforme (Landau, 2012), o torcedor deve ser visto como o principal stakeholder da indústria do esporte.

Se é necessário pensar no consumidor desde o início, é fundamental conhecer o consumidor e saber quem ele é. Seu comportamento pode ser moldado por fatores externos e internos e, por isso, a ciência do comportamento do consumidor leva em consideração aspectos não apenas econômicos, mas também psicológicos e sociais do ser humano (AbdelGhany, 2001). Conforme Tokuyama e Greenwell (2011) torcedores e praticantes de esportes tendem a ter hábitos de consumo diferentes. Assim, esta pesquisa terá como foco os consumidores de esportes, a que chamaremos torcedores ou fãs.

Adotaremos como premissa, conforme Gladden e Funk (2002), que o torcedor só se torna uma fonte de receita quando os clubes criam uma relação de proximidade com ele, possibilitando-o vivenciar momentos únicos e inesquecíveis. Para que isso aconteça, é necessário que os clubes saibam quem são seus consumidores, como pensam e o que procuram.

Neste trabalho, consideraremos clubes nacionais ou estrangeiros, dos mais variados esportes, como organizações esportivas ou entidades esportivas. Adotaremos, indistintamente, a nomenclatura times, clubes e equipes, que serão vistas como firmas, com sua estrutura organizacional estreitamente relacionada à sua forma de apresentação ao público consumidor. Assumiremos como premissa que clubes não devem ser apenas organizados como um winmaximizer, mas como um profit-maximizing (Dietl, Lang, \& Werner, 2009).

Entendemos que o consumidor passa por constantes mudanças. Essas mudanças afetam os hábitos de consumo das pessoas e por consequência afetam as organizações. Um 
exemplo está na crescente demanda dos consumidores esportivos por produtos/serviços melhores (por exemplo: arenas multiuso). Além disso, a utilização cada vez maior de dispositivos móveis com internet, mídias sociais, exigem que as empresas repensem seu ambiente de negócios (Kandampully, Zhang, \& Bilgihan, 2015).

Essa mudança no comportamento dos consumidores vem proporcionando aos consumidores um novo papel (Wirtz et al., 2013). Neste sentido, os times e equipes esportivas devem assumir uma visão na qual o torcedor seja visto como alguém que contribui significativamente para o valor do produto/serviço e que, ao mesmo tempo, direciona as estratégias da organização. Assim, os times devem buscar caminhos para aumentar o envolvimento ativo dos torcedores com o time e com as empresas patrocinadoras, incentivando-os a ser embaixadores da marca (James, 2013).

\subsection{Estrutura da Pesquisa}

Um time de futebol para ter sucesso precisa ter seus onze jogadores bem entrosados e alinhados. Analogamente a essa disposição tática, esta pesquisa consiste de onze capítulos, os quais estão estruturados conforme demostrado a seguir.

O presente capítulo introduz o leitor ao tema estudado, apresentando o contexto do tema do trabalho. Mostramos a importância de abordar o tema das organizações esportivas e de entender o torcedor para além desta nomenclatura, como consumidor. Pois isso pode ser o paradigma central da mudança de posicionamento das organizações esportivas dentro da indústria do esporte. Apontamos a complexidade deste trabalho e apresentamos a questão de pesquisa, os objetivos e as delimitações deste estudo.

No segundo capítulo, tratamos da fundamentação teórica necessária à sustentação do trabalho. Primeiramente, abordamos os conceitos relativos à vantagem competitiva e situamos o torcedor como tal. Em seguida, falamos a respeito da teoria da identidade social e da identificação do torcedor com o time. Trazemos à luz os conhecimentos teóricos relativos à teoria da lealdade, momento em que abordamos o comportamento do consumidor e, em específico, do consumidor esportivo. Por fim, mostramos os paradigmas relacionados ao patrocínio esportivo. 
No terceiro capítulo, o tema é a transferência da lealdade. Para tal, abordamos os fundamentos da teoria da transferência e da teoria do equilíbrio, que, juntas, servem de alicerce para construção teórica da transferência da lealdade.

No quarto capítulo, apresentamos o modelo teórico, bem como o quadro resumo das hipóteses, sustentadas nos capítulos dois e três. O quinto capítulo fala a respeito do desenvolvimento da escala. São apresentados os indicadores utilizados para desenvolvimento da mesma.

No sexto capítulo, tratamos dos procedimentos metodológicos utilizados neste estudo. Apresentamos e justificamos os métodos adotados e mostramos o desenho da pesquisa. Explicamos os critérios utilizados para definição da população e seleção das amostras e como efetuamos as coletas.

A modelagem de equação estrutural, técnica utilizada nesta tese, é apresentada de forma detalhada no sétimo capítulo. Abordamos os tipos de modelagem e os parâmetros utilizados para mensurar os dados deste trabalho.

O oitavo e nono capítulo são destinados ao desenvolvimento da análise das amostras. Apresentamos os resultados dos modelos de mensuração e estrutural, bem como dos testes de hipóteses das duas amostras desta pesquisa. Assim, no décimo capítulo, apresentamos os resultados cruzados das amostras.

Por fim, no décimo primeiro capítulo, apresentamos as considerações finais. Introduzimos as discussões de encerramento, apresentamos nossas contribuições gerenciais e acadêmicas. Finalizamos nosso trabalho com as limitações do trabalho e sugestões para pesquisas futuras. 


\section{FUNDAMENTAÇÃO TEÓRICA}

$\mathrm{Na}$ primeira parte da fundamentação teórica, apresentam-se os conceitos centrais que norteiam a visão que esta tese tem a respeito do modelo do futebol brasileiro e do modelo de organização do esporte, além de um panorama geral das relações envolvendo patrocinadores, clubes e torcedores no Brasil, com o objetivo de apresentar o torcedor como vantagem competitiva. O capítulo segue com a apresentação dos principais conceitos, tipologias e mensurações referentes à identificação do torcedor. Na sequência, abordam-se os conceitos a respeito dos construtos envolvidos nesta tese, que se relacionam com lealdade e patrocínio. A teoria do equilíbrio e da transferência será o alicerce para construção do framework proposto. Por fim, apresentam-se os conceitos existentes sobre vantagem competitiva e mostra-se como a lealdade do torcedor pode se tornar uma.

\subsection{Vantagem competitiva}

Neste trabalho, entendemos o futebol como parte de uma grande indústria: a indústria do esporte. Por isso, buscamos ver os times de futebol como empresas, e não como associações ou organizações sem fins lucrativos. Ocorre que o esporte como indústria apresenta algumas peculiaridades que fazem com que os processos produtivos sejam diferentes. Tais processos abrangem duas etapas distintas, mas relacionadas (Franck, 2003).

A primeira etapa diz respeito ao time em si, ou seja, aos clubes considerados de forma individual. Porém nenhuma equipe é capaz de produzir um produto comercializável sozinha. É neste sentindo que o esporte, diferente de outra indústria, cria a necessidade de concorrentes (Dietl, Franck, Hasan, \& Lang, 2009). Em suma, não existe produto comercial sem adversários.

Com isso, chegamos à segunda etapa: o campeonato. Quando os times se unem e criam um campeonato em que podem medir suas forças, eles estão produzindo um produto comercial. É por meio deste processo de produção que o esporte abre as portas para diversos outros produtos serem fabricados e produzidos. Ídolos, camisas, patrocínios, cotas de TV só existem por que há uma competição entre as equipes. 
"However, when comparing revenues from exhibition games to those from championship games, one begins to see that the value of the latter significantly exceeds that of the former. The value of any game depends on the strength of the participating teams. However, the relevance of the game for the championship contributes more significantly to the game's value" (Dietl, Franck, Lang, \& Rathke, 2011, p. 2)

Assim, a competição iniciada dentro das quatro linhas do campo é o pontapé inicial para criação da indústria do esporte. Dentro deste cenário, os clubes devem atender a uma necessidade específica de seu mercado: vencer os campeonatos de que participa. E, ao mesmo tempo, gerar lucro. Assim, poderá continuar a exercer suas atividades.

Dentro desta visão econômica, que toma os times de futebol como empresas, numa indústria competitiva, pode-se imaginar que os clubes devem buscar entender sua cadeia de valor, para poder competir e criar vantagem competitiva dentro de seu mercado (Porter, 1990). Neste sentido, o comportamento dos agentes econômicos é que determina o desempenho das empresas (no caso, os clubes), e o posicionamento de cada clube nesta indústria será determinante para seu sucesso ou fracasso.

"At the broadest level, firm success is a function of two areas: the attractiveness of the industry in which the firm competes and its relative position in that industry. Firm profitability can be decomposed into an industry effect and a positioning effect. Some firm successes come almost wholly from the industry in which they compete; most of their rivals are successful, too! ", (Porter, 1991, pp. 99-100)

Entender as diferenças entre atratividade do setor e a posição relativa na indústria é fundamental na hora de definir estratégias empresariais, pois, entre outras coisas, as empresas podem escolher por estratégias que beneficiam uns, mas prejudicam outros (Porter, 1991).

Essas definições de vantagens competitivas apresentadas são oriundas da corrente de pensamento chamada de Análise do Posicionamento de Estratégica (APE). Mas há outra

5 'No entanto, quando se comparam as receitas de jogos de exibição com a dos jogos do campeonato, começamos a ver que o valor destes é maior de forma significante. O valor de qualquer jogo depende da força das equipes participantes. No entanto, a relevância do jogo para o campeonato contribui mais significativamente para o valor do jogo".

6 “No nível mais amplo, o sucesso da empresa é em função de duas áreas: a atratividade do setor em que a empresa compete e sua posição relativa na indústria. A rentabilidade da empresa pode ser dividida em efeito da indústria e efeito do posicionamento. Alguns sucessos destas empresas vêm quase totalmente do setor em que eles competem; a maioria de seus rivais são bem-sucedidos também”. 
linha importante de pensamento, que é importante compreender: a Teoria Baseada em Recursos $\left(\mathrm{RBT}^{7}\right.$ ) (Ito, Hayashi Junior, Gimenez, \& Fensterseifer, 2012). A APE baseia seu pensamento de vantagem competitiva no valor que a empresa consegue criar para seu comprador e que ultrapassa seu custo de fabricação (Porter, 1998). Por outro lado, a RBT acredita que a vantagem competitiva é oriunda de uma estratégia de criação de valor que não pode ser copiada pelos concorrentes.

"A firm is said to have competitive advantage when it is implementing a value creating strategy not simultaneously being implemented by any current or potential competitor. A firm is said to have a sustained competitive advantage when it is implementing a value creating strategy not simultaneously being implemented by any current or potential competitor and when these other firms are unable to duplicate the benefits of this strategy. ", (Barney, 1991, p. 102)

Apesar da distinção entre as linhas de pensamento (APE ou RBT), uma coisa é comum a elas: a criação de valor (Porter \& Kramer, 2011). Donde a necessidade de definir "valor":

"valor tanto está relacionado com dimensões ao mesmo tempo internas e externas à organização, pois satisfaz as necessidades dos consumidores em termos de produtos e serviços, quanto está relacionado ao modo como a firma concebe e operacionaliza suas estratégias. "(Ito et al., 2012, p. 292)

Dentro desta concepção, é interessante notar que as organizações esportivas vêm passando por uma série de mudanças, e a visão de trabalho em ligas organizadas dentro de um sistema de governança cooperativa, oriundas do modelo norte-americano, começa a ser consenso mundial.

"Professional team sports are characterized by legally independent entities that jointly produce a product which essentially is the championship race. In contrast to their North American

${ }^{7}$ Do inglês Resource-based Theory

8 “A empresa diz ter vantagem competitiva quando implementa uma estratégia de criação de valor que não pode ser simultaneamente implementada por qualquer concorrente atual ou potencial. A empresa diz ter uma vantagem competitiva sustentável quando implementa uma estratégia de criação de valor que não pode ser simultaneamente implementada por qualquer concorrente atual ou potencial e quando essas outras empresas não são capazes de duplicar os benefícios desta estratégia”. 
counter-parts, most European professional sports leagues have only quite recently transformed their organizational structure into one of cooperative governance." "(Dietl et al., 2009, p. 127).

Este modelo de governança cooperativa permite que os times continuem autônomos nas decisões que lhe são individuais (primeira etapa do processo de produção (Franck, 2003). Por outro lado, quando analisamos a produção do campeonato (segunda etapa no processo de produção), os clubes, como proprietários da liga, passam a pensar no todo, visando a ganhos oriundos de um campeonato mais vantajoso para todos.

Neste cenário, assim como já ocorria no mercado norte-americano, o consumidor de esporte e mesmo o torcedor passam a ser mais exigentes, o que é similar ao que Woodruff (1997, p. 139) descreveu do mercado geral:

\footnotetext{
"We are witnessing an amazing transformation in organizations. Driven by more demanding customers, global competition, and slow-growth economies and industries, many are on a journey, searching for new ways to achieve and retain competitive advantage. ${ }^{10}$,
}

$\mathrm{Na}$ indústria do esporte, a vantagem competitiva pode estar em descobrir novas maneiras de atender ao cliente. Uma compreensão mais profunda do mercado pode impulsionar os times a lucrar mais. Neste trabalho propomos que o torcedor de futebol, além de consumidor do time, é também uma vantagem competitiva para sua equipe. Porém, para que as equipes possam apresentar ao mercado (patrocinadores, TV etc.) seus torcedores como vantagem competitiva, são necessárias grandes mudanças na forma como as organizações são geridas.

\subsubsection{O torcedor como vantagem competitiva e o esporte no Brasil}

Dentre todos os stakeholders envolvidos no esporte talvez nenhum seja mais importante do que o torcedor (Landau, 2012). Aliás, conforme dissemos, a premissa desta tese

9 "Equipe esportivas profissionais são caracterizadas por serem entidades juridicamente independentes que produzem conjuntamente um produto que essencialmente é a diferença do campeonato. Em contraste com seus homólogos norte-americanos, a maioria das ligas europeias profissionais de só muito recentemente transformaram suas estruturas organizacionais em uma de governança cooperativa".

10 "Estamos testemunhando uma transformação incrível nas organizações. Impulsionada por clientes mais exigentes, concorrência global, economia em crescimento econômico e industrial lento, muitos estão em uma viagem em busca de novas maneiras de alcançar e manter a vantagem competitiva”. 
é a de que o torcedor é não apenas um dos mais importantes, mas sim o mais importante participante do mercado esportivo. É ele que gera o interesse e a riqueza que cerca o futebol.

São os consumidores que adquirem ingressos para assistir aos jogos in loco, que são alvo da televisão, que compram camisas e outros itens oficias (e, em muitos casos, não oficiais) de seus times "de coração" e gastam horas na internet lendo e pesquisando sobre seus clubes. Por isso, eles são o objeto de desejo dos times e dos patrocinadores. Assim, o sucesso extracampo de um time ou de um patrocinador passa necessariamente por conhecer melhor estes consumidores.

Quando falamos em sucesso de uma equipe esportiva logo associamos este sucesso a vitórias em campo. São os títulos conquistados, ao lado seu peso e sua relevância, que nos fazem dizer se um time é grande ou não. Porém, quando analisamos essa questão do ponto de vista comercial, pelo olhar do negócio, analisar apenas resultados de campo é pouco eficiente. Diversos estudos mostram que o sucesso de um evento está relacionado diretamente ao consumo in loco do evento esportivo. Em outras palavras, estádio cheio é um sinal de sucesso. Estes fãs - torcedores em geral - saem de suas casas, deixam de lado outras atividades, para acompanhar ao vivo suas equipes. E a participação deles é fundamental para o sucesso do evento. Quanto mais pessoas nos estádios e mais animadas, mais valor elas agregam ao espetáculo. Imaginem como seria uma Copa do Mundo sem público. Uma final sem torcida.

A visão de uma arquibancada vazia é imediatamente associada ao fracasso do evento. Seja para quem está no estádio, seja para quem está assistindo pela televisão. Não à toa, o público no estádio, ou melhor, a falta de público no estádio vem sendo um dos temas mais discutidos pelos envolvidos com a realização das atividades futebolísticas no país. Casa vazia é sinal de pouco interesse por parte do torcedor e transmite diretamente a impressão de que a qualidade do espetáculo é ruim. E produto ruim vale menos.

Nesse sentido, o esporte mostra sua face de crueldade para com o torcedor: quanto mais ele, como peça chave para valorização do espetáculo, demonstra presença e animação, mais caro o show fica (Fleury, Brashear-Alejandro, \& Feldmann, 2014).

E, por tudo isso, entender o torcedor, em todos os seus aspectos, é tão importante. Nessa pesquisa, a teoria da identidade social (Tajfel \& Turner, 1986) será utilizada para compreender a relação entre o torcedor e seu time. 


\subsection{Teoria da Identidade Social}

As pessoas normalmente definem a si mesmo e aos outros tendo como base um sistema de categorias sociais. Isso significa que os indivíduos desenvolvem e definem sua identidade social por meio de suas características pessoais, bem como suas associações e posições dentro de grupos sociais (Tajfel \& Turner, 1979). Neste sentido, conforme Tajfel (1972, p.292), podemos entender a identidade social como "the individual's knowledge that he belongs to certain social groups together with some emotional and value significance to him of this group membership ${ }^{11 "}$.

A identidade social é composta por duas dimensões de "identidade": uma dimensão pessoal pertencente às características comportamentais da pessoa, tais como habilidades e interesses, e uma dimensão social baseada em conexões, associação ou relações com grupos maiores. Comumente as pessoas têm por hábito, ao se apresentar, destacar suas ligações sociais. Enfatizamos nossos laços familiares (pai de quem, filho de quem), profissionais (onde e com quem trabalhamos) e de lazer (onde e com quem nos divertimos).

Esses grupos sociais, de ambas dimensões de identidade, possuem diversas naturezas. Podemos encontrar singularidades e semelhanças, que refletem um pouco de cada um de nós, numa sala de aula, na igreja, num grupo político, num grupo de fãs de Star Wars. Percebe-se nesta constituição dos grupos um ponto importante: o interesse em comum. É esse interesse comum (Ashforth \& Mael, 1989; Carlson \& Donavan, 2013) que estabelece o elo entres os indivíduos do grupo.

Assim, pensando no torcedor e em sua identificação com o time pelo qual ele torce e com o qual, por consequência, possui laços, podemos compreender com a construção dessa identidade é relevante. Assistir a uma partida esportiva é, em todo lugar do mundo, uma atividade de lazer. Normalmente uma atividade popular (como jogos do campeonato estadual), mas que em muitos momentos pode se tornar cara (no caso de jogos da Copa do Mundo). Assim, particularmente interessante é ver que muitas pessoas se definem em função

\footnotetext{
11 "O conhecimento do indivíduo de que ele pertence a certos grupos sociais, que possuam para ele algum significado emocional e de valor".
} 
do time para qual torcem. Ser torcedor faz parte da identidade social. Ser "corintiano", "flamenguista", "colorado", "são-paulino" nos define, não apenas como torcedores, mas como sujeitos sociais. A identificação com o time é parte da identidade de cada brasileiro e de muitos povos ao redor do mundo.

Essa identificação com o time se forma a partir da identidade social (Kwon \& Kwak, 2014). É a orientação do self em relação ao time pelo qual o indivíduo torce que gera um sentimento de pertencimento (Fink, Trail, \& Anderson, 2002), o que está em acordo ao que (Turner, 1975) apresentava como central para o desenvolvimento da teoria da identidade social: a necessidade que as pessoas possuem de encontrar distinção para si e para os grupos dos quais ela faz parte.

Assim, esse sentimento de exclusividade é uma necessidade que o indivíduo tem para si e para os grupos a que ele pertence, que são formados pela soma das características individuais de cada um de seus membros (Fisher \& Wakefield, 1998). Mesmo tendo em conta as particularidades de cada indivíduo, estes possuem algum interesse em comum que justifica fazer parte de um determinado grupo, que se torna parte da identidade social da pessoa (Carlson \& Donavan, 2013).

Assim como os membros de uma organização (por exemplo, funcionários) tendem a se identificar com as empresas que trabalham (Kang, Alejandro, \& Groza, 2015), é natural pressupor que os torcedores também se identifiquem com seus times por meio da teoria da identidade social.

Em suma, torcer para determinado time ajuda o torcedor a responder à questão de quem ele é. E, por meio de uma série de fatores que fazem esse torcedor demonstrar seu pertencimento ao grupo de que ele faz parte (o time para o qual ele torce), elevar sua autoestima (Branscombe \& Wann, 1991).

Produzir um vínculo psicossocial é fundamental na criação da identidade social do indivíduo. Para que esse vínculo aconteça, os consumidores (torcedores) precisam encontrar na identidade da empresa (time) atratividade e, com isso, desenvolver uma identificação que o ajude a satisfazer necessidades básicas de autodefinição, incluindo um aumento de autoestima, alcançado ao expressar uma avaliação positiva de si mesmo ao mundo exterior (Brashear-Alejandro, Kang, \& Groza, 2016). 
O vínculo entre consumidor (torcedor) e uma organização (time) influencia a redução do distanciamento psicológico entre os membros do mesmo grupo. A partir do momento em que as pessoas dos grupos começam a se relacionar, o "eu” passa a dar lugar ao "nós", com o interesse coletivo se sobrepondo ao individual. "A customer identifies with a company if doing so increases feelings of self-worth through enhanced connections and social standing ${ }^{12}$ " (Kang et al., 2015. P. 1191).

Portanto, a autoestima auxilia as pessoas a identificar quem são os membros que pertencem ao mesmo grupo (Gwinner, Larson, \& Swanson, 2009), ao enxergar elementos semelhantes a si mesmo em outras pessoas. Assim, a identificação com o time é influenciada pelo conceito da identidade social que a pessoa procura para si mesma. Essa identificação pode ser mensurada pela ligação psicológica entre o time e o torcedor (Gau, James, \& Kim, 2009).

\subsection{Identificação com o time}

A teoria da identidade social propõe que as pessoas buscam, entre outras coisas, benefícios psicológicos, quando se associam a seus grupos de interesse. Assim, no contexto esportivo, essa teoria foi adaptada para explicar a relação existente entre torcedores e seus times (Yoshida, Heere, \& Gordon, 2015; Bodet \& Bernache-Assollant, 2011).

A identificação com um grupo social indica o grau pelo qual as pessoas veem este grupo como parte delas mesmas (Dutton, Dukerich, \& Harquail, 1994). (Fisher \& Wakefield, 1998) mostram que a identificação social pode ser conceituada como uma orientação psicológica em que os indivíduos se definem em função dos grupos dos quais fazem parte. No caso dos torcedores, eles se identificam com seus clubes ao incorporarem atributos dos times a suas descrições (Greenwell, Fink, \& Pastore, 2002). Ser parte do "bando de loucos"13, por exemplo, define não o grau de insanidade do torcedor, mas sim caracteriza-o como um

\footnotetext{
${ }^{12}$ Um cliente identifica-se com uma empresa, se isso aumenta o sentimento de autoestima por meio de conexões reforçadas e de posição social. nos estádios.

${ }^{13}$ Bando de loucos é uma das formas pela qual a torcida do Corinthians tem por hábito se apresentar
} 
aficionado por seu clube. O mesmo acontece com a nação "rubro-negra ${ }^{14 ", ~ " o ~ p o r c o ~}{ }^{15 "}$ e tantas outras definições presentes Brasil a fora.

Mas o grau de identificação com o time não é uma variável estável, pois isso pode mudar através do tempo e ser diferente entre os mais variados torcedores e times. Os torcedores, apesar de compartilharem pontos em comum, não são iguais e podem consumir esporte e seus produtos derivados das mais variadas formas. Alguns torcedores são mais abertos em relação a seus times, outros gostam de ir a todos os jogos, alguns preferem ir somente aos jogos mais especiais e outros preferem assistir pela televisão (Stewart, Smith, \& Nicholson, 2003).

Assim, conhecer os torcedores por meio do processo de segmentação de consumidores permite entender melhor as necessidades e características dos torcedores (Tapp \& Clowes, 2002). Uma tipologia destes torcedores, do ponto de vista estratégico, pode ajudar times, patrocinadores e demais envolvidos com esporte a responder melhor às demandas dos torcedores, permitindo, assim, ações de marketing direcionada (Hunt, Bristol, \& Bashaw, 1999).

Como veremos a seguir, os torcedores podem ser segmentados em diversos grupos. As tipologias existentes, em sua maioria, tiveram como foco entender o porquê de o torcedor fazer parte de um grupo, porém, nesta tese, a tipologia dos torcedores será empregada, também, para entender "que" grupos estes torcedores formam.

A literatura atual propõe as mais variadas categorias de torcedor, mas todas são baseadas sempre em função de uma maior ou menor identificação com o clube. (Sloan, 1989) foi um dos primeiros a mostrar que torcedores se comportam de maneira diferente de acordo com seu grau de identificação com o time. Sua proposta apresentava dois tipos de torcedores: os chamados fãs de verdade e os meros espectadores.

\footnotetext{
${ }^{14}$ Apesar de não ser uma nação, não do ponto de vista do Estado, muitas torcidas se apresentam como tal. Neste caso a torcida do Flamengo, representada por suas cores (rubro e negro) foi utilizada como exemplo.

${ }^{15}$ Por anos o "apelido" dado aos torcedores palmeirenses foi motivo de chacota. Hoje, incorporado ao time e a torcida, é utilizado para identificar o torcedor palmeirense.
} 
Dentro do conceito proposto por Sloan (1989), os torcedores verdadeiros são considerados devotos a seus times. Identificam-se fortemente com o clube, comparecem aos jogos e não possuem receio de demostrar seu apoio. Já os meros espectadores são torcedores que se identificam de maneira parcial ou moderada. Comparecem raramente aos estádios e demostram seu apoio ao time de maneira cautelosa ou tímida.

Wann \& Branscombe (1990) dividiram os torcedores em dois grupos, classificados como die-hard fans e fair-weather fans ${ }^{16}$. A base desta classificação está atrelada ao grau de identificação do torcedor com sua equipe. Assim, os die-hard fans são aqueles apaixonados e obstinados por seus times. Possuem alta frequência na busca por informações do clube, têm orgulho ao expressar seu apoio ao clube de coração e não se abalam com maus resultados. Do outro lado, temos os fair-weather fans, que dependem de uma série de fatores positivos para manifestar sua paixão.

Outro estudo importante para o entendimento do consumidor esportivo é o de Madrigal (1995). O autor analisa o processo de cognição e as reações afetivas do torcedor, mostrando como elas se relacionam com um jogo. A pesquisa mostra que, entre outras variáveis, a identificação do torcedor com o clube afeta o processo cognitivo. Torcedores que possuem um grau mais alto de identificação são mais propensos a experimentar alegrias nos resultados positivos do que sofrer com as derrotas.

Uma nova proposta de segmentação dos torcedores, ainda seguindo as questões relacionadas com a identificação com a equipe foi apresentado por Sutton, McDonald, Milne, e Cimperman (1997). Esta identificação é baseada em quatro características: da equipe (sucesso no campo), da organização (tradição do time), de afiliação (necessidade de pertencer a um grupo) e de atividade (informação sobre futuros jogos).

No modelo proposto por Sutton et al. (1997), os torcedores são divididos em três grupos: os torcedores sociais possuem baixa identificação com o time e são atraídos para os jogos pela possibilidade de socialização e interação com outros adeptos; os torcedores focados possuem média identificação com o time e podem ser atraídos ao estádio por fatores sociais,

\footnotetext{
${ }^{16}$ Uma tentativa próxima de tradução dos termos propostos seria: fãs obstinados (die-hard fans) e fãs das horas certas (fair-weather fans). Porém, acredita-se que a tradução pode não representar os conceitos empregados pelos autores. Desta maneira optou-se por manter o original em inglês.
} 
devido a um jogador específico ou à performance do time; e os torcedores que vestem a camisa possuem alta identificação com seu time de coração e estão dispostos a investir para assistir a seu time jogar, apoiando-o sempre.

Evidenciado em pesquisas passadas (Cialdini et al., 1976; Fisher \& Wakefield, 1998; Madrigal, 1995; Snyder, Lassegard, \& Ford, 1986; Sutton et al., 1997), o sucesso da equipe tem uma relação direta com a identificação do torcedor. Assim, equipes que obtêm sucesso em campo tendem a ter torcedores mais identificados do que outras equipes. Porém o sucesso em campo não pode ser medido apenas por vitórias. Se imaginarmos o campeonato brasileiro de futebol, com 20 equipes, sendo que 12 destas equipes são consideradas tradicionais no futebol brasileiro e, por isso, seus torcedores esperam, sempre, que elas vençam as competições que disputam, podemos indagar a respeito da dificuldade do que é ter sucesso em campo se ele for mensurado apenas por títulos.

Kelman (1961)propôs que qualidades desejáveis do grupo são determinantes na identificação do grau em que os indivíduos se identificam com seus grupos. Vencer pode ser uma qualidade desejável, mas não a única. Fisher e Wakefield (1998) encontram evidências que mostram que, independentemente do sucesso do time, torcedores mais identificados iam mais aos jogos e comprovam mais produtos de suas equipes.

Nesse sentido, podemos pressupor que a identificação com o time pode ajudar a superar possíveis frustrações com resultados adversos em campo. Os estudos de Matsuoka, Chelladurai e Harada (2003) apoiam esta análise quando mostram que comparecer a jogos futuros era muito mais reflexo da identificação com o time do que dos resultados momentâneos da equipe em campo. Tal fato explica, em parte, como equipes que possuem "características indesejáveis" conseguem manter seus torcedores ou mesmo fazer crescer o número de sócios.

Um exemplo é o Chicago Cubs ${ }^{17}$, equipe de beisebol dos Estados Unidos que continuou vendendo ingressos para jogos, apesar de a equipe não vencer um campeonato por diversos anos (Scully, 1995). Já em território nacional, temos como exemplo o rebaixamento

17 “O Chicago Cubs venceu o campeonato (World Series) após 108 anos de "jejum”, em 3 de novembro de 2016. Este lapso temporal é considerado a mais longa seca de títulos de uma equipe esportiva profissional nos Estados Unidos". 
das chamadas equipes tradicionais para a segunda divisão do futebol brasileiro: em vez de diminuir a número de pessoas no estádio, como seria esperado com base nas teorias apresentadas, esse número muitas vezes cresceu. Esse comportamento "não adequado" pode ser explicado pela complexa conexões psicológicas entre os torcedores e a suas equipes (Funk \& James, 2001), o que ajuda a suportar os achados de Fisher e Wakefield (1998).

Mahony, Madrigal e Howard (2000) e Murrell e Dietz (1992) também contribuem para entender esta questão, quando demonstram que o apoio à equipe pode estar desconectado do comparecimento aos estádios, que, como medida de comportamento, pode ser enganosa. Ir ao jogo pode ser resultado de um hábito, falta de alternativa ou mesmo comodidade (por exemplo, quando o estádio está perto da casa do torcedor) (Mahony et al., 2000).

Como podemos perceber, desde os primeiros trabalhos a respeito do comportamento do consumidor esportivo, com Cialdini et al. (1976) e Funk \& James (2001), compreender a relação entre torcedores e equipes vem sendo um campo de interesse e de importância para a escola da administração e, por consequência, para o marketing. Diversas pesquisas buscaram entender os mais variados fenômenos, tais como as características demográficas e ambientais (Baade \& Tiehen, 1990; Hansen \& Gauthier, 1989), os fatores cognitivos, afetivos e comportamentais (Madrigal, 1995; Murrell \& Dietz, 1992; Wann \& Branscombe, 1990; Wann \& Branscombe, 1993) e o comprometimento do torcedor (Mahony et al., 2000; Smith, Patterson, Williams, \& Hogg, 1981).

Apesar dos esforços para compreender as características do torcedor neste domínio único que é o esporte (Neale, 1964), as pesquisas nesta área continuam extremamente fragmentadas e vários termos eram utilizados para descrever a relação dos torcedores com o esporte ou equipe (Funk \& James, 2001)

Greenwell et al. (2002) mostram que torcedores eram recursos a ser explorados, uma vez que eles são fundamentais para o sucesso financeiro de suas equipes ao comprarem ingressos, uniformes e suvenires em geral. Neste ponto, a identificação com a equipe sempre teve destaque e aparece como um forte antecedente da lealdade: intenção de participar dos futuros jogos da equipe (Matsuoka, Chelladurai \& Harada, 2003; Wakefield, 1995); (Bernache-Assollant, Bouchet, \& Lacassagne, 2007, Wann \& Branscombe, 1993), o dinheiro gasto na equipe e mercadorias relacionadas (Fisher \& Wakefield, 1998), o comparecimento atual aos jogos (Fisher, 1998; Murrell \& Diet, 1992; Wann \& Branscombe, 1993), o 
acompanhamento das partidas por TV ou rádio (Bernache-Assollant, Bouchet, \& Lacassagne, 2007, Fisher, 1998; Melnick \& Wann, 2004).

Neste sentindo, a literatura de gestão do esporte vem de forma consistente demonstrando que a identificação com o time é um ponto nevrálgico na construção de uma relação sólida com os torcedores. E diversos estudos apontam o impacto positivo da identificação nas atitudes a seu time. (Lee \& Kang, 2015).

Assim, nesta pesquisa, defende-se a ideia de que identificação e lealdade com o time são coisas distintas. Também se entende que o fanatismo, que muitas vezes é tratado como o nível máximo da identificação (ou lealdade) do torcedor para com seu time, é na verdade um construto independente da identificação. Desta forma, trabalha-se nesta pesquisa com a identificação como um antecedente do fanatismo e, ambos, como antecedentes da lealdade, conforme apresentado na Figura 3.

Em linha com esse pensamento Lee e Joon-Ho Kang, (2015, p. 225) afirmam que

"While many researchers have examined the impact of team identification on various sport fan behaviors, the research community has gained only limited understanding of the antecedents that generate sport fans' team identification ${ }^{18, "}$.

Posto isso, faz-se necessário construir um modelo para embasar as ideias defendidas nesta pesquisa. Assim, a seguir, apresentaremos nosso entendimento dos antecedentes da identificação com o time. Também serão apresentados os conceitos que norteiam nossa visão sobre fanatismo e lealdade.

18 "Embora muitos pesquisadores tenham examinado o impacto da identificação com o time em diversos comportamentos do torcedor, a comunidade de pesquisa ganhou apenas uma compreensão limitada dos antecedentes que geram essa identificação". 
Figura 3: Modelo Proposta da Relação entre Identificação, Fanatismo e Lealdade

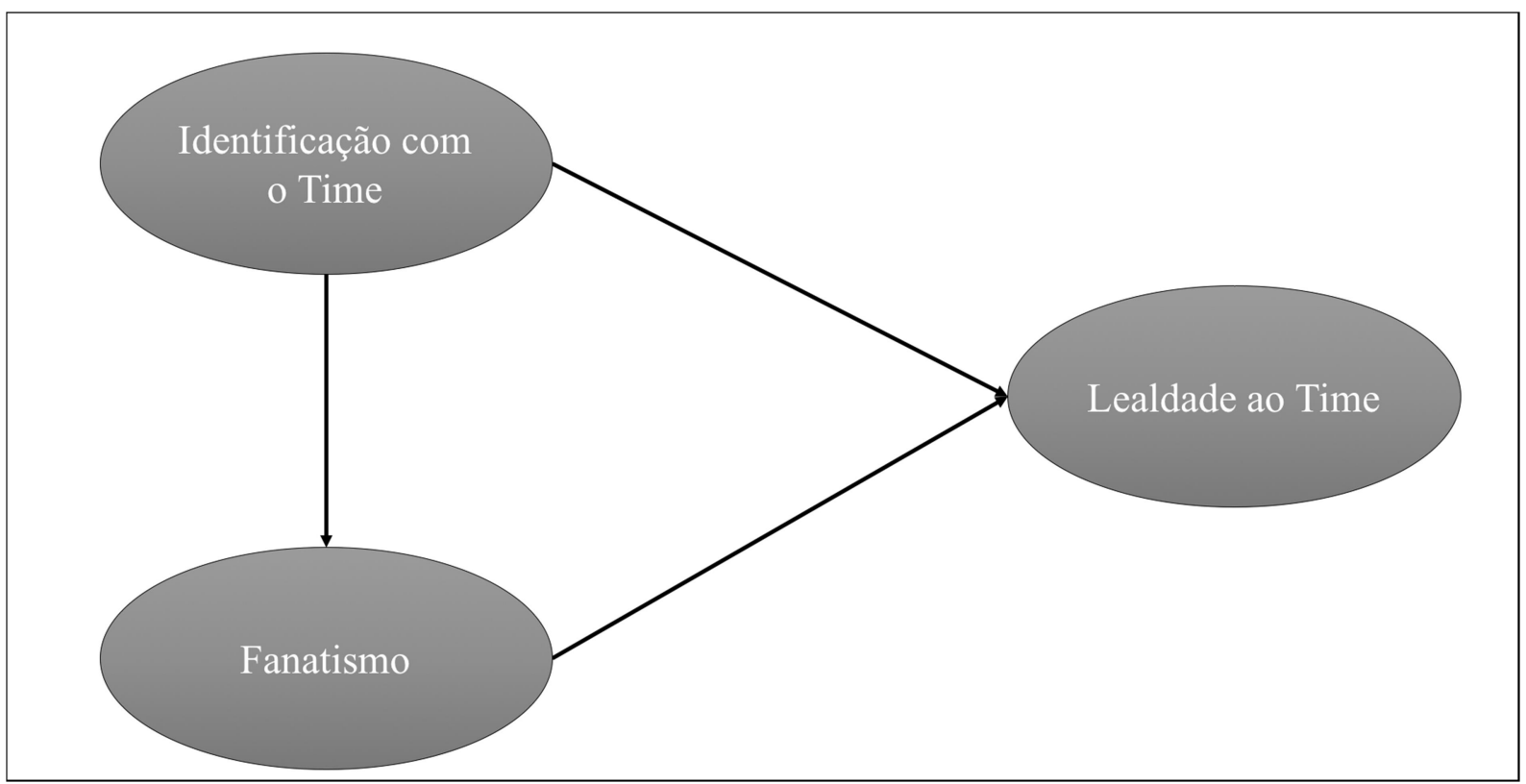

Fonte: Desenvolvido pelo autor

\subsection{Antecedentes da Identificação com o time}

A identificação com o time está entre os conceitos mais estudados na academia (conforme demostrando no item 2.2.1). Essa extensa linha de pesquisa pode ser explicada, em parte, pelo fato de que essa identificação leva a uma série de atitudes e comportamentos diferentes, de acordo com o grau desta identificação. Quanto maior o grau de identificação do torcedor para com o time, mais efusivas são as atitudes.

Assim, muitos estudos se preocuparam em analisar a manifestação dessas diferenças por meio da propensão em ir ao estádio, comprar produtos dos times, ver o time na televisão, entre outras. E, embora os trabalhos sobre a identificação tenham se concentrado nos resultados gerados por essa identificação, alguns estudos também centraram seus esforços em entender o desenvolvimento dessa identificação (seção 2.3, pág. 41).

De forma geral, estudar os antecedentes da identificação com o time não é novidade no que tange aos estudos do marketing esportivo e à gestão do esporte na academia. De fato, Wann (2006) apontou mais de 300 fatores que poderiam ser listados para explicar a origem da identificação com um time. Porém o próprio autor conclui que, apesar de extensa, a literatura a respeito de tais antecedentes, dentro do marketing esportivo e da gestão do esporte, apresenta alguns antecedentes padronizados. Em suma, podemos resumir estes antecedentes em três dimensões gerais: psicológico, ambiental e de equipe (Tabela 1). 


\begin{tabular}{|c|c|c|}
\hline DIMENSÃO & FATORES & AUTORES \\
\hline \multirow{3}{*}{ Psicológico } & & $\begin{array}{l}\text { Sutton, McDonald, Milne \& Cimperman, } \\
\text { 1997; Gwinner \& Swanson, } 2003 .\end{array}$ \\
\hline & $\begin{array}{l}\text { Necessidade de estabelecer e manter } \\
\text { relação com grupos distintos. }\end{array}$ & $\begin{array}{l}\text { Ashforth \& Mael, 1989; Dechesne, } \\
\text { Greenberg, Arndt \& Schimel, } 2000 .\end{array}$ \\
\hline & $\begin{array}{l}\text { Fatores cognitivos, afetivos e } \\
\text { comportamentais. }\end{array}$ & $\begin{array}{l}\text { Madrigal, 1995; Murrell \& Dietz, 1992; } \\
\text { Wann \& Branscombe, 1990; Wann \& } \\
\text { Branscombe, 1993Theodorakis, Wann, } \\
\text { and Weaver, 2012; Trail, Anderson, Fink, } \\
2005 .\end{array}$ \\
\hline \multirow{5}{*}{ Ambiental } & Agentes de Socialização. & Wann, 1997. \\
\hline & Pais e famílias. & Funk \& James, 2001. \\
\hline & Amigos e colegas. & Kolbe \& James, 2003. \\
\hline & Estádios. & $\begin{array}{l}\text { Lee, Lee, Seo, \& Green, 2012; Yoshida e } \\
\text { Jamezs, } 2010 .\end{array}$ \\
\hline & Demografia e ambiente. & $\begin{array}{l}\text { Baade \& Tiehan, 1990; Hansen \& } \\
\text { Gauthier, } 1989\end{array}$ \\
\hline \multirow{3}{*}{ Equipe } & Características Organizacionais. & $\begin{array}{l}\text { Sutton et al., 1997; Underwood, Bond, \& } \\
\text { Baer, 2001. }\end{array}$ \\
\hline & Sucesso da Equipe. & $\begin{array}{l}\text { Sutton et al., 1997; Wann et al., } 1996 . \\
\text { Madrigal, 1995; Snyder, Lassegard, \& } \\
\text { Ford, } 1986 .\end{array}$ \\
\hline & Jogadores. & $\begin{array}{l}\text { Fisher \& Wakefield, 1998; Ashforth e } \\
\text { Mael, } 1989 .\end{array}$ \\
\hline
\end{tabular}

Fonte: Desenvolvido pelo autor, baseado em Wann, 2006)

Nesta pesquisa, entendemos que os indivíduos (no caso, os torcedores) possuem uma necessidade de autoestima que, em parte, é estabelecida pelos grupos sociais (times) (Tajfel \& Turner, 1979). Assim, quando um indivíduo se identifica com uma organização, busca nessa relação um sentimento de pertencimento. E o sentimento faz com que ele acabe por definir a si próprio dentro dos termos da organização da qual ele faz parte (Carlson \& Donavan, 2013). 
Ou seja, existe uma força de identidade dos indivíduos que reside nos grupos sociais (Theodorakis, Wann, \& Weaver, 2012).

É importante para o indivíduo que essa identificação seja percebida como positiva, pois do contrário ele irá procurar grupos que sejam mais bem percebidos pelos outros (Tajfel \& Turner, 1979). Isso está ligado a necessidade que o indivíduo tem de reduzir a incerteza do autoconceito. “...social identity processes are also motivated by a need to reduce subjective uncertainty about one's perceptions, attitudes, feelings, and behaviors and, ultimately, one's self-concept and place within the social world ${ }^{19}$ " (Hogg \& Terry, 2000, p. 124).

Assim, a redução da incerteza ajuda a diferenciar grupos sociais. Não só ajuda a determinar quem é diferente (isto é, fora do grupo), mas também quem é semelhante (isto é, dentro do grupo) (Cooper D. \&., 2010). Fazer parte desses grupos e se identificar fortemente com eles reduz o risco e a incerteza sobre o "eu" social, ao mesmo tempo em que proporciona benefícios sociais contínuos com base em seu apego e interação com o grupo.

Ashforth e Mael (1989) propõem que a teoria da identidade social é relevante no estudo das relações entre indivíduos e organizações. No caso do esporte, podemos analisar a autoestima como um conceito positivo que o indivíduo faz de si mesmo por meio do sucesso do time para que torce (Gwinner, Larson \& Swanson, 2009). Essas associações de pertencimento e elevação da autoestima se manifestam por meio do envolvimento dos torcedores com seus times (organizações).

Entender melhor esta relação da identidade social com as relações entre as organizações, bem como seu funcionamento e consequências, é de alta relevância para as empresas (Brashear-Alejandro, Kang, \& Groza, 2016). No esporte, essa relação se dá por meio dos torcedores (cliente/consumidor), times e patrocinadores (organizações). A manifestação desses sentimentos se dá por meio de uma série de fatores. Por exemplo, ostentação de roupas e acessórios apresentando a torcida a um time (Cialdini et al., 1976; Kwon \& Kwak, 2014); apego e pertencimento ao grupo (Branscombe \& Wann, 1991;

\footnotetext{
19 “... os processos de identidade social também são motivados pela necessidade de reduzir a incerteza subjetiva sobre suas percepções, atitudes, sentimentos e comportamentos e, em última instância, seu autoconceito e lugar dentro do mundo social"
} 
Tsiotsou, 2013); demonstração de imagem pessoal (Wann, Royalty, \& Rochelle, 2002; Lee, Trail, Lee, \& Schoenstedt, 2013).

Para avaliar essa relação entre consumidor e organização um dos modelos comumente usado é o customer-company identification ${ }^{20}$ (CCID). Esse modelo apresenta um mecanismo sociológico eficaz por meio do qual as empresas podem construir e manter um relacionamento com seus consumires e clientes (Kang et al., 2015). Assim, notam-se semelhanças na identificação com time, que pode ser entendida como "the extent that an individual maintains a psychological connection with a sporting team and the emotional value he or she attaches to team support ${ }^{21}$ " (Lock, Funk, Doyle, \& McDonald, 2014, p. 119) e o CCDI, que se apresenta como um substrato psicológico da relação entre uma organização e seus clientes (Kang, Alejandro, \& Groza, 2015). Ambas têm como suporte teórico a teoria da identidade social.

Nessa relação entre cliente e empresa, os consumidores buscam dois tipos de benefícios: financeiros/econômicos (Mimouni-Chaabane \& Volle, 2010) ou sociais/não financeiros (Gwinner, Gremler, \& Bitner, 1998). No contexto das organizações, os benefícios não financeiros proporcionam a elas construir uma base mais sólida para o desenvolvimento da relação com o consumidor. Diversos estudos a respeito de programas de fidelidade (por exemplo, Lacey (2007); Brashear-Alejandro, Kang, \& Groza (2016); Drèze \& Nunes (2009); Melnyk, (2015)) vêm apontando esse mesmo caminho.

Esses benefícios vão desde os mais simples, como os privilégios fornecidos aos participantes do grupo, até avaliações psicológicas mais elevadas de si mesmo. Estes elementos de ordem mais elevada podem ser o estatuto de membro do grupo (torcer para um time) e a redução do risco psicológico associado à inclusão do grupo (ser reconhecido positivamente por ser torcedor desse time). Esses fatores possibilitam, assim, que os consumidores (torcedores) construam uma identidade mais profunda com as organizações (times). (Fleury, Alejandro, Isabella, \& Araujo, 2016). Com isso, a relação conduz a

\footnotetext{
${ }^{20}$ Identificação do cliente com a empresa (CCID)

21 “a medida em que um indivíduo mantém uma conexão psicológica com uma equipe esportiva e o valor emocional que ele atribui a esse apoio"
} 
resultados favoráveis, como lealdade, boca a boca positiva e disposição de pagamento (Netemeyer, Heilman, \& Maxham, 2012).

Outra linha de pesquisa que suporta as hipóteses deste trabalho está relacionada com os estudos do marketing de serviços no esporte. Essa abordagem nos parece propícia, pois, conforme Lee e Joon-Ho Kang (2015), muitos produtos esportivos ou derivados dos esportes possuem características similares às características principais de serviços: são intangíveis, inseparáveis, heterogêneos e perecíveis (para maior aprofundamento, ver (Zeithaml, Parasuraman, \& Berry, 1985).

Assim, no que tange ao marketing de serviços, diversos estudos vêm analisando e encontrando respostas positivais e significativas sobre a importância da percepção da qualidade do serviço em ambientes esportivos (estádios e arenas multiuso) (Theodorakis, Alexandris \& Ko, 2011; Ko, Zhang, Cattani \& Pastor, 2011; Lee, Lee, Seo, \& Green, 2012; Yoshida \& James, 2010; Balaji \& Chakraborti, 2015; Lee e Joon-Ho Kang, 2015).

No entanto, este trabalho identifica uma lacuna que merece atenção: a falta de pesquisas que estudem a identificação com o time como resultado de benefícios sociais/não financeiros ofertados ao torcedor pelo time de maneira direta ou indireta.

Como a autoestima é vista tanto de forma específica (avaliação individual) como global (avaliação total), a identificação com time também funciona desta maneira (Theodorakis, Wann, \& Weaver, 2012). Assim, fatores específicos (como os propostos neste trabalho) podem servir de antecedentes para identificação com o time (fator global).

Urge então analisar a convergência dos fatores que antecedem a identificação com o time em torno do que denominamos benefícios sociais. Propõe-se que os torcedores torcem com mais intensidade para seus times quando percebem neles benefícios sociais/nãofinanceiros (tratamento pessoal; pertencimento; reconhecimento pessoal; sentimento de status; avaliação pessoal, avaliação dos outros; e satisfação) que alimentam sua autoestima (Social Benefits Scale in Sport ${ }^{22}$ - SBSS).

\footnotetext{
${ }^{22}$ Escala de Benefícios Sociais no Esporte - nome dado para a escala desenvolvida pelo autor para este trabalho.
} 


\subsubsection{Benefícios Sociais (Benefícios não financeiros) e a Identificação com o time}

Conforme já mencionado anteriormente, indivíduos buscam se associar a grupos que os represente, ao mesmo tempo que pretendem nesses grupos se diferenciar dos demais. Essa diferenciação tanto do grupo quanto do "eu" é uma necessidade da condição humana. Todos queremos ser únicos. Essa condição é transportada, mesmo que inconscientemente, para a relação consumidor/empresa. Consumidores desejam se sentir especiais em relação a outros consumidores e, para isso, as organizações precisam desenvolver ofertas especiais que atendam aos anseios particulares de cada consumidor. (Lacey, 2007).

Esse tratamento pessoal diferenciado também tende a ser benéfico para as organizações (Söderlund, et al., 2014) A relação existente entre satisfação do consumidor, comprometimento, intenção de compra e outras variáveis resultantes de relação consumidor/empresa são estudadas na academia e possuem resultado positivo e significativo (Xia \& Kukar-Kinney, 2014; Park \& Jang, 2015), pois o tratamento preferencial produz claramente um benefício positivo para ambos os lados.

Do ponto de vista do consumidor, podemos definir o tratamento preferencial como " $a$ consumer's perception of the extent to which a firm treats and serves its regular customers better than its non-regular customers ${ }^{23}$ " (Xia, 2014, p. 2370). Assim, não à toa, o tratamento preferencial, visto sob a ótica do marketing de relacionamento, consiste em analisar como empresas tratam seus clientes melhor que outros (Gwinner, 1998). Esse esforço, por parte de uma organização, é recompensado com o aumento da lealdade e da identificação dos consumidores com a empresa (Choi , 2008).

No caso do torcedor de futebol, ao transpor esses pontos para a relação torcedor/time, podemos indagar se, na cesta de escolhas, quando da construção da identificação com um time, ser reconhecido de forma diferenciada auxilia ou não o fortalecimento dessa relação e sua manutenção. Num ambiente social envolvendo vários clientes é natural que os consumidores comparem o que recebem com o que os outros clientes recebem (Söderlund, et

\footnotetext{
23 “a percepção que o consumidor possuí da forma como uma empresa trata e serve seus clientes regulares melhor do que seus clientes não regulares”
} 
al., 2014). No caso da relação time/torcedor, comparar-se com torcedores de outros times acaba por ser uma prática comum.

O tratamento preferencial ajuda a criar um vínculo emocional com a empresa (Rust \& Zahorik, 1993) e, por consequência, influencia o compromisso do torcedor com seu time. Desta forma, propõe-se que:

\section{H1. Tratamento preferencial tem efeito positivo e significante na identificação com o time.}

A identidade com um grupo proporciona autoestima e orgulho ao indivíduo. Desta forma, a identificação com determinados grupos permite que uma pessoa enxergue nesses grupos suas crenças e seus valores (Fleury, Alejandro, Isabella, \& Araujo, 2016). Torcer para determinado time pode proporcionar sensações de reconhecimento pessoal a que torcedores de outros times não tenham acesso, na visão deste torcedor. Com isso, quanto maior a identificação com o grupo, maior a percepção dos benefícios não financeiros que este grupo retransmite para o indivíduo.

Porém, somente fazer parte do grupo não reforça, necessariamente, a percepção de tais benefícios se o indivíduo não se identifica com o grupo (Brashear-Alejandro, Kang, \& Groza, 2016). Drèze \& Nunes (2009) mostram, em programas de fidelidade, que ser reconhecido por funcionários da empresa detentora do programa, demonstra para o cliente que ele pertence a um nível diferenciado. Ou seja, ser reconhecido positivamente por ser filiado ao programa aumenta a autoestima do consumidor. E pode até mesmo levar a um sentimento de superioridade em relação aos demais (Henderson et al., 2011).

Assim, quando as organizações conseguem criar um processo de personalização para o consumidor, ela está transferindo diversos benefícios não financeiros para seu cliente. Essa personalização pode ser entendida como "a consumer's perception of the extent to which a 
retailer interacts with its regular customers in a warm and personal way ${ }^{24,}$ (Henderson et al., 2011).

No caso do futebol, além de transpor essa relação, podemos inferir que, até mais importante do que a forma como o time trata o torcedor, é como a sociedade o trata. Fazer parte de uma torcida (torcer para um time) fortalece a identidade social do indivíduo, aumentando sua autoestima. Porém existe a necessidade de que este grupo propicie para o torcedor prestígio e sensação de poder (Fink, Trail, \& Anderson, 2002). Por isso, é comum que torcedores constantemente se comparem a torcedores de outros times para avaliar sua posição em relação aos "adversários”. Isso está ligado a uma necessidade do indivíduo. E essa comparação pode ser mensurada na forma de como a sociedade dá valor a essa escolha do torcedor.

O reconhecimento pessoal, como benefício social/não financeiro, descreve os aspectos emocionais do relacionamento entre cliente/organização. Esse reconhecimento aumenta a identificação do indivíduo para com o grupo do qual ele faz parte. Indivíduos com altos níveis de identificação incorporam atributos de seu grupo como parte de sua descrição pessoal (Fink et al., 2002). Com isso, se o time é reconhecido positivamente pelos outros, o torcedor tende a também sentir-se reconhecido. Assim,

\section{H2. Reconhecimento pessoal tem efeito positivo e significante na} identificação com o time.

Empresas estão cada vez mais trabalhando de forma segmentada com seus clientes. Entre as bases de segmentação mais utilizadas, pode-se ressaltar o nível de comprometimento (gasto) e a lealdade, entre outros. Esse processo de segmentação cria grupos altamente definidos, que auxiliam as empresas em suas estratégias. Por outro lado, permitem ao

\footnotetext{
24 “a percepção que um consumidor tem a respeita da forma como varejista interage com seus clientes regulares de uma maneira calorosa e pessoal"
} 
consumidor identificar a quais benefícios ele tem direito, de acordo com seu nível ou com o nível do seu grupo. (Drèze \& Nunes, 2009).

Essa relação pode propiciar ao consumidor um sentimento de status perante a outros grupos, pois os indivíduos se comparam a grupos e a outros indivíduos (Tajfel \& Turner, 1986). Esse sentimento acaba por refletir a posição que o indivíduo tem dentro do seu grupo e também fora dele (Brasehar, 2016). No contexto esportivo, pode-se exemplificar isso ao considerar o sentimento que o torcedor do time campeão tem perante aos seus rivais.

Status, em seu sentido mais puro, pode ser entendido como "as one's position in society. More specifically, a person with status possesses a high ranking that is socially recognized and typically carries prestige, power, or entitlement ${ }^{25, "}$ (Drèze \& Nunes, 2009, p. 123). Isso significa que consumidores desenvolvem sentimentos de status perante seus grupos e outros grupos por meio de posições hierárquicas (Fleury et al., 2016).

$\mathrm{Na}$ relação entre torcedor e time, experimentar sensações que permitam a esse torcedor se diferenciar dos demais, colocando-se, conforme a teoria da identidade social, em posição superior aos demais torcedores de outros times, tende a aumentar seu sentimento de status.

Desta forma, assim como nas empresas, o status concedido aos melhores clientes é reconhecido por eles como resultado de um esforço próprio (Drèze \& Nunes (2009). No que tange à identificação com o time, assume-se que:

\section{H3. Sentimento de status de tem efeito positivo e significante na} identificação com o time.

A necessidade de pertencer é uma motivação humana fundamental (Skaalvik \& Skaalvik, 2011). Pertencer está relacionado à ideia de sentir-se como parte de uma

\footnotetext{
25 “A posição da pessoa na sociedade. De forma mais específica, uma pessoa com status possui um alto grau de reconhecimento pela sociedade e normalmente carrega prestígio, poder ou direito".
} 
comunidade maior (So, Danaher, \& Gupta, 2015). Assim, quando as pessoas começam a desenvolver um senso de comunidade, esse senso acaba por implicar um sentimento de pertencimento (Zhang, Kandampully, \& Bilgihan, 2015). Essa construção psicológica também encontra sustentação na Teoria da Identidade Social, que demonstra que indivíduos se associam a grupos quando estes exibem comportamentos ou atitudes semelhantes ao do próprio indivíduo.

Esse sentimento de pertencimento está associado à necessidade e à expectativa que os indivíduos possuem de serem reconhecidos, por membros de seu próprio grupo associado, como parte do grupo. Esse sentimento, em conjunto a uma conexão emocional, torna-se um elemento central na definição da identidade social do indivíduo. (Brashear et al., 2016). Em suma, podemos definir o sentimento de pertencer como a mensuração do grau por meio do qual as pessoas acreditam serem reconhecidas como parte daquele grupo.

Nesse sentindo, é importante salientar que a espontaneidade e a informalidade dos grupos ajudam a destacar a importância dos resultados individuais gerados. Assim, os indivíduos devem ser livres para optar em participar ou não dos grupos e, ao decidirem participar, fazem-no porque identificam como de seu interesse particular fazer parte (Bettina e Raub, 2002). Essas ideias se sustentam em pesquisas, nas mais diversas áreas, que demostram que indivíduos tendem a se identificar com os grupos aos quais eles se sentem pertencer (Epitropaki, 2013).

O sentimento de pertencimento, bem como o reconhecimento dos outros como parte do grupo, age como juiz de suas próprias ideias, valores e desempenho. E a possibilidade de poder compartilhar suas ideias com pessoas que possuem ideias e interesses comuns ao do indivíduo age como um motivador para que este se sinta pertencente cada vez mais ao grupo (Bettina \& Raub, 2002). Por isso, a adesão ao grupo é o primeiro passo para a construção da identificação com o grupo, mas o desenvolvimento da emoção, o valor percebido e a valorização da pessoa são elementos fundamentais para a manutenção dessa identificação (Brasherar et al., 2016).

Os estudos de programa de fidelidade mostram que o sentimento de pertencimento associado ao programa ajuda os consumidores a se identificar e a se sentir apreciados pelas empresas participantes do programa (So, Danaher, \& Gupta, 2015). Não apenas este elemento (sentimento de pertencimento), mas diversos outros elementos não financeiros vêm sendo 
estudados na construção de identidade entre consumidor/empresa, por meio dos programas de fidelidade (Melnyk \& Bijmolt, 2015).

Assim, propõe-se que o sentimento de pertencer a um time, que se aprofunda ao longo do tempo, leva a sentimentos positivos e a uma avaliação positiva dos membros do grupo, gerando um senso de identificação cada vez mais forte. Por isso,

\section{H4. Sentimento de Pertencimento tem efeito positivo e significante na identificação com o time.}

A identificação do torcedor com seu time muitas vezes é associada diretamente ao sucesso da equipe (Cialdini et al., 1976; Fisher \& Wakefield, 1998; Madrigal, 1995; Snyder, Lassegard, \& Ford, 1986; Sutton et al., 1997). Porém outros estudos mostram que o grau de lealdade do torcedor não difere entre uma equipe vitoriosa ou não (Wann, Schrader, 1996; Dimmock, Grove \& Eklund, 2005). Torcedores mais comprometidos com suas equipes tendem a permanecer fieis a seus times mesmo no caso de derrotas (Wann et al., 2001).

Esse comprometimento é um traço emocional resultante do processo de redução da incerteza propiciada pela associação com o grupo (Hogg, Mullin,1999)). Isso se deve ao fato de que a redução da incerteza "resides in agreement with similar others, then it is likely that preferences for sport teams are influenced by the preferences of similar others ${ }^{26, " ~(D i m o o c k, ~}$ Grove, 2006, p. 1024).

Apesar da identificação com um time ser trada comumente como unidimensional (Theodorakis, Wann, Weaver, 2012)), alguns estudos como Dimmock, Grove, Eklund (2005) e Theodorakis, Wann, Weaver (2012) vêm mostrando que, assim como nesta pesquisa, ela pode ser tratada de forma multidimensional. A lógica desta multidimensionalidade está na própria teoria da identidade social: "that part of an individual's self-concept which derives

\footnotetext{
26 “reside em acordos com outros semelhantes, então é provável que as preferências por um time sejam influenciadas pelas preferências de pessoas semelhantes".
} 
from his knowledge of his membership of a social group (or groups) together with the value and emotional significance attached to that membership ${ }^{27, " ~(T a j f e l, ~ 1978, ~ p . ~ 63) . ~ N a ~ T a b e l a ~} 2$ podem-se encontrar as relações destas dimensões e suas definições.

Tabela 2: Multidimensionalidade da Teoria da Identidade Social

\begin{tabular}{lcc}
\hline \multicolumn{1}{c}{ DIMENSÃO } & DEFINIÇÃo \\
\hline \hline (1) Cognitivo & $\bullet$ & Conhecimento relacionado ao pertencer a um grupo. \\
\hline (2) Avaliativo & $\bullet$ & O valor de pertencer a grupo. \\
\hline (3) Afetivo & $\bullet$ & Significado emocional de pertencer a um grupo. \\
\hline \hline
\end{tabular}

Fonte: Desenvolvido pelo autor (Adaptado de Dimmock, Grove, Eklund, 2005; Dimmock \& Grove, 2006)

Desta forma, os conceitos abordados na necessidade do indivíduo de reduzir suas incertezas são comumente usados em pesquisa a respeito da formação de preferência do consumidor (Dimmock \& Grove, 2006). Neste caso, utilizar esta relação para analisar os antecedentes da identificação com o time parece lógico.

Assim, assume-se que, conforme Dimmock, Grove, Eklund (2005), no processo de redução da incerteza, o envolvimento emocional mais profundo com o grupo, quando legitimado positivamente, produz avaliações positivas. Tanto pessoais, quanto do próprio grupo. Isso significa que:

\section{H5. Avaliação Pessoal tem efeito positivo e significante na identificação com o time.}

$\mathrm{e}$,

\section{H6. Avaliação dos Outros tem efeito positivo e significante na identificação com o time.}

\footnotetext{
27 "é a parte do autoconceito de um indivíduo que deriva do seu conhecimento de seu pertencimento a um grupo social (ou grupos), juntamente com o valor e o significado emocional associados a esse grupo"
} 
A satisfação do torcedor em relação ao desempenho do time ou evento esportivo é objeto de estudo há muito tempo. Wakefield e Sloan (1995) e Fleury, Cardoso, Fouto, Vance e Marques (2014) encontram relação positiva e significativa entre satisfação com o time e a intenção de frequentar o estádio. Madrigal (1995), Matsuoka et al. (2003) e Trail, Anderson, e Fink (2005), entre outros, também encontraram evidência entre a satisfação do torcedor e a intenção de compra futura de produtos relacionados ao time.

Anderson, Fornell, e Lehman, (1994) relataram que a satisfação do consumidor pode ser mensurada em dois aspectos: uma é a satisfação gerada por uma transação específica (por exemplo, uma avaliação pós-compra); e a segunda é uma avaliação geral de todas as experiências vividas pelo consumidor (ou seja, uma satisfação acumulada).

No contexto do esporte, essa satisfação, tendo como base o desempenho da equipe, resulta em duas análises distintas: limitada no tempo, ou ilimitada (Bodet \& BernacheAssollant, 2011). A limitada no tempo, relacionada com a satisfação de um evento específico, pode ser dividida em curto ou longo prazo. Por exemplo: uma análise específica de uma temporada é de curto prazo, enquanto a satisfação gerada em diversas temporadas consecutivas é de longo prazo. Já a ilimitada está relacionada à satisfação geral e é resultado direto de todos os jogos da equipe a que o torcedor teve, de algum modo, acesso.

Na literatura do marketing esportivo, encontram-se exemplos tanto da satisfação gerada num período limitado como ilimitado (Moreno, Prado-Gascó, Hervás, Núñez-Pomar, \& Sanz, 2015). Porém a satisfação gerada por uma transação específica tem sido analisada com mais constância. Os resultados destes estudos corroboram a pressuposição de que o bom desempenho do time se transforma em satisfação positiva. Assim como os desempenhos negativos resultam em insatisfação e em diminuição da intenção de ir ao estádio e/ou de compras futuras (Matsuoka et al., 2003)

A variabilidade relacionada ao consumo e à prestação do serviço influenciam os resultados mais significativos encontrados no impacto gerado por transação específica na satisfação em um contexto esportivo (Bodet Bernache-Assollant, 2011). Porém, de modo geral, os estudos relacionados à satisfação se tornam um ponto focal para gestão e pesquisa na área do Esporte (Moreno, Prado-Gascó, Hervás, Núñez-Pomar e Sanz, 2015), já que a satisfação do consumidor (torcedor) é resultado de um bom serviço, produto, benefício ou recompensa (Oliver, 1997). 
Nestes estudos, a satisfação com o time foi sempre analisada como satisfação com o desempenho esportivo, ou seja, com o resultado em campo. Por outro lado, outros pesquisadores (Greenwell et al., 2002; Yoshida \& James, 2010; Lee et al 2012) também avaliaram a satisfação da qualidade do serviço prestado pelas equipes, dentro das arenas e/ou estádios. No entanto, a maioria desses estudos analisou a satisfação com elementos periféricos ou de suporte ao produto esportivo (Theodoraki, Alexandris, Tsigilis \& Karvounis, 2013), como instalações, ambiente, estética, estacionamento e etc.

A relação entre a qualidade do serviço e a satisfação do consumidor tem sido um amplo objeto de estudo na literatura de serviço. No contexto do esporte a satisfação do torcedor tem sido analisada para desenvolver a lealdade dos torcedores para com seus times (Koo et al., 2009 ). A satisfação um precedente de intenções futuras do consumidor é um meio pelo qual é possível avaliar a lealdade do torcedor. Por isso, entende-se que ela também pode ser analisada como um antecedente da identificação com o time. Desta forma, propõe-se que:

\section{H7. Satisfação como o time tem efeito positivo e significante na identificação com o time.}

\subsubsection{Envolvimento com o Esporte e a Identificação com o time}

Apesar de normalmente relacionarmos o ato de torcer a um time específico, nem sempre um fã do esporte possui um time de preferência. Em alguns casos, o espectador de uma partida pode se interessar mais pelo evento ou pelo esporte do que por um time especificamente (Hill \& Green, 2000). No esporte, pode-se encontrar esse tipo de comportamento em grandes eventos como Copa do Mundo ou Olímpiadas. Muitos que lá estão não torcem para um atleta, time ou país, mas são apenas fãs do esporte.

Uhrich \& Benkenstei (2010) mostram que, na tentativa de aumentar o público num estádio, este deve causar prazer, estímulo sensorial e excitação no torcedor, para que seja 
criado o hábito de frequentá-lo. Neste caminho, podemos pressupor que esportes que transmitam sensações boas também acabam por terem mais público.

Podemos definir o envolvimento com o esporte como a simbiose formada pelo indivíduo e uma modalidade esportiva específica (Gwinner \& Bennett, 2008). O esporte age como um assistente na personificação dos valores intrínsecos a sua prática ou condução para os fãs. Com isso, o esporte acaba por preencher as necessidades de autoestima do indivíduo (Mael \& Ashforth, 2001).

O esporte pode ser visto como a manifestação de um grupo social por meio de um time. Neste sentido,

\section{H8. Envolvimento com o Esporte tem efeito positivo e significativo na identificação com o time.}

\subsubsection{Fanatismo}

Muitas das escalas de mensuração da identificação do torcedor com seu time ou esporte permitem compreender o grau de comprometimento do torcedor. Porém, nesta pesquisa, propomos que, além da identificação com o time, existem dois outros aspectos que devem ser estudos: a lealdade para com o time e o torcedor fanático.

Entende-se que, ao contrário do que a literatura apresenta, existe uma grande diferença entre a identificação com o time e a lealdade ao time (este aspecto será melhor detalhado no item 2.5.2, p. 73). Também consideramos que o fanatismo não é um ponto máximo ou um grau da identificação com o time. Para este trabalho, adotaremos os preceitos acerca de devoção patológica para estudar o indicador de fanatismo: "The notion of pathology is 
inextricably linked to that of the extremity of the celebrity worship ${ }^{28 "}$ (McCutcheon, Lange, \& Houran, 2002).

Propõe-se que a devoção do fã a celebridades é similar à devoção do torcedor a seu time. Celebridades, muitas vezes, assumem um papel na vida dos fãs que produz sentimentos intensos. Muitas vezes, tais fãs veem as celebridades como sagradas. (Radford \& Bloch, 2012). Uma boa referência é a perda de um título. Para os fanáticos, o sentimento de derrota é deles também. Não foi apenas o time que perdeu, mas eles mesmos.

"[fans] devoted, but otherwise unrelated, fans of recently deceased celebrities sometimes experience bereavement hallucinations that are common reactions to grief and loss in surviving loved ones ${ }^{29, " . ~(M c C u t c h e o n ~ e t ~ a l ., ~ 2002, ~ p . ~ 69) ~}$

Redden e Steiner (2000) analisam o fanatismo como um hábito de consumo excitado, quase irracional, cometido por indivíduos altamente envolvidos. A diferença entre o consumo racional e irracional está diretamente ligada ao comprometimento voluntário e de longo prazo existente entre o consumidor e seu objeto de desejo (Wei Heng, Zhang \& Hung, 2013). Indo mais além, o fanático muitas vezes não considera a realidade em sua adoração. Com isso, acaba por não aceitar limitação, inclusive aquelas impostas pela sociedade, para atingir seu objetivo (Thorne \& Bruner, 2006).

O objeto de adoração de um fanático pode ser quase tudo: pessoa, grupo, arte, ideia. A questão não é o objeto de apego, e sim o comportamento disfuncional e transgressor das boas normais sociais (Thorne \& Bruner, 2006). Em muitos casos, o fanático pode até acreditar ter princípios dignos (Redden \& Steiner, 2000), como o fanático religioso que acredita estar lutando por seu povo.

No caso do esporte, a veemência de alguns torcedores por seus times se casa com os conceitos ora expostos. A disposição para acompanhar o time, vendendo a casa, endividandose por anos, correndo o risco de perder o emprego ou a família, é um exemplo conhecido de atitude que, dentro das normais sociais estabelecidas, pode ser considerada irracional e

${ }^{28}$ a noção de patologia está intimamente ligada à da adoração extrema às celebridades.

${ }^{29}$ [fãs] devotados, mas que não possuem outra relação, os fãs de celebridades recentemente falecidos, por vezes, passam por alucinações relacionadas ao luto que são reações comuns a dor e perda de entes queridos. 
extrema. Em muitos casos, essa adoração extrema pode acarretar em prejuízo tanto para o próprio fanático, quanto para aqueles a sua volta (Ortiz et al., 2013).

Exemplos destes prejuízos são encontrados no esporte quando se analisam as brigas de torcida. A violência gerada por grupos de torcedores em muitos casos pode ser vista como uma necessidade disfuncional de identificação social positiva para com seu grupo. O excesso de identificação de um torcedor com seu time pode levar a um comportamento disfuncional (Wakefield \& Wann, 2006).

Sendo o fanatismo um processo gradual de identificação com objeto de adoração (Pichler \& Hemetsberger, 2008), entende-se que:

\section{H9. Identificação com o time tem efeito positivo e significativo no} fanatismo.

e,

\section{H10. Envolvimento com o futebol tem efeito positivo e significativo no} fanatismo.

Para dar sequência ao desenvolvimento do trabalho, analisar mais detidamente o conceito de lealdade se faz fundamental. Este trabalho considera que o torcedor pode e deve ser visto como uma vantagem competitiva no mercado. Esta vantagem se dá, não por meio da identificação com o time. Ter um time de coração ou um clube para apoiar é uma atividade rotineira para os brasileiros, pois apenas $20 \%$ das pessoas aproximadamente dizem não ter um time de coração (Pluri \& Stochos, 2013).

Destaque-se que o torcedor só pode ser considerado uma vantagem competitiva para os times que torcem quanto se desenvolve um lanço que vai além da identificação. É preciso que haja lealdade ao time, que é o primeiro passo para transformar o torcedor em vantagem competitiva.

Por isso, desde (Rosenberg \& Czepiel, 1984), a retenção dos consumidores deve ser uma prioridade para as organizações que atuam em mercados em que a competitividade é 
acirrada ou desordenada (Bauer, Stokburger-Sauer, \& Exler, 2008). A conquista de novos clientes pode ser uma estratégia arriscada e cara, e a manutenção dos clientes atuais está relacionada à lealdade (Kaynak, Salman, Tatoglu, 2008; Rundle-Thiele, 2005; Srinivasan, Anderson, Ponnavolu, 2002).

Dentro desse raciocínio, equipes esportivas pelo mundo (e, em especial, para o mercado que envolve os times de futebol) passam a ser uma vitrine única. Afinal, que mercado possui taxa de retenção tão alto quanto os times de futebol? Que empresas contam com a família, por exemplo, para incentivar os mais jovens a se identificar com suas marcas sem necessitar de grandes esforços? O esporte, em geral, constrói automaticamente essa identificação.

Mas a inclusão do esporte na indústria do entretenimento coloca-o sob uma nova perspectiva. Surgem novos concorrentes, agora não mais dentro do campo apenas. São empresas, marcas, produtos, serviços que buscam cada vez mais fidelizar os consumidores. Não à toa pesquisas na área do marketing de relacionamento vêm se dedicando aos estudos relacionados aos programas de fidelidade, que são utilizados na construção e na manutenção da relação empresa-consumidor (Kamg et al., 2015), com os elos desta relação sendo firmados por ações baseadas em incentivos não financeiros (Brashear-Alejandro, Kang, \& Groza, 2016; Drèze \& Nunes, 2009).

Por tanto, não basta apenas ter torcedores identificados. Conhecer os caminhos que levam a essa identificação é pré-requisito para transpor o sentimento de identificação para uma relação de lealdade. Entendemos que identificação e lealdade são construtos distintos, donde a necessidade de ir além e analisar a lealdade por meio de suas fases, conforme proposta de (Oliver, 1999): lealdade cognitiva, lealdade afetiva, lealdade conativo e lealdade à ação.

\subsection{Teoria da Lealdade}

O conceito de lealdade tem sido exaustivamente estudado na literatura. Jacoby e Kyner (1973) já apontavam que, apesar da evolução dos estudos nas últimas décadas, muitos resultados eram inconclusivos, ambíguos ou contraditórios. Os avanços dos últimos anos ajudaram a entender melhor tanto a formação da lealdade, como as consequências dela (Dick \& Basu, 1994; Oliver L. , 2014) 
Porém, mesmo com diversos estudos, a falta de consenso a respeito dos componentes da lealdade, sua mensuração e os resultados por ela gerados se mantém (Kapil \& Kapil, 2009; Oliver, 1999; Oliver, 1999). Daí que seja necessário um maior entendimento e compreensão em relação à lealdade do consumidor (Knox \& Walker, 2001). (Pan, Sheng, \& Xie, 2012) demonstram que compreensão da lealdade é limitada por diversos fatores. Esses fatores acabam por bloquear um maior entendimento dos resultados (Tabela 3).

Tabela 3: Fatores impeditivos para compreensão da lealdade

\begin{tabular}{ll}
\hline \multicolumn{1}{c}{ FATORES } & \multicolumn{1}{c}{ CONCEITOS } \\
\hline \hline Raridade de Consenso & $\begin{array}{l}\text { Por exemplo: enquanto alguns estudos apontam intenção de compra } \\
\text { (lealdade) de um produto no futuro como resultado da satisfação para } \\
\text { com uma marca, outros não conseguem provar essa ligação. }\end{array}$ \\
\hline Inconsistência dos achados & $\begin{array}{l}\text { Estudos anteriores foram realizados sobre vários contextos e } \\
\text { trouxeram resultados heterogêneos. }\end{array}$ \\
\hline $\begin{array}{l}\text { Falta de acordo no conceito e } \\
\text { operacionalização do construto }\end{array}$ & $\begin{array}{l}\text { Não existe consenso na escolha dos instrumentos de medição da } \\
\text { lealdade. }\end{array}$ \\
\hline \hline
\end{tabular}

Fonte: Desenvolvido pelo autor, Adaptado de Pan et al. (2012)

Em termos gerais, a lealdade é vista como a fidelidade que os consumidores têm para uma marca ou organização. Para isso, a literatura se concentra no estudo do comportamento do consumidor e da perspectiva de lealdade do consumidor (Chaudhuri \& Holbook, 2001; Day, 1969; Dick \& Basu, 1994; Jacoby \& Kyner, 1973; Kapil \& Kapil, 2010; Keller, 1993; Kressmann et al., 2006; Oliver, 1999; Sirdeshmukh, Singh, \& Sabol, 2002). Assim, a lealdade à uma marca é comprovada por meio da compra e recompra ao longo do tempo. Porém a recompra pode não ser resultado da fidelidade, mas da inércia do consumidor (hábito), da indiferença ou mesmo das barreiras de saídas (Reichheld, 2003).

A literatura aponta dois tipos de abordagem nos estudos da lealdade: lealdade comportamental e lealdade atitudinal (Assael, 1998; Hallowell, 1996; Jones \& Sasser, 1995; R. Oliver, 1999; Rust \& Zahorik, 1993). Porém não necessariamente os componentes comportamentais e/ou atitudinais irão apresentar a mesma intensidade na formação do construto lealdade, quando operacionalizado por meio da análise da intenção de compra e recompra (Dick \& Basu, 1994; Larán \& Espinoza, 2004).

A lealdade comportamental pode ser definida de uma maneira unidimensional, partindo da existência, ou não, de padrões de recompra de uma mesma marca. Neste modelo, 
são desconsiderados os aspectos cognitivos e afetivos. Tuker (1964) apontava que o grau de lealdade podia ser determinado a partir da frequência com que o consumidor escolhe uma marca, sem a necessidade de considerar o que o consumidor pensa a respeito.

Tal abordagem deixava margem a dúvidas sobre a intenção do comportamento ao desconsiderar questões cognitivas e afetivas. Assim, autores como (Day, 1976) e Dick e Basu (1994) questionaram se a lealdade comportamental não é uma lealdade espúria, em vez de verdadeira, visto que ela não tenta explicar a razão para recompra da marca. (Bennett \& Rundle-Thiele, 2002) apontam que, ao não questionar a intencionalidade do comportamento, perdem-se fatores que teriam potencial para explicar o surgimento de um padrão de recompra.

Para Day (1969), a lealdade baseia-se numa decisão racional após a avaliação das marcas concorrentes. Esta decisão seria um compromisso assumido com a marca e que, após algum tempo, poderia se tornar rotineira, descontinuando o processo de decisão anterior à compra. Isso diferencia a lealdade verdadeira da espúria. A lealdade espúria pode surgir por meio de diversos outros fatores que favorecem a ação do consumidor, tais como preço mais baixo, falta de opção ou mesmo indiferença (Assael, 1998; Day, 1969).

Dick e Basu (1994) sugeriram que a lealdade é a relação entre atitude e comportamento. Essa visão permitiu a identificação dos fatores que influenciam a lealdade através de investigações do conceito por meio de uma perspectiva causal (Bandyopadhyay \& Martell, 2007). A combinação destes dois componentes (atitude e comportamento) leva a quatro situações distintas de lealdade.

Assim, por meio da relação comportamento/atitude (Figura 4), podemos definir uma tipologia da lealdade com base na intensidade da atitude e na frequência de compra (Tabela 4). 


\begin{tabular}{|c|c|c|c|}
\hline & & \multicolumn{2}{|c|}{ COMPORTAMENTO } \\
\hline & & Forte & Fraco \\
\hline \multirow{2}{*}{ ATITUDE } & Forte & $\begin{array}{l}\text { Lealdade } \\
\text { Verdadeira }\end{array}$ & $\begin{array}{l}\text { Lealdade } \\
\text { Latente }\end{array}$ \\
\hline & Fraco & $\begin{array}{l}\text { Lealdade } \\
\text { Espúria }\end{array}$ & $\begin{array}{l}\text { Falta de } \\
\text { Lealdade }\end{array}$ \\
\hline
\end{tabular}

Fonte: Desenvolvido pelo autor (Adaptado de Dick \& Basu (1994)

Tabela 4: Tipologia da Lealdade

TIPOS

OCORRENCIA

\begin{tabular}{ll}
\hline \hline Lealdade Verdadeira & Quando a atitude é favorável e a compra é consistente. \\
\hline Lealdade Latente & $\begin{array}{l}\text { Quando o cliente compra regularmente (comportamento forte), mas demonstra } \\
\text { baixo comprometimento em termos de atitude (não possui preferência). }\end{array}$ \\
\hline Lealdade Espúria & $\begin{array}{l}\text { Quando o cliente, apesar de demonstrar atitude forte, apresenta nível baixo de } \\
\text { compra. }\end{array}$ \\
\hline Falta de Lealdade & $\begin{array}{l}\text { Quando há nível baixo de atitude (não há preferência) e de comportamento } \\
\text { (frequência irregular de compras). }\end{array}$ \\
\hline \hline
\end{tabular}

Fonte: Desenvolvido pelo autor (Adaptado de Dick \& Basu, 1994)

Os estudos de Oliver (1999) a respeito da relação entre a lealdade e satisfação do consumidor corroboram com as análises de Dick e Basu (1994). O autor definiu o processo da lealdade em quatro fases: na fase inicial, da lealdade cognitiva, a cognição está baseada no conhecimento prévio ou indireto, ou em informações recentes baseadas na experiência; a fase dois, da lealdade afetiva, é uma combinação entre gostar da marca e experimentar satisfação; na fase três, da lealdade conativa, o aumento da lealdade é significativo. É aqui que se inicia a motivação. Os indivíduos indicam uma intenção de recompra, compra no futuro ou suas preferências. Na fase final, denominada como fase da ação, o consumidor atinge o mais alto nível de lealdade. O comportamento de compra torna-se uma resposta rotineira ou hábito (Tabela 5). 
Lealdade Cognitiva

As informações de atributo da marca disponíveis para o consumidor indicam se uma marca é preferível às suas alternativas. A cognição pode ser baseada em conhecimento prévio ou indireto ou em informações recentes baseadas na experiência. A lealdade nesta fase é direcionada para a marca por causa dessas informações. Essa lealdade é superficial. Se a compra é rotineira, a satisfação não é processada, e a lealdade não cria profundidade, tornando-se mero desempenho. Se a satisfação é processada, torna-se parte da experiência do consumidor e começa a assumir conotações afetivas.

O acumulo da satisfação, gerado pelo uso contínuo, cria um gosto ou atitude positiva com em relação à marca. Isso reflete a dimensão de prazer da definição de satisfação. O compromisso nessa fase é codificado na mente do

Lealdade Afetiva consumidor como cognição e afeto. A lealdade à marca é direcionada para 0 grau de afeto (gosto) pela marca. O afeto, diferentemente da cognição, não é tão facilmente desalojado. No entanto, esta forma de lealdade permanece sujeita a mudanças.

A conação, por definição, implica um compromisso de recompra da marca. A lealdade conativa, então, é um estado de lealdade que contém o que, no início, parece ser o aprofundamento do compromisso de comprar, observado na

Lealdade Conativa definição de lealdade. Porém este compromisso é a intenção de recompra da marca e é semelhante à definição de motivação de compra. É, na verdade, uma intenção comportamental, influenciada por ações repetidas já no nível da lealdade afetiva em relação à marca.

A motivação gerada na lealdade conativa é transformada em prontidão para agir. Muitas vezes essa prontidão leva a um desejo adicional de superar os obstáculos que possam impedir a ação. Esse movimento é percebido como um resultado necessário no engajamento de ambos os estados.

Lealdade de Ação

Fonte: Desenvolvido pelo autor (Adaptado de Oliver, 1999)

Bennett e Rundle-Thiele (2002) também criticam a abordagem comportamental ao dizer que ela não investiga o que leva ao comportamento adotado pelo consumidor. Isso, por sua vez, acaba por não fornecer bons subsídios para a elaboração de programas que busquem aumentar a lealdade do consumidor. Assim, os modelos multidimensionais ajudam a demonstrar as ligações entre a lealdade e as variáveis que a influenciam. Com isso, processos afetivos e cognitivos são inseridos na mensuração da lealdade por meio de uma dimensão atitudinal.

Essa dimensão avalia a lealdade como como uma atitude em relação ao ato de comprar uma marca ou produto (Bennett \& Rundle-Thiele, 2002; Dick \& Basu, 1994). E pode ser medida por meio da intenção de compra e do comprometimento para com uma marca ou produto. Neste sentido, o modelo de multidimensional de Dick e Basu (1994) apresenta um 
conjunto composto por antecedentes cognitivos, afetivos e conativos, que buscam integrar todos os aspectos do consumidor

Figura 5: Modelo multidimensional

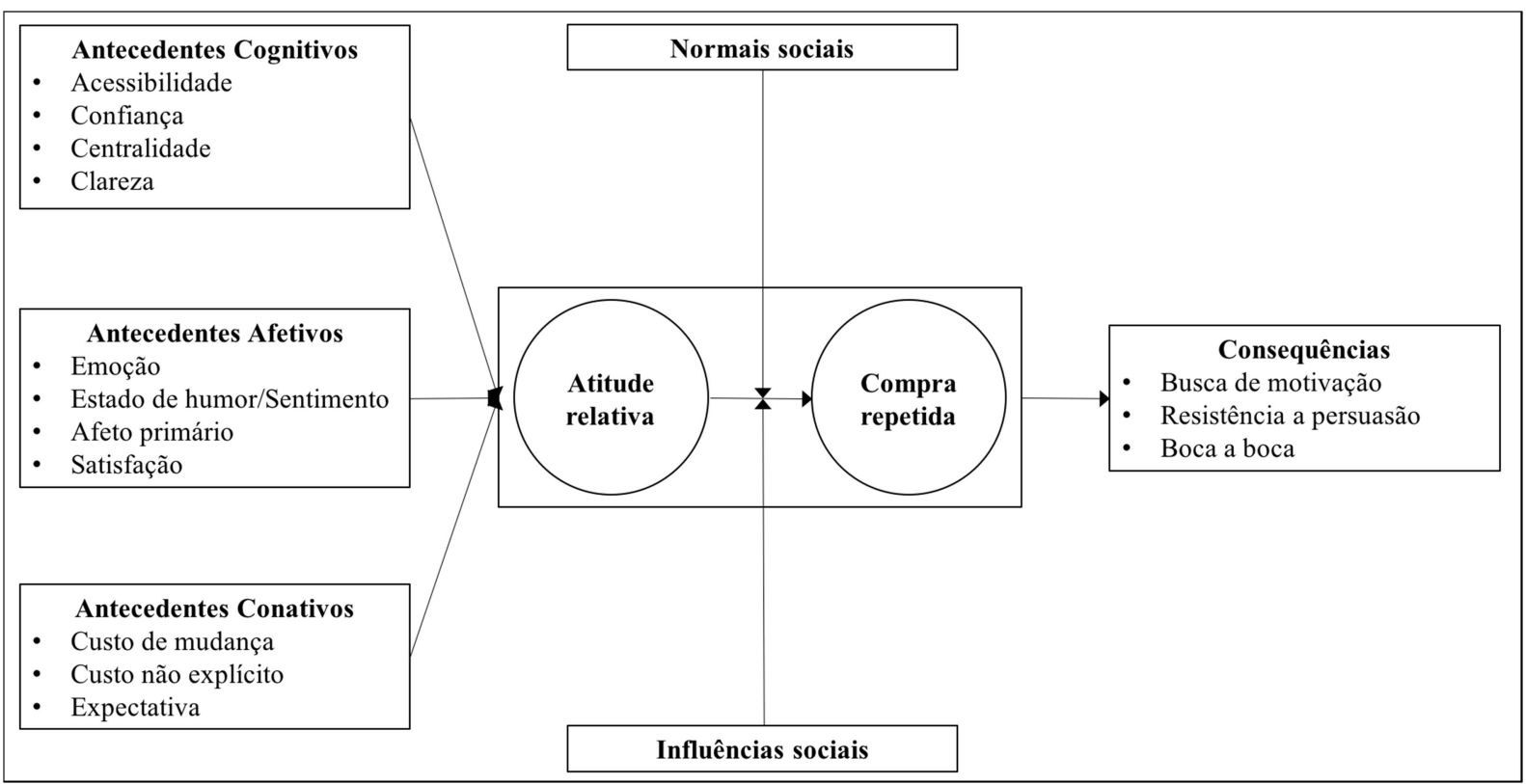

Fonte: Dick \& Basu (1994)

\subsubsection{Lealdade do consumidor}

A lealdade do consumidor vem sendo fortemente analisada como um componente vital para o sucesso das organizações (Yuksel, Yuksel, \& Bilim, 2010). A importância da lealdade nos estudos de marketing pode ser notada pelo volume substancial de pesquisas publicadas em jornais acadêmicos importantes (Pan et al, 2012). Não à toa, grande parte das pesquisas acadêmicas tem se preocupado em compreender melhor que tipo de recompensas e caraterísticas são mais eficientes no processo de fidelização do consumidor (Reczek, Haws, \& Summers, 2014)).

A lealdade do consumidor é algo desejável por diversos motivos: manter clientes é mais simples e barato do que desenvolver novos consumidores (Kim, Vogt, \& Knutson, 2015) consumidores leais apresentam mais afeto e comprometimento com a marca ou organização (Bilgihan, Madanoglu, \& Ricci, 2016), o que ajuda a desenvolver um relacionamento de longo prazo (Pan et al, 2012); consumidores leais veem mais riscos à troca de marcas (Evanschitzky et al., 2006); consumidores leais pagam, compram e desenvolvem comportamento positivos de boca a boca (Evanschitzky et al., 2012). 
Embora não exista uma definição universal sobre o significado da lealdade, parece-nos existir um consenso geral de que a lealdade é formada por duas dimensões distintas: atitudinal e comportamental (Reczek, Haws, \& Summers, 2014)). Neste sentido, o framework proposto por Oliver (1997) (Tabela 5, p. 68) vem sendo usado como modelo da formação da lealdade do consumidor. A relação cognitiva-afetiva-conativa-comportamental são processos chaves na formação da lealdade de qualquer consumidor.

Entender os aspectos atitudinais e comportamentais nos parece essencial para o desenvolvimento das estratégias organizacionais, que podem estar ligadas ao desenvolvimento de novos produtos e/ou serviços, a retenção e a manutenção de clientes, a valorização da marca, entre outras.

Neste trabalho, adotamos proposta de Oliver (1997) com algumas modificações. Lealdade, para nós, é entendida como um processo atitudinal-conativo-comportamental. Enquanto Oliver trata a lealdade cognitiva e afetiva como sequencias, nós entendemos que elas se influenciam diretamente, de tal forma que a lealdade atitudinal absorve os efeitos provocados pela lealdade afetiva e cognitiva.

"Attitudinal loyalty has been often defined in the context of brand as it captures the affective and cognitive aspects of brand loyalty, such as brand preference and commitment [...] Attitudinal loyalty represents a higher-order, or long-term, commitment of a customer to the organization that cannot be inferred by merely observing customer repeat purchase behavior "'(Kumar \& Shah, 2004, p. 319)

Nossa afirmação baseia-se no fato de que a compreensão de como os consumidores se relacionam com uma marca começa por analisar as atitudes do consumidor. E a atitude é formada por dois atributos atitudinais: cognitivo e afetivo (Alwi \& Kitchen, 2014).

Partimos então do pressuposto de que ora a cognição poderá interagir com a afeição, ora a afeição ou a cognição pode ser dominante no processo (Kim, Vogt, \& Knutson, 2015). A cognição está relacionada à análise do desempenho percebido, em relação à expectativa

${ }^{30}$ Lealdade atitudinal é definida no contexto da marca, uma vez que capta os aspectos afetivos e cognitivos da lealdade, como a preferência e compromisso com uma marca [...] Lealdade atitudinal representa uma relação maior, ou a longo prazo, um compromisso do consumidor com a organização que não se pode ser medido apenas observando o comportamento de compra repetitivo. 
preliminar do consumidor (Yu \& Dean, 2001). Por outro lado, a afetividade está ligada a componentes emocionais, configurando-se como a percepção afetiva do consumidor em relação ao desempenho da marca (Dubé \& Menon, 2000). Por isso, parece-nos plausível afirmar que a atitude é formada pela junção da cognição e do afeto.

A atitude é uma tendência psicológica que se propaga por meio da análise de um objeto, assunto, pessoa ou ação, com algum grau de favor ou desfavor (Assael, Pope, Brennan, \& Voges, 2007). Ou seja, “the term 'attitude' represents a hypothetical construct referring to a general and enduring positive or negative feeling towards or evaluative response to some person, object or issue ${ }^{31 "}$ (Funk \& James, 2006, p. 3).

Como a lealdade atitudinal é desenvolvida com base na construção da atitude, podemos definir a lealdade atitudinal como o grau de compromisso em termos de alguma associação de valor único com a marca (Chaudhuri \& Holbrook, 2001). É, na verdade, um reflexo da disposição psicológica do consumidor para com a marca.

Deste modo, nesta pesquisa, definimos a lealdade atitudinal como a predisposição do consumidor para uma marca, ou seja, a relação cognitiva e afetiva do torcedor para com seu time, o que demostra as reais preferências e compromissos do torcedor.

A lealdade conativa, por sua vez, aponta para a intenção de comportamento (Choi, Lu $\&$ Cai, 2015) e consiste no que parece ser o primeiro compromisso realizado profundamente com uma compra (Oliver, 1997). Ela está associada à intenção dos consumidores em continuar usando uma marca no futuro (Pedersen \& Nysveen, 2001). Assim, a lealdade conativa implica uma tendência para agir em direção a uma marca, e tal tendência, geralmente, é medida por meio da intenção de compra (Assael et al., 2007).

\footnotetext{
31 "O termo "atitude" representa um constructo hipotético que se refere a sentimento positivo ou negativa general e duradouro em relação a uma avaliação ou resposta a pessoas, objetos ou assuntos".
} 
"However, this commitment is to the intention to rebuy the brand and is more akin to motivation. In effect, the consumer desires to repurchase, but similar to any "good intention," this desire may be an anticipated but unrealized action.32"(Oliver, 1999, p. 35)

Assim, podemos entender que um dos componentes principais da lealdade conativa é a intenção baseada em compromisso forte e poderoso, que produz o desejo firme de agir na busca de um objetivo (Oliver, 1997). Essa lealdade é mensurada por meio da intenção comportamental. Sendo um elo de ligação entre a lealdade atitudinal (primeira e segunda fase de Oliver, 1997) e a lealdade comportamental (quarta fase de Oliver, 1997), diversos estudos acharam papel importante da lealdade conativa na indução da lealdade comportamental (por exemplo: Back, 2005; Han et al., 2011; Choi, Lu\& Cai, 2015), fornecendo evidências plausíveis para embasar nossa linha de pensamento.

Por fim, a lealdade é composta também pela lealdade comportamental. (Kim, Vogt, \& Knutson, 2015) definem a lealdade comportamental como uma tendência de compra e recompra de uma marca ou produto. Esse comportamento deve ser passível de mensuração e afeta diretamente a venda dos produtos e marcas.

Lealdade comportamental pode ser entendia como a frequência de compra do consumidor com uma determinada marca, ou mesmo o valor gasto com uma marca em relação ao montante gasto com outras (Zhang, Kandampully, \& Bilgihan, 2015). Essa lealdade é uma conversão de intenções para agir, acompanhada por uma vontade de superar os obstáculos para que a ação ocorra (Harris \& Goode, 2004).

"the construct of behavioral loyalty, defined as a composite measure based on a consumer's purchasing frequency and amount at other retailers from which the consumer buys. In other words, behavioral loyalty is measured as a unique combination of behavioral indicators ${ }^{33}$ ")(De Wulf, Odekerken-Schroder, \& Iacobucci, 2001, p. 37)

\footnotetext{
32 "No entanto, este compromisso é com a intenção de recomprar a marca e é mais semelhante a motivação. De fato, o consumidor deseja recomprar, mas similar a qualquer "boa intenção", esse desejo pode ser uma ação antecipada, mas não realizada".

33 “a lealdade comportamental é definida como uma medida composta com base na frequência de compra do consumidor e o montante gasto em outras lojas a partir do qual o consumidor compra. Em outras palavras, a lealdade comportamental é medida como uma combinação única de indicadores comportamentais".
} 
Assim, a lealdade comportamental deve corresponder o máximo possível ao comportamento real (Srivastava, 2016). Existem vários caminhos para mensurar a lealdade comportamental. Chitty et al. (2007) definiram a lealdade comportamental pelo comportamento de compra repetido. Tal meio nos parece uma forma mais correta de abordar a questão comportamental, pois diversas pesquisas mostram que pode existir uma grande diferença entre intenção e comportamento (por exemplo: (Srivastava, 2016; Choi, Lu \& Cai, 2015).

Com isso posto, podemos definir a lealdade do consumidor como a mensuração do conhecimento (lealdade cognitiva) e do afeto, além da disposição (lealdade afetiva) do consumidor a uma marca e sua intenção (lealdade conativa) de recomprar a marca consistentemente (lealdade comportamental) no futuro. Mas isso sem esquecer que as características do consumidor e da marca acabam por interatuar e harmonizar-se para moldar a lealdade do consumidor a marca, que, nesta pesquisa, é um construto de segunda ordem, composto por três construtos de primeira ordem (lealdade atitudinal, conativa e comportamental)

A escolha desta formação se deu pela falta de trabalhos encontrados na literatura que operem de forma simultânea com as dimensões atitudinais e comportamentais (Bilgihan, Madanoglu, \& Ricci, 2016; Bodet G. , 2008; Bodet \& Bernache-Assollant, 2011). Tal escolha também se deu devido à importância dessa relação para o escopo desta pesquisa, pois buscase aqui verificar o grau de lealdade do torcedor com seu time e quantificar o quanto dessa lealdade pode ser transferida para as marcas patrocinadoras.

Assim, na sequência, apresenta-se a lealdade do consumidor sob a ótica do esporte.

\subsubsection{Lealdade do Consumidor no Esporte}

De forma geral, nota-se que a lealdade possui muitas definições e seu debate decorre, principalmente, da questão de diferenciar comportamento e atitude (Kapil \& Kapil, 2010). Kim, Morris e Swait (2008) apresentam a lealdade à marca ou ao conjunto de marcas como uma definição de fidelidade (lealdade) à marca. Já Xu, Lu, Goh, Jiang \& Zhu (2009) mostram que a lealdade do consumidor é uma ligação direta ao produto ou serviço. Por outro lado, importante ressaltar que o intuito deste trabalho é investigar a lealdade dentro do contexto do esporte ou, conforme Bristow, Schneider e Sebastian (2010), a lealdade do fã e torcedor no 
que se refere a uma equipe esportiva. Investiga-se nesta pesquisa como transferir lealdade do torcedor a seu time para as marcas patrocinadoras. Assim, entender mais profundamente o conceito de lealdade dentro do esporte se faz fundamental para o desenvolvimento deste trabalho.

Não existe nada mais leal do que o torcedor. Essa afirmação, muito popular Brasil, não é exclusividade de brasileiro. Pensa-se frequentemente no consumidor esportivo como o derradeiro consumidor, com uma inabalável lealdade, paixão e amor por seu time. Torcedores fanáticos, fãs fiéis e leais. Essa lealdade dos torcedores beneficia os times por duas vias: direta e indireta (Tabela 6).

Tabela 6: Meios pelo quais a lealdade do torcedor beneficia seu time

VIA DE BENEFICIOS

\begin{tabular}{l}
\hline Direta (Bauer et al., 2008) \\
Indireta (Heere \& Dickson, 2008; \\
Mahony et al., 2000; Rosner \& \\
Shropshire, 2004)
\end{tabular}

\section{DEFINIÇÃO}

Por meio de:

- $\quad$ compra e recompra de produtos do clube (merchandising);

- $\quad$ associação ao clube (sócio torcedor);

- boca a boca positivo;

- frequência no estádio;

- $\quad$ assistir a jogos na TV;

- buscar informações nas mais variadas mídias (impressa, televisiva, radiofónica e electrónica).

- base de fãs leais pode garantir uma maior cobertura da mídia, gerando mais exposição.

- $\quad$ por consequência, isso aumenta a capacidade da equipe em buscar recursos financeiros por meio dos patrocinadores.

\section{Fonte: Desenvolvido pelo autor}

A maneira direta não é foco de estudo desta pesquisa. Este trabalho concentra suas atividades na forma indireta, mas por meio de uma nova via. Entende-se, neste trabalho, que a lealdade pode se tornar uma vantagem competitiva para os times em busca do aumento dos valores dos patrocinadores. Isso ocorre porque a lealdade do torcedor para com o clube é o que muitas marcas, fora da indústria do esporte, anseiam (Smith \& Westerbeek, 2007).

Para que isso ocorra, obrigatoriamente se deve separar os construtos "identificação com o time" e "lealdade com time". Isso porque um torcedor pode se identificar com seu time - dentro da teoria da identidade social - mas, não necessariamente, ser fiel a ele no contexto da teoria da lealdade. Porém seria impossível esse torcedor ser leal a um time, sem que houvesse uma identificação antecipada. 
Assim, nesse trabalho, entendemos a identificação com o time como a construção da autoimagem que o torcedor faz de si mesmo. Essa autoimagem é derivada dos valores e significados emocionais atribuídos ao time e a torcida. Pois, os torcedores buscam aumentar sua autoestima por meio de suas associações com os grupos sociais a que pertencem. E esta associação ajuda a construir uma imagem positiva de si mesmo e de seu grupo. A união em torno de um time permite a ele se relacionar com grupos de interesse, ao mesmo tempo que lhe permite se identificar perante aos outros e ser identificados pelos outros (do grupo e de fora do grupo) como membro de um grupo (seu time).

Por outro lado, seguindo o postulado em nossa definição de lealdade, a lealdade ao time é um compromisso, um reflexo da disposição psicológica do torcedor para com o time. Esse compromisso deve ser forte, duradouro e persistente. Deve ser capaz de mensurar conhecimento (lealdade cognitiva), afeto e disposição (lealdade afetiva) do torcedor. Ao mesmo tempo também deve mensurar a intenção de compra futura (lealdade conativa) e também consistente no presente (lealdade comportamental) de produtos e serviços que envolvam seu time (ou marca) de forma direta. Essas definições se fazem importantes para ajudar na compreensão da diferença existente entre identificação com o time e lealdade com o time.

Apesar de as pesquisas acadêmicas no marketing esportivo definirem bem o conceito de identificação com o time como "the extent to which individuals perceive themselves as fans of the team, are involved with the team, are concerned with the team's performance, and view

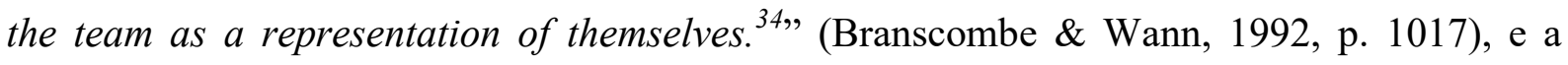
lealdade com o time, como sendo "In the context of sport teams, allegiance can be characterized as a commitment to a specific team that is persistent, resistant to change, and influences cognitive thoughts and behavior" (Funk \& James, 2006, pág. 190), existe uma série de termos quem vem sendo utilizado na literatura:

"The terms used include: identification (Wann \& Branscombe, 1990), attraction (Hansen \& Gauthier, 1989), association, (Gladden, Milne, \& Sutton, 1998), attachment (Funk et al., 2000),

\footnotetext{
34 “A medida em que os indivíduos se percebem como torcedores de um time, estão envolvidos e preocupados com o desempenho do time e veem no time a representação de si mesmos"
} 
involvement (Kerstetter \& Kovich, 1997), importance (Funk \& Pastore, 2000), commitment (Mahony et al., 2000), and loyalty (Murrell \& Dietz, 199235)’. (Funk \& James, 2001 pág 120)

Tais termos, apesar dos esforços de Funk \& James (2001, p. 120) para "This paper seeks to bring some order to the chaos ${ }^{36,}$, continuam sendo utilizados sem grandes cuidados. Não só na questão da lealdade, mas também no que tange aos estudos da identificação com o time.

Por exemplo, Wann e Branscombe (1993), um dos percursores da área, definiram "team identification" 37 " como o grau que um torcedor se sente psicologicamente ligado ao seu time. Já a identificação com o time foi, e vem sendo, tratada de formas distintas. Estudos importantes usaram termos como: "team loyalty" (Wakefield \& Sloan, 1995); "fan identification $39 "$ (Sutton et al., 1997); "team allegiance" 40 (Funk \& James, 2001); e "psychological attachment ${ }^{41 "}$ (Kwon \& Armstrong, 2004).

Entre tantos termos possíveis, a lealdade é um dos mais citados: "Loyalty, often labelled team identification, has been found to have a positive influence on (...)" (Gray \& Gray, 2012), dando, claramente, margem para uma confusão generalizada, que dificulta a compreensão das teorias e até mesmo um levantamento bibliográfico mais cuidadoso.

Essa confusão semântica é reconhecida e aceita na academia:

"Whatever the precise terminology that has been employed, the degree of allegiance to a sports team has been extensively studied by researchers in an attempt to explain the consumption behavior of sports spectators. ${ }^{42, "}$ (Theodorakis, Koustelios, Robinson \& Barlas (2009).

35 “Os termos utilizados incluem: identificação (Wann \& Branscombe, 1990), atração (Hansen \& Gauthier, 1989), associação (Gladden, Milne \& Sutton, 1998), ligação (Funk et al., 2000), envolvimento (Kerstetter \& Kovich, 1997), importância (Funk \& Pastore, 2000), compromisso (Mahony et al., 2000) e lealdade (Murrell \& Dietz, 1992)"

${ }^{36}$ Este artigo procura trazer alguma ordem para o caos

${ }^{37}$ Identificação com o time

${ }^{38}$ Lealdade ao time

${ }^{39}$ Identificação do torcedor

${ }^{40}$ Fidelidade ao time

${ }^{41}$ Afeto psicológico

42 "Seja qual for a terminologia precisa empregada, o grau de lealdade a uma equipe esportiva tem sido extensivamente estudado por pesquisadores na tentativa de explicar o comportamento de consumo dos espectadores de esportes". 
Como a área de comportamento do consumidor umas das mais estudadas no que tange a gestão do esporte (Kim, Chelladuria, \& Kim, 2015), parece-nos um equívoco muito grande para acontecer com tamanha constância.

Tendo em conta que os jornais acadêmicos relevantes na área de esporte são bastantes questionados pelos medidores de impacto da produção quanto a falta de citação externa (Shilbury, 2011), cremos ser importante alinhar algumas nomenclaturas. Parece-nos apropriado, ao cruzar a Teoria da Identidade Social (Tajfel \& Turner, 1979) com a Teoria da Lealdade, fazer essa importante ressalva. Não só para este trabalho, mas para trabalhos futuros na área.

A lealdade costuma ser vista como uma atitude favorável do consumidor que se prova por meio da compra e recompra de uma marca ao longo do tempo (Keller, 1993; Oliver, 1999; Srinivasan et al., 2002). Oliver (1999) demonstra que, apesar de satisfação e lealdade serem intrinsicamente ligadas, a satisfação não se traduz, necessariamente, em lealdade. $O$ autor conclui que a satisfação é necessária para a formação da lealdade, porém ela pode se tornar menos significativa à medida que a lealdade vai sendo construída no indivíduo por meio de outros fatores.

\footnotetext{
"These mechanisms, omitted from consideration in current models, include the roles of personal determinism ("fortitude") and social bonding at the institutional and personal level. When these additional factors are brought into account, ultimate loyalty emerges as a combination of perceived product superiority, personal fortitude, social bonding, and their synergistic effects ${ }^{43}$." (Oliver, 1999 pág. 33).
}

Desta forma, separando satisfação e lealdade, muitas organizações não podem incluir em suas metas buscar ou alcançar a lealdade de seus consumidores. A satisfação do consumidor passa a ser o único resultado possível para essas organizações. Oliver (1999). Assim, no esporte, ao utilizar a satisfação como um antecedente da identificação com o time, podemos pensar que muitos times podem alcançar a identificação com o torcedor. Mas não necessariamente alcançarem a lealdade do torcedor.

43 Esses mecanismos, omitidos das considerações nos modelos atuais, incluem os papéis do determinismo pessoal ("fortaleza") e do vínculo social a nível institucional e pessoal. Quando esses fatores adicionais são levados em conta, a lealdade final emerge como uma combinação de superioridade percebida do produto, fortaleza pessoal, vínculo social e seus efeitos sinérgicos. 
Alguns autores entendem que é possível torcedores demonstrarem lealdade comportamental, mesmo sem se identificar com algum time (por exemplo: Yoshida \& Heere, 2015; Katz \& Heere, 2013). Discordamos desse entendimento, pois a lealdade comportamental apresentada pelos torcedores analisados não está direcionada ao time.

Por exemplo, indivíduos leais a marcas como Star Wars, Marvel ou Apple são pessoas que consomem tudo e qualquer coisa relacionada a essas marcas. Essa lealdade à marca só existe porque, antes de ser leal, o indivíduo se identifica com a marca.

Nesta pesquisa, definimos a identificação com o time como uma conexão psicológica entre o torcedor e o time, fazendo com que aquele veja este como seu representante mesmo (Abrams \& Hogg, 2004; Madrigal, 2003; Tajfel \& Turner, 1986, Ashforth \& Mael, 1989; (Heere, James, et al., 2011; Wann \& Branscombe, 1993).

Neste sentido, parece-nos razoável entender a identificação com o time como um preditor, não apenas da lealdade atitudinal (Boret, 2011) ou da lealdade comportamental (Yoshida \& Heere, 2015), mas sim da lealdade do torcedor ao time geral.

Esta pesquisa também entende que o fanatismo, conforme os conceitos de McCutcheon, Lange \& Houran (2002), como um construto diferente da identificação com o time. O fanatismo é um sentimento patológico que faz com o que o torcedor sinta o time, não apenas como representante de sua imagem, mas como uma extenção de si mesmo. É uma forte conexão que leva o torcedor a projetar em si os fracassos e sucessos do time. Apesar de autores utilizarem esse conceito como identificação com o time (por exemplo: Gwinner e Swanson, 2003; Mael \& Ashforth, \& Branscombe, 1993; Fink et al, 2005), nós propomos que:

H11. Identificação com o time, fanatismo, lealdade ao time são construtos distintos.

No contexto esportivo, o conceito de lealdade sempre gerou bastantes dúvidas. Além das questões já citadas, que envolvem a confusão semântica entre identificação com o time e lealdade ao time, artigos acadêmicos comumente usam "loyalty" (lealdade) ou "allegiance" 
(fidelidade/lealdade) para se referir ao conceito de lealdade no esporte. Em termos gerais, ambas podem ter o mesmo significado. Funk e Pastore (2000) caracterizaram o termo fidelidade/lealdade (allegiance) no esporte como um compromisso para com o time. Este compromisso deve ser persistente, resistentes à mudança, e irá influenciar pensamentos cognitivos e comportamentos.

Diante da complexidade desse conceito, cabem aqui algumas explicações a respeito deste trabalho. Entende-se que a descrição de Funk e Pastore (2000) caracteriza aquilo que, comumente, os brasileiros usam para descrever um torcedor fiel. Essa fidelidade, em certos casos incondicional, levará ao processo que o marketing denomina lealdade e que foi detalhado na seção 2.5 (pág. 64). Assim, para efeitos deste trabalho, entende-se que a fidelidade e lealdade (comportamental e atitudinal) são sinônimos. Assim, adotaremos ora um, ora outro, dando preferência para o termo lealdade, por ser este mais comum na literatura geral.

Identificar caminhos e processos psicológicos que levam o consumidor a se tornar leal a uma marca vem sendo uma das questões centrais trabalhadas pela academia. A literatura geral propões diversos fatores que auxiliam nessa construção. Por exemplo: a confiança (Morgan \& Hunt, 1994), a satisfação (Oliver, 1999) e o valor percebido (Sirdeshmukh et al., 2002).

O esporte, como objeto de estudo, parece não escapar dessa tendência (Boret, 2011). Diversos são os casos na literatura acadêmica esportiva que mostram a importância de estudar a lealdade (loyalty) ou a lealdade do torcedor (fan loyalty). Bauer et al. (2008) argumentava que a importância dos consumidores leais ia além dos atos de recompra ou da vontade de assistir aos jogos do time. Consumidores leais tendem a ver seus times de forma mais favorável e, como consequência, possuem maior propensão a assistir aos jogos ou mesmo comprar produtos de seu time (Mahony et al., 2000).

Outro ponto importante com relação à lealdade dos torcedores é que, quanto mais leais, menos influenciados pelos resultados dentro das quatro linhas eles são. E como parte da essência de qualquer time é manter e conquistar torcedores (Yoshido \& Heer, 2015), os gerentes e diretores de marketing no esporte devem entender a importância deste componente.

As vitórias ou derrotas entram na área da imprevisibilidade do esporte (Heere \& Dickson, 2008; Rosner \& Shropshire, 2004) e fogem ao controle operacional da 
administração. Por isso, é um grande desafio para os profissionais do esporte garantir a qualidade do espetáculo, diferentemente do que acontece com outras alternativas de entretenimento como cinema, teatro, novelas e etc. (Yashido \& Heer, 2015).

Assim, devido à importância do torcedor para o esporte e à necessidade de entender sua lealdade, o conceito de lealdade do consumidor esportivo vem sendo bastante estudado na literatura recente por meio de variados estudos. Bauer et al. (2008) mostram como a imagem do time (marca) é importante para a lealdade. Além da questão da identificação com o time, os autores ainda mostram que tanto o logotipo como a tradição do time impactam na atitude e no comportamento para com a marca.

Funk \& James (2006) demostraram que existe uma ligação direta entre a lealdade e as razões para gostar de uma equipe. Assim, a lealdade é resultado desse processo por meio do qual os torcedores desenvolvem fortes reações emocionais, desejam mais conhecimento sobre o time e dão valor simbólico para benefícios e atributos associadas ao clube. Por outro lado, a intenção de compra de produtos ligados a patrocinadores pode não estar relacionada diretamente com a identificação com a equipe. Nesse sentido, o estudo de Kwon, Trail \& James (2007) mostra que o valor percebido pelo torcedor no produto a ser vendido é mais importante que a relação direta com a equipe.

A maior parte das pesquisas acadêmicas no esporte vem focando os estudos com base na teoria da atitude, por exemplo, satisfação (Matsuoka, Chelladurai, \& Harada, 2003; Trail, Anderson, \& Fink, 2005; Yoshida \& James, 2010), compromisso psicológico (Mahony, Madrigal \& Howard, 2000), afeto (Funk \& James, 2001, 2006; Trail, Robinson, Dick e Gillentine, 2003) e identificação de equipes (Fisher \& Wakefield, 1998; , 2001, Wann \& Branscombe, 1993, Fink 2005).

Isso ocorre porque os profissionais de marketing no esporte que buscam, num mercado cada vez mais competitivo, construir uma base sólida de torcedores (Doyle Filo McDonald b, Funk 2013). Nessa construção de uma base de torcedores, uma série de fatores podem influenciar a relação entre o torcedor e seu time (Kunkel Doyle Funk a, 2014). Esses fatores podem ser tanto internos, por exemplo, motivação dos torcedores (Funk ePastore, 2000,), afeto (Funk e James, 2001, 2006), demografia (Trail et al., 2005, Wann et al., 2001), quanto externos, como cidade (Kwon et al., 2005; Mahony et al., 2002; Trail et al., 2003), 
Universidade (Heere et al., 2011; Kwon et al., 2005; Trail et al., 2003) ou a comunidade (Katz \& Heere, 2013)

Em suma, devido ao papel fundamental que possui na indústria do esporte, estudar as diversas características individuais, psicológicas, sociais e outras dos consumidores do esporte se tornam essenciais. Dietz-Uhler, Harrick, End, \& Jacquemotte (2000) definiram como torcedor alguém que se percebe ou que outros percebem como torcedor de um time ou de um esporte em geral. Nesse contexto, o grau de lealdade (e não de identificação) com o time é o que diferencia um torcedor de outro. $\mathrm{O}$ que remete ao que identificamos como lealdade atitudinal (Bauer et al., 2008).

Essa definição ajudou os pesquisadores do consumidor esportivo a ir além das tradicionais pesquisas que buscavam analisar apenas índices de frequência como indicadores de lealdade ao time (lealdade comportamental), tais como (Boyle \& Haynes, 2009; DeSchriver \& Jensen, 2002; Funk, Mahony, \& Ridinger, 2002; Sloan, 1989; Sutton et al., 1997; Trail et al., 2005). Assim, para compreender o torcedor, espectador ou fã de um time, devem-se analisar suas atitudes e seus comportamentos para com a equipe (Funk \& James, 2006), e não apenas sua identificação. Isso se faz fundamental para que os gestores esportivos possam transforma uma "simples partida" num espetáculo de entretenimento. Na literatura a respeito do comportamento do consumidor, quando falamos de comportamento do consumidor esportivo, detecta-se que a lealdade precisa ser vista além das características comportamentais, de modo que considerações sobre atitude são necessárias.

A importância de adotar medidas comportamentais e atitudinais para analisar a construção lealdade do consumidor já foi bastante debatida na literatura (Backman \& Crompton, 1991; Day, 1969). No campo do esporte, o primeiro trabalho a fazer tal relação foi Mahony et al. (2000), que desenvolveram a escala Psychological Commitment to Team (PCT) para auxiliar na segmentação dos torcedores de acordo com sua lealdade, oferecendo uma série de estratégias que poderiam aumentar ou intensificar essa lealdade (Figura 6).

Esse trabalho percursor na área do esporte abriu espaço para a percepção de que, por meio da lealdade comportamental e atitudinal, o fortalecimento da lealdade pode ser realizado. Para isso o PCT apresentou quatro quadrantes (Figura 6), divididos em Psychological Commitment (Compromisso Psicológico) - forte ou fraco - e Behavioral Consistency (Coerência Comportamental) - alta ou baixa. Nota-se forte semelhança entre o 
modelo psicológico proposto por Mahony et al. (2000) e o de lealdade proposto por Dick \& Basu (1994).

Figura 6: Psychological Commitment to Team (PCT)

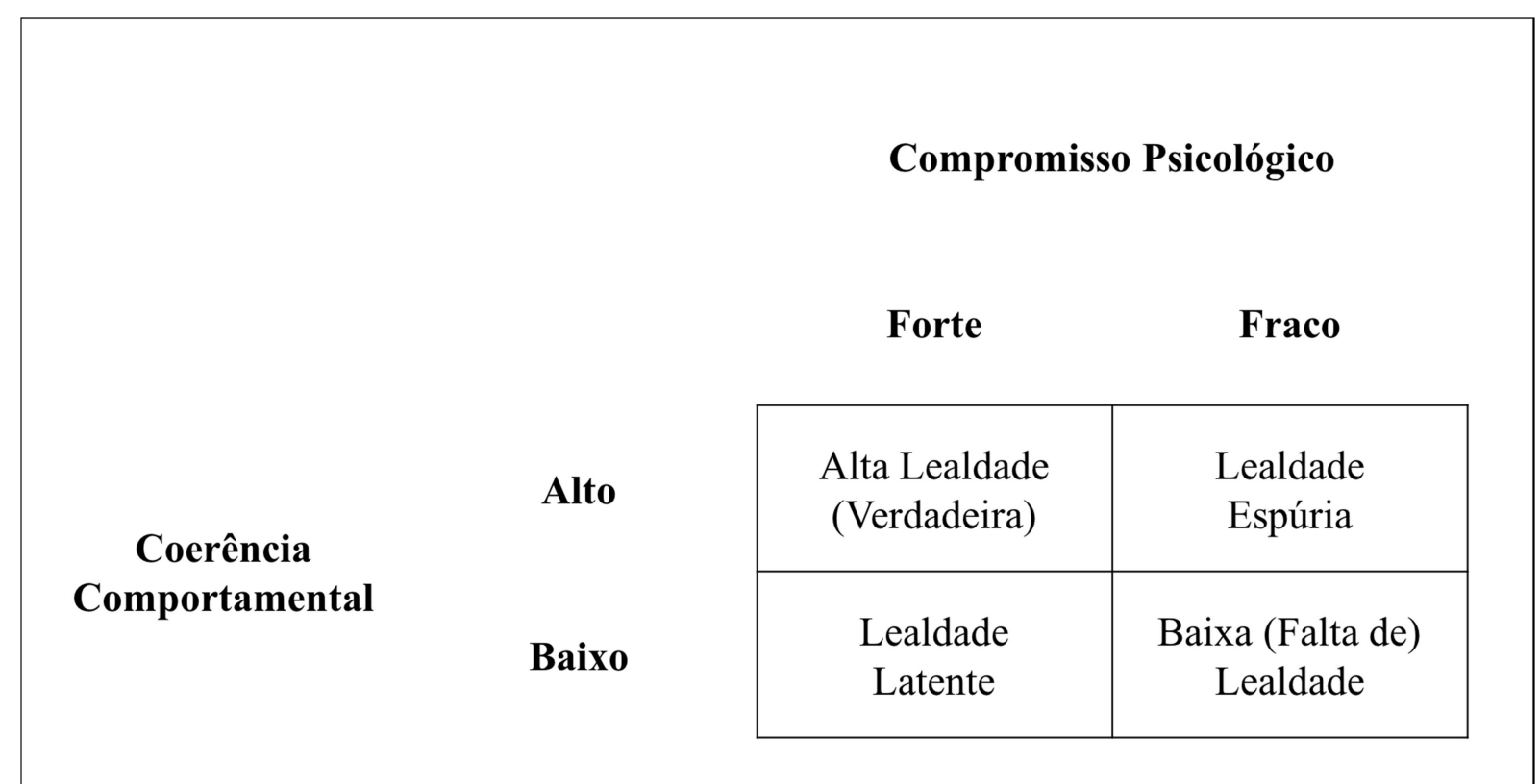

Fonte: Mahony et al. (2000

Outro modelo que ajudou a romper o paradigma de analisar o consumidor esportivo apenas por meio da lealdade comportamental foi o modelo proposto por Funk \& James (2001): Psychological Continuum Model (PCM) (Figura 7). Foi a partir do PCT e PCM que os estudos a respeito do comportamento do consumidor esportivo avançaram e deram espaço para introdução de uma nova forma de avaliar a relação torcedor e equipes esportivas. 
Figura 7: Psychological Continuum Model (PCM)

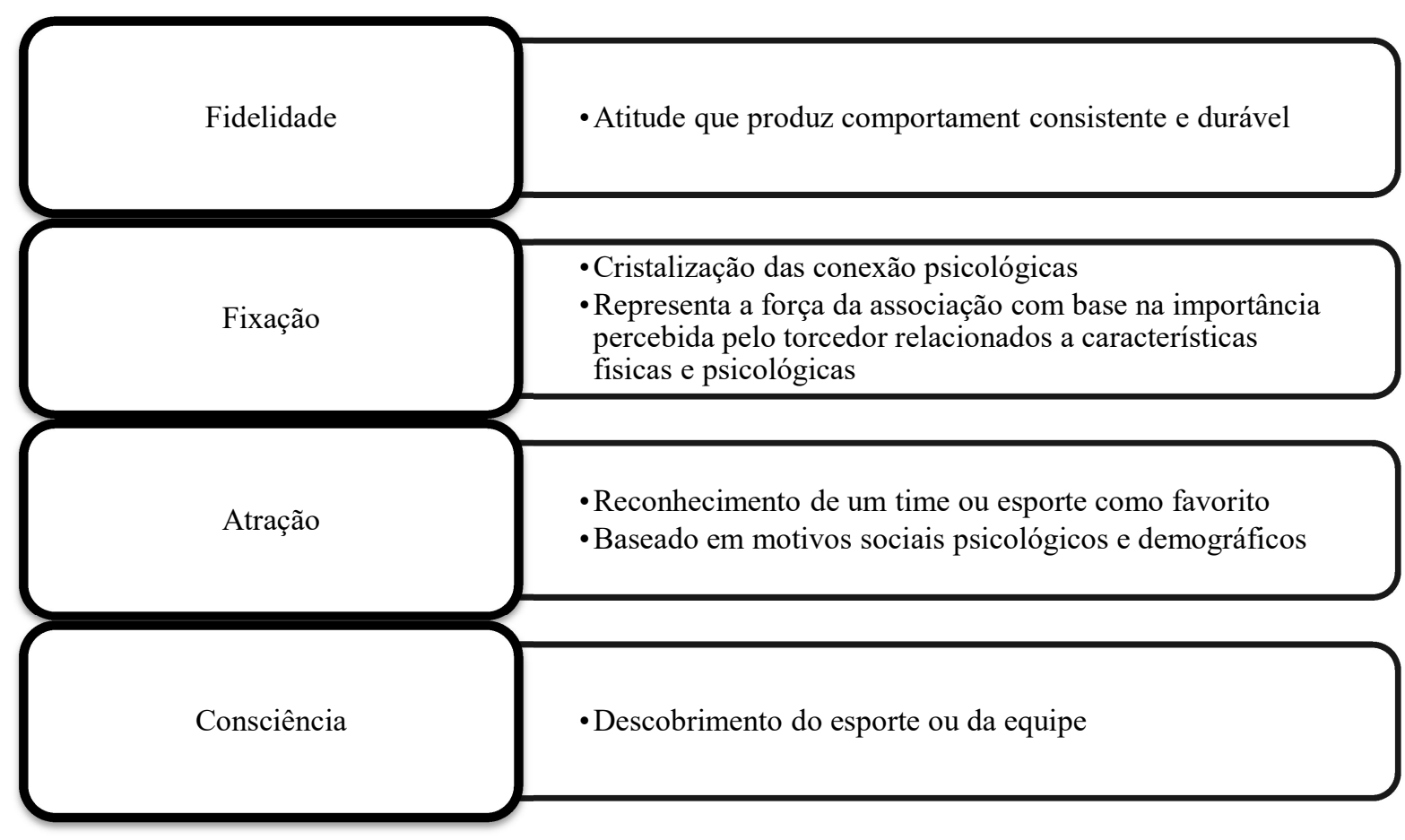

Fonte: Funk \& James, 2001

Por meio de uma abordagem cognitiva, o PCM analisa quatro níveis de associação entre torcedores, times e suas conexões psicológicas. Porém, o PCM apresenta apenas um caminho de ida. Ou seja, ao chegar à fidelidade, os autores não trabalham com a ideia de que ela pode ser "perdida":

"The different ways in which spectators and fans may relate to a sport object (e.g., a sport or team) have been conceptualized here in terms of distinct stages along a vertical psychological continuum. The continuum describes motives relating to the sport object and the evaluative processes by which a person internalizes features of the social situation. It seems unlikely that a person wakes up one day and finds that he or she is a loyal fan (buying season tickets, wearing related apparel, conversing about a team with friends, sharing in a team's wins and losses) ${ }^{44, "}$ (Funk \& James, 2001 pág 121)

${ }^{44}$ As diferentes maneiras pelas quais espectadores e fãs (torcedores) podem se relacionar com um objeto desportivo (por exemplo, um esporte ou time) foram conceituadas aqui em termos de etapas distintas ao longo de um contínuo psicológico vertical. O contínuo descreve os motivos relativos ao objeto esportivo e os processos de avaliação pelos quais uma pessoa internaliza características da situação social. Parece improvável que uma pessoa acorde um dia e acha que é um torcedor leal (compra de bilhetes de temporada, vestindo roupas relacionadas, conversando sobre um time com amigos, compartilhando as vitórias e derrotas do time). 
O PCM vem sendo utilizado como base teórica para se entender a relação entre o torcedor e seu time (Kunkel Doyle Funk a, 2014). E serviu de base para que pudéssemos separar a identificação com o time e a lealdade com o time. O PCM afirma que fatores internos (necessidades psicológicas) e externos (socialização) interagem. Essa interação influencia na avaliação final do torcedor em relação a lealdade com seu time.

Esses processos são determinados pelo conhecimento e envolvimento prévio dos torcedores (Funk \& James, 2001). Ou seja, são antecipados pela identificação com o time. Desta forma, esse trabalho compartilha da ideia de que lealdade do torcedor ao time é um construto diferente da identificação. Porém entendemos que a lealdade é transitória por natureza (Kandampully and Zhang, 2015). Ela pode diminuir ou aumentar com o passar do tempo ou como consequência das ações (ou falta de ações) das organizações (time). Todavia a identificação com o time tem efeito mais duradouro.

Para nós, é nessa análise que reside a problemática da relação entre identificação e lealdade. A identificação é um estado psicológico enraizado no torcedor e construído ao longo do tempo. Já a lealdade, como base no PCM:

"These processes include motivation, perception, learning and memory, which each influence the evaluation of the internal and external factors and, therefore, create psychological and behavioral outcomes, such as involvement or game attendance 45 ". Kunkel Doyle Funk a, 2014 pág 471

Desta forma, para o desenvolvimento deste trabalho, a lealdade com o time é proposta como um construto multidimensional. Isso se deve ao fato de o trabalho entender que a lealdade do torcedor com o time não pode estar baseada apenas em seu desejo de torcer, comparecer a jogos ou mesmo comprar uniformes. Acredita-se que a verdadeira lealdade ao time é um construto de segunda ordem, formado pela lealdade atitudinal, conativa e comportamental, que são os construtos de primeira ordem. A lealdade ao time, por sua vez, é precedida da identificação com o time e do fanatismo (Figura 8).

45 "Estes processos incluem motivação, percepção, aprendizagem e memória, que influenciam a avaliação dos fatores internos e externos e, portanto, geram resultados psicológicos e comportamentais, como o envolvimento ou a participação no jogo". 
Figura 8: Lealdade ao time

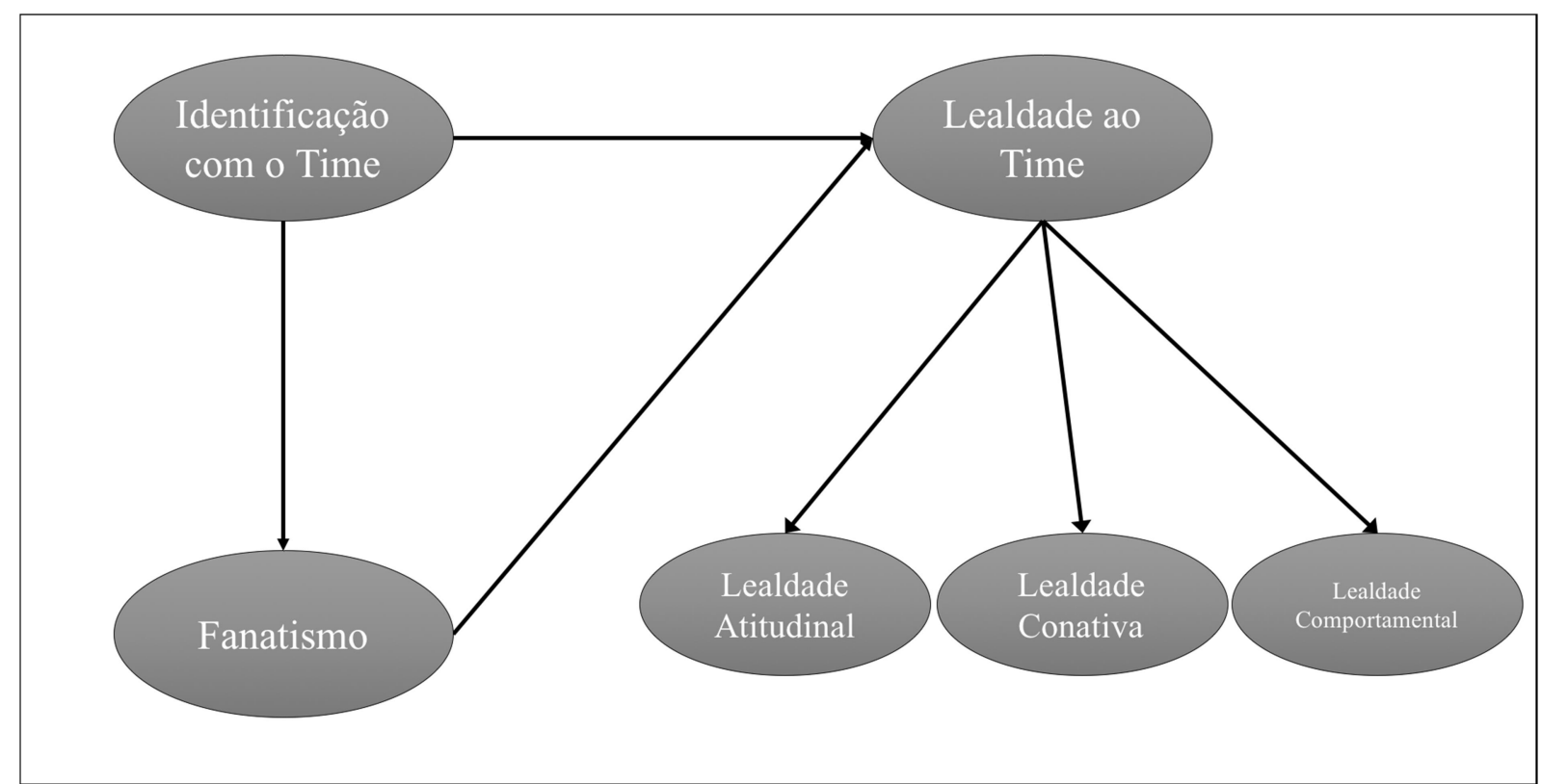

Fonte: Desenvolvido pelo autor

H12. Lealdade ao time é afetada positivamente e de forma significativa por (a) identificação com o time; e (b) fanatismo.

\subsection{Patrocínio Esportivo}

Patrocínio não é uma atividade recente. Desde a Antiguidade, os mecenas já patrocinavam esporte e artes com o intuito de autopromoção. A importância do patrocínio na atividade econômica pode ser analisada por meio dos valores introduzidos no mercado. $\mathrm{O}$ ano de 2014 movimentou aproximadamente 55 bilhões de dólares no mundo todo (Tabela 7).

Tabela 7: Valores de patrocínio Global (Em Bilhões de Dólares)

\begin{tabular}{ccc}
\hline ANO & GASTO GLOBAL & $\begin{array}{c}\text { CRESCIMENTO } \\
\text { (ano anterior) }\end{array}$ \\
\hline $\mathbf{2 0 1 5}$ & 57,5 & $3,98 \%$ \\
\hline $\mathbf{2 0 1 4}$ & 55,3 & $4,14 \%$ \\
\hline $\mathbf{2 0 1 3}$ & 53,1 & $3,91 \%$ \\
\hline $\mathbf{2 0 1 2}$ & 51,1 & $5,14 \%$ \\
\hline $\mathbf{2 0 1 1}$ & 48,6 & $4,97 \%$ \\
\hline $\mathbf{2 0 1 0}$ & 46,3 & $5,23 \%$ \\
\hline $\mathbf{2 0 0 9}$ & 44 & $2,09 \%$ \\
\hline $\mathbf{2 0 0 8}$ & 43,1 & $13,72 \%$ \\
\hline
\end{tabular}


Fonte: Desenvolvido pelo autor baseado em IEG (2011, 2012, 2013, 2014)

A América do Norte lidera a captação do patrocínio com aproximadamente 20,5 bilhões de dólares (37\%), seguido pela Europa (26\% - US\$14,8 bilhões) e Ásia (24\% - US\$ 13,3 bilhões) (Figura 9).

Figura 9: Patrocínio por Região do Globo (Bilhões de Dólares)

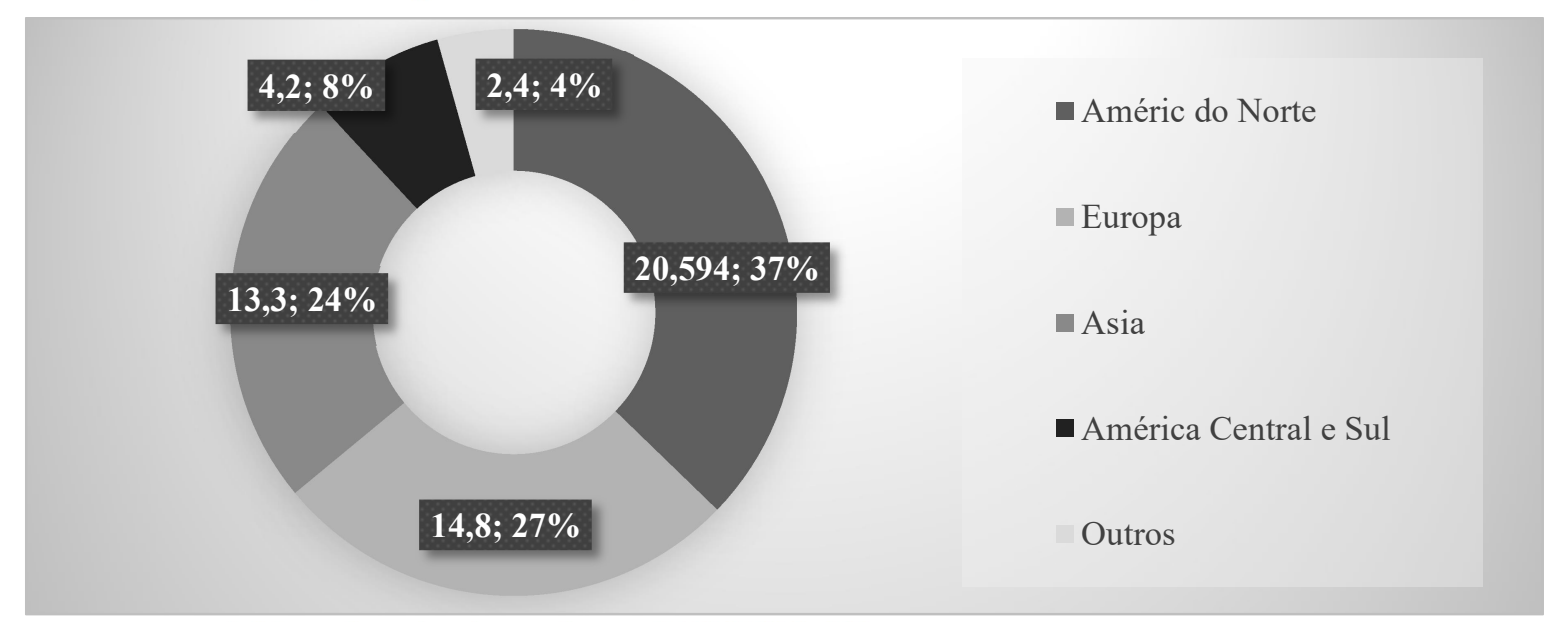

Fonte: Desenvolvido pelo autor baseado em IEG (2011, 2012, 2013, 2014)

Quando falamos de patrocínio, não estamos nos referindo apenas ao esporte (apesar de ser o contexto desta pesquisa), mas sim a recursos provenientes de uma empresa (patrocinadora) que paga por uma propriedade (patrocinado), em troca de poder explorar o potencial econômico da propriedade associada (Ukman, 1995). São estes patrocinadores que disponibilizam os recursos necessários “para fazer as coisas acontecerem” (Busby, 1997).

Porém a grande fatia do dinheiro envolvido no patrocínio é direcionada ao esporte. $\mathrm{Na}$ América do Norte, $70 \%$ do dinheiro relacionado à patrocínios é destinado ao esporte. Patrocínios a atividades de entretenimento e causa vêm logo em seguida, com cerca de $10 \%$ para cada uma das atividades (Figura 10). Muito disso está relacionado ao fato de o esporte profissional ser reconhecido como um negócio multimilionário capaz de gerar inúmeras oportunidades de ações de marketing para as mais variadas empresas (Shannon, 1999) e, por isso, tornar-se, cada vez mais, o objeto de desejo daqueles que veem no patrocínio uma forma de investimento (Walliser, 2003). 
Figura 10: Patrocínio por tipo de atividade na América do Norte (Bilhões de Dólares)

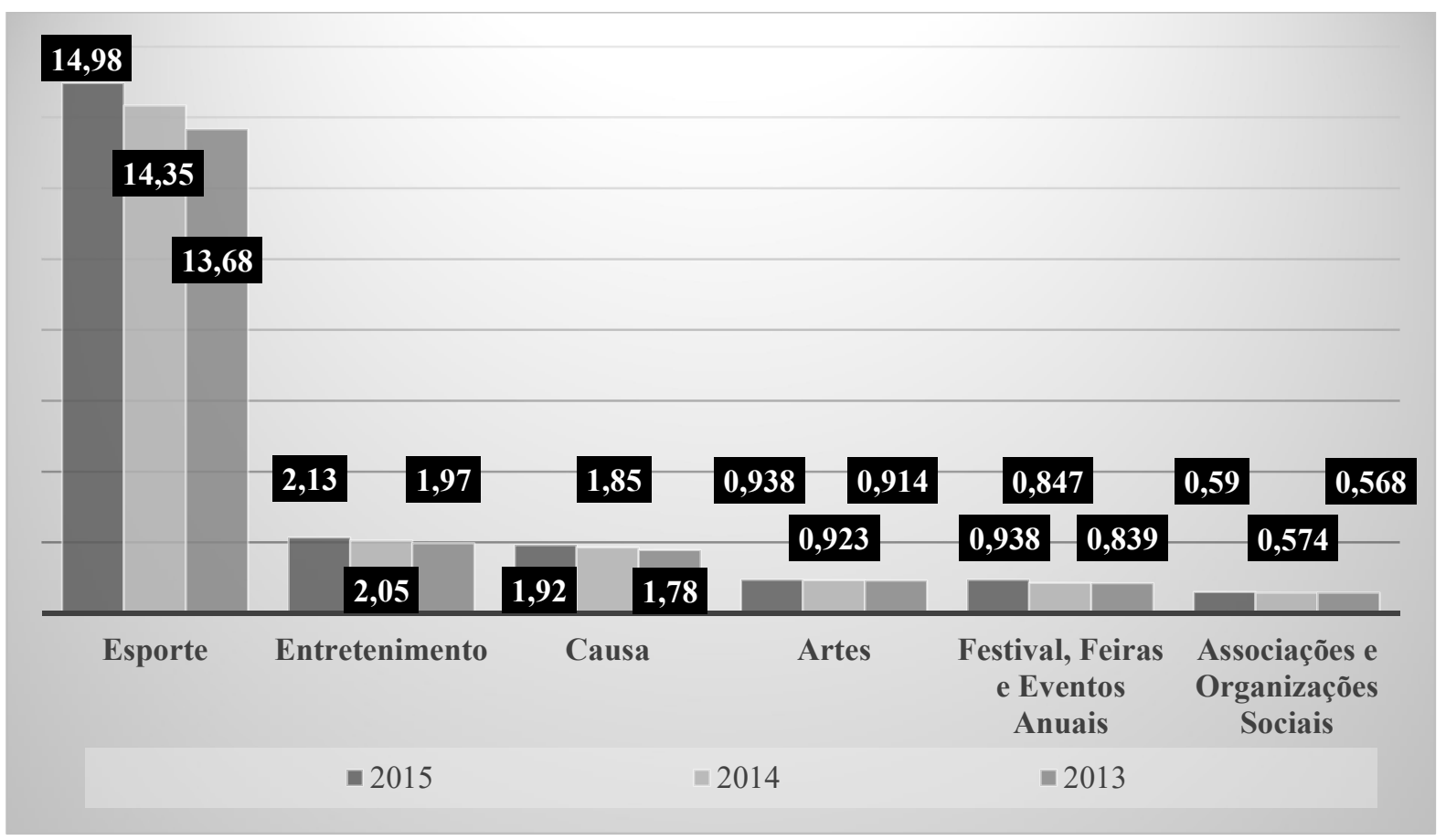

Fonte: Baseado em IEG (2011, 2012, 2013, 2014)

Lachowetz, McDonald, Sutton, \& Hedrick (2003) já apontavam para o crescimento constante dos investimentos em patrocínio. A Tabela 7 e as Figura 9 e Figura 10 corroboram essa visão e nos ajudam a entender que o patrocínio, em especial no esporte, é um objeto de estudo que merece ser analisado pelo meio acadêmico. Ponto importante com relação ao patrocínio é o peso que eles têm nas receitas das equipes. Dados do futebol europeu mostram que patrocínio e atividades correlacionadas representam em média $41 \%$ das receitas dos principais times do futebol mundial (Tabela 8). A televisão (broadcasting) vem em seguida com $39 \%$, e o chamado matchday ${ }^{46}$ com $20 \%$. Porém, analisando a Tabela 8 , é interessante notar que os principais clubes europeus estão buscando cada vez mais diminuir a dependência das redes de televisão e criando situações em que os departamentos internos das equipes tenham ação direta.

\footnotetext{
46 “Matchday é um termo inglês usado para descrever acontecimentos no dia da partida. Neste caso são consideradas todas as receitas no dia do jogo".
} 
Tabela 8: Receita dos clubes europeus

\begin{tabular}{|c|c|c|c|c|}
\hline ANO & TIPO DE RECEITA & TOP 20 & TOP 10* & TOP 5* \\
\hline \multirow{3}{*}{2014} & Matchday & $20 \%$ & $21 \%$ & $20 \%$ \\
\hline & $\mathrm{TV}$ & $39 \%$ & $35 \%$ & $29 \%$ \\
\hline & Comercial & $41 \%$ & $45 \%$ & $50 \%$ \\
\hline \multirow{3}{*}{2013} & Matchday & $22 \%$ & $23 \%$ & $22 \%$ \\
\hline & $\mathrm{TV}$ & $36 \%$ & $34 \%$ & $31 \%$ \\
\hline & Comercial & $42 \%$ & $43 \%$ & $47 \%$ \\
\hline \multirow{3}{*}{2012} & Matchday & $23 \%$ & $26 \%$ & $26 \%$ \\
\hline & $\mathrm{TV}$ & $39 \%$ & $36 \%$ & $33 \%$ \\
\hline & Comercial & $37 \%$ & $38 \%$ & $41 \%$ \\
\hline \multirow{3}{*}{2011} & Matchday & $23 \%$ & $27 \%$ & $26 \%$ \\
\hline & $\mathrm{TV}$ & $42 \%$ & $38 \%$ & $35 \%$ \\
\hline & Comercial & $32 \%$ & $35 \%$ & $38 \%$ \\
\hline
\end{tabular}

* Em todos os anos foram usadas as receitas dos clubes ranqueados em 2014

Fonte: Desenvolvido pelo autor baseado em DElloite (2011, 2012, 2013, 2014)

Os clubes brasileiros, por outro lado, parecem ir na contramão do mercado mundial (Tabela 9). As cotas de televisão ainda são predominantes nas fontes de receita dos clubes brasileiros. Apesar de os clubes não divulgarem as receitas totais do chamado matchday em seus balanços, podemos analisar essa receito por sua similar nas fontes brasileiros - bilheteria. Bilheteria ainda tem baixa representatividade nas fontes de receita e, em conjunto com a rubrica patrocínio e publicidade, não chega a $50 \%$ da receita total. Tais dados nos ajudam a inferir que existe um grande campo profissional a ser trabalhado pelos clubes. Conhecer seus torcedores, de modo a aumentar a presença deles no estádio e poder transformá-los em vantagem competitiva dos seus clubes parece um caminho seguro a ser seguido.

Tabela 9: Receita dos clubes brasileiros

\begin{tabular}{|c|c|c|c|c|}
\hline ANO & TIPO DE RECEITA & TOP 24 & TOP $12 *$ & TOP 4* \\
\hline \multirow{3}{*}{2014} & Patrocínio e Publicidade & $25 \%$ & $26 \%$ & $31 \%$ \\
\hline & TV & $56 \%$ & $55 \%$ & $52 \%$ \\
\hline & Bilheteria & $19 \%$ & $19 \%$ & $17 \%$ \\
\hline \multirow{3}{*}{2013} & Patrocínio e Publicidade & $26 \%$ & $28 \%$ & $24 \%$ \\
\hline & TV & $61 \%$ & $60 \%$ & $62 \%$ \\
\hline & Bilheteria & $13 \%$ & $12 \%$ & $14 \%$ \\
\hline \multirow{2}{*}{2012} & Patrocínio e Publicidade & $28 \%$ & $29 \%$ & $30 \%$ \\
\hline & TV & $59 \%$ & $58 \%$ & $53 \%$ \\
\hline
\end{tabular}




\begin{tabular}{lllll} 
& Bilheteria & $13 \%$ & $13 \%$ & $17 \%$ \\
\hline \multirow{2}{*}{2011} & Patrocínio e Publicidade & $25 \%$ & $26 \%$ & $31 \%$ \\
& TV & $56 \%$ & $55 \%$ & $52 \%$ \\
& Bilheteria & $19 \%$ & $19 \%$ & $17 \%$ \\
\hline \hline
\end{tabular}

* Em todos os anos foram usadas as receitas dos clubes ranqueados em 2013

Fonte: Desenvolvido pelo autor baseado em BDO)

Outro ponto importante é que a propaganda e a promoção de vendas são usadas, tradicionalmente, como ação de marketing de curto prazo, e empresas patrocinadoras começam a ver o esporte e as ações de patrocínio como parceria estratégica de longo prazo (Farrelly, Quester, \& Burton, 2006; Meenaghan, Mcloughlin, \& McCormarck, 2013). A Tabela 10 nos ajuda a ver isso. Exceto pelos investimentos projetados para 2015, até 2014 os investimentos em patrocínio sempre superaram as outras atividades de marketing.

Tabela 10: Divisão dos Investimento em Marketing no Mundo (\% de crescimento)

\begin{tabular}{lccc}
\hline ANO & PROPAGANDA & PROMOÇÃO DE VENDAS & PATROCÍNIO \\
\hline \hline $\mathbf{2 0 1 5}$ & 4,9 & 4,1 & 4,1 \\
\hline $\mathbf{2 0 1 4}$ & 3,9 & 3,7 & 4,1 \\
\hline $\mathbf{2 0 1 3}$ & 3,3 & 3,7 & 3,9 \\
\hline $\mathbf{2 0 1 2}$ & 3.7 & 3,8 & 5,1 \\
\hline
\end{tabular}

Fonte: Desenvolvido pelo autor baseado em IEG $(2011,2012,2013,2014)$

Analisando o mercado o mercado da América do Norte (Tabela 11), responsável por receber $37 \%$ de toda a receita mundial em patrocínio (Figura 9), percebe-se um crescimento ainda mais acelerado nos investimentos em patrocínio. Nota-se que nos anos pares, quando ocorrem Jogos Olímpicos ou Copa do Mundo, o crescimento é ainda mais acentuado. Assim, as ações de patrocínio são uma válvula de escape à mídia tradicional, já saturada (Meenaghan, 2001).

Tabela 11: Divisão dos investimentos de Marketing na América do Norte (\% de crescimento)

\begin{tabular}{cccc}
\hline ANO & PROPAGANDA & PROMOÇÃO DE VENDAS & PATROCÍNIO \\
\hline \hline 2015 & 3,8 & 3,5 & 4 \\
\hline 2014 & 3,1 & 2,8 & 4,2 \\
\hline 2013 & 2,1 & 1,5 & 2,8 \\
\hline 2012 & 3,8 & 0,7 & 4,4 \\
\hline 2011 & 3,2 & 3,6 & 5,5 \\
\hline 2010 & 2.0 & $-0,9$ & 2 \\
\hline \hline
\end{tabular}


Fonte: Desenvolvido pelo autor baseado em IEG $(2011,2012,2013,2014)$

Porém sabe-se que o patrocínio é uma das ferramentas que a área de marketing possui para buscar alcançar os consumidores e despertar o interesse na compra dos produtos (Mason, 2005). Desta forma, a dificuldade existente para analisar a influência do patrocínio no que se refere à intenção de compra está em separar o efeito das outras atividades de marketing (promoção de vendas e propaganda) (Miles, 2000; Miyazaki \& Morgan, 2001).

Os estudos nesta área são poucos, e seus resultados não são contundentes. Smith et al. (2008) apontam que a identificação com o time influencia na decisão do consumidor, mesmo que não diretamente. Na pesquisa com torcedores dos clubes profissionais de futebol da Austrália, sem fins lucrativos, os resultados apontam que a intenção de compra está associada à paixão do torcedor e à percepção de integridade que ele tem com relação a marca patrocinadora. Gwinner \& Swanson (2003) e Madrigal (2001) também encontram relação positiva entre identificação com o time e patrocínio nos resultados cognitivos, afetivos e comportamentais, porém sem isolar variáveis que poderiam influenciar no processo, tais como o conhecimento preliminar da marca.

Por outro lado, Kwon et al. (2007) investigaram o efeito mediador do valor percebido entre a identificação com a equipe e a intenção de compra de produtos licenciados. A pesquisa com estudantes universitários americanos apontou que o efeito direto não existia. A identificação com o time explicou $13,2 \%$ da variação no valor percebido. Já valor percebido explicou 42,6\% da variação nas intenções de compra. Os resultados, como os autores salientam, mostram que apenas a identificação com a equipe não é capaz de suportar a intenção de compra.

Tais resultados podem estar relacionados com aspectos importantes da intenção de compra (Pope \& Voges, 1999; Pope \& Vogues, 2000): atitude positiva em relação à marca e familiaridade com ela. A familiaridade pode ser obtida através da exposição, que se torna um elemento importante no determinação do valor de um patrocínio (Cornwell, Relyea, Irwin, \& Maignan, 2000), e pode ajudar a aumentar o consumo (Levin, Joiner, \& Cameron, 2001; Pope, 1998).

Evidencia-se, por meio dos resultados das pesquisas anteriores, que estudos entre relação ao patrocínio esportivo, a identificação com a equipe e os resultados desta relação se fazem necessários. Não apenas pela escassez de trabalhos desse tipo, mas pelos resultados não 
definitivos encontrados naqueles que abordaram a questão. Um ponto de partida pode estar no entendimento de que um patrocínio eficaz acontece quando se compreende a atitude do consumidor e o componente cognitivo comportamental (Mason, 2005).

Neste ponto, nos estudos acadêmicos que abrangem a questão do patrocínio, é possível notar uma diversidade de indicadores atitudinais e comportamentais. Miloch \& Lambrecht (2006) analisaram recordação (recall), taxa de reconhecimento (recognition rates) e intenção de compra (purchase intentions) dos consumidores em eventos esportivos. Os resultados apontaram que tanto o recall como a taxa de reconhecimento podem ser influenciadas pela ativação do patrocínio, pela localização dos anúncios e pela familiaridade com o evento. Já intenção de compra foi influenciada pela idade do consumidor.

Também por meio de patrocínios a eventos esportivos, no caso específico os Jogos Olímpicos de Atenas 2004, Tsiotsou \& Lalountas (2005) estudaram o efeito do patrocínio no preço das ações das empresas. Apesar da ressalva dos autores com relação ao momento vivido na Europa na época dos jogos e de que boa parte das empresas patrocinadoras eram empresas púbicas (7 de 12), os resultados encontrados apontaram para um efeito nulo no preço das ações. Destacam-se como prováveis fatores o custo do orçamento olímpico (alto), má publicidade dos Jogos (momento negativo na Europa) e a comunicação limitada por meio de contratos.

Pope \& Voges (1999) apresentaram estudo interessante no que diz respeito à questão da melhora da imagem corporativa das empresas por meio do patrocínio esportivo. Os achados dos autores mostraram que as pessoas que respondiam positivamente ao patrocínio eram usuários da marca. Assim, a utilização anteriormente da marca explicava a consciência do patrocínio (sponsorship awareness). Meenaghan (2001) apresentou um modelo teórico bastante abrangente envolvendo a boa vontade com relação ao patrocinador (goodwill in sponsorship), a transferência de imagem e o envolvimento do torcedor.

Cornwell, Weeks, \& Roy (2005) apresentaram um modelo de comunicação de marketing com foco na ligação entre patrocinador e o consumidor (Figura 11), o que ajuda a ao fazer uma interpretação teórica dos diversos estudos até então. Ativação do patrocínio como fator de gestão da marca aparece com destaque na influência que pode causar no processo de identificação para com a marca. Como saída desta relação, os autores apontam 
fatores cognitivos, afetivos e comportamentais que poderiam ajudar na criação da lealdade para com a marca patrocinadora.

Apesar do reconhecimento da importância do patrocínio para o desenvolvimento do esporte profissional, a maior partes dos estudos na área possuem foco no reconhecimento ou na recordação do patrocínio na mente do consumidor (Meenaghan \& O’Sullivan, 2001). Isso acontece porque o foco dos estudos tem sido analisar os benefícios em patrocinar eventos ou equipes esportivas para o patrocinador, e poucos são os estudos que possuem foco em estudar a relação entre os patrocinadores e os consumidores esportivos (Delia, 2014).

A explicação para isso é simples: essas medidas (reconhecimento e recordação) permitem ao profissional de marketing justificar seus gastos (ou investimentos) com o patrocínio de maneira prática (Stotlar, 2004). Desta forma, o que vemos hoje é que a "caixa preta" do patrocínio (Cornwell et al., 2005), ou seja, o entendimento a respeito de como funciona o processo cognitivo, afetivo e comportamental nas decisões dos consumidores acerca do patrocínio, ainda não foi plenamente compreendida pelos profissionais ou acadêmicos (Delia, 2014).

Dolphin (2003) corrobora com a questão da facilidade para os profissionais de marketing quando aponta em seus estudos que uma das causas do aumento do patrocínio esportivo por partes das empresas é a visibilidade em mídia espontânea. Isso porque o esporte permite uma exposição das marcas patrocinadoras, em mídia não pagas, bem com o envolvimento com o público, de forma a permitir uma maior exposição, em que aspectos como emoção e a competitividade ligadas ao esporte podem ser transferidas para a marca patrocinadora Wakefield (2012) e ajudam a reforçar a imagem coorporativa do patrocinador Wakefield \& Bennett (2010). 
Figura 11: Sponsor of Consumer-Focused Sponsorship-Linked Marketing Communications

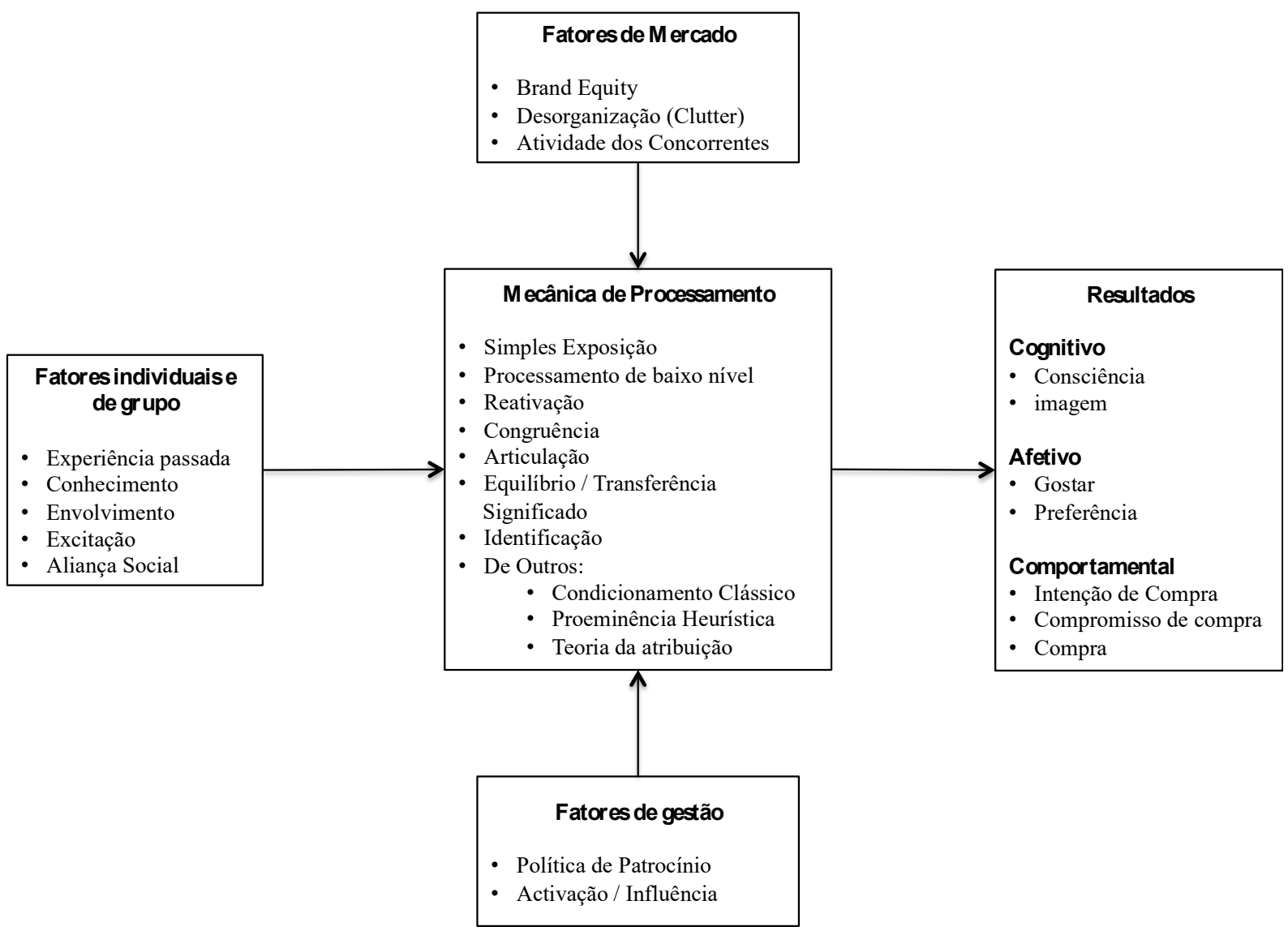

Fonte: Baseado Cornwell, Weeks e Roy (2005)

Entender os motivos que levam empresas a patrocinar o esporte é importante, pois os objetivos de patrocinadores e patrocinados são, por muitas vezes, distintos entre si (Geng, Burton, \& Blakemore, 2002). Afinal, conforme demostrado até o momento, os valores investidos no patrocínio esportivo são altos, e os patrocinadores esperam uma associação positiva com os patrocinados (Geng et al., 2002; O’Reilly \& Madill, 2007; Pichot, Tribou, \& O’Reilly, 2008).

Objetivos institucionais são bastante citados na literatura. Entre os principais objetivos institucionais, pode-se destacar a mudança da percepção do público com relação à imagem da empresa (Irwin, Sutton, \& McCarthy (2008); Irwin \& Asimakopoulos (1992), a construção da imagem corporativa (Cornwell, Pruitt, \& Clark, 2005; Davies \& Tsiantas, 2008; Gwinner, 1997; Irwin \& Asimakopoulos, 1992; Koo, Quarterman, \& Flynn, 2006; Kuzma, Shanklin, \& McCally Jr, 1993; Pope \& Vogues, 2000; Tsiotsou, 2011; Walliser, 2003) e a melhora da 
conscientização do segmento trabalhado com relação à empresa (Lough \& Irwin, 2014; Lough, 1996; Mack, 1999; Meenaghan, 1991).

Outras questões que envolvam relacionamento, em suas mais variadas formas, também merecem destaque, como o relacionamento com a comunidade (Apostolopoulou \& Papadimitriou, 2004; Lough \& Irwin, 2014; Mack, 1999; Seguin, Teed, \& O’Reilly, 2005), com outras empresas ou clientes comerciais e institucionais (Crowley, 1991; Ludwig \& Karabetsos, 1999; Mack, 1999; Meenaghan, 1991) e também com funcionários da própria empresa (Apostolopoulou \& Papadimitriou, 2004; Lough \& Irwin, 2014; Lough, 1996; Ludwig \& Karabetsos, 1999; Papadimitriou, Apostolopoulou, \& Dounis, 2008; Seguin et al., 2005).

Por fim, destaquem-se os objetivos relacionados diretamente com o mercado em que o patrocinador atue, como o aumento de venda (Fullerton \& Merz, 2008; Irwin \& Asimakopoulos, 1992; Shank \& Lyberge, 2015), que não pode ser esquecido, bem como objetivos que contemplem conquista de mercado, desenvolvimento de novos negócios e ações competitivas (Copeland, Frisby, \& Mccarville, 1996; Cornwell et al., 2005; Davies \& Tsiantas, 2008; Irwin \& Asimakopoulos, 1992; Koo et al., 2006; Kuzma et al., 1993).

Apesar dos mais variados objetivos expostos pela literatura, um ponto relevante é que o simples fato de patrocinar não irá garantir, necessariamente, que os objetivos sejam atingidos. Para que isso aconteça, é necessário ativar o patrocínio de forma a estabelecer uma base que permita que patrocinadores, patrocinados e torcedores fiquem alinhados (Rines, 2007). Fullerton \& Merz (2008) destacam que essa ligação ajuda a posicionar a empresa patrocinadora dento do cenário esportivo de forma a explorar o potencial do patrocínio na mente do consumidor.

Miloch \& Lambrecht (2006) demonstra que a ativação do patrocínio é capaz de influenciar o efeito de reconhecimento e recordação da marca. Os estudos de Westerbeek \& Smith, (2002) ajudam a ratificar este pensamento, ao mostrar que a ativação deve acontecer por meio de uma comunicação clara, permitindo a associação entre o patrocinador e patrocinado.

Desta forma, a relação entre patrocinador, patrocinado e torcedores deve buscar sempre uma relação de equilíbrio, permitindo que as parte envolvidas na relação estejam " $a$ 
harmonious state, one in which the entities comprising the situation and the feelings about them fit together without stress ${ }^{47, "}$ (Heider, 1958, p. 180).

Assim, nos dias de hoje, é difícil imaginar um evento esportivo sem patrocínio (Mazodier \& Quester, 2014), pois, de um lado, os eventos e equipes participantes depende dos recursos financeiros oriundos dos patrocinadores e, de outro, os patrocinadores utilizam de forma significativa o patrocínio como uma ferramenta estratégica de marketing (Novais \& Arcodia, 2013; Maxwell \& Lough, 2009).

De fato, o patrocínio é visto pelas organizações como uma ferramenta bastante relevante para se alcançar os objetivos de marketing (Olson, 2010). Devido ao volume de dinheiro investido neste setor, ele se faz importante economicamente para o mercado, além de contribuir na mudança de alguns paradigmas, devido à sua natureza estratégica, que envolve avanços tecnológicos, comunicação e responsabilidade social (Pappu e Cornwell, 2014). Por isso, vem sendo bastante investigado pela academia (Novais \& Arcodia, 2013) e também pelas organizações patrocinadoras na busca de avaliar a eficiência e a eficácia do patrocínio (Kim, Ko, \& James, 2011).

Dentre as diversas formas atuais de mensurar a eficiência e a eficácia dos patrocínios, três variáveis são bastante utilizadas: atitude em relação ao patrocinador (Kim, Ko, \& James, 2011; Gwinner e Swanson 2003; Alexandris e Tsiotsou 2012 ; Olson 2010); percepção do patrocínio (Alexandris, Tsaousi, James 2007; Gwinner e Swanson 2003); e congruência (Macdougall, Nguyen, \& Karg, 2014; Olson 2010; Menon e Kahn 2003).

A mudança de atitude por parte do consumidor com relação ao patrocínio é algo esperado e procurado pelas empresas patrocinadoras. Do ponto de vista desta pesquisa, entendemos que os patrocinadores devem buscar aquilo que é mais valioso para qualquer equipe esportiva: seus torcedores ou, melhor dizendo, a lealdade destes torcedores, que consideramos uma vantagem competitiva das equipes.

\footnotetext{
47 "um estado harmonioso, no qual as entidades que compõem a situação e os sentimentos sobre eles se encaixam sem estresse".
} 
Os estudos revisados neste trabalho apresentam diversas questões que foram analisadas da relação entre o torcedor, seu time e o patrocinador (ou patrocinadores) de sua equipe. Porém, não encontramos na literatura nenhuma análise que versasse sobre a questão da lealdade do torcedor e o impacto dela na construção da lealdade ao patrocinador. Este processo, que neste trabalho denominamos Transferência de Lealdade, parece um caminha natural, não apenas para as equipes, mas também para os patrocinadores, devido às mudanças apresentadas nos últimos anos nos interesses envolvidos no esporte.

A academia, conforme dito anteriormente, vem mostrando a necessidade de as organizações estreitarem o laço com os consumidores. Os programas de fidelidade vêm ganhando espaço e relevância na academia, mostrando a importância de se estar cada vez mais perto do consumidor. Assim, parece-nos coerente que os patrocinadores possam vislumbrar no patrocínio esportivo motivos além dos já apresentados neste trabalho. Portanto, propomos que os patrocinadores devem ter como um dos objetivos, absorver a fidelidade do torcedor ao seu time para sua marca e/ou produto. Assim, como forma de mensurar a transferência da lealdade, propomos que:

H13. Atitude (a) afeta positivamente e de forma significativa a lealdade ao patrocinador; (b) não modera a relação entre lealdade ao time e lealdade ao patrocinador; e (c) não media a relação entre lealdade ao time e lealdade ao patrocinador.

H14. Congruência (a) afeta positivamente e de forma significativa a lealdade ao patrocinador; (b) não modera a relação entre lealdade ao time e lealdade ao patrocinador; e (c) não media a relação entre lealdade ao time e lealdade ao patrocinador.
H15. Percepção (a) afeta positivamente e de forma significativa a lealdade ao patrocinador; (b) não modera a relação entre lealdade ao time e lealdade ao patrocinador; e (c) não media a relação entre lealdade ao time e lealdade ao patrocinador. 
No que condiz aos estudos sobre patrocínio, a base das análises vem sendo realizadas por meio do que a academia denomina transferência de imagem. A transferência de imagem, neste sentido, mostra o caminho pelo qual o patrocinador se beneficia dos atributos inerentes aos eventos esportivos (Gwinner, 1997; Speed \& Thompson, 2000). Na literatura, a transferência de imagem vem sendo analisa sob a ótica de diferentes teorias, porém três são as que predominam (Grohs \& Reisinger, 2014): teoria do condicionamento clássico (Speed \& Thompson, 2000), transferência de significados (McCracken, 1989) e transferência de imagem (Gwinner, 1997).

Assim, no próximo capítulo, abordaremos a teoria da transferência de imagem, apresentando seus conceitos e relacionando-a à transferencia da lealdade que esta pesquisa propõe. Para tanto, usaremos a Teoria do Equilíbrio (Balance Theory - (Heider, 1958) para explicar as questões psicológicas que justificam a transferência da lealdade, que é apresentada na sequência. 


\section{Transferência da Lealdade}

O objetivo central desse trabalho é mostrar que o torcedor pode vir a ser uma vantagem competitiva para seu time. Essa vantagem competitiva não está relacionada à identificação com time, que é algo que grande parte dos times (talvez todos) alcança, mas sim à lealdade para com o time. Assim, enquanto muitos torcedores continuam leais aos seus times, mesmo em fases ruins, com críticas ou escândalos, outros preferem se afastar. O torcedor é formado por um público diversificado, mas que pode ter momentos de oscilação em sua lealdade (Comptom, 2015). Porém a identificação com o time não diminui. Por isso, defendemos que apenas a identificação não é uma vantagem competitiva, já que praticamente todos os times a possuem.

O valor desta vantagem competitiva reside na lealdade demonstrada ao time. Ele não está nas características psicológicas, mas sim no comprometimento consistente com a marca do time. Acreditamos que esse comprometimento do torcedor com seu time não está relacionado apenas com produtos ou serviços diretamente relacionados ao time. A verdadeira vantagem competitiva encontra-se na capacidade que o time também de transferir a lealdade do seu torcedor para as marcas patrocinadores.

O grande desafio é o time fazer com que seu torcedor passe a ser um consumidor leal dos produtos e serviços das marcas que apoiam sua equipe. Porém, se esse comportamento existe, ele não é fixo. Daí nosso entendimento, conforme Kandampully and Zhang (2015), de que a lealdade é um processo transitório. O torcedor transfere (ou empresta) sua lealdade para o patrocinador, mas a retira quando este deixa de patrocinar seu time.

Os gastos globais com patrocínio vêm aumentando ano a ano, e os esforços acadêmicos para medir o efeito do patrocínio vêm acompanhando este crescimento. No entanto, grande parte da literatura sobre patrocínio considera a influência do patrocínio na perspectiva do negócio (Delia, 2014). Poucos são os estudos que analisam o impacto da identificação com o time e a percepção do patrocinador na intenção de compra (por exemplo: Smith et al. (2008); Gwinner \& Swanson (2003); Madrigal (2001)).

Assim, identifica-se uma lacuna existente na academia na questão da relação existente na tríade torcedor/time/patrocinador. Donde a necessidade de ir além de estudar a lealdade com o time e começar a estudar a relação existente entre a lealdade com o time e a lealdade 
com as marcas patrocinadoras. Para isso se faz necessário entender o conceito de patrocínio e a influência das variáveis atitude, percepção e congruência.

Entendemos que tal comportamento não é natural ao torcedor, pois a relação de cumplicidade existente é entre torcedor e clube, que é a base da teoria da identidade social. E é dessa identificação que surge a lealdade para com o time. Neste ponto, pode-se inferir que o patrocinador é visto apenas como um recurso financeiro desejável para o time (do ponto de vista da gestão), mas indesejável ao mesmo tempo (do ponto de vista do torcedor), por "manchar" o uniforme, muitas vezes visto como "manto sagrado" da equipe.

Tome-se como exemplo, o tempo que o Barcelona demorou para aceitar um patrocinador em sua camisa. A dificuldade existente em fazer com que o torcedor não só o aceitasse, mas fosse consultado, para que o processo fosse feito adequadamente. O mercado norte-americano também enfrenta, atualmente, este dilema.

Dentre as cinco principias ligas americanas - National Football League (NFL); National Basketball Association (NBA); Major League Baseball (MLB); National Hockey League (NHL) e National Collegiate Athletic Association (NCAA) -, apenas a NBA permite, atualmente, patrocinadores no uniforme. Em reportagem do jornal New York Time ${ }^{48} \mathrm{o}$ comissário da NBA foi taxativo ao afirmar a necessidade do apoio à camisa, mesmo contra a vontade dos torcedores: "Even if some fans would find it jarring. Exactly when it's going to come, I'm not sure, but I do think it's inevitable in our sport. ${ }^{49,}$

Assim, como forma de suprir a lacuna existente na literatura, esta pesquisa acrescenta à teoria de lealdade a ideia de que ela pode ser transferida. Para isso, conceituaremos nos próximos tópicos a teoria da transferência e do equilíbrio (balance theory). Por fim, apresentaremos os conceitos existentes na literatura esportiva no que diz respeito aos estudos de patrocínio.

${ }^{48}$ Acessado em 21 de maio de 2015.

http://www.nytimes.com/aponline/2015/01/14/sports/basketball/ap-bkn-nba-in-london.html?_r=0

49 "Mesmo que alguns fãs achem isso chocante. Exatamente quando ele (patrocínio) vai vir, eu não tenho certeza, mas eu acho que é inevitável em nosso esporte". 


\subsection{Teoria da Transferência}

Transferência é uma área bastante explorada nos estudos acadêmicos. Especificamente no esporte, a relação entre patrocinadores e patrocinados já foi analisada inúmeras vezes, sobretudo no que diz respeito à transferência de imagem de grandes eventos esportivos para a imagem do patrocinador ou da marca patrocinadora. Um dos primeiros estudos do gênero foi o de Gwinner (1997), datado da época em que o aumento dos eventos de lazer para a sociedade abriu portas para o surgimento do patrocínio a esses eventos. $\mathrm{O}$ autor ainda destaca que, até a década de 1980, o patrocínio era visto como uma obrigação com a comunidade.

Em seu estudo preliminar, ele aponta que, entre muitos fatores que levavam uma empresa a patrocinar um evento, dois se destacavam entre os mais importantes: (1) aumentar a notoriedade da marca; e (2) estabelecer, fortalecer ou mudar a imagem da marca. Apesar disso, a maioria dos estudos se concentrava em awareness e recall do patrocinador. Pouca atenção era dada às questões relacionadas com imagem da marca, mesmo sendo o patrocínio uma ferramenta bastante utilizada para ajudar no posicionamento da marca (Gwinner \& Eaton, 1999).

Os autores foram pioneiros em demonstrar que a atividade de patrocínio em grandes eventos resultava em transferência de imagem. Em seu estudo com graduandos, identificaram que indivíduos expostos no evento à marca patrocinadora eram mais propensos a relatar semelhanças de personalidade entre a marca (patrocinadora) e o evento (patrocinado) do que aqueles que não foram expostos. Outro ponto importante identificado no estudo é a relação de congruência entre marca e evento. Ou seja, quando o evento e a marca conseguem combinar suas marcas, a transferência tende a ser ainda maior.

Essa associação entre marcas podem ser desenvolvidas por meio de várias fontes (Keller, 1993). Elas podem ser influenciadas, também, quando a marca se liga a uma celebridade por meio do endosso ou quando se cria um vínculo com um evento esportivo por meio do patrocínio. Assume-se que associações pré-existentes na memória do consumidor a respeito do evento ou da celebridade serão projetadas sobre o produto patrocinado ou endossado. Esse pensamento é coerente com as ideias de Mccracken (1989) no que tange ao processo de endosso de celebridades, em que a transferência é concluída quando o consumidor adquire ou consome o produto endossado (Gwinner \& Eaton, 1999). 
Assim, nesta pesquisa, entendemos que a transferência é vista como a transferência de significado (Smith, 2004). Mccracken (1989) teoriza sobre esta termologia ao desenvolver o modelo da transferência de significado (meaning transfer model), em que "significado" se refere a uma avaliação global de que uma celebridade (objeto de estudo do autor) representa para o consumidor (Figura 12).

Figura 12: Movimento do Significado e o Processo de Endosso

Cultura

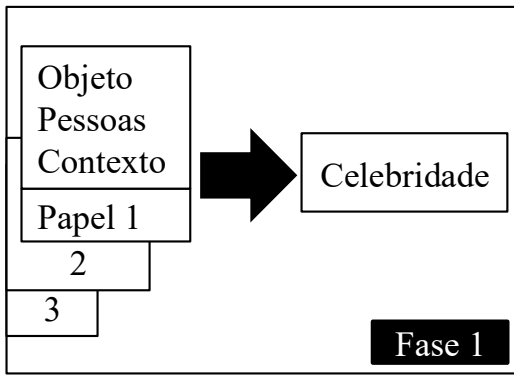

Endosso

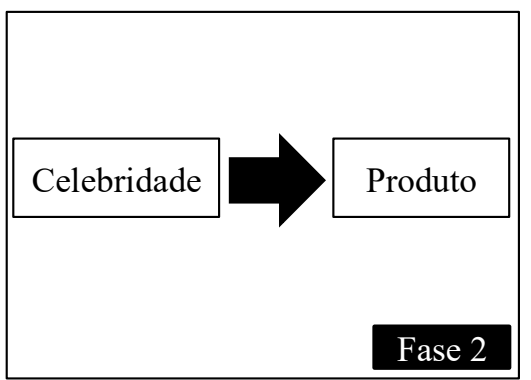

Consumo

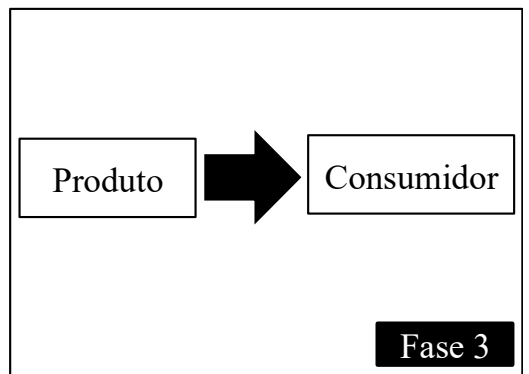

Fonte: Mccracken (1989)

Um caso clássico no esporte brasileiro de transferência de imagem é o patrocínio do Banco do Brasil à seleção brasileira de vôlei. Desde a década de 1990, o Banco do Brasil vem patrocinando as seleções masculina e feminina, associando sua imagem à imagem de uma seleção vencedora. Essa transferência de imagem proporcionou um rejuvenescimento da marca.

Smith (2004) sugere quatro fatores que podem influenciar a transferência de imagem: (1) domínio, (2) composição, (3) status, (4) duração. O domínio do patrocínio está associado ao meio em que o patrocínio será inserido. Os domínios mais comuns são: caridade, artes, mídia e esporte. Porém cada domínio produz imagens próprias e particulares na mente dos consumidores. Por exemplo, patrocinar obras de caridade tende a produzir elevado grau de boa vontade devido à visão altruísta relacionada. O mesmo já não ocorreria com um patrocínio de um programa de televisão.

No esporte, estas imagens particulares podem ser ainda mais ressaltadas. Patrocinar times da mesma cidade, apesar de estar no mesmo domínio (esporte) e no mesmo esporte, acarretará em transferências distintas de imagem. Associar a imagem ao Corinthians, por exemplo, visto como um time popular, guerreiro e lutador, remeterá a transferências dentro deste estilo. Já um patrocínio ao São Paulo, tido como um time com torcedores mais elitizados e exclusivos, transferirá para marca outro modelo de imagem. 
A composição se refere à quantidade de patrocínios envolvidos. Podemos identificar três modelos de composição: simples - um único patrocinador (Maratona do Pão de Açúcar); composto - um número limitado de grandes patrocinadores (transmissão de futebol na TV Globo: Ambev, Itáu, Johnson \& Johnson, Magazine Luiza, Vivo e Volswagen [Exame, 2014]); e complexos - grande números de patrocinadores, de diferentes níveis (Copa do Mundo: em 2014, podemos identificar os chamados Parceiros FIFA, que se colocam num grupo de destaque; os Patrocinadores da Copa do Mundo, num nível intermediário; e, por último, os apoiadores nacionais [Figura 13]).

$\mathrm{O}$ status se refere ao número de patrocinadores locais, que interagem com a comunidade, por meio de grandes eventos. É uma relação entre a importância do evento e a interação com a comunidade local.

A duração, como o próprio nome diz, refere-se ao tempo em que a relação ocorre. Estudos vêm mostrando que o tempo de duração não está baseado no quanto mais longo melhor. Eventualmente um patrocínio longo pode se tornar "invisível” para o consumidor. "The later examples suggest that increasing familiarity can eventually make the sponsor synonymous with the event until it becomes almost 'invisible' to consumers and consequently less effective in transferring brand image” (Smith, 2004, p. 462).

Apesar da exposição da marca patrocinadora ser um dos fatores principais que um patrocinador busca ao patrocinar um evento (Gwinner, 1997), em muitos casos esta relação não é significativa se não houver um ajuste entre a marca patrocinadora e o evento patrocinado. Podemos entender este ajuste como a relação entre o evento patrocinado e o patrocinador, que tende a ser um dos pontos centrais para o sucesso da transferência de imagem e, neste caso, o tempo de exposição terá reflexo positivo sobre o indivíduo (Grohs \& Reisinger, 2005).

De forma resumida, podemos explicar exposição como a quantidade de tempo que alguém é apresentado à mensagem do patrocinador. Já a relação ou o ajuste entre a marca patrocinadora e o patrocinado está baseada na percepção que o indivíduo tem na ligação entre ambos (Grohs \& Reisinger, 2005). A sinergia entre patrocinador e patrocinado é essencial para o sucesso da transferência de imagem nesta relação. 
Figura 13: Patrocinadores Oficias da Copa do Mundo 2014

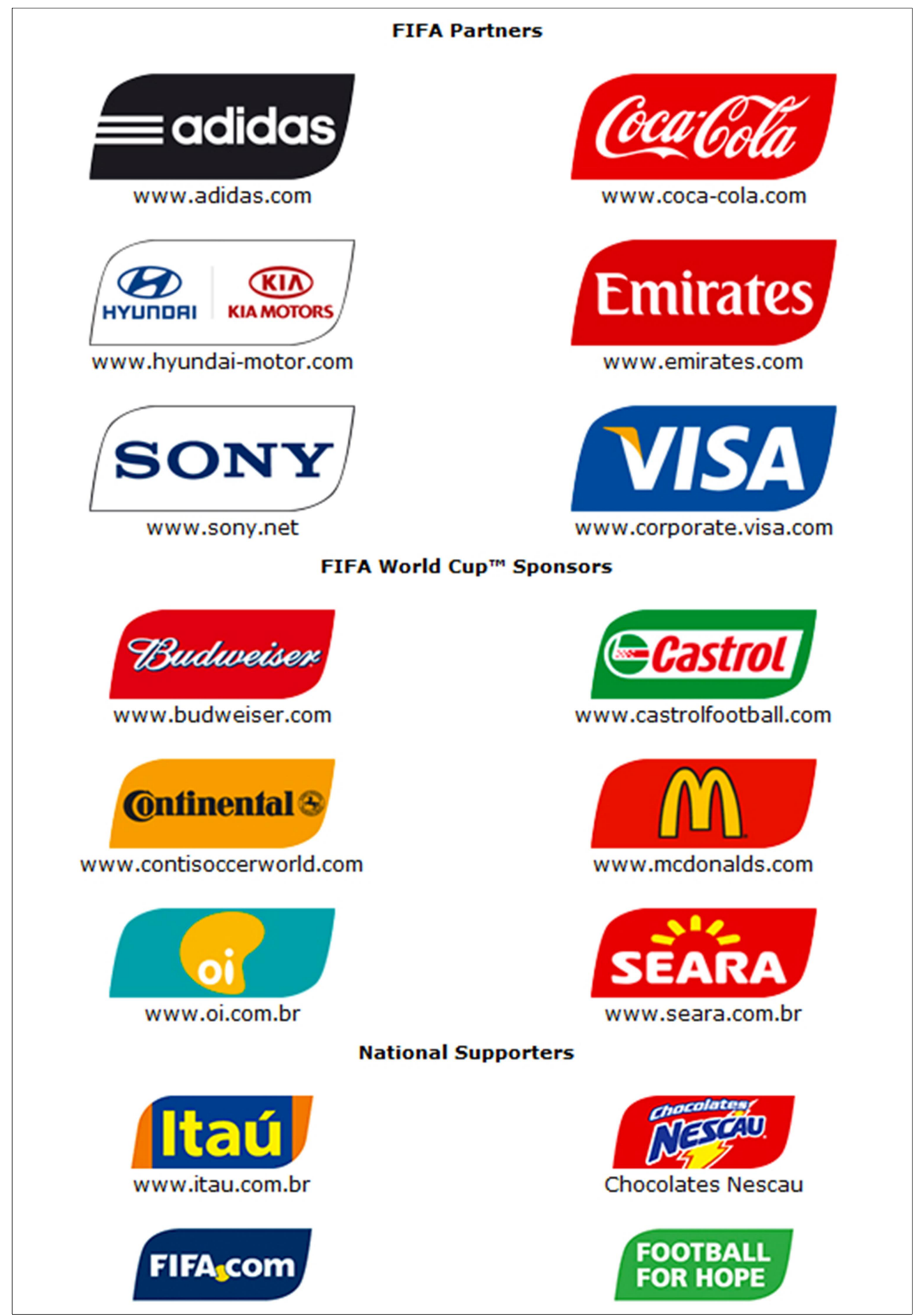

Fonte: www.fifa.com

Fica evidente que os eventos esportivos compartilham associações, imagens e características específicas (Grohs \& Reisinger, 2005), transferindo, assim, sentimentos e atitudes positivas e criando uma ligação entre o patrocinador e o patrocinado. É essa 
transferência de associações entre ambos que Gwinner (1997) chamou de Transferência de Imagem. Quanto mais forte for a associação criada entre a marca patrocinadora e o objeto patrocinado, maior será a transferência de imagem (Gwinner \& Eaton, 1999). Assim, podemos dizer que a transferência de imagem ocorre quando a imagem de um evento afeta a imagem do patrocinador após o evento (Grohs \& Reisinger, 2005).

Apesar de as marcas buscarem sempre a transferência positiva, em alguns momentos a transferência pode ser potencialmente negativa (Donahay \& Rosenberger, 2007). Isso porque essa transferência é habilitada de forma não verbal ou mesmo de forma inconsciente (Quester \& Farrelly, 1998). Além disso, em determinados circunstâncias, os consumidores podem começar a confundir os patrocinadores (Johar \& Pham, 1999).

Essa confusão está relacionada aos modelos complexos de patrocínio (Smith, 2004). Marques, Fleury e Gonçalves (2015), analisando os patrocinadores das Olímpiadas 2016, chegaram ao resultado de que mais de $50 \%$ dos respondentes confundiam os patrocinadores da Copa do Mundo (que havia sido no ano anterior), com os patrocinadores das Olimpíadas (que seriam realizadas um ano depois). Estes resultados corroboram com os estudos de Johar \& Pham (1999), que mostram que, dos 20 patrocinadores mais citados, pelos respondentes, dos Jogos Olímpicos de Inverno de 1998, 11 não eram patrocinadores reais.

Assim, as pesquisas a respeito de patrocínio mostram a importância de haver forte ligação (link) (Quester \& Farrelly, 1998; Donahay \& Rosenberger, 2007; Grohs \& Reisinger, 2005; Gwinner \& Eaton, 1999; Gwinner, 1997; Keller, 1993; Koo, Quarterman, \& Flynn, 2006; Roy \& Cornwell, 2004; Smith, 2004; Speed \& Thompson, 2000), ajuste (fit) (Quester \& Farrelly, 1998; Donahay \& Rosenberger, 2007; Grohs \& Reisinger, 2005; Koo et al., 2006; McDaniel, 1999; Roy \& Cornwell, 2004; G. Smith, 2004; Speed \& Thompson, 2000), congruência (congruency) (Quester \& Farrelly, 1998; Donahay \& Rosenberger, 2007; Gwinner \& Eaton, 1999; Koo et al., 2006; McDaniel, 1999; Roy \& Cornwell, 2004; Smith, 2004; Speed \& Thompson, 2000), relação/parentesco (related/relatedness) (Johar \& Pham, 1999; Koo et al., 2006; McDaniel, 1999; Roy \& Cornwell, 2004), proeminência (prominence) (Grohs \& Reisinger, 2005; Johar \& Pham, 1999; Roy \& Cornwell, 2004) ou combinação (matching up) (Grohs \& Reisinger, 2005; McDaniel, 1999; Roy \& Cornwell, 2004; Smith, 2004) entre a marca patrocinadora e o patrocinado, para que a transferência possa ocorrer. 
Porém, não é apenas a transferência de imagem que vem sendo pesquisada na academia. Transferência da confiança também é um tópico bastante estudado. Devido à crescente importância das agências de rating e de negócios baseados em redes sociais, o conceito de transferência de confiança vem sendo tratado de maneira relevante em diversas situações organizacionais e interpessoais (Delgado-Márquez, Hurtado-Torres, \& AragónCorrea, 2013)

A transferência de confiança é um processo cognitivo (Lu, Yang, Chau, \& Cao, 2011). O processo de transferência da confiança acontece quando um indivíduo (the trustor) passa a confiar num agente desconhecido (the trustee) com base nas relações deste agente com uma terceira parte envolvida que é de confiança do the trustor (Stewart, 2003). A confiança é transferida entre agentes (pessoas, grupos, organizações) desconhecidas, mas que possuem uma terceira parte em comum que é confiável (Delgado-Márquez et al., 2013).

Strub e Priest (1976), ao investigar os usuários de maconha, descreveram o processo de extensão de confiança como um processo em que a confiança numa terceira parte envolvida é tão confiável como na base inicial. A confiança pode se desenvolver por meio de um processo de transferência a partir de uma fonte confiável para outra pessoa, grupo ou empresa com a qual o indivíduo inicial tenha pouco ou nenhum acesso (Doney \& Cannon, 1997).

Delgado-Márquez, Hurtado-Torres e Aragón-Correa (2013) definem transferência de confiança como uma situação em que o conhecimento direto sobre um objeto qualquer não está disponível, mas os interessados podem ser capazes de reunir informações por meio de terceiros. Assim, o interessado no objeto recebe as informações transferidas e passa a confiar naquilo.

A lógica do processo de transferência da confiança está baseada na relação que a terceira parte envolvida tem com o trustor e com o trustee. Se estas relações forem estreitas, a confiança do trustor na terceira parte envolvida será transferida para o trustee. Por isso, a terceira parte é também chamado de fonte de transferência (N. Wang, Shen, \& Sun, 2013).

Doney e Cannon (1997) propuseram cinco processos para a construção de confiança: (1) processo de computação; (2) processo de previsão; (3) processo de recurso; (4) processo de intenção; (5) processo de transferência. Para os autores, um processo de transferência de confiança (5) é aquele em que a confiança pode ser transferida de um objeto de confiança para 
outro objeto desconhecido. Stewart (2003) sugeriu que a confiança pode ser transferida dentro de um ambiente confiável.

McKnight, Choudhury e Kacmar (2002) apresentaram três modelos que permitem a construção da confiança: (1) Processo Baseado em Instituição (Institution-Based Process): a confiança é construída por meio garantias institucionais - feedbacks, garantia de cartão de crédito são exemplos deste modelo; (2) Processo de Conhecimento (Knowledge-Based Process): a confiança é construída por meio de suas ações e interações passadas; (3) Processo de Transferência de Confiança (Trust Transfer Process): a confiança é construída em uma pessoa/empresa/objeto desconhecida, por meio da confiança em uma pessoa/empresa/objeto conhecida.

Tomemos como exemplo o esporte, foco deste trabalho de pesquisa. Um torcedor do time A tende a confiar em seu time. Quando seu time aceita um novo patrocinador, o torcedor tende a ver isso como um endosso a marca patrocinadora. Assim, pode-se inferir que a confiança no time será transferida para a marca patrocinadora.

A relação com a transferência de imagem fica evidente se pensarmos que a confiança trabalha lado a lado com a reputação. Uma reputação favorável pode ser transferida entre empresas de maneira simples. Ela é construída por meio de seu comportamento confiável e consistente ao longo do tempo (Ganesan, 1994). A confiança pode ser transferida por meio de palavras (boca a boca) ou ações entre pessoas e organizações, sendo possível usar o processo de transferência para prever uma relação positiva entre as partes envolvidas (Doney \& Cannon, 1997).

Tal processo, descrito por Ganesan (1994), corrobora as ideias dos estudiosos da Transferência da Imagem ou da Imagem da Marca, que buscam nas associações positivas o reforço para construção de novos valores. As relações entre patrocinador e patrocinado são relações sugestíveis ao processo de confiança e de reputação dos parceiros.

Stewart (2003) explicou, por meio do processamento de informações, o efeito da transferência da confiança e como a percepção da interação e da semelhança entre pessoas conhecidas e desconhecidas pode aumentar a confiança nas pessoas desconhecidas. Assim, é esperado que, uma vez que um julgamento é feito a respeito da confiabilidade de um membro do grupo, outros membros também estarão sujeitos a serem julgados para ter o mesmo nível de confiança. 
Pode-se inferir que tal relação ocorre à medida que os indivíduos, membros de um mesmo grupo, buscam equilíbrio ${ }^{50}$ em suas relações. A transferência de confiança ocorre de forma a confirmar as ideias de Heider (1958) e Newcomb (1968) de que os indivíduos querem harmonia em suas vidas.

Assim, a transferência de confiança implica que as recomendações da (A) fonte confiável (empresa, grupo ou indivíduo) causem confiança em (B) fonte receptora das informações para com o (C) objeto recomendado (Seigneur, Gray, \& Jensen, 2005) Figura 14)

Figura 14: Processo de Transferência da Confiança

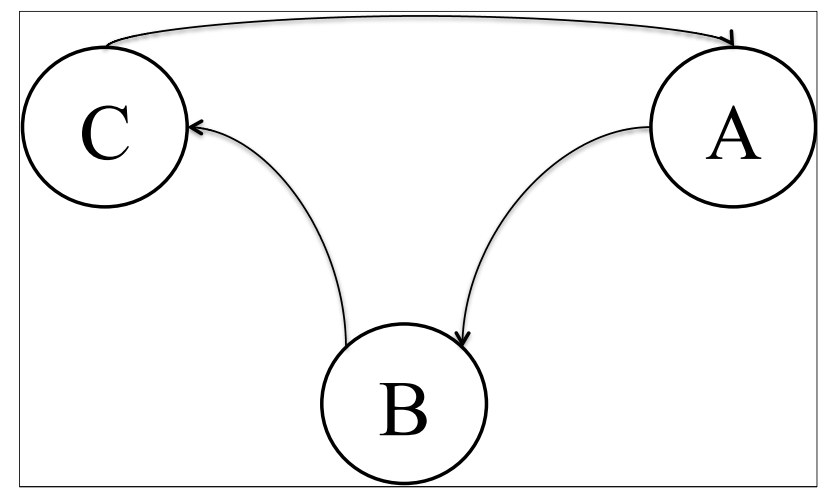

Fonte: Seigneur et al., 2005)

A transferência da confiança está baseada em dois tipos de relações entre a fonte e o trustee: similaridade e laços de negócios. A similaridade está relacionada com questões internas entre a fonte e o trustee. Eles compartilham determinadas características que passam percepções parecidas para o trustor. Os laços de negócios dizem respeito a questões externas entre a fonte e o trustee. Ambos não possuem natureza semelhante, mas compartilham conceitos externos que os aproximam.

Lu et al. (2011) propõem que existem dois tipos de transferência de confiança: intracanais (em que a confiança em um canal pode influenciar a avaliação de um produto ou serviço do mesmo canal) e intercanais (que resultam em transferência de confiança entre canais diferentes). Pesquisas existentes sugerem que a confiança pode ser transferida a partir de diversos tipos de fontes, como indivíduos, lugares ou organizações (Hong \& Cho, 2011).

\footnotetext{
${ }^{50}$ Maiores explicações se encontram na seção teoria do equilíbrio
} 
O trabalho de Stewart (2003), de transferência de confiança por meio de link de hipertexto no universo online, evidenciou que os internautas tendem a confiar em organizações que eles não conhecem, mas que se assemelham as organizações que conhecem, tanto quanto confiam nestas. A confiança no intermediário de uma relação pode ajudar a construir a confiança do consumidor na comunidade nova em que ele se insere para comprar (Pavlou \& Gefen, 2004). Por exemplo: a confiança do torcedor pode ser transferida de seu time para canais tradicionais de vendas, ajudando a impulsionar o consumo por determinados produtos.

Um ponto interessante, e que merece destaque, é que uma outra maneira de ocorrer a transferência da confiança é por meio de grupos (Zucker, 1986). Podemos exemplificar a ideia por meio dos torcedores. Um determinado membro do grupo pode transferir a confiança para um membro de um mesmo grupo ao qual ele pertence. Delgado-Márquez et al. (2013) propõem uma extensão deste pensamento por meio da transferência da confiança para um grupo externo, do qual o transmissor da confiança não faz parte.

Dentro da lógica estabelecida podemos inferir que o clube pode ser uma fonte de confiança para o torcedor, que se identifica com um time e, como consequência, torna-se leal a ele. E, com isso, tende a aceitar o patrocinador do seu time como sendo uma marca mais confiável. É nesse momento que o clube faz o torcedor tornar-se uma vantagem competitiva e que transferência de lealdade ocorre. Esse processo pode ser explicado por meio da teoria do equilíbrio.

Assim, nesta pesquisa, também se busca analisar o impacto da ativação do patrocínio na relação torcedor-patrocinador. Entende-se que a lealdade existente entre torcedor e time pode ser transferida, auxiliando patrocinados (times) e patrocinadores (marcas) a alcançar seus objetivos. Esse processo transforma os torcedores numa vantagem competitiva para seus times, em um mercado cada vez mais promissor e mais competitivo. Esse triângulo, para efeito deste trabalho, é analisado por meio da identificação do torcedor com seu time (teoria da identidade social [Tajfel \& Turner, 1986]) e pela teoria do equilíbrio (balance theory, Heider, 1958). 


\subsection{Teoria do Equilíbrio (Balance Theory)}

O patrocínio encontrou no esporte um caminho para florescer. Howard \& Crompton (2005) já relatavam que o esporte absorvia, em 2003, 69\% do total de US 7 bilhões investido em patrocínio. E surgia com potencial agressivo para as empresas: "has emerged as a primary communication vehicle for many thousands of corporations" $" 51$ (Howard \& Crompton, 2005, p. 436). As empresas patrocinadoras viam no patrocínio uma forma de alcançar uma satisfação altruísta para chegar ao seu objetivo final (Meenaghan, 2001).

A entrada dos dólares dos patrocinadores criou uma nova situação no mercado, por meio de uma relação de dependência. Equipes começaram a contar com o dinheiro dos patrocinadores, como meio de financiamento e os patrocinadores viram no esporte uma alternativa interessante para atingir a conexão emocional dos torcedores (Madrigal, 2001). De um lado, as equipes, objeto a ser patrocinado, necessitam do dinheiro dos patrocinadores. Do outro lado, os patrocinadores querem maximizar o lucro do investimento do patrocínio (Stotlar, 2004).

Esse triângulo do esporte (torcedor-time-patrocinador), que mistura atitude e emoção, é o objeto central desta pesquisa. O produto esporte, sob a ótica dos serviços, possui fortes semelhantes como outros serviços e mercados (Boret, 2011). Especificamente na indústria do entretenimento como cinema, teatro e shows, nota-se forte semelhança no processo de construção da lealdade. Porém, quando incluímos a "variável" torcedor na equação, percebese que a ligação emocional existente entre consumidor (torcedor) e o produto de consumo (time) fazem o processo ser diferente (Funk \& James 2001, 2006).

Desta forma, conforme demostrado nas sessões 2.2.1(pág 41) e 2.3 (pág. 64), pesquisas anteriores já atestaram a existência de uma forte relação entre torcedor e seu time de coração. Esta relação, que nesta pesquisa é estudada como um processo que se inicia pela identificação com o time e pode se tornar lealdade demonstrada para com a equipe, é caracterizada por diversos fatores.

\footnotetext{
51 "Emergiu como um veículo de comunicação primário para milhares de corporações"
} 
Assim, conhecer profundamente esse (quase) triângulo amoroso (torcedor-timepatrocinador) se torna fundamental (Parker, Fink, 2010). É esse entendimento que dará base para compreender como a relação entre patrocinado e patrocinadores são capazes de influenciar a lealdade do torcedor. Essa relação pode ser explicada por meio da teoria da identidade social e teoria do equilíbrio (Fink, Parker, Brett e Higgins, 2009). Isso porque a teoria do equilíbrio sugere que as pessoas necessitam manter um senso de equilíbrio (balanço) em suas vidas (Dalakas \& Levin, 2005; Chang Cheng, 2014, Han, Seo, 2016). Essa necessidade de manter uma "vida equilibrada" pode afetar ações, crenças e os julgamentos de cada indivíduo (Heider, 1958).

Assim, se, em determinado momento existe um "desequilíbrio" numa relação, as pessoas podem mudar seu comportamento, suas atitudes e até seus valores de modo a buscar restaurar o equilíbrio (Dalakas \& Levin, 2005; Chang Cheng, 2014, Han, Seo, 2016; Rambarana, Dijkstraa, Munniksmab, 2015,). Conceitualmente, modificar (ou adequar) atributos ou características de uma marca para atender melhor o consumidor tende a ter impacto positivo na relação (Funk \& James, 200; Thilo 2014)). Porém, de acordo com a teoria do equilíbrio, acreditamos que o consumidor também buscará adaptar-se a marcas patrocinadoras de seus times para ajustar a relação.

O resultado desta ação (equilíbrio) é que as pessoas têm mais chances de gostar de tudo o que se relaciona com coisas de que ela já gosta e a não gostar do que já não gostam. Por isso, a teoria do equilíbrio ajuda a entender como como certos relacionamentos influenciam o sentimento do indivíduo (Rambarana, Dijkstraa, Munniksmab, 2015). Ao levar isso para o estudo da relação entre torcedor-time-patrocinador, encontramos aquilo que Heider (1958) chamou de tríades relacionais (relational triads).

A ideia central da teoria do equilíbrio é que as pessoas preferem relações harmoniosas a relações desarmoniosas:

\footnotetext{
"having the same opinion about certain objects as those who you are friends with is in line with one's expectations of what a friendship should look like. This leads to configurations that are congruent as they are perceived as comfortable and stable. In contrast, people tend to avoid configurations that are imbalanced as disagreeing with friends causes strain and tension, and
} 


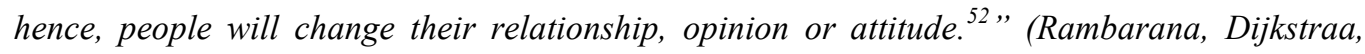
Munniksmab, 2015. Pág. 163).

Esse equilíbrio pode ser determinado multiplicando os sinais da tríade relacional. Um resultado positivo indicaria equilíbrio. Assim, uma relação entre, por exemplo, três indivíduos pode ser examinada a partir da perspectiva de um dos indivíduos e o saldo da tríade pode conter relações entre entidades ou pessoas (Basil \& Herr, 2006). Heider (1958) destaca que as relações entre pessoas são referidas como sentimentos, enquanto as relações entre entidades são tidas como uma relação de unidade.

Assim, por meio da teoria do equilíbrio, pode-se analisar como os indivíduos processam seus sentimentos, de modo que uma pessoa focal $(\mathrm{X})$ demonstre-os positivamente ou negativamente a respeitos de outra pessoa/empresa (Y) e questões (Z) (Chang Cheng, 2014). Carson, Carson, Knouse e Roe (1997) propõem que, além dos sentimentos, existe um acordo informal que ajuda a formar a tríade apresentada. Esse acordo demonstra que (X) e (Y) compartilham percepções semelhantes a (Z). A Figura 15 ajuda a ilustrar a tríada relacional proposta por Heider (1958).

Figura 15: Ilustração da Teoria do Equilíbrio

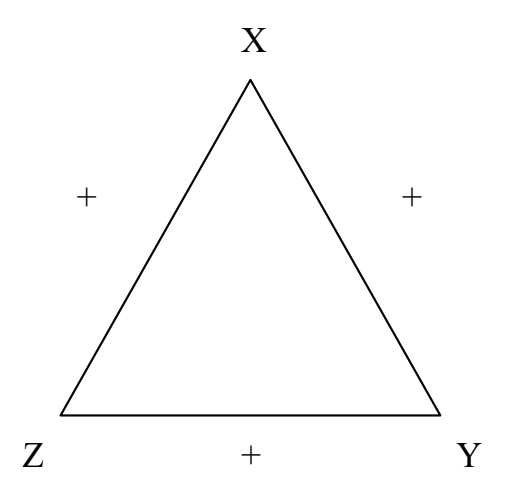

Relação Equilibrada

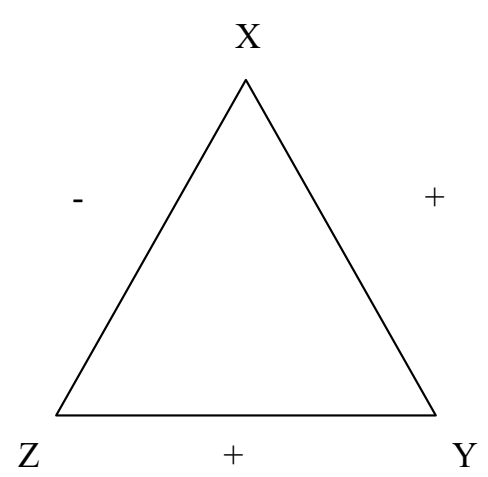

Relação Desequilibrada

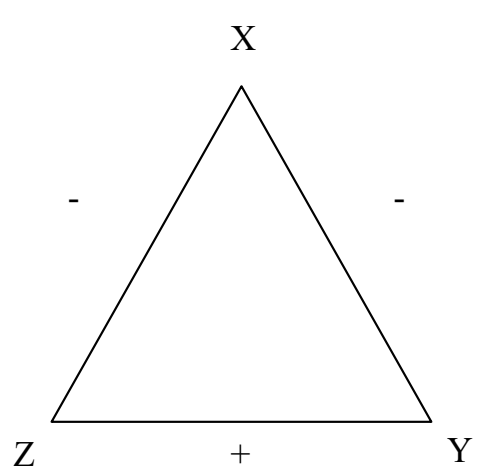

Relação Equilibrada

Fonte: Heider (1958)

\footnotetext{
${ }^{52}$ Ter a mesma opinião de seus amigos sobre certos objetos está em linha com as expectativas da pessoa de como deve ser uma amizade. Isso leva a configurações que são congruentes ao serem percebidas como confortável e estável. Em contraste, as pessoas tendem a evitar configurações que são desequilibradas, tais como discordar de amigos que pode causa tensão, e, portanto, as pessoas vão mudar o seu relacionamento, opinião ou atitude.
} 
No âmbito do esporte, trataremos da relação que envolve (X) indivíduos (torcedores) (Y) times e $(\mathrm{Z})$ patrocinadores. Propomos que, ao mostrar aos torcedores que a parceria é apropriada para seu time (ativação do patrocínio), eles irão transferir sua lealdade para a marca patrocinadora, de forma a produzir um equilíbrio em suas atitudes e comportamentos.

No modelo $\mathrm{A}$, temos que $\mathrm{X}$ se sente positivo com relação a $\mathrm{Y}$. Y se sente positivo com relação a Z. X se sente positivo com relação a Z. Ou seja, existe uma relação de equilíbrio acontecendo. Porém, quando se $\mathrm{X}$ se sentir negativo com relação a $\mathrm{Z}$ (modelo B), nota-se um desequilíbrio na relação. Já no modelo $\mathrm{C}$, temos a relação invertida. $\mathrm{X}$ se sente negativo em relação a $\mathrm{Z}$ e $\mathrm{Y}$. Desta forma, para que a relação seja equilibrada, $\mathrm{Z}$ e $\mathrm{Y}$ devem se sentir positivos na relação entre eles. Caso contrário, encontraremos um desequilíbrio na equação.

Chang e Cheng (2014, p. 2010) definem esse equilíbrio como "affective states (pleasantness or harmony) and as cognitive states (expectancy or consistency) ${ }^{53}$ ". Assim, se a tríade se encontra desequilibrada, a pessoa tende a alterar suas atitudes e comportamentos de forma a equilibrar a relação (Han, Seo, 2016), ou, conforme Awa \& Nwuche (2010), o desequilíbrio é a motivação para a alteração das atitudes e comportamentos em relação ao objeto $(\mathrm{Y})$

De maneira geral, a teoria do equilíbrio ajuda a entender a máxima: "The commonly known statements "my friends' enemies are my enemies" and "my enemies' enemies are my

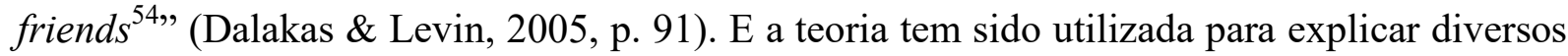
fenômenos sociopsicológicos, como privação relativa, opiniões políticas, gestão de conflitos, mobilidade de trabalho, processos de comparação social, liderança e eficácia de grupo, comportamento social e comunicação (Rambarana, Dijkstraa, Munniksmab, 2015.). Assim, ao utilizar a teoria do equilíbrio para explicar o processo de transferência da lealdade, buscamos não só criar uma base conceitual para o desenvolvimento do processo de transferência, mas também preencher uma lacuna na área de gestão e de gestão do esporte.

As relações entre entidades também devem se encaixar de forma equilibrada. $\mathrm{O}$ estado equilibrado acontece quando as associações possuem o mesmo sinal (positivo ou negativo).

\footnotetext{
53 "como estado afetivo (prazer ou harmonia) e como estado cognitivo (expectativa ou consistência)".

54 “as demonstrações comumente conhecidas como o inimigo do meu amigo é meu inimigo e o inimigo do meu inimigo é meu amigo".
} 
Assim, existirá harmonia na relação. Porém percebe-se com isso que sentimentos não são independentes das percepções. (Han, Seo, 2016). Quando o equilíbrio não acontece na relação, forças surgirão para modificar o estado de desequilíbrio. Se a mudança não acontecer, temos o que Heider (1958) chamou de tensão na relação.

$\mathrm{Na}$ área do esporte a teoria do equilíbrio vem sendo usado para estudar, por exemplo, como o comportamento e o sentimento de atletas influenciam os demais membros do time. Boss e Kleinert (2015) comentam como mudanças repentinas no desempenho de um time (de bom para mal ou vice-versa) afetam a maioria dos jogadores simultaneamente. Essa alteração de comportamento é influenciada pelo que a literatura chama de contágio social. que, conforme os autores, deriva da teoria do equilíbrio e permite a transferência de comportamento de um atleta para outro:

“(.) the present study aims to reproduce the phenomenon of social contagion in sport experimentally. The theoretical background for the experimental design postulates a model of social contagion derived from Heider's (1958) balance theory, explaining the social transfer of underperformance in sport. This theory views the conditions of the transfer process as motivational factors, both in terms of the athlete's self-perception and of the athlete's perception (and appraisal) of motivational factors of the partner. ${ }^{55}$ "' Boss e Kleinert (2015. Pág. 160).

Levy e Nail (1993, p. 271) definem o contágio social como:

"the spread of affect, attitude, or behavior from Person A (the 'imitator') to Person B (the 'recipient'), where the recipient does not perceive an intentional influence attempt on the part of the initiator. ${ }^{56,}$

Scarapicchia, Sabiston e Anderse (2013) abordam o contágio social em seu estudo sobre motivação para práticas de exercícios. Os autores demostram que, quando determinadas pessoas se mostram motivadas para praticar exercícios, essa motivação pode contagiar as pessoas ao seu redor. $\mathrm{Na}$ literatura. os termos contágio social, contágio comportamental e

55 “(...) o presente estudo pretende reproduzir experimentalmente o fenômeno do contágio social no esporte. Os fundamentos teóricos para o desenho experimental postulam um modelo de contágio social baseado da na teoria do equilíbrio de Heider (1958), explicando a transferência social do baixo desempenho no esporte. Esta teoria considera as condições do processo de transferência como fatores motivacionais, tanto em termos da auto percepção do atleta quanto da percepção (e avaliação) do atleta dos fatores motivacionais do parceiro".

56 “a propagação de afeto, atitude ou comportamento da Pessoa A (o "imitador") para a Pessoa B (o “destinatário"), onde o destinatário não percebe uma tentativa de influência intencional por parte do iniciador". 
contágio emocional vêm sendo usados como sinônimos, apesar de representarem diferentes aspectos do fenômeno (Boss, Kleinert, 2015).

Um dos primeiros estudos a relacionar a teoria do equilíbrio com patrocínio foi o trabalho de Dean (2002). Apesar de não estar ligado diretamente com o esporte, seu estudo abriu espaço para que outros pudessem aprimorar a questão da tríade do esporte (torcedortime-patrocinador), por trabalhar a relação com endosso. Ele analisou como patrocínio, endosso e marcas populares, num evento de caridade, afetavam a percepção dos consumidores.

Dean (2002) utilizou a teoria do equilíbrio para justificar a relação entre os três participantes do evento: o endossante, o objeto do endosso e o consumidor. Partindo do pressuposto de que as pessoas buscam harmonizar suas relações, os consumidores alterariam suas atitudes, de forma a garantir que a relação se equilibrasse. Neste pressuposto, é esperado que os espectadores do evento assumam uma relação positiva em relação ao evento. Inicia-se aqui uma relação de sentimento em relação ao evento que, quando trabalhado pela marca patrocinadora, deverá ser transferido para ela. Assim, o sentimento positivo deverá correr em direção à empresa patrocinadora ou ao produto da empresa (Dean, 2002).

Desta maneira, o que temos é a presença de duas fontes: o evento (A), o consumidor (B) e a conjunção da relação deles para com o objeto patrocinador (C). Assim é esperado que exista uma relação de atração entre A e B, visto que o consumidor é livre para decidir ir ou não ao evento. Existe uma atitude positiva de $\mathrm{A}$ em relação a $\mathrm{C}$, pois existe uma relação de patrocínio. Por último, existe uma relação, positiva ou negativa, de B com relação a C.

Neste aspecto, é necessário entender que as decisões podem ser influenciadas por relações anteriores entre a tríade. Por exemplo: o evento (A) acredita que B (consumidor) e C (patrocinador) já possuem alguma relação. Desta forma, ao aceitar o patrocínio, além de estar recebendo dinheiro, também estará beneficiando o consumidor. Da mesma forma, o patrocinador (C) acredita que B goste de A e que estar relacionado com A tende a ser bom para C.

Newcomb (1968), dando continuidade aos estudos relacionados à teoria do equilíbrio, escreveu a respeito de duas pessoas, (A) e (B), e a relação de ambas para algum objeto (X) e como a relação é percebida por eles. Ou seja, se analisarmos do pondo de vista de (A), temos 
três análises possíveis de entendimento: (1) A relação de (A) para com (B); (2) A atitude de (A) para com (X); e (3) A percepção de (A) com relação a atitude de (B) para com (X).

Conforme Curry \& Emerson (1970), o objeto (X) pode ser qualquer coisa, inclusive o próprio $(\mathrm{A})$. O importante é que $(\mathrm{X})$ tenha relevância para a relação de $(\mathrm{AB})$. É por meio desta relação que analisamos se existe o equilíbrio entre os três conjuntos de hipóteses da situação AB-X Newcomb (1968). Assim, se (A) perceber, por exemplo, que (B) possui relação com (X) igual à de (A), aumenta a chance de (A) gostar de (B). Analisando a atração em direção a (B), se (A) percebe que (B) gosta de (X), (A) está sujeito a ir na mesma direção e gostar de (X). Por fim, se (A) tiver atração por (B) e (X), ele tende a ver (B) atraído por (X) também.

Por fim, Newcomb (1968) sugeriu que, se (A) não gostar de (B), ambos serão indiferentes ao que o outro pensa em relação a $(\mathrm{X})$. Assim, conforme Curry \& Emerson (1970), tanto Newcomb como outros pesquisadores que estudaram a Teoria do Equilíbrio demonstram a tendência de compensação na relação. Quando existe tensão na relação, ocorrem as chamadas incongruências cognitivas. Como a própria incongruência é fonte da tensão, remover a incongruência tende a eliminar a tensão. Essa remoção pode ocorrer por meio de mudança de atitude ou de percepção (Curry \& Emerson, 1970).

Assim, a Teoria do Equilíbrio demonstra que o indivíduo analisado irá buscar sempre um caminho para um estado de equilíbrio ao longo de um estado de desequilíbrio, demonstrando assim um comportamento que irá proporcionar equilíbrio sempre que possível (Sussmann \& Davis, 1975).

Dalakas \& Levin (2005), ao analisar os fãs da $\mathrm{Nascar}^{57}$, encontraram uma relação positiva entre os fãs de determinados pilotos e seus patrocinadores. Por outro lado, os autores também encontraram uma relação negativa entre fãs da Nascar e os patrocinadores de pilotos pelos quais tais fãs demostravam antipatia. Ou seja, as relações positivas entre patrocinado e patrocinador reproduziram relação positiva na atitude do fã para com o patrocinador. Já do outro lado, uma relação negativa entre o patrocinado e o torcedor tende a levar a uma relação negativa entre fã e patrocinador.

\footnotetext{
${ }^{57}$ A National Association for Stock Car Auto Racing (em português: Associação Nacional de Stock Car Auto Racing; abreviação oficial: NASCAR) é uma associação automobilística norte-americana que controla os campeonatos de stockcar nos Estados Unidos.
} 
Figura 16: Relação entre Fã, Patrocinador e Time

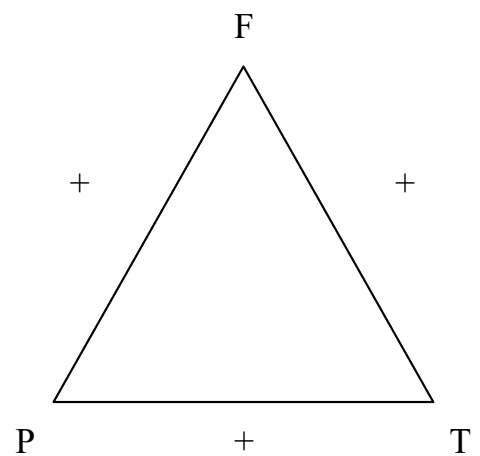

Relação Equilibrada

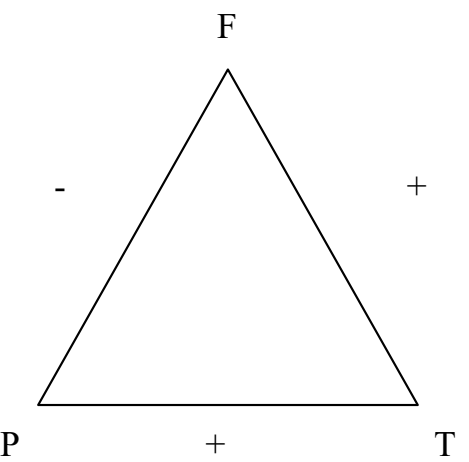

Relação Desequilibrada

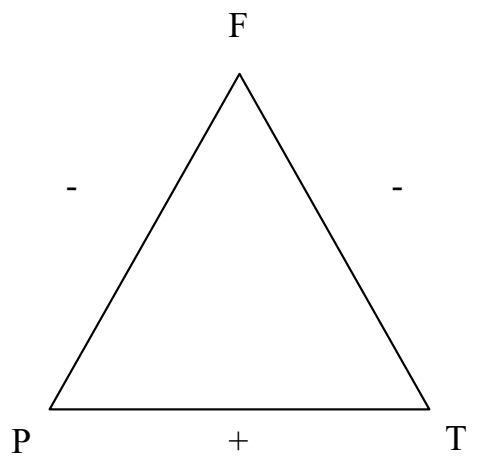

Relação Equilibrada

Fonte: Dalakas \& Levin (2005)

O ponto de ligação entre todos os participantes da tríade é o relacionamento com o patrocinado esportivo, que, no nosso estudo, é o time de futebol. Madrigal (2000) demonstrou esta relação positiva entre a identificação com o time e a intenção de compra de produtos dos patrocinados utilizando equipes universitárias. Gwinner \& Swanson (2003), também analisando times universitários e envolvimento dos fãs com seus times, encontraram atitudes positivas em relação ao patrocinador, reconhecimento do patrocinador e satisfação com o patrocinador nos torcedores que são mais altamente identificados.

Desta maneira, podemos esperar que os torcedores busquem equilibrar suas relações, de forma a harmonizá-las, e com isso tendam a transferir a lealdade que possuem com seu time para as marcas patrocinadoras. Cria-se, assim, uma oportunidade para que os patrocinadores possam se relacionar com os times patrocinados e busquem o retorno na relação entre consumidor e seu time.

Desta forma propomos que:

\section{H16. Lealdade ao time terá efeito positivo e significativo na lealdade ao patrocinador.}

Uma vez concluída a revisão da literatura apresentada nestes capítulos de fundamentação teórica, pode-se verificar uma série de estudos que ajudam a identificar o torcedor e entender o conceito de lealdade aplicado ao esporte. Buscou-se também considerar 
o patrocínio como uma estratégia de marketing capaz de diferenciar as marcas patrocinadoras das demais. Nesse sentido, estudos como os Fisher \& Wakefield (1998), Madrigal (1995), Matsuoka et al. (2003) e Wann \& Branscombe (1990, 1993) mostram que a identificação com o time tende a impulsionar uma série de atividades do torcedor, tais como ir ao estádio, assistir a jogos na TV, sua intenção de compra de produtos relacionados ao time, entre outros.

Do ponto de vista da lealdade, podemos destacar os estudos de Bauer et al. (2008) e Gladden \& Funk (2002) no que diz respeito à importância da lealdade comportamental e de Mahony et al. (2000) sobre lealdade atitudinal. Encontraram-se diversos estudos que analisam a transferência de imagem de um evento patrocinador para a marca patrocinadora. Nesse ponto, destacam-se os estudos de Gwinner \& Eaton (1999), Gwinner (1997) e Smith (2004).

Porém, apesar dos inúmeros estudos a respeito de lealdade no esporte e transferência, não se encontrou nenhum estudo que analisasse a transferência da lealdade do torcedor para as marcas patrocinadoras. Mas, como demonstrado nesta seção, a confiança é objeto de estudos de diversos autores, tais como Delgado-Márquez et al. (2013), Doney \& Cannon (1997) e Stewart (2003), que demostram que a confiança pode ser transferida. De maneira geral, o conceito já estudado de transferência que mais se aproxima da lealdade é a confiança, que em muitos casos é um antecessor da lealdade.

A lealdade do torcedor ou fã com seu time é única. É uma relação de cumplicidade que envolve, conforme se buscou demostrar ao longo deste trabalho, conceitos de identidade social - que servem para unir torcedor e time numa relação peculiar a existente em outros mercados - e lealdade. Assim, por mais que exista uma relação indivíduo/marca, dificilmente ele será similar à relação torcedor/time.

No que diz respeito aos efeitos do patrocínio, os principais resultados esperados são: rentabilidade da imagem do patrocinador, transferência da imagem, resposta do consumidor, geração de consciência e uso (Novais \& Arcodia, 2013; Deeks, Bennett 2008; Meenaghan, 2001). Desse modo, verifica-se nos estudos de comportamento do consumidor, no ambiente do esporte, uma lacuna no que diz respeito ao modo como a lealdade do consumidor a seu time impacta na marca patrocinadora, no que diz respeito à preferência do consumidor pela marca patrocinadora, à intenção de compra dos produtos do patrocinador e à disposição de pagar mais pelo produto do patrocinador. Assim, propomos que: 
H17. A transferência da lealdade ao patrocinador terá efeito positivo e significativo: (a) boca a boca; (b) intenção de compra; (c) disposição a pagar mais; (d) uso; (e) interesse. 


\section{MODELO TEÓRICO}

Este trabalho busca, como principal contribuição, desenvolver um modelo integrativo de três dimensões: identificação com o time, lealdade ao time e lealdade ao patrocinador. O modelo teórico proposto inclui construtos previamente trabalhados, tanto no contexto de marketing geral como marketing esportivo, assim como construtos desenvolvidos a partir da revisão da teoria sobre as dimensões analisadas.

Também destacamos que outra contribuição oriunda do modelo teórico proposto é o desenvolvimento de uma escala que relaciona a identificação com o time a benefícios sociais/não financeiros, bem como a escala que permite analisar a proposição da transferência de lealdade.

Tabela 12: Quadro resumo de hipóteses e contribuições da tese

\begin{tabular}{|c|c|c|c|}
\hline DIMENSÃO & CONTRIBUIÇÃO & HIPÓTESE & $\begin{array}{l}\text { OBJETIVO } \\
\text { ESPECÍFICO }\end{array}$ \\
\hline \multirow[t]{2}{*}{$\begin{array}{l}\text { Identificação } \\
\text { com o time }\end{array}$} & $\begin{array}{l}\text { Apesar da amplitude de estudos que } \\
\text { analisam a identificação com o time, } \\
\text { propomos, neste trabalho, que essa } \\
\text { identificação é influenciada, entre } \\
\text { outras variáveis, por benefícios } \\
\text { sociais/não financeiros. }\end{array}$ & $\begin{array}{l}\text { H1. Tratamento preferencial tem } \\
\text { efeito positivo e significante na } \\
\text { identificação com o time. } \\
\text { H2. Reconhecimento pessoal tem } \\
\text { efeito positivo e significante na } \\
\text { identificação com o time. } \\
\text { H3. Sentimento de status tem efeito } \\
\text { positivo e significante na } \\
\text { identificação com o time. } \\
\text { H4. Sentimento de pertencimento } \\
\text { tem efeito positivo e significante na } \\
\text { identificação com o time. } \\
\text { H5. Avaliação pessoal tem efeito } \\
\text { positivo e significante na } \\
\text { identificação com o time. } \\
\text { H6. Avaliação dos outros tem efeito } \\
\text { positivo e significante na } \\
\text { identificação com o time. } \\
\text { H7. Satisfação com o time tem efeito } \\
\text { positivo e significante na } \\
\text { identificação com o time. }\end{array}$ & (a); (b) \\
\hline & $\begin{array}{l}\text { Além dos benefícios sociais/não } \\
\text { financeiros, a relação com o esporte } \\
\text { também influencia a identificação } \\
\text { com o time. Apesar desta variável ser } \\
\text { bastante estudada mundialmente, } \\
\text { faltam estudos no Brasil que analisem } \\
\text { a relação do torcedor com seu time }\end{array}$ & $\begin{array}{l}\text { H8. Envolvimento com o esporte } \\
\text { tem efeito positivo e significante na } \\
\text { identificação com o time. }\end{array}$ & (a); (b) \\
\hline
\end{tabular}


Grande parte dos estudos e pesquisas realizadas caracterizam o fanatismo como o grau máximo que um torcedor pode ter na sua relação de identificação com o time. Neste trabalho, vemos o fanatismo como um construto independente, ou seja, o torcedor pode ter um alto grau de identificação, mas não ser necessariamente fanático. Isso porque identificamos o fanatismo como um fator patológico.
H9. Identificação com o time tem efeito positivo e significante no fanatismo.

H10. Envolvimento com o futebol tem efeito positivo e significante no fanatismo.
Lealdade ao time
Conceitualmente, existe uma clara distinção entre identificação e lealdade. Porém muitos estudos na área do esporte acabam por utilizar de maneira errada os termos. Tal comportamento contribui para que a Gestão do Esporte encontre algumas barreiras em outras áreas. Assim, neste trabalho, apresentamos um debate crítico para diferenciar os construtos e mostrar por meio de modelagem de equação estrutural que esses construtos são diferentes entre si.
H11. Identificação com o time, fanatismo, lealdade ao time são construtos distintos.
Por serem construtos separados e únicos, a lealdade ao time é uma consequência da identificação com o time. Do mesmo modo que, como fanatismo e identificação são vistos neste trabalho como dois construtos, fanatismo influência na lealdade ao time.
H12. Lealdade ao time é afetada positivamente e de forma significante por (a) identificação com o time; (b) fanatismo.
Lealdade ao patrocinador
Por meio da teoria do equilíbrio, em conjunto com os conceitos de transferência de imagem e confiança, apresentamos o conceito de transferência da lealdade.
H13. Atitude (a) afetada positivamente e de forma significativa a lealdade ao patrocinador; (b) não modera a relação entre lealdade ao time e lealdade ao patrocinador; (c) não media a relação entre lealdade ao time e lealdade ao patrocinador

H14. Congruência (a) afetada positivamente e de forma significativa a lealdade ao (c); (d) patrocinador; (b) não modera a relação entre lealdade ao time e lealdade ao patrocinador; (c) não media a relação entre lealdade ao time e lealdade ao patrocinador

H15. Percepção (a) afetada positivamente e de forma significativa a lealdade ao patrocinador; (b) não modera a relação entre lealdade ao time e 
lealdade ao patrocinador; (c) não media a relação entre lealdade ao time e lealdade ao patrocinador

H16. Lealdade ao time terá efeito positivo e significativo na lealdade ao patrocinador.

Como resultado da transferência de lealdade analisamos e conceituamos não apenas o construto lealdade ao patrocinador, mas as variáveis consequentes desta transferência.
H17. A transferência da lealdade ao patrocinador terá efeito positivo e significativo: (a) boca a boca; (b) intenção de compra; (c) disposição a pagar mais; (d) uso; (e) interesse. (e)

\section{Fonte: Desenvolvido pelo autor}


Figura 17: Modelo Teórico Proposto

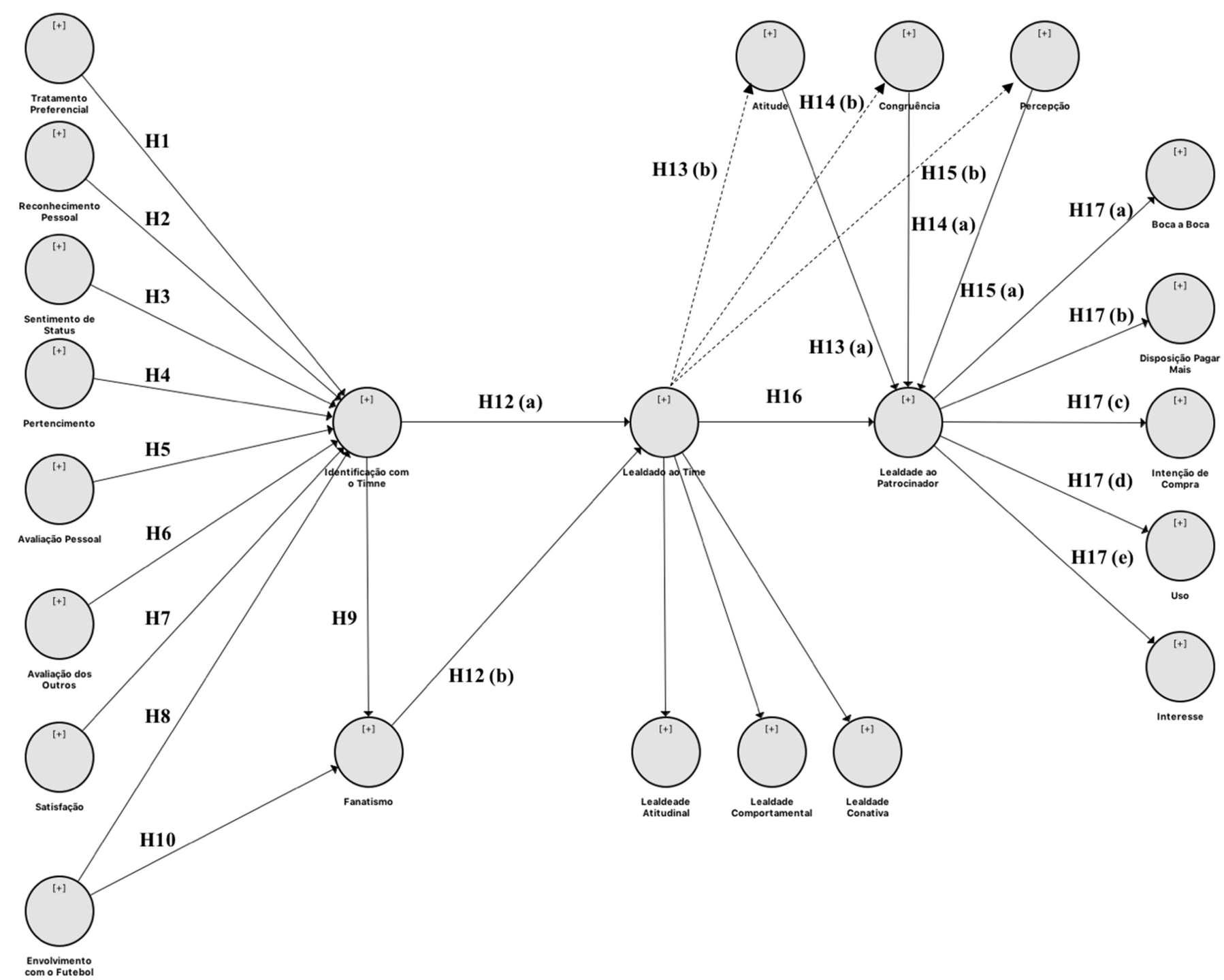

Fonte: Desenvolvido pelo autor por meio do SmartPLS (3.2.6) 


\section{DESENVOLVIMENTO DA ESCALA}

As diversas variáveis utilizadas nesta pesquisa já foram mensuradas das mais diversas formas. Porém é extremamente importante que, ao tentar mensurar uma variável, o pesquisador busque garantir ao máximo a certeza de que os dados levantados correspondem ao que se tenta mensurar (Reinold, T., \& Tropp, J., 2012). Não atentar a esse processo pode gerar informações de pouca validade, que, por sua vez, levarão a conclusões erronias.

Assim, utilizar processos estruturados de mensuração é uma forma de evitar tais erros. Tais processos, originados de técnicas corretas, ajudam na obtenção de dados válidos e confiáveis (Churchill Jr, 1979), que permitem ao pesquisador alcançar seus objetivos e responder com mais veracidade sua pergunta de partida.

Desta forma, adaptaram-se os procedimentos sugeridos por Hinkin (1998) e DeVellis (2012), como forma de tentar garantir a maior confiabilidade e validade possível na construção da escala de mensuração aplicada neste trabalho (Tabela 13).

Tabela 13: Procedimentos metodológicos para desenvolvimento da escala de mensuração do modelo conceitual

\begin{tabular}{|c|c|c|c|}
\hline PASSO & DESCRIÇÃO & DETALHAMENTO & $\begin{array}{l}\text { ONDE NESSA } \\
\text { PESQUISA }\end{array}$ \\
\hline 1 & Definição das dimensões & $\begin{array}{l}\text { Definir de forma clara o que está incluído } \\
\text { ou não na definição das dimensões } \\
\text { estudadas na pesquisa. }\end{array}$ & Fundamentação teórica \\
\hline 2 & Lista de indicadores & $\begin{array}{l}\text { Definir os itens que irão servir como } \\
\text { indicadores dos construtos pesquisados. }\end{array}$ & $\begin{array}{c}\text { Operacionalização das } \\
\text { variáveis }\end{array}$ \\
\hline 3 & Medidas das escalas & $\begin{array}{l}\text { Definir qual os "tipos de perguntas" mais } \\
\text { adequados para obtenção dos resultados } \\
\text { esperados. }\end{array}$ & $\begin{array}{l}\text { Operacionalização das } \\
\text { variáveis }\end{array}$ \\
\hline 4 & Revisão por especialistas & $\begin{array}{l}\text { Validar com especialistas os indicadores } \\
\text { propostos. Com isso, avaliar se } \\
\text { indicadores devem: } \\
\text { - Ser incluídos, de forma a analisar } \\
\text { outros construtos, que não fazem } \\
\text { parte do modelo conceitual proposto } \\
\text { e/ou dos atuais construtos; e } \\
\text { - Ser excluídos por não responderem } \\
\text { corretamente pelas variáveis a eles } \\
\text { atreladas. }\end{array}$ & Validade de conteúdo \\
\hline 5 & $\begin{array}{l}\text { Amostra de } \\
\text { desenvolvimento }\end{array}$ & $\begin{array}{l}\text { Validar com uma amostra de } \\
\text { desenvolvimento a escala proposta: }\end{array}$ & Validade de face \\
\hline
\end{tabular}


- Verificar se os itens são bem

entendidos pelos respondentes.

Aplicar a uma amostra a escala

desenvolvida:

- Purificar a escala, mantendo-se somente os indicadores de maior

6 Amostra pré-teste relevância ao modelo conceitual.

- Analisar possíveis trade-offs entre a eventual exclusão de um indicador e

Validade convergente, validade discriminante e confiabilidade do modelo conceitual e do modelo estrutural a perda de confiabilidade da escala.

- Tornar o questionário mais curto.

Aplicar a escala ajustada a uma nova amostra independente para:

$7 \quad$ Amostra teste
- Verificar a capacidade de replicação do modelo de mensuração e do modelo estrutural
Validade convergente, validade discriminante e confiabilidade do modelo conceitual e do modelo estrutural

Fonte: Desenvolvido pelo autor (Adaptado de Hinkim, 1998; DeVellis, 2012)

\subsection{Lista de indicadores}

No capítulo 2 (pág. 34) são apresentadas as dimensões ou construtos que fazem parte desta pesquisa. A fundamentação na teoria serve como base para a construção das variáveis latentes, mas também deve ser aplicada para o passo 2 do desenvolvimento da escala (Tabela 23) - lista dos indicadores. Estes itens são aqueles que devem representar as variáveis latentes analisadas.

Para escolha dos indicadores que comporiam cada construto, optou-se por adaptar a proposição de DeVellis (2012). Desta forma, os parâmetros analisados para definição dos indicadores foram: (1) clareza e relevância; (2) simplicidade e brevidade; (3) capacidade de discriminação e variabilidade; (4) redundância (Tabela 14).

Tabela 14: Passos para escolha dos indicadores de cada variável

ITEM DEFINIÇÃO

Clareza e relevância

- Os respondentes devem entender facilmente cada indicador, ou seja, os indicadores devem ser claros;

- Deve-se levar em conta a relevância de cada indicador para mensurar cada variável.

Simplicidade e brevidade

Capacidade de discriminação e
- Vocabulário e expressões simples, que formem frases curtas e de fácil entendimento.

- Os indicadores devem ser capazes de gerar respostas positivas e negativas dos respondentes, como forma de aumentar a variância 


\begin{tabular}{ll}
\hline variabilidade & entre as respostas. \\
\hline & $\bullet \quad \begin{array}{l}\text { Grupo de indicadores são usados para medir o mesmo construto. } \\
\text { Assim, é esperado que exista uma certa redundância entre os }\end{array}$ \\
indicadores da mesma variável; \\
Redundância & $\begin{array}{l}\text { Evitar a repetição de indicadores que só se diferenciam por } \\
\text { variações semânticas ou por inclusão ou exclusão de um artigo. }\end{array}$ \\
\hline
\end{tabular}

Fonte: Desenvolvido pelo autor (Adaptado de DeVellis, 2012)

Assim, realizou-se a análise de diversas escalas já utilizadas para medir cada dimensão deste trabalho. Este passo foi realizado em conjunto com a fundamentação teórica. $\mathrm{Na}$ sequência, escolheram-se os itens que seriam representantes dos construtos trabalhados. Por fim, optou-se por adaptar os processos sugeridos por Hinkin (1998) e DeVellis (2012) (Tabela 15), para definição final dos itens.

Tabela 15: Processo para definição dos indicadores

\begin{tabular}{lll}
\hline \multicolumn{1}{c}{ PASSO } & \multicolumn{1}{c}{ DEFINIÇÃO } \\
\hline \hline (1) Adaptação e Tradução & $\bullet$ & $\begin{array}{l}\text { Adaptar os indicadores ao tema da pesquisa; } \\
\text { Traduzir para a língua portuguesa os itens definidos. }\end{array}$ \\
\hline (2) Validação da Tradução & $\bullet$ & $\begin{array}{l}\text { Por meio de profissionais com domínio na língua portuguesa e inglesa e } \\
\text { conhecimento das questões relacionadas aos fenômenos analisados. }\end{array}$ \\
\hline $\begin{array}{l}\text { (3) Tradução reversa (back- } \\
\text { translation) }\end{array}$ & $\bullet$ & $\begin{array}{l}\text { Revalidar a tradução por meio da conversão da versão dos indicadores do } \\
\text { português para o inglês. }\end{array}$ \\
\hline \hline
\end{tabular}

Fonte: Desenvolvido pelo autor (Adaptado de Hinkin, 1998; DeVellis, 2012)

A adaptação dos indicadores foi necessária quando estes, apesar de já testados na mensuração das variáveis latentes escolhidas, não necessariamente eram passíveis de serem utilizado no esporte. Após essa adaptação, realizou-se a tradução de todos os indicadores definidos. Nesta etapa foram tomados alguns cuidados visando à equivalência cultural dos itens escolhidos.

De forma a garantir que os termos escolhidos na língua portuguesa mantivessem a adequada correspondência com os termos na língua inglesa (originais ou adaptados), as versões em inglês e português foram submetidas para dois professores da área de marketing com notório conhecimento da língua inglesa: uma professora na Shidler College of Business, University of Hawaií; e um professor do programa de Mestrado Profissional em Gestão do Esporte. Solicitou-se que eles fizessem críticas ou mesmo sugestões de alterações nas palavras escolhidas. Foram feitos diversos ajustes, em ambas as línguas, de forma a garantir que os termos escolhidos, em cada língua, tivessem o mesmo significado. 
Na sequência, os indicadores, em sua versão em português, foram enviados para um tradutor profissional, solicitando-se que fosse realizada a tradução reversa (conversão para a língua inglesa). A simples tradução e a tradução reversa não garantem que o instrumento será compreendido pelos respondentes. Por isso, faz-se necessário que se utilizem alguns procedimentos para que se assegure a consistência interna e externa das escalas. Porém o processo de tradução e tradução reversa visa a garantir o máximo de equivalência semântica.

Por fim, os itens foram submetidos aos dois professores, para que eles realizassem a checagem final das versões em português e inglês. As definições de cada construto passaram pelo mesmo processo nas etapas de tradução e tradução reversa. A escolha deste procedimento deveu-se pela opção de realizar a validade de face da escala com professores brasileiros e estrangeiros.

\subsubsection{Operacionalização da variável identificação com o time}

A variável identificação com o time é uma variável de primeira ordem que antecede as variáveis fanatismo e lealdade ao time. Com base na fundamentação teórica, optou-se por adaptar e integrar escalas já previamente testadas de Gladden e Funk (2002), Trail, Anderson e Fink (2005) e Fisher e Wakefield (1998).

Tabela 16: indicadores da identificação com o time

\begin{tabular}{|c|c|c|}
\hline CONSTRUTO & REFERÊNCIA & INDICADOR \\
\hline Identificação com o Time & $\begin{array}{l}\text { Gladden \& Funk, } \\
\text { 2002; Trail, } \\
\text { Anderson e Fink } \\
\text { 2005; Fisher e } \\
\text { Wakefield } 1998\end{array}$ & $\begin{array}{l}\text { 1. Amigos e familiares me identificam como torcedor } \\
\text { apaixonado do [Time]. } \\
\text { 2. É importante para mim que meus amigos me vejam } \\
\text { como um torcedor apaixonado pelo [Time]. } \\
\text { 3. Eu me considero um torcedor apaixonado do [Time]. } \\
\text { 4. Ser torcedor do [Time] é parte importante de quem } \\
\text { sou. } \\
\text { 5. Eu me sentiria muito mal se tivesse que parar de } \\
\text { torcer para o [Time]. } \\
\text { 6. Torcer para o [Time] é importante para mim. }\end{array}$ \\
\hline
\end{tabular}

Fonte: Desenvolvido pelo autor

Entendem-se nesse trabalho que a identificação com o time possui alguns antecedentes que auxiliam em seu desenvolvimento. Esses antecedentes são os benefícios sociais e o envolvimento com o próprio esporte. Para mensuração de tais variáveis, foram adaptadas e integradas escalas de Brashear (2016), Dimmock eGrove (2006) e Trail, Anderson e Fink 
(2005), no que tange aos benefícios sociais, e Gwinner e Swanson 2003, na questão do envolvimento com o esporte.

Tabela 17: indicadores dos antecedentes da identificação com o time

\begin{tabular}{|c|c|c|}
\hline CONSTRUTO & REFERÊNCIA & INDICADOR \\
\hline Tratamento Preferencial & Brashear, 2016 & $\begin{array}{l}\text { 1. Sinto que sou melhor tratado do que torcedores de } \\
\text { outros times. } \\
\text { 2. Sinto que sou tratado com mais respeito do que } \\
\text { torcedores de outros times. } \\
\text { 3. Sinto que eu sou especial em relação a torcedores de } \\
\text { outros times. }\end{array}$ \\
\hline Reconhecimento Pessoal & Brashear, 2016 & $\begin{array}{l}\text { 1. Eu sou reconhecido positivamente pela sociedade por } \\
\text { ser torcedor do [Time]. } \\
\text { 2. Ser torcedor do [Time] facilita conhecer novas } \\
\text { pessoas. } \\
\text { 3. Ser torcedor do [Time] facilita fazer amizades. } \\
\text { 4. Ser torcedor do [Time] faz com que as pessoas } \\
\text { pensem coisas boas de mim. }\end{array}$ \\
\hline Sentimento de Status & Brashear, 2016 & $\begin{array}{l}\text { 1. Ser torcedor do [Time] me faz me sentir especial. } \\
\text { 2. Eu sou respeitado por ser torcedor do [Time]. } \\
\text { 3. É difícil torcedores de outros times terem o mesmo } \\
\text { status que eu tenho sendo torcedor do [Time]. }\end{array}$ \\
\hline Pertencimento & Brashear, 2016 & $\begin{array}{l}\text { 1. Eu pertenço a uma comunidade de pessoas que } \\
\text { compartilham os mesmos valores que eu sendo } \\
\text { torcedor do [Time]. } \\
\text { 2. Eu me sinto próximo do [Time]. } \\
\text { 3. Sinto que o [Time] compartilha os mesmos valores } \\
\text { que eu. }\end{array}$ \\
\hline Avaliação Pessoal & $\begin{array}{l}\text { Dimmock, J. A., } \\
\text { \& Grove, J. R. } \\
(2006) .\end{array}$ & $\begin{array}{l}\text { 1. O \Timel tem muito do que se orgulhar. } \\
\text { 2. Eu sou orgulhoso de ser um torcedor do [Time]. } \\
\text { 3. Vale a pena torcer para o [Timel. }\end{array}$ \\
\hline Avaliação dos Outros & $\begin{array}{l}\text { Dimmock, J. A., } \\
\text { \& Grove, J. R. } \\
(2006) .\end{array}$ & $\begin{array}{l}\text { 1. Em geral as pessoas têm uma visão positiva do } \\
\text { [Time]. } \\
\text { 2. Em geral as pessoas respeitam o [Time]. } \\
\text { 3. No geral a maioria das pessoas consideram o [Time] } \\
\text { melhor do que os times rivais. }\end{array}$ \\
\hline Satisfação & $\begin{array}{l}\text { Trail,Anderson, } \\
\text { Fink (2005) }\end{array}$ & $\begin{array}{l}\text { 1. Eu estou satisfeito com as decisões da atual diretoria } \\
\text { do [Time]. } \\
\text { 2. Eu estou satisfeito com as últimas contratações do } \\
\text { [Time]. } \\
\text { 3. Eu estou satisfeito com os resultados do [Time]. } \\
\text { 4. Eu estou satisfeito com desempenho do [Time]. }\end{array}$ \\
\hline
\end{tabular}

Fonte: Desenvolvido pelo autor

Tabela 18: indicadores do envolvimento com o futebol 


\begin{tabular}{clll}
\hline CONSTRUTO & REFERENCIA & \multicolumn{1}{c}{ INDICADOR } \\
\hline \hline & & 1. Futebol é muito importante para mim. \\
& & 2. Eu penso sobre futebol a todo momento. \\
Envolvimento com o Futebol & Gwinner e & 3. Eu assisto futebol sempre que eu posso. \\
& Swanson 2003 & 4. O futebol é meu esporte favorito. \\
& & 5. As pessoas pensam que o futebol é muito importante \\
& & para mim.
\end{tabular}

Fonte: Desenvolvido pelo autor

O fanatismo constituí um fator patológico que transcende a identificação do torcedor com seu time. Adotamos para efeito de mensuração a escala de McCutcheon et al., 2002, adaptada para o esporte.

Tabela 19: indicadores do fanatismo

\begin{tabular}{|c|c|c|}
\hline CONSTRUTO & REFERÊNCIA & INDICADOR \\
\hline Fanatismo & $\begin{array}{l}\text { McCutcheon et } \\
\text { al., } 2002\end{array}$ & 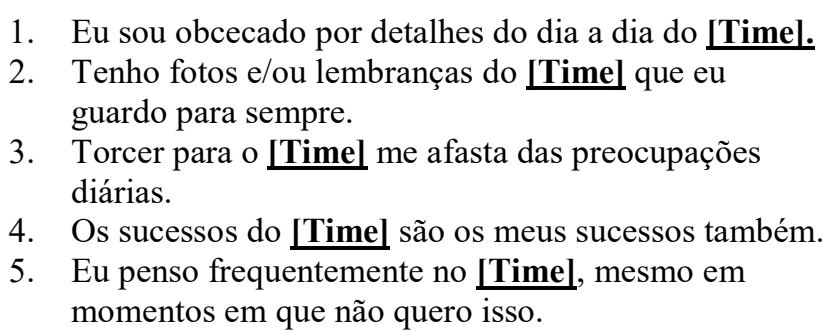 \\
\hline
\end{tabular}

Fonte: Desenvolvido pelo autor

\subsubsection{Operacionalização da variável Lealdade ao time}

Lealdade ao time, conforme demostrado na fundamentação teórica deste trabalho, é um construto ainda indefinido na literatura. Diversos são os autores que estudaram as mais diferentes formas de lealdade do torcedor. Para este trabalho, é importante analisar a lealdade dentro de um modelo multidimensional, pois tal modelo integrativo, apesar de sua importância, não foi encontrado na academia, no que tange ao esporte.

"Apart from behavioral characteristics, fans can be differentiated by their degree of attachment to a team, which is their attitudinal loyalty to the team. Although attitudinal loyalty is a 
particularly important concept in the sports context, it has only recently been examined ${ }^{58} . "($ Bauer et al., 2008, p. 206).

Assim, para operacionalizar o construto, com base na fundamentação teórica, foram selecionados indicadores utilizados por Park, Kim 2000; Heere e Dickson 2008; Funk e Pastore 2000; Suhartanto \& Clemes, 2011; Matsuoka, Chelladurai e Harada 2003; Trail, Anderson e Fink 2005; Wang, Zhang e Tsuji 2011; Matsuoka, Chelladurai e Harada 2003; Funk e Pastore 2000.

Tabela 20: indicadores da Lealdade ao Time

\begin{tabular}{|c|c|c|}
\hline CONSTRUTO & REFERÊNCIA & INDICADOR \\
\hline Lealdade Atitudinal & $\begin{array}{l}\text { Park, Kim 2000; } \\
\text { Heere e Dickson } \\
\text { 2008; Funk e } \\
\text { Pastore } 2000\end{array}$ & 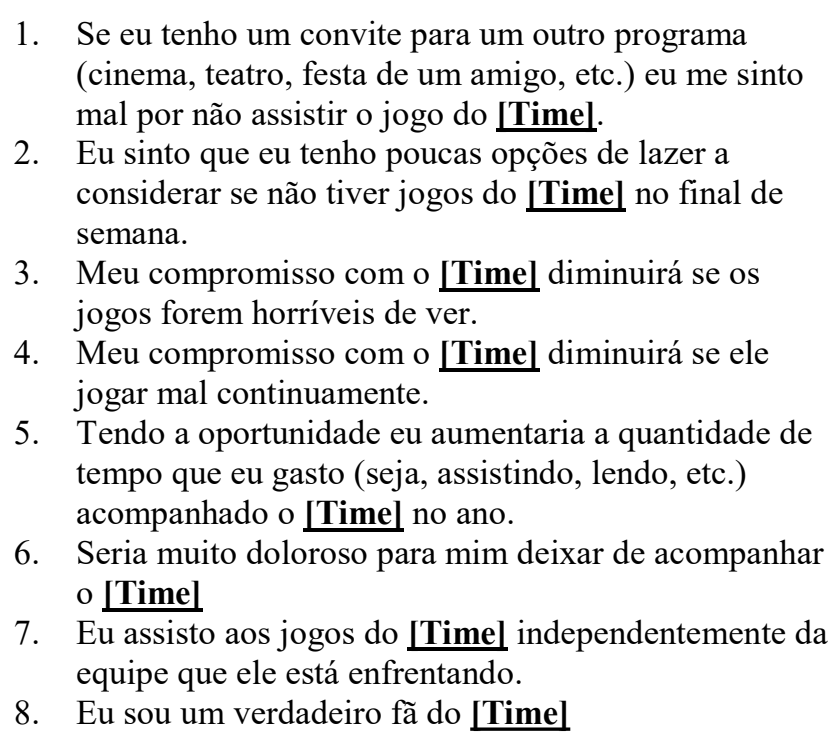 \\
\hline Lealdade Conativa & $\begin{array}{l}\text { Suhartanto \& } \\
\text { Clemes, 2011; } \\
\text { Matsuoka, } \\
\text { Chelladurai e } \\
\text { Harada 2003; } \\
\text { Trail, Anderson e } \\
\text { Fink } 2005\end{array}$ & $\begin{array}{l}\text { 1. Mesmo que outras opções de lazer (cinema, teatro, } \\
\text { etc.) ofereçam entradas mais baratas eu prefiro ir aos } \\
\text { jogos do 【Time]. } \\
\text { 2. Mesmo que o \Time】 aumentasse os preços dos } \\
\text { ingressos eu continuaria indo aos jogos. } \\
\text { 3. Eu tenho intenção de ir aos futuros jogos do โTime】. } \\
\text { 4. Eu tenho intenção de comprar produtos do [Time】 no } \\
\text { futuro. } \\
\text { 5. Eu tenho intenção de comprar a camisa oficial do } \\
\text { [Time】 no futuro. }\end{array}$ \\
\hline Lealdade Comportamental & $\begin{array}{l}\text { Wang, Zhang e } \\
\text { Tsuji 2011; } \\
\text { Matsuoka, }\end{array}$ & $\begin{array}{l}\text { 1. Eu acompanho o [Timel por meio de programas de } \\
\text { televisão, internet ou rádio todos os dias. } \\
\text { 2. Eu assisto a muitos jogos no ano do [Timel pela TV. }\end{array}$ \\
\hline
\end{tabular}

${ }^{58}$ Além de características comportamentais, os fãs podem ser diferenciados pelo seu grau de ligação a uma equipe, que é a sua lealdade atitudinal à equipe. Embora a lealdade atitudinal seja um conceito particularmente importante no contexto esportivo, que só recentemente foi examinado. 
Chelladurai e

Harada 2003;

Funk e Pastore

2000
3. Eu evito usar as cores dos maiores rivais do [Time]

4. Acompanhar o [Timel (pela TV ou no estádio) é uma das minhas principais atividades de lazer.

5. Eu assistiria mais jogos do [Time] se eu tivesse tempo e dinheiro.

Fonte: Desenvolvido pelo autor

\subsubsection{Operacionalização do constructo Lealdade ao Patrocínio}

Tendo por base os conceitos de propostos por Cornwell, Relyea, Irwin e Maignan (2000) e Gwinner (1997) e com as observações e propostas firmadas por Gwinner e Swanson (2003) e Speed e Thompson (2000), a relação do torcedor com o patrocinador aqui é vista como a atitude e percepção que os torcedores têm perante o patrocinador: "The response to a sponsorship will be affected by the attitudes consumers hold toward the sponsor, toward the event, and by their perception of sponsor-event fit ${ }^{59}$." (Speed \& Thompson, 2000, p. 235)

As marcas patrocinadoras buscam cada vez mais explorar o potencial econômico do patrocínio Cell, Weeks, \& Roy, 2005; Irwin, Sutton, \& McCarthy, 2008: "researchers have noted the importance of sponsorship as a means of achieving organizational marketing objectives, which typically include specific financial goals. ${ }^{60}$ " (Hoek, Gendall, Jeffcoat, \& Orsman, 1997). Em outras palavras, os patrocinadores buscam efetivamente retorno sobre o investimento realizado, o que torna importante a identificação de resultados comportamentais e atitudinais para analisar a eficiência do patrocínio (K. Gwinner \& Swanson, 2003).

Assim, os indicadores dos antecedentes da lealdade foram gerados a partir da revisão dos itens de escalas utilizados por Alexandris, Tsaousi e James (2007), Alexandris e Tsiotsou (2012), Dees, Bennett e Villegas (2008), Gwinner e Swanson (2003), Madrigal (2001), Menon e Kahn (2003) e Olson (2010).

59 “As respostas a um patrocínio serão afetadas pelas atitudes dos consumidores em relação ao patrocinador, ao evento, e por sua percepção da relação entre o patrocinador e evento (patrocinado).”

60 "pesquisadores observaram a importância do patrocínio como um meio de alcançar objetivos de marketing organizacionais, que tipicamente incluem metas financeiras específicas." 
Tabela 21: indicadores dos antecedentes da Lealdade ao Patrocinador

\begin{tabular}{|c|c|c|}
\hline CONSTRUTO & REFERÊNCIA & INDICADOR \\
\hline Percepção & $\begin{array}{l}\text { Alexandris, } \\
\text { Tsaousi, James } \\
\text { 2007; Gwinner e } \\
\text { Swanson } 2003\end{array}$ & 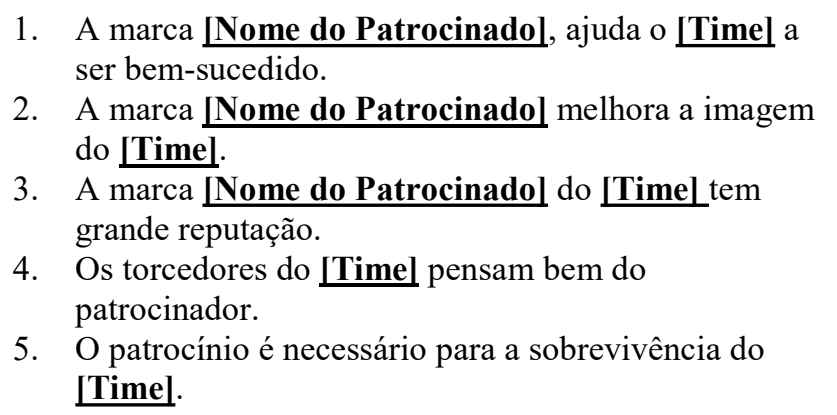 \\
\hline Congruência & $\begin{array}{l}\text { Olson } 2010 \\
\text { Menon e Kahn } \\
2003\end{array}$ & $\begin{array}{l}\text { 1. Existe uma perfeita conexão entre o [Time] e a marca } \\
\text { [Nome do Patrocinado]. } \\
\text { 2. O patrocinador e o [Time] representam coisas } \\
\text { parecidas. } \\
\text { 3. A principal razão pela qual o patrocinador está } \\
\text { envolvido com meu time é porque eles acreditam no } \\
\text { meu time. } \\
\text { 4. É estranho para mim ver este patrocinador ligado ao } \\
\text { meu time (R). } \\
\text { 5. No geral, o [Time] e o patrocinador formam uma boa } \\
\text { combinação. }\end{array}$ \\
\hline Atitude & $\begin{array}{l}\text { Gwinner e } \\
\text { Swanson 2003; } \\
\text { Alexandris e } \\
\text { Tsiotsou } 2012 \text {; } \\
\text { Olson } 2010\end{array}$ & 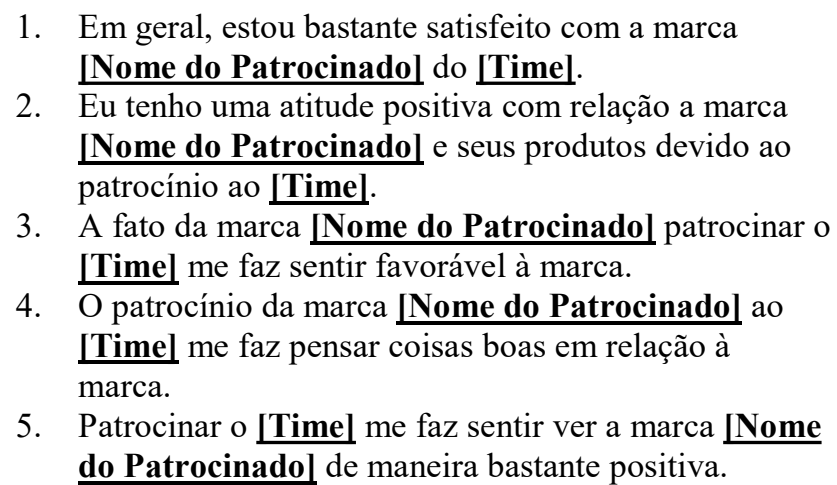 \\
\hline
\end{tabular}

Nota: (R) Escala reversa

Fonte: Desenvolvido pelo autor

Para esta pesquisa optou-se por definir lealdade por meio dos conceitos propostos por Oliver (1999).

\footnotetext{
"a deeply held psychological commitment to re-buy or re-patronize a preferred product/service consistently in the future, thereby causing repetitive same-brand or same brand-set purchasing,
} 
despite situational influences and marketing efforts having the potential to cause switching behavior $^{61}$ "(R. Oliver, 1999, p. 34).

Assim, a lealdade do torcedor com o patrocinador tem de ser vista como a força da relação entre a atitude relativa do torcedor com a marca patrocinadora de seu time. Assim, não apenas a compra, mas o hábito de recompra da marca patrocinadora é fundamental para analisar a lealdade do torcedor. Porém não seria correto afirmar que a lealdade existe apenas com base em padrões de compra ou recompra.

"não é correto fazer qualquer inferência sobre lealdade apenas com base em padrões de compra repetida, uma vez que a lealdade verdadeira inclui, além do comportamento, uma resposta atitudinal, constituida por componentes cognitivos e afetivos." (Larán \& Espinoza, 2004, p. 55).

Para mensurar o construto lealdade ao patrocinador, usamos Anderson e Srinivasan 1993 e Lichtenstein, Drumwright e Braig (2004).

Tabela 22: indicadores da Lealdade ao patrocinador

\begin{tabular}{|c|c|c|}
\hline CONSTRUTO & REFERÊNCIA & INDICADOR \\
\hline Lealdade & $\begin{array}{l}\text { Anderson \& } \\
\text { Srinivasan 1993; } \\
\text { Lichtenstein, } \\
\text { Drumwright, and } \\
\text { Braig (2004) }\end{array}$ & $\begin{array}{l}\text { 1. Enquanto o patrocínio ao [Time] continuar eu duvido } \\
\text { que eu troque de produtos. } \\
\text { 2. Eu gosto de usar produtos da marca [Nome do } \\
\text { Patrocinado], patrocinadora do [Time]. } \\
\text { 3. Eu acho que os produtos da marca [Nome do } \\
\text { Patrocinado], patrocinadora do [Time] são os } \\
\text { melhores que existem. } \\
\text { 4. Eu tenho um sentimento de lealdade para com a } \\
\text { marca \Nome do Patrocinado], patrocinadora do } \\
\text { [Time]. } \\
\text { 5. Eu sou um comprador comprometido com a marca } \\
\text { [Nome do Patrocinado], patrocinadora do \Time]. }\end{array}$ \\
\hline
\end{tabular}

Fonte: Desenvolvido pelo autor

${ }^{61} \mathrm{Um}$ compromisso psicológico profundamente no ato de recompra de um produto e/ou serviço no futuro, causando assim compras repetitivas da mesma marca, apesar das influências situacionais e esforços de marketing que têm o potencial de causar um comportamento de comutação. 


\subsubsection{Operacionalização dos outputs da Lealdade}

Seguindo os pressupostos de Dick \& Basu (1994), que ressaltam a questão dos tipos de lealdade (verdadeira, latente, espúria e a falta de lealdade), um consumidor pode parecer leal a uma organização até que ele encontre uma alternativa melhor. E, apoiado nas pesquisas de Zeithaml et al. (1996), este trabalho visa a mostrar que a lealdade ao time não é influenciada por alternativas similares ou mais atraentes.

Acredita-se, e pretendemos mostrar isso, que a lealdade do torcedor com seu time é uma lealdade verdadeira, com alto vínculo entre as partes. Desta forma, a lealdade não indica apenas uma maior preferência, disposição a falar bem (boca a boca) e intenção de compra ou recompra. Ela também ajuda a criar resistência contra persuasão e opinião contrária de especialistas, criando uma disposição a pagar mais no torcedor.

Assim, com base em Brown et al. (2005); Hardesty, Carlson, and Bearden (2002); Lepkowska-White, Elzbieta (2005), Chaudhuri(ve ano); Srinivasan et al. 2002 e Speed \& Thompson 2000 foram selecionados e adaptados os indicadores a seguir.

Tabela 23: indicadores da Lealdade ao Patrocinador

\begin{tabular}{|c|c|c|}
\hline CONSTRUTO & REFERÊNCIA & INDICADOR \\
\hline Boca a Boca & $\begin{array}{l}\text { Brown et al. } \\
(2005)\end{array}$ & $\begin{array}{l}\text { 1. Eu comento com amigos que eu compro produtos da } \\
\text { marca [Nome do Patrocinado], patrocinadora do } \\
\text { [Time]. } \\
\text { 2. Eu recomendo produtos da marca [Nome do } \\
\text { Patrocinado], patrocinadora do [Time] para meus } \\
\text { familiares. } \\
\text { 3. Eu falo positivamente da marca [Nome do } \\
\text { Patrocinado], patrocinadora [Time] para outras } \\
\text { pessoas. } \\
\text { 4. Eu recomendo produtos da marca [Nome do } \\
\text { Patrocinado], patrocinadora do [Time] para } \\
\text { conhecidos. } \\
\text { 5. Eu recomendo produtos marca [Nome do } \\
\text { Patrocinado], patrocinadora do [Time] para amigos } \\
\text { próximos. }\end{array}$ \\
\hline Intenção de compra & $\begin{array}{l}\text { Hardesty, } \\
\text { Carlson, and } \\
\text { Bearden (2002); } \\
\text { Lepkowska- } \\
\text { White, Elzbieta } \\
(2005),\end{array}$ & $\begin{array}{l}\text { 1. Eu tenho intenção de comprar produtos da marca } \\
\text { [Nome do Patrocinado], patrocinadora \Nome do } \\
\text { Patrocinado] devido ao patrocínio ao \Time]. } \\
\text { 2. No preço atual eu tenho intenção de comprar } \\
\text { produtos da marca [Nome do Patrocinado] devido } \\
\text { ao patrocínio ao \Time]. } \\
\text { 3. Eu passei a ter vontade de comprar produtos da marca } \\
\text { [Nome do Patrocinado] após começarem a } \\
\text { patrocinar o [Time]. }\end{array}$ \\
\hline
\end{tabular}




\begin{tabular}{|c|c|c|}
\hline & & $\begin{array}{l}\text { 4. Numa próxima compra eu tenho intenção de comprar } \\
\text { produtos da marca [Nome do Patrocinado] devido } \\
\text { ao patrocínio ao \Time]. } \\
\text { 5. Mesmo que a marca da marca [Nome do } \\
\text { Patrocinado], seja patrocinadora do [Time】 eu não } \\
\text { tenho intenção de comprar produtos dela. (R) }\end{array}$ \\
\hline Disposição a pagar mais & $\begin{array}{l}\text { Chaudhuri(ve } \\
\text { ano); Srinivasan } \\
\text { et al. } 2002\end{array}$ & $\begin{array}{l}\text { 1. Estou disposto a pagar mais por produtos da marca } \\
\text { [Nome do Patrocinado], patrocinadora do [Time] } \\
\text { em relação a outras marcas. } \\
\text { 2. Eu compraria produtos de patrocinadores dos times } \\
\text { rivais do [Time] que oferecem preços melhores que } \\
\text { da marca [Nome do Patrocinado]. (R) } \\
\text { 3. Eu continuarei comprando produtos da marca [Nome } \\
\text { do Patrocinado], patrocinadora mesmo que ele } \\
\text { aumente levemente os preços. } \\
\text { 4. Eu pagaria um preço mais elevado por produtos da } \\
\text { marca [Nome do Patrocinado] em relação a marcas } \\
\text { patrocinadoras dos times rivais. } \\
\text { Eu pararia de comprar produtos da marca \Nome do } \\
\text { Patrocinado], se os preços dos produtos dos } \\
\text { patrocinadores dos times rivais do 【Time】diminuírem } \\
\text { um pouco. }\end{array}$ \\
\hline Uso & $\begin{array}{l}\text { Speed \& } \\
\text { Thompson } 2000\end{array}$ & $\begin{array}{l}\text { 1. Este patrocínio me faria mais propensos a usar o } \\
\text { produto do patrocinador. } \\
\text { 2. Este patrocínio me faria mais propensos a considerar } \\
\text { produtos da empresa a próxima vez que eu compro } \\
\text { 3. Eu seria mais propenso a comprar de o patrocinador, } \\
\text { como resultado deste patrocínio }\end{array}$ \\
\hline Favorabilidade & $\begin{array}{l}\text { Speed \& } \\
\text { Thompson } 2000\end{array}$ & $\begin{array}{l}\text { 1. Este patrocínio me faz sentir mais favorável com o } \\
\text { patrocinador } \\
\text { 2. Este patrocínio melhora minha percepção do } \\
\text { patrocinador } \\
\text { 3. Este patrocínio me faz gostar mais do patrocinador }\end{array}$ \\
\hline Interesse & $\begin{array}{l}\text { Speed \& } \\
\text { Thompson } 2000\end{array}$ & $\begin{array}{l}\text { 1. Este patrocínio me faz mais propenso a perceber o } \\
\text { nome do patrocinador em outras ocasiões } \\
\text { 2. Este patrocínio me faria mais propensos a lembrar } \\
\text { promoção do patrocinador. } \\
\text { 3. Este patrocínio me faz mais propenso a prestar } \\
\text { atenção as propagandas do patrocinador }\end{array}$ \\
\hline
\end{tabular}

Nota: (R) Escala reversa

Fonte: Desenvolvido pelo autor

\subsection{Medida das Escalas}

Todos os indicadores foram mensurados por meio de escala likert de sete pontos. As alterações nas escalas se deu por meio de sua pergunta inicial. A escolha da escolha da escala likert se deu devido ao fato de os modelos mensurados por meio de modelagem de equação estrutural, por meio do método de PLS (partial least squares structural equation modeling), 
quando trabalhados com indicadores reflexivos, não suportarem adequadamente dados nominais ou binários.

Likewise, using binary indicators in reflective models violates this PLS assumption, because reflective indicators are regressed on the latent variable scores when estimating outer weights. [...] "when working with continuous data [...], PLS does not face any problems, but when working with nominal or binary data it is not possible to suppose there is any underlying continuous distribution. ${ }^{62, "}$ (Hair, 2011)

Assim, para que o modelo pudesse ser analisado, foi necessário pensar no desenvolvimento de uma escala contínua, exigência da técnica de modelagem de equação estrutural. A escala likert atendia esse pré-requisito (Nunally \& Berstein, 1995). A opção por uma escala de sete pontos se deu por ela ser mais versátil e apresentar melhores resultados do coeficiente de determinação de Person $\left(\mathrm{R}^{2}\right)$ (Oliver, 2010). Também, em conjunto com os números de um a sete, foram acrescentados adjetivos que auxiliassem na avaliação do respondente (Tabela 24).

62 "Da mesma forma, o uso de indicadores binários em modelos reflexivos viola esse pressuposto do PLS, porque os indicadores reflexivos são regredidos nos escores de variáveis latentes ao estimar pesos externos. [...] "ao trabalhar com dados contínuos [...], o PLS não enfrenta problemas, mas ao trabalhar com dados nominais ou binários não é possível supor que haja distribuição contínua". 
Tabela 24: Formato das medidas de Mensuração da Escala

\section{DIMENSÃO}

Tratamento Preferencial

Reconhecimento Pessoal

Sentimento de Status

Avaliação Pessoal

Pertencimento

Avaliação dos Outros

Satisfação

Envolvimento com o Futebol

Identificação com o Time

Fanatismo

Lealdade Atitudinal

Lealdade Conativa

Lealdade Comportamental

Percepção

Congruência

Atitude

Lealdade ao patrocinador

Boca a Boca

Intenção de compra

Disposição a pagar mais

Uso

Favorabilidade

Interesse
ESCALA LIKERT

ADJETIVOS

(1) Discordo totalmente

(2) Discordo

(1) Discordo Totalmente -

(7) Concordo Totalmente

(3) Discordo parcialmente

(4) Nem concordo, nem discordo

(5) Concordo parcialmente

(6) Concordo

(7) Concordo totalmente

Fonte: Desenvolvido pelo autor 


\section{METODOLOGIA}

Neste capítulo, abordaremos os procedimentos metodológicos adotados na presente pesquisa, escolhidos em função dos objetivos que o estudo se propõe a atingir. Apresentaremos o desenho da tese, que está dividida em duas fases: a primeira tem um caráter qualitativo e a segunda traz a pesquisa quantitativa. Apresentaremos cada uma das fases e suas distintas etapas, mostrando os métodos adotados, os critérios utilizados para seleção das amostras, os instrumentos empregados na coleta de dados e as técnicas utilizadas para tratamento e análise dos dados.

\subsection{Classificação da Pesquisa}

O planejamento da pesquisa é passo importante para o sucesso do projeto, pois é o elo entre os objetivos propostos inicialmente e os resultados obtidos. Assim, o primeiro passo para o bom andamento dos trabalhos é saber classificar o projeto. Porém, nas Ciências Sociais, esta nem sempre é uma tarefa simples (Neuman, 2011).

Para a realização de uma pesquisa científica, faz-se necessária a adoção de um ou mais métodos, que irão auxiliar o pesquisador a delinear as normas e etapas corretas a serem seguidas para atingir o objetivo proposto. Assim, o método de pesquisa pode ser caracterizado como o conjunto de recursos utilizados pelo pesquisador para formular ou responder o problema de pesquisa (Hair, Anderson, Tatham, \& Black, (2009). ).

Em suma, o planejamento correto da pesquisa ajuda a transparecer a questão do trabalho (Cooper \& Schindle, 2011) e elucida os caminhos corretos a serem seguidos. Assim, vale ressaltar que, no que tange ao ambiente acadêmico brasileiro, pouca importância vinha se dando ao tema proposto nesta pesquisa.

Para (Malhotra, 2012), as pesquisas podem ser classificadas da maneira indicada na Figura 17. 
Figura 17: Tipos de Pesquisa

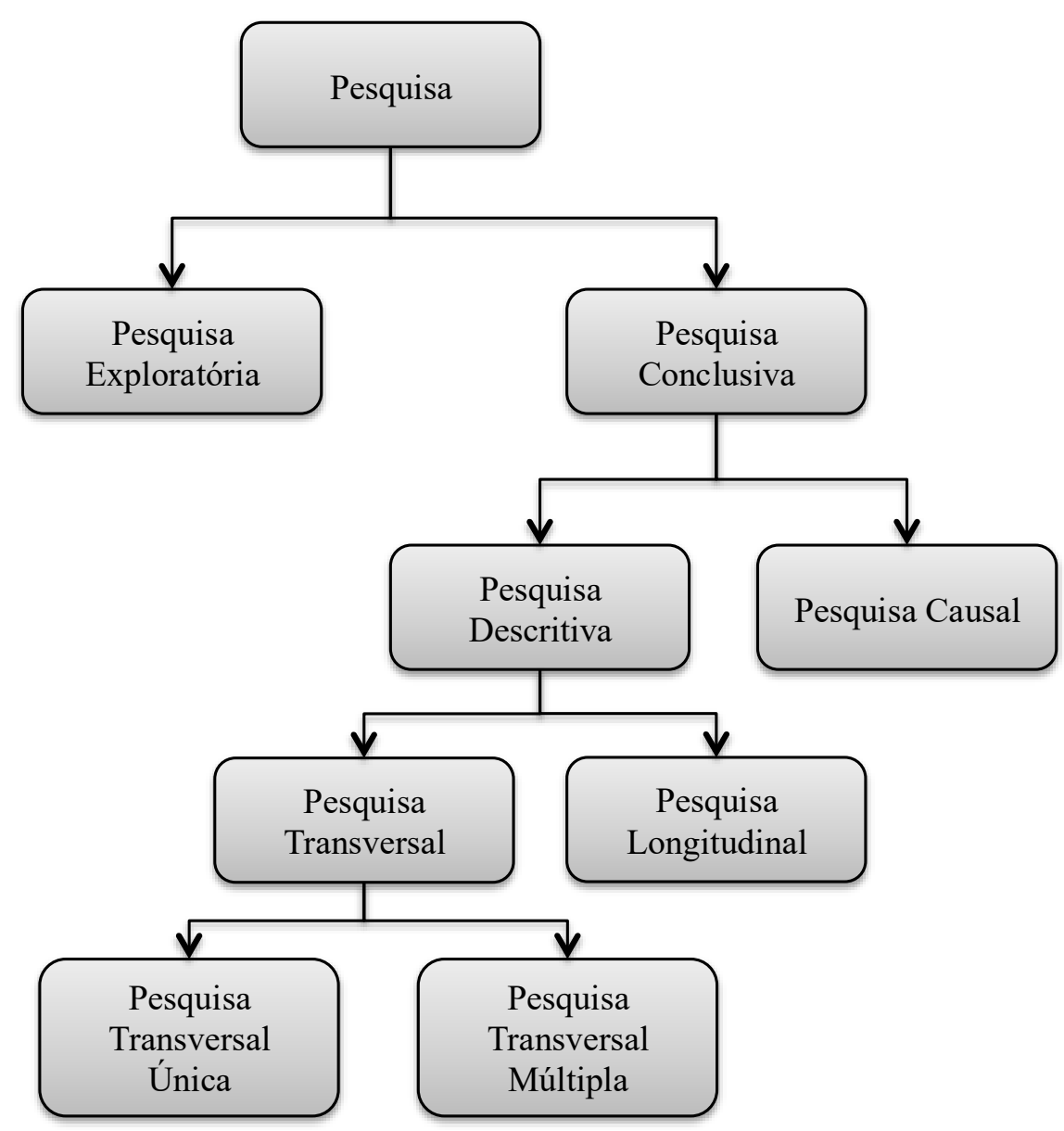

Fonte: Adaptado de (Malhotra, 2012, p. 105)

A pesquisa exploratória visa a proporcionar ao pesquisador maior familiaridade com o problema em estudo. Esse tipo de pesquisa procura explorar uma situação para prover a compreensão do problema enfrentado pelo pesquisador ( (Vieira, 2002)). (Malhotra, 2012) define a pesquisa conclusiva como sendo concebida para auxiliar o responsável pelas decisões a determinar, avaliar e selecionar o melhor curso de ação a ser tomado em determinada situação.

Assim, com relação aos objetivos traçados, num primeiro momento, esta pesquisa caracteriza-se por ser uma pesquisa exploratória, pois é recomendável utilizar a pesquisa exploratória quando se quer descobrir novas proposições a respeito de um tema que não se tem muita informação.

"The purpose of survey research in exploration is to become more familiar with a topic and to try out preliminary concepts about it. A survey in this context is used to discover the range of responses likely to occur in some population of interest (end users, IS managers, Fortune 500 
companies, etc.) and to refine the measurement of concepts. ${ }^{63}$ " (Pesrsonneault \& Kraemer, 1993).

Avaliando a aplicação do tema proposto e verificando que o conhecimento sobre ele ainda é escasso, esta pesquisa, em sua primeira fase, teve um caráter exploratório sobre os assuntos que permeiam a relação entre esporte, economia e marketing, buscando compreendêlos de forma a propiciar o surgimento de novas ideias ou hipóteses, estabelecendo analogias e comparações com o referencial teórico aplicado a situações semelhantes.

Nesta parte do trabalho, etapa qualitativa, optou-se por fazer um levantamento sistemático na literatura disponível (periódicos acadêmicos, anais de congressos, dissertações, teses e livros), para encontrar temas relacionados a: identificação com time, lealdade, lealdade no esporte, patrocínio, teoria do equilíbrio, da transferência de imagem e de confiança. Desta forma, o objetivo da fase exploratória foi definir de forma cristalina o desenho da pesquisa a ser realizada.

Pesquisas exploratórias são importantes para que o pesquisador possa aprofundar-se sobre o tema. E, para garantir a viabilidade do estudo, que deve ter condições de identificar as variáveis importantes que delimitam o fenômeno a ser estudado (Cooper \& Schindle, 2011). Neste sentido, "a pesquisa exploratória está de alguma forma associada a antigos vieses de pesquisa qualitativa: subjetividade, não representatividade e planejamento não sistemático" (Cooper \& Schindle, 2011, p. 132). Por isso, apesar de sua importância, nem sempre os pesquisadores dão o devido valor a ela.

Assim, a fase exploratória do trabalho compreende as etapas necessárias para formular o modelo teórico proposto, as variáveis que serão operacionalizadas, bem como as hipóteses apresentadas na seção anterior. A pesquisa exploratória é realizada com o intuito de buscar mais informações dobre o tema pesquisado, podendo ser utilizada na definição de termos e conceitos empregados na etapa descritiva (Burns \& Bush, 2013). A Figura 18 ajuda a visualizar como esta pesquisa foi dividida.

\footnotetext{
63 "O objetivo da pesquisa exploratória é tornar-se mais familiarizado com um tema e experimentar conceitos preliminares sobre ele. Uma pesquisa neste contexto é usada para descobrir uma gama de respostas prováveis de acontecer em parte da população interessada e para aperfeiçoar a medição de conceitos".
} 
Figura 18: Fluxograma das etapas metodológicas

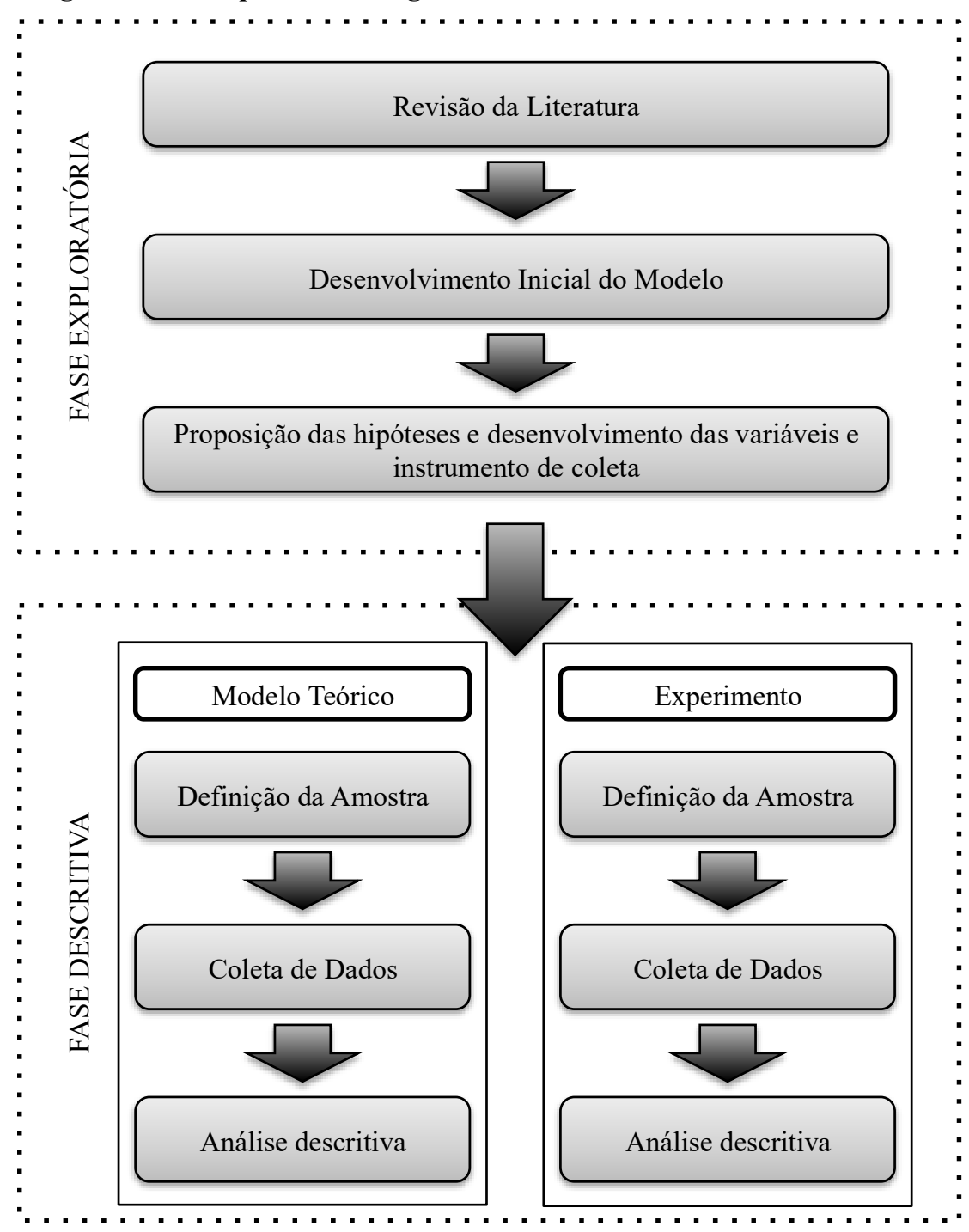

A segunda fase desta pesquisa caracteriza-se como pesquisa conclusiva, pois foi voltada ao teste de hipóteses e à análise de relações entre variáveis (Aaker, Kumar, \& Day, 2012; Malhotra, 2012). A pesquisa conclusiva visa a identificar os fatores que determinam ou contribuem para a ocorrência dos fenômenos, aprofundando o conhecimento da realidade (Gil, 2008). Desta forma, espera-se que o pesquisador observe, registre, interprete e relacione os fatos. Assim, pretende-se descrever as características de determinada população ou estabelecer relação entre as variáveis.

A pesquisa conclusiva engloba duas divisões: descritiva ou causal. Segundo Malhotra (2012), a pesquisa descritiva tem como principal objetivo a descrição de algo - normalmente características ou funções de mercado. Isso inclui descrever características de um determinado fenômeno ou, mesmo, a identificar possíveis relações entre as variáveis a serem estudadas (Dooley, 2000). 
A pesquisa descritiva pode ser realizada de forma transversal ou longitudinal. O estudo transversal envolve a coleta de informações de qualquer amostra da população uma única vez, enquanto o estudo longitudinal envolve uma amostra fixa de elementos da população, a qual é medida repetidamente ao longo do tempo (Malhotra, 2012). O autor ainda divide a pesquisa transversal em única ou múltipla. Pesquisa transversal única consiste em estudo no qual é extraída da população alvo uma amostra de entrevistados e as informações são obtidas somente uma vez. Pesquisa transversal múltipla refere-se ao estudo no qual há duas ou mais amostras de entrevistados, e as informações de cada uma delas também são obtidas somente uma vez.

Assim, com base nos objetivos propostos para esta pesquisa, sustenta-se a classificação deste trabalho como sendo uma pesquisa descritiva.

Pesquisa descritiva visa a determinar a frequência de ocorrência de um fenômeno e de que forma variáveis podem covariar (Churchill Jr, 1979). Assume-se que o pesquisador já tem cristalina a definição do seu problema de pesquisa. No caso deste trabalho, tal conhecimento foi adquirido na fase exploratória.

Outra etapa importante da definição de uma pesquisa é saber que caminho o pesquisador usará para responder sua pergunta de partida e, com isso, alcançar os objetivos propostos. Pesquisas quantitativas podem ser utilizadas em resposta a perguntas a respeito das relações entre as variáveis dentro do estudo ora realizado (Williams, 2007).

"Quantitative researchers seek explanations and predictions that will generate to other persons and places. The intent is to establish, confirm, or validate relationships and to develop generalizations that contribute to theory ${ }^{64 ”}$. (Leedy \& Ormrod, 2012, p. 102).

Assim, a pesquisa quantitativa tem seu início por meio da formulação de problema, necessita de hipóteses a serem testadas e envolve a revisão da literatura e uma análise de dados quantitativos (Williams, 2007). A pesquisa quantitativa apresenta opiniões encontradas por meio de números e pressupõe o uso de técnicas estatísticas para as análises. Ela envolve a

\footnotetext{
${ }^{64}$ "Pesquisadores quantitativos buscam explicações e previsões que serão geradas por outras pessoas e lugares. A intenção é estabelecer, confirmar ou validar as relações e desenvolver generalizações que contribuam para a teoria.
} 
coleta de dados para que as informações possam ser quantificadas e tratadas por técnicas estatísticas que irão apoiar ou refutar as hipóteses desenvolvidas (Creswell, 2009; Hair, Anderson, Tatham, \& Black, (2009). )

Diante das questões estabelecidas, foi realizada uma pesquisa pré-experimental correlacional, pois, nesta etapa, não existem variáveis a serem manipuladas. O design préexperimental envolve uma variável independente que não varia ou um grupo de controle que não é selecionado aleatoriamente (Williams, 2007). Já as pesquisa correlacionais possuem como objetivo empírico analisar a extensão e caminho de relação entre as variáveis (Ary, Jacobs, Razavieh, \& Sorensen, 2009).

O modelo de pesquisa correlacional possuí três etapas básicas para sua execução. Primeiramente, o pesquisador deve definir o problema e propor as hipóteses acerca da relação entre as variáveis. Este passo foi realizado na seção de hipóteses desta pesquisa, bem como as relações esperadas entre as variáveis. Na sequência, o pesquisador deve definir como os construtos serão quantificados, o que exige uma definição operacional das variáveis envolvidas no trabalho. Por fim, delimita-se a amostra que servirá para testar as supostas relações entre variáveis ${ }^{65}$.

Esta primeira etapa da fase descritiva-quantitativa do trabalho serviu para testar a escala desenvolvida neste trabalho e o modelo teórico proposto. Assim, este trabalho definese como uma pesquisa pré-experimental, transversal por meio do corte temporal, já que as coletas de dados foram realizadas em momentos únicos e distintos e não houve possibilidade de mudança nas repostas.

\subsection{Escolha da População e Amostra}

O intuito de apresentar um plano amostral é facilitar o entendimento a respeito de qual população a pesquisa pretende abranger e de que forma tal população será representada no estudo (Bussab \& Morettin, 2013). Segundo Richardson (2010), em geral é impossível obter as informações de todos os indivíduos a serem pesquisados, porque o número de elementos é

\footnotetext{
${ }^{65}$ As etapas dois e três serão descritos no próximo tópico desta seção
} 
muito grande, o custo é elevado e o tempo seria demasiado grande, podendo distorcer a informação. Por isso, é necessário aplicar uma técnica que permita selecionar uma parte adequada dos elementos para averiguar algo sobre o conjunto ao qual pertencem.

Este número menor de elementos é chamado de amostra. Uma amostra deve ser representativa e permitir analisar a população (Fávero, Belfiore, \& Silva, 2009). A amostra consiste na seleção de um grupo de elementos, com a intenção de descobrir algo sobre a população da qual os dados foram extraídos (Hair et al., 2009).

As amostras podem ser divididas em dois grupos: probabilística ou não probabilística. Estes por sua vez podem ser: analisar quais tipos e intencional, conveniência e quotas (Sampieri, Collado \& Lucio, 2012). A Tabela 25 apresenta um resumo de cada grupo e tipo de pesquisa.

Tabela 25: Tipos de grupos de amostras

\begin{tabular}{|c|c|c|}
\hline GRUPOS & DESRIÇÃO & TIPOS \\
\hline Probabilística & $\begin{array}{l}\text { Todos os elementos têm a mesma } \\
\text { probabilidade de serem } \\
\text { escolhidos para formarem a } \\
\text { amostra; } \\
\text { Requer um procedimento para } \\
\text { obter os respondentes com uma } \\
\text { probabilidade conhecida. }\end{array}$ & \\
\hline Não-Probabilística & $\begin{array}{l}\text { Os custos e o trabalho envolvidos } \\
\text { no desenvolvimento de uma } \\
\text { estrutura de amostragem são } \\
\text { eliminados }\end{array}$ & $\begin{array}{l}\text { - Intencional: um perito usa seu julgamento } \\
\text { para identificar amostras representativas; } \\
\text { Conveniência: utilizada para obtenção } \\
\text { rápida e barata de informações, contatando } \\
\text { unidades de amostra que sejam } \\
\text { convenientes; e } \\
\text { Quotas: uma amostragem intencional, com } \\
\text { a imposição de que a amostra inclua um } \\
\text { número mínimo de cada um dos subgrupos } \\
\text { da população. }\end{array}$ \\
\hline
\end{tabular}

Fonte: Desenvolvido pelo autor

Assim, definiu-se a população deste estudo como sendo a dos torcedores dos times de futebol brasileiros. Partiu-se do pressuposto inicial deste trabalho de que o torcedor é o principal stakeholder do mercado esportivo (Landau, 2012). As organizações esportivas a serem estudadas foram escolhidas analisando as pesquisas de torcidas realizadas recentemente no país, tais como Ibope (2014) e Pluri \& Stochos (2013). Por meio destas pesquisas, analisou-se que 26 equipes do país são responsáveis por $80 \%$ dos torcedores. Destas, 12 representam $80 \%$ do volume financeiro do mercado futebol (BDO, 2014). 
De maneira facilitar o acesso ao respondente e buscar ter uma amostra que possa ser representativa, aplicou-se o questionário a qualquer pessoa que se declarasse torcer para algum time de futebol brasileiro. Assim, propôs-se que a unidade amostral desta pesquisa fosse o indivíduo, pessoal física, brasileiro, morando no Brasil ou não, que se considerasse torcedor de algum time de futebol do país.

\subsection{Procedimento de Coleta}

De forma a atender os procedimentos estabelecidos na seção 5 (Tabela 13, pág. 123) a aplicação da coleta de dado foi realizada em dois momentos distintos. Primeiramente, atendendo ao passo 6 (amostra pré-teste), foi aplicado questionário validado por especialistas. Essa amostra foi composta por alunos da Universidade de São Paulo (Administração e Economia), Instituto Mauá de Tecnologia (Administração) e Universidade Nove de Julho (Administração).

Para essa amostra, adotou-se a plataforma QuestionPro (www.questionpro.com) para aplicação do questionário. O intuito deste pré-teste foi, por meio da aplicação com alunos da graduação, validar a escala de mensuração e o modelo estrutural. Para isso, analisou-se a validade convergente, discriminante e a confiabilidade composta. Tal análise permitiu purificar a escala, identificar possíveis problemas (e solucioná-los), bem como tornar o questionário mais curto.

Num segundo momento, seguindo o passo 7 do procedimento adotado para desenvolvimento da escala, aplicou-se o questionário final, após ajustes realizados no passo 6 , em uma amostra mais ampla e espalhado por todo Brasil. Para essa amostra adotaram-se duas formas distintas de aplicação: envio de e-mails para banco de dados existente e snowball por meio de redes sociais.

Para o envio dos e-mails, foi utilizado o banco de dados de um site já desativado (www.fanaticosporfutebol.com.br). Assim, foram disparados 50.000 e-mails, sendo que 15.000 mil retornaram como inexistentes. Em conjunto com os e-mails disparados, foi utilizada postagens na rede social facebook (www.facebook.com), solicitando apoio dos internautas para responderam os e-mails, bem como que estes divulgassem em suas páginas (snowball). 


\subsection{Elaboração do instrumento de coleta de dados}

Um modelo é um aglomerado de relações de dependência que podem ser testadas empiricamente. Assim, um modelo é a manifestação da teoria apresentada de forma compreensiva das relações a serem examinadas nos construtos (Hair et al., 2009). Um construto por sua vez é "a conceptual term used to describe a phenomenon of theoretical interest $^{66, "}$. (Edwards \& Bagozzi, 2000, pp. 156-157).

Assim, para que se pudesse avaliar o modelo teórico proposto e as hipóteses desta tese, foi preciso coletar os dados para amostra. Tais dados foram levantados por meio de questionário próprio (survey), desenvolvido por meio da análise de diversas escalas já testadas e, por muitas vezes, adaptadas ao contexto do esporte, de forma a desenvolver uma escala única para esta pesquisa.

Para tal, seguimos recomendações de (Churchill Jr, 1979), de acordo com as quais se deve primeiro especificar o domínio do construto (ou construtos) a serem pesquisados no modelo, de forma a gerar itens para a escala de mensuração das variáveis propostas no modelo.

\subsection{Técnica de Análise dos Resultados}

Para responder à pergunta de partida desta tese, bem como alcançar os objetivos propostos e verificar a validade das hipóteses apresentadas no modelo conceitual este trabalho, propôs-se a utilização do uso de Modelagem de Equações Estruturais $\left(\mathrm{MEE}^{67}\right)$. Tal método foi escolhido por diversos motivos, entre eles a possibilidade de analisar, simultaneamente, diversas relações de dependência (Hoyle, 1995; Hair et al., 1998).

Outro aspecto que levou a escolha do uso da MEE foram as variáveis que esta pesquisa se propôs a estudar. Existem dois tipos de variáveis: variáveis latentes (VL) também conhecida como construto - são variáveis que não podem ser observadas

\footnotetext{
${ }^{66}$ é um termo conceitual usado para descrever um fenómeno de interesse teórico.

${ }^{67}$ Do inglês Structural Equation Modeling (SEM)
} 
diretamente, pois são fenômenos abstratos e complexos; e variáveis observadas (VO) também conhecidas como manifestas (ou variáveis manifestas), indicadores ou itens - são variáveis que podem ser medidas diretamente e que ajudam a mensurar as variáveis observadas (Hair Jr, Hult, Ringle, \& Sarstedt, 2014).

\subsection{Distinção entre varáveis}

Conforme (Kline, 2011), basicamente existem dois grandes grupos de variáveis no uso da modelagem estrutural: as variáveis latentes e as variáveis observadas, também chamadas de variáveis manifestas, que nada mais são do que as variáveis coletadas por meio da pesquisa e inseridas no banco de dados. Essas variáveis podem ser categóricas, ordinais ou contínuas. Quando usada como uma medida indireta de uma variável latente, ela nada mais é do que um indicador ou item.

Já as variáveis latentes são aquelas que representam os fatores hipotéticos ou as construções analisadas. Essas variáveis são explicativas de algo que não pode ser mensurado. Elas podem ser exógenas (independentes) ou endógenas (dependentes). As exógenas trabalham como variáveis preditoras das endógenas, que por sua vez são dependentes das exógenas.

Esta pesquisa trabalha com diversas variáveis latentes, porém três podem ser consideradas principais: identificação com o time, lealdade ao time e lealdade ao patrocinador. Estas variáveis podem se manifestar de muitas formas, por meio de vários indicadores. Por exemplo: a identificação com o time pode ser mensurada por meio de quão é importante torcer para um time ou quanto um torcedor se considera apaixonado por seu time. Nota-se, assim, que as variáveis latentes podem representar uma ampla gama de fenômenos.

Como esta pesquisa possui diversas variáveis latentes, faz-se imprescindível que a técnica para analisar os resultados permita que as relações entre elas sejam mensuradas. Desta forma optou-se por utilizar da técnica baseada em Modelagem de Equações Estruturais (MEE), que será explicada no capitulo 7. 


\section{Modelagem de Equações Estruturais (MEE)}

A modelagem de equação estrutural (MEE), do inglês Structural Equation Modeling $\left(\mathrm{SEM}^{68}\right)$, é um método que leva em conta o modelo de interações causais entre as variáveis e o erro de mensuração (Klein, 2011), ou seja, o grau em que as variáveis manifestas não descrevem com exatidão os construtos que representam. Neste sentido, a SEM apresenta alguns modelos a serem utilizados: regressões múltiplas, análise de caminhos (path analysis), análise fatorial confirmatória, análises baseadas em covariância ou variância, entre outros. (Bido, Silva, Souza, \& Godoy, 2010; Hair Jr, Hult, Ringle, \& Sarstedt, 2014; Kline, 2011; Ringle, Da Silva, \& Bido, 2014)

"SEM is a class of multivariate techniques that combine aspects of factor analysis and regression, enabling the researcher to simultaneously examine relationships among measured variables and latent variables as well as between latent variables". (Hair, 2014, pág. xi)

Assim, nota-se que o termo modelagem de equação estrutural não é utilizado apenas para uma técnica, mas para diversas técnicas estatísticas multivariadas que permitem analisar variáveis.

Nesta pesquisa, como comumente acontece nas pesquisas focadas em tratar fenômenos que não podem ser mensurados diretamente (VL) (Bearden, Netemeyer, \& Haws, 2011), existem variáveis que em alguns momentos são dependentes e, em outros, são independentes. Essas relações simultâneas ajudam a entender melhor alguns fenômenos, porém só podem ser consideradas por meio de análises multivariadas, como por variância (Henseler, Ringle \& Sinkovics, 2009). Desta maneira, por haver variáveis dependentes que se tornam independentes em relações subsequentes de dependência, o uso da SEM se faz o mais apropriado (Hair et al., 2014).

A SEM pode ser definida como um procedimento mais confirmatório do que exploratório (Golob, 2003). Sua flexibilidade permite ao pesquisador trabalhar com técnicas

68 "Este trabalho adotará, daqui em diante, o uso do termo SEM para designar a Modelagem de Equação Estrutural. O uso da nomenclatura em inglês foi escolhido devido a esse ser comumente usado na literatura nacional e internacional". 
analíticas adequadas para muito objetivos de pesquisa (Hair et al., 2009), ou seja, ela não corresponde a uma técnica específica estatística, mas sim a uma variedade de procedimentos.

\begin{abstract}
"Pode-se considerar que sua função principal é a especificação e estimação de modelos de relações lineares entre variáveis. Essas variáveis podem incluir tanto variáveis mensuráveis (VM) quanto variáveis latentes (VL). VL's são construtos hipotéticos que não podem ser mensurados diretamente. Em SEM, tais construtos são tipicamente representados por múltiplas VM's que servem como indicadores dos construtos. Assim, um modelo de equações estruturais é um suposto padrão de relacionamentos lineares entre um conjunto de VM's e $V L$ 's. Apesar do termo SEM designar um conjunto de técnicas ou métodos, algumas funções e características em comum podem ser identificadas entre elas"(Brei \& Liberali Neto, 2006, p. 133).
\end{abstract}

Assim, pode-se definir a SEM como uma técnica de análise quantitativa multivariada que testa um modelo teórico desenvolvido com base na fundamentação teórica do fenômeno pesquisado, ajudando a avaliar as relações estruturais existentes entre os construtos, que são mensurados por meio das variáveis manifestas (indicadores). Evidencia-se na SEM uma característica muito importante: o conhecimento sobre a área estudada (Klein, 2011).

Portanto, entendemos que por meio da fundamentação teórica (capítulo 2, pág. 33) e do processo utilizado para desenvolvimento da escala (seção 5, pág. 123), esta pesquisa apresentou elementos suficientes para utilizar-se da SEM e, por meio dela, verificar, analisar e testar o modelo conceitual e estrutural aqui desenvolvido.

\title{
7.1. Tipos de Modelagem de Equação Estrutural (SEM)
}

A escolha do método estatístico correto para análise e interpretação de dados é fundamental em qualquer pesquisa. Nos estudos de comportamento e das ciências sociais em geral, muitas vezes os pesquisadores deparam com situações em que existem modelos complexos (muitas variáveis latentes ou manifestas), modelos formativos ou modelos de amostra reduzidas ou não aderentes a uma distribuição normal Ringle et al. (2014). Nestes casos, nem sempre os métodos mais comuns poderão ser utilizados. Assim, concentrar nas características e objetivos que ajudem a distinguir os métodos existentes pode ser a diferença entre a aceitação ou não das hipóteses (Hair et al., 2012).

Para estimar as relações em um modelo de equação estrutural, duas abordagens são possíveis: os modelos baseados em covariância (CB-SEM - covariance base structural 
equation modeling) e os modelos baseados em correlação (VB-SEM - variance base structural equation modeling), também tratadas atualmente como PLS-SEM (partial least squares structural equation modeling) (Hair et al, 2014).

A principal diferença entre os dois modelos está na forma como os dados são tratados. As análises em CB-SEM calculam as regressões lineares múltiplas mesmo tempo. Já as análises realizadas em PLS-SEM calculam primeiramente as correlações entre as variáveis latentes e manifestas (modelo de mensuração), para depois realizar as regressões lineares múltiplas entre as variáveis latentes (modelo estrutural) Ringle et al. (2014). Portanto, os modelos CB baseiam-se em modelagem pesada (hard modeling), enquanto os modelos PLS em modelagem suave (soft modeling) (Kline, 2011).

Essa diferença entre os modelos explica o porquê da inclusão do termo "partial" na abordagem PLS (partial least squares structural), pois na iteração cada modelo trabalha em momentos distintos (mensuração e estrutural) Bido et al. (2010).

Assim, é importante que o pesquisador defina a priori se o objetivo de sua pesquisa é testar teorias ou fazer predição. É o objetivo da pesquisa que deve guiar a escolha do método, e não o inverso. Os modelos CB-SEM são mais adequados quando se busca testar teorias. Nestes modelos, os índices de adequação de ajuste permitem a comparação de modelos. Por outro lado, se o objetivo for fazer previsões, sem necessariamente analisar um modelo teórico, os modelos baseados em Redes Neurais Artificiais $\left(\mathrm{RNA}^{69}\right)$ são mais recomendados. Por fim, no meio entre os dois modelos (teoria ou predição) que se encontram os modelos baseados em PLS-SEM. Esses modelos permitem que se construam modelos teóricos, de análise mais exploratória que confirmatória, pois não existem índices de adequação de ajuste. E, ao mesmo tempo, fazer predições. Bido et al. (2010) (Figura 19).

Essa diferença acontece devido ao método de regressão utilizados nos modelos. Os modelos baseados em CB-SEM utilizam estimação de ajuste de máxima verossimilhança (maximum likelihood estimation - MLE). Os modelos baseados em PLS-SEM utilizam estimação de ajuste de mínimos quadrados parciais (partial least square - PLS). Assim, a

\footnotetext{
${ }^{69}$ Este trabalho não focará sua análise em Redes Neurais Artificiais e foi usado apenas para ampliar o entendimento das diferenças entre CB-SEM e VB-SEM
} 
análise das relações de caminhos é estimada por meio dos coeficientes (path coefficient), maximizando os valores $\mathrm{R}^{2}$ das variáveis latentes dependentes no modelo conceitual em teste. Portanto, para pesquisas que busquem desenvolver teorias e fazer predições, é a mais indicada. (Hair et al. 2014).

Figura 19: objetivo da análise

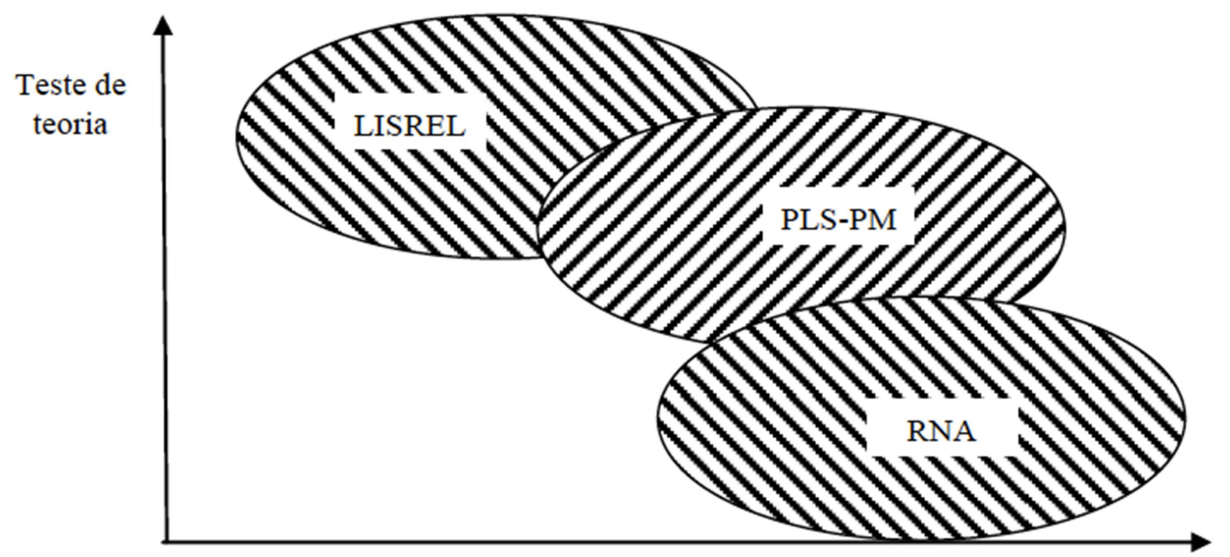

Fonte: Henseler, Ringle e Sinkovics (2009, p.296)

Predição

Legenda: RNA = Redes Neurais Artificiais

Hair, Ringle \& Sarstedt (2011) apontam quatro questões que devem ser analisadas para se aplicar a PLS-SEM: os dados; as propriedades do modelo; o algoritmo PLS-SEM; e a avaliação do modelo (Tabela 26)

Tabela 26: Questão para aplicação do método PLS-SEM

\begin{tabular}{cl}
\hline PASSO & \multicolumn{1}{c}{ DESCRIÇÃO } \\
\hline \hline Dados & Permite o uso de amostras pequenas e modelos complexos. \\
\hline Propriedades & $\begin{array}{l}\text { Permite o uso de modelos de medição reflexivos e formativos e variáveis } \\
\text { latentes de item único. }\end{array}$ \\
\hline Algoritmo & Alta eficiência na estimação de parâmetros. \\
\hline Avaliação & $\begin{array}{l}\text { Maior probabilidade de tornar uma relação específica significativa quando é } \\
\text { de fato significativa na população. }\end{array}$ \\
\hline \hline
\end{tabular}

Fonte: Desenvolvido pelo autor (Adaptado de Hair, 2014)

Vale ressaltar que esta pesquisa não tem como objetivo focar nas diferenças dos modelos CB ou PLS. Esta seção serve de base apenas para justificar a utilização do PLS neste trabalho. Assim, apesar de reconhecermos as limitações existentes no uso do método escolhido (PLS) e de estarmos cientes de que tais limitações são normalmente enfatizadas por 
aqueles que defendem (ou preferem) o método CB, este trabalho suporta-se nos estudos realizados por diversos autores (Reinartz, Haenlein, \& Henseler, 2009; Bido et al. (2010); Hair, et al., 2014) que apontam que os resultados entre os métodos não diferem muito entre si.

"The results for CB-SEM and PLS-SEM typically do not differ much, and PLS-SEM estimates can therefore be good proxies of CB-SEM results. In certain cases, particularly when there is little a priori knowledge on structural model relationships or the measurement of the constructs or when the emphasis is more on exploration than confirmation, PLS-SEM is an attractive alternative to CB-SEM". (Hair, 2014, pág. 18)

Por fim, entende-se que esta pesquisa possui um modelo que pode ser caracterizado como complexo, com amostra que não adere à normalidade e que, em algumas situações, é pequena (ver capítulo de resultados). Premissas que violariam a utilização do método CBSEM (Hair, 2014). Além disso, acredita-se que, conforme Jöreskog e Wold (1982, pág. 270), "as abordagens CB-SEM e PLS-SEM não deveriam ser vistas como concorrentes e, sim, como complementares".

Dando sequência à pesquisa, na próxima seção, são apresentados os estágios da análise da Modelagem de Equação Estrutural (SEM). Adotou-se, como critério de análise, os dois estágios sugeridos por Hair et al. (1998): mensuração do modelo, que expõe todas as ligações entre as variáveis latentes e também entre suas variáveis observáveis.; e avaliação do modelo estrutural, que exibe as ligações postulados conceitualmente entre as variáveis latentes (hipóteses).

\subsection{Avaliação do Modelo de Mensuração (measurement model assessment)}

O modelo de mensuração ajuda a definir quais variáveis latentes serão utilizadas no modelo e quais indicadores (variáveis observadas) podem ser atribuídos a cada uma delas (Barroso \& Gabriel Cepeda Carri'on, 2010). Nesta medição, é importante observar qual tratamento é dado para os indicadores. Eles podem ter dois tratamentos distintos: reflexivos,

70 “Tipicamente os resultados entre CB-SEM e PLS-SEM não diferem muito e, portanto, as estimativas de PLS-SEM podem ser boas proxies dos resultados de CB-SEM. Em certos casos, particularmente quando há pouco conhecimento a priori das relações do modelo estrutural ou das medições das variáveis ou quando a ênfase está mais na exploração do que na confirmação, o PLS-SEM é uma alternativa atraente ao CB-SEM”. 
quando são efeitos das variáveis latentes, ou formativo, quando formam as variáveis latentes (Chin, 1998).

Esta definição deve ser tomada com cuidado pelo pesquisador, com subsídios das teorias utilizadas, pois a escolha entre modelos reflexivos ou formativos pode afetar os procedimentos de estimação do modelo conceitual:

"these studies demonstrate that some potentially serious consequences of measurement model misspecification exist, and researchers need to think carefully about the direction of causality between constructs and their measures ${ }^{71}$ ". (Jarvis, 2003, pág. 200)

Os indicadores reflexivos têm origem na teoria clássica dos testes (Henseler, 2009) e dos modelos de análise fatorial (Jarvis, 2003). Eles são utilizados como meios para explicar variância ou covariância nas variáveis mensuráveis. Importante, também, que apresentem correlações positivas, pois, como reflexo da variável latente, todos as variáveis mensuráveis devem medir o mesmo fenômeno implícito, ou seja, se a variável latente mudar, as variáveis observadas devem manter a consistência interna (Dijkstra \& Henseler, 2015).

A Figura 20 apresenta a visualização gráfica do modelo, com múltiplos indicadores reflexivos. Nota-se que a seta está direcionada da variável latente (VL1) para as variáveis observadas (VO1, VO2 e VO3). Desta forma, indica-se a ideia de que o construto (VL1) causa a medição (covariância). Por fim, $\left(\mathrm{e}_{1}\right)$ representa o termo de erro dos indicadores reflexivos (Hair, 2014).

Os indicadores formativos, por outro lado, possuem uma relação causal do item para o construto (Hair, 2012). Por isso, alterações nas variáveis manifestas devem impactar no constructo, mas não o inverso. Os indicadores não precisam partilhar tema comum e, desta forma, não precisam se relacionar ou covariar (Dijkstra \& Henseler, 2015). Em suma, indicadores formativos não são modelados para explicar a variância as variáveis observadas (Jarvis, 2003).

71 “esses estudos demonstram que existem algumas consequências potencialmente graves da especificação de modelos de medição, e os pesquisadores precisam pensar cuidadosamente sobre a direção da causalidade entre construções e suas medidas". 
Figura 20: Modelo reflexivo

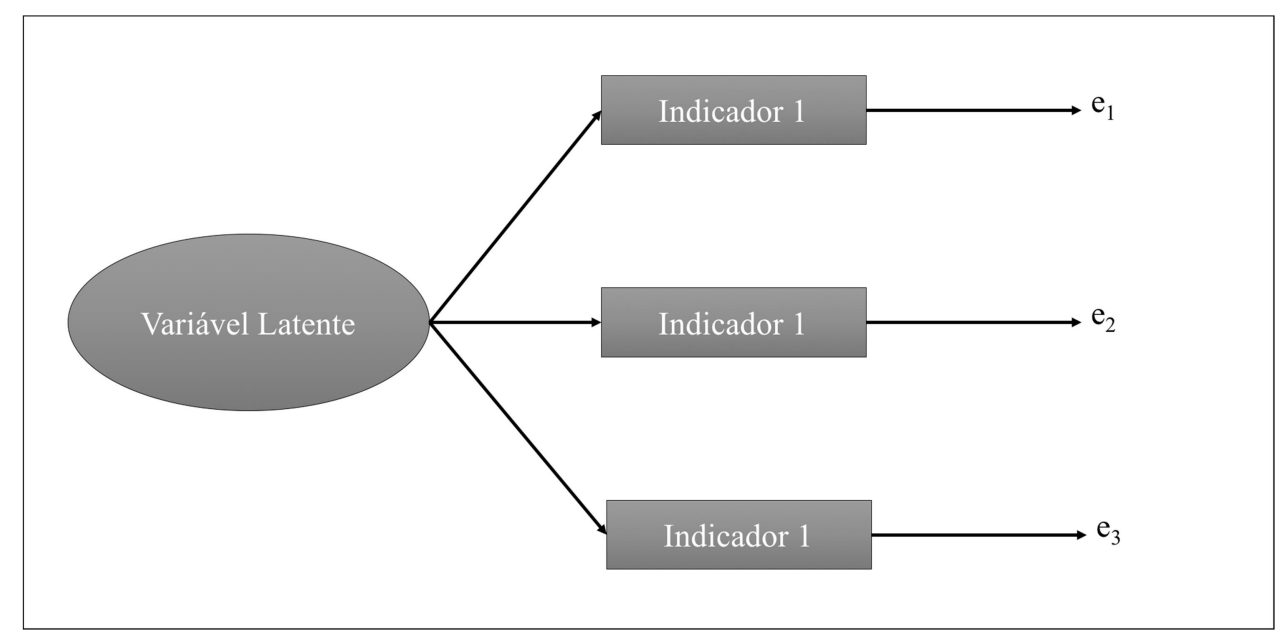

Fonte: Desenvolvido pelo autor

A Figura 21 apresenta a visualização gráfica do modelo, com múltiplos indicadores formativos. A seta direcionada das variáveis observadas (VO1, VO2 e VO3) para a variável latente (VL1) indicam a relação causal (predição) dos modelos formativos. Conforme Diamntopoulos (2011), nota-se que modelos formativos são livres de erros. (Hair, 2014).

Figura 21: Modelo formativo

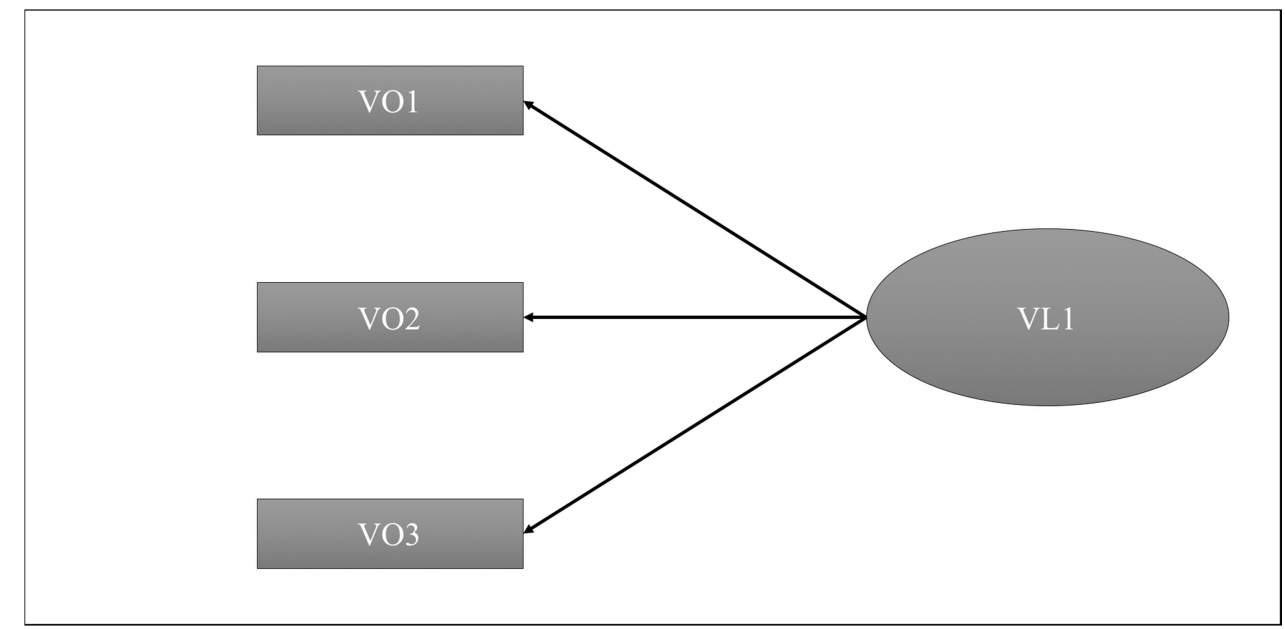

Fonte: Desenvolvido pelo autor

É importante ressaltar que a análise da SEM é divida em duas partes (Kline, 2011): a primeira é a mensuração dos indicadores que fazem parte das variáveis latentes (conforme demostrado nessa seção). Porém, para que possamos analisar o modelo de mensuração se faz necessário o uso da análise fatorial confirmatória (AFC). Na segunda parte, da SEM, busca-se analisar o modelo conceitual por meio da avaliação do modelo estrutural. 


\subsubsection{Análise Fatorial Confirmatória (AFC)}

Análise fatorial "é uma coleção de métodos para explicar a correlação entre entidades chamados de fatores" (Cudeck, 2000, p. 265). O intuito de uma análise fatorial é explicar a covariância entre muitas variáveis observadas por meio da relação com algumas variáveis latentes (Cudeck, 2000), o que faz com que se possa considerá-la uma técnica de redução.

Existem dois tipos mais conhecidos de análise fatorial: análise fatorial exploratória $\left(\mathrm{AFE}^{72}\right)$ e análise fatorial confirmatório $\left(\mathrm{AFC}^{73}\right)$. A característica que mais diferencia a $\mathrm{AFE}$ de outras análises fatoriais é a não exigência de uma especificação do modelo que relacione antecipadamente as variáveis latentes e as manifestas.

Esse não conhecimento antecipado pode acontecer por incertezas ou por falta de conhecimento a respeito dos fatores analisados (Cudeck, 2000). Assim, a AFE ajuda o pesquisador a verificar quais variáveis manifestas são mais representativas dentro de um conjunto maior de indicadores (Hair et al., 2005). Em suma, a análise fatorial exploratória não exige hipóteses para ser aplicada (Klein, 2011).

Por outro lado, diferentemente da AFE, a análise fatorial confirmatória trabalha com a definição do modelo a priori. A AFC necessita de um modelo inicial em que as variáveis latentes são definidas antes de inicializar a análise estatística. É uma técnica multivariada para testar uma relação especificada previamente. Diferente do que acontece, normalmente, na $\mathrm{AFE}$, a AFC exige que os números de fatores existentes sejam especificados antecipadamente (Hair et al. 2009).

A análise fatorial confirmatória, por responder por metade da análise da SEM, é "uma técnica crucial em SEM" (Klein, 2011, p. 230) para alcançar os objetivos pré-determinados. Por ser uma análise que requer a definição de um modelo antecipado, uma forte fundamentação empírica ou conceitual, que sirva de base para especificações e avaliações dos modelos fatoriais, é fundamental na AFC (Brown, 2006).

\footnotetext{
${ }^{72}$ Do inglês Exploratory Factor Analysis (EFA)

${ }^{73}$ Do inglês Confirmatory Factor Analysis (CFA)
} 
A AFC deve ser utilizada quando o pesquisador possui ideia clara a respeito das variáveis latentes a serem analisadas em sua pesquisa e das relações do modelo teórico proposto com as variáveis observadas e os construtos (Hair, 2009). Busca-se analisar se os dados pesquisados assumem o comportamento previamente identificado na teoria.

Se a resposta da análise for positiva, ou seja, se as respostas e a teoria convergem, pode-se assumir que os dados são válidos e que a pesquisa corrobora a teoria. Por outro lado, se os resultados não são convergentes, deve-se buscar entender se o problema está na teoria ou nos dados pesquisas, sendo que, muitas vezes, o problema pode estar em ambos.

A AFC também é usada com frequência nas fases finais do desenvolvimento de escalas ou na validação de construtos que já tenham sidos analisados em pesquisas anteriores ou sobre fortes bases teóricas (Brown, 2006). Por consequência, a AFC acaba sendo, também, uma técnica primária para muitos pesquisadores, especialmente para aqueles que conduzem estudos relacionados à avaliação e desenvolvimento de indicadores já trabalhados (Klein, 2011).

Apesar da SEM ser um método para análise multivariada (Hair, 2014; Klein, 2011, Brown, 2006), muitos autores acabam por usar a nomenclatura, SEM, para definir apenas a segunda etapa proposta por Kline (2011), a análise do modelo estrutural. Assim, é importante frisar que metodologias estatísticas baseadas em estimar uma rede de relações causais entre dois ou mais construtos (variáveis latentes) são parte do método de análise SEM, incluindo aí as análises por PLS, CB, AFC e outras (Vinzi, Trinchera, \& Amato, 2011).

Desta forma, a AFC pode ser considerada uma técnica do método SEM (Kline 2011; Hair, 2009). Nela é possível verificar a combinação entre o modelo conceitual criado e os dados pesquisados. De acordo com Hair (2009), o modelo conceitual é fundamentado em uma teoria específica e em suas relações causais. O ponto em comum, que liga (e por vezes confunde os pesquisadores) todas essas técnicas do método SEM, é a ideia central de que um sistema pode ser analisado por meio de sua rede de causalidade entre os construtos e indicadores (Vinzi, Trinchera, \& Amato, 2011).

Assim, o diferencial da AFC, por meio da SEM, é a capacidade de analisar a validade da variável latente, sem a necessidade de distinguir as variáveis endógenas das exógenas. Porém, conforme Hair (2009) e Kline (2011), ela é a primeira parte de um teste completo de um modelo estrutural. A teoria de mensuração, que especifica como as variáveis latentes são 
medidas (Hair, 2014), só se sustenta quando a AFC está ajustada e a validade do construto confirmada (Hair, 2009). Em suma, alguns princípios da AFC suportam a análise do modelo de mensuração da PLS-SEM, que é a primeira etapa da SEM. Na Tabela 27 apresenta-se os indicadores utilizados nesta pesquisa para avaliação do modelo de mensuração.

Tabela 27: Princípios da AFC aplicados na análise de mensuração do modelo por meio da PLS-SEM

\begin{tabular}{|c|c|c|c|}
\hline ANÁLISE & INDICADORES & DESCRIÇÃO & REFERÊNCIA \\
\hline \multirow{2}{*}{$\begin{array}{l}\text { Validade } \\
\text { Convergente: } \\
\text { Indicadores de um } \\
\text { construto devem } \\
\text { ter alta proporção } \\
\text { de variância, } \\
\text { convergida e } \\
\text { compartilhada. }\end{array}$} & $\begin{array}{l}\text { Cargas } \\
\text { Fatoriais }\end{array}$ & $\begin{array}{l}\text { Todas as cargas fatoriais devem ser } \\
\text { significantes (indicadores) e altas (construtos) } \\
(\lambda>0,7) \text { demonstrando convergirem para um } \\
\text { ponto em comum. }\end{array}$ & Hair (2014) \\
\hline & $\begin{array}{l}\text { Variância } \\
\text { Média } \\
\text { Extraída } \\
\left(\text { AVE }^{74}\right)\end{array}$ & $\begin{array}{l}\text { Variáveis latentes devem ser iguais ou } \\
\text { superiores a } 0,5 \text {. Esse valor representa o } \\
\text { quanto cada construto explica os dados e o } \\
\text { grau de correlação positiva entre indicador e } \\
\text { variável, latente. }\end{array}$ & $\begin{array}{c}\text { (Henseler, } \\
\text { RIngle 2009) }\end{array}$ \\
\hline \multirow{2}{*}{$\begin{array}{l}\text { Validade } \\
\text { Discriminante: } \\
\text { Construtos devem } \\
\text { se distinguir dos } \\
\text { demais do modelo. } \\
\text { Quanto mais } \\
\text { discriminante, } \\
\text { maior a evidencia } \\
\text { de que um } \\
\text { construto captura } \\
\text { um fenômeno } \\
\text { único. }\end{array}$} & $\begin{array}{l}\text { Fornell- } \\
\text { Lacker }\end{array}$ & $\begin{array}{l}\text { Comparam-se as raízes quadradas dos valores } \\
\text { das AVEs de cada construto com as } \\
\text { correlações (de Pearson) entre os construtos. } \\
\text { As raízes quadradas das AVEs devem ser } \\
\text { maiores que as correlações entre os dos } \\
\text { construtos. }\end{array}$ & $\begin{array}{c}\text { (Fornell \& } \\
\text { Larker, 1981) }\end{array}$ \\
\hline & $\begin{array}{l}\text { Cargas } \\
\text { Cruzadas }\end{array}$ & $\begin{array}{l}\text { As cargas fatoriais de cada indicador têm que } \\
\text { ser mais altas em suas respectivas variáveis } \\
\text { latentes do que nos outros construtos. }\end{array}$ & (Chin, 1998) \\
\hline \multirow{2}{*}{$\begin{array}{l}\text { Confiabilidade: } \\
\text { Indicador de } \\
\text { consistência } \\
\text { interna. Índices } \\
\text { mais altos } \\
\text { demonstram que } \\
\text { que os indicadores } \\
\text { representam o } \\
\text { mesmo construto. }\end{array}$} & $\begin{array}{l}\text { Composite } \\
\text { Rabilyt (p) }\end{array}$ & $\begin{array}{l}\text { Prioriza as variáveis de acordo com as suas } \\
\text { confiabilidades. Índices devem ser igual ou } \\
\text { superior a } 0,7 \text {. }\end{array}$ & (Hair, 2014) \\
\hline & Alpha:) & $\begin{array}{l}\text { Baseado em intercorrelações, é um indicador } \\
\text { tradicional. Porém ele é muito sensível à } \\
\text { quantidade de variáveis em cada construto. } \\
\text { Assim, deve-se dar preferência a analisar o } \\
\text { Composite. Valor igual ou superior a } 0,7 \text { é o } \\
\text { recomendado. }\end{array}$ & Hair (2014) \\
\hline
\end{tabular}

Fonte: Desenvolvido pelo autor (Adaptado de Hair, 2009; Hair 2014; Ringle et al., 2014) pesquisa

${ }^{74}$ Sigla para a definição em inglês Average Variance Extracted. AVE será adotada como padrão nesta (2) 


\subsection{Avaliação do Modelo Estrutural (structural model assessment)}

Conforme já exposto ao longo deste trabalho, um modelo de variáveis latentes só pode ser definido como completo quando possui dois modelos analisados: modelo de mensuração e modelo estrutural. O modelo de mensuração é aquele que expõe todas as ligações entre as variáveis latentes e também entre suas variáveis observáveis. Já o modelo estrutural exibe as ligações postulados conceitualmente entre as variáveis latentes.

Assim, o modelo estrutural define as relações causais entre as variáveis latentes. O modelo estrutural é avaliado de acordo com a significância e significado das relações de hipótese entre as construções (Barroso \& Gabriel Cepeda Carri'on, 2010). Ou seja, o modelo estrutural permite analisar como um construto causa (direta ou indiretamente) mudanças em outro construto.

$\mathrm{Na}$ análise do modelo estrutural, deve-se verificar se os construtos possuem relação significante entre si e, também, se existe uma relação, ou não, de medição entre esses construtos. Essa análise é feita por meio do coeficiente de caminho (path coefficients). Assim, um coeficiente de caminho próximo de +1 demostra uma relação positiva forte $(-1$ uma relação negativa forte) e próximo do zero indicam relações fracas. A significância da relação é analisada por meio do teste $\mathrm{t}$ (Hair, 2014). Na Tabela 28 encontram-se os indicadores que esta pesquisa adotou para avaliar o modelo estrutural.

Tabela 28: Indicadores utilizados para avaliar o modelo estrutural

\begin{tabular}{|c|c|c|}
\hline INDICADOR & DESCRIÇÃO & REFERÊNCIA \\
\hline $\begin{array}{l}\text { Coeficiente de } \\
\text { Caminhos }\end{array}$ & $\begin{array}{l}\text { Avaliação das relações causais. Indica o quanto cada } \\
\text { construto se relaciona com outro. Próximo de }+1 \text { demostra } \\
\text { uma relação positiva forte ( }-1 \text { uma relação negativa forte) e } \\
\text { próximo do zero indicam relações fracas. Análise } \\
\text { interpretativa baseada na teoria utilizada. Necessário que a } \\
\text { relação seja significante para comprovar a teoria. }\end{array}$ & Hair (2014) \\
\hline $\mathbf{R}^{2}$ & $\begin{array}{l}\text { Quanto cada variável endógena é explicada pelo modelo } \\
\text { estrutural. Indica a qualidade do modelo ajustado. Para área } \\
\text { de ciências sociais e comportamentais } \mathrm{R}^{2}=0,02 \text { efeito } \\
\text { pequeno; } \mathrm{R}^{2}=0,13 \text { efeito moderado; e } \mathrm{R}^{2}=0,26 \text { efeito grande }\end{array}$ & Cohen (1998) \\
\hline Teste $\mathbf{t}$ & $\begin{array}{l}\text { Significância das correlações e regressões do modelo. Usado } \\
\text { no teste de hipótese Assim, Ho: } \lambda=0 ; \Gamma=0 .(p<0,05)\end{array}$ & Hair (2014) \\
\hline $\begin{array}{l}\text { Validade Preditiva } \\
\left(Q^{2}\right)-\text { Indicador de }\end{array}$ & $\begin{array}{l}\text { Avalia a acurácia (ou precisão) do modelo ajustado. } \mathrm{O}^{2} \\
\text { avalia a qualidade da predição (modelo). Um modelo perfeito } \\
\text { teria } \mathrm{Q} 2=1 \text { (mostra que o modelo reflete a realidade }- \text { sem }\end{array}$ & Hair (2014) \\
\hline
\end{tabular}




\begin{tabular}{lll}
\hline Stone-Geisser & erros). $\left(\mathrm{Q}^{2}>0\right)$ & Hair (2014) \\
\hline $\begin{array}{l}\text { Tamanho do efeito } \\
\left(\mathbf{f}^{2}\right)-\text { Indicador de } \\
\text { Cohen }\end{array}$ & $\begin{array}{l}\text { Avalia o quanto cada variável latente é útil para o ajusto do } \\
\text { modelo. Valores de } 0,02 ; 0,1 ; \text { e } 0,35 \text { são considerados } \\
\text { pequenos, médios e grandes. }\end{array}$ & Hair (2014) \\
\hline VIF & Análise de multicolinearidade do modelo. VIF $<5,0$. & Hair (2014) \\
\hline $\begin{array}{l}\text { VAccounted for) } \\
\text { Variance }\end{array}$ & $\begin{array}{l}\text { Teste de mediação do construto. VAF } \leq 0,20=\text { sem mediação; } \\
0,20 \leq \text { VAF } \leq 0,80=\text { mediação parcial; e VAF } \leq 0,80=\text { mediação }\end{array}$ & \\
\hline \hline
\end{tabular}

Fonte: Desenvolvido pelo autor (Adaptado de Hair, 2009; Hair 2014; Ringle et al., 2014)

\subsection{Revisão por especialista}

Conforme apresentado na Tabela 13 (pág. 123), após executados os passos 1 (definição das dimensões), 2 (lista dos indicadores) e 3 (definir as medidas das escalas) o próximo passo (4) foi a revisão por especialistas. O objetivo desse procedimento foi verificar se os indicadores possuíam os atributos adequados para representar os construtos definidos de acordo com a fundamentação teórica.

A amostra de especialistas foi definida por julgamento e conveniência. Os profissionais foram definidos intencionalmente, de acordo com seu conhecimento sobre os fenômenos estudados e a relevância do tema para eles. Foram considerados também questões como disponibilidade e facilidade de acesso. Seis professores brasileiros (um professor da Universidade de São Paulo, um da Universidade Nove de julho, um da Unisinos, um do Insper e dois professores da Universidade Federal de Uberlândia) e oito professores estrangeiros (um professor da Hospitality Management - University of Missouri, um da Sport Management - Southern New Hampshire University, um da Shidler College of Business, University of Hawaií, um da Academy of Sport and Physical Activity - Sheffield Hallam University, dois da School of Tourism and Hospitality Management - Temple University e dois da Isenberg School of Management - University of Massachusetss) participaram desta etapa.

Um professor estrangeiro e um brasileiro foram selecionados para avaliar todos os indicadores. Os demais professores foram divididos em quatro grupos, de acordo com as especialidades, de forma a ter- sempre professores brasileiros e estrangeiros em todos grupos. 


\begin{tabular}{|c|c|c|c|}
\hline GRUPO & DIMENSÕES & $\begin{array}{l}\text { QUANTIDADE DE } \\
\text { INDICADORES }\end{array}$ & ESPECIALISTAS \\
\hline \multirow{3}{*}{1} & Antecedentes da Identificação com o Time & 23 & \multirow{3}{*}{$\begin{array}{l}\text { - } 3 \text { brasileiros } \\
\text { - } 3 \text { estrangeiros }\end{array}$} \\
\hline & Identificação com o Time & 5 & \\
\hline & Fanatismo & 5 & \\
\hline 2 & Lealdade ao time & 18 & $\begin{array}{l}\text { - } 2 \text { brasileiros } \\
\text { - } 5 \text { estrangeiros }\end{array}$ \\
\hline 3 & Antecedentes da Lealdade ao Patrocinador & 15 & $\begin{array}{l}\text { - } 3 \text { brasileiros } \\
\text { - } 3 \text { estrangeiros }\end{array}$ \\
\hline & Lealdade ao Patrocinador & 5 & \multirow{2}{*}{$\begin{array}{l}\text { - } 3 \text { brasileiros } \\
\text { - } 6 \text { estrangeiros }\end{array}$} \\
\hline & Outputs da Lealdade ao Patrocinador & 24 & \\
\hline
\end{tabular}

Fonte: Desenvolvido pelo autor (Adaptado de Hair, 2009; Hair 2014; Ringle et al., 2014)

Assim, apresentou-se a cada especialista uma definição operacional de cada construto e solicitou-se que avaliassem cada indicador em dois aspectos: (1) se o item era apropriado para medir a variável latente do qual fazia parte; e (2) se existia clareza de significado dos itens (Bearden et al., 2011; Hinkin (1998) e DeVellis (2012).

O objetivo dessa fase foi fazer a validade de conteúdo da escala. Assim, cada especialista contribuiu de forma a melhorar a qualidade da escala, bem como o nível de confiabilidade de cada variável latente. Também foi solicitado que apontassem eventuais ausências de indicadores para mensurar algum construto específico e também se existia alguma variável latente que eles julgassem importante ser incluída na escala.

Com base na avaliação de cada especialista, bem como nos comentários e recomendações chegou-se a escala a ser aplicada no pré-teste.

\subsection{Amostra de desenvolvimento}

Antes da aplicação do pré-teste a escala desenvolvida foi submetida a uma avaliação de 21 pessoas. Este passo visou a analisar a validade de face da escala, verificando se os itens seriam bem entendidos pelos respondentes. O principal aspecto identificado nessa fase foi a introdução, com mais frequência, de frases explicando o funcionamento da escala e que não 
existiam respostas certas ou erradas, apenas a opinião do respondente. A escolha dessas inserções foi para mitigar um possível viés de respostas muito positivas. 


\section{AMOSTRA PRÉ-TESTE}

Neste capítulo, analisa-se a aplicação da escala desenvolvida conforme os passos estabelecidos anteriormente. A aplicação em uma amostra pré-teste serviu de base para iniciar os procedimentos de análise por meio da técnica de Modelagem de Equação Estrutural (SEM).

Assim, analisou-se a validade convergente e a validade discriminante do modelo de mensuração, bem como sua confiabilidade. Em seguida, foi analisado o modelo estrutural por meio dos indicadores definidos neste trabalho. Com isso, foi possível verificar uma eventual necessidade de refinamento do modelo teórico proposto, os treads-offs do modelo e purificar a escala, visando a torná-la mais curta e dinâmica.

\subsection{Teste de Normalidade}

Uma das premissas para uso da técnica SEM-PLS é sua capacidade de rodar modelos de equação estrutural que utilizam variáveis que possuem distribuição não normal. Desta forma, esta pesquisa decidiu aplicar o teste de Kolmogorov-Smirnov e Shapiro-Wilk em todas as variáveis indicadoras da pesquisa. Para isso, adotou-se o software IBM SPSS Statistic (versão 20).

Também se verificou, conforme proposto por Hau \& Marsh (2004), os índices de Skewness e Kurtosi (Tabela 30). Por meio deles, é possível analisar, não apenas se as variáveis possuem (ou não) distribuição normal, mas também quanto a distribuição se distancia da normal. Valores negativos (esquerda) possuem assimetria (Skewness) negativa. Assim, a cauda da distribuição aponta para esquerda. A assimetria positiva (direita) apresenta valores positivos, e sua cauda aponta para a direita. Uma distribuição normal terá como valor Skwness $=0$.

A curtose (Kurtosi) ajuda a entender as características gerais da distribuição dos dados. Na assimetria, valores de curtose em zero (Kurtosi=0) mostram que os dados possuem distribuição normal. Desta forma, valores acima de zero (positivo) mostram que a distribuição possui picos mais pontudos que a distribuição normal. Por outro lado, curtose negativa (abaixo de zero) apresenta picos menos achatados que a distribuição normal. 
Tabela 30: Indicadores de Skewness e Kurtosi

\begin{tabular}{lcc}
\hline \multicolumn{1}{c}{ DISTRIBUIÇÃO DOS DADOS } & SKEWNESS & KURTOSI \\
\hline \hline Normal & $=0$ & 0 \\
\hline Levemente não normal & $-0,5 \leq$ ou $\geq 0,5$ & $-0,5 \leq$ ou $\geq 0,5$ \\
\hline Moderadamente não normal & $-1,0 \leq$ ou $\geq 1,0$ & $-1,5 \leq$ ou $\geq 1,5$ \\
\hline Severamente não normal & $-1>$ ou $<1,0$ & $-3,25>$ ou $<3,25$ \\
\hline \hline
\end{tabular}

Fonte: Desenvolvido pelo autor ( adaptado de Hau \& Marsh, 2004)

Assim, ao analisar as variáveis observadas pelos testes propostos de normalidade, identifica-se que todas as variáveis atendem aos requisitos de uma distribuição não normal. Os testes de Kolmogorov-Smirnov e Shapiro-Wilk foram significativos $(\rho<0,001)$ para todos os indicadores. O nível de não normalidade (critério de Hau \& Marsh, 2004) encontra-se no APÊNDICE C - Teste de normalidade da amostra pré-teste

\subsection{Tamanho e poder da amostra pré-teste}

Para definição da amostra mínima a ser pesquisada, adotamos as recomendações de Hair (2014), por meio do software G*Power (versão 3.1.9.2). Para efeito de cálculo foram considerados os parâmetros com base nas recomendações de Cohen (1998) e Hair (2014) (Tabela 31).

Tabela 31: Parâmetros para amostra mínima

\begin{tabular}{lc}
\hline \multicolumn{1}{c}{ PARÂMETRO } & VALOR \\
\hline \hline Poder do teste (Power $=\mathbf{1}$ - $\boldsymbol{\beta}$ erro prob) & 0,95 \\
\hline Tamanho do efeito $\left(\mathbf{f}^{2}\right)$ & 0,15 \\
\hline Nível de significância & 0,05 \\
\hline Número de preditores & 8 \\
\hline \hline
\end{tabular}

Fonte: Desenvolvido pelo autor

Nos modelos baseados em PLS, o construto com maior número de preditores deve ser usado para decidir a amostra mínima a ser pesquisada. Com tais parâmetros definidos, chegou-se ao número de 160 respondentes como amostra mínima para o modelo conceitual 
proposto (Figura 22). Ringle et al. (2014) sugere que, para maior consistência do modelo, é interessante adotar o dobro do valor apontado.

\section{Figura 22: G*power (amostra mínima)}

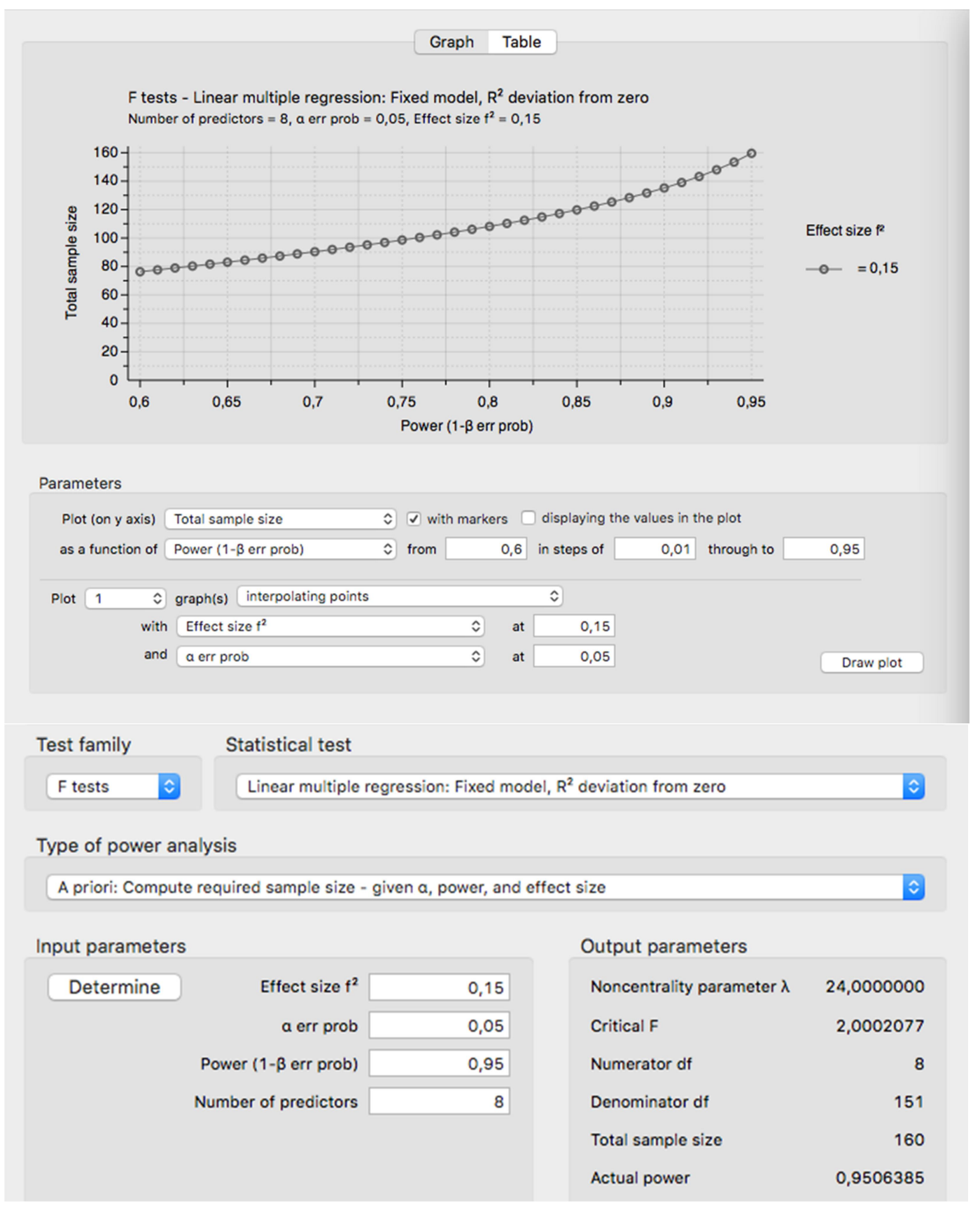

Fonte: G*Power (versão 3.1.9.2).

$\mathrm{Na}$ amostra pré-teste, o número de respondentes válidos foi de $263(\mathrm{n}=263)$. Portanto, acima da amostra mínima necessária. Tratando-se de uma amostra pré-teste, entendeu-se que os requisitos mínimos necessários foram mais do que cumpridos. 


\subsection{Perfil da amostra pré-teste}

De forma a entender melhor a amostra utilizada nesta etapa, apresenta-se a análise descritiva da amostra (Tabela 32), obtida pelo software IBM SPSS Statistic (versão 20). Essa amostra foi composta por alunos do curso de graduação da Universidade de São Paulo (administração e economia), Instituto Mauá de Tecnologia (administração) e Universidade Nove de Julho (administração).

O total de alunos entrevistos foi de 421 estudantes $(n=421)$. Deste total 158 alunos responderam não comprar produtos dos patrocinadores de seus times e/ou não identificaram de forma correta estes patrocinadores (outliers).

Tabela 32: Análise descritiva da amostra pré-teste

\begin{tabular}{|c|c|c|}
\hline DADOS DEMOGRÁFICOS & FREQUENCIA & $\%$ / Estatística \\
\hline \multicolumn{3}{|l|}{ Gênero - Total } \\
\hline Torcedor & 341 & 81,0 \\
\hline Torcedora & 80 & 19,0 \\
\hline Total & 421 & - \\
\hline \multicolumn{3}{|l|}{ Gênero - Válidos } \\
\hline Torcedor & 221 & 84,4 \\
\hline Torcedora & 42 & 15,6 \\
\hline Total & 263 & - \\
\hline \multicolumn{3}{|l|}{ Idade } \\
\hline Média & - & 29,5 \\
\hline Desvio Padrão & - & 7,70 \\
\hline Mínimo & - & 17 \\
\hline Máximo & - & 54 \\
\hline \multicolumn{3}{|l|}{ Estado Civil } \\
\hline Solteiro (a) & 163 & 61,9 \\
\hline Casado (a) / União Estável & 95 & 36,5 \\
\hline Divorciado / Separado & 5 & 1,90 \\
\hline Outro & - & - \\
\hline Total & 263 & - \\
\hline \multicolumn{3}{|l|}{ Compra Produtos do Patrocinador } \\
\hline Homens & 229 & 67,2 \\
\hline Mulheres & 43 & 53,8 \\
\hline Total & 272 & - \\
\hline \multicolumn{3}{|l|}{ Sabe quem é o patrocinador } \\
\hline Homens & 245 & 71,8 \\
\hline Mulheres & 47 & 58,8 \\
\hline Total & 292 & - \\
\hline
\end{tabular}

Fonte: Desenvolvido pelo autor por meio do IBM SPSS Statistic (versão 20) 


\subsection{Avaliação do Modelo de Mensuração (measurement model assessment) - Amostra pré-teste}

Ao usar a técnica de análise multivariada SEM, o primeiro passo a ser dado é a avaliação do modelo de mensuração (Klein, 2011, Hair, 2009). Para tal, é necessário adotar a análise fatorial confirmatória (AFC), para que os indicadores possam ser aferidos.

Para tanto, decidiu-se usar o software SmartPls (versão 3.2.6). Para rodar a AFC no SmartPls, deve-se ter em mente que nos softwares que trabalham com SEM-PLS é necessário adotar alguns procedimentos diferentes dos adotados quando utilizados softwares que trabalhem com SEM-CB Ringle et al. (2014).

Via de regra, a AFC, no PLS, é usada - principalmente - para validar escalas (Bido, Silva, Souza, \& Godoy, 2010). Portanto, os valores de coeficiente de caminhos, bem como $\mathrm{R}^{2}, f^{2}, \mathrm{Q}^{2}$ e $\mathrm{q}^{2}$ não devem ser considerados, pois tais coeficientes se alteram a cada composição do modelo.

Um segundo ponto a ser destacado é a necessidade de analisar todos os itens como indicadores reflexivos (Hair et al., 2014; Mackenzie, Podsakoff, Jarvis, 2005), quando se usa a AFC. Para tanto, deve-se ter como subsídio as definições dos construtos fundamentadas em teoria.

Também é importante atentar que, para realização da AFC no PLS, devem-se conectar todos os itens que medem os construtos entre si (Brown, 2006). Ao conectar todos os construtos, é preciso estimar o modelo com o esquema de ponderação factor weighting scheme (Ringle, Wende, Becker, 2015), que se utiliza das correlações entre os entre os scores dos construtos como peso. Já o path weighting scheme usa os pesos de regressão para os preditores e das correlações para outras variáveis (Dijkstra \& Henseler, 2015; Monecke \& Leisch, 2012). Porém, a AFC não distingue variáveis endógenas de exógenas (Hair et al.,, 2009). 
Fonte: Desenvolvido pelo autor

Assim, já que nos modelos PLS "The factor weighting scheme uses the correlations. The path weighting scheme pays tribute to the arrow orientations in the path model 75 , (Henseler, Ringle \& Sinkovics, 2009, p. 287), optou-se nesta pesquisa pela ponderação por fatores. Tal escolha também é subsidiada por meio da nomenclatura pela qual a path weighting scheme também é conhecida: Structural Scheme (Tenenhausa, Vinzia, Chatelinc \& Laurob, 2004).

\subsection{Validade Convergente}

Para analisar a validade convergente do modelo de mensuração, adotaram-se os princípios apresentados na Tabela 27 (pág. 156), tais como: as correlações entre os construtos e variáveis observadas - as cargas fatoriais dos indicadores devem ser significantes e as cargas fatoriais das relações entre variável manifesta e variável latente deve ser alta; e a variância média extraída (AVE) para cada variável latente (por exemplo: (Barroso \& Gabriel Cepeda Carri'on, 2010).

\footnotetext{
${ }^{75} \mathrm{O}$ esquema de ponderação dos fatores utiliza correlações. O esquema de ponderação de caminhos baseia-se nas orientações de seta do modelo de caminho.
} 


\subsubsection{Cargas fatoriais}

Para analisar a significância das cargas fatoriais de cada indicador por meio do SmartPls (versão 3.2.6), foi utilizada a opção bootstrappingping, com 5.000 amostras (Hair, 2014), com ponderação por factor weighting scheme. Desta forma, verificou-se o nível de significância de cada coeficiente fatorial.

Tabela 33: Avaliação do nível de significância dos indicadores - Amostra pré-teste

\begin{tabular}{|c|c|c|c|c|}
\hline Construto & Indicadores & Carga Fatorial $(\beta)$ & Desvio Padrão & t-valor \\
\hline \multirow{4}{*}{ Avaliação Pessoal } & AVP1 & 0,657 & 0,057 & $11,609^{\mathrm{a}}$ \\
\hline & AVP3 & 0,866 & 0,020 & $42,664^{\mathrm{a}}$ \\
\hline & AVP4 & 0,857 & 0,022 & $39,514^{\mathrm{a}}$ \\
\hline & AVP5 & 0,824 & 0,029 & $28,368^{a}$ \\
\hline \multirow{3}{*}{$\begin{array}{l}\text { Percepção da Avaliação } \\
\text { dos Outros }\end{array}$} & PAO1 & 0,845 & 0,025 & $33,941^{\mathrm{a}}$ \\
\hline & PAO2 & 0,833 & 0,028 & $29,946^{\mathrm{a}}$ \\
\hline & PAO3 & 0,840 & 0,025 & $34,215^{\mathrm{a}}$ \\
\hline \multirow{3}{*}{ Pertencimento } & PERTENC1 & 0,775 & 0,034 & $22,744^{\mathrm{a}}$ \\
\hline & PERTENC2 & 0,859 & 0,017 & $50,880^{\mathrm{a}}$ \\
\hline & PERTENC3 & 0,807 & 0,030 & $26,756^{\mathrm{a}}$ \\
\hline \multirow{4}{*}{ Reconhecimento Pessoal } & $\mathrm{RCP} 1$ & 0,844 & 0,021 & $40,987^{\mathrm{a}}$ \\
\hline & $\mathrm{RCP} 2$ & 0,885 & 0,016 & $55,744^{\mathrm{a}}$ \\
\hline & $\mathrm{RCP} 3$ & 0,886 & 0,016 & $55,515^{a}$ \\
\hline & $\mathrm{RCP} 4$ & 0,751 & 0,037 & $20,174^{\mathrm{a}}$ \\
\hline \multirow{6}{*}{ Satisfação } & SAT1 & 0,780 & 0,034 & $22,877^{\mathrm{a}}$ \\
\hline & SAT2 & 0,825 & 0,029 & $28,480^{\mathrm{a}}$ \\
\hline & SAT3 & 0,862 & 0,020 & $43,000^{\mathrm{a}}$ \\
\hline & SAT4 & 0,823 & 0,026 & $31,918^{\mathrm{a}}$ \\
\hline & SAT5 & 0,217 & 0,091 & $2,392^{\mathbf{b}}$ \\
\hline & SAT6 & 0,871 & 0,017 & $50,743^{a}$ \\
\hline \multirow{3}{*}{ Sentimento de Status } & SST1 & 0,858 & 0,014 & $59,327^{\mathbf{a}}$ \\
\hline & SST2 & 0,811 & 0,029 & $27,915^{\mathrm{a}}$ \\
\hline & SST3 & 0,749 & 0,043 & $17,624^{\mathrm{a}}$ \\
\hline \multirow{3}{*}{ Tratamento Preferencial } & TRP1 & 0,898 & 0,016 & $55,981^{a}$ \\
\hline & TRP2 & 0,909 & 0,015 & $60,291^{a}$ \\
\hline & TRP3 & 0,881 & 0,020 & $43,131^{\mathrm{a}}$ \\
\hline \multirow{3}{*}{ Fanatismo } & FAT1 & 0,885 & 0,015 & $59,225^{a}$ \\
\hline & FAT2 & 0,707 & 0,036 & $19,634^{\mathrm{a}}$ \\
\hline & FAT3 & 0,764 & 0,033 & $23,384^{\mathrm{a}}$ \\
\hline
\end{tabular}




\begin{tabular}{|c|c|c|c|c|}
\hline & FAT4 & 0,841 & 0,020 & $42,589^{\mathrm{a}}$ \\
\hline & FAT5 & 0,860 & 0,017 & $51,377^{\mathbf{a}}$ \\
\hline \multirow{5}{*}{$\begin{array}{l}\text { Envolvimento com o } \\
\text { Futebol }\end{array}$} & IDF1 & 0,909 & 0,016 & $56,750^{\mathrm{a}}$ \\
\hline & IDF2 & 0,857 & 0,014 & $59,276^{\mathrm{a}}$ \\
\hline & IDF3 & 0,814 & 0,047 & $17,318^{\mathrm{a}}$ \\
\hline & IDF4 & 0,764 & 0,049 & $15,750^{\mathrm{a}}$ \\
\hline & IDF5 & 0,856 & 0,024 & $35,219^{a}$ \\
\hline \multirow{5}{*}{ Identificação com o Time } & IDT1 & 0,825 & 0,031 & $26,537^{\mathrm{a}}$ \\
\hline & IDT2 & 0,813 & 0,022 & $37,801^{\mathrm{a}}$ \\
\hline & IDT3 & 0,900 & 0,015 & $58,477^{\mathbf{a}}$ \\
\hline & IDT4 & 0,854 & 0,025 & $34,117^{\mathrm{a}}$ \\
\hline & IDT6 & 0,866 & 0,022 & $39,793^{\mathrm{a}}$ \\
\hline \multirow{7}{*}{ Lealdade Atitudinal } & LAT2 & 0,650 & 0,036 & $18,060^{\mathrm{a}}$ \\
\hline & LAT3 & 0,290 & 0,095 & $3,052^{\mathrm{a}}$ \\
\hline & LAT4 & 0,280 & 0,095 & $2,953^{a}$ \\
\hline & LAT5 & 0,773 & 0,030 & $25,715^{\mathrm{a}}$ \\
\hline & LAT6 & 0,817 & 0,032 & $25,578^{a}$ \\
\hline & LAT7 & 0,698 & 0,055 & $12,601^{\mathrm{a}}$ \\
\hline & LAT8 & 0,818 & 0,025 & $32,647^{\mathrm{a}}$ \\
\hline \multirow{10}{*}{$\begin{array}{l}\text { Lealdade } \\
\text { Comportamental }\end{array}$} & LCM1 & 0,739 & 0,031 & $23,472^{a}$ \\
\hline & LCM2 & 0,700 & 0,038 & $18,321^{\mathrm{a}}$ \\
\hline & LCM3 & 0,664 & 0,037 & $17,858^{\mathrm{a}}$ \\
\hline & LCM4 & 0,651 & 0,052 & $12,546^{\mathrm{a}}$ \\
\hline & LCM5 & 0,663 & 0,038 & $17,681^{\mathrm{a}}$ \\
\hline & LCM6 & 0,503 & 0,050 & $10,040^{\mathrm{a}}$ \\
\hline & LCM7 & 0,761 & 0,035 & $22,040^{\mathrm{a}}$ \\
\hline & LCM8 & 0,743 & 0,030 & $24,431^{\mathrm{a}}$ \\
\hline & LCM9 & 0,525 & 0,063 & $8,296^{\mathbf{a}}$ \\
\hline & LCM10 & 0,592 & 0,058 & $10,270^{a}$ \\
\hline \multirow{5}{*}{ Lealdade Conativa } & LEC1 & 0,816 & 0,020 & $40,029^{a}$ \\
\hline & LEC2 & 0,683 & 0,037 & $18,362^{\mathrm{a}}$ \\
\hline & LEC6 & 0,756 & 0,039 & $19,351^{\mathbf{a}}$ \\
\hline & LEC7 & 0,775 & 0,035 & $22,227^{\mathbf{a}}$ \\
\hline & LEC8 & 0,722 & 0,046 & $15,640^{\mathrm{a}}$ \\
\hline \multirow{5}{*}{ Atitude } & ATT1 & 0,713 & 0,053 & $13,364^{a}$ \\
\hline & ATT2 & 0,857 & 0,025 & $34,686^{\mathrm{a}}$ \\
\hline & ATT3 & 0,885 & 0,020 & $44,696^{\mathrm{a}}$ \\
\hline & ATT4 & 0,890 & 0,022 & $39,913^{a}$ \\
\hline & ATT5 & 0,897 & 0,021 & $42,159^{\mathrm{a}}$ \\
\hline
\end{tabular}




\begin{tabular}{|c|c|c|c|c|}
\hline \multirow{5}{*}{ Percepção } & PERCEP1 & 0,792 & 0,029 & $26,975^{a}$ \\
\hline & PERCEP2 & 0,833 & 0,027 & $30,963^{\mathrm{a}}$ \\
\hline & PERCEP3 & 0,707 & 0,057 & $12,421^{\mathrm{a}}$ \\
\hline & PERCEP4 & 0,820 & 0,027 & $29,953^{\mathrm{a}}$ \\
\hline & PERCEP5 & 0,269 & 0,086 & $3,121^{\mathrm{a}}$ \\
\hline \multirow{5}{*}{ Congruência } & CONG1 & 0,821 & 0,026 & $31,136^{\mathrm{a}}$ \\
\hline & CONG2 & 0,790 & 0,028 & $28,237^{\mathrm{a}}$ \\
\hline & CONG3 & 0,808 & 0,027 & $29,991^{\text {a }}$ \\
\hline & CONG4 & 0,515 & 0,083 & $6,228^{\mathrm{a}}$ \\
\hline & CONG5 & 0,855 & 0,019 & $44,447^{\mathrm{a}}$ \\
\hline \multirow{4}{*}{ Boca a Boca } & $\mathrm{BaB} 1$ & 0,905 & 0,016 & $56,032^{a}$ \\
\hline & $\mathrm{BaB} 2$ & 0,940 & 0,010 & $98,662^{a}$ \\
\hline & $\mathrm{BaB} 3$ & 0,930 & 0,010 & $95,276^{\mathrm{a}}$ \\
\hline & BaB5 & 0,951 & 0,007 & $138,706^{\mathrm{a}}$ \\
\hline \multirow{5}{*}{ Disposição a pagar mais } & DISP_M1 & 0,904 & 0,015 & $61,808^{\mathrm{a}}$ \\
\hline & DISP_M2 & 0,519 & 0,088 & $5,928^{\mathrm{a}}$ \\
\hline & DISP_M3 & 0,856 & 0,028 & $30,107^{\mathrm{a}}$ \\
\hline & DISP_M4 & 0,927 & 0,013 & $73,926^{\mathrm{a}}$ \\
\hline & DISP_M5 & 0,302 & 0,110 & $2,742^{\mathrm{a}}$ \\
\hline \multirow{4}{*}{ Interesse } & INTER1 & 0,944 & 0,011 & $82,724^{a}$ \\
\hline & INTER2 & 0,938 & 0,010 & $98,603^{\mathrm{a}}$ \\
\hline & INTER3 & 0,933 & 0,014 & $68,056^{\mathrm{a}}$ \\
\hline & INTER4 & 0,906 & 0,018 & $50,211^{\mathrm{a}}$ \\
\hline \multirow{5}{*}{ Intenção de Compra } & INT_COMP1 & 0,944 & 0,008 & $113,565^{a}$ \\
\hline & INT_COMP2 & 0,915 & 0,013 & $71,055^{\mathrm{a}}$ \\
\hline & INT_COMP3 & 0,924 & 0,015 & $63,221^{\mathrm{a}}$ \\
\hline & INT_COMP4 & 0,918 & 0,013 & $72,609^{\mathrm{a}}$ \\
\hline & INT_COMP5 & 0,338 & 0,081 & $4,174^{\mathrm{a}}$ \\
\hline \multirow{5}{*}{$\begin{array}{l}\text { Lealdade ao } \\
\text { Patrocinador }\end{array}$} & LPAT1 & 0,872 & 0,020 & $42,806^{\mathrm{a}}$ \\
\hline & LPAT2 & 0,764 & 0,027 & $28,236^{\mathrm{a}}$ \\
\hline & LPAT3 & 0,839 & 0,026 & $32,886^{\mathrm{a}}$ \\
\hline & LPAT4 & 0,869 & 0,022 & $38,869^{\mathrm{a}}$ \\
\hline & LPAT5 & 0,906 & 0,011 & $82,815^{\mathrm{a}}$ \\
\hline \multirow{3}{*}{ Uso } & USO1 & 0,972 & 0,006 & $150,664^{\mathrm{a}}$ \\
\hline & USO2 & 0,962 & 0,008 & $115,625^{a}$ \\
\hline & USO3 & 0,969 & 0,008 & $122,733^{a}$ \\
\hline
\end{tabular}

Nota: O t-valor foi estimado por meio de bootstrapping no SmartPLS (263 casos e 5.000 re-amostras). $\mathrm{a}=p<0,01 ; \mathrm{b}=p<0,05$.

Valores em negrito $=$ valores abaixo do valor mínimo recomendado.

Fonte: Desenvolvido pelo autor por meio do SmartPLS (3.2.6) 
Assim, conforme apresentado na Tabela 33, verificou-se que todos os indicadores possuem coeficiente significante $(\rho<0,05)$. Porém, nem todas as cargas fatoriais $(\beta)$ atendem as recomendações $(\beta>0,7)$. Desta forma, decidiu-se por analisar a variância média extraída (AVE) e os índices de confiabilidade (Composite Ratability [CR] e Alpha de Cronbachs [a]) por construto. Adotou-se esse critério, conforme Hair et al. (2014), como forma de purificar e ajustar a escala.

\subsection{Variância Média Extraída (AVE) e Confiabilidade}

Para analisar o AVE e os índices de confiabilidade de cada indicador por meio do SmartPls (versão 3.2.6), bem como as cargas fatoriais, foi utilizada a opção PLS algorithm Hair et al. (2014), com ponderação factor weighting scheme. Os dados a seguir são apresentados de forma separada por grupos: (1) identificação como time; (2) lealdade ao time; (3) Lealdade ao Patrocinador; e (4) outputs da lealdade ao patrocinador. Porém, ressalta-se que o modelo foi analisado como um todo e a separação foi adotada apenas para tornar mais fácil a interpretação dos dados.

\subsubsection{Identificação com o time}

A identificação com o time é composta por oito construtos. Esses construtos, conforme apresentado na fundamentação teórica, analisam os antecedentes da identificação com o time: (1) avaliação pessoal; (2) percepção da avaliação dos outros; (3) pertencimento; (4) reconhecimento pessoal; (5) satisfação; (6) sentimento de status; (7) tratamento preferencial; e (8) envolvimento com o futebol (Tabela 34).

Tabela 34: Modelo de mensuração - Identificação com o time - Amostra pré-teste

\begin{tabular}{|c|c|c|c|c|c|}
\hline Construto & Indicadores & Carga Fatorial ( $\beta$ ) & $\alpha$ & $\rho$ & AVE \\
\hline \multirow{4}{*}{ Avaliação Pessoal } & AVP1 & 0,657 & \multirow{4}{*}{0,816} & \multirow{4}{*}{0,880} & \multirow{4}{*}{0,649} \\
\hline & AVP3 & 0,866 & & & \\
\hline & AVP4 & 0,857 & & & \\
\hline & AVP5 & 0,824 & & & \\
\hline \multirow{3}{*}{$\begin{array}{l}\text { Percepção da } \\
\text { Avaliação dos Outros }\end{array}$} & PAO1 & 0,845 & \multirow{3}{*}{0,790} & \multirow{3}{*}{0,877} & \multirow{3}{*}{0,704} \\
\hline & $\mathrm{PAO} 2$ & 0,833 & & & \\
\hline & PAO3 & 0,840 & & & \\
\hline
\end{tabular}




\begin{tabular}{|c|c|c|c|c|c|}
\hline \multirow{3}{*}{ Pertencimento } & PERTENC1 & 0,775 & \multirow{3}{*}{0,746} & \multirow{3}{*}{0,855} & \multirow{3}{*}{0,663} \\
\hline & PERTENC2 & 0,859 & & & \\
\hline & PERTENC3 & 0,807 & & & \\
\hline \multirow{4}{*}{$\begin{array}{l}\text { Reconhecimento } \\
\text { Pessoal }\end{array}$} & $\mathrm{RCP} 1$ & 0,844 & \multirow{4}{*}{0,862} & \multirow{4}{*}{0,907} & \multirow{4}{*}{0,711} \\
\hline & $\mathrm{RCP} 2$ & 0,885 & & & \\
\hline & $\mathrm{RCP} 3$ & 0,886 & & & \\
\hline & $\mathrm{RCP} 4$ & 0,751 & & & \\
\hline \multirow{6}{*}{ Satisfação } & SAT1 & 0,780 & \multirow{6}{*}{0,828} & \multirow{6}{*}{0,885} & \multirow{6}{*}{0,586} \\
\hline & SAT2 & 0,825 & & & \\
\hline & SAT3 & 0,862 & & & \\
\hline & SAT4 & 0,823 & & & \\
\hline & SAT5 & 0,217 & & & \\
\hline & SAT6 & 0,871 & & & \\
\hline \multirow{3}{*}{ Sentimento de Status } & SST1 & 0,858 & \multirow{3}{*}{0,736} & \multirow{3}{*}{0,848} & \multirow{3}{*}{0,652} \\
\hline & SST2 & 0,811 & & & \\
\hline & SST3 & 0,749 & & & \\
\hline \multirow{3}{*}{$\begin{array}{l}\text { Tratamento } \\
\text { Preferencial }\end{array}$} & TRP1 & 0,898 & \multirow{3}{*}{0,877} & \multirow{3}{*}{0,924} & \multirow{3}{*}{0,803} \\
\hline & TRP2 & 0,909 & & & \\
\hline & TRP3 & 0,881 & & & \\
\hline \multirow{5}{*}{ Fanatismo } & FAT1 & 0,885 & \multirow{5}{*}{0,871} & \multirow{5}{*}{0,907} & \multirow{5}{*}{0,663} \\
\hline & FAT2 & 0,707 & & & \\
\hline & FAT3 & 0,764 & & & \\
\hline & FAT4 & 0,841 & & & \\
\hline & FAT5 & 0,860 & & & \\
\hline \multirow{5}{*}{$\begin{array}{l}\text { Envolvimento com o } \\
\text { Futebol }\end{array}$} & IDF1 & 0,909 & \multirow{5}{*}{0,896} & \multirow{5}{*}{0,924} & \multirow{5}{*}{0,708} \\
\hline & IDF2 & 0,857 & & & \\
\hline & IDF3 & 0,814 & & & \\
\hline & IDF4 & 0,764 & & & \\
\hline & IDF5 & 0,856 & & & \\
\hline \multirow{5}{*}{$\begin{array}{l}\text { Identificação com o } \\
\text { Time }\end{array}$} & IDT1 & 0,825 & & & \\
\hline & IDT2 & 0,813 & & & \\
\hline & IDT3 & 0,900 & 0,906 & 0,930 & 0,727 \\
\hline & IDT4 & 0,854 & & & \\
\hline & IDT6 & 0,866 & & & \\
\hline
\end{tabular}

Nota: $\mathrm{O}$ t-valor foi estimado por meio de bootstrapping no SmartPLS (263 casos e 5.000 re-amostras). $\mathrm{a}=p<0,01 ; \mathrm{b}=p<0,05$.

Valores em negrito $=$ valores abaixo do valor mínimo recomendado.

Fonte: Desenvolvido pelo autor por meio do SmartPLS (3.2.6) 
Os construtos que formam o grupo denominado identificação com o time apresentaram índices de confiabilidade adequado $(\alpha \leq 0,7 ; \rho \leq 0,7)$. Na questão da validade convergente, todas as variáveis observadas apresentaram AVE acima do recomendando (AVE $\leq 0,5)$. Porém, na questão das cargas fatoriais, as variáveis manifestas AVP1 $(0,657)$ e SAT5 $(0,217)$ apresentaram carga fatorial inferior ao recomendando $(\beta \leq 0,7)$. Hair et al. $(2014)$, cita que cargas fatoriais acima de 0,6 são aceitáveis desde que outros índices analisados estejam dentro dos parâmetros mínimos.

\subsubsection{Lealdade ao time}

A lealdade do torcedor, nesta pesquisa, é entendida como um construto multidimensional de segunda ordem. Assim, as variáveis latentes que foram o construto lealdade ao time são: (1) lealdade atitudinal; (2) lealdade conativa; e (3) lealdade comportamental (Tabela 35).

Tabela 35: Modelo de mensuração - Lealdade ao time - Amostra pré-teste

\begin{tabular}{|c|c|c|c|c|c|}
\hline Construto & Indicadores & Carga Fatorial $(\beta)$ & $\alpha$ & $\rho$ & AVE \\
\hline \multirow{7}{*}{ Lealdade Atitudinal } & LAT2 & 0,650 & \multirow{7}{*}{0,771} & \multirow{7}{*}{0,824} & \multirow{7}{*}{0,429} \\
\hline & LAT3 & 0,290 & & & \\
\hline & LAT4 & 0,280 & & & \\
\hline & LAT5 & 0,773 & & & \\
\hline & LAT6 & 0,817 & & & \\
\hline & LAT7 & 0,698 & & & \\
\hline & LAT8 & 0,818 & & & \\
\hline \multirow{10}{*}{$\begin{array}{l}\text { Lealdade } \\
\text { Comportamental }\end{array}$} & LCM1 & 0,739 & \multirow{10}{*}{0,807} & \multirow{10}{*}{0,866} & \multirow{10}{*}{0,565} \\
\hline & LCM2 & 0,700 & & & \\
\hline & LCM3 & 0,664 & & & \\
\hline & LCM4 & 0,651 & & & \\
\hline & LCM5 & 0,663 & & & \\
\hline & LCM6 & 0,503 & & & \\
\hline & LCM7 & 0,761 & & & \\
\hline & LCM8 & 0,743 & & & \\
\hline & LCM9 & 0,525 & & & \\
\hline & LCM10 & 0,592 & & & \\
\hline \multirow{2}{*}{ Lealdade Conativa } & LEC1 & 0,816 & \multirow{2}{*}{0,852} & \multirow{2}{*}{0,883} & \multirow{2}{*}{0,435} \\
\hline & LEC2 & 0,683 & & & \\
\hline
\end{tabular}




$\begin{array}{ll}\text { LEC6 } & 0,756 \\ \text { LEC7 } & 0,775 \\ \text { LEC8 } & 0,722\end{array}$

Nota: O t-valor foi estimado por meio de bootstrapping no SmartPLS (263 casos e 5.000 re-amostras). $\mathrm{a}=p<0,01 ; \mathrm{b}=p<0,05$. Valores em negrito $=$ valores abaixo do valor mínimo recomendado.

Fonte: Desenvolvido pelo autor por meio do SmartPLS (3.2.6)

As cargas fatoriais das três dimensões apresentaram números inferiores ao recomendado: LAT2 $(0,650)$, LAT3 $(0,290)$ LAT4 $(0,280)$; LEC2 $(0,683)$; LCM3 $(0,664)$, LCM4 (0,651), LCM5 (0,663), LCM6 (0,503), LCM9 (0,525), LCM10 (0,592). Nota-se também que as variáveis latentes lealdade atitudinal e lealdade comportamental apresentam valores de AVE inferiores a 0,5, ou seja, uma baixa correlação entre os indicadores e seu construto, além de uma baixa explicação dos dados, o que levou à necessidade de ajustes nestas variáveis.

\subsubsection{Lealdade ao patrocinador}

As variáveis latentes (1) atitude, (2) percepção e (3) congruência são variáveis exógenas (independentes) preditoras do construto lealdade ao patrocinador. Diferentemente da lealdade ao time, que se apresenta como um construto de segunda ordem (sem variável observada atrelada a ele), a lealdade ao patrocinador possui suas variáveis manifestas (Tabela 36).

Tabela 36: Modelo de mensuração - Lealdade ao patrocinador - Amostra pré-teste

\begin{tabular}{|c|c|c|c|c|c|}
\hline Construto & Indicadores & Carga Fatorial ( $\beta)$ & $\alpha$ & $\rho$ & AVE \\
\hline \multirow{5}{*}{ Atitude } & ATT1 & 0,713 & \multirow{5}{*}{0,904} & \multirow{5}{*}{0,929} & \multirow{5}{*}{0,725} \\
\hline & ATT2 & 0,857 & & & \\
\hline & ATT3 & 0,885 & & & \\
\hline & ATT4 & 0,890 & & & \\
\hline & ATT5 & 0,897 & & & \\
\hline \multirow{5}{*}{ Percepção } & PERCEP 1 & 0,792 & \multirow{5}{*}{0,739} & \multirow{5}{*}{0,828} & \multirow{5}{*}{0,513} \\
\hline & PERCEP2 & 0,833 & & & \\
\hline & PERCEP3 & 0,707 & & & \\
\hline & PERCEP4 & 0,820 & & & \\
\hline & PERCEP5 & 0,269 & & & \\
\hline Congruência & CONG1 & 0,821 & 0,818 & 0,875 & 0,589 \\
\hline
\end{tabular}




\begin{tabular}{llllll} 
& CONG2 & 0,790 & & & \\
CONG3 & 0,808 & & \\
& CONG4 & $\mathbf{0 , 5 1 5}$ & & \\
& CONG5 & 0,855 & & \\
\hline & LPAT1 & 0,872 & & \\
Lealdade ao & LPAT2 & 0,764 & & \\
Patrocinador & LPAT3 & 0,839 & 0,904 & 0,725 \\
& LPAT4 & 0,869 & & & \\
& LPAT5 & 0,906 & & & \\
\hline
\end{tabular}

Nota: O t-valor foi estimado por meio de bootstrapping no SmartPLS (263 casos e 5.000 re-amostras). $\mathrm{a}=p<0,01 ; \mathrm{b}=p<0,05$.

Valores em negrito $=$ valores abaixo do valor mínimo recomendado.

Fonte: Desenvolvido pelo autor por meio do SmartPLS (3.2.6)

As variáveis observadas da variável latente lealdade ao patrocinador apresentaram índices de convergência ( $\beta$ e AVE) satisfatórios. O mesmo ocorreu para a variável exógena atitude. Por outro lado, em relação às variáveis latentes percepção e congruência, apesar de terem os índices de confiabilidade acima do mínimo esperado, suas variáveis manifestas não apresentam carga fatorial aceitável. PERCP5 $(0,269)$ e CONG4 $(0,515)$ devem ser retiradas do modelo. Ambas variáveis apresentam AVE dentro do padrão mínimo.

\subsubsection{Outputs da lealdade ao patrocinador}

O grupo denominado outputs da lealdade ao patrocinador possibilitou analisar os resultados da lealdade. Conforme dissemos anteriormente, a lealdade só se torna efetiva quando apresenta resultados tais como: (1) boca a boca; (2) disposição a pagar mais; (3) interesse; (4) intenção de compra; e (5) uso (Tabela 37).

Tabela 37: Modelo de mensuração - Outputs da lealdade ao patrocinador - Amostra pré-teste

\begin{tabular}{|c|c|c|c|c|c|}
\hline Construto & Indicadores & Carga Fatorial ( $\beta)$ & $\alpha$ & $\rho$ & AVE \\
\hline \multirow{4}{*}{ Boca a Boca } & $\mathrm{BaB} 1$ & 0,905 & \multirow{4}{*}{0,949} & \multirow{4}{*}{0,963} & \multirow{4}{*}{0,868} \\
\hline & $\mathrm{BaB} 2$ & 0,940 & & & \\
\hline & $\mathrm{BaB} 3$ & 0,930 & & & \\
\hline & $\mathrm{BaB5}$ & 0,951 & & & \\
\hline \multirow{4}{*}{$\begin{array}{l}\text { Disposição a pagar } \\
\text { mais }\end{array}$} & DISP_M1 & 0,904 & \multirow{4}{*}{0,791} & \multirow{4}{*}{0,847} & \multirow{4}{*}{0,554} \\
\hline & DISP_M2 & 0,519 & & & \\
\hline & DISP_M3 & 0,856 & & & \\
\hline & DISP_M4 & 0,927 & & & \\
\hline
\end{tabular}




\begin{tabular}{llllll}
\multicolumn{1}{c}{ DISP_M5 } & $\mathbf{0 , 3 0 2}$ & & & \\
\hline \multirow{4}{*}{ Interesse } & INTER1 & 0,944 & & \\
& INTER2 & 0,938 & 0,948 & 0,963 & 0,865 \\
& INTER3 & 0,933 & & \\
& INTER4 & 0,906 & & 0,708 \\
Intenção de Compra & INT_COMP1 & 0,944 & & \\
& INT_COMP2 & 0,915 & 0,877 & 0,918 & \\
& INT_COMP3 & 0,924 & & & \\
& INT_COMP4 & 0,918 & & & \\
& INT_COMP5 & $\mathbf{0 , 3 3 8}$ & & & \\
Uso & USO1 & 0,972 & & \\
& USO2 & 0,962 & 0,948 & 0,963 & \\
& USO3 & 0,969 & & & \\
\hline
\end{tabular}

Nota: O t-valor foi estimado por meio de bootstrapping no SmartPLS (263 casos e 5.000 re-amostras). $\mathrm{a}=p<0,01 ; \mathrm{b}=p<0,05$.

Valores em negrito $=$ valores abaixo do valor mínimo recomendado.

Fonte: Desenvolvido pelo autor por meio do SmartPLS (3.2.6)

Os indicadores INT_COM_5 (0,338); DISP_M2 $(0,519)$ e DISP_M2 $(0,302)$ apresentaram cargas fatoriais baixas, porém com AVE e índices de confiabilidade aceitáveis. Os demais construtos (boca a boca, uso e interesse) apresentaram validade convergente e confiabilidade.

Mediante aos resultadas apresentado nos quatros grupos, notou-se uma clara necessidade de ajuste no modelo de mensuração. Estes ajustes devem ser feitos de forma parcimoniosa e unitária. Ou seja, mesmo que vários itens de um mesmo construto estejam abaixo dos valores mínimos recomendados se faz necessário retirá-los um a um (REMARK). Todavia, antes de apresentar os ajustes realizados, discute-se na sequência a validade discriminante, pois é importante analisar ambas as validades dentro de um único contexto.

\subsection{Validade discriminante}

Validade discriminante deve ser avaliada de duas maneiras (Hair, (2014), REMARK, HENSEL 2009 e outros). Primeiramente, no nível do construto, deve-se observar o critério de Fornell-Larcker (Fornell \& Larcker, 1981). Por este critério comparam-se as raízes quadradas dos valores das AVEs de cada constructo com as correlações (de Pearson) entre os 
constructos. As raízes quadradas das AVEs devem ser maiores que as correlações entre os dos constructos (análise vertical e horizontal) (Tabela 38).

Em segundo lugar, verifica-se, no nível dos indicadores, as cargas cruzadas. Assim, as cargas fatoriais dos indicadores devem ser, sempre, superiores às cargas cruzadas (Chin, 1998). Adicionalmente, ao analisar as cargas cruzadas, deve-se, além de verificar a questão de ela ser inferior à carga fatorial da variável latente, analisar se ela é alta. Valores altos indicam alta correlação, o que pode sugerir que existam fatores de segunda ordem (Tabela 39).

$\mathrm{Na}$ análise discriminante, por meio da matriz de Fornell-Larcker (Tabela 38), nota-se que algumas variáveis latentes possuem cargas fatoriais maiores que a raiz quadrada do AVE (Fornell-Larcker, 1981). Existem duas maneiras de ajustar a relação entre as cargas fatoriais e a raiz do AVE. Em primeiro lugar, podem-se analisar as cargas fatoriais, na validade convergente, e excluir os indicadores com cargas fatoriais mais baixos. Com isso, aumenta-se AVE e, por consequência, sua raiz.

Outra maneira é analisar as cargas cruzadas dos construtos em que as cargas fatoriais são superiores à raiz quadrada do AVE e excluir aqueles que apresentam cargas cruzadas alta. Assim, analisando a Tabela 39, percebe-se que diversos indicadores possuem cargas cruzadas altas, mesmo que menos que as cargas fatoriais. Outro ponto é que existem outros indicadores que, conforme Chin (1998), possuem carga cruzada mais alta que as cargas fatoriais. Tais itens devem ser eliminados.

Da mesma forma que na análise de validade convergente, a retirada dos indicadores deve ser feita um a um e de forma parcimoniosa. Desta forma, após a primeira análise realizada do modelo de mensuração, destacam-se alguns pontos-chaves na próxima seção. 
Tabela 38: Estatística descritiva e correlações - Amostra pré-teste

\begin{tabular}{|c|c|c|c|c|c|c|c|c|c|c|c|c|c|c|c|c|c|c|c|c|c|c|c|}
\hline$\#$ & Construto & 1 & 2 & 3 & 4 & 5 & 6 & 7 & 8 & 9 & 10 & 11 & 12 & 13 & 14 & 15 & 16 & 17 & 18 & 19 & 20 & 21 & 22 \\
\hline 1 & Atitude & 0,851 & & & & & & & & & & & & & & & & & & & & & \\
\hline 2 & Avaliação Pessoal & 0,245 & 0,805 & & & & & & & & & & & & & & & & & & & & \\
\hline 3 & Avaliação dos Outros & 0,171 & 0,443 & 0,839 & & & & & & & & & & & & & & & & & & & \\
\hline 4 & Boca a Boca & 0,582 & 0,299 & 0,225 & 0,932 & & & & & & & & & & & & & & & & & & \\
\hline 5 & Congruência & 0,740 & 0,189 & 0,204 & 0,424 & 0,768 & & & & & & & & & & & & & & & & & \\
\hline 6 & Dispo. Pagar Mais & 0,438 & 0,298 & 0,237 & 0,703 & 0,352 & 0,744 & & & & & & & & & & & & & & & & \\
\hline 7 & Fanatismo & 0,218 & 0,627 & 0,293 & 0,367 & 0,068 & 0,313 & 0,814 & & & & & & & & & & & & & & & \\
\hline 8 & Identificação Futebol & 0,194 & 0,470 & 0,197 & 0,236 & 0,082 & 0,155 & 0,630 & 0,841 & & & & & & & & & & & & & & \\
\hline 9 & Identificação Time & 0,263 & 0,639 & 0,285 & 0,338 & 0,095 & 0,257 & 0,807 & 0,608 & 0,852 & & & & & & & & & & & & & \\
\hline 10 & Intenção de Compra & 0,649 & 0,327 & 0,268 & 0,825 & 0,471 & 0,720 & 0,385 & 0,207 & 0,389 & 0,841 & & & & & & & & & & & & \\
\hline 11 & Interesse & 0,776 & 0,377 & 0,220 & 0,643 & 0,587 & 0,499 & 0,341 & 0,236 & 0,383 & 0,671 & 0,930 & & & & & & & & & & & \\
\hline 12 & L. Comportamental & 0,238 & 0,583 & 0,366 & 0,374 & 0,153 & 0,295 & 0,770 & 0,664 & 0,701 & 0,358 & 0,332 & 0,660 & & & & & & & & & & \\
\hline 13 & Lealdade Conativa & 0,278 & 0,587 & 0,336 & 0,407 & 0,124 & 0,372 & 0,680 & 0,546 & 0,725 & 0,411 & 0,367 & 0,728 & 0,752 & & & & & & & & & \\
\hline 14 & L. ao Patrocinador & 0,583 & 0,257 & 0,220 & 0,819 & 0,503 & 0,703 & 0,278 & 0,133 & 0,273 & 0,777 & 0,590 & 0,311 & 0,332 & 0,851 & & & & & & & & \\
\hline 15 & Lealdade Atitudinal & 0,211 & 0,671 & 0,263 & 0,378 & 0,078 & 0,286 & 0,770 & 0,638 & 0,774 & 0,381 & 0,336 & 0,762 & 0,739 & 0,280 & 0,655 & & & & & & & \\
\hline 16 & Percepção & 0,710 & 0,202 & 0,144 & 0,359 & 0,754 & 0,283 & 0,037 & 0,057 & 0,146 & 0,402 & 0,544 & 0,099 & 0,097 & 0,439 & 0,077 & 0,716 & & & & & & \\
\hline 17 & Pertencimento & 0,224 & 0,623 & 0,418 & 0,420 & 0,149 & 0,421 & 0,665 & 0,442 & 0,641 & 0,439 & 0,380 & 0,596 & 0,593 & 0,385 & 0,614 & 0,140 & 0,814 & & & & & \\
\hline 18 & Reconhecimento P. & 0,263 & 0,557 & 0,392 & 0,382 & 0,130 & 0,375 & 0,594 & 0,436 & 0,602 & 0,386 & 0,357 & 0,516 & 0,510 & 0,338 & 0,561 & 0,155 & 0,754 & 0,843 & & & & \\
\hline 19 & Satisfação & 0,135 & 0,431 & 0,499 & 0,184 & 0,181 & 0,263 & 0,208 & 0,101 & 0,215 & 0,232 & 0,201 & 0,216 & 0,272 & 0,235 & 0,223 & 0,258 & 0,418 & 0,313 & 0,765 & & & \\
\hline 20 & Sentimento de Status & 0,276 & 0,570 & 0,447 & 0,348 & 0,193 & 0,350 & 0,586 & 0,344 & 0,583 & 0,367 & 0,374 & 0,502 & 0,493 & 0,315 & 0,551 & 0,203 & 0,747 & 0,790 & 0,346 & 0,807 & & \\
\hline 21 & Tratamento Pref. & 0,119 & 0,390 & 0,362 & 0,328 & 0,072 & 0,279 & 0,409 & 0,275 & 0,403 & 0,267 & 0,225 & 0,389 & 0,333 & 0,236 & 0,372 & 0,137 & 0,590 & 0,714 & 0,289 & 0,716 & 0,896 & \\
\hline 22 & Uso & 0,751 & 0,306 & 0,208 & 0,685 & 0,549 & 0,536 & 0,316 & 0,196 & 0,358 & 0,746 & 0,885 & 0,309 & 0,360 & 0,642 & 0,289 & 0,504 & 0,346 & 0,323 & 0,158 & 0,302 & 0,173 & 0,968 \\
\hline
\end{tabular}

Nota 1: Os valores na diagonal (negrito) são a raiz quadrada dos valores de AVE. As entradas fora da diagonal são correlações entre os construtos. A raiz quadrada do AVE maior do que os coeficientes de correlação indica validade discriminante suficiente.

Nota 2: Demais valores em negrito apresentam coeficientes que são superiores a raiz do AVE.

Fonte: Desenvolvido pelo autor por meio do SmartPLS (3.2.6) 
Tabela 39: Matriz de carga cruzada - Amostra pré-teste

\begin{tabular}{|c|c|c|c|c|c|c|c|c|c|c|c|c|c|c|c|c|c|c|c|c|c|c|}
\hline Indicador & 1 & 2 & 3 & 4 & 5 & 6 & 7 & 8 & 9 & 10 & 11 & 12 & 13 & 14 & 15 & 16 & 17 & 18 & 19 & 20 & 21 & 22 \\
\hline AVP1 & 066 & 0,657 & 0,340 & 0,115 & 0,080 & 0,163 & 421 & 0,191 & 0,441 & 0,158 & 0,173 & 0,339 & 0,349 & 0,131 & 0,431 & 0,123 & 0,458 & 0,409 & 0,326 & 0,446 & 0,267 & 0,158 \\
\hline AVP3 & 230 & 66 & 68 & 272 & 0156 & 227 & 606 & 0,483 & 0,616 & 298 & 0,331 & 0,576 & 580 & 0,229 & 663 & 0,140 & 0,499 & 0,424 & 323 &, 448 & 0,270 & 0,275 \\
\hline AVP4 & 196 & 0,857 & 0,397 & 0,230 & 0,176 & 0,270 & 511 & 0,397 & 0,496 & 266 & 0,314 & 0,477 & 0,536 & 0,200 & 0,534 & 0,185 & 0,545 & 0,454 & 0,451 & 0,465 &, 342 & 0,253 \\
\hline AVP5 & 0,270 & 0,824 &, 326 & 0,321 & 0,183 & 0,288 & 0,467 & 0,402 & 0,494 & 0,311 & 0,372 & 0,462 & 0,400 & 0,256 & 0,514 & 0,201 & 0,507 & 0,513 & 0,294 & 0,486 & 0,377 & 0,284 \\
\hline PAO1 & 0,141 & 0,358 & 845 & 0,162 & 0,158 & 0,144 & 0,261 & 0,172 & 0,265 & 0,189 & 0,208 & 0,314 & 0,273 & 0,152 & 0,213 & 0,153 & 0,338 & 0,306 & 0,472 & 0,328 & 0,275 & 0,163 \\
\hline PAO2 & 0,172 & 0,385 & 0,833 & 0,202 & 0,233 & 0,221 & 0,196 & 0,174 & 0,212 & 0,235 & 0,200 & 0,286 & 0,314 & 0,187 & 0,210 & 0,141 & 0,294 & 0,309 & 0,331 & 0,359 & 0,270 & 0,216 \\
\hline PAO3 & 0,120 & 0,372 & 0,840 & 0,202 & 0,127 & 0,229 & 0,277 & 0,151 & 0,241 & 0,250 & 0,150 & 0,320 & 0,262 & 0,212 & 0,237 & 0,074 & 0,415 & 0,368 & 0,450 & 0,432 & 0,360 & 0,147 \\
\hline PERTENC1 & 0,133 & 0,403 & 0,292 & 0,314 & 0,102 & 0,335 & 0,522 & 0,316 & 0,449 & 0,318 & 0,286 & 0,492 & 0,422 & 0,264 & 0,416 & 0,097 & 0,775 & 0,684 & 0,228 & 0,588 & 0,550 & 0,265 \\
\hline PERTENC2 & 0,163 & 0,590 & 0,372 & 0,359 & 0,078 & 0,355 & 0,613 & 0,425 & 0,614 & 0,372 & 0,298 & 0,540 & 0,558 & 0,323 & 0,620 & 0,089 & 0,859 & 0,618 & 0,385 & 0,661 & 0,497 & 0,256 \\
\hline PERTEN & 0,253 & 0,517 & 0,354 & 0,352 & 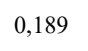 & 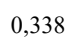 & 0,484 & 0,331 & 0,492 & 0,38 & 0,347 & 0,420 & 0,462 & 0,353 & 0,449 & 0,160 & 0,807 & 0,546 & 0,402 & 0,572 & 0,399 & 329 \\
\hline RCP1 & 0,229 & 0,490 & 0,355 & 0,309 & 0,108 & ,200 & 0,534 & 0,414 & 0,560 & 0,325 & 0,285 & 0,469 & $0,4+1$ & 0,283 & (I) & 0,145 & 0,631 & 0,844 & 0,253 & 0,718 & 0,631 & 0,248 \\
\hline RCP2 & 0,214 & 0,516 & 0,300 & 0,313 & 0,125 & 0,334 & 0,516 & 0,368 & 0,508 & 0,337 & 0,316 & 0,422 & 0,462 & 0,275 & 0,492 & 0,127 & 0,660 & 0,885 & 0,279 & 0,654 & 0,535 & 0,299 \\
\hline RCP3 & 0,239 & 0,488 & 0,309 & 0,362 & 0,104 & 0,326 & 0,552 & 0,402 & 0,527 & 0,350 & 0,307 & 0,459 & 0,422 & 0,304 & 0,503 & 0,109 & 0,657 & 0,886 & 0,224 & 0,650 & 0,587 & 0,279 \\
\hline RCP4 & 0,201 & 0,376 & 0,359 & 0,302 & 0,100 & 0,341 & 0,391 & 0,276 & 0,427 & 0,287 & 0,298 & 0,383 & 0,394 & 0,279 & 0,362 & 0,142 & 0,591 & 0,751 & 0,302 & 0,638 & 0,659 & 0,262 \\
\hline SAT1 & 0,081 & 0,249 & 0,391 & 0,127 & 0,129 & 0,165 & 0,114 & 0,054 & 0,109 & 0,166 & 0,168 & 0,102 & 0,163 & 0,146 & 0,101 & 0,196 & 0,273 & 0,140 & 0,780 & 0,200 & 0,174 & 0,117 \\
\hline SAT2 & 0,110 & 0,325 & 0,411 & 0,140 & 0,132 & 0,171 & 0,177 & 0,136 & 0,176 & 0,181 & 0,208 & 0,165 & 0,251 & 0,154 & 0,152 & 0,206 & 0,306 & 0,223 & 0,825 & 0,243 & 0,217 & 0,172 \\
\hline SAT3 & 0 & 0 & 0 & 0,1 & 0 , & 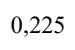 & 0 & 0 , & 0 & 2 & 0,120 & 0 , & 0,193 & 0,210 & 0,175 & 6 & 0,384 & 0,274 & 62 & 0,304 & 0,232 & 087 \\
\hline SAT & 0 & 0,339 & 0,385 & 0 & 0,131 & 0,296 & c & 0 , & 0,146 & 0,230 & 1 & 0,1 & ברט & 0,222 & . & 7 & 0,358 & 0,276 & 3 & 0,310 & 0,281 & 107 \\
\hline SAT5 & 0,126 & 0,231 & 0,20 & 0,01 & 0,14 & 0,086 & 0 , & 0, & 0 , & 0 & 0,090 & 0 , & 0,0 & 0, & 0, & 0,143 & 9 & 77 & 7 & 12 & 0,146 & 048 \\
\hline SAT6 & 0,157 & 0,435 & 0,440 & 0,1 & 0,191 & 0,211 & 0,202 & 0,119 & 0,210 & 0,209 & 0,201 & 0,234 & 0,271 & 0,217 & 0,232 & 0,251 & 0,377 & 0,306 & 0,871 & 0,324 & 0,242 & 0,160 \\
\hline SST1 & 0,304 & 0,593 & 0,404 & 0,317 & 0,203 & 0,297 & 0,629 & 0,389 & 0,656 & 0,372 & 0,384 & 0,538 & 0,536 & 0,259 & 0,618 & 0,210 & 0,704 & 0,659 & 0,320 & 0,858 & 0,498 & 0,341 \\
\hline SST2 & 0,194 & 0,415 & 0,374 & 0,269 & 0,129 & 0,271 & 0,375 & 0,226 & 0,379 & 0,245 & 0,278 & 0,346 & 0,340 & 0,243 & 0,350 & 0,154 & 0,594 & 0,693 & 0,333 & 0,811 & 0,672 & 0,185 \\
\hline SST3 & 0,141 & 0,326 & 0,289 & 0,249 & 0,119 & 281 & 0,370 & 0,179 & 0,313 &, 253 & 0,217 & 0,287 & 0,274 & 0,267 & 0,310 & 0,111 & 0,478 & 0,557 & 0,162 & 0,749 & 0,603 & 0,175 \\
\hline TRP1 & 0076 & 0,315 & 0,365 & 0,307 & 0,060 & 258 & 0,371 & 0237 & 0,351 & 234 & 0,170 & 0,354 & 0300 & 0,218 & 0,318 & 0,071 & 0,499 & 5 & 0,277 & 0,602 & 8 & 136 \\
\hline TRP2 & 0,090 & 0,302 & 0,368 & 0,249 & 0,04 & 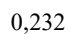 & 3 & 0,205 & 0,320 & 5 & 0,185 & 0,326 & 3 & 0,154 & 0, & 5 & 0,519 & 643 & 8 & 0,656 & 909 & ,130 \\
\hline TRP3 & 0,151 & 0,422 & 0,246 & 0,321 & 0,086 & 0,257 & 0,383 & 0,291 & 0,406 & 0,275 & 0,246 & 0,364 & 0,303 & 0,258 & 0,385 & 0,167 & 0,565 & 0,639 & 0,244 & 0,665 & 0,881 & 0,194 \\
\hline FAT1 & 0,173 & 0,595 & 0,268 & 0,299 & 0,068 & 0,285 & 0,885 & 0,647 & 0,742 & 0,318 & 0,301 & 0,732 & 0,627 & 0,239 & 0,744 & 0,030 & 0,603 & 0,520 & 0,218 & 0,544 & 0,350 & 0,271 \\
\hline FAT2 & 0,150 & 0,460 & 0,138 & 0,200 & $-0,003$ & 0,170 & 0,707 & 0,421 & 0,598 & 0,224 & 0,167 & 0,532 & 0,508 & 0,106 & 0,535 & 0,026 & 0,376 & 0,368 & 0,034 & 0,334 & 0,245 & 0,130 \\
\hline
\end{tabular}




\begin{tabular}{|c|c|c|c|c|c|c|c|c|c|c|c|c|c|c|c|c|c|c|c|c|c|c|}
\hline FAT3 & 0,162 & 0,500 & 0,295 & 0,299 & 0,079 & 0,226 & 0,764 & 0,426 & 0,567 & 0,298 & 0,274 & 0,578 & 0,440 & 0,251 & 0,563 & 0,024 & 0,546 & 0,494 & 0,241 & 0,458 & 0,332 & 0,292 \\
\hline FAT4 & 0,260 & 0,511 & 0,234 & 0,341 & 0,095 & 0,309 & 0,841 & 0,477 & 0,700 & 0,386 & 0,395 & 0,597 & 0,588 & 0,265 & 0,617 & 0,082 & 0,584 & 0,553 & 0,169 & 0,543 & 0,384 & 0,353 \\
\hline FAT5 & 0,135 & 0,478 & 0,243 & 0,338 & 0,026 & 0,265 & 0,860 & 0,568 & 0,665 & 0,326 & 0,225 & 0,677 & 0,591 & 0,246 & 0,654 & $-0,015$ & 0,569 & 0,464 & 0,161 & 0,477 & 0,341 & 0,218 \\
\hline IDF1 & 0,184 & 0,430 & 0,160 & 0,219 & 0,080 & 0,158 & 0,584 & 0,909 & 0,563 & 0,217 & 0,223 & 0,587 & 0,515 & 0,110 & 0,573 & 0,063 & 0,420 & 0,411 & 0,066 & 0,317 & 0,212 & 0,203 \\
\hline IDF2 & 0,134 & 0,384 & 0,193 & 0,190 & 0,068 & 0,155 & 0,616 & $\mathbf{0 , 8 5 7}$ & 0,514 & 0,141 & 0,182 & 0,583 & 0,484 & 0,095 & 0,532 & 0,030 & 0,412 & 0,381 & 0,122 & 0,350 & 0,302 & 0,138 \\
\hline IDF3 & 0,170 & 0,378 & 0,167 & 0,230 & 0,093 & 0,183 & 0,420 & $\mathbf{0 , 8 1 4}$ & 0,462 & 0,171 & 0,204 & 0,559 & 0,460 & 0,173 & 0,531 & 0,047 & 0,332 & 0,348 & 0,106 & 0,247 & 0,198 & 0,148 \\
\hline DF4 & 0,202 & 0,396 & 0,134 & 0,215 & 0,113 & 0,072 & 0,431 & 0,764 & 0,481 & 0,181 & 0,235 & 0,492 & 0,401 & 0,119 & 0,507 & 0,104 & 0,295 & 0,257 & 0,115 & 0,201 & 0,172 & 0,210 \\
\hline DF5 & 0,130 & 0,390 & 0,173 & 0,143 & $-0,003$ & 0,078 & 0,580 & $\mathbf{0 , 8 5 6}$ & 0,532 & 0,162 & 0,155 & 0,568 & 0,432 & 0,068 & 0,542 & 0,001 & 0,387 & 0,423 & 0,022 & 0,317 & 0,264 & 0,127 \\
\hline IDT1 & 0,158 & 0,490 & 0,213 & 0,259 & 0,006 & 0,181 & 0,655 & 0,486 & 0,825 & 0,290 & 0,238 & 0,542 & 0,587 & 0,235 & 0,630 & 0,049 & 0,516 & 0,498 & 0,206 & 0,447 & 0,375 & 0,203 \\
\hline DT2 & 0,283 & 0,489 & 0,351 & 0,371 & 0,156 & 0,294 & 0,675 & 0,452 & 0,813 & 0,401 & 0,386 & 0,586 & 0,606 & 0,339 & 0,563 & 0,189 & 0,602 & 0,583 & 0,244 & 0,581 & 0,463 & 0,379 \\
\hline TT3 & 0,231 & 0,616 & 0,248 & 0,270 & 0,099 & 0,187 & 0,71 & 0,618 & 0,900 & 0,315 & 0,337 & 0,671 & 0,646 & 0,213 & 0,725 & 0,137 & 0,543 & 0,513 & 0,208 & 0,482 & 0,300 & 0,292 \\
\hline IDT4 & 0,244 & 0,562 & 0,197 & 0,288 & 0,042 & 0,215 & 0,689 & 0,521 & 0,854 & 0,351 & 0,353 & 0,587 & 0,635 & 0,204 & 0,697 & 0,150 & 0,536 & 0,522 & 0,147 & 0,516 & 0,330 & 0,363 \\
\hline IDT6 & 0,193 & 0,560 & 0,197 & 0,247 & 0,092 & 0,214 & 0,705 & 0,507 & 0,866 & 0,291 & 0,305 & 0,594 & 0,612 & 0,165 & 0,685 & 0,084 & 0,529 & 0,441 & 0,107 & 0,447 & 0,243 & 0,275 \\
\hline LAT2 & 0,061 & 0,375 & 0,204 & 0,353 & 0,011 & 0,307 & 0,509 & 0,368 & 0,412 & 0,293 & 0,242 & 0,471 & 0,468 & 0,270 & 0,650 & $-0,022$ & 0,438 & 0,388 & 0,203 & 0,401 & 0,305 & 0,208 \\
\hline LAT3 & $-0,016$ & 0,223 & $-0,004$ & $-0,045$ & $-0,041$ & $-0,029$ & 0,175 & 0,119 & 0,137 & $-0,066$ & $-0,001$ & 0,156 & 0,134 & $-0,012$ & 0,290 & $-0,014$ & 0,163 & 0,105 & $-0,015$ & 0,181 & 0,111 & $-0,044$ \\
\hline LAT4 & 0,021 & 0,216 & $-0,004$ & $-0,048$ & $-0,018$ & $-0,037$ & 0,120 & 0,075 & 0,135 & $-0,041$ & 0,050 & 0,109 & 0,166 & $-0,045$ & 0,280 & 0,063 & 0,127 & 0,162 & 0,017 & 0,199 & 0,153 & 0,026 \\
\hline LAT5 & 0,173 & 0,564 & 0,237 & 0,335 & 0,052 & 0,269 & 0,632 & 0,494 & 0,602 & 0,337 & 0,265 & 0,619 & 0,618 & 0,248 & 0,773 & 0,038 & 0,571 & 0,476 & 0,220 & 0,438 & 0,353 & 0,216 \\
\hline AT6 & 0,185 & 0,551 & 0,234 & 0,289 & 0,072 & 0,219 & 0,61 & 0,499 & 0,668 & 0,329 & 0,278 & 0,638 & 0,621 & 0,199 & 0,817 & 0,088 & 0,445 & 0,440 & 0,158 & 0,440 & 0,263 & 0,256 \\
\hline AT7 & 122 & 0,428 & 0,162 & 0,235 & 0,067 & 0,145 & 0,4 &, 5 & 0,443 & 0,213 & 0,162 & 0,554 & 0,436 & 0,162 & 0,698 & 0,069 & 0,336 & 0,283 & 0,108 & 0,263 & 0,138 & 0,140 \\
\hline AT8 & 0,250 & 0,566 & 0,185 & 0,288 & 0,106 & 0,193 & 0,68 & 0,5 & 0,768 & 0,322 & 0,329 & 0,617 & 0,632 & 0,226 & 0,818 & 0,104 & 0,509 & 0,501 & 0,172 & 0,487 & 0,304 & 0,290 \\
\hline CM1 & 0,240 & 0,513 & 0,333 & 0,332 & 0,273 & 0,277 & 0,597 & 0,519 & 0,502 & 0,292 & 0,358 & 0,739 & 0,513 & 0,255 & 0,557 & 0,142 & 0,501 & 0,457 & 0,257 & 0,493 & 0,346 & 0,316 \\
\hline LCM10 & 0,171 & 0,297 & 0,172 & 0,193 & 0,068 & 0,079 & 0,420 & 0,410 & 0,472 & 0,173 & 0,190 & 0,592 & 0,505 & 0,163 & 0,427 & 0,108 & 0,339 & 0,288 & 0,087 & 0,277 & 0,187 & 0,158 \\
\hline LCM2 & 0,232 & 0,430 & 0,242 & 0,278 & 0,138 & 0,248 & 0,595 & 0,539 & 0,519 & 0,278 & 0,309 & 0,700 & 0,471 & 0,254 & 0,575 & 0,131 & 0,414 & 0,373 & 0,208 & 0,390 & 0,269 & 0,255 \\
\hline LCM3 & 0,124 & 0,339 & 0,258 & 0,242 & 0,127 & 0,255 & 0,445 & 0,383 & 0,340 & 0,184 & 0,170 & 0,664 & 0,350 & 0,223 & 0,444 & 0,042 & 0,342 & 0,324 & 0,147 & 0,288 & 0,242 & 0,159 \\
\hline LCM4 & 0,166 & 0,316 & 0,273 & 0,176 & 0,168 & 0,0 & 0,400 & 0,482 & 0,420 & 0,18 & 0,151 & 0,651 & 0,408 & 0,173 & 0,465 & 0,086 & 0,293 & 0,227 & 0,095 & 0,260 &, 102 & 0,144 \\
\hline LCM5 & 0,066 & 0,326 & 0,191 & 0,252 & 0,002 & 0,2 & 0,5 & 0,379 & 0,424 & 0,2 & 0,200 & 0,663 & 0,515 & 0,183 & 0,464 & $-0,021$ & 0,366 & 0,333 & 0,045 & 0,263 & ,318 & 0,212 \\
\hline LCM6 & 0,130 & 0,346 & 0,132 & 0,298 & 0,012 & 0,289 & 0,449 & 0,262 & 0,409 & 0,307 & 0,174 & 0,503 & 0,433 & 0,268 & 0,474 & 0,005 & 0,423 & 0,354 & 0,025 & 0,299 & 0,317 & 0,199 \\
\hline LCM7 & 0,196 & 0,447 & 0,323 & 0,245 & 0,113 & 0,128 & 0,609 & 0,534 & 0,565 & 0,279 & 0,217 & 0,761 & 0,476 & 0,220 & 0,611 & 0,110 & 0,423 & 0,362 & 0,188 & 0,365 & 0,222 & 0,220 \\
\hline LCM8 & 0,066 & 0,433 & 0,225 & 0,215 & 0,006 & 0,191 & 0,625 & 0,473 & 0,546 & 0,215 & 0,174 & 0,743 & 0,610 & 0,149 & 0,552 & $-0,040$ & 0,445 & 0,379 & 0,099 & 0,314 & 0,264 & 0,186 \\
\hline LCM9 & 0,144 & 0,327 & 0,234 & 0,206 & 0,050 & 0,155 & 0,331 & 0,334 & 0,373 & 0,169 & 0,186 & 0,525 & 0,511 & 0,145 & 0,392 & 0,062 & 0,325 & 0,237 & 0,222 & 0,287 & 0,268 & 0,131 \\
\hline
\end{tabular}




\begin{tabular}{|c|c|c|c|c|c|c|c|c|c|c|c|c|c|c|c|c|c|c|c|c|c|c|}
\hline $\mathrm{C} 1$ & 174 &, 509 & 0,326 & 0,349 & 0,070 & 0,338 & 0,634 & 0,516 & 0,614 & 0,349 & 0,238 & 0,635 & 0,816 & 0,267 & 0,678 & 0,012 & 0,536 & 0,491 & 0,211 & 0,440 & 0,308 & 0,223 \\
\hline $\mathrm{EC} 2$ & 215 & 0,464 & 0,269 & 0,322 & 0,093 & 0,417 & 0,458 & 0,344 & 0,423 & 0,328 & 0,317 & 0,431 & 0,683 & 0,226 & 0,516 & 0,057 & 0,377 & 0,347 & 0,251 & 0,330 &, 225 & 0,267 \\
\hline EC6 & 0,228 & 0,453 & 0,231 & 0,263 & 0,135 & 0,204 & 0,492 & 0,409 & 0,538 & 0,251 & 0,290 & 0,607 & 0,756 & 0,254 & 0,513 & 0,070 & 0,421 & 0,355 & 0,136 & 0,348 & ,216 & 0,276 \\
\hline EC7 & 0,184 & 0,462 & 0,215 & 0,273 & 0,059 & 0,216 & 0,532 & 0,392 & 0,628 & 0,282 & 0,291 & 0,589 & 0,775 & 0,239 & 0,582 & 0,108 & 0,493 & 0,382 & 0,261 & 0,433 & 0,277 & 0,282 \\
\hline LEC8 & 0,260 & 0,297 & 0,213 & 0,327 & 0,122 & 0,220 & 0,411 & 0,374 & 0,504 & 0,340 & 0,257 & 0,452 & 0,722 & 0,263 & 0,458 & 0,136 & 0,381 & 0,320 & 0,161 & 0,283 & 0,213 & 0,32 \\
\hline ATT1 & 0,713 & 0,048 & 0,062 & 0,320 & 0,701 & 0,301 & $-0,037$ & $-0,038$ & 0,019 & 0,366 & 0,429 & $-0,007$ & 0,039 & 0,408 & $-0,045$ & 0,687 & 0,006 & 0,071 & 0,090 & 0,083 & 0,054 & 0,417 \\
\hline ATT2 & 0,857 & 0,233 & 0,146 & 0,526 & 0,599 & 0,380 & 0,207 & 0,153 & 0,267 & 0,576 & 0,620 & 0,234 & 0,288 & 0,544 & 0,210 & 0,592 & 0,215 & 0,247 & 0,137 & 0,276 & 0,094 & 0,612 \\
\hline ATT3 & 0,885 & 0,229 & 0,169 & 0,516 & 0,570 & 0,387 & 0,227 & 0,217 & 0,216 & 0,602 & 0,718 & 0,243 & 0,241 & 0,500 & 0,210 & 0,548 & 0,225 & 0,271 & 0,072 & 0,272 & 0,104 & 0,729 \\
\hline ATT4 & 0,890 & 0,193 & 0,135 & 0,516 & 0,708 & 0,383 & 0,189 & 0,167 & 0,232 & 0,575 & 0,723 & 0,186 & 0,248 & 0,507 & 0,173 & 0,635 & 0,218 & 0,198 & 0,147 & 0,214 & 0,067 & 0,683 \\
\hline ATT5 & 0,897 & 0,291 & 0,192 & 0,559 & 0,620 & 0,403 & 0,271 & 0,259 & 0,322 & 0,603 & 0,757 & 0,291 & 0,309 & 0,514 & 0,279 & 0,611 & 0,236 & 0,288 & 0,124 & 0,287 & 0,174 & 0,702 \\
\hline PERCEP1 & 0,556 & 0,225 & 0,117 & 0,342 & 0,519 & 0,307 & 0,087 & 0,087 & 0,199 & 0,396 & 0,534 & 0,128 & 0,148 & 0,367 & 0,143 & 0,792 & 0,206 & 0,160 & 0,262 & 0,206 & 0,115 & 0,495 \\
\hline PERCEP2 & 0,607 & 0,160 & 0,142 & 0,274 & 0,633 & 0,223 & 0,008 & 0,051 & 0,096 & 0,300 & 0,451 & 0,112 & 0,111 & 0,340 & 0,040 & 0,833 & 0,119 & 0,160 & 0,219 & 0,159 & 0,128 & 0,405 \\
\hline PERCEP3 & 0,428 & 0,154 & 0,080 & 0,139 & 0,567 & 0,087 & 0,049 & 0,038 & 0,135 & 0,168 & 0,269 & 0,058 & 0,011 & 0,262 & 0,085 & 0,707 & 0,055 & 0,067 & 0,160 & 0,139 & 0,090 & 0,232 \\
\hline PERCEP4 & 0,636 & 0,123 & 0,129 & 0,340 & 0,684 & 0,229 & $-0,013$ & 0,013 & 0,039 & 0,371 & 0,431 & 0,022 & 0,026 & 0,400 & 0,002 & 0,820 & 0,052 & 0,093 & 0,166 & 0,144 & 0,089 & 0,412 \\
\hline PERCEP5 & 0,147 & $-0,048$ & $-0,044$ & 0,088 & 0,148 & 0,101 & $-0,039$ & $-0,041$ & 0,019 & 0,077 & 0,105 & $-0,033$ & $-0,023$ & 0,108 & $-0,068$ & 0,269 & 0,000 & 0,011 & 0,046 & 0,002 & 0,067 & 0,134 \\
\hline CONG1 & 0,597 & 0 & 0,144 & 0 & 0,821 & 3 & 0,089 & 0,119 & 0,136 & 0,37 & 0,504 & 0,162 & 0,1 & 0,437 & 0,073 & 0,616 & 0,146 & 0,169 & 0,113 & 0,258 & 109 & 0,473 \\
\hline$\sqrt{3}$ & 0,55 & 0,125 & 0,197 & 0,399 & ,790 & 0,348 & 0,053 & 0,06 & 0,062 & 0,407 & 0,475 & 0,131 & 0,110 & 0,414 & 0,059 & 0,545 & 169 & 0,114 & 0,192 & 0,121 & 0,047 & 0,448 \\
\hline CONG3 & 0,572 & 0,103 & 0,157 & 0,371 & 0,808 & 0,359 & 0,000 & 0,010 & $-0,021$ & 0,357 & 0,446 & 0,062 & 0,012 & 0,429 & 0,005 & 0,616 & 0,080 & 0,095 & 0,194 & 0,130 & 0,088 & $0,40 c$ \\
\hline CONG4 & 0,401 & 0,176 & 0,060 & 0,147 & 0,515 & 0,083 & 0,117 & 0,073 & 0,125 & 0,227 & 0,286 & 0,065 & 0,125 & 0,160 & 0,102 & 0,375 & 0,045 & $-0,004$ & 0,041 & 0,010 & $-0,046$ & 0,295 \\
\hline CONG5 & 0,687 & 0,154 & 0,194 & 0,328 & 0,855 & 0,248 & 0,033 & 0,056 & 0,084 & 0,414 & 0,503 & 0,149 & 0,134 & 0,425 & 0,079 & 0,696 & 0,109 & 0,087 & 0,129 & 0,167 & 0,042 & 0,466 \\
\hline BaB1 & 0,481 & 0,252 & 0,218 & 0,905 & 0,315 & 0,591 & 0,350 & 0,237 & 0,333 & 0,748 & 0,567 & 0,384 & 0,398 & 0,712 & 0,375 & 0,266 & 0,378 & 0,383 & 0,211 & 0,345 & 0,327 & 0,598 \\
\hline BaB2 & 0,528 & 0,309 & 0,221 & 0,940 & 0,394 & 0,678 & 0,331 & 0,219 & 0,302 & 0,732 & 0,587 & 0,350 & 0,388 & 0,779 & 0,356 & 0,339 & 0,387 & 0,336 & 0,160 & 0,331 & 0,309 & 0,629 \\
\hline $\mathrm{BaB}$ & 0,602 & 0,280 & 0,211 & 0,930 & 0,461 & 0,664 & 0,347 & 0,213 & 0,301 & 0,801 & 0,634 & 0,337 & 0,359 & 0,758 & 0,340 & 0,393 & 0,396 & 0,338 & 0,163 & 0,296 & 0,274 & 0,666 \\
\hline tat & 0,553 & 0,272 & 0,190 & 0,95 & 0,407 & 0,684 & 0,339 & 0,211 & 0,325 & 0,794 & 0,606 & 0,325 & 0,376 & 0,801 & 0,340 & 0,336 & 0,404 & 0,368 & 0,154 & 0,327 & 0,313 & 0,656 \\
\hline ISP_N & 0,450 & 0,294 & 0,199 & $0,70\}$ & 0,340 & 0,904 & 0,346 & 0,158 & 0,307 & 0,730 & 0,502 & 0,321 & 0,352 & 0,674 & 0,294 & 0,290 & 0,390 & 0,353 & 0,211 & 0,328 & 0,284 & 0,542 \\
\hline DISP_M2 & 0,146 & 0,097 & 0,150 & 0,334 & 0,097 & 0,519 & 0,140 & 0,062 & 0,091 & 0,304 & 0,194 & 0,163 & 0,217 & 0,358 & 0,127 & 0,044 & 0,242 & 0,232 & 0,139 & 0,195 & 0,151 & 0,215 \\
\hline DISP_M3 & 0,387 & 0,222 & 0,196 & 0,569 & 0,324 & $\mathbf{0 , 8 5 6}$ & 0,194 & 0,104 & 0,156 & 0,592 & 0,422 & 0,164 & 0,275 & 0,579 & 0,203 & 0,259 & 0,306 & 0,269 & 0,246 & 0,254 & 0,192 & 0,445 \\
\hline DISP_M4 & 0,385 & 0,316 & 0,234 & 0,625 & 0,331 & 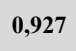 & 0,307 & 0,165 & 0,248 & 0,646 & 0,451 & 0,297 & 0,362 & 0,640 & 0,286 & 0,272 & 0,419 & 0,362 & 0,259 & 0,347 & 0,267 & 0,49 \\
\hline ISP_M5 & 35 & 059 &, 003 & 118 & 0,042 & 30 & $-0,027$ & $-0,051$ &, 111 &, 11 & 044 & 0,058 & $-0,004$ & 0,108 & $-0,095$ & $-0,070$ & 0,057 & 0,083 & $-0,013$ & 0,058 & 10 & 0,00 \\
\hline NTER1 & 0,743 & 0,328 & 0,212 & 0,589 & 0,550 & 0,465 & 0,294 & 0,203 & 0,344 & 0,626 & 944 &, 302 & 0,338 & 0,529 & ,318 & 0,506 & 0,329 & 0,318 & 0,161 & 0,323 & 0,180 & 8 \\
\hline
\end{tabular}




\begin{tabular}{|c|c|c|c|c|c|c|c|c|c|c|c|c|c|c|c|c|c|c|c|c|c|c|}
\hline TER2 & 706 & 0,348 & ,195 & 0,581 & 0,524 &, 460 & 0,305 & 0,191 & 0,344 & 0,621 & 0,938 & 0,308 & 0,334 & 0,553 & 0,292 & 0,502 & 0,346 & 0,284 & 0,185 & 0,315 & 0,181 & 0,840 \\
\hline TTER3 &, 714 & 0,372 & 0,228 & 0,615 & 0,525 & 0,478 & 0,356 & 0,240 & 0,380 & 0,642 & 0,933 & 0,325 & 0,366 & 0,567 & 0,341 & 0,496 & 0,385 & 0,372 & 0,213 & 0,400 & 0,243 & 0,825 \\
\hline TER4 &, 725 & 0,354 & 0,183 & 0,607 & 0,583 & 0,453 & 0,310 & 0,242 & 0,357 & 0,609 & 0,906 & 0,301 & 0,328 & 0,546 & 0,299 & 0,522 & 0,351 & 0,353 & 0,188 & 0,352 & 0,233 & 0,789 \\
\hline NT_COMP1 & 0,617 & 0,323 & 0,256 & 0,762 & 0,451 & 0,652 & 0,370 & 0,204 & 0,403 & 0,944 & 0,682 & 0,347 & 0,403 & 0,709 & 0,365 & 0,378 & 0,413 & 0,356 & 0,224 & 0,345 & 0,244 & 0,740 \\
\hline INT_COMP2 & 0,588 & 0,305 & 0,227 & 0,752 & 0,427 & 0,670 & 0,357 & 0,194 & 0,381 & 0,915 & 0,580 & 0,308 & 0,371 & 0,703 & 0,340 & 0,381 & 0,411 & 0,400 & 0,207 & 0,369 & 0,278 & 0,655 \\
\hline INT_COMP3 & 0,584 & 0,294 & 0,272 & 0,774 & 0,415 & 0,683 & 0,366 & 0,198 & 0,328 & 0,924 & 0,599 & 0,362 & 0,398 & 0,744 & 0,372 & 0,369 & 0,412 & 0,355 & 0,204 & 0,344 & 0,261 & 0,662 \\
\hline INT_COMP4 & 0,563 & 0,305 & 0,253 & 0,788 & 0,422 & 0,690 & 0,360 & 0,178 & 0,349 & 0,918 & 0,610 & 0,345 & 0,390 & 0,729 & 0,371 & 0,337 & 0,440 & 0,349 & 0,257 & 0,345 & 0,247 & 0,673 \\
\hline INT_COMP5 & 0,394 & 0,051 & 0,041 & 0,209 & 0,250 & 0,143 & 0,034 & 0,046 & 0,053 & 0,338 & 0,268 & $-0,005$ & 0,004 & 0,229 & $-0,001$ & 0,220 & $-0,029$ & 0,027 & $-0,037$ & $-0,027$ & $-0,047$ & 0,358 \\
\hline PAT1 & 0,435 & 0,257 & 0,236 & 0,785 & 0,313 & 0,671 & 0,293 & 0,139 & 0,280 & 0,709 & 0,489 & 0,324 & 0,342 & 0,872 & 0,314 & 0,250 & 0,367 & 0,317 & 0,199 & 0,281 & 0,271 & 0,539 \\
\hline AT2 & 0,604 & 0,198 & 0,144 & 0,589 & 0,558 & 0,425 & 0,187 & 0,092 & 0,205 & 0,624 & 0,535 & 0,202 & 0,255 & 0,764 & 0,156 & 0,454 & 0,222 & 0,156 & 0,170 & 0,156 & 0,033 & 0,599 \\
\hline AT & 456 & 0,179 & 0,201 & 0,581 & 0,464 & 0,521 & 0,177 & 0,075 & 0,167 & 0,555 & 0,43 & 0,234 & 0,195 & 0,839 & 0,151 & 0,395 & 0,294 & 0,261 & 0,241 & 0,258 & 0,171 & 0,444 \\
\hline AT & 0,493 & 0,168 & 0,124 & 0,689 & 0,452 & 0,691 & 0,191 & 0,071 & 0,165 & 0,656 & 0,482 & 0,212 & 0,249 & 0,869 & 0,192 & 0,417 & 0,307 & 0,280 & 0,185 & 0,260 & 0,196 & 0,525 \\
\hline AT5 &, 504 & 0,278 & 0,224 & 0,809 & 0,387 & 0,658 & 0,311 & 0,172 & 0,321 & 0,741 & 0,566 & 0,334 & 0,348 & 0,906 & 0,344 & 0,371 & 0,425 & 0,399 & 0,211 & 0,364 & 0,303 & 0,615 \\
\hline SO1 & 725 & 0,286 & 0,195 & 0,653 & 0,520 & 0,504 & 0,285 & 0,162 & 0,342 & 0,711 & 0,840 & 0,276 & 0,342 & 0,608 & 0,267 & 0,495 & 0,312 & 0,298 & 0,146 & 0,276 & 0,145 & 0,972 \\
\hline 502 & 737 & 0,296 & 0,206 & 0,677 & 0,524 & 538 & 0,31 & 0,210 & 0,353 & 0,744 & 0,852 & 0,317 & 0,351 & 0,646 & 0,284 & 0,487 & 0,355 & 0,331 & 0,160 & 0,298 & 0,182 & 0,962 \\
\hline USO3 & 0,717 & 0,306 & 0,203 & 0,657 & 0,548 & 0,514 & 0,320 & 0,194 & 0,345 & 0,710 & 0,876 & 0,305 & 0,352 & 0,610 & 0,288 & 0,481 & 0,337 & 0,307 & 0,151 & 0,303 & 0,173 & 0,969 \\
\hline
\end{tabular}

Nota1: Em destaque $=$ cargas fatoriais

Nota2: As nomenclaturas das colunas foram suprimidas para facilitar a montagem da tabela. Assim: (1) atitude; (2) avaliação pessoal; (3) avaliação dos outros; (4) boca a boca; (5) congruência; (6) disposição a pagar mais; (7) fanatismo; (8) envolvimento com o futebol; (9) identificação time; (10) intenção de compra; (11) interesse; (12) lealdade comportamental; (13) lealdade conativa; (14) lealdade ao patrocinador; (15) lealdade atitudinal; (16) percepção; (17) pertencimento; (18) reconhecimento pessoal; (19) satisfação; (20) sentimento de status; (21) tratamento pessoal; e 


\subsection{Modelo final ajustado}

Para chegar ao modelo teórico final proposto neste trabalho, foram necessárias sete rodadas de análise, pois havia a a necessidade de retirar os itens um a um para mensuração do modelo. Assim, a cada rodada, eram analisadas a validade convergente, a discriminante e a confiabilidade do modelo. A apresentação das rodadas não foi inserida neste trabalho, pois optou-se por apresentar o modelo inicial proposto (seção anterior) e o modelo final já ajustado, resultando na Tabela 40 .

Tabela 40: Modelo de Mensuração final: Avaliação dos itens utilizados

\begin{tabular}{|c|c|c|c|c|c|}
\hline Construto & Indicadores & $\begin{array}{c}\text { Carga } \\
\text { Fatorial }(\beta)\end{array}$ & $\alpha$ & $\rho$ & AVE \\
\hline \multirow{4}{*}{ Avaliação Pessoal } & AVP1 & 0,680 & \multirow{4}{*}{0,804} & \multirow{4}{*}{0,873} & \multirow{4}{*}{0,634} \\
\hline & AVP3 & 0,880 & & & \\
\hline & AVP4 & 0,836 & & & \\
\hline & AVP5 & 0,774 & & & \\
\hline \multirow{3}{*}{$\begin{array}{l}\text { Percepção da Avaliação } \\
\text { dos Outros }\end{array}$} & PAO1 & 0,839 & \multirow{3}{*}{0,766} & \multirow{3}{*}{0,864} & \multirow{3}{*}{0,68} \\
\hline & $\mathrm{PAO} 2$ & 0,808 & & & \\
\hline & $\mathrm{PAO} 3$ & 0,826 & & & \\
\hline \multirow{3}{*}{ Pertencimento } & PERTENC1 & 0,787 & \multirow{3}{*}{0,759} & \multirow{3}{*}{0,861} & \multirow{3}{*}{0,675} \\
\hline & PERTENC2 & 0,865 & & & \\
\hline & PERTENC3 & 0,811 & & & \\
\hline \multirow{4}{*}{ Reconhecimento Pessoal } & $\mathrm{RCP} 1$ & 0,841 & \multirow{4}{*}{0,867} & \multirow{4}{*}{0,91} & \multirow{4}{*}{0,717} \\
\hline & $\mathrm{RCP} 2$ & 0,879 & & & \\
\hline & $\mathrm{RCP} 3$ & 0,879 & & & \\
\hline & $\mathrm{RCP} 4$ & 0,783 & & & \\
\hline \multirow{5}{*}{ Satisfação } & SAT1 & 0,792 & \multirow{5}{*}{0,895} & \multirow{5}{*}{0,922} & \multirow{5}{*}{0,703} \\
\hline & SAT2 & 0,836 & & & \\
\hline & SAT3 & 0,881 & & & \\
\hline & SAT4 & 0,825 & & & \\
\hline & SAT6 & 0,856 & & & \\
\hline \multirow{3}{*}{ Sentimento de Status } & SST1 & 0,853 & \multirow{3}{*}{0,751} & \multirow{3}{*}{0,856} & \multirow{3}{*}{0,665} \\
\hline & SST2 & 0,808 & & & \\
\hline & SST3 & 0,785 & & & \\
\hline \multirow{3}{*}{ Tratamento Preferencial } & TRP1 & 0,902 & \multirow{3}{*}{0,879} & \multirow{3}{*}{0,925} & \multirow{3}{*}{0,805} \\
\hline & TRP2 & 0,912 & & & \\
\hline & TRP3 & 0,878 & & & \\
\hline \multirow{4}{*}{ Fanatismo } & FAT1 & 0,898 & \multirow{4}{*}{0,866} & & \\
\hline & FAT3 & 0,787 & & 0909 & 0714 \\
\hline & FAT4 & 0,835 & & , & 0,114 \\
\hline & FAT5 & 0,858 & & & \\
\hline Envolvimento com o & IDF1 & 0,902 & 0003 & 0928 & 0721 \\
\hline Futebol & IDF2 & 0,853 & 0,903 & $0,9<8$ & $0, / \angle 1$ \\
\hline
\end{tabular}




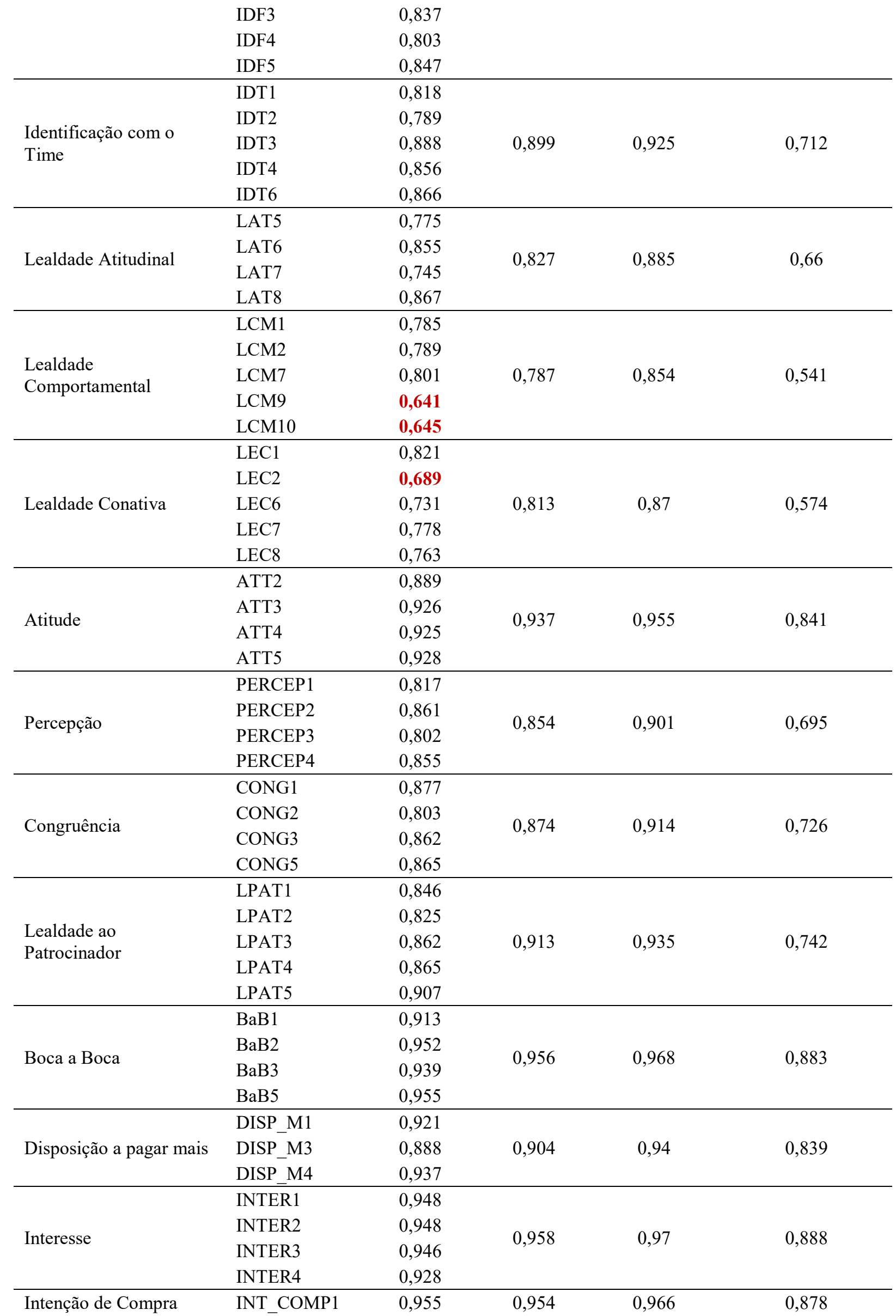




\begin{tabular}{llllll} 
& INT_COMP2 & 0,918 & & & \\
& INT_COMP3 & 0,938 & & & \\
& INT_COMP4 & 0,936 & & & \\
Uso & USO1 & 0,975 & & \\
& USO2 & 0,966 & 0,97 & \\
\hline
\end{tabular}

Nota: $\alpha=$ Cronbach's alpha; $\rho=$ Composite Reliability; $\mathrm{AVE}=$ Average Variance Extracted.

Valores em negrito $=$ valores abaixo do valor mínimo recomendado.

Fonte: Desenvolvido pelo autor por meio do SmartPLS (3.2.6)

$\mathrm{Na}$ dimensão relacionada à identificação com o time, o item SAT5 foi excluído, devido à carga fatorial abaixo do recomendando. Com sua exclusão, o construto satisfação alcançou validade convergente e confiabilidade adequada. Foi necessário ajustar o construto fanatismo, apesar de ele mesmo ter alcançado validade convergente e confiabilidade, para que o modelo pudesse ter validade discriminante. Assim, foi retirado o item FAT2.

$\mathrm{Na}$ dimensão lealdade ao time, para ter o modelo com validade discriminante, convergente e confiabilidade adequados, foram retirados os itens LAT2, LAT3, LAT4, LCM,3, LCM4, LCM5, LCM6 e LCM8. Os itens PERCEP5 e CONG4 também foram excluídos da dimensão lealdade ao patrocinador.

Por fim, nas dimensões que mensuram o resultado da lealdade ao patrocinador (outputs) foram retirados os itens DISP_M2, DISP_M3 e INT_COMP5. Todos os demais itens foram mantidos e o modelo, conforme exposto na Tabela 40, foi considerado validado e confiável.

$\mathrm{Na}$ Tabela 41, são apresentados os resultados, no nível do construto (critério de Fornell-Larcker), para validade discriminante. Todos os construtos, após os ajustes, atenderam ao critério estabelecido. Também são apresentadas, as cargas cruzadas. Todas os construtos tiveram suas cargas fatoriais superiores às cargas fatoriais cruzadas, atendendo, desta forma, ao critério proposto por Chin (1998).

Importante ressaltar que os itens AVP1, LCM3 e LCM7 foram mantidos, apesar da carga fatorial abaixo do mínimo recomendando. Essa opção se deu utilizando as recomendações de Hair (2014) que diz ser aceitável cargas fatoriais entre 0,6 e 0,7 desde que os outros indicadores estejam dentro do mínimo recomendado. Essa exigência foi satisfeita em todos os construtos. 
Tabela 41: Estatística descritiva e correlações - Amostra pré-teste ajuste final

\begin{tabular}{|c|c|c|c|c|c|c|c|c|c|c|c|c|c|c|c|c|c|c|c|c|c|c|c|}
\hline$\#$ & Construto & 1 & 2 & 3 & 4 & 5 & 6 & 7 & 8 & 9 & 10 & 11 & 12 & 13 & 14 & 15 & 16 & 17 & 18 & 19 & 20 & 21 & 22 \\
\hline 1 & Atitude & 0,917 & & & & & & & & & & & & & & & & & & & & & \\
\hline 2 & Avaliação Pessoal & 0,302 & 0,796 & & & & & & & & & & & & & & & & & & & & \\
\hline 3 & Avaliação dos Outros & 0,249 & 0,442 & 0,824 & & & & & & & & & & & & & & & & & & & \\
\hline 4 & Boca a Boca & 0,648 & 0,264 & 0,228 & 0,940 & & & & & & & & & & & & & & & & & & \\
\hline 5 & Congruência & 0,758 & 0,225 & 0,227 & 0,517 & 0,852 & & & & & & & & & & & & & & & & & \\
\hline 6 & Dispo. Pagar Mais & 0,499 & 0,264 & 0,212 & 0,743 & 0,423 & 0,916 & & & & & & & & & & & & & & & & \\
\hline 7 & Fanatismo & 0,313 & 0,635 & 0,295 & 0,346 & 0,166 & 0,295 & 0,845 & & & & & & & & & & & & & & & \\
\hline 8 & Identificação Futebol & 0,201 & 0,485 & 0,191 & 0,203 & 0,108 & 0,126 & 0,612 & 0,849 & & & & & & & & & & & & & & \\
\hline 9 & Identificação Time & 0,320 & 0,676 & 0,292 & 0,287 & 0,168 & 0,219 & 0,782 & 0,588 & 0,844 & & & & & & & & & & & & & \\
\hline 10 & Intenção de Compra & 0,696 & 0,284 & 0,267 & 0,841 & 0,539 & 0,759 & 0,357 & 0,171 & 0,322 & 0,937 & & & & & & & & & & & & \\
\hline 11 & Interesse & 0,820 & 0,332 & 0,248 & 0,649 & 0,637 & 0,512 & 0,352 & 0,229 & 0,336 & 0,691 & 0,942 & & & & & & & & & & & \\
\hline 12 & L. Comportamental & 0,349 & 0,607 & 0,357 & 0,339 & 0,275 & 0,263 & 0,701 & 0,650 & 0,684 & 0,346 & 0,367 & 0,736 & & & & & & & & & & \\
\hline 13 & Lealdade Conativa & 0,404 & 0,627 & 0,357 & 0,409 & 0,235 & 0,360 & 0,666 & 0,509 & 0,710 & 0,434 & 0,403 & 0,662 & 0,758 & & & & & & & & & \\
\hline 14 & L. ao Patrocinador & 0,659 & 0,239 & 0,238 & 0,855 & 0,577 & 0,730 & 0,302 & 0,131 & 0,255 & 0,822 & 0,647 & 0,315 & 0,377 & 0,861 & & & & & & & & \\
\hline 15 & Lealdade Atitudinal & 0,307 & 0,692 & 0,283 & 0,325 & 0,163 & 0,258 & 0,728 & 0,606 & 0,785 & 0,354 & 0,326 & 0,722 & 0,722 & 0,282 & 0,812 & & & & & & & \\
\hline 16 & Percepção & 0,705 & 0,247 & 0,186 & 0,455 & 0,783 & 0,364 & 0,149 & 0,101 & 0,208 & 0,482 & 0,593 & 0,277 & 0,224 & 0,515 & 0,204 & 0,834 & & & & & & \\
\hline 17 & Pertencimento & 0,281 & 0,617 & 0,405 & 0,357 & 0,223 & 0,355 & 0,675 & 0,455 & 0,650 & 0,364 & 0,318 & 0,576 & 0,602 & 0,336 & 0,580 & 0,195 & 0,821 & & & & & \\
\hline 18 & Reconhecimento P. & 0,246 & 0,541 & 0,390 & 0,312 & 0,176 & 0,320 & 0,567 & 0,428 & 0,573 & 0,317 & 0,275 & 0,498 & 0,488 & 0,294 & 0,502 & 0,150 & 0,761 & 0,847 & & & & \\
\hline 19 & Satisfação & 0,148 & 0,420 & 0,425 & 0,142 & 0,179 & 0,197 & 0,259 & 0,122 & 0,243 & 0,177 & 0,186 & 0,270 & 0,300 & 0,170 & 0,223 & 0,205 & 0,374 & 0,289 & 0,838 & & & \\
\hline 20 & Sentimento de Status & 0,303 & 0,570 & 0,448 & 0,321 & 0,243 & 0,328 & 0,592 & 0,357 & 0,591 & 0,335 & 0,308 & 0,526 & 0,518 & 0,299 & 0,515 & 0,224 & 0,760 & 0,791 & 0,302 & 0,816 & & \\
\hline 21 & Tratamento Pref. & 0,155 & 0,362 & 0,355 & 0,284 & 0,130 & 0,257 & 0,404 & 0,244 & 0,391 & 0,248 & 0,190 & 0,360 & 0,327 & 0,235 & 0,324 & 0,142 & 0,609 & 0,721 & 0,251 & 0,735 & 0,897 & \\
\hline 22 & Uso & 0,824 & 0,296 & 0,226 & 0,713 & 0,632 & 0,579 & 0,354 & 0,210 & 0,335 & 0,775 & 0,884 & 0,350 & 0,423 & 0,707 & 0,307 & 0,565 & 0,314 & 0,267 & 0,142 & 0,288 & 0,164 & 0,971 \\
\hline
\end{tabular}

Nota 1: Os valores na diagonal (negrito) são a raiz quadrada dos valores de AVE. As entradas fora da diagonal são correlações entre os construtos. A raiz quadrada do AVE maior do que os coeficientes de correlação indica validade discriminante suficiente.

Fonte: Desenvolvido pelo autor por meio do SmartPLS (3.2.6) 


\subsection{Avaliação do Modelo de Estrutral (structural model assessment) - Amostra pré- teste}

Conforme apresentado na avaliação do modelo de mensuração, os construtos deste trabalho foram avaliados quanto à validade convergente, à validade discriminante e à confiabilidade. As avaliações seguiram as recomendações de Bagozzi e Yi (1998), Chin e Newsted (1999) e Hair et al. (2014), entre outros. Todas as medições apresentaram cargas padronizadas $(\gamma)$ significantes, isto é, acima de 0,6.

Quanto à validade convergente no nível das variáveis latentes, observa-se que a variância média extraída (AVE) apresentou valores acima de 0,5. Estes valores são considerados adequados. Em relação a confiabilidade, os valores do Alfa de Cronbach $(\alpha)$ ficaram acima de 0,7 , bem como confiabilidade composta $(\rho)$, que são valores considerados adequados. Também é observado que a raiz quadrada da variância média extraída, valores na diagonal, foi maior do que os valores fora da diagonal (correlações), demonstrando a validade discriminante da escala utilizada.

Iniciamos a análise do modelo estrutural (Figura 24) verificando a validade preditiva do modelo. Esta pode ser calculada por meio do indicador Stone-Geisser de relevância preditiva $\left(\mathrm{Q}^{2}\right)$. O software SmartPls (versão 3.2.6) calcula, por meio de um processo conhecido como blindfolding, o índice $\mathrm{Q}^{2}$. Em modelos reflexivos, analisados por meio da SEM, valores de $\mathrm{Q}^{2}$ acima de zero indicam que o modelo tem relevância preditiva para a variável dependente em questão. Por outro lado, valores iguais ou menores que zero indicam que não há relevância preditiva no modelo. Como medida relativa, adotaremos os valores de 0,02, 0,15 e 0, 35 como efeito pequeno, médio e grande, respectivamente (Hair et al. (2014),).

Para calculo do índice $\mathrm{Q}^{2}$ adotamos, conforme sugerido por Hair et al. (2014), a construct crossvalidated redundancy como técnica estatística. O valor de D (distância) considerado foi de sete. Desta forma, em conjunto com a analise do $\mathrm{R}^{2}$, podemos avaliar a precisão preditiva do modelo. 
Figura 24: Modelo Estrutural

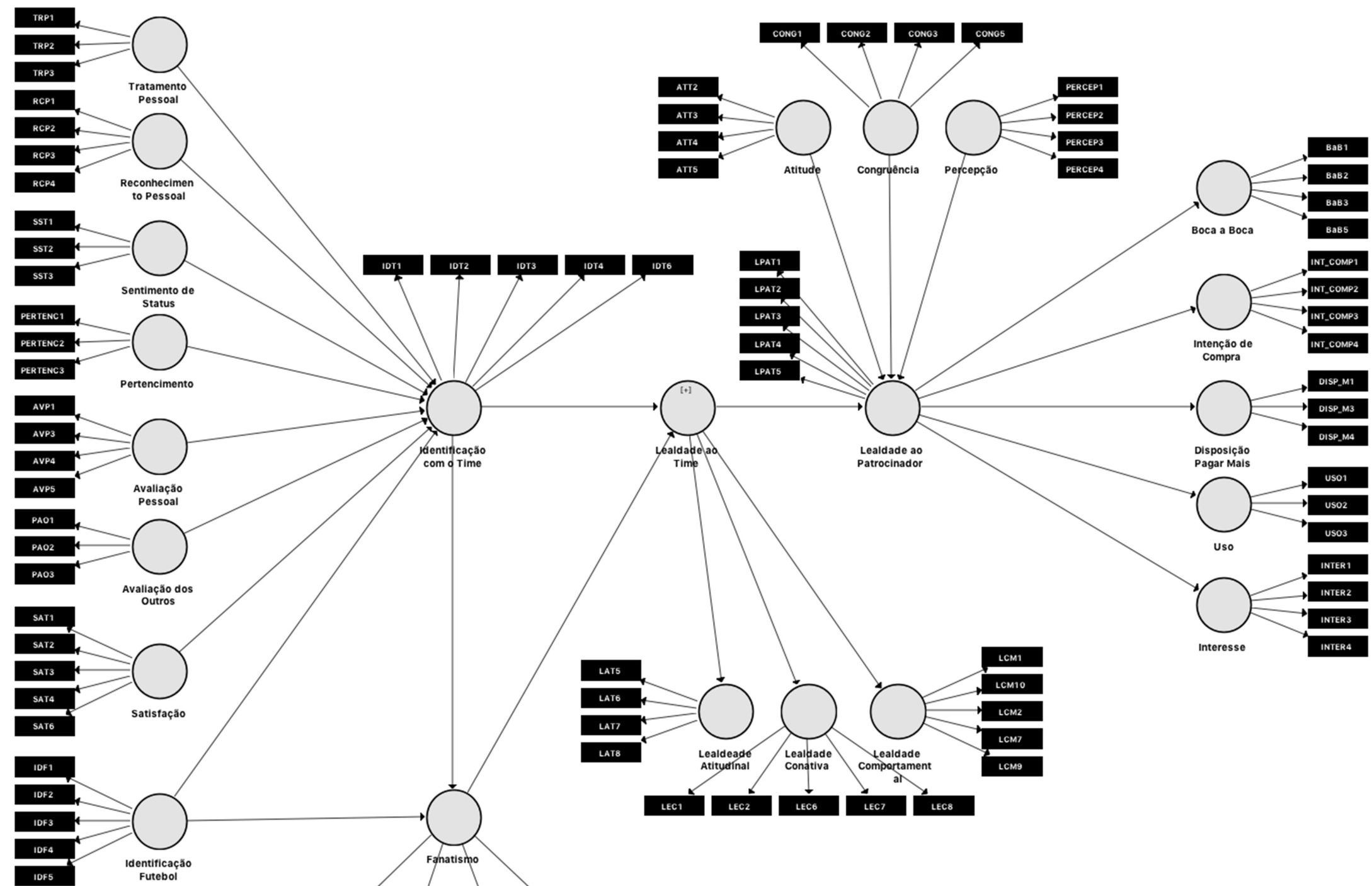

Fonte: Desenvolvido pelo autor por meio do SmartPLS (3.2.6) 
Tabela 42: Validade Preditiva $\left(Q^{2}\right)$ - Indicador de Stone-Geisser - Modelo pré-teste

\begin{tabular}{lcc}
\hline \multicolumn{1}{c}{ Construto } & $\mathbf{R}^{2}$ & $\mathbf{Q}^{2}$ \\
\hline Identificação com o Time & 0,634 & 0,417 \\
Lealdade ao patrocinador & 0,464 & 0,268 \\
Lealdade ao time & 0,723 & 0,304 \\
Fanatismo & 0,650 & 0,446 \\
Boca a Boca & 0,731 & 0,547 \\
Disposição Pagar Mais & 0,533 & 0,375 \\
Intenção de Compra & 0,677 & 0,489 \\
Interesse & 0,419 & 0,283 \\
Uso & 0,500 & 0,365 \\
\hline
\end{tabular}

Fonte: Desenvolvido pelo autor por meio do SmartPLS (3.2.6)

Analisando a Tabela 42, podemos inferir que o modelo teórico proposto tem uma relevância preditiva bastante alta. Todos os construtos analisados apresentaram $\mathrm{Q}^{2}$ superiores a 0,26, o que, dentro dos critérios adotados neste trabalho, pode ser considerado bastante satisfatório. $\mathrm{O} \mathrm{R}^{2}$, por sua vez, teve todos os valores acima de 0,419 , o que também é considerado extremamente satisfatório.

Apesar de $\mathrm{R}^{2}$ e $\mathrm{Q}^{2}$ serem satisfatórios devemos ter atenção para uma questão bastante importante: o efeito de multicolinearidade do modelo. Assim, utilizamos o software SmartPls (versão 3.2.6) na opção PLS algorithmg Hair et al. (2014), ,com ponderação path weighting scheme, para analisar a Variance Inflation Factor (VIF) e o tamanho do efeito $\left(f^{2}\right)$.

Primeiramente, analisamos, por meio do Variance Inflation Factor (VIF), se há problema de multicolinearidade no modelo proposto. A multicolinearidade é um problema no ajuste do modelo que pode causar impactos na estimativa dos parâmetros. A ausência de multicolinearidade é uma das premissas para estabelecer um modelo de regressão múltipla correto (Hair et al. (2014).

Ou seja, a multicolinearidade refere-se à correlação entre duas variáveis explicativas ou entre uma delas e as demais incluídas na equação de um modelo. Significa que a multicolinearidade ocorre quando, por exemplo, duas variáveis x1 e x2 medem aproximadamente a mesma coisa, ou seja, a correlação entre elas é quase perfeita. 
Figura 25: Modelo Estrutural (Cargas Fatoriais e R2)

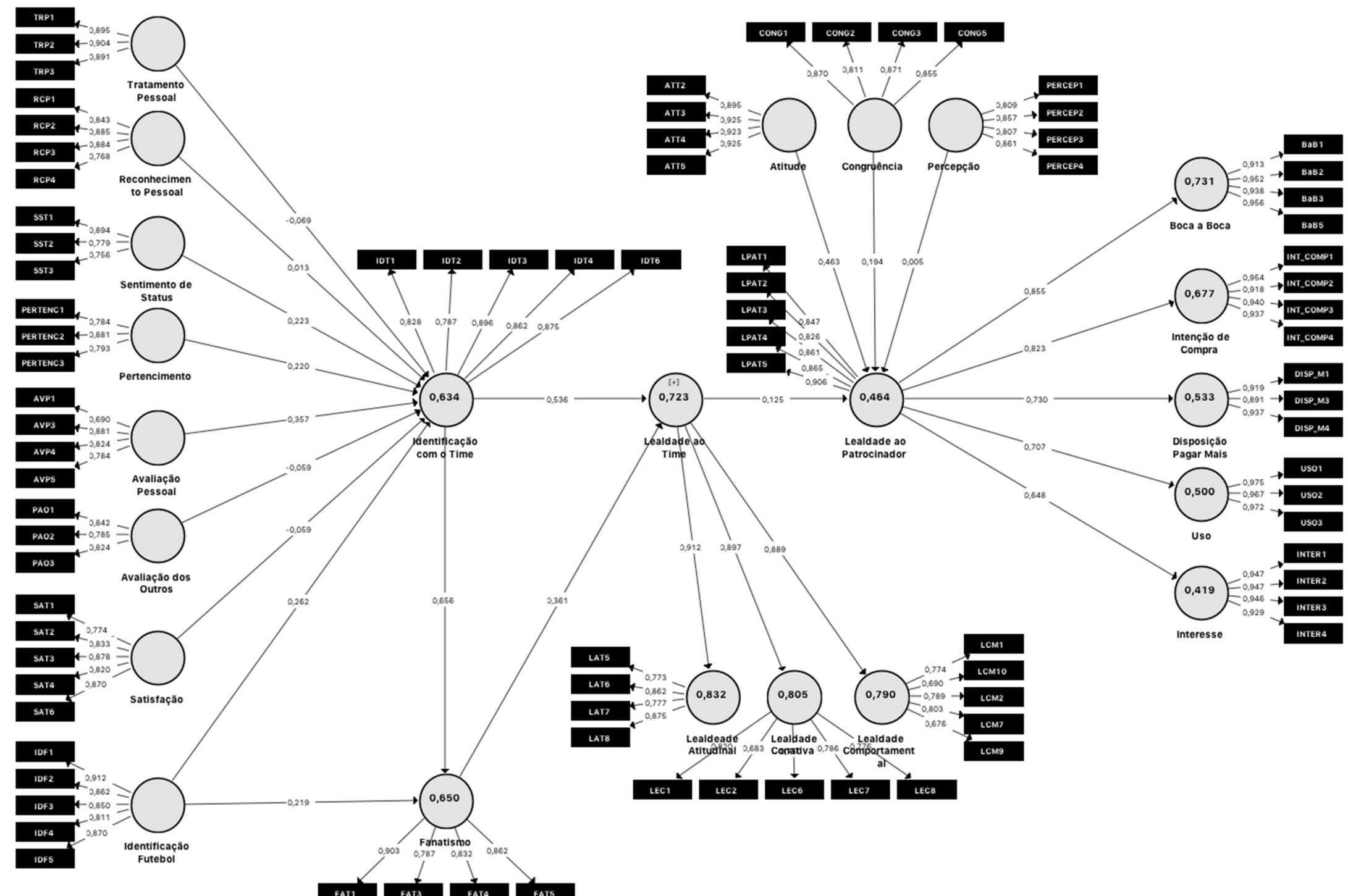

Fonte: Desenvolvido pelo autor por meio do SmartPLS (3.2.6) 
Tabela 43: Analise da Multicolinearidade (VIF) Modelo pré-teste

\begin{tabular}{|c|c|c|c|}
\hline Preditora & $\begin{array}{c}\text { Identificação com o } \\
\text { time }\end{array}$ & Lealdade ao time & $\begin{array}{c}\text { Lealdade ao } \\
\text { patrocinador }\end{array}$ \\
\hline Avaliação Pessoal & 2,064 & & \\
\hline Avaliação dos Outros & 1,525 & & \\
\hline Envolvimento com Futebol & 1,432 & & \\
\hline Pertencimento & 3,193 & & \\
\hline Reconhecimento Pessoal & 3,632 & & \\
\hline Satisfação & 1,486 & & \\
\hline Sentimento de Status & 3,610 & & \\
\hline Tratamento Preferencial & 2,298 & & \\
\hline Atitude & & & 2,475 \\
\hline Congruência & & & 2,892 \\
\hline Lealdade ao time & & & 1,317 \\
\hline Percepção & & & 2,709 \\
\hline Fanatismo & & 2,665 & \\
\hline Identificação com o time & & 2,665 & \\
\hline
\end{tabular}

Fonte: Desenvolvido pelo autor por meio do SmartPLS (3.2.6)

Os resultados do VIF (Tabela 41) nas variáveis dependente encontram-se abaixo de 5. Desta forma, podemos afirmar que não há problemas de multicolinearidade no modelo teórico proposto. Com isso, damos sequência à pesquisa, analisando o tamanho do efeito $\left(f^{2}\right)$ em nosso modelo.

O tamanho do efeito $\left(f^{2}\right)$ é um índice para medir o impacto de uma variável preditora específica em uma variável endógena. $\mathrm{O}$ índice $f^{2}$ mede a alteração no valor $\mathrm{R}^{2}$ quando uma variável exógena especificada é retirada do modelo. Desta forma, pode-se avaliar o tamanho do impacto do construto preditor omitindo nos valores de $\mathrm{R}^{2}$ dos construtos endógenos.

Tabela 44: tamanho do efeito $\left(f^{2}\right)$ - Modelo pré-teste

\begin{tabular}{lcc}
\hline \multicolumn{1}{c}{ Preditora } & $\begin{array}{c}\text { Identificação com o } \\
\text { time }\end{array}$ & $\begin{array}{c}\text { Lealdade ao time } \\
\text { Lealdade ao } \\
\text { patrocinador }\end{array}$ \\
\hline Avaliação Pessoal & 0,103 \\
Avaliação dos Outros & 0,004 \\
Envolvimento com Futebol & 0,177 \\
Pertencimento & 0,033 \\
Reconhecimento Pessoal & 0,007
\end{tabular}




\begin{tabular}{llc} 
Satisfação & 0,011 & \\
Sentimento de Status & 0,031 & \\
Tratamento Preferencial & 0,010 & 0,095 \\
\hline Atitude & & 0,033 \\
Congruência & 0,064 \\
Lealdade ao time & 0,001 \\
Percepção & 0,186 & \\
\hline Fanatismo & 0,352 & \\
Identificação com o time & & \\
\hline
\end{tabular}

Fonte: Desenvolvido pelo autor por meio do SmartPLS (3.2.6)

Para análise do índice $f^{2}$, consideramos, como já dissemos, o valor de 0,02 como efeito pequeno, 0,15 como efeito médio e 0,35 como efeito grande (Cohen, 1988). Com base nesses valores de referência, podemos definir o tamanho dos efeitos para uma variável exógena específica sobre uma variável endógena.

Na Tabela 44 podemos observar que os efeitos individuais das variáveis exógenas são múltiplos. Na identificação com o time, o envolvimento com o futebol e a avaliação pessoal apresentam os índices mais elevados. Já no construto lealdade ao time, tanto fanatismo quanto identificação com o time apresentam índices expressivos. Por fim, a lealdade ao patrocinador apresenta a atitude e a lealdade ao time como principais variáveis.

\subsection{Teste de hipóteses}

Os índices propostos na Tabela 28: path coefficents e $\mathrm{R}^{2}$ são usados, respectivamente, para avaliar as relações causais do modelo e o quanto as variáveis dependentes são explicadas pelo modelo estrutural. Por fim, utilizamos o t-valor (Ho: $\lambda=0 ; \Gamma=0$. $[\mathrm{p}<0,05]$ ) para testar as hipóteses ora apresentadas e analisar os resultados do modelo estrutural proposto.

Como no modelo de mensuração, utilizamos o software SmartPls (versão 3.2.6) para análise. Adotamos a opção Bootstrappingping com reamostragem de 5.000 (Hair, 2014) para calcular o t-valor. Os dados a seguir são apresentados por grupos: (1) identificação como time; (2) lealdade ao time; (3) lealdade ao patrocinador; e (4) outputs da lealdade ao patrocinador. Porém, ressalte-se que o modelo foi avaliado como um todo e a separação foi adotada apenas para tornar mais fácil a interpretação dos dados. 
Os coeficientes estimados padronizados (path coefficients), valores $\mathrm{p}$ e $\mathrm{R}^{2}$ são apresentados na Tabela 45. Os coeficientes padronizados indicam o sinal e a força da relação entre os construtos, os valores " $p$ " informam a significância estatística da relação (t-valor) e os $\mathrm{R}^{2}$ demonstram o quanto da variabilidade da variável independente é explicada pelas preditoras.

$\mathrm{Na}$ dimensão identificação com o time, de maneira geral, todas as relações entre os construtos $(\gamma)$ foram positivas. Porém nem todas foram significativas. As relações positivas e significativas com identificação com o time foram alcançadas por meio dos construtos satisfação $(\gamma=0,223 ; p<0,05)$; pertencimento $(\gamma=0,220 ; p<0,01)$; avaliação pessoal $(\gamma=$ 0,357; $p<0,01)$; e envolvimento com o futebol $(\gamma=0,262 ; p<0,01)$. O R $\mathrm{R}^{2}(0,634)$ e o $\mathrm{Q}^{2}$ $(0,417)$ permitem inferir que que as variáveis preditoras, propostas em nosso modelo teórico, explicam em alto grau o construto dependente.

No construto fanatismo, tanto a variável envolvimento com o futebol $(\gamma=0,219 ; p<$ $0,01)$, quanto a identificação com o time $(\gamma=0,656 ; p<0,01)$ tiveram impacto positivo e significante no construto. $\mathrm{O} \mathrm{R}^{2}(0,650)$ e o $\mathrm{Q}^{2}(0,446)$ também mostram o grau alto de poder explicativo das variáveis. Isso significa que o fanatismo é uma variável consequente da identificação com o time, e, não mais um grau da identificação.

Identificação com o time $(\gamma=0,536 ; p<0,01)$ e fanatismo $(\gamma=0,361 ; p<0,01)$ afetaram positivamente e de forma significante o construto lealdade ao time. As duas variáveis antecedentes da lealdade ao time também possuem alto poder de explicação no construto. $\mathrm{O} \mathrm{R}^{2}(0,723)$ e o $\mathrm{Q}^{2}(0,304)$ permitem fazer essa inferência.

Esses resultados apresentados mostram que, conforme proposto neste trabalho, a identificação com o time, o fanatismo e a lealdade ao time são construtos distintos. Evidenciase, também, que identificação e fanatismo são antecedentes bastante robustos da lealdade ao time. 
Tabela 45: Coeficientes do modelo estrutural - Amostra pré-teste

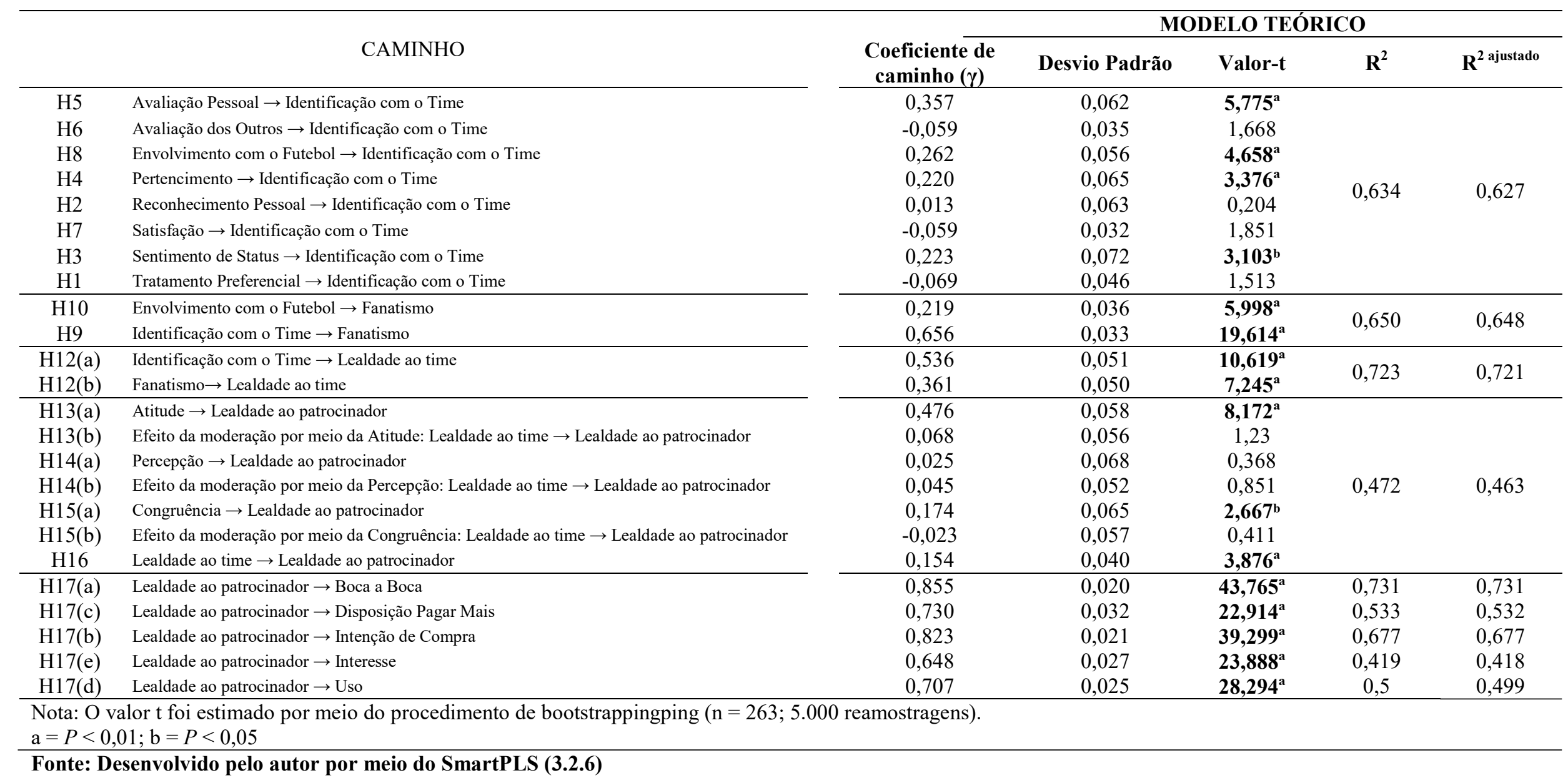


A lealdade ao patrocinador foi analisada por meio das variáveis atitude, percepção e congruência, que são três variáveis, conforme revisão da literatura, bastante utilizadas para medir o construto proposto. Porém, neste trabalho, apenas atitude $(\gamma=0,476 ; p<0,01) \mathrm{e}$ congruência $(\gamma=0,174 ; p<0,05)$ apresentaram resultado positivo e significativo. Além dessas variáveis, propusemos que a lealdade ao time também afetaria a relação com a lealdade ao patrocinador. Esse impacto, se positivo e significante, é o primeiro passo para validar a proposição central desta pesquisa: a lealdade ao time pode ser transferida ao patrocinador. Desta forma, por meio dos resultados analisados $(\gamma=0,154 ; p<0,01)$, podemos verificar que existe transferência da lealdade ao time para a marca patrocinadora. $\mathrm{O} \mathrm{R}^{2}(0,464)$ e o $\mathrm{Q}^{2}$ $(0,268)$ também corroboram com a hipótese apresentada.

A análise do efeito da moderação da relação lealdade ao time e lealdade ao patrocinador, por meio das variáveis atitude, congruência e percepção, fortalecem a ideia central proposta nesta pesquisa. A relação de moderação, apesar de positiva, não é significativa, o que permite dizer que o caminho direto é mais forte que o caminho moderado.

Os índices adotados por este trabalho para validar a lealdade ao patrocinador também desempenharam bons resultados. Todos os índices foram impactados de forma positiva e significativa pela variável lealdade ao time. Os $\mathrm{R}^{2}$ e o $\mathrm{Q}^{2}$ também apresentaram resultados iguais ou superiores a 0,500 e 0,418 , respectivamente. Ou seja, acima do valor adotado $(0,35)$ para validar o efeito das variáveis como grande.

\subsection{Mediação}

Após os testes de hipóteses verificamos a existência de efeito mediador das variáveis apresentadas neste trabalho. Para tanto, conforme apresentado na Tabela 28, optamos por verificar a mediação por meio da análise da Variância Explicada (VAF - Variance Accounted For), apresentado em Hair et al. (2014),

O objetivo de analisar a mediação é avaliar se a variável mediadora provê a mediação entre uma variável independente X e uma variável dependente Y. No caso deste trabalho, buscou-se verificar as mediações possíveis apresentadas no modelo teórico: (a) mediação da identificação com o time na relação entre os construtos antecedentes da identificação com o time e a lealdade ao time; (b) mediação do fanatismo na relação entre a identificação com o time e a lealdade ao time; (c) mediação da lealdade ao time na relação entre fanatismo e 
identificação com o time com a lealdade ao patrocinador; e (d) mediação da relação entre a lealdade ao time e a lealdade ao patrocinador por meio da atitude, congruência e percepção.

Tabela 46: Teste de mediação

\begin{tabular}{|c|c|c|}
\hline CAMINHO & VAF (\%) & RESULTADO \\
\hline $\begin{array}{l}\text { Tratamento Preferencial } \rightarrow \text { Identificação com o Time } \\
\text { Identificação com o Time } \rightarrow \text { Lealdade ao time }\end{array}$ & $\begin{array}{l}\text { Efeito direto é não } \\
\text { significante }\end{array}$ & - \\
\hline $\begin{array}{l}\text { Pertencimento } \rightarrow \text { Identificação com o Time } \rightarrow \text { Lealdade ao } \\
\text { time }\end{array}$ & 39,26 & Mediação parcial \\
\hline $\begin{array}{l}\text { Reconhecimento Pessoal } \rightarrow \text { Identificação com o Time } \rightarrow \\
\text { Lealdade ao time }\end{array}$ & $\begin{array}{l}\text { Efeito direto é não } \\
\text { significante }\end{array}$ & - \\
\hline $\begin{array}{l}\text { Sentimento de Status } \rightarrow \text { Identificação com o Time } \rightarrow \text { Lealdade } \\
\text { ao time }\end{array}$ & 47,19 & Mediação parcial \\
\hline $\begin{array}{l}\text { Avaliação Pessoal } \rightarrow \text { Identificação com o Time } \rightarrow \text { Lealdade ao } \\
\text { time }\end{array}$ & 32,99 & Mediação parcial \\
\hline $\begin{array}{l}\text { Avaliação dos Outros } \rightarrow \text { Identificação com o Time } \rightarrow \text { Lealdade } \\
\text { ao time }\end{array}$ & $\begin{array}{l}\text { Efeito direto é não } \\
\text { significante }\end{array}$ & - \\
\hline Satisfação $\rightarrow$ Identificação com o Time $\rightarrow$ Lealdade ao time & $\begin{array}{l}\text { Efeito direto é não } \\
\text { significante }\end{array}$ & - \\
\hline $\begin{array}{l}\text { Envolvimento com o Futebol } \rightarrow \text { Identificação com o Time } \rightarrow \\
\text { Lealdade ao time }\end{array}$ & 41,87 & Mediação parcial \\
\hline Identificação com o Time $\rightarrow$ Fanatismo $\rightarrow$ Lealdade ao time & 23,45 & Mediação parcial \\
\hline Fanatismo $\rightarrow$ Lealdade ao time $\rightarrow$ Lealdade ao patrocinador & 27,56 & Mediação parcial \\
\hline $\begin{array}{l}\text { Identificação com o Time } \rightarrow \text { Lealdade ao time } \rightarrow \text { Lealdade ao } \\
\text { patrocinador }\end{array}$ & 67,60 & Mediação parcial \\
\hline Lealdade ao time $\rightarrow$ Atitude $\rightarrow$ Lealdade ao patrocinador & 32,08 & Mediação parcial \\
\hline Lealdade ao time $\rightarrow$ Congruência $\rightarrow$ Lealdade ao patrocinador & 9,72 & Sem mediação \\
\hline Lealdade ao time $\rightarrow$ Percepção $\rightarrow$ Lealdade ao patrocinador & 1,68 & Sem mediação \\
\hline
\end{tabular}

Fonte: Desenvolvido pelo autor por meio do SmartPLS (3.2.6)

Na Tabela 47 apresentamos os resultados das hipóteses propostas nesta pesquisa. 
Tabela 47: Teste de Hipótese - Amostra pré-teste

H1. Tratamento preferencial tem efeito positivo e significante na identificação com o time.

Não confirmada

H2. Reconhecimento pessoal tem efeito positivo e significante na identificação com o time.

Não confirmada

H3. Sentimento de status de tem efeito positivo e significante na identificação com o time.

Confirmada

H4. Sentimento de Pertencimento tem efeito positivo e significante na identificação com o time.

Confirmada

H5. Avaliação Pessoal tem efeito positivo e significante na identificação com o time.

Confirmada

H6. Avaliação dos Outros tem efeito positivo e significante na identificação com o time.

Não confirmada

H7. Satisfação como o time tem efeito positivo e significante na identificação com o time.

Não confirmada

H8. Envolvimento com o Esporte com o tem efeito positivo e significante na identificação com o time.

Confirmada

H9. Identificação com o time tem efeito positivo e significante no fanatismo.

Confirmada

H10. Envolvimento com o futebol tem efeito positivo e significante no fanatismo.

Confirmada

H11. Identificação com o time, fanatismo e lealdade ao time são construtos distintos.

Confirmada

H12 a. Lealdade ao time é afetada positivamente e de forma significante por identificação com o time.

Confirmada

H12 b. Lealdade ao time é afetada positivamente e de forma significante por fanatismo.

Confirmada

H13 a. Atitude afetada positivamente e de forma significativa a lealdade ao patrocinador.

Confirmada

H13 b. Atitude não modera a relação entre lealdade ao time e lealdade ao patrocinador.

Confirmada

H13 c. Atitude não media a relação entre lealdade ao time e lealdade ao patrocinador

Confirmada parcialmente

H14 a. Congruência afetada positivamente e de forma significativa a lealdade ao patrocinador.

Confirmada

H14 b. Congruência não modera a relação entre lealdade ao time e lealdade ao patrocinador.

Confirmada

H14 c. Congruência não media a relação entre lealdade ao time e lealdade ao

Confirmada 
patrocinador

H15 a. Percepção afetada positivamente e de forma significativa a lealdade ao patrocinador.

Confirmada

Confirmada

H15 b. A Percepção não modera a relação entre lealdade ao time e lealdade ao patrocinador.

H15 c. Percepção não media a relação entre lealdade ao time e lealdade ao patrocinador

Confirmada

H16. Lealdade ao time terá efeito positivo e significativo na lealdade ao patrocinador.

Confirmada

H17 a. A transferência da lealdade ao patrocinador terá efeito positivo e significativo no boca a boca.

Confirmada

H17 b. A transferência da lealdade ao patrocinador terá efeito positivo e significativo na Intenção de compra.

Confirmada

H17 c. A transferência da lealdade ao patrocinador terá efeito positivo e significativo na disposição a pagar mais.

Confirmada

H17 d. A transferência da lealdade ao patrocinador terá efeito positivo e significativo no uso.

Confirmada

H17 e. A transferência da lealdade ao patrocinador terá efeito positivo e significativo no interesse.

Confirmada

\subsection{Breve resultado da amostra pré-teste}

A ideia por trás da análise da amostra pré-teste é testar o modelo teórico proposto e verificar se ele atende os requisitos mínimos exigidos para sua validação. Não se pretende, portanto, concluir algo, pois, nesta etapa, estamos apenas iniciando as análises. Assim, é fundamental comparar os resultados da amostra pré-teste com os resultados da amostra teste. Por isso, mesmo os construtos que não tiveram suas hipóteses confirmadas foram reaplicados na amostra final.

Essa etapa mostrou que a transferência da lealdade é possível. A confirmação das hipóteses $13 \mathrm{~b} ; 14 \mathrm{~b} ; 14 \mathrm{c} ; 15 \mathrm{~b} ; 15 \mathrm{c}$ e 16 permitem inferir que a lealdade ao time afeta a lealdade ao patrocinador. Importante ressaltar que a lealdade ao time apresentou coeficiente significativos em $p<0,01$, enquanto congruência apresentou em $p<0,05$. A atitude, conforme esperado, foi a variável como maior força no construto lealdade ao time. A revisão da literatura já mostrava esse caminho e neste aspecto este trabalho corrobora os diversos estudos já realizados. Porém, apesar de a hipótese H13c (efeito de mediação na relação 
lealdade ao time $\rightarrow$ lealdade ao patrocinador por meio da atitude) não ter sido confirmada, indicando que existe uma mediação parcial, deve-se ter em conta que a atitude é considerada pela maioria dos estudos revisados como a principal variável para mensurar a eficácia de um patrocínio.

$\mathrm{Na}$ dimensão da variável identificação com o time, quatro hipóteses não foram confirmadas: tratamento preferencial, reconhecimento pessoal, avaliação dos outros e satisfação não afetam a identificação com o time de forma significativa. Os testes de mediação corroboram esses resultados, ou seja, essas variáveis também não impactam na lealdade ao time. Porém três hipóteses relacionadas aos benefícios sociais/não financeiros foram confirmadas. Os valores de $\mathrm{R}^{2}$ e $\mathrm{Q}^{2}$ ainda mostram que as variáveis preditoras confirmadas possuem alto poder de explicação e predição do construto identificação com o time, o que significa que os benefícios sociais/não financeiros podem ser um caminho na identificação do torcedor com seu time.

A amostra pré-teste também serviu para ajustar alguns pontos importantes no questionário final desenvolvido. Notou-se que existem dois pontos importantes envolvendo a questão das marcas patrocinadoras. Primeiramente, há uma confusão grande por parte do torcedor quando perguntamos a respeito do patrocinador. Muitos torcedores acabam por responder a marca fornecedora de uniforme. Em segundo lugar, os patrocinadores dos times, quando da aplicação do questionário, foram identificados como fornecedores de serviços ou fabricantes de produtos de grande apelo para consumo por parte do torcedor.

Assim, com base nesses dois pontos, optamos por separar no questionário final os respondentes em dois grupos, de forma aleatória. Um grupo respondendo sobre a relação com a marca fornecedora de uniforme e o outro grupo respondendo a respeito do patrocinador. Consideramos que ambas as empresas são, ao final, patrocinadoras dos times e buscam resultados parecidos.

De forma a auxiliar na análise da transferência da lealdade, inserimos também duas novas questões. Ambas relacionadas a marcas fornecedoras de uniforme. Perguntamos aos torcedores qual a sua marca esportiva preferida. A pergunta era fechada e fornecia dez opções de escolha. Também para corroborar a análise da transferência, solicitamos que os torcedores avaliassem dez marcas esportivos em termos de preço, qualidade e design. Desta forma, na 
amostra final, foi possível verificar se existe relação na preferência à marca com o time de coração. Estas questões foram aplicadas a todos os participantes. 


\section{AMOSTRA TESTE}

Conforme exposto na Tabela 13 (p.123), este trabalho adotou os procedimentos sugeridos por Hinkin (1998) e DeVellis (2012) para desenvolvimento da escala de mensuração. A adaptação dos procedimentos resultou em nove passos para auxiliar essa construção. Assim, chegamos à amostra teste, de que trataremos neste capítulo.

A amostra teste é utilizada como forma de verificar a capacidade de replicação da escala. Desta forma, ela deve ser aplicada a uma nova amostra independente e analisada em seu modelo de mensuração e estrutural. O questionário aplicado conteve apenas as perguntadas já validadas na amostra pré-teste. Para aplicação do questionário, a amostra final utilizamos a plataforma Qualtrics (www.qualtrics.com).

\subsection{Teste de Normalidade}

Como já mencionado, a técnica SEM-PLS tem como premissa rodar modelos de equação estrutural que trabalhem com variáveis que possuam distribuição não normal. Novamente, conforme usado na amostra pré-teste, optamos por aplicar o teste KolmogorovSmirnov e Shapiro-Wilk em todas as variáveis indicadoras da pesquisa. Também verificamos, conforme proposto por Hau \& Marsh (2004), os índices de Skewness e Kurtosi. Para isso, adotou-se o software IBM SPSS Statistic (versão 20).

Assim, ao analisar os indicadores finais pelos testes propostos de normalidade, notamos que todas as variáveis atendem aos requisitos de uma distribuição não normal. Os testes de Kolmogorov-Smirnov e Shapiro-Wilk foram significativos $(\rho<0,001)$ para todos os indicadores. O nível de não normalidade (critério de Hau \& Marsh, 2004) também atendeu aos requisitos sugeridos.

\subsection{Perfil da amostra teste}

Assim como na análise da amostra pré-teste, utilizamos o software IBM SPSS Statistic (versão 20) para análise descritiva da amostra. Importante observar que, nesta etapa, não vimos necessidade de analisar novamente o tamanho e o poder da amostra. Tal decisão se 
deve ao fato de que, ao final da análise da amostra pré-teste, não alteramos os construtos e os caminhos hipotetizados a priori.

O questionário aplicado na amostra teste teve abrangência mais ampla que na amostra pré-teste. Assim, para aplicação do questionário utilizamos dois caminhos. O primeiro, por meio de um grupo de e-mails. O segundo por meio em redes sociais (facebook e twitter). No total, foram respondidos 1.245 questionários. Destes, $608(48,8 \%)$ responderam por meio dos e-mails enviados. As redes sociais contribuíram com 637 respondentes $(51,2 \%)$.

A maior parte dos respondentes foram oriundos do estado de São Paulo ( $n=640$ 51,4\%), seguidos do Rio de Janeiro $(n=120-9,6 \%)$ e de Minas Gerais ( $n=118-9,5 \%)$. Comumente, no Brasil, o esporte adota a visão de que os 12 maiores times (tradicionais) encontram-se nos estados de São Paulo, Rio de Janeiro, Minas Gerais e Rio Grande do Sul ${ }^{76}$. Os quatro estados, em nossa pesquisa, responderam por $74,8 \%$ da amostra final total. Com exceção dos estados de Rondônia e Roraima, todos os outros estados, incluindo a capital federal, foram pesquisados. Também tivemos doze respondentes que residem fora do Brasil (Tabela 48).

Tabela 48: Distribuição da amostra teste por Estado

\begin{tabular}{|c|c|c|}
\hline ESTADOS & FREQUENCIA & $\%$ \\
\hline Acre & 3 & 0,2 \\
\hline Alagoas & 4 & 0,3 \\
\hline Amapá & 2 & 0,2 \\
\hline Amazonas & 2 & 0,2 \\
\hline Bahia & 23 & 1,8 \\
\hline Ceará & 15 & 1,2 \\
\hline Distrito Federal & 16 & 1,3 \\
\hline Espírito Santo & 10 & 0,8 \\
\hline Goiás & 14 & 1,1 \\
\hline Maranhão & 1 & 0,1 \\
\hline Mato Grosso & 4 & 0,3 \\
\hline Mato Grosso do Sul & 3 & 0,2 \\
\hline Minas Gerais & 118 & 9,5 \\
\hline Pará & 2 & 0,2 \\
\hline
\end{tabular}


Paraíba

Paraná

Pernambuco

Piauí

Rio de Janeiro

Rio Grande do Norte

Rio Grande do Sul

$54 \quad 4,3$

Santa Catarina

São Paulo

640

51,4

Sergipe

4

Tocantins

2

Mora fora do Brasil

12

\begin{tabular}{lcc}
\hline Total & $\mathbf{1 . 2 1 8}$ & $\mathbf{9 7 , 8}$ \\
\hline Não responderam & 27 & 2,2 \\
\hline Total & $\mathbf{1 . 2 4 5}$ & $\mathbf{1 0 0}$ \\
\hline
\end{tabular}

Fonte: Desenvolvido pelo autor por meio do IBM SPSS Statistic (versão 20)

Os 12 times mais tradicionais do país responderam por $69,7 \%$ dos respondentes. 45 entrevistados responderam torcer para times que não se encontravam na lista apresentada. Foram citados, neste caso, times de menor expressão no Brasil, bem como times estrangeiros. A amostra teve, também, 17 torcedores que disseram não torcer para ninguém (direcionados para o fim do questionário) e três torcedores que declararam torcer para a seleção brasileira. 226 respondentes optaram por não responder essa questão e foram direcionados para o fim do questionário. No total, 26 times brasileiros, foram pesquisados neste trabalho.

Tabela 49: Distribuição da amostra teste por time de futebol

\begin{tabular}{|c|c|c|}
\hline ESTADOS & FREQUENCIA & $\%$ \\
\hline Atlético-MG & 52 & 4,2 \\
\hline Atlético-PR & 16 & 1,3 \\
\hline Avaí & 4 & 0,3 \\
\hline Bahia & 4 & 0,3 \\
\hline Botafogo & 31 & 2,5 \\
\hline Ceará & 3 & 0,2 \\
\hline Chapecoense & 2 & 0,2 \\
\hline Corinthians & 232 & 18,6 \\
\hline Coritiba & 16 & 1,3 \\
\hline Cruzeiro & 26 & 2,1 \\
\hline Figueirense & 2 & 0,2 \\
\hline Flamengo & 74 & 5,9 \\
\hline Fluminense & 31 & 2,5 \\
\hline Fortaleza & 4 & 0,3 \\
\hline Goiás & 5 & 0,4 \\
\hline Grêmio & 33 & 2,7 \\
\hline Internacional & 22 & 1,8 \\
\hline
\end{tabular}




\begin{tabular}{lcc} 
Náutico & 9 & 0,7 \\
Outro time & 45 & 3,6 \\
Palmeiras & 112 & 9 \\
Ponte Preta & 6 & 0,5 \\
Santa Cruz & 5 & 0,4 \\
Santos & 77 & 6,2 \\
São Paulo & 150 & 12 \\
Seleção brasileira & 3 & 0,2 \\
Sport & 9 & 0,7 \\
Vasco & 27 & 2,2 \\
Vitória & 2 & 0,2 \\
\hline Não torce & $\mathbf{1 7}$ & $\mathbf{1 , 4}$ \\
\hline Total & $\mathbf{1 0 1 9}$ & $\mathbf{8 1 , 8}$ \\
\hline Não responderam & 226 & 18,2 \\
\hline Total & $\mathbf{1 2 4 5}$ & $\mathbf{1 0 0}$ \\
\hline Font
\end{tabular}

Fonte: Desenvolvido pelo autor por meio do IBM SPSS Statistic (versão 20)

Do total de respondentes, 59,6\% (742) se declaram torcedores e 9,4\% (117) torcedoras. 386 respondentes (31\%) optaram por não responder à pergunta de gênero. A idade média dos entrevistados foi de 24,6 anos. $23,5 \%$ dos entrevistados possuem nível superior completo e 25,9\% possuem pós graduação (MBA, Pós, Mestrado ou Doutorado). 386 respondentes optaram por não responder a essa questão.

A amostra final teve ainda $28,9 \%$ dos entrevistados se declarando solteiros. $35,2 \%$ disseram serem casados ou estar em união estável. 397 entrevistados não responderam a essa questão. Na questão da renda familiar, $36,8 \%$ dos entrevistados preferiram não informar. $\mathrm{O}$ maior grupo de entrevistados $(22,8 \%)$ ficou na faixa de rende familiar mensal de $\mathrm{R} \$ 1.760,00$ a $\mathrm{R} \$ 8.800,00$.

A grande maioria dos entrevistados não faz parte de torcidas organizadas (809 respondentes) e apenas 31 torcedores declaram ter vínculo com torcida organizada. Por outro lado, 25,5\% dos entrevistados disseram fazer parte de algum programa de sócio torcedor relacionado a seu time. A maior parte da amostra $(50,55 \%)$ de declarou empregado no momento da entrevista.

O hábito de frequência ao estádio da amostra foi bastante equilibrado. 19,4\% dos torcedores declaram nunca ir ou ir raramente ao estádio. 18,9\% costumam ir uma vez por ano ou uma vez a cada seis meses. $18,1 \%$ possuem o hábito de ir uma vez por mês ou a cada três meses ao estádio. Na Tabela 50, encontram-se os dados demográficos da amostra teste. 
Tabela 50: Perfil demográfico da amostra final

\begin{tabular}{|c|c|c|}
\hline DADOS DEMOGRÁFICOS & FREQUENCIA & $\%$ / Estatística \\
\hline \multicolumn{3}{|l|}{ Gênero } \\
\hline Torcedor & 742 & 59,6 \\
\hline Torcedora & 117 & 9,4 \\
\hline Não responderam & 386 & 31 \\
\hline \multicolumn{3}{|l|}{ Idade } \\
\hline Média & - & 24,58 \\
\hline Desvio Padrão & - & 19,05 \\
\hline Mínimo & - & 14 \\
\hline Máximo & - & 75 \\
\hline Não responderam & 388 & - \\
\hline \multicolumn{3}{|l|}{ Grau de Instrução } \\
\hline Fundamental incompleto & 1 & 0,1 \\
\hline Fundamental completo & 2 & 0,2 \\
\hline Secundário incompleto & 9 & 0,7 \\
\hline Secundário completo & 50 & 4,0 \\
\hline Superior incompleto & 127 & 10,2 \\
\hline Superior completo & 293 & 23,5 \\
\hline Pós incompleto & 55 & 4,4 \\
\hline Pós completo & 322 & 25,9 \\
\hline Total & 859 & 69,0 \\
\hline Não responderam & 386 & 31,0 \\
\hline \multicolumn{3}{|l|}{ Estado Civil } \\
\hline Solteiro(a) & 360 & 28,9 \\
\hline Casado(a)/União Estável & 438 & 35,2 \\
\hline DIvorciado/Separado & 46 & 3,7 \\
\hline Outro & 4 &, 3 \\
\hline Total & 848 & 68,1 \\
\hline Não responderam & 397 & 31,9 \\
\hline \multicolumn{3}{|l|}{ Sócio Torcedor } \\
\hline Sim & 315 & 25,3 \\
\hline Não & 525 & 42,2 \\
\hline Não responderam & 405 & 32,5 \\
\hline \multicolumn{3}{|l|}{ Torcida Organizada } \\
\hline Sim & 31 & 2,5 \\
\hline Não & 809 & 65,0 \\
\hline Não responderam & 405 & 32,5 \\
\hline \multicolumn{3}{|l|}{ Situação de trabalho } \\
\hline Estudante & 121 & 9,7 \\
\hline Empregado & 629 & 50,5 \\
\hline Desempregado & 70 & 5,6 \\
\hline Aposentado & 31 & 2,5 \\
\hline Não responderam & 394 & 31,6 \\
\hline \multicolumn{3}{|l|}{ Frequência ao estádio } \\
\hline Nunca/Raramente & 242 & 19,4 \\
\hline Uma vez por ano & 120 & 9,6 \\
\hline Uma vez a cada seis meses & 116 & 9,3 \\
\hline
\end{tabular}




\begin{tabular}{llcc} 
& Uma vez a cada três meses & 126 & 10,1 \\
& Uma vez por mês & 99 & 8,0 \\
& Todos ou quase todos os jogos & 137 & 11,0 \\
& Não respondeu & 405 & 32,5 \\
\hline Renda & & & \\
\hline & Até $\mathrm{R} \$ 1.760,00$ & 23 & 1,8 \\
De $\mathrm{R} \$ 1.760,01$ a $\mathrm{R} \$ 3.520,00$ & 118 & 9,5 \\
De $\mathrm{R} \$ 3.520,01$ a $\mathrm{R} \$ 8.800,00$ & 284 & 22,8 \\
De $\mathrm{R} \$ 8.800,01$ a $\mathrm{R} \$ 13.200,00$ & 139 & 11,2 \\
De $\mathrm{R} \$ 13.200,01$ a $\mathrm{R} \$ 17.600,00$ & 63 & 12,9 \\
Acima de $\mathrm{R} \$ 17.600,01$ & 160 & 36,8 \\
\hline Não respondeu & 458 &
\end{tabular}

Fonte: Desenvolvido pelo autor por meio do IBM SPSS Statistic (versão 20)

Conforme já explicado, na aplicação da pesquisa na amostra final, não realizamos alterações para tornar o questionário mais claro. A primeira parte do questionário era comum a todos os entrevistados. Nesta parte, as perguntas visavam a analisar o envolvimento do torcedor com o futebol, sua identificação com o time de que ele se declarava torcedor e sua lealdade a ele.

$\mathrm{Na}$ segunda parte da pesquisa, de forma randômica, os entrevistados foram divididos em dois grupos de respondentes. Um grupo foi direcionado para responder perguntas a respeito do fornecedor de material esportivo ou do patrocinador da equipe (Quem é o atual patrocinador do [time do entrevistado]? / Quem é o atual fornecedor de uniforme do [time do entrevistado]?). A pergunta buscava respostas espontâneas, ou seja, tinha a intenção de mensurar o grau de lembrança do patrocínio na mente do consumidor. Foi dada também, para o entrevistado, a opção de ele responder não se lembrar do patrocinador/fornecedor (caso não se lembre, clique aqui). Nesta opção, o entrevistado era redirecionado para uma questão contendo 42 marcas (nome) de diversas empresas/produtos e também a opção de nenhuma das marcas. Desta forma, quando o entrevistado não se lembrou do patrocinador/fornecedor, pudemos medir o grau de reconhecimento do patrocínio.

Dos entrevistados (1.245), 42,3\% responderam a respeito do fornecedor de uniforme e $31,2 \%$ sobre o patrocinador da equipe. $26,5 \%$ dos entrevistados não responderam à questão, retirando-se do questionário sem terminá-lo, ou, após a opção de visualizar o possível patrocinador, marcaram a opção "nenhuma das marcas apresentadas". Os respondentes de ambos os casos foram retirados da amostra final válida (Tabela 51). 


\begin{tabular}{lccc}
\hline FORNECEDOR/PATROCINADOR & LEMBRANÇA/RECONHECIMENTO & FREQUENCIA & \% \\
\hline \hline \multirow{2}{*}{ Patrocinador } & Lembrança & 336 & 27,0 \\
& Reconhecimento & 52 & 4,2 \\
\hline \multirow{2}{*}{ Fornecedor de uniforma } & Lembrança & 475 & 38,2 \\
& Reconhecimento & 51 & 4,1 \\
\hline Total & & 914 & 73,5 \\
\hline Não responderam & & 331 & 26,5 \\
\hline Total & & $\mathbf{1 . 2 5 4}$ & $\mathbf{1 0 0}$ \\
\hline
\end{tabular}

Fonte: Desenvolvido pelo autor por meio do IBM SPSS Statistic (versão 20)

Antes de iniciar as análises dos dados, também verificamos os respondentes que acertaram o patrocinador/fornecedor do seu time. Importante ressaltar que mesmo aqueles que não acertaram não eram informados disso durante a entrevista. Dessa forma, 914 respondentes continuaram a responde ao questionário. A purificação dos dados foi realizada apenas após o término, e os respondentes não foram informados se acertaram ou não essa questão, pois, em nenhum momento, destacamos a importância dela. Essa decisão foi tomada para evitar vieses nas respostas (por exemplo: buscar na internet informação). Assim, a amostra final analisada, após purificação, totalizou 787 respondentes (Tabela 52).

Tabela 52: Perfil amostra final por acerto do patrocinador/fornecedor

\begin{tabular}{|c|c|c|c|c|c|c|}
\hline GENERO & $\begin{array}{c}\text { LEMBRANÇA / } \\
\text { RECONHECIMENTO }\end{array}$ & $\begin{array}{c}\text { FORNECEDOR / } \\
\text { PATROCINADOR }\end{array}$ & ACERTO & $\%$ & ERRO & $\%$ \\
\hline \multirow{5}{*}{ Torcedor } & \multirow{2}{*}{ Lembrança } & Patrocinador & 251 & 92,3 & 21 & 7,7 \\
\hline & & Fornecedor & 370 & 93,9 & 24 & 61,1 \\
\hline & \multirow{2}{*}{ Reconhecimento } & Patrocinador & 16 & 44,4 & 20 & 55,6 \\
\hline & & Fornecedor & 4 & 16,7 & 20 & 83,3 \\
\hline & \multicolumn{2}{|c|}{ Total } & 641 & 88,3 & 85 & 11,7 \\
\hline \multirow{5}{*}{ Torcedora } & \multirow{2}{*}{ Lembrança } & Patrocinador & 24 & 96,0 & 1 & 4,0 \\
\hline & & Fornecedor & 51 & 100,0 & 0 & 0,0 \\
\hline & \multirow{2}{*}{ Reconhecimento } & Patrocinador & 3 & 27,3 & 8 & 72,7 \\
\hline & & Fornecedor & 6 & 26,1 & 17 & 73,9 \\
\hline & \multicolumn{2}{|c|}{ Total } & 84 & 76,4 & 26 & 23,6 \\
\hline \multirow{5}{*}{$\begin{array}{c}\text { Não } \\
\text { informaram }\end{array}$} & \multirow{2}{*}{ Lembrança } & Patrocinador & 27 & 81,8 & 6 & 18,2 \\
\hline & & Fornecedor & 29 & 96,7 & 1 & 3,3 \\
\hline & \multirow{2}{*}{ Reconhecimento } & Patrocinador & 4 & 80,0 & 1 & 20,0 \\
\hline & & Fornecedor & 2 & 50,0 & 2 & 50,0 \\
\hline & \multicolumn{2}{|c|}{ Total } & 62 & 86,1 & 10 & 13,9 \\
\hline \multirow{2}{*}{ Total Geral } & \multirow{2}{*}{ Lembrança } & Patrocinador & 302 & 91,5 & 28 & 8,5 \\
\hline & & Fornecedor & 450 & 94,7 & 25 & 5,3 \\
\hline
\end{tabular}




\begin{tabular}{lccccc}
\hline \multirow{2}{*}{ Reconhecimento } & Patrocinador & 23 & 44,2 & 29 & 55,8 \\
& Fornecedor & 12 & 23,5 & 39 & 76,5 \\
\hline \multirow{2}{*}{ Total } & $\mathbf{7 8 7}$ & $\mathbf{8 6 , 7}$ & $\mathbf{1 2 1}$ & $\mathbf{1 3 , 3}$ \\
\hline
\end{tabular}

Fonte: Desenvolvido pelo autor por meio do IBM SPSS Statistic (versão 20)

Além das análises demonstradas, também questionamos os entrevistados a respeito de seus hábitos de compra de produtos e/ou serviços da marca patrocinadora ou fornecedora de material esportivo (Tabela 53). Mais uma vez, o fator lembrança parece influenciar bastante na relação do torcedor com as marcas patrocinadoras. 180 entrevistados $(43,37 \%)$, que lembraram de forma correta do patrocinador, declararam comprar seus produtos. Do outro lado, $2,89 \%$ dos que reconheceram o patrocinador compram produtos relacionados.

$\mathrm{Na}$ questão do fornecedor de uniformes, os resultados mostram que a escolha, na amostra teste, de subdividir o questionário entre fornecedor e patrocinador (devido ao tipo de produto) se mostrou adequada e assertiva. $72,22 \%$ dos entrevistados que lembraram e acertaram a fornecedora têm o hábito de comprar produtos da marca.

Tabela 53: Perfil amostra final - Compra ou Não Produtos

\begin{tabular}{|c|c|c|c|c|}
\hline TIPO & $\begin{array}{c}\text { LEMBRANÇA / } \\
\text { RECONHECIMENTO }\end{array}$ & $\begin{array}{l}\text { COMPRA DE } \\
\text { PRODUTOS }\end{array}$ & FREQUENCIA & $\%$ \\
\hline \multirow{5}{*}{ Patrocinador } & \multirow{2}{*}{ Lembrança } & Compra & 180 & 47,24 \\
\hline & & Não compra & 201 & 52,76 \\
\hline & \multirow{2}{*}{ Reconhecimento } & Compra & 12 & 35,29 \\
\hline & & Não compra & 22 & 64,71 \\
\hline & \multicolumn{2}{|c|}{ Total } & 415 & - \\
\hline \multirow{5}{*}{ Fornecedor } & \multirow{2}{*}{ Lembrança } & Compra & 327 & 82,37 \\
\hline & & Não compra & 70 & 17,63 \\
\hline & \multirow{2}{*}{ Reconhecimento } & Compra & 25 & 78,13 \\
\hline & & Não compra & 7 & 21,88 \\
\hline & \multicolumn{2}{|c|}{ Total } & 429 & 100 \\
\hline \multicolumn{3}{|c|}{ Total } & 844 & - \\
\hline
\end{tabular}

Fonte: Desenvolvido pelo autor por meio do IBM SPSS Statistic (versão 20)

Outro dado importante levantado na amostra teste foi por meio da questão: qual é sua marca esportiva preferida? $\mathrm{Na}$ Tabela 54, podemos verificar que lembram de forma correta a fornecedora de uniforme e compram produtos da marca $41,38 \%$ dos entrevistados que tem preferência pela marca patrocinadora. 
Tabela 54: Perfil amostra final - marca esportiva preferida

\begin{tabular}{|c|c|c|c|c|c|c|}
\hline TIPO & $\begin{array}{c}\text { LEMBRANÇA / } \\
\text { RECONHECIMENTO }\end{array}$ & $\begin{array}{l}\text { COMPRA DE } \\
\text { PRODUTOS }\end{array}$ & TIME & $\%$ & OUTRA & $\%$ \\
\hline \multirow{5}{*}{ Fornecedor } & \multirow{2}{*}{ Lembrança } & Compra & 132 & 41,38 & 187 & 58,62 \\
\hline & & Não compra & 11 & 15,94 & 58 & 84,06 \\
\hline & \multirow{2}{*}{ Reconhecimento } & Compra & 7 & 28,00 & 18 & 72,00 \\
\hline & & Não compra & 2 & 28,57 & 5 & 71,43 \\
\hline & \multicolumn{2}{|c|}{ Total } & 152 & & 268 & \\
\hline
\end{tabular}

Fonte: Desenvolvido pelo autor por meio do IBM SPSS Statistic (versão 20)

\subsection{Avaliação do Modelo de Mensuração (measurement model assessment) -}

Amostra teste

Seguindo os procedimentos estabelecidos para uso da técnica de análise multivariada SEM, primeiramente fizemos a avaliação do modelo de mensuração, conforme proposto por Klein (2011) e Hair (2009). Desta forma, por meio software SmartPls (versão 3.2.6), rodamos a análise fatorial confirmatória (AFC) para avaliar os indicadores propostos na Tabela 27 (pág. 156).

Nesta etapa, todos os destaques recomendados, na seção 8.4 (pág.165), a respeito das características do usa da AFC em softwares que trabalham com SEM-PLS foram seguidos e se mantêm válidos. Adotamos, novamente, as recomendações de Brown (2006) para efeito de cálculo.

Importante destacar que nesta etapa as análises, tanto do modelo de mensuração quanto do modelo estrutural, serviram para comparar os resultados alcançados entre a amostra pré-teste e a amostra teste e para que pudéssemos analisar o poder de replicação do modelo, pois, nesta etapa, o modelo é avaliado e analisado, mas, mesmo que os valores resultantes não atendam os requisitos mínimos, o modelo não é alterado, já que o objetivo central é poder verificar exatamente essa questão da replicação.

\subsubsection{Validade convergente}

Para analisar a validade convergente do modelo de mensuração, adotaram-se os princípios apresentados na Tabela 27 (pág. 156), tais como as correlações entre os construtos 
e variáveis observadas - as cargas fatoriais dos indicadores devem ser significantes e as cargas fatoriais das relações entre variável manifesta e variável latente deve ser alta; e a variância média extraída (AVE) para cada variável latente.

\subsubsection{Cargas fatoriais}

Para analisar a significância das cargas fatoriais de cada indicador por meio do SmartPls (versão 3.2.6), foi utilizada a opção bootstrappingping, com 5.000 amostras (Hair, 2014), com ponderação por factor weighting scheme. Desta forma, verificou-se o nível de significância de cada coeficiente fatorial.

Tabela 55: Avaliação do nível de significância dos indicadores - Amostra teste

\begin{tabular}{|c|c|c|c|c|}
\hline Construto & Indicadores & Carga Fatorial $(\beta)$ & $\begin{array}{l}\text { Desvio } \\
\text { Padrão }\end{array}$ & t-valor \\
\hline \multirow{3}{*}{ Tratamento Preferencial } & TRP1 & 0,911 & 0,009 & $101,915^{a}$ \\
\hline & TRP2 & 0,910 & 0,009 & $102,457^{\mathbf{a}}$ \\
\hline & TRP3 & 0,885 & 0,012 & $75,884^{a}$ \\
\hline \multirow{4}{*}{ Reconhecimento Pessoal } & $\mathrm{RCP} 1$ & 0,840 & 0,013 & $66,796^{a}$ \\
\hline & $\mathrm{RCP} 2$ & 0,881 & 0,010 & $92,301^{a}$ \\
\hline & $\mathrm{RCP} 3$ & 0,888 & 0,009 & $96,052^{a}$ \\
\hline & $\mathrm{RCP} 4$ & 0,814 & 0,016 & $51,332^{a}$ \\
\hline \multirow{3}{*}{ Sentimento de Status } & SST1 & 0,847 & 0,009 & $89,230^{a}$ \\
\hline & SST2 & 0,812 & 0,016 & $50,482^{a}$ \\
\hline & SST3 & 0,819 & 0,015 & $56,171^{a}$ \\
\hline \multirow{3}{*}{ Pertencimento } & PERTENC1 & 0,802 & 0,016 & $49,072^{a}$ \\
\hline & PERTENC2 & 0,866 & 0,010 & $88,538^{a}$ \\
\hline & PERTENC3 & 0,828 & 0,014 & $58,821^{a}$ \\
\hline \multirow{4}{*}{ Avaliação Pessoal } & AVP1 & 0,719 & 0,024 & $29,470^{a}$ \\
\hline & AVP3 & 0,869 & 0,012 & $75,164^{\mathrm{a}}$ \\
\hline & AVP4 & 0,831 & 0,016 & $53,043^{a}$ \\
\hline & AVP5 & 0,804 & 0,017 & $47,575^{a}$ \\
\hline \multirow{3}{*}{ Avaliação dos Outros } & PAO1 & 0,812 & 0,019 & $42,240^{a}$ \\
\hline & $\mathrm{PAO} 2$ & 0,807 & 0,020 & $40,604^{a}$ \\
\hline & $\mathrm{PAO} 3$ & 0,803 & 0,020 & $40,416^{a}$ \\
\hline \multirow{3}{*}{ Satisfação } & SAT1 & 0,796 & 0,019 & $42,015^{a}$ \\
\hline & SAT2 & 0,829 & 0,016 & $52,168^{a}$ \\
\hline & SAT3 & 0,880 & 0,010 & $84,134^{\mathrm{a}}$ \\
\hline
\end{tabular}




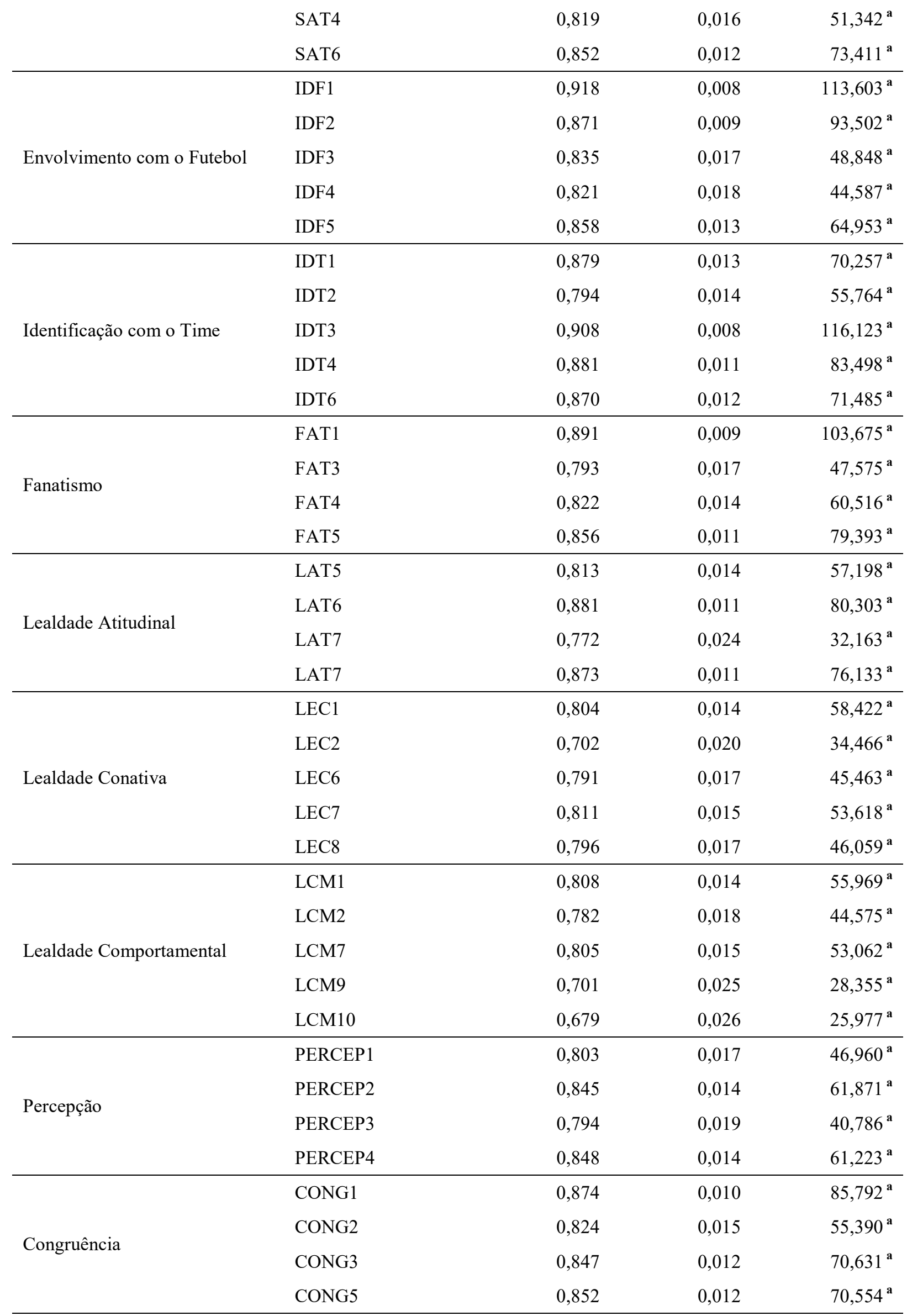




\begin{tabular}{|c|c|c|c|c|}
\hline \multirow{4}{*}{ Atitude } & ATT2 & 0,895 & 0,010 & $85,342^{a}$ \\
\hline & ATT3 & 0,922 & 0,007 & $127,188^{\mathrm{a}}$ \\
\hline & ATT4 & 0,915 & 0,008 & $112,787^{\mathrm{a}}$ \\
\hline & ATT5 & 0,923 & 0,008 & $118,950^{\mathrm{a}}$ \\
\hline \multirow{5}{*}{ Lealdade ao Patrocinador } & LPAT1 & 0,867 & 0,012 & $70,916^{a}$ \\
\hline & LPAT2 & 0,849 & 0,011 & $74,463^{\mathrm{a}}$ \\
\hline & LPAT3 & 0,853 & 0,013 & $65,681^{\mathrm{a}}$ \\
\hline & LPAT4 & 0,872 & 0,012 & $74,209^{\mathrm{a}}$ \\
\hline & LPAT5 & 0,917 & 0,006 & $141,854^{\mathrm{a}}$ \\
\hline \multirow{4}{*}{ Boca a Boca } & $\mathrm{BaB} 1$ & 0,928 & 0,008 & $120,838^{\mathbf{a}}$ \\
\hline & $\mathrm{BaB} 2$ & 0,955 & 0,004 & $214,523^{a}$ \\
\hline & $\mathrm{BaB} 3$ & 0,942 & 0,005 & $179,104^{\mathrm{a}}$ \\
\hline & BaB5 & 0,959 & 0,004 & $249,357^{\mathbf{a}}$ \\
\hline \multirow{4}{*}{ Intenção de compra } & INT_COMP1 & 0,961 & 0,003 & $285,175^{\mathrm{a}}$ \\
\hline & INT_COMP2 & 0,925 & 0,008 & $117,632^{\mathrm{a}}$ \\
\hline & INT_COMP3 & 0,944 & 0,006 & $156,710^{\mathrm{a}}$ \\
\hline & INT_COMP4 & 0,947 & 0,005 & $189,468^{a}$ \\
\hline \multirow{3}{*}{ Disposição a pagar mais } & DISP_M1 & 0,938 & 0,006 & $162,801^{\mathrm{a}}$ \\
\hline & DISP_M3 & 0,891 & 0,012 & $76,349^{a}$ \\
\hline & DISP_M4 & 0,931 & 0,007 & $141,191^{\mathrm{a}}$ \\
\hline \multirow{3}{*}{ Uso } & USO1 & 0,968 & 0,004 & $276,300^{a}$ \\
\hline & USO2 & 0,954 & 0,006 & $157,027^{\mathrm{a}}$ \\
\hline & USO3 & 0,965 & 0,005 & $198,989^{a}$ \\
\hline \multirow{4}{*}{ Interesse } & INTER1 & 0,938 & 0,007 & $131,795^{\mathrm{a}}$ \\
\hline & INTER2 & 0,938 & 0,006 & $165,409^{a}$ \\
\hline & INTER3 & 0,941 & 0,006 & $150,456^{\mathrm{a}}$ \\
\hline & INTER4 & 0,911 & 0,010 & $91,582^{\mathrm{a}}$ \\
\hline
\end{tabular}

Nota: O t-valor foi estimado por meio de bootstrapping no SmartPLS (263 casos e 5.000 re-amostras). $\mathrm{a}=\mathrm{p}<0,01 ; \mathrm{b}=p<0,05$.

Fonte: Desenvolvido pelo autor por meio do SmartPLS (3.2.6)

\subsubsection{Variância Média Extraída (AVE) e Confiabilidade}

Para analisar o AVE e os índices de confiabilidade de cada indicador por meio do SmartPls (versão 3.2.6), bem como as cargas fatoriais, foi utilizada a opção PLS algorithmg (Hair, 2014), com ponderação factor weighting scheme. 


\begin{tabular}{|c|c|c|c|c|c|}
\hline Construto & Indicadores & $\begin{array}{c}\text { Carga Fatorial } \\
(\beta)\end{array}$ & $\boldsymbol{\alpha}$ & $\boldsymbol{\rho}$ & AVE \\
\hline \multirow{3}{*}{ Tratamento Preferencial } & TRP1 & 0,911 & \multirow{3}{*}{0,885} & \multirow{3}{*}{0,929} & \multirow{3}{*}{0,813} \\
\hline & TRP2 & 0,910 & & & \\
\hline & TRP3 & 0,885 & & & \\
\hline \multirow{4}{*}{ Reconhecimento Pessoal } & $\mathrm{RCP} 1$ & 0,840 & \multirow{4}{*}{0,878} & \multirow{4}{*}{0,917} & \multirow{4}{*}{0,733} \\
\hline & $\mathrm{RCP} 2$ & 0,881 & & & \\
\hline & $\mathrm{RCP} 3$ & 0,888 & & & \\
\hline & $\mathrm{RCP} 4$ & 0,814 & & & \\
\hline \multirow{3}{*}{ Sentimento de Status } & SST1 & 0,847 & \multirow{3}{*}{0,769} & \multirow{3}{*}{0,866} & \multirow{3}{*}{0,683} \\
\hline & SST2 & 0,812 & & & \\
\hline & SST3 & 0,819 & & & \\
\hline \multirow{3}{*}{ Pertencimento } & PERTENC1 & 0,802 & \multirow{3}{*}{0,778} & \multirow{3}{*}{0,871} & \multirow{3}{*}{0,693} \\
\hline & PERTENC2 & 0,866 & & & \\
\hline & PERTENC3 & 0,828 & & & \\
\hline \multirow{4}{*}{ Avaliação Pessoal } & AVP1 & 0,719 & \multirow{4}{*}{0,821} & \multirow{4}{*}{0,882} & \multirow{4}{*}{0,653} \\
\hline & AVP3 & 0,869 & & & \\
\hline & AVP4 & 0,831 & & & \\
\hline & AVP5 & 0,804 & & & \\
\hline \multirow{3}{*}{ Avaliação dos Outros } & PAO1 & 0,812 & \multirow{3}{*}{0,734} & \multirow{3}{*}{0,849} & \multirow{3}{*}{0,652} \\
\hline & $\mathrm{PAO} 2$ & 0,807 & & & \\
\hline & $\mathrm{PAO} 3$ & 0,803 & & & \\
\hline \multirow{5}{*}{ Satisfação } & SAT1 & 0,796 & \multirow{5}{*}{0,892} & \multirow{5}{*}{0,920} & \multirow{5}{*}{0,698} \\
\hline & SAT2 & 0,829 & & & \\
\hline & SAT3 & 0,880 & & & \\
\hline & SAT4 & 0,819 & & & \\
\hline & SAT6 & 0,852 & & & \\
\hline & IDF1 & 0,918 & & & \\
\hline & IDF2 & 0,871 & & & \\
\hline $\begin{array}{l}\text { Envolvimento com o } \\
\text { Futebol }\end{array}$ & IDF3 & 0,835 & 0,913 & 0,935 & 0,742 \\
\hline & IDF4 & 0,821 & & & \\
\hline & IDF5 & 0,858 & & & \\
\hline & IDT1 & 0,879 & & & \\
\hline & IDT2 & 0,794 & & & \\
\hline Identificação com o Time & IDT3 & 0,908 & 0,917 & 0,938 & 0,752 \\
\hline & IDT4 & 0,881 & & & \\
\hline & IDT6 & 0,870 & & & \\
\hline Fanatismo & FAT1 & 0,891 & 0,862 & 0,906 & 0,708 \\
\hline
\end{tabular}




\begin{tabular}{|c|c|c|c|c|c|}
\hline & FAT3 & \multicolumn{4}{|l|}{0,793} \\
\hline & FAT4 & \multicolumn{4}{|l|}{0,822} \\
\hline & FAT5 & \multicolumn{4}{|l|}{0,856} \\
\hline \multirow{4}{*}{ Lealdade Atitudinal } & LAT5 & 0,813 & \multirow{4}{*}{0,856} & \multirow{4}{*}{0,902} & \multirow{4}{*}{0,699} \\
\hline & LAT6 & 0,881 & & & \\
\hline & LAT7 & 0,772 & & & \\
\hline & LAT7 & 0,873 & & & \\
\hline \multirow{5}{*}{ Lealdade Conativa } & LEC1 & 0,804 & \multirow{5}{*}{0,840} & \multirow{5}{*}{0,887} & \multirow{5}{*}{0,611} \\
\hline & LEC2 & 0,702 & & & \\
\hline & LEC6 & 0,791 & & & \\
\hline & LEC7 & 0,811 & & & \\
\hline & LEC8 & 0,796 & & & \\
\hline \multirow{5}{*}{ Lealdade Comportamental } & LCM1 & 0,808 & \multirow{5}{*}{0,813} & \multirow{5}{*}{0,870} & \multirow{5}{*}{0,573} \\
\hline & LCM2 & 0,782 & & & \\
\hline & LCM7 & 0,805 & & & \\
\hline & LCM9 & 0,701 & & & \\
\hline & LCM10 & 0,679 & & & \\
\hline \multirow{4}{*}{ Percepção } & PERCEP1 & 0,803 & \multirow{4}{*}{0,841} & \multirow{4}{*}{0,893} & \multirow{4}{*}{0,677} \\
\hline & PERCEP2 & 0,845 & & & \\
\hline & PERCEP3 & 0,794 & & & \\
\hline & PERCEP4 & 0,848 & & & \\
\hline \multirow{4}{*}{ Congruência } & CONG1 & 0,874 & \multirow{4}{*}{0,871} & \multirow{4}{*}{0,912} & \multirow{4}{*}{0,722} \\
\hline & CONG2 & 0,824 & & & \\
\hline & CONG3 & 0,847 & & & \\
\hline & CONG5 & 0,852 & & & \\
\hline \multirow{4}{*}{ Atitude } & ATT2 & 0,895 & \multirow{4}{*}{0,934} & \multirow{4}{*}{0,953} & \multirow{4}{*}{0,835} \\
\hline & ATT3 & 0,922 & & & \\
\hline & ATT4 & 0,915 & & & \\
\hline & ATT5 & 0,923 & & & \\
\hline & LPAT1 & 0,867 & & & \\
\hline & LPAT2 & 0,849 & & & \\
\hline Lealdade ao Patrocinador & LPAT3 & 0,853 & 0,921 & 0,941 & 0,760 \\
\hline & LPAT4 & 0,872 & & & \\
\hline & LPAT5 & 0,917 & & & \\
\hline & $\mathrm{BaB} 1$ & 0,928 & & & \\
\hline Dort Do & $\mathrm{BaB} 2$ & 0,955 & 0069 & (007ר & 0005 \\
\hline Bocd a Bocd & $\mathrm{BaB} 3$ & 0,942 & 0,901 & 0,912 & 0,095 \\
\hline & BaB5 & 0,959 & & & \\
\hline
\end{tabular}




\begin{tabular}{|c|c|c|c|c|c|}
\hline \multirow{4}{*}{ Intenção de compra } & INT_COMP1 & 0,961 & \multirow{4}{*}{0,959} & \multirow{4}{*}{0,971} & \multirow{4}{*}{0,892} \\
\hline & INT_COMP2 & 0,925 & & & \\
\hline & INT_COMP3 & 0,944 & & & \\
\hline & INT_COMP4 & 0,947 & & & \\
\hline \multirow{3}{*}{ Disposição a pagar mais } & DISP_M1 & 0,938 & \multirow{3}{*}{0,909} & \multirow{3}{*}{0,943} & \multirow{3}{*}{0,847} \\
\hline & DISP_M3 & 0,891 & & & \\
\hline & DISP_M4 & 0,931 & & & \\
\hline \multirow{3}{*}{ Uso } & USO1 & 0,968 & \multirow{3}{*}{0,960} & \multirow{3}{*}{0,974} & \multirow{3}{*}{0,926} \\
\hline & USO2 & 0,954 & & & \\
\hline & USO3 & 0,965 & & & \\
\hline \multirow{4}{*}{ Interesse } & INTER1 & 0,938 & \multirow{4}{*}{0,950} & \multirow{4}{*}{0,964} & \multirow{4}{*}{0,869} \\
\hline & INTER2 & 0,938 & & & \\
\hline & INTER3 & 0,941 & & & \\
\hline & INTER4 & 0,911 & & & \\
\hline
\end{tabular}

Nota: O t-valor foi estimado por meio de bootstrapping no SmartPLS (787 casos e 5.000 re-amostras). $\mathrm{a}=\mathrm{p}<0,01 ; \mathrm{b}=p<0,05$.

Fonte: Desenvolvido pelo autor por meio do SmartPLS (3.2.6)

A análise da Tabela 56 nos permite algumas comparações interessantes com a Tabela 40 (pág. 182). Os indicadores AVP1 $(\beta=0,608)$; LCM9 $(\beta=641)$; LCM10 $(\beta=0,645)$; e LEC2 $(\beta=0,689)$, no modelo de mensuração da amostra pré-teste, apresentaram resultados, conforme esperado, atendendo ao mínimo recomendando: AVP1 ( $\beta=0,719)$; LCM9 $(\beta=0,701)$; e LEC2 $(\beta=0,702)$. Por sua vez, o LCM10 $(\beta=0,679)$, apesar de se manter ligeiramente abaixo do mínimo recomendado, mantém o atendimento das recomendações de Hair (2014) de estar acima de 0,6 quando todos os outros indicadores atendem as demais recomendações.

\subsubsection{Validade Discriminante}

Para a análise da validade discriminante, deve-se primeiramente analisar no nível do construto. Para isso, utilizamos o critério de Fornell-Larcker (Tabela 57). Em segundo lugar, verificou-se, no nível dos indicadores, as cargas cruzadas. Assim, as cargas fatoriais dos indicadores devem ser, sempre, superiores às cargas cruzadas (Tabela 58).

Pelo critério de Fornell-Larcker (Fornell \& Larcker, 1981) deve-se comparar as raízes quadradas dos valores das AVEs de cada constructo com as correlações (de Pearson) entre os constructos. As raízes quadradas das AVEs devem ser maiores que as correlações entre os dos constructos (analise vertical e horizontal). Na Tabela 57 nota-se que esse critério foi atendido. 
$\mathrm{Na}$ analise das cargas cruzadas verificamos se as cargas fatoriais dos indicadores são superiores as cargas cruzadas (Chin, 1998). Adicionalmente, ao se analisar as cargas cruzadas, deve-se, além de verificar a questão dela ser inferior a carga fatorial da variável latente, se ela é alta. A Tabela 58 apresenta os indicadores de cargas cruzadas e o possível perceber que todos os critérios também foram atendidos.

Com a analise da validade convergente e discriminante, assim com o a confiabilidade, confirmadas podemos passar para a próxima etapa. Desta forma, o próximo passo é avaliar o modelo estrutural (Figura 24; pág.187). 
Tabela 57: Estatística descritiva e correlações - Amostra teste

\begin{tabular}{|c|c|c|c|c|c|c|c|c|c|c|c|c|c|c|c|c|c|c|c|c|c|c|c|}
\hline$\#$ & Construto & 1 & 2 & 3 & 4 & 5 & 6 & 7 & 8 & 9 & 10 & 11 & 12 & 13 & 14 & 15 & 16 & 17 & 18 & 19 & 20 & 21 & 22 \\
\hline 1 & Atitude & 0,914 & & & & & & & & & & & & & & & & & & & & & \\
\hline 2 & Avaliação Pessoal & 0,315 & 0,808 & & & & & & & & & & & & & & & & & & & & \\
\hline 3 & Avaliação dos Outros & 0,206 & 0,432 & $\mathbf{0 , 8 0 7}$ & & & & & & & & & & & & & & & & & & & \\
\hline 4 & Boca a Boca & 0,629 & 0,264 & 0,211 & 0,946 & & & & & & & & & & & & & & & & & & \\
\hline 5 & Congruência & 0,706 & 0,209 & 0,168 & 0,507 & 0,849 & & & & & & & & & & & & & & & & & \\
\hline 6 & Dispo. Pagar Mais & 0,503 & 0,229 & 0,194 & 0,764 & 0,452 & 0,920 & & & & & & & & & & & & & & & & \\
\hline 7 & Fanatismo & 0,319 & 0,618 & 0,289 & 0,350 & 0,188 & 0,288 & 0,841 & & & & & & & & & & & & & & & \\
\hline 8 & Identificação Futebol & 0,241 & 0,535 & 0,216 & 0,223 & 0,155 & 0,149 & 0,639 & 0,861 & & & & & & & & & & & & & & \\
\hline 9 & Identificação Time & 0,355 & 0,685 & 0,287 & 0,324 & 0,203 & 0,242 & 0,794 & 0,672 & 0,867 & & & & & & & & & & & & & \\
\hline 10 & Intenção de Compra & 0,646 & 0,256 & 0,232 & 0,841 & 0,509 & 0,807 & 0,337 & 0,189 & 0,331 & 0,944 & & & & & & & & & & & & \\
\hline 11 & Interesse & 0,792 & 0,308 & 0,213 & 0,653 & 0,584 & 0,529 & 0,343 & 0,258 & 0,348 & 0,687 & 0,932 & & & & & & & & & & & \\
\hline 12 & L. Comportamental & 0,327 & 0,618 & 0,306 & 0,319 & 0,241 & 0,215 & 0,705 & 0,692 & 0,716 & 0,279 & 0,326 & 0,757 & & & & & & & & & & \\
\hline 13 & Lealdade Conativa & 0,382 & 0,675 & 0,331 & 0,386 & 0,224 & 0,323 & 0,683 & 0,595 & 0,749 & 0,372 & 0,381 & 0,693 & 0,782 & & & & & & & & & \\
\hline 14 & L. ao Patrocinador & 0,659 & 0,242 & 0,192 & 0,862 & 0,568 & 0,767 & 0,324 & 0,191 & 0,310 & 0,831 & 0,661 & 0,295 & 0,364 & 0,872 & & & & & & & & \\
\hline 15 & Lealdade Atitudinal & 0,343 & 0,683 & 0,253 & 0,341 & 0,172 & 0,251 & 0,737 & 0,689 & 0,833 & 0,325 & 0,353 & 0,735 & 0,777 & 0,314 & 0,836 & & & & & & & \\
\hline 16 & Percepção & 0,697 & 0,236 & 0,145 & 0,430 & 0,777 & 0,375 & 0,171 & 0,161 & 0,225 & 0,432 & 0,555 & 0,234 & 0,220 & 0,494 & 0,206 & 0,823 & & & & & & \\
\hline 17 & Pertencimento & 0,356 & 0,606 & 0,363 & 0,402 & 0,281 & 0,351 & 0,699 & 0,502 & 0,676 & 0,378 & 0,357 & 0,590 & 0,621 & 0,373 & 0,618 & 0,238 & 0,832 & & & & & \\
\hline 18 & Reconhecimento P. & 0,284 & 0,503 & 0,370 & 0,349 & 0,223 & 0,301 & 0,595 & 0,447 & 0,602 & 0,325 & 0,294 & 0,492 & 0,515 & 0,315 & 0,532 & 0,182 & 0,769 & 0,856 & & & & \\
\hline 19 & Satisfação & 0,138 & 0,404 & 0,395 & 0,130 & 0,161 & 0,172 & 0,206 & 0,121 & 0,182 & 0,126 & 0,129 & 0,218 & 0,231 & 0,135 & 0,170 & 0,162 & 0,271 & 0,223 & 0,836 & & & \\
\hline 20 & Sentimento de Status & 0,322 & 0,553 & 0,406 & 0,361 & 0,252 & 0,324 & 0,619 & 0,449 & 0,630 & 0,353 & 0,317 & 0,540 & 0,542 & 0,331 & 0,554 & 0,209 & 0,762 & 0,794 & 0,235 & 0,826 & & \\
\hline 21 & Tratamento Pref. & 0,218 & 0,347 & 0,344 & 0,339 & 0,209 & 0,288 & 0,420 & 0,270 & 0,404 & 0,311 & 0,232 & 0,347 & 0,346 & 0,289 & 0,339 & 0,151 & 0,615 & 0,715 & 0,217 & 0,730 & 0,902 & \\
\hline 22 & Uso & 0,818 & 0,293 & 0,206 & 0,703 & 0,575 & 0,581 & 0,342 & 0,236 & 0,349 & 0,738 & 0,883 & 0,315 & 0,388 & 0,706 & 0,337 & 0,546 & 0,356 & 0,295 & 0,133 & 0,309 & 0,228 & 0,962 \\
\hline
\end{tabular}

Nota 1: Os valores na diagonal (negrito) são a raiz quadrada dos valores de AVE. As entradas fora da diagonal são correlações entre os construtos. A raiz quadrada do AVE maior do que os coeficientes de correlação indica validade discriminante suficiente

Fonte: Desenvolvido pelo autor por meio do SmartPLS (3.2.6) 
Tabela 58: Matriz de carga cruzada - Amostra pré-teste Modelo Ajustado

\begin{tabular}{|c|c|c|c|c|c|c|c|c|c|c|c|c|c|c|c|c|c|c|c|c|c|c|}
\hline Indicador & 1 & 2 & 3 & 4 & 5 & 6 & 7 & 8 & 9 & 10 & 11 & 12 & 13 & 14 & 15 & 16 & 17 & 18 & 19 & 20 & 21 & 22 \\
\hline AVP1 & 0,201 & 0,719 & 0,333 & 0,162 & 0,134 & 0,137 & 0,432 & 0,343 & 0,528 & 0,172 & 0,184 & 0,443 & 0,481 & 0,172 & 0,511 & 0,171 & 0,470 & 0,372 & 0,273 & 0,438 & 0,263 & 0,180 \\
\hline AVP3 & 0,245 & 0,869 & 0,334 & 0,197 & 0,148 & 0,165 & 0,540 & 0,459 & 0,598 & 0,202 & 0,231 & 0,532 & 0,577 & 0,167 & 0,597 & 0,175 & 0,482 & 0,390 & 0,365 & 0,445 & 0,261 & 0,237 \\
\hline AVP4 & 0,295 & 0,831 & 0,349 & 0,249 & 0,194 & 0,238 & 0,493 & 0,416 & 0,515 & 0,238 & 0,301 & 0,477 & 0,588 & 0,230 & 0,518 & 0,195 & 0,482 & 0,359 & 0,366 & 0,421 & 0,264 & 0,280 \\
\hline AVP5 & 0,271 & 0,804 & 0,378 & 0,238 & 0,193 & 0,196 & 0,525 & 0,497 & 0,571 & 0,211 & 0,274 & 0,539 & 0,532 & 0,209 & 0,577 & 0,218 & 0,521 & 0,497 & 0,297 & 0,480 & 0,331 & 0,245 \\
\hline Att2 & 0,895 & 0,286 & 0,174 & 0,601 & 0,643 & 0,476 & 0,310 & 0,222 & 0,335 & 0,603 & 0,701 & 0,317 & 0,367 & 0,639 & 0,321 & 0,637 & 0,315 & 0,251 & 0,143 & 0,298 & 0,183 & 0,719 \\
\hline Att3 & 0,922 & 0,283 & 0,176 & 0,576 & 0,607 & 0,461 & 0,282 & 0,222 & 0,309 & 0,591 & 0,725 & 0,294 & 0,334 & 0,598 & 0,304 & 0,602 & 0,325 & 0,266 & 0,089 & 0,290 & 0,195 & 0,776 \\
\hline Att4 & 0,915 & 0,258 & 0,194 & 0,560 & 0,679 & 0,450 & 0,254 & 0,186 & 0,297 & 0,589 & 0,725 & 0,264 & 0,317 & 0,590 & 0,279 & 0,654 & 0,329 & 0,253 & 0,125 & 0,277 & 0,196 & 0,738 \\
\hline Att5 & 0,923 & 0,323 & 0,209 & 0,562 & 0,651 & 0,449 & 0,319 & 0,249 & 0,357 & 0,577 & 0,744 & 0,319 & 0,376 & 0,580 & 0,348 & 0,654 & 0,332 & 0,269 & 0,148 & 0,312 & 0,220 & 0,757 \\
\hline $\mathrm{BaB} 1$ & 0,556 & 0,240 & 0,230 & 0,928 & 0,436 & 0,709 & 0,333 & 0,210 & 0,304 & 0,779 & 0,590 & 0,310 & 0,361 & 0,812 & 0,327 & 0,367 & 0,375 & 0,337 & 0,143 & 0,343 & 0,334 & 0,651 \\
\hline $\mathrm{BaB} 2$ & 0,596 & 0,255 & 0,186 & 0,955 & 0,476 & 0,726 & 0,335 & 0,215 & 0,307 & 0,785 & 0,620 & 0,308 & 0,369 & 0,843 & 0,325 & 0,405 & 0,395 & 0,336 & 0,113 & 0,356 & 0,315 & 0,663 \\
\hline $\mathrm{BaB} 3$ & 0,629 & 0,254 & 0,197 & 0,942 & 0,519 & 0,713 & 0,323 & 0,221 & 0,299 & 0,805 & 0,639 & 0,294 & 0,363 & 0,830 & 0,322 & 0,456 & 0,374 & 0,319 & 0,122 & 0,326 & 0,321 & 0,678 \\
\hline BaB5 & 0,598 & 0,249 & 0,187 & 0,959 & 0,485 & 0,744 & 0,334 & 0,200 & 0,315 & 0,812 & 0,621 & 0,297 & 0,369 & 0,851 & 0,316 & 0,397 & 0,378 & 0,330 & 0,115 & 0,340 & 0,312 & 0,668 \\
\hline Cong1 & 0,622 & 0,218 & 0,141 & 0,422 & 0,874 & 0,369 & 0,178 & 0,171 & 0,206 & 0,420 & 0,526 & 0,223 & 0,221 & 0,486 & 0,164 & 0,686 & 0,251 & 0,199 & 0,138 & 0,247 & 0,193 & 0,507 \\
\hline Cong2 & 0,543 & 0,141 & 0,144 & 0,438 & 0,824 & 0,409 & 0,152 & 0,110 & 0,144 & 0,445 & 0,472 & 0,194 & 0,170 & 0,476 & 0,136 & 0,569 & 0,236 & 0,199 & 0,122 & 0,182 & 0,185 & 0,463 \\
\hline Cong3 & 0,583 & 0,106 & 0,145 & 0,469 & 0,847 & 0,419 & 0,143 & 0,078 & 0,113 & 0,447 & 0,479 & 0,159 & 0,128 & 0,508 & 0,083 & 0,623 & 0,226 & 0,193 & 0,136 & 0,210 & 0,209 & 0,494 \\
\hline Cong5 & 0,646 & 0,237 & 0,140 & 0,396 & 0,852 & 0,345 & 0,165 & 0,162 & 0,223 & 0,420 & 0,503 & 0,241 & 0,239 & 0,463 & 0,198 & 0,755 & 0,242 & 0,168 & 0,152 & 0,213 & 0,124 & 0,490 \\
\hline DispM1 & 0,489 & 0,241 & 0,192 & 0,754 & 0,424 & 0,938 & 0,315 & 0,159 & 0,267 & 0,784 & 0,526 & 0,235 & 0,325 & 0,743 & 0,266 & 0,348 & 0,361 & 0,318 & 0,156 & 0,327 & 0,295 & 0,570 \\
\hline DispM3 & 0,455 & 0,174 & 0,177 & 0,653 & 0,421 & 0,891 & 0,185 & 0,091 & 0,163 & 0,707 & 0,449 & 0,136 & 0,241 & 0,673 & 0,174 & 0,352 & 0,251 & 0,207 & 0,176 & 0,238 & 0,222 & 0,503 \\
\hline DispM4 & 0,442 & 0,214 & 0,166 & 0,698 & 0,405 & 0,931 & 0,285 & 0,156 & 0,230 & 0,733 & 0,481 & 0,216 & 0,319 & 0,699 & 0,245 & 0,336 & 0,348 & 0,297 & 0,146 & 0,322 & 0,273 & 0,527 \\
\hline FAT1 & 0,287 & 0,571 & 0,255 & 0,293 & 0,178 & 0,238 & 0,891 & 0,623 & 0,721 & 0,268 & 0,301 & 0,672 & 0,629 & 0,270 & 0,683 & 0,174 & 0,604 & 0,496 & 0,177 & 0,522 & 0,353 & 0,295 \\
\hline FAT3 & 0,216 & 0,486 & 0,232 & 0,270 & 0,130 & 0,225 & 0,793 & 0,437 & 0,568 & 0,269 & 0,241 & 0,538 & 0,493 & 0,262 & 0,535 & 0,116 & 0,553 & 0,481 & 0,204 & 0,493 & 0,349 & 0,267 \\
\hline FAT4 & 0,298 & 0,512 & 0,235 & 0,304 & 0,180 & 0,254 & 0,822 & 0,489 & 0,683 & 0,309 & 0,322 & 0,553 & 0,568 & 0,272 & 0,604 & 0,137 & 0,627 & 0,543 & 0,166 & 0,553 & 0,376 & 0,313 \\
\hline FAT5 & 0,268 & 0,509 & 0,249 & 0,310 & 0,142 & 0,251 & 0,856 & 0,589 & 0,689 & 0,289 & 0,286 & 0,601 & 0,601 & 0,286 & 0,650 & 0,147 & 0,567 & 0,481 & 0,149 & 0,513 & 0,337 & 0,275 \\
\hline IDF1 & 0,251 & 0,486 & 0,180 & 0,202 & 0,156 & 0,116 & 0,601 & 0,918 & 0,641 & 0,178 & 0,243 & 0,638 & 0,558 & 0,176 & 0,641 & 0,164 & 0,484 & 0,427 & 0,098 & 0,421 & 0,229 & 0,233 \\
\hline IDF2 & 0,216 & 0,458 & 0,223 & 0,203 & 0,139 & 0,146 & 0,618 & 0,871 & 0,579 & 0,158 & 0,243 & 0,621 & 0,516 & 0,176 & 0,572 & 0,149 & 0,478 & 0,419 & 0,137 & 0,427 & 0,284 & 0,209 \\
\hline IDF3 & 0,169 & 0,482 & 0,181 & 0,181 & 0,125 & 0,117 & 0,479 & 0,835 & 0,541 & 0,153 & 0,183 & 0,634 & 0,524 & 0,160 & 0,601 & 0,100 & 0,382 & 0,347 & 0,120 & 0,334 & 0,202 & 0,174 \\
\hline
\end{tabular}




\begin{tabular}{|c|c|c|c|c|c|c|c|c|c|c|c|c|c|c|c|c|c|c|c|c|c|c|}
\hline IDF4 & 0,181 & 0,442 & 0,147 & 0,186 & 0,127 & 0,132 & 0,476 & 0,821 & 0,538 & 0,157 & 0,210 & 0,556 & 0,471 & 0,150 & 0,579 & 0,141 & 0,366 & 0,312 & 0,105 & 0,340 & 0,185 & 0,192 \\
\hline F5 & 0,213 & 0,434 & 194 & 0,189 & 0,116 & 0,131 & 0,566 & 0,858 & 0,590 & 0,167 & 0,229 & 0,529 & 0,490 & 0,160 & 0,572 & 0,136 & 0,441 & 0,413 & 0,061 & 0,402 & ,256 &, 206 \\
\hline IDT1 & 0,301 & 0,582 & 0,215 & 0,298 & 0,166 & 0,204 & 0,669 & 0,637 & 0,879 & 0,286 & 0,296 & 0,639 & 0,669 & 0,288 & 0,746 & 0,176 & 0,572 & 0,499 & 0,144 & 0,514 & 0,351 & 0,289 \\
\hline IDT2 & 0,289 & 0,510 & 0,301 & 0,319 & 0,188 & 0,263 & 0,681 & 0,487 & 0,794 & 0,315 & 0,297 & 0,569 & 0,572 & 0,297 & 0,593 & 0,168 & 0,603 & 0,568 & 0,200 & 0,598 & 0,448 & 0,295 \\
\hline IDT3 & 0,303 & 0,621 & 0,249 & 0,258 & 0,198 & 0,184 & 0,692 & 0,643 & 0,908 & 0,263 & 0,289 & 0,663 & 0,681 & 0,249 & 0,778 & 0,194 & 0,571 & 0,507 & 0,145 & 0,531 & 0,311 & 0,288 \\
\hline IDT4 & 0,336 & 0,618 & 0,246 & 0,282 & 0,161 & 0,214 & 0,725 & 0,585 & 0,881 & 0,299 & 0,327 & 0,608 & 0,671 & 0,269 & 0,747 & 0,222 & 0,617 & 0,548 & 0,155 & 0,570 & 0,345 & 0,334 \\
\hline IDT6 & 0,312 & 0,637 & 0,234 & 0,248 & 0,168 & 0,186 & 0,673 & 0,560 & 0,870 & 0,272 & 0,297 & 0,625 & 0,650 & 0,241 & 0,744 & 0,213 & 0,565 & 0,486 & 0,146 & 0,518 & 0,299 & 0,308 \\
\hline INTER1 & 0,750 & 0,265 & 0,189 & 0,589 & 0,536 & 0,482 & 0,285 & 0,218 & 0,292 & 0,639 & 0,938 & 0,277 & 0,356 & 0,611 & 0,317 & 0,503 & 0,316 & 0,264 & 0,101 & 0,272 & 0,202 & 0,821 \\
\hline INTER2 & 0,727 & 0,299 & 0,211 & 0,620 & 0,553 & 0,507 & 0,331 & 0,241 & 0,328 & 0,647 & 0,938 & 0,324 & 0,369 & 0,627 & 0,336 & 0,517 & 0,343 & 0,266 & 0,147 & 0,301 & 0,223 & 0,841 \\
\hline INTER3 & 0,750 & 0,284 & 0,197 & 0,619 & 0,538 & 0,494 & 0,327 & 0,242 & 0,332 & 0,642 & 0,941 & 0,314 & 0,343 & 0,626 & 0,330 & 0,519 & 0,336 & 0,271 & 0,133 & 0,298 & 0,214 & 0,833 \\
\hline INTER4 & 0,727 & 0,300 & 0,199 & 0,606 & 0,549 & 0,490 & 0,335 & 0,260 & 0,343 & 0,633 & 0,911 & 0,299 & 0,353 & 0,602 & 0,332 & 0,531 & 0,337 & 0,297 & 0,099 & 0,308 & 0,223 & 0,798 \\
\hline INT_COMP1 & 0,632 & 0,241 & 0,217 & 0,792 & 0,485 & 0,747 & 0,309 & 0,171 & 0,322 & 0,961 & 0,669 & 0,259 & 0,352 & 0,786 & 0,306 & 0,418 & 0,339 & 0,294 & 0,118 & 0,333 & 0,281 & 0,728 \\
\hline INT_COMP2 & 0,604 & 0,244 & 0,207 & 0,772 & 0,486 & 0,790 & 0,297 & 0,169 & 0,290 & 0,925 & 0,610 & 0,243 & 0,336 & 0,759 & 0,275 & 0,420 & 0,340 & 0,305 & 0,143 & 0,323 & 0,274 & 0,668 \\
\hline INT_COMP3 & 0,608 & 0,228 & 0,224 & 0,796 & 0,470 & 0,739 & 0,334 & 0,193 & 0,313 & 0,944 & 0,669 & 0,280 & 0,352 & 0,800 & 0,323 & 0,398 & 0,364 & 0,312 & 0,093 & 0,333 & 0,303 & 0,702 \\
\hline INT_COMP4 & 0,595 & 0,253 & 0,227 & 0,816 & 0,481 & 0,773 & 0,333 & 0,180 & 0,324 & 0,947 & 0,646 & 0,270 & 0,363 & 0,793 & 0,322 & 0,398 & 0,383 & 0,317 & 0,123 & 0,344 & 0,316 & 0,690 \\
\hline LAT5 & 0,287 & 0,573 & 0,232 & 0,338 & 0,129 & 0,278 & 0,625 & 0,529 & 0,631 & 0,319 & 0,302 & 0,599 & 0,642 & 0,316 & 0,813 & 0,160 & 0,568 & 0,481 & 0,180 & 0,502 & 0,382 & 0,295 \\
\hline LAT6 & 0,301 & 0,591 & 0,224 & 0,310 & 0,147 & 0,239 & 0,673 & 0,594 & 0,752 & 0,296 & 0,326 & 0,631 & 0,694 & 0,283 & 0,881 & 0,171 & 0,556 & 0,490 & 0,124 & 0,502 & 0,297 & 0,305 \\
\hline LAT7 & 0,234 & 0,489 & 0,153 & 0,208 & 0,115 & 0,121 & 0,502 & 0,573 & 0,586 & 0,187 & 0,236 & 0,600 & 0,557 & 0,186 & 0,772 & 0,141 & 0,400 & 0,330 & 0,083 & 0,332 & 0,162 & 0,219 \\
\hline LAT8 & 0,317 & 0,620 & 0,228 & 0,272 & 0,180 & 0,185 & 0,648 & 0,612 & 0,800 & 0,270 & 0,306 & 0,633 & 0,691 & 0,255 & 0,873 & 0,210 & 0,524 & 0,460 & 0,171 & 0,496 & 0,273 & 0,299 \\
\hline LCM1 & 0,268 & 0,528 & 0,281 & 0,265 & 0,241 & 0,205 & 0,587 & 0,552 & 0,560 & 0,236 & 0,269 & 0,808 & 0,541 & 0,236 & 0,560 & 0,172 & 0,502 & 0,423 & 0,230 & 0,478 & 0,299 & 0,273 \\
\hline LCM10 & 0,165 & 0,346 & 0,146 & 0,163 & 0,139 & 0,059 & 0,435 & 0,407 & 0,465 & 0,126 & 0,158 & 0,679 & 0,447 & 0,140 & 0,460 & 0,165 & 0,403 & 0,343 & 0,103 & 0,348 & 0,257 & 0,149 \\
\hline LCM2 & 0,310 & 0,502 & 0,243 & 0,269 & 0,211 & 0,206 & 0,576 & 0,578 & 0,596 & 0,240 & 0,309 & 0,782 & 0,565 & 0,255 & 0,601 & 0,220 & 0,465 & 0,385 & 0,131 & 0,436 & 0,258 & 0,279 \\
\hline LCM7 & 0,254 & 0,527 & 0,261 & 0,247 & 0,159 & 0,172 & 0,602 & 0,597 & 0,590 & 0,223 & 0,244 & 0,805 & 0,550 & 0,242 & 0,630 & 0,175 & 0,456 & 0,378 & 0,182 & 0,397 & 0,239 & 0,239 \\
\hline LCM9 & 0,221 & 0,410 & 0,208 & 0,252 & 0,152 & 0,146 & 0,442 & 0,459 & 0,486 & 0,213 & 0,233 & 0,701 & 0,511 & 0,227 & 0,515 & 0,151 & 0,401 & 0,326 & 0,165 & 0,373 & 0,268 & 0,234 \\
\hline LEC1 & 0,298 & 0,565 & 0,256 & 0,325 & 0,161 & 0,266 & 0,653 & 0,580 & 0,639 & 0,278 & 0,292 & 0,615 & 0,804 & 0,295 & 0,693 & 0,152 & 0,559 & 0,475 & 0,168 & 0,493 & 0,328 & 0,287 \\
\hline LEC2 & 0,282 & 0,484 & 0,252 & 0,326 & 0,133 & 0,355 & 0,462 & 0,355 & 0,454 & 0,321 & 0,307 & 0,374 & 0,702 & 0,304 & 0,516 & 0,125 & 0,409 & 0,337 & 0,225 & 0,368 & 0,244 & 0,323 \\
\hline LEC6 & 0,263 & 0,547 & 0,236 & 0,215 & 0,171 & 0,138 & 0,506 & 0,487 & 0,582 & 0,201 & 0,264 & 0,606 & 0,791 & 0,213 & 0,587 & 0,161 & 0,468 & 0,391 & 0,163 & 0,408 & 0,223 & 0,255 \\
\hline LEC7 & 0,305 & 0,531 & 0,264 & 0,314 & 0,204 & 0,263 & 0,539 & 0,426 & 0,640 & 0,324 & 0,314 & 0,561 & 0,811 & 0,301 & 0,624 & 0,209 & 0,506 & 0,408 & 0,176 & 0,451 & 0,296 & 0,318 \\
\hline
\end{tabular}




\begin{tabular}{|c|c|c|c|c|c|c|c|c|c|c|c|c|c|c|c|c|c|c|c|c|c|c|}
\hline LEC 8 & 0,343 & 0,509 & 0,287 & 0,329 & 0,206 & 0,248 & 0,493 & 0,461 & 0,594 & 0,331 & 0,315 & 0,531 & 0,796 & 0,310 & 0,598 & 0,210 & 0,470 & 0,387 & 0,180 & 0,388 & 0,253 & 0,339 \\
\hline LPAT1 & 0,537 & 0,204 & 0,195 & 0,783 & 0,383 & 0,667 & 0,278 & 0,165 & 0,277 & 0,744 & 0,596 & 0,240 & 0,318 & 0,867 & 0,282 & 0,304 & 0,316 & 0,280 & 0,106 & ,289 & 0,288 & ,610 \\
\hline LPAT2 & 0,666 & 0,224 & 0,146 & 0,712 & 0,582 & 0,608 & 0,251 & 0,189 & 0,280 & 0,733 & 0,619 & 0,258 & 0,353 & 0,849 & 0,279 & 0,510 & 0,284 & 0,235 & 0,092 & 0,263 & 0,186 & 0,681 \\
\hline LPAT3 & 0,526 & 0,198 & 0,153 & 0,701 & 0,534 & 0,645 & 0,266 & 0,156 & 0,242 & 0,655 & 0,498 & 0,268 & 0,274 & 0,853 & 0,250 & 0,481 & 0,300 & 0,250 & 0,169 & 0,268 & 0,220 & 0,546 \\
\hline LPAT4 & 0,562 & 0,194 & 0,150 & 0,779 & 0,514 & 0,704 & 0,283 & 0,137 & 0,236 & 0,705 & 0,547 & 0,224 & 0,289 & 0,872 & 0,240 & 0,459 & 0,340 & 0,268 & 0,139 & 0,279 & 0,247 & 0,589 \\
\hline LPAT5 & 0,578 & 0,231 & 0,193 & 0,863 & 0,467 & 0,720 & 0,329 & 0,184 & 0,311 & 0,780 & 0,616 & 0,292 & 0,347 & 0,917 & 0,315 & 0,403 & 0,381 & 0,337 & 0,088 & 0,342 & 0,314 & 0,646 \\
\hline PAO1 & 0,181 & 0,321 & 0,812 & 0,210 & 0,130 & 0,168 & 0,197 & 0,129 & 0,215 & 0,212 & 0,198 & 0,201 & 0,257 & 0,172 & 0,175 & 0,110 & 0,286 & 0,304 & 0,372 & 0,309 & 0,295 & 0,187 \\
\hline $\mathrm{PAO} 2$ & 0,141 & 0,370 & 0,807 & 0,129 & 0,114 & 0,124 & 0,211 & 0,199 & 0,226 & 0,159 & 0,158 & 0,237 & 0,273 & 0,131 & 0,217 & 0,093 & 0,244 & 0,259 & 0,258 & 0,305 & 0,216 & 0,156 \\
\hline PAO3 & 0,174 & 0,355 & 0,803 & 0,170 & 0,158 & 0,174 & 0,285 & 0,194 & 0,251 & 0,188 & 0,160 & 0,298 & 0,272 & 0,160 & 0,221 & 0,144 & 0,341 & 0,328 & 0,322 & 0,366 & 0,315 & 0,157 \\
\hline PERCEP1 & 0,552 & 0,234 & 0,139 & 0,369 & 0,594 & 0,320 & 0,170 & 0,155 & 0,210 & 0,371 & 0,488 & 0,220 & 0,224 & 0,401 & 0,200 & 0,803 & 0,246 & 0,187 & 0,157 & 0,201 & 0,142 & 0,462 \\
\hline PERCEP2 & 0,583 & 0,152 & 0,109 & 0,370 & 0,681 & 0,345 & 0,115 & 0,096 & 0,157 & 0,381 & 0,462 & 0,153 & 0,156 & 0,425 & 0,132 & 0,845 & 0,180 & 0,146 & 0,151 & 0,164 & 0,160 & 0,453 \\
\hline PERCEP3 & 0,504 & 0,200 & 0,089 & 0,268 & 0,607 & 0,236 & 0,142 & 0,140 & 0,183 & 0,266 & 0,373 & 0,205 & 0,147 & 0,353 & 0,162 & 0,794 & 0,158 & 0,123 & 0,091 & 0,159 & 0,102 & 0,369 \\
\hline PERCEP4 & 3 & 0,191 & 0,136 & 0,396 & 0,673 & 0,322 & 0,138 & 0,140 & 0,190 & 0,391 & 0,492 & 0,194 & 0,193 & 0,440 & 0,182 & 0,848 & 0,193 & 0,141 & 0,128 &, 163 & 0,093 & 0,501 \\
\hline PERTENC1 & 0,240 & 0,428 & 0,301 & 0,320 & 0,212 & 0,290 & 0,559 & 0,372 & 0,515 & 0,288 & 0,273 & 0,435 & 0,444 & 0,276 & 0,462 & 0,188 & 0,802 & 0,688 & 0,178 & 0,642 & 0,571 & 0,257 \\
\hline PERTENC2 & 0,316 & 0,572 & 0,283 & 0,344 & 0,208 & 0,275 & 0,660 & 0,510 & 0,660 & 0,323 & 0,308 & 0,567 & 0,623 & 0,326 & 0,615 & 0,189 & 0,866 & 0,650 & 0,217 & 0,669 & 0,486 & 0,304 \\
\hline PERTENC3 & 0,331 & 0,503 & 0,327 & 0,341 & 0,286 & 0,314 & 0,519 & 0,361 & 0,501 & 0,333 & 0,311 & 0,464 & 0,471 & 0,327 & 0,455 & 0,219 & 0,828 & 0,585 & 0,284 & 0,591 & 0,485 & 0,327 \\
\hline RCP1 & 0,233 & 0,421 & 0,360 & 0,303 & 0,165 & 0,256 & 0,500 & 0,396 & 0,520 & 0,289 & 0,241 & 0,437 & 0,449 & 0,284 & 0,473 & 0,138 & 0,637 & 0,840 & 0,172 & 0,695 & 0,639 & 0,243 \\
\hline $\mathrm{RCP} 2$ & 0,230 & 0,469 & 0,282 & 0,272 & 0,203 & 0,231 & 0,548 & 0,410 & 0,534 & 0,239 & 0,254 & 0,443 & 0,466 & 0,230 & 0,486 & 0,170 & 0,694 & 0,881 & 0,191 & 0,650 & 0,541 & 0,243 \\
\hline $\mathrm{RCP} 3$ & 0,250 & 0,451 & 0,292 & 0,294 & 0,201 & 0,247 & 0,553 & 0,422 & 0,536 & 0,263 & 0,254 & 0,435 & 0,447 & 0,259 & 0,477 & 0,160 & 0,670 & 0,888 & 0,191 & 0,672 & 0,565 & 0,251 \\
\hline $\mathrm{RCP} 4$ & 0,259 & 0,381 & 0,334 & 0,329 & 0,194 & 0,296 & 0,433 & 0,302 & 0,469 & 0,323 & 0,260 & 0,367 & 0,398 & 0,307 & 0,387 & 0,157 & 0,634 & 0,814 & 0,210 & 0,702 & 0,707 & 0,273 \\
\hline SAT1 & 0,107 & 0,243 & 0,300 & 0,117 & 0,152 & 0,148 & 0,129 & 0,040 & 0,079 & 0,109 & 0,098 & 0,119 & 0,131 & 0,108 & 0,069 & 0,139 & 0,177 & 0,104 & 0,796 & 0,133 & 0,147 & 0,098 \\
\hline SAT2 & 0,119 & 0,326 & 0,333 & 0,074 & 0,144 & 0,113 & 0,163 & 0,088 & 0,133 & 0,077 & 0,123 & 0,157 & 0,189 & 0,078 & 0,118 & 0,160 & 0,205 & 0,154 & 0,829 & 0,143 & 0,160 & 0,111 \\
\hline SAT3 & 0,085 & 0,373 & 0,334 & 0,069 & 0,124 & 0,123 & 0,187 & 0,106 & 0,179 & 0,069 & 0,067 & 0,185 & 0,186 & 0,102 & 0,170 & 0,125 & 0,235 & 0,200 & 0,880 & 0,201 & 0,170 & 0,076 \\
\hline SAT4 & 0,126 & 0,324 & 0,331 & 0,147 & 0,135 & 0,191 & 0,169 & 0,098 & 0,137 & 0,146 & 0,117 & 0,180 & 0,195 & 0,142 & 0,129 & 0,117 & 0,256 & 0,208 & 0,819 & 0,228 & 0,227 & 0,133 \\
\hline SAT6 & 0,135 & 0,395 & 0,346 & 0,131 & 0,126 & 0,143 & 0,200 & 0,152 & 0,207 & 0,121 & 0,130 & 0,244 & 0,244 & 0,127 & 0,198 & 0,140 & 0,245 & 0,236 & 0,852 & 0,250 & 0,191 & 0,131 \\
\hline SST1 & 0,343 & 0,585 & 0,343 & 0,312 & 0,223 & 0,255 & 0,618 & 0,486 & 0,686 & 0,318 & 0,335 & 0,559 & 0,586 & 0,294 & 0,616 & 0,212 & 0,683 & 0,639 & 0,222 & 0,847 & 0,481 & 0,317 \\
\hline SST2 & 0,224 & 0,388 & 0,369 & 0,281 & 0,202 & 0,254 & 0,407 & 0,292 & 0,416 & 0,261 & 0,224 & 0,367 & 0,383 & 0,243 & 0,359 & 0,157 & 0,610 & 0,719 & 0,226 & 0,812 & 0,719 & 0,210 \\
\hline SST3 & 0,214 & 0,369 & 0,294 & 0,300 & 0,196 & 0,299 & 0,488 & 0,309 & 0,423 & 0,292 & 0,209 & 0,389 & 0,345 & 0,282 & 0,364 & 0,140 & 0,587 & 0,616 & 0,127 & 0,819 & 0,640 & 0,226 \\
\hline
\end{tabular}




\begin{tabular}{lllllllllllllllllllllll}
\hline TRP1 & 0,202 & 0,305 & 0,347 & 0,325 & 0,186 & 0,280 & 0,380 & 0,247 & 0,359 & 0,301 & 0,216 & 0,316 & 0,332 & 0,289 & 0,301 & 0,106 & 0,540 & 0,636 & 0,199 & 0,652 & 0,911 & 0,217 \\
\hline TRP2 & 0,191 & 0,296 & 0,368 & 0,299 & 0,192 & 0,268 & 0,368 & 0,220 & 0,338 & 0,273 & 0,197 & 0,278 & 0,297 & 0,242 & 0,276 & 0,144 & 0,556 & 0,674 & 0,211 & 0,668 & 0,910 & 0,196 \\
\hline TRP3 & 0,195 & 0,339 & 0,216 & 0,292 & 0,186 & 0,232 & 0,388 & 0,263 & 0,395 & 0,267 & 0,213 & 0,346 & 0,308 & 0,250 & 0,341 & 0,160 & 0,567 & 0,624 & 0,177 & 0,655 & 0,885 & 0,204 \\
\hline Uso1 & 0,793 & 0,287 & 0,201 & 0,673 & 0,547 & 0,560 & 0,323 & 0,223 & 0,337 & 0,710 & 0,844 & 0,299 & 0,379 & 0,677 & 0,329 & 0,533 & 0,333 & 0,276 & 0,119 & 0,283 & 0,212 & 0,968 \\
\hline Uso2 & 0,785 & 0,268 & 0,199 & 0,678 & 0,556 & 0,547 & 0,333 & 0,230 & 0,331 & 0,709 & 0,854 & 0,307 & 0,358 & 0,678 & 0,318 & 0,528 & 0,343 & 0,285 & 0,144 & 0,302 & 0,224 & 0,954 \\
\hline Uso3 & 0,784 & 0,292 & 0,196 & 0,679 & 0,558 & 0,569 & 0,332 & 0,231 & 0,340 & 0,712 & $\mathbf{0 , 8 5 1}$ & 0,303 & 0,383 & 0,683 & 0,327 & 0,517 & 0,351 & 0,290 & 0,121 & 0,308 & 0,223 & 0,965 \\
\hline
\end{tabular}

Nota1: Em destaque $=$ cargas fatoriais

Nota2: As nomenclaturas das colunas foram suprimidas para facilitar a montagem da tabela. Assim: (1) atitude; (2) avaliação pessoal; (3) avaliação dos outros; (4) boca a boca; (5) congruência; (6) disposição a pagar mais; (7) fanatismo; (8) envolvimento com o futebol; (9) identificação time; (10) intenção de compra; (11) interesse; (12) lealdade comportamental; (13) lealdade conativa; (14) lealdade ao patrocinador; (15) lealdade atitudinal; (16) percepção; (17) pertencimento; (18) reconhecimento pessoal; (19) satisfação; (20) sentimento de status; (21) tratamento pessoal; e (22) uso.

Fonte: Desenvolvido pelo autor por meio do SmartPLS (3.2.6) 


\subsection{Avaliação do Modelo Estrutural (structural model assessment) - Amostra teste}

Conforme apresentado na avaliação do modelo de mensuração, os construtos deste trabalho foram avaliados quanto à validade convergente, à validade discriminante e à confiabilidade. As avaliações seguiram as recomendações de Bagozzi e Yi (1998), Chin e Newsted (1999) e Hair et al. (2014), entre outros. Todas as medições apresentaram cargas padronizadas $(\gamma)$ significantes, isto é, acima de 0,6 .

Quanto à validade convergente no nível das variáveis latentes, observa-se que a variância média extraída (AVE) apresentou valores acima de 0,5. Estes valores são considerados adequados. Em relação à confiabilidade, os valores do Alfa de Cronbach $(\alpha)$ ficaram acima de 0,7 , bem como a confiabilidade composta $(\rho)$, valores que são considerados adequados. Também é observado que a raiz quadrada da variância média extraída, valores na diagonal, foi maior do que os valores fora da diagonal (correlações), demonstrando a validade discriminante da escala utilizada.

Desta forma, analisando os mesmos atributos do modelo final ajustado da amostra préteste por meio dos mesmos princípios, verificamos que o modelo de mensuração também foi adequado na amostra teste. Assim, o modelo de mensuração tem validade convergente, validade discriminante e confiabilidade validados também na amostra teste.

Por consequência, podemos passar para próxima etapa, em que analisamos o modelo estrutural da amostra pré-teste (Figura 26) na amostra teste. Assim como na amostra pré-teste, adotaremos como medidas de análise: a verificação da validade preditiva do modelo, por meio do indicador Stone-Geisser de relevância preditiva $\left(\mathrm{Q}^{2}\right)$; a existência de problema de multicolinearidade no modelo proposto, por meio do Variance Inflation Factor (VIF); e, por fim, o tamanho do efeito de uma variável preditora específica em uma variável endógena, por meio do índice $f^{2}$, que mede a alteração no valor $\mathrm{R}^{2}$ quando uma variável exógena especificada é retirada do modelo. 
Figura 26: Modelo Estrutural (Cargas Fatoriais e $\mathbf{R}^{2}$ )

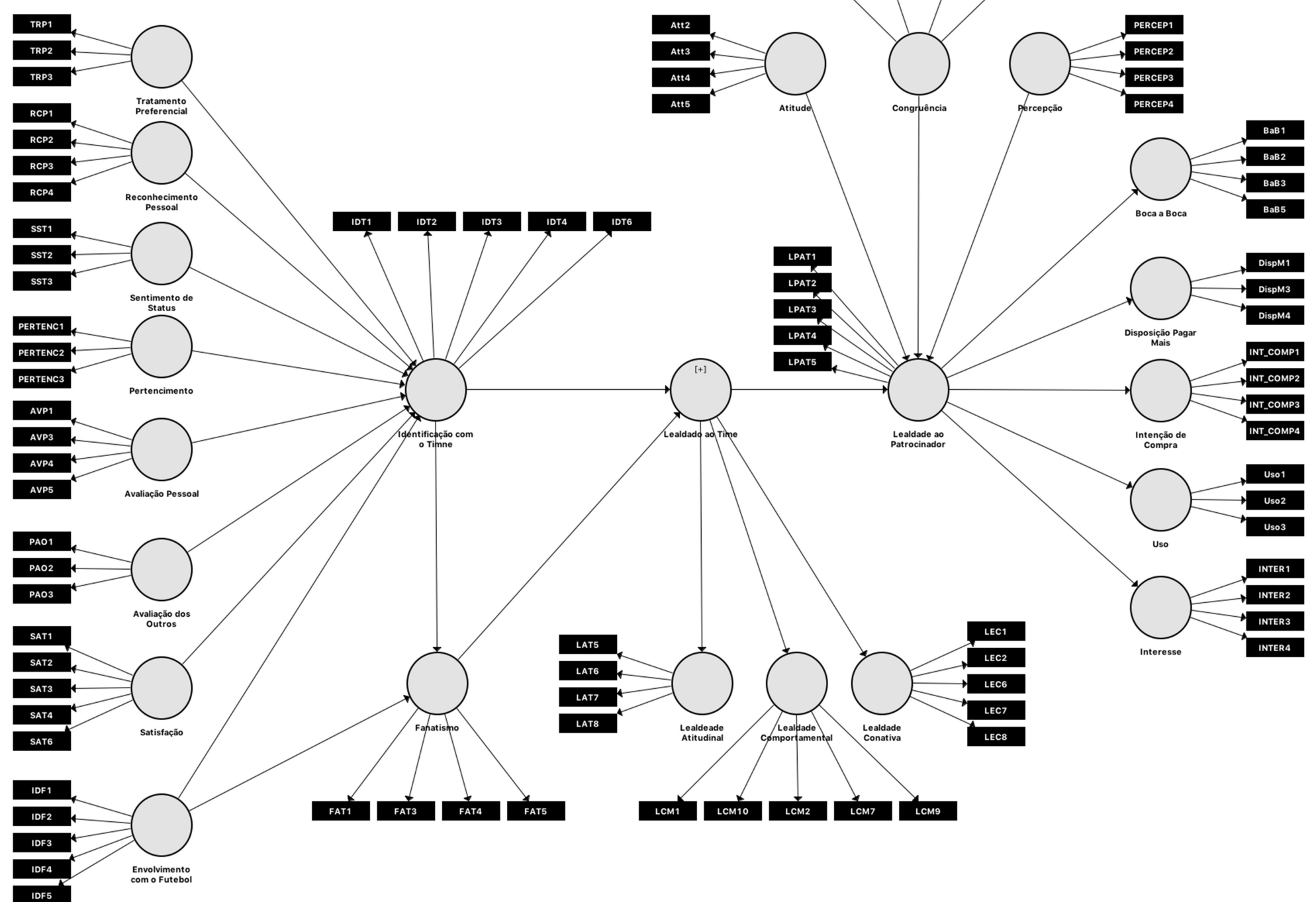

Fonte: Desenvolvido pelo autor por meio do SmartPLS (3.2.6) 
Para cálculo do índice $\mathrm{Q}^{2}$, adotamos o software SmartPls (versão 3.2.6) por meio do processo blindfolding com técnica estatística construct crossvalidated redundancy. $\mathrm{O}$ valor de D (distância) considerado foi de sete, mantendo o mesmo padrão utilizado no modelo estrutural da amostra pré-teste.

Tabela 59: Validade Preditiva $\left(Q^{2}\right)$ - Indicador de Stone-Geisser - Amostra teste

\begin{tabular}{ccc}
\hline Construto & $\mathbf{R}^{2}$ & $\mathbf{Q}^{2}$ \\
\hline Identificação com o Time & 0,685 & 0,482 \\
Lealdade ao patrocinador & 0,484 & 0,342 \\
Lealdade ao time & 0,746 & 0,355 \\
Fanatismo & 0,651 & 0,433 \\
Boca a Boca & 0,778 & 0,654 \\
Disposição Pagar Mais & 0,589 & 0,471 \\
Intenção de Compra & 0,691 & 0,579 \\
Interesse & 0,438 & 0,357 \\
Uso & 0,498 & 0,436 \\
\hline
\end{tabular}

Fonte: Desenvolvido pelo autor por meio do SmartPLS (3.2.6)

Ao analisar a Tabela 59, podemos confirmar a relevância preditiva do modelo. Assim como na amostra pré-teste (ver Tabela 42; pág. 188), na amostra teste os valores de $Q^{2}$ são superiores a 0,342 . Da mesma forma, o $\mathrm{R}^{2}$ também tem valores significativos, ficando acima de 0,438. Para essa conclusão usamos como valores referência os recomendados por Hair (2014): 0,02; 0,15; e 0, 35 como efeito pequeno, médio e grande, respectivamente.

Para analisar a Variance Inflation Factor (VIF) e o tamanho do efeito $\left(f^{2}\right)$, utilizamos o software SmartPls (versão 3.2.6) na opção PLS algorithmg (Hair, 2014). Assim, por meio do Variance Inflation Factor (VIF), verificamos se há problemas de multicolinearidade no modelo proposto (Tabela 60). E, por meio do índice $f^{2}$, mensuramos o tamanho do impacto do construto preditor omitido nos valores de $\mathrm{R}^{2}$ dos construtos endógenos (Tabela 61).

Tabela 60: Analise da Multicolinearidade (VIF) Amostra teste

\begin{tabular}{|c|c|c|c|}
\hline Preditora & $\begin{array}{c}\text { Identificação com o } \\
\text { time }\end{array}$ & Lealdade ao time & $\begin{array}{c}\text { Lealdade ao } \\
\text { patrocinador }\end{array}$ \\
\hline Avaliação Pessoal & 2,184 & & \\
\hline Avaliação dos Outros & 1,401 & & \\
\hline Envolvimento com Futebol & 1,572 & & \\
\hline
\end{tabular}




\begin{tabular}{lll} 
Pertencimento & 3,333 & \\
Reconhecimento Pessoal & 3,561 & \\
Satisfação & 1,319 & \\
Sentimento de Status & 3,736 & \\
Tratamento Preferencial & 2,416 & 2,493 \\
\hline Atitude & & 2,947 \\
Congruência & & 1,325 \\
Lealdade ao time & & 2,875 \\
Percepção & 2,702 & \\
\hline Fanatismo & 2,702 & \\
Identificação com o time & & \\
\hline
\end{tabular}

Fonte: Desenvolvido pelo autor por meio do SmartPLS (3.2.6)

Para verificação do VIF, adotamos os pressupostos de Hair (2014): o valor de VIF deve ser inferior a 5,0. Os valores referência para o índice $f^{2}$ seguiram as recomendações de Cohen (1988): 0,02, efeito pequeno; 0,15, efeito médio; e 0,35, efeito grande. As duas mensurações seguiram a mesma sequência executada na amostra pré-teste.

Os valores de VIF e $f^{2}$ atendem às exigências mínimas. Desta forma, assim como na amostra pré-teste, a amostra teste não apresenta efeito de multicolinearidade. Todos os valores estão abaixo de cinco (Tabela 60). Por sua vez, o índice $f^{2}$ apresenta resultados bastante variados. Na identificação com o time, destacam-se o envolvimento com o futebol $(0,200)$ e a avaliação pessoal $(0,155)$. No construto lealdade ao time, a identificação possui índice bastante elevado $(0,542)$ e apresenta-se como uma varável com alta influência sobre a variável endógena. E, por último, a variável lealdade ao patrocinador: atitude, como esperado, possui efeito grande no construto; já lealdade ao time possui efeito médio, assim como a congruência.

Tabela 61: tamanho do efeito $\left(f^{2}\right)-$ Amostra teste

\begin{tabular}{lcc}
\hline \multicolumn{1}{c}{ Preditora } & $\begin{array}{c}\text { Identificação com o } \\
\text { time }\end{array}$ & $\begin{array}{c}\text { Lealdade ao time } \\
\text { Lealdade ao } \\
\text { patrocinador }\end{array}$ \\
\hline Avaliação Pessoal & 0,155 \\
Avaliação dos Outros & 0,006 \\
Envolvimento com Futebol & 0,200 \\
Pertencimento & 0,034 \\
Reconhecimento Pessoal & 0,006 \\
Satisfação & 0,011
\end{tabular}




\begin{tabular}{lcc} 
Sentimento de Status & 0,034 & \\
Tratamento Preferencial & 0,009 & 0,184 \\
\hline Atitude & & 0,037 \\
Congruência & & 0,041 \\
Lealdade ao time & & 0,002 \\
Percepção & & \\
\hline Fanatismo & 0,127 & \\
Identificação com o time & 0,542 & \\
\hline
\end{tabular}

Fonte: Desenvolvido pelo autor por meio do SmartPLS (3.2.6)

\subsection{Teste de hipóteses - Amostra teste}

Como na amostra pré-teste, utilizamos o software SmartPls (versão 3.2.6) para realizar os testes de hipótese. Adotamos a opção Bootstrapping com re-amostragem de 5.000 (Hair, 2014) para calcular o t-valor, path coefficents e $\mathrm{R}^{2}$. O path coefficents é utilizado para avaliar as relações causais do modelo. Por sua vez, o $\mathrm{R}^{2}$ permite mensurar quanto as variáveis dependentes são explicadas pelo modelo estrutural (Tabela 62).

O grupo relacionado ao construto da identificação com o time apresenta todas as relações com coeficientes significativos. As relações avaliação dos outros $(\gamma=-0,050 ; p<$ $0,05)$; satisfação $(\gamma=-0,066 ; p<0,05)$; e tratamento pessoal $(\gamma=-0,082 ; p<0,05)$ apesar de significativas, diferentemente do esperado, apresentaram efeito negativo sobre a identificação com o time. Porém é importante ressaltar que todas as relações foram, independentemente do sinal, significativas, indicando que as variáveis relacionadas aos benefícios sociais/não financeiros podem ser avaliadas como antecedentes da identificação com o time.

As variáveis envolvimento com o futebol $(\gamma=0,197 ; p<0,01)$ e identificação com o time $(\gamma=0,661 ; p<0,01)$ mantiveram sua relação positiva e significativa com o construto fanatismo. Assim, a proposta de avaliar o fanatismo como um construto independente e, não como um nível da identificação mais uma vez é confirmada. Do mesmo modo, a identificação com o time $(\gamma=0,610 ; p<0,01)$ e fanatismo $(\gamma=0,295 ; p<0,01)$ também permaneceram com a relação positiva e de significativa com o construto lealdade ao time. 
Tabela 62: Coeficientes do modelo estrutural-Amostra teste

\begin{tabular}{|c|c|c|c|c|c|c|}
\hline \multirow{2}{*}{\multicolumn{2}{|c|}{ CAMINHO }} & \multirow{3}{*}{$\begin{array}{c}\begin{array}{c}\text { Coeficiente de } \\
\text { caminho }(\gamma)\end{array} \\
0,326\end{array}$} & \multicolumn{4}{|c|}{ MODELO TEÓRICO } \\
\hline & & & Desvio Padrão & Valor-t & $\mathbf{R}^{2}$ & $\mathbf{R}^{2 \text { ajustado }}$ \\
\hline H5 & Avaliação Pessoal $\rightarrow$ Identificação com o Time & & 0,040 & $8,127^{a}$ & \multirow{8}{*}{0,685} & \multirow{8}{*}{0,682} \\
\hline H6 & Avaliação dos Outros $\rightarrow$ Identificação com o Time & $-0,050$ & 0,025 & $1,99^{b}$ & & \\
\hline $\mathrm{H} 8$ & Envolvimento com o Futebol $\rightarrow$ Identificação com o Time & 0,315 & 0,037 & $8,557^{a}$ & & \\
\hline $\mathrm{H} 4$ & Pertencimento $\rightarrow$ Identificação com o Time & 0,189 & 0,045 & $4,238^{\mathrm{a}}$ & & \\
\hline $\mathrm{H} 2$ & Reconhecimento Pessoal $\rightarrow$ Identificação com o Time & 0,084 & 0,040 & $2,083^{b}$ & & \\
\hline $\mathrm{H} 7$ & Satisfação $\rightarrow$ Identificação com o Time & $-0,066$ & 0,022 & $3,047^{b}$ & & \\
\hline $\mathrm{H} 3$ & Sentimento de Status $\rightarrow$ Identificação com o Time & 0,200 & 0,049 & $4,119^{\mathrm{a}}$ & & \\
\hline $\mathrm{H} 1$ & Tratamento Preferencial $\rightarrow$ Identificação com o Time & $-0,082$ & 0,032 & $2,594^{b}$ & & \\
\hline $\mathrm{H} 10$ & Envolvimento com o Futebol $\rightarrow$ Fanatismo & 0,197 & 0,028 & $7,021^{\mathrm{a}}$ & \multirow{2}{*}{0,651} & \multirow{2}{*}{0,650} \\
\hline H9 & Identificação com o Time $\rightarrow$ Fanatismo & 0,661 & 0,026 & $25,422^{a}$ & & \\
\hline H12(a) & Identificação com o Time $\rightarrow$ Lealdade ao time & 0,610 & 0,035 & $17,635^{\mathrm{a}}$ & \multirow{2}{*}{0,746} & \multirow{2}{*}{0,745} \\
\hline $\mathrm{H} 12(\mathrm{~b})$ & Fanatismo $\rightarrow$ Lealdade ao time & 0,295 & 0,034 & $8,695^{a}$ & & \\
\hline H13(a) & Atitude $\rightarrow$ Lealdade ao patrocinador & 0,487 & 0,040 & $12,172^{\mathrm{a}}$ & \multirow{7}{*}{0,484} & \multirow{7}{*}{0,479} \\
\hline H13(b) & Efeito da moderação por meio da Atitude: Lealdade ao time $\rightarrow$ Lealdade ao patrocinador & 0,075 & 0,039 & 1,919 & & \\
\hline H14(a) & Percepção $\rightarrow$ Lealdade ao patrocinador & $-0,058$ & 0,046 & 1,268 & & \\
\hline H14(b) & Efeito da moderação por meio da Percepção: Lealdade ao time $\rightarrow$ Lealdade ao patrocinador & 0,001 & 0,040 & 0,034 & & \\
\hline $\mathrm{H} 15(\mathrm{a})$ & Congruência $\rightarrow$ Lealdade ao patrocinador & 0,238 & 0,045 & $5,262^{\mathrm{a}}$ & & \\
\hline $\mathrm{H} 15(\mathrm{~b})$ & Efeito da moderação por meio da Congruência: Lealdade ao time $\rightarrow$ Lealdade ao patrocinador & 0,033 & 0,037 & 0,907 & & \\
\hline $\mathrm{H} 16$ & Lealdade ao time $\rightarrow$ Lealdade ao patrocinador & 0,168 & 0,031 & $5,328^{a}$ & & \\
\hline H17(a) & Lealdade ao patrocinador $\rightarrow$ Boca a Boca & 0,882 & 0,011 & $83,067^{a}$ & 0,778 & 0,778 \\
\hline $\mathrm{H} 17(\mathrm{c})$ & Lealdade ao patrocinador $\rightarrow$ Disposição Pagar Mais & 0,767 & 0,020 & $38,218^{a}$ & 0,589 & 0,588 \\
\hline $\mathrm{H} 17$ (b) & Lealdade ao patrocinador $\rightarrow$ Intenção de Compra & 0,831 & 0,016 & $52,327^{a}$ & 0,691 & 0,691 \\
\hline $\mathrm{H} 17(\mathrm{e})$ & Lealdade ao patrocinador $\rightarrow$ Interesse & 0,662 & 0,019 & $34,441^{a}$ & 0,438 & 0,437 \\
\hline $\mathrm{H} 17(\mathrm{~d})$ & Lealdade ao patrocinador $\rightarrow$ Uso & 0,706 & 0,019 & $37,893^{\mathrm{a}}$ & 0,498 & 0,498 \\
\hline
\end{tabular}


Como propusemos como foco central desta tese, a lealdade ao time afetou positivamente e de forma significante $(\gamma=0,168 ; p<0,01)$ a variável lealdade ao patrocinador. Todas as moderações mantiveram-se não significativas, fortalecendo ainda mais a proposição principal do trabalho.

\subsection{Mediação - Amostra teste}

Após os testes de hipóteses, assim como com a amostra pré-teste, verificamos a existência de efeito mediador das variáveis apresentadas neste trabalho. A estatística utilizada foi a análise da Variância Explicada (VAF - Variance Accounted For) (Hair et al. (2014).

Novamente as mediações analisadas foram: (a) mediação da identificação com o time na relação entre os construtos antecedentes da identificação com o time e a lealdade ao time; (b) mediação do fanatismo na relação entre a identificação com o time e a lealdade ao time; (c) mediação da lealdade ao time na relação entre fanatismo e identificação com o time com a lealdade ao patrocinador; e (d) mediação da relação entre a lealdade ao time e a lealdade ao patrocinador por meio da atitude, congruência e percepção. Os resultados das mediações encontram-se na Tabela 63.

Tabela 63: Teste de mediação - Amostra teste

\begin{tabular}{lcc}
\hline \multicolumn{1}{c}{ CAMINHO } & VAF (\%) & RESULTADO \\
\hline $\begin{array}{l}\text { Tratamento Preferencial } \rightarrow \text { Identificação com o Time } \\
\text { Identificação com o Time } \rightarrow \text { Lealdade ao time }\end{array}$ & $\begin{array}{c}\text { Efeito direto é não } \\
\text { significante }\end{array}$ & - \\
\hline $\begin{array}{l}\text { Pertencimento } \rightarrow \text { Identificação com o Time } \rightarrow \text { Lealdade } \\
\text { ao time }\end{array}$ & 33,96 & parcial \\
\hline $\begin{array}{l}\text { Reconhecimento Pessoal } \rightarrow \text { Identificação com o Time } \rightarrow \\
\text { Lealdade ao time }\end{array}$ & $\begin{array}{c}\text { Efeito direto é não } \\
\text { significante }\end{array}$ & - \\
\hline $\begin{array}{l}\text { Sentimento de Status } \rightarrow \text { Identificação com o Time } \rightarrow \\
\text { Lealdade ao time }\end{array}$ & $\begin{array}{c}\text { Efeito direto é não } \\
\text { significante }\end{array}$ & - \\
\hline $\begin{array}{l}\text { Avaliação Pessoal } \rightarrow \text { Identificação com o Time } \rightarrow \\
\text { Lealdade ao time }\end{array}$ & $\begin{array}{c}30,79 \\
\text { Avaliação dos Outros } \rightarrow \text { Identificação com o Time } \rightarrow \\
\text { Lealdade ao time }\end{array}$ & $\begin{array}{c}\text { Efeito direto é não } \\
\text { significante }\end{array}$ \\
\hline $\begin{array}{l}\text { Satisfação } \rightarrow \text { Identificação com o Time } \rightarrow \text { Lealdade ao } \\
\text { time }\end{array}$ & $\begin{array}{c}\text { Efeito direto é não } \\
\text { significante }\end{array}$ \\
\hline
\end{tabular}




\begin{tabular}{lcc}
\hline $\begin{array}{l}\text { Envolvimento com o Futebol } \rightarrow \text { Identificação com o Time } \\
\rightarrow \text { Lealdade ao time }\end{array}$ & 27,54 & Mediação parcial \\
\hline $\begin{array}{l}\text { Identificação com o Time } \rightarrow \text { Fanatismo } \rightarrow \text { Lealdade ao } \\
\text { time }\end{array}$ & 19,50 & Sem Mediação \\
\hline $\begin{array}{l}\text { Fanatismo } \rightarrow \text { Lealdade ao time } \rightarrow \text { Lealdade ao } \\
\text { patrocinador }\end{array}$ & $\begin{array}{c}\text { Efeito direto é não } \\
\text { significante }\end{array}$ & Mediação parcial \\
\hline $\begin{array}{l}\text { Identificação com o Time } \rightarrow \text { Lealdade ao time } \rightarrow \\
\text { Lealdade ao patrocinador }\end{array}$ & 50,19 & Mediação parcial \\
\hline $\begin{array}{l}\text { Lealdade ao time } \rightarrow \text { Atitude } \rightarrow \text { Lealdade ao patrocinador } \\
\text { Lealdade ao time } \rightarrow \text { Congruência } \rightarrow \text { Lealdade ao } \\
\text { patrocinador }\end{array}$ & 32,19 & Sem Mediação \\
\hline \begin{tabular}{l} 
Lealdade ao time $\rightarrow$ Percepção $\rightarrow$ Lealdade ao \\
\hline
\end{tabular}
\end{tabular}

Fonte: Desenvolvido pelo autor por meio do SmartPLS (3.2.6)

$\mathrm{Na}$ Tabela 64, apresentamos os resultados das hipóteses propostas nesta pesquisa e analisados por meio da aplicação do questionário desenvolvido e aplicado na amostra teste. Do total de 28 hipóteses, uma hipótese (H15b) não foi confirmada. As hipóteses H1, H6, H7 e $\mathrm{H} 13 \mathrm{c}$ foram confirmadas parcialmente. As demais hipóteses foram confirmadas.

Tabela 64: Teste de Hipótese - Amostra pré-teste

HIPÓTESE RESULTADO

H1. Tratamento preferencial tem efeito positivo e significante na identificação com o time.

Confirmada parcialmente

H2. Reconhecimento pessoal tem efeito positivo e significante na identificação com o time.

Confirmada

H3. Sentimento de status de tem efeito positivo e significante na identificação com o time.

Confirmada

H4. Sentimento de Pertencimento tem efeito positivo e significante na identificação com o time.

Confirmada

H5. Avaliação Pessoal tem efeito positivo e significante na identificação com o time.

Confirmada

H6. Avaliação dos Outros tem efeito positivo e significante na identificação com o time.

Confirmada parcialmente

H7. Satisfação como o time tem efeito positivo e significante na identificação com o time.

Confirmada parcialmente

H8. Envolvimento com o Esporte com o tem efeito positivo e significante na identificação com o time.

Confirmada 
H9. Identificação com o time tem efeito positivo e significante no fanatismo.

Confirmada

H10. Envolvimento com o futebol tem efeito positivo e significante no fanatismo.

Confirmada

H11. Identificação com o time, fanatismo e lealdade ao time são construtos distintos.

Confirmada

H12 a. Lealdade ao time é afetada positivamente e de forma significante por identificação com o time.

Confirmada

H12 b. Lealdade ao time é afetada positivamente e de forma significante por fanatismo.

Confirmada

H13 a. Atitude afetada positivamente e de forma significativa a lealdade ao patrocinador.

Confirmada

H13 b. Atitude não modera a relação entre lealdade ao time e lealdade ao patrocinador.

Confirmada

H13 c. Atitude não media a relação entre lealdade ao time e lealdade ao patrocinador

Confirmada parcialmente

H14 a. Congruência afetada positivamente e de forma significativa a lealdade ao patrocinador.

\section{Confirmada}

H14 b. Congruência não modera a relação entre lealdade ao time e lealdade ao patrocinador.

\section{Confirmada}

H14 c. Congruência não media a relação entre lealdade ao time e lealdade ao patrocinador

Confirmada

H15 a. Percepção afetada positivamente e de forma significativa a lealdade ao patrocinador.

Não confirmada

H15 b. A Percepção não modera a relação entre lealdade ao time e lealdade ao patrocinador.

Confirmada

H15 c. Percepção não media a relação entre lealdade ao time e lealdade ao patrocinador

Confirmada

H16. Lealdade ao time terá efeito positivo e significativo na lealdade ao patrocinador.

Confirmada

H17 a. A transferência da lealdade ao patrocinador terá efeito positivo e significativo no boca a boca.

Confirmada

H17 b. A transferência da lealdade ao patrocinador terá efeito positivo e significativo na Intenção de compra.

Confirmada

H17 c. A transferência da lealdade ao patrocinador terá efeito positivo e significativo na disposição a pagar mais.

Confirmada

H17 d. A transferência da lealdade ao patrocinador terá efeito positivo e significativo no uso.

Confirmada

H17 e. A transferência da lealdade ao patrocinador terá efeito positivo e

Confirmada 
significativo no interesse.

\subsection{Variável de controle do viés do método}

$\mathrm{Na}$ aplicação de pesquisa por meio de questionário, muitas vezes todas as variáveis são medidas de forma similar bastante similar. Um exemplo é, como no caso deste trabalho, utilizar uma coleta de dados, por um único questionário para todas as variáveis latentes em que o formato das respostas seja idêntico. Em nosso caso, utilizamos uma escala padronizada de 1 a 7 . Outro ponto está relacionado com a fonte de informação, ou seja, o respondente. Quando a fonte é a mesma e o questionário possui uma escala redundante, corre-se o risco de haver um aumento na correlação entres as variáveis latentes. Esse descompasso é conhecido como viés do método (common method bias ou common method variance) (Podsakoff, Mackenzie, Lee, \& Podsakoff, 2003).

De forma a mensurar esse efeito, em modelos de equação estrutural que utilizam PLSSEM, Chin, Thatcher, Wright e Steel (2013) recomendam a inclusão de uma nova variável latente no modelo. Essa variável deve ser inserida no questionário, portanto deve ser pensada previamente e precisa ser mensurada por quatro a doze indicadores formativos. Os itens que formam essa nova variável não devem ter relação teórica com o modelo em estudo (Chin, Thatcher, Wright, \& Steel, 2013).

Essa variável de controle do viés do método (VCVM) deve ser ligada a cada um dos construtos dependentes (ou endógenos). Com isso, deve-se rodar com a inclusão desta variável e comprar os resultados dos coeficientes de caminho e do $\mathrm{R}^{2}$ (Chin et al., 2013). A diferença existente entre eles é o chamado viés do método.

Nesta etapa da pesquisa, de forma a garantir um controle mais elaborado da aplicação do questionário e, também, reforçar o desenvolvimento da escala proposta, selecionamos 11 variáveis relacionadas ao interesse do respondente por tipos de livros. Assim, foi perguntado por exemplo, numa escala de 1 a 7 , o quão interessante é para o respondente ler livros biográficos.

A Tabela 65 apresenta o path coefficent e o $\mathrm{R}^{2}$ com e sem a variável de controle. As diferenças entre os modelos (com e sem) são mínimas, variando de 0,01 a 0,03. Estas 
diferenças são o efeito que foi captado e neutralizado em relação ao viés do método. Em outras palavras, podemos dizer que a técnica utilizada para aplicação não influenciou nas respostas dos participantes.

Com isso, garantiu-se o controle da aplicação do questionário, exceto em relação aos. os passos propostos na Tabela 13 (pág. 123), tanto na amostra pré-teste e na amostra teste. Apresentaremos na próxima seção os resultados finais. 
Tabela 65: Controle de Viés do Método

\begin{tabular}{|c|c|c|c|c|c|c|c|}
\hline \multirow{2}{*}{\multicolumn{2}{|c|}{ CAMINHOS }} & \multicolumn{3}{|c|}{ MODELO TEÓRICO } & \multicolumn{3}{|c|}{ VARIÁVEL DE CONTROLE DO VIÉS DO MÉTODO } \\
\hline & & $\begin{array}{c}\text { Coeficiente de } \\
\text { caminho }(\gamma)\end{array}$ & Valor-t & $\mathbf{R}^{2}$ & $\begin{array}{c}\text { Coeficiente de } \\
\text { caminho }(\gamma)\end{array}$ & Valor-t & $\mathbf{R}^{2}$ \\
\hline H5 & Avaliação Pessoal $\rightarrow$ Identificação com o Time & 0,326 & $8,127^{\mathrm{a}}$ & \multirow{8}{*}{0,685} & 0,315 & $7,824^{\mathrm{a}}$ & \multirow{8}{*}{0,688} \\
\hline H6 & Avaliação dos Outros $\rightarrow$ Identificação com o Time & $-0,050$ & $1,99^{\mathrm{b}}$ & & $-0,05$ & $2,014^{\mathrm{b}}$ & \\
\hline $\mathrm{H} 8$ & Envolvimento com o Futebol $\rightarrow$ Identificação com o Time & 0,315 & $8,557^{\mathrm{a}}$ & & 0,313 & $8,637^{\mathrm{a}}$ & \\
\hline $\mathrm{H} 4$ & Pertencimento $\rightarrow$ Identificação com o Time & 0,189 & $4,238^{\mathrm{a}}$ & & 0,204 & $4,221^{\mathrm{a}}$ & \\
\hline $\mathrm{H} 2$ & Reconhecimento Pessoal $\rightarrow$ Identificação com o Time & 0,084 & $2,083^{\mathrm{b}}$ & & 0,096 & $2,258^{\mathrm{b}}$ & \\
\hline $\mathrm{H} 7$ & Satisfação $\rightarrow$ Identificação com o Time & $-0,066$ & $3,047^{\mathrm{b}}$ & & $-0,073$ & $3,139^{\mathrm{b}}$ & \\
\hline $\mathrm{H} 3$ & Sentimento de Status $\rightarrow$ Identificação com o Time & 0,200 & $4,119^{\mathrm{a}}$ & & 0,196 & $3,931^{\mathrm{a}}$ & \\
\hline $\mathrm{H} 1$ & Tratamento Preferencial $\rightarrow$ Identificação com o Time & $-0,082$ & $2,594^{\mathrm{b}}$ & & $-0,078$ & $2,484^{\mathrm{b}}$ & \\
\hline H10 & Envolvimento com o Futebol $\rightarrow$ Fanatismo & 0,197 & $7,021^{\mathrm{a}}$ & \multirow{2}{*}{0,651} & 0,208 & $6,999^{\mathrm{a}}$ & \multirow{2}{*}{0,65} \\
\hline $\mathrm{H} 9$ & Identificação com o Time $\rightarrow$ Fanatismo & 0,661 & $25,422^{\mathrm{a}}$ & & 0,651 & $23,891^{\mathrm{a}}$ & \\
\hline H12(a) & Identificação com o Time $\rightarrow$ Lealdade ao time & 0,610 & $17,635^{\mathrm{a}}$ & \multirow{2}{*}{0,746} & 0,6 & $17,319^{\mathrm{a}}$ & \multirow{2}{*}{0,753} \\
\hline H12(b) & Fanatismo $\rightarrow$ Lealdade ao time & 0,295 & $8,695^{\mathrm{a}}$ & & 0,271 & $8,181^{\mathrm{a}}$ & \\
\hline H13(a) & Atitude $\rightarrow$ Lealdade ao patrocinador & 0,487 & $12,172^{\mathrm{a}}$ & \multirow{7}{*}{0,484} & 0,489 & $11,703^{\mathrm{a}}$ & \multirow{7}{*}{0,484} \\
\hline H13(b) & $\begin{array}{l}\text { Efeito da moderação por meio da Atitude: Lealdade ao time } \rightarrow \text { Lealdade ao } \\
\text { patrocinador }\end{array}$ & 0,075 & 1,919 & & 0,057 & 1,4 & \\
\hline H14(a) & Percepção $\rightarrow$ Lealdade ao patrocinador & $-0,058$ & 1,268 & & $-0,032$ & 0,665 & \\
\hline H14(b) & $\begin{array}{l}\text { Efeito da moderação por meio da Percepção: Lealdade ao time } \rightarrow \text { Lealdade ao } \\
\text { patrocinador }\end{array}$ & 0,001 & 0,034 & & $-0,005$ & 0,127 & \\
\hline H15(a) & Congruência $\rightarrow$ Lealdade ao patrocinador & 0,238 & $5,262^{\mathrm{a}}$ & & 0,217 & $4,672^{\mathrm{a}}$ & \\
\hline $\mathrm{H} 15(\mathrm{~b})$ & $\begin{array}{l}\text { Efeito da moderação por meio da Congruência: Lealdade ao time } \rightarrow \text { Lealdade } \\
\text { ao patrocinador }\end{array}$ & 0,033 & 0,907 & & 0,044 & 1,153 & \\
\hline H16 & Lealdade ao time $\rightarrow$ Lealdade ao patrocinador & 0,168 & $5,328^{\mathrm{a}}$ & & 0,17 & $4,972^{\mathrm{a}}$ & \\
\hline H17(a) & Lealdade ao patrocinador $\rightarrow$ Boca a Boca & 0,882 & $83,067^{\mathrm{a}}$ & 0,778 & 0,879 & $76,927^{\mathrm{a}}$ & 0,773 \\
\hline $\mathrm{H} 17(\mathrm{c})$ & Lealdade ao patrocinador $\rightarrow$ Disposição Pagar Mais & 0,767 & $38,218^{\mathrm{a}}$ & 0,589 & 0,762 & $36,648^{\mathrm{a}}$ & 0,581 \\
\hline $\mathrm{H} 17(\mathrm{~b})$ & Lealdade ao patrocinador $\rightarrow$ Intenção de Compra & 0,831 & $52,327^{\mathrm{a}}$ & 0,691 & 0,836 & $55,854^{\mathrm{a}}$ & 0,7 \\
\hline $\mathrm{H} 17(\mathrm{e})$ & Lealdade ao patrocinador $\rightarrow$ Interesse & 0,662 & $34,441^{\mathrm{a}}$ & 0,438 & 0,671 & $35,525^{\mathrm{a}}$ & 0,45 \\
\hline $\mathrm{H} 17(\mathrm{~d})$ & Lealdade ao patrocinador $\rightarrow$ Uso & 0,706 & $37,893^{\mathrm{a}}$ & 0,498 & 0,72 & $40,724^{\mathrm{a}}$ & 0,518 \\
\hline
\end{tabular}




\section{Análise dos Resultados na comparação entre as amostras}

Os resultados deste trabalho são descritos neste seção. Como um dos objetivos da pesquisa é o desenvolvimento de uma nova escala que permitisse mensurar não apenas a transferência de lealdade (objetivo principal do trabalho), mas também um novo caminho na formação da identificação do torcedor com seu time, uma das premissas básicas foi a aplicação do modelo em duas amostras distintas, que, aqui, denominamos amostra pré-teste e amostra teste. Assim, nesta seção, focamos em comparar os dados combinados e analisar os resultados alcançados.

Mantendo o critério adotado desde início do desenvolvimento deste trabalho, nesta seção, mantivemos a apresentação dividida nos dois estágios de análise sugeridos por Hair (1998): (1) mensuração do modelo, que expõe todas as ligações entre as variáveis latentes e também entre suas variáveis observáveis.; e (2) avaliação do modelo estrutural, que exibe as ligações postulados conceitualmente entre as variáveis latentes (hipóteses).

Assim, as análises dos dados seguiram as etapas de verificação de missings e outliers, avaliação do modelo de mensuração (validade convergente, validade discriminante e confiabilidade) e análise do modelo estrutural (estimação dos coeficientes de caminhos, de moderação e mediação e, por fim, teste das hipóteses). O modelo estrutural foi estimado por mínimos quadrados parciais (PLS-SEM). Este método foi utilizado por melhor se adequar ao contexto da pesquisa, isto é, à necessidade de estimar o relacionamento entre variáveis latentes em que não há condições suficientes para assumir a suposição de normalidade multivariada. Além disso, o modelo teórico proposto pode ser definido como um modelo complexo. Desta forma, conforme apresenta Hair et al. (2014), o uso da técnica foi apropriado. O modelo foi estimado no software SmartPLS v.3.2.6 (Ringle et al.,2015).

\subsection{Modelo de mensuração}

No modelo de mensuração, os construtos foram avaliados quanto à validade convergente, à validade discriminante e à confiabilidade. As avaliações seguiram as recomendações de Bagozzi e Yi (1998), Chin e Newsted (1999) e Hair et al. (2014). Com relação à validade convergente (Tabela 2), todas as medições apresentaram cargas 
padronizadas $(\gamma)$ significantes, isto é, acima de 0,6 . No nível das variáveis latentes, a variância média extraída (AVE) apresentou valores acima de 0,5 . Por fim, com relação à confiabilidade, a confiabilidade composta $(\rho)$ e o Alpha de Cronbach $(\alpha)$ apresentaram valores superiores a 0,7 (Tabela 66).

Tabela 66: Avaliação do nível de significância dos indicadores - Amostra teste

\begin{tabular}{|c|c|c|c|c|c|c|c|c|}
\hline \multirow{2}{*}{ Indicadores } & \multicolumn{4}{|c|}{ Amostra Pré-teste } & \multicolumn{4}{|c|}{ Amostra Teste } \\
\hline & $\begin{array}{c}\text { Carga } \\
\text { Fatorial }(\gamma)\end{array}$ & $\alpha$ & $\rho$ & AVE & $\begin{array}{c}\text { Carga } \\
\text { Fatorial }(\gamma)\end{array}$ & $\boldsymbol{\alpha}$ & $\boldsymbol{\rho}$ & AVE \\
\hline \multicolumn{9}{|c|}{ Tratamento Preferencial } \\
\hline TRP1 & 0,902 & \multirow{3}{*}{0,879} & \multirow{3}{*}{0,925} & \multirow{3}{*}{0,805} & 0,911 & \multirow{3}{*}{0,885} & \multirow{3}{*}{0,929} & \multirow{3}{*}{0,813} \\
\hline TRP2 & 0,912 & & & & 0,910 & & & \\
\hline TRP3 & 0,878 & & & & 0,885 & & & \\
\hline \multicolumn{9}{|c|}{ Reconhecimento Pessoal } \\
\hline RCP1 & 0,841 & \multirow{4}{*}{0,867} & \multirow{4}{*}{0,910} & \multirow{4}{*}{0,717} & 0,840 & \multirow{4}{*}{0,878} & \multirow{4}{*}{0,917} & \multirow{4}{*}{0,733} \\
\hline $\mathrm{RCP} 2$ & 0,879 & & & & 0,881 & & & \\
\hline $\mathrm{RCP} 3$ & 0,879 & & & & 0,888 & & & \\
\hline RCP4 & 0,783 & & & & 0,814 & & & \\
\hline \multicolumn{9}{|c|}{ Sentimento de Status } \\
\hline SST1 & 0,853 & \multirow{3}{*}{0,751} & \multirow{3}{*}{0,856} & \multirow{3}{*}{0,665} & 0,847 & \multirow{3}{*}{0,769} & \multirow{3}{*}{0,866} & \multirow{3}{*}{0,683} \\
\hline SST2 & 0,808 & & & & 0,812 & & & \\
\hline SST3 & 0,785 & & & & 0,819 & & & \\
\hline \multicolumn{9}{|l|}{ Pertencimento } \\
\hline PERTENC1 & 0,787 & \multirow{3}{*}{0,759} & \multirow{3}{*}{0,861} & \multirow{3}{*}{0,675} & 0,802 & \multirow{3}{*}{0,778} & & \\
\hline PERTENC2 & 0,865 & & & & 0,866 & & 0,871 & 0,693 \\
\hline PERTENC3 & 0,811 & & & & 0,828 & & & \\
\hline Avaliação Pessoa & & & & & & & & \\
\hline AVP1 & 0,680 & & & & 0,719 & & & \\
\hline AVP3 & 0,880 & 0804 & 0873 & 0624 & 0,869 & ? & $090 ?$ & 0, \\
\hline AVP4 & 0,836 & & & & 0,831 & & & \\
\hline AVP5 & 0,774 & & & & 0,804 & & & \\
\hline Avaliação dos $\mathrm{O}$ & & & & & & & & \\
\hline PAO1 & 0,839 & & & & 0,812 & & & \\
\hline $\mathrm{PAO} 2$ & 0,808 & 0,766 & 0,864 & 0,680 & 0,807 & 0,734 & 0,849 & 0,652 \\
\hline PAO3 & 0,826 & & & & 0,803 & & & \\
\hline Satisfação & & & & & & & & \\
\hline SAT1 & 0,792 & 0805 & ר?0 & 0703 & 0,796 & ר? & תרת & 608 \\
\hline SAT2 & 0,836 & & & ( ) & 0,829 & & & \\
\hline
\end{tabular}




\begin{tabular}{|c|c|c|c|c|c|c|c|c|}
\hline SAT3 & 0,881 & & & & 0,880 & & & \\
\hline SAT4 & 0,825 & & & & 0,819 & & & \\
\hline SAT6 & 0,856 & & & & 0,852 & & & \\
\hline \multicolumn{9}{|c|}{ Envolvimento com o Futebol } \\
\hline IDF1 & 0,902 & \multirow{5}{*}{0,903} & \multirow{5}{*}{0,928} & \multirow{5}{*}{0,721} & 0,918 & \multirow{5}{*}{0,913} & \multirow{5}{*}{0,935} & \multirow{5}{*}{0,742} \\
\hline IDF2 & 0,853 & & & & 0,871 & & & \\
\hline IDF3 & 0,837 & & & & 0,835 & & & \\
\hline IDF4 & 0,803 & & & & 0,821 & & & \\
\hline IDF5 & 0,847 & & & & 0,858 & & & \\
\hline \multicolumn{9}{|c|}{ Identificação com o Time } \\
\hline IDT1 & 0,818 & \multirow{5}{*}{0,899} & \multirow{5}{*}{0,925} & \multirow{5}{*}{0,712} & 0,879 & \multirow{5}{*}{0,917} & \multirow{5}{*}{0,938} & \multirow{5}{*}{0,752} \\
\hline IDT2 & 0,789 & & & & 0,794 & & & \\
\hline IDT3 & 0,888 & & & & 0,908 & & & \\
\hline IDT4 & 0,856 & & & & 0,881 & & & \\
\hline IDT6 & 0,866 & & & & 0,870 & & & \\
\hline \multicolumn{9}{|l|}{ Fanatismo } \\
\hline FAT1 & 0,898 & \multirow{4}{*}{0,866} & \multirow{4}{*}{0,909} & \multirow{4}{*}{0,714} & 0,891 & \multirow{4}{*}{0,862} & \multirow{4}{*}{0,906} & \multirow{4}{*}{0,708} \\
\hline FAT3 & 0,787 & & & & 0,793 & & & \\
\hline FAT4 & 0,835 & & & & 0,822 & & & \\
\hline FAT5 & 0,858 & & & & 0,856 & & & \\
\hline \multicolumn{9}{|c|}{ Lealdade Atitudinal } \\
\hline LAT5 & 0,775 & \multirow{4}{*}{0,827} & \multirow{4}{*}{0,885} & \multirow{4}{*}{0,66} & 0,813 & & & \\
\hline LAT6 & 0,855 & & & & 0,881 & 0856 & בח0 & 0600 \\
\hline LAT7 & 0,745 & & & & 0,772 & 0,050 & 0,902 & 0,099 \\
\hline LAT7 & 0,867 & & & & 0,873 & & & \\
\hline Lealdade Cor & & & & & & & & \\
\hline LEC1 & 0,821 & & & & 0,804 & & & \\
\hline LEC2 & 0,689 & & & & 0,702 & & & \\
\hline LEC6 & 0,731 & 0,813 & 0,870 & 0,574 & 0,791 & 0,840 & 0,887 & 0,611 \\
\hline LEC7 & 0,778 & & & & 0,811 & & & \\
\hline LEC8 & 0,763 & & & & 0,796 & & & \\
\hline Lealdade Cor & & & & & & & & \\
\hline LCM1 & 0,785 & & & & 0,808 & & & \\
\hline LCM2 & 0,789 & & & & 0,782 & & & \\
\hline LCM7 & 0,801 & 0,787 & 0,854 & 0,541 & 0,805 & 0,813 & 0,870 & 0,573 \\
\hline LCM9 & 0,641 & & & & 0,701 & & & \\
\hline LCM10 & 0,645 & & & & 0,679 & & & \\
\hline Percepção & & & & & & & & \\
\hline PERCEP1 & 0,817 & 0,854 & 0,901 & 0,695 & 0,803 & 0,841 & 0,893 & 0,677 \\
\hline
\end{tabular}




\begin{tabular}{|c|c|c|c|c|c|c|c|c|}
\hline PERCEP2 & 0,861 & & & & 0,845 & & & \\
\hline PERCEP3 & 0,802 & & & & 0,794 & & & \\
\hline PERCEP4 & 0,855 & & & & 0,848 & & & \\
\hline \multicolumn{9}{|l|}{ Congruência } \\
\hline CONG1 & 0,877 & \multirow{4}{*}{0,874} & \multirow{4}{*}{0,914} & \multirow{4}{*}{0,726} & 0,874 & \multirow{4}{*}{0,871} & \multirow{4}{*}{0,912} & \multirow{4}{*}{0,722} \\
\hline CONG2 & 0,803 & & & & 0,824 & & & \\
\hline CONG3 & 0,862 & & & & 0,847 & & & \\
\hline CONG5 & 0,865 & & & & 0,852 & & & \\
\hline \multicolumn{9}{|l|}{ Atitude } \\
\hline ATT2 & 0,889 & \multirow{4}{*}{0,937} & \multirow{4}{*}{0,955} & \multirow{4}{*}{0,841} & 0,895 & \multirow{4}{*}{0,934} & \multirow{4}{*}{0,953} & \multirow{4}{*}{0,835} \\
\hline ATT3 & 0,926 & & & & 0,922 & & & \\
\hline ATT4 & 0,925 & & & & 0,915 & & & \\
\hline ATT5 & 0,928 & & & & 0,923 & & & \\
\hline \multicolumn{9}{|c|}{ Lealdade ao Patrocinador } \\
\hline LPAT1 & 0,846 & \multirow{5}{*}{0,913} & \multirow{5}{*}{0,935} & \multirow{5}{*}{0,742} & 0,867 & \multirow{5}{*}{0,921} & \multirow{5}{*}{0,941} & \multirow{5}{*}{0,760} \\
\hline LPAT2 & 0,825 & & & & 0,849 & & & \\
\hline LPAT3 & 0,862 & & & & 0,853 & & & \\
\hline LPAT4 & 0,865 & & & & 0,872 & & & \\
\hline LPAT5 & 0,907 & & & & 0,917 & & & \\
\hline \multicolumn{9}{|l|}{ Boca a Boca } \\
\hline $\mathrm{BaB} 1$ & 0,913 & \multirow{4}{*}{0,956} & \multirow{4}{*}{0,968} & \multirow{4}{*}{0,883} & 0,928 & & & \\
\hline BaB2 & 0,952 & & & & 0,955 & 0061 & 0077 & 0805 \\
\hline $\mathrm{BaB} 3$ & 0,939 & & & & 0,942 & & 2, & נינס, \\
\hline BaB5 & 0,955 & & & & 0,959 & & & \\
\hline Intenção de com & & & & & & & & \\
\hline INT_COMP1 & 0,955 & & & & 0,961 & & & \\
\hline INT_COMP2 & 0,918 & 0.054 & 0066 & 0878 & 0,925 & 0050 & 0071 & 0807 \\
\hline INT_COMP3 & 0,938 & היל, & טסלוס & , & 0,944 & צ & 1 ו ו & 2 \\
\hline INT_COMP4 & 0,936 & & & & 0,947 & & & \\
\hline Disposição a pag & & & & & & & & \\
\hline DISP_M1 & 0,921 & & & & 0,938 & & & \\
\hline DISP_M3 & 0,888 & 0,904 & 0,94 & 0,839 & 0,891 & 0,909 & 0,943 & 0,847 \\
\hline DISP_M4 & 0,937 & & & & 0,931 & & & \\
\hline Uso & & & & & & & & \\
\hline USO1 & 0,975 & & & & 0,968 & & & \\
\hline USO2 & 0,966 & 0,97 & 0,98 & 0,944 & 0,954 & 0,960 & 0,974 & 0,926 \\
\hline USO3 & 0,973 & & & & 0,965 & & & \\
\hline Interesse & & & & & & & & \\
\hline INTER1 & 0,948 & 0,958 & 0,970 & 0,888 & 0,938 & 0,950 & 0,964 & 0,869 \\
\hline
\end{tabular}




$\begin{array}{lll}\text { INTER2 } & 0,948 & 0,938 \\ \text { INTER3 } & 0,946 & 0,941 \\ \text { INTER4 } & 0,928 & 0,911\end{array}$

Nota: O t-valor foi estimado por meio de bootstrapping no SmartPLS (263 casos e 5.000 re-amostras). $\mathrm{a}=\mathrm{p}<0,01 ; \mathrm{b}=p<0,05$.

Fonte: Desenvolvido pelo autor por meio do SmartPLS (3.2.6)

É importante ressaltar que o intuito da amostra teste não é melhorar os resultados, mas sim compará-los e verificar o poder de replicação da escala desenvolvida. Os ajustes feitos no modelo, durante a aplicação da amostra pré-teste, mostraram-se bastante eficientes. No nível dos indicadores, os resultados nas duas amostras demonstram a validade convergente do modelo, bem como sua confiabilidade.

A validade discriminante foi analisada conforme as recomendações de Hensel (2009) e Hair (2014). No nível do construto, comparamos as raízes quadradas dos valores das AVEs de cada construto com as correlações (de Pearson) entre os constructos. Os resultados esperados, raízes quadradas das AVEs maiores que as correlações entre os dos construtos (analise vertical e horizontal), foram atingidos. Tanto na amostra pré-teste (Tabela 41, p. 185), quanto na amostra teste (Tabela 58, p. 217), o critério de Fornell-Larcker (Fornell \& Larcker, 1981) foi alcançado com êxito.

No nível dos indicadores, verificamos as cargas cruzadas, ou seja, comparamos as cargas fatoriais de cada indicador com sua carga cruzada. Nesta análise, seguimos as recomendações de Chin (1998). Primeiramente, verificamos se as cargas cruzadas eram inferiores às cargas fatoriais. A amostra pré-teste e a amostra teste satisfizeram essa condição.

Também analisamos se as cargas cruzadas das variáveis latentes são altas. Esse critério serve não para anular o indicador ou o construto, mas para permitir uma visão mais abrangente dele. Valores altos indicam uma alta correlação Chin (1998). Em determinados casos, essas altas correlações são esperadas, como quando analisamos os chamados outputs da lealdade ao patrocinador ou mesmo os construtos de lealdade atitudinal, comportamental e conativa. Altas correlações podem indicar, também, que existem fatores de segunda ordem na relação.

As duas amostras apresentam, em determinados indicadores cargas elevadas, mas esperadas. Justamente por causa da relação próxima entre as variáveis estudadas. Isso não invalida o modelo ou a escala, mas sugere que novos modelos, avaliando outras alternativas 
teóricas, sejam feitos utilizando a escala desenvolvida neste trabalho. Assim, as duas amostraram demonstraram que a escala possui validade convergente, validade discriminante e confiabilidade dentro dos parâmetros mínimos necessários.

Com este princípio em mente, podemos inferir que o primeiro objetivo específico (Desenvolver uma escala de identificação com o time, alternativa aos modelos já existentes), foi alcançado.

\subsection{Modelo de estrutural}

Por meio do modelo de mensuração, analisamos a exposição das ligações entre as variáveis latentes e, também, entre as variáveis observáveis (indicadores). Porém, um modelo que trabalhe com variáveis dependentes que se tornam independentes em relações subsequentes de dependência, só pode ser analisado por completo quando tanto o modelo de mensuração, quanto o estrutural são analisados ( Hair, Ringle, \& Sarstedt, 2011; Reinartz, Haenlein, \& Henseler, 2009; Hair, 1998).

No modelo estrutural, analisamos as relações causais entre as variáveis latentes. Sua validade é analisada por meio da verificação da significância e da força das relações de hipóteses entre as construções (Barroso \& Gabriel Cepeda Carri'on, 2010). Nesta pesquisa, adotamos os indicadores expostos na Tabela 28 para avaliar as relações causais e verificar as hipóteses apresentadas a priori (Hair, 2014).

Assim, no modelo estrutural, buscamos analisar os coeficientes de caminho, com o intuito de avaliar as relações causais e verificar o quanto cada construto se relaciona com outro. Próximo de +1 demostra uma relação positiva forte (-1 uma relação negativa forte) e próximo do zero indicam relações fracas. $\mathrm{O}^{2}$ nos ajuda a analisar o quanto cada variável endógena é explicada pelo modelo estrutural. Este índice indica a qualidade do modelo ajustado.

Também analisamos a validade preditiva $\left(\mathrm{Q}^{2}\right)$, buscando mensurar acurácia do modelo ajustado, o tamanho do efeito $\left(f^{2}\right)$, para entender o quanto cada variável latente é útil para o ajuste do modelo, e o Variance Inflation Factor (VIF), para verificar se existe multicolinearidade. 


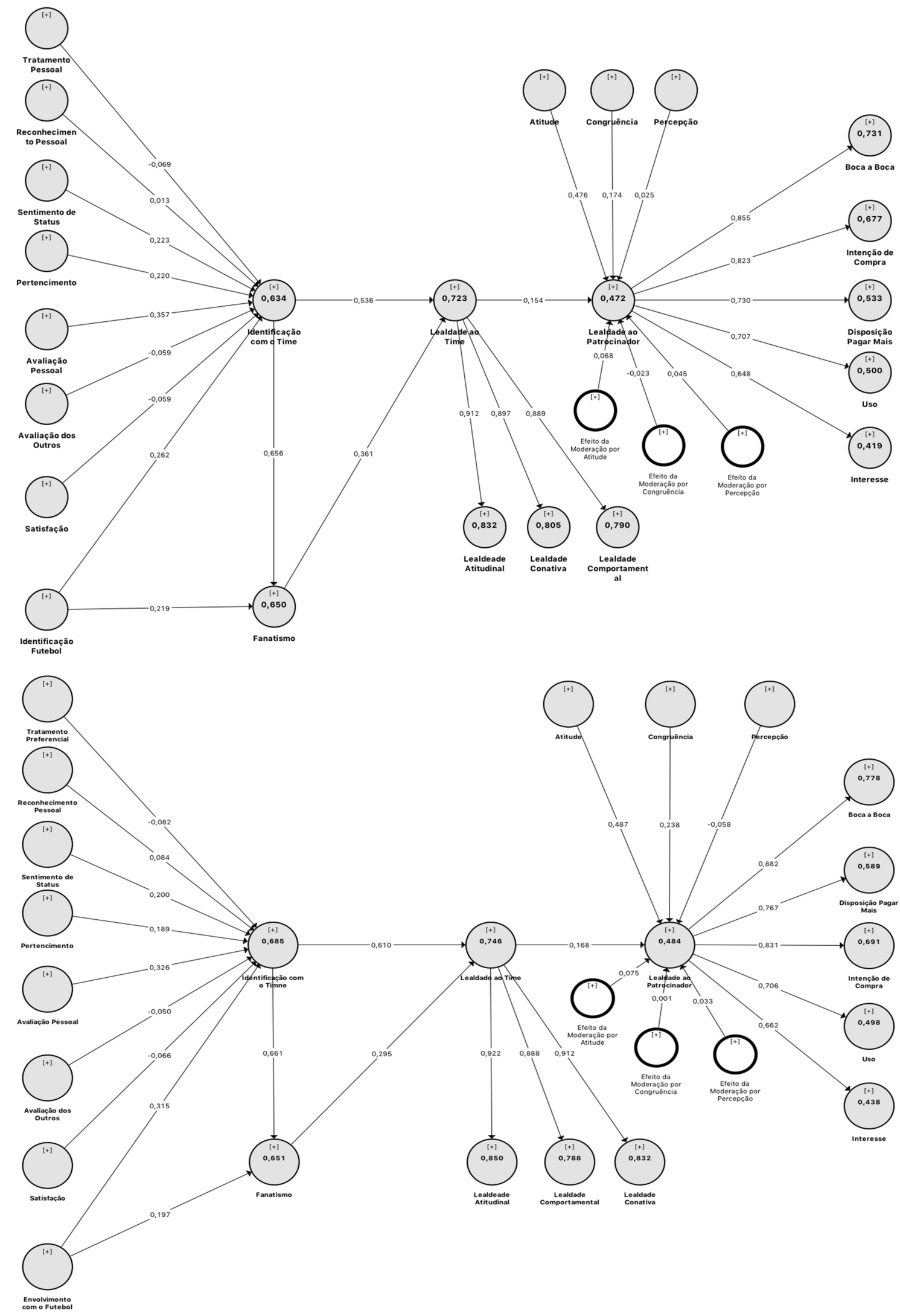

Fonte: Desenvolvido pelo autor por meio do SmartPLS (3.2.6) 
Na Figura 27, podemos verificar o modelo estrutural para ambas as amostras. No centro de cada construto, temos os valores $\mathrm{R}^{2}$ e nas setas os valores dos coeficientes de caminho. A analise dos índices propostos mostra que, no geral, os indicadores atenderam às recomendações mínimas, ou seja, o modelo estrutural se apresenta consistente.

Por fim, analisamos o VAF (Variance Accounted For) e realizamos o teste-t. O VAF nos auxiliar a verificar possíveis relações de mediação existente entre as variáveis. O teste-t se faz necessário para testar as hipóteses propostas por meio da significância das correlações e das regressões. Esses dois índices permitem validar (ou não) o modelo estrutural.

Os testes de hipóteses de ambos os modelos foram bastante satisfatórios. As hipóteses, de maneira geral, foram confirmadas integral ou parcialmente na amostra pré-teste (Tabela 47, p. 196). Apenas as hipóteses H1, H2, H6 e H7 não foram confirmadas. Porém, na amostra teste (Tabela 64; pág. 228), apenas a hipótese H15a não foi confirmada.

Aqui, cabe uma atenção especial ao resultado encontrado por meio das hipóteses relacionadas a proposições dos benefícios sociais/não financeiros, como antecedentes da identificação com o time. As hipóteses H1 (Tratamento preferencial tem efeito positivo e significante na identificação com o time), H6 (Avaliação dos outros tem efeito positivo e significante na identificação com o time) e H7 (Satisfação como o time tem efeito positivo e significante na identificação com o time) foram confirmadas com relação a sua significância, mas com o sinal do coeficiente de caminha invertido. Portanto, o efeito dessa relação não é positivo e sim negativo.

As três variáveis estudados por meio das hipóteses propostas possuem características comuns importante: elas refletem o tratamento que o time dá ao seu torcedor e como isso impacta nele diretam (relação com o time) ou indiretamente (relação com a sociedade). Com base na revisão da literatura, utilizamos a teoria da identidade social para analisar essa relação entre torcedores e seus times, conforme as adaptações já realizadas por diversos outros autores (Yoshida, Heere, \& Gordon, 2015; Bodet \& Bernache-Assollant, 2011).

Conforme Wann (2006), consideramos que três dimensões são as principais a serem analisadas (em conjunto ou separado), quando se estudam os antecedentes da identificação com o time: psicológico, ambiental e a equipe (Tabela 1, p. 48). Neste trabalho, buscamos analisar as três dimensões, porém com maior força a dimensão psicológica. Um dos pressupostos utilizados para a construção de nossas hipóteses foi a autoestima. Assim, 
entendemos que os torcedores possuem uma necessidade de autoestima que, em parte, é estabelecida pelo time para o qual o torcedor torce. Essa relação, sob a ótica dos estudos da relação entre empresa/consumidor, é considerada de alta relevância para as empresas (Brashear-Alejandro, Kang, \& Groza, 2016) e, portanto, sob a ótica do esporte como um negócio, também o é.

Assim, para entender os conceitos dos benefícios sociais/não financeiros concentramos nossas análises em diversos estudos relacionados aos programas de fidelidade (por exemplo, Lacey, 2007; Brashear-Alejandro, et al, 2016; Drèze \& Nunes, 2009; Melnyk, 2015) e marketing de serviços (por exemplo, Theodorakis, Alexandris, \& Ko, 2011, Ko, Zhang, Cattani, \& Pastor (2011); Lee, Lee, Seo, \& Green (2012); Yoshida \& James (2010); Balaji \& Chakraborti (2015); Lee e Joon-Ho Kang, (2015); Yoshida e Heer, 2015). Esses estudos encontraram respostas positivais e significativas de questões relacionadas a autoestima.

Desta forma, nossas hipóteses foram formuladas por entendermos que ser bem tratado pelo time aumentaria a autoestima do torcedor e, por consequência, sua identificação. Porém o resultado da amostra teste aponta uma característica bastante peculiar para este trabalho: ser bem tratado não é um diferencial. Isso o mínimo exigido pelo torcedor. Por consequência, sentir-se melhor tratado do que torcedores de outros times, a sociedade ver com bons olhos o time do torcedor ou mesmo os resultados dentro e fora do campo do time não têm impacto positivo na identificação. Porém não ter isso irá afetar negativamente e de forma significante a relação do torcedor com o time. Claramente, encontramos aqui um indício de que o torcedor quer ser visto como um consumidor.

\subsection{Matriz Importância-Desempenho}

A matriz de importância-desempenho relaciona a importância de cada construto, representado pelos efeitos totais, com o desempenho, representado pelo nível de associação de cada construto na variável que se quere mensurar. Em nosso caso, o objetivo do trabalho é verificar se a lealdade do torcedor ao time pode ser transferida para a marca patrocinadora. Assim, na matriz de importância-desempenho, analisamos a importância de cada construto antecedente à lealdade ao patrocinador, em relação à própria lealdade ao patrocinador. 
Essa análise serve para apoiar as decisões a respeito de quais construtos independentes devem ser priorizados na hora de investir. Assim, são analisados ao mesmo tempo os efeitos totais de cada variável independente (importância) e o nível de associação dos construtos independentes para a lealdade ao patrocinador (desempenho) (Hair, 2014).

Figura 28: Matriz Importância-Desempenho (Amostra Pré-Teste)

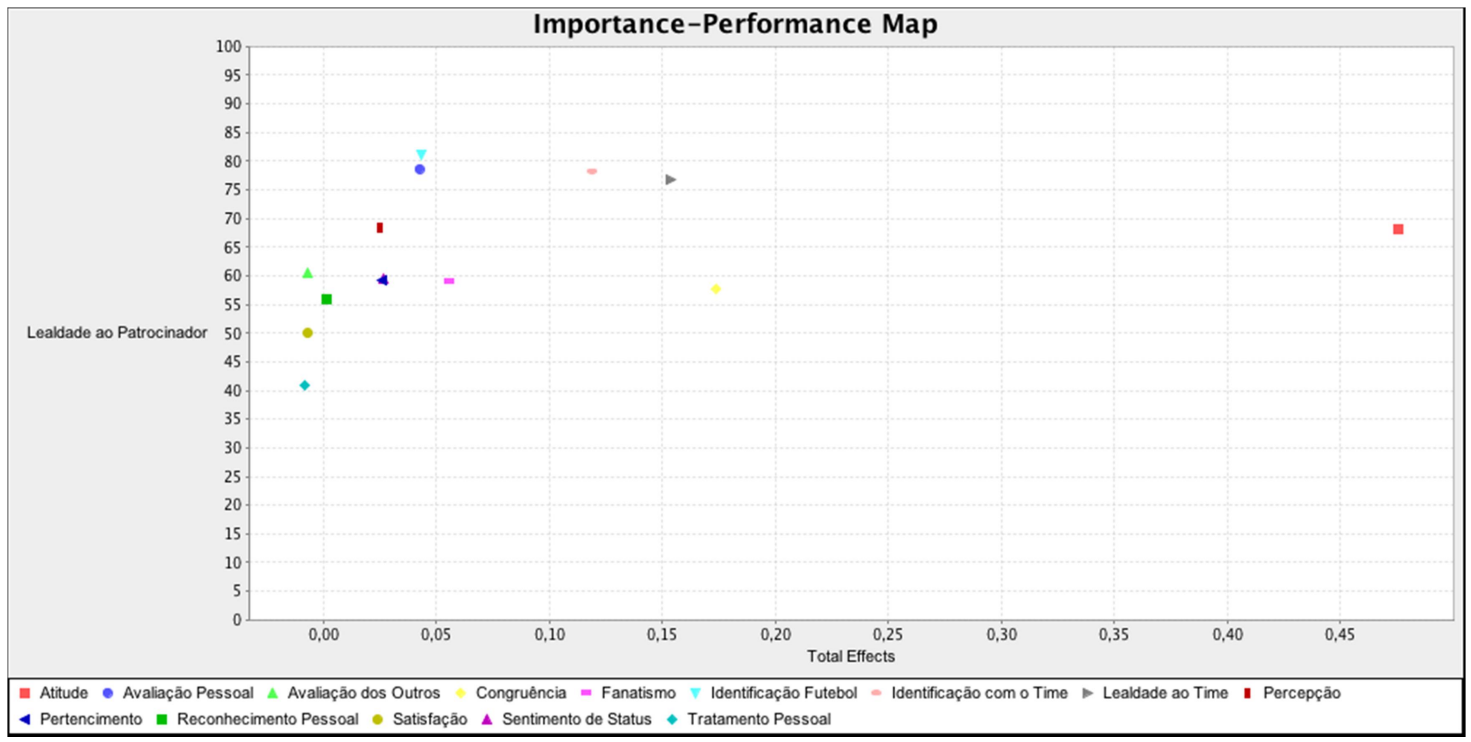

Fonte: Desenvolvido pelo autor por meio do SmartPLS (3.2.6)

Figura 29 Matriz Importância-Desempenho (Amostra Teste)

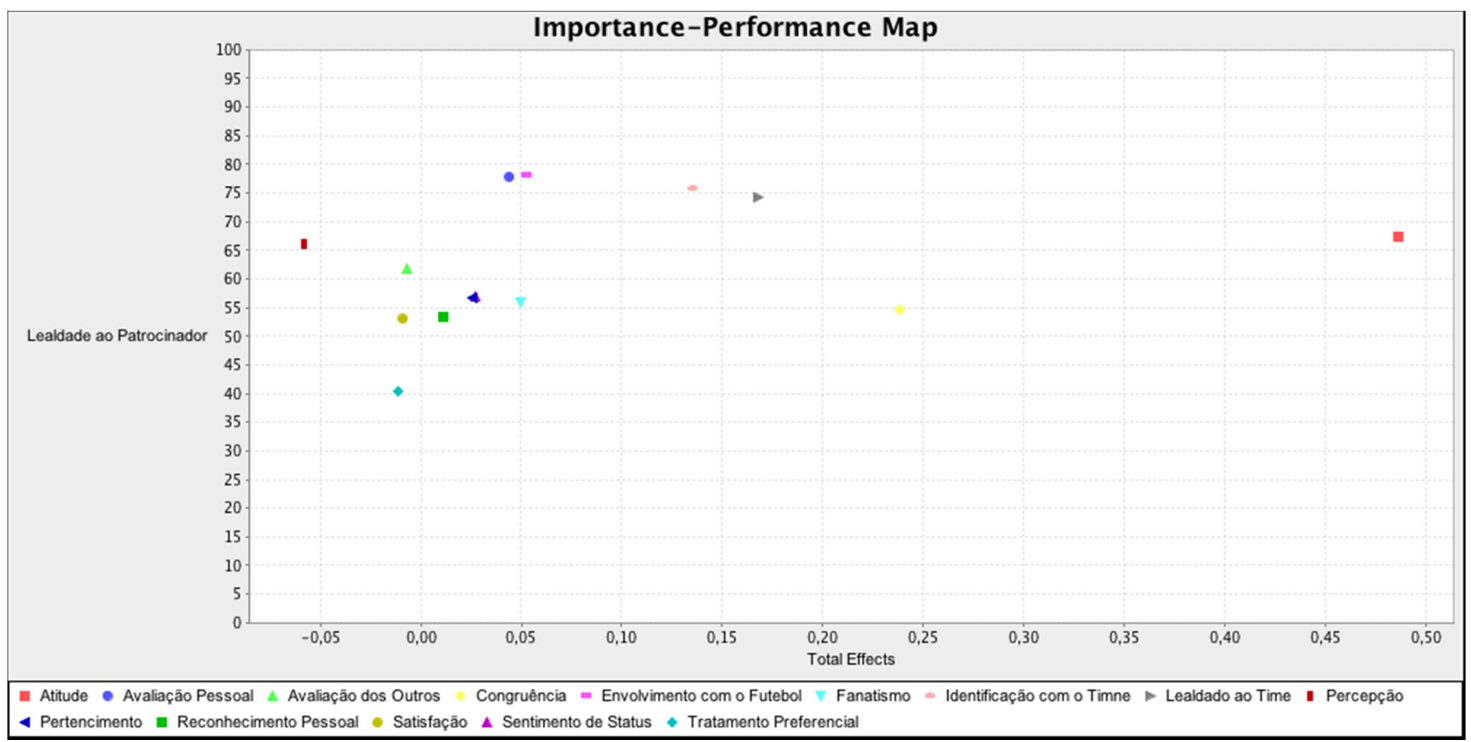

Fonte: Desenvolvido pelo autor por meio do SmartPLS (3.2.6)

A Figura 28 e Figura 29 apresentam a representação gráfica das amostras pré-teste e teste na matriz de importância-desempenho. Como esperado, o construto atitude tem grande 
importância na variável lealdade ao time e um alta desempenho nas duas amostras. Porém as figuras permitem notarmos que três variáveis (congruência; lealdade ao time e identificação com o time) formam um grupo intermediário na análise importância-desempenho.

A variável que apresentou maior diferença entre as amostras foi a de envolvimento com o futebol. Na amostra pré-teste, a variável apresentava um alto desempenho. Já na amostra teste este desempenho ficou em nível bem inferior. A percepção é um caso que requer atenção. Apesar de muitos estudos destacaram o construto percepção nas análises da eficiência do patrocinador, nas duas amostrar ele apresenta um desempenho alto. Porém, nos dois casos, tem baixa importância.

\subsection{Discussões Finais acerca dos resultados}

O objetivo deste estudo foi verificar se a lealdade do torcedor ao time poderia ser transferida para organizações que possuem relação direta com os times. No caso deste estudo, consideramos patrocinadores e fornecedores de uniforme. Para isso, propusemos um modelo teórico multidimensional que permitisse analisar a relação identificação com o time, lealdade ao time e lealdade ao patrocinador.

Para que pudéssemos propor o modelo teórico, foi necessário partir de uma revisão crítica da literatura dos três construtos principais deste trabalho: identificação com o time, lealdade ao time e lealdade ao patrocinador. Pois, em suma, um modelo é a representação gráfica e compreensiva das teorias estudas (Edwards \& Bagozzi, 2000).

Optamos por não embasar as construções teóricas apenas na literatura da gestão esportiva ou do comportamento do consumidor esportivo. Percorremos outras áreas das ciências, tais quais marketing, psicologia e economia, de forma a permitir uma abrangência maior em nossa revisão. Essa decisão se mostrou acertada, pois permitiu encontrarmos uma lacuna na área do comportamento do consumidor esportivo relacionada à questão dos benefícios sociais/não financeiros que podem influenciar na identificação com o time.

Assim, com relação ao desenvolvimento de uma escala de identificação com o time objetivo específico ([a]), os resultados das duas amostrar permitem concluirmos que o objetivo foi alcançado com êxito. Mostramos que fatores relacionados a benefícios sociais/não financeiros podem influenciar no processo de identificação do torcedor com seu 
time. A analise do $\mathrm{R}^{2}$ e do $\mathrm{Q}^{2}$ da amostra pré-teste e teste $(0,634 ; 0,417 / 0,685 ; 0,482)$ mostram o alto poder preditivo das variáveis antecedentes da identificação com o time no modelo teórico proposto.

Além disso, o índice $f^{2}$, que mensura o tamanho do impacto do construto preditor omitido nos valores de $\mathrm{R}^{2}$ dos construtos endógenos, na análise do construto identificação com o time, permite algumas ponderações importantes. Era esperado, conforme a revisão da literatura, e isso foi confirmado, que o envolvimento como futebol tivesse grande influência na variável $\left(f^{2}=0,200 / 0,177\right.$ - pré-teste/teste). Porém algumas das variáveis adicionais propostas neste trabalho também apresentaram índice $f^{2}$ alto. Em especial, destacamos a avaliação pessoal $\left(f^{2}=0,155 / 0,103\right.$ - pré-teste/teste). Porém pertencimento $\left(\left(f^{2}=0,034 / 0,033-\right.\right.$ pré-teste/teste $)$ e sentimento de status $\left(f^{2}=0,034 / 0,031\right.$ - pré-teste/teste $)$ também se apresentam com média influência.

Desta forma, parece-nos procedente afirmar que a escala desenvolvida neste trabalho para mensuração das variáveis propostas atendeu aos pré-requisitos definidos neste trabalho. Assim, a Social Benefits Scale in Sport $^{77}$ (SBSS) atende ao objetivo específico proposto para auxiliar no atingimento do objetivo principal.

Outro ponto que merece destaque é que, apesar de as pesquisas acadêmicas, na área de esporte, terem bem definidos os conceitos teóricos de identificação e lealdade, existe uma grande confusão semântica, que, muitas vezes, atrapalha e dificulta um levantamento mais profundo dos trabalhos já realizados. Assim, neste trabalho, propusemos como objetivos específicos mensurar esses construtos de forma separada e evidenciar, com auxílio da revisão da literatura, essa distinção.

Além da questão semântica entre lealdade e identificação, a revisão da literatura apresentou o fanatismo, não como um construto, mas com o grau mais elevado da identificação com o time. Em nosso trabalho, adotamos os preceitos acerca de devoção patológica (McCutcheon, Lange, \& Houran, 2002) para analisar o fanatismo como um

\footnotetext{
${ }^{77}$ Escala de Benefícios Sociais no Esporte - nome dado para a escala desenvolvida pelo autor para este
} trabalho 
construto separado da identificação. Desta forma, em nosso modelo teórico, o envolvimento com o futebol, mas principalmente a identificação com o time, precedem à variável fanatismo.

Os resultados das duas amostras permitem concluir que tanto o item b (mensurar identificação com o time, fanatismo e lealdade ao time como variáveis distintas), como o item c (evidenciar a distinção entre os construtos identificação, fanatismo e lealdade ao time) foram atingidos.

A análise das correlações entre os indicadores e as cargas cruzadas, bem como o AVE no modelo de mensuração das amostras confirmam que os três construtos podem ser analisados de forma independentes. Além disso, os testes de mediação do modelo também auxiliam nessa questão. Quando analisamos a identificação com o time como uma variável mediadora da relação entre seus antecedentes e a lealdade ao time (variáveis de benefícios sociais/não financeiros $\rightarrow$ Identificação com o time $\rightarrow$ Lealdade ao time) quatro variáveis não apresentam efeito direto significante ( $\beta 13$ não significante).

Assim, de acordo com Hair (2014), quando o efeito direto entre a variável $\beta 1$ e a variável $\beta 3$ é não significante não existe a necessidade de verificar a mediação, pois a relação direta não existe. Tratamento preferencial, reconhecimento pessoal, avaliação dos outros e satisfação possuem teste de mediação que resultam nessa posição (Tabela 46, p. 195; Tabela 63 , p. 227)

A escolha do método estatístico para trabalhar os dados é um ponto que merece discussão. Para alcançar o quarto objetivo específico ([d] - desenvolver modelo para analisar a transferência da lealdade do torcedor para as marcas patrocinadoras), a modelagem de equação estrutural foi essencial. A SEM é um método que leva em conta o modelo de interações causais entre as variáveis e o erro de mensuração (Klein, 2011), ou seja, o grau em que as variáveis manifestas não descrevem com exatidão os construtos que representam.

Para estimação das relações em um modelo de equação estrutural, duas abordagens são possíveis: os modelos baseados em covariância (CB-SEM - covariance base structural equation modeling) e os modelos baseados em correlação (VB-SEM - variance base 
structural equation modeling), também tratadas atualmente como PLS-SEM (partial least squares structural equation modeling) ${ }^{78}$ (Hair, 2014).

A escolha do PLS-SEM se deu devido à natureza da pesquisa. Neste trabalho, propúnhamos analisar, ao mesmo tempo, um modelo teórico e fazer predições. Além disso, a complexidade do modelo, apesar dos indicadores serem todos reflexivos, e o fato de as amostras (pré-teste e teste) serem não normais embasam a escolha do PLS-SEM para análise dos dados deste trabalho.

A SEM permite a explicação do relacionamento entre diversos construtos. No caso deste trabalho, buscamos integrar, em um único modelo, os fatores antecedentes da identificação com o time, os fatores relativos à lealdade do torcedor ao time e os efeitos dos fatores que permitem a transferência desta lealdade para as marcas patrocinadoras.

Essa integração permitiu o discernimento da importância do efeito dos fatores relacionados aos benefícios sociais/não financeiros como antecedentes da identificação com o time. E auxiliou na tarefa de analisar a lealdade ao time como um construto multidimensional. Este passo se mostrou importante para poder analisar se a lealdade do torcedor poderia ou não ser transferida.

Para isso, além de trabalhar no construto multidimensional relacionado ao time, buscamos os principais fatores que auxiliam na análise da eficiência de um patrocínio: atitude em relação ao patrocinador (Gwinner \& Swanson, 2003; Olson, 2010), percepção do patrocínio (Alexandris, Tsaousi \& James 2007; Gwinner \& Swanson 2003) e congruência (Macdougall, Nguyen, \& Karg, 2014; Olson, 2010; Menon \& Dubé, 2000).

A vantagem dessa escolha foi poder comparar os resultados dos testes de hipóteses destes fatores tradicionais com os resultados dos testes de hipóteses relacionados à lealdade ao time. Para que pudéssemos caracterizar a transferência da lealdade era fundamental que o coeficiente do caminho direto entre lealdade ao time e lealdade ao patrocinador (Lealdade ao

\footnotetext{
${ }^{78}$ Para mais detalhes ler capítulo 7
} 
time $\rightarrow$ Lealdade ao patrocinador) fosse mais forte que os coeficientes mediados e/ou moderados por atitude, congruência e percepção.

Os resultados das duas amostras confirmaram as hipóteses relacionadas a esta questão (H13b, H14b, H14c, H15b e H15c) e de forma parcial a hipótese H13c. Ou seja, tanto os três construtos apresentaram coeficientes não significativos na moderação da relação (Lealdade ao time $\rightarrow$ Atitude/Congruência/Percepção $\rightarrow$ Lealdade ao patrocinador). Por sua vez, na relação mediada, nas duas amostras, congruência e percepção apresentam índices VAF, que demonstram não existir mediação. Já a análise da atitude apresentou uma mediação parcial da relação, confirmando parcialmente a hipótese.

Além disso, o coeficiente do caminho direto (Lealdade ao time $\rightarrow$ Lealdade ao patrocinador) - $\beta=0,154$ (amostra pré-teste) e $\beta=0,168$ (amostra teste) - mostrou-se significativo (e positivo) confirmando a hipótese H16. E mais: os valores do coeficiente de caminho da variável lealdade ao time foi superior (nas duas amostras) à percepção e próximo ao coeficiente de congruência. O índice $f^{2}$, que mensura o tamanho do impacto do construto preditor omitido nos valores de $\mathrm{R}^{2}$ dos construtos endógenos da variável lealdade ao time, foi superior $\left(f^{2}=0,41 / f^{2}=0,064\right)$ ao índice da congruência $\left(f^{2}=0,037 / f^{2}=0,033\right)$ e percepção $\left(f^{2}=0,002 / f^{2}=0,001\right)$, na amostra pré-teste e teste, respectivamente. A variável atitude apresentou índices superiores a lealdade ao time $\left(f^{2}=0,184 / f^{2}=0,095\right.$ - pré-teste e teste).

O resultado da variável atitude corrobora diversos estudos que apontam a atitude como uma variável forte na mensuração do patrocínio (por exemplo, Kim, Ko \& James, 2011; Gwinner \& Swanson 2003; Alexandris \& Tsiotsou 2012 ; Olson 2010). Por sua vez, os resultados obtidos permitem inferir que a lealdade ao time é uma variável que pode anteceder a lealdade ao patrocinador.

Desta forma, faz sentido analisar a questão sob a ótica da teoria do equilíbrio. Para tal, precisamos analisar a Tabela 55 (pág. 209) e a Tabela 54 (pág. 208). Destacamos, antes, que apesar de não ser a análise deste trabalho, os resultados mostram que existe grande diferença no comportamento dos torcedores quando, de maneira espontânea, são convidados a lembrar os patrocinadores/fornecedores e, caso não lembrem, recebem ajuda para tentar reconhecêlos. Tanto os patrocinadores, quanto os fornecedores tiveram um alto índice de acertos quando lembrados espontaneamente (91,5\% e 94,7\%, respectivamente). Porém, quando o 
respondente não sabia e era direcionado a tentar reconhecer o patrocinador/fornecedor, apenas $44,2 \%$ e $23,5 \%$ dos respondentes acertaram (Tabela 52, p. 206).

Assim, analisando a Tabela 55, nota-se que $64,45 \%$ dos respondentes que se lembraram do patrocinador ou do fornecedor declararam comprar (ou já ter comprado) produtos da marca analisada. Levando em consideração o tipo de produto/serviço que patrocina atualmente os grandes times brasileiros o resultado de $47,24 \%$ de respondentes que dizem comprar (ou já ter comprado) produtos/serviços dos patrocinadores nos parece bastante elevado. No caso do fornecedores, mesmo considerando o tipo de produto, o valor de $82,37 \%$ de respondentes que lembraram e afirmam terem comprado ou comprar produtos dos fornecedores também corrobora nossa proposição.

Os preceitos da tríade propostos por (Heider, 1958) parecem se confirmar na afirmação que postulamos: "Porém, de acordo com a teoria do equilíbrio, nós acreditamos que o consumidor também buscará se adequar a marcas patrocinadoras de seus times para ajustar (equilibrar) a relação (pág 95)". Os resultados apresentados neste trabalho permitem inferir que o torcedor busca, mesmo que inconscientemente, ajustar seu comportamento de compra e equilibrar sua relação com o patrocinador que apoia seu time, conforme o modelo apresentado na Figura 16 (pág. 116).

Com isso exposto, podemos concluir que as evidências resultantes da pesquisa desta tese permitem responder ao objetivo principal deste trabalho: analisar se a lealdade do torcedor com seu clube pode ser transferida para as organizações patrocinadoras

Sim, a lealdade do torcedor pode ser transferida para as marcas patrocinadoras. E é possível analisar e mensurar essa transferência. A capacidade que os times têm de auxiliar esse processo faz com que os torcedores sejam vistos como uma vantagem competitiva em relação a seus concorrentes.

Em suma, buscamos nesta pesquisa uma nova perspectiva para os estudos relacionados ao comportamento do consumidor, principalmente do consumidor esportivo. Do ponto de vista do torcedor, os times são mais do que simples organizações. Os times são uma extensão social da vida do torcedor. Não à toa, Neal (1964), já havia denominado a indústria do esporte como uma economia peculiar. 
O torcedor é, em nossa definição, uma vantagem competitiva peculiar e extremamente importante para os times. 


\section{CONSIDERAÇÕES FINAIS}

Além das discussões finais, traremos as contribuições gerencias e acadêmicas, bem como as limitações deste trabalho. Por fim, apresentamos proposições de pesquisas futuras relacionadas ao tema.

Comecemos por uma revisão sintética da estrutura metodológica utilizada nesta tese. Destacando algumas questões referentes à análise dos dados. Apesar de o objetivo principal da tese ser analisar se a lealdade do torcedor com seu clube pode ser transferida para as organizações patrocinadoras, para atingir este objetivo foi necessário estruturar um modelo de investigação que permitisse responder a questão: $\mathbf{O}$ torcedor pode ser considerado uma vantagem competitiva para o clube pelo qual ele torce?

Para isso, quatro etapas se fizeram necessárias. Primeiramente, uma extensa revisão da literatura. Essa etapa foi fundamental não só para embasar as questões que suportam essa tese, mas para nortear o desenvolvimento do trabalho. Assim, por meio da revisão, buscamos não só sustentar as hipóteses, mas verificar lacunas que pudessem ser preenchidas por este trabalho. Tanto do ponto de vista acadêmico, como gerencial. Sempre tendo em mente que a ciência é uma questão universal e, apesar do estudo ser realizado no Brasil, uma tese deve ter a capacidade de estender seus achados para o mundo.

No centro desta revisão, tomamos alguns cuidados para não classificar este trabalho como um estudo de esporte, do ponto de vista da educação física. Focamos no esporte como objeto a ser estudado, assim como diversos pesquisadores buscam estudar outros segmentos. Desta forma, fundamentar a base teórica de nossa pesquisa em teorias clássicas do comportamento de consumo tanto da economia, como da psicologia, foi mais que necessário, foi uma obrigação.

“(...) a lack of analytical rigor, along with conceptual and operational fragmentation, can undermine the strength and clarity of work in a discipline. The cumulative effect of this can lead 
to a limited, narrow application of work that results in poor citation rates and narrow audiences where we speak only to ourselves instead of other disciplines ${ }^{79,}$. (Funk, 2016; pág 113)

Desta forma, foi possível perceber a necessidade de, para responder à nossa questão central, desenvolver uma escala que nos permitisse mensurar os construtos levantados dentro de preceitos gerais da administração, da economia e do marketing. Assim, avançamos para a segunda etapa. Nesta etapa, junto com diversos especialistas e seguindo as recomendações de (Churchill Jr, 1979), caminhamos para desenvolver uma escala que permitisse testar o modelo teórico multidimensional proposto.

Num terceiro momento, realizamos a pesquisa quantitativa por modelagem de equação estrutural, aplicada à amostra pré-teste. Essa etapa, aplicada a 267 respondentes válidos, mostrou-se crucial para ajudar na purificação da escala e antever possíveis problemas relacionados ao entendimento das questões ou de termos específicos. Basear o processo nos sete passos propostos na Tabela 13 (pág. 123) se mostrou assertivo e permitiu passar para a quarta e última etapa: a pesquisa qualitativa por modelagem estrutural aplicada à amostra teste.

Nessa etapa, o intuito foi testar o poder de replicação da escala e do modelo teórico proposto. Buscamos um público mais abrangente, de forma a verificar o poder preditivo do modelo. Atingimos 25 estados brasileiros (considerando o Distrito Federal), com uma amostra de 787 respondentes válidos. A comparação das etapas três e quatro foi apresentada no capítulo 10.

Resumidamente, podemos afirmar, por meio da análise dos dados das duas amostras, que a escolha do método SEM-PLS se mostrou adequada. A análise fatorial confirmatória (AFC) apresentou níveis de validade convergente, validade discriminante e confiabilidade adequados (Tabela 28) no modelo de mensuração. Ademais, os índices de validação do modelo estrutural, tais como coeficientes de caminho e validade preditiva (Tabela 29), satisfizeram as exigências.

${ }^{79}$ a falta de rigor analítico, juntamente com a fragmentação conceitual e operacional, pode minar a força e a clareza do trabalho em uma disciplina. O efeito cumulativo disso pode levar a uma aplicação limitada e estreita do trabalho resultando em baixas taxas de citação e audiências estreitas em que falamos apenas para nós mesmos em vez de outras disciplinas. 
Desta forma, os dados estudados auxiliaram a atingir os objetivos específicos definidos no começo deste trabalho: (a) desenvolver uma escala de identificação com o time, alternativa aos modelos já existentes; (b) mensurar identificação com o time, fanatismo e lealdade ao time como variáveis distintas; (c) evidenciar a distinção entre os construtos identificação, fanatismo e lealdade ao time; (d) desenvolver modelo para analisar a transferência da lealdade do torcedor para as marcas patrocinadoras; e (e) propor alternativas gerenciais para os clubes e patrocinadores que auxiliem a atingir melhores resultados.

\subsection{Contribuições gerenciais para equipes esportivas}

O último objetivo específico desta tese foi (e) propor alternativas gerenciais para os clubes e patrocinadores que os auxiliem a atingir melhores resultados. Perceber o torcedor como consumidor e, mais, como uma vantagem competitiva em seu setor é o primeiro passo para uma mudança de paradigmas na indústria do esporte, principalmente na indústria do esporte no Brasil, que, quando comparada ao mercado americano ou europeu, apresenta números bem inferiores.

Um ponto-chave para os clubes é entender a diferença entre ter torcedores identificados, fanáticos e leais. Via de regra, no linguajar popular, as expressões: "torcedores fanáticos" ou "torcedores fiéis" (no sentido de "leais") representam a manifestação de paixão do torcedor por seu time. Porém, neste trabalho, buscamos apresentar que existem três dimensões que devem ser trabalhadas pelos clubes para potencializar ao máximo a relação com seu torcedor e, com isso, transformá-lo em vantagem competitiva.

Desta forma, na Tabela 67, apresentamos as definições destes construtos, resultantes desta pesquisa:

Tabela 67: Definições finais dos construtos

CONSTRUTO

Identificação com o time

\section{DEFINIÇÃO}

A identificação com o time é parte da identidade social do torcedor. Ela deve ser vista como uma conexão psicológica entre torcedor e time. Essa conexão envolve uma relação inserida nas necessidades e interações sociais do torcedor, que auxiliam a satisfazer suas necessidades básicas de autodefinição, incluindo um aumento de autoestima. 
extrema. Exige um alto envolvimento por parte do indivíduo, que demonstra, normalmente, hábitos de consumo excitados e quase irracionais.

Lealdade ao time é formada por três dimensões de lealdade: atitudinal, conativa e comportamental. Ela é caracterizada por um consumo frequente da marca e pela sua defesa e recomendação.

Fonte: Desenvolvido pelo autor por meio do SmartPLS (3.2.6)

O desenvolvimento da escala Social Benefits Scale in Sport ${ }^{80}$ (SBSS) oferece aos times uma oportunidade neste sentido. Muitos estudos anteriores apresentaram diversas formas de como a identificação é construída. Propusemos um novo modo. Porém não encontramos nenhum trabalho que analisasse o impacto da identificação na lealdade ao time. Existem, sim, muito trabalhos que mostram o impacto na lealdade ao patrocinador.

Desta forma, por meio da SBSS, os clubes podem analisar desde a construção da identificação, passando pela lealdade ao time e culminando na transferência de lealdade para as marcas patrocinadoras. Neste processo, recomendamos que os times iniciem suas análises conhecendo o nível de identificação de seus torcedores e, além disso, o processo de formação desta identificação.

Uma descoberta chave deste trabalho é o papel das variáveis tratamento preferencial, avaliação dos outros e satisfação no processo de identificação com o time. Os efeitos negativos causados por essas variáveis requerem atenção por parte dos times, poiss representam valores que, quando percebidos, não impactam positivamente. Porém, quando não percebidos, tendem a refletir de forma negativa na identificação.

Tratamento preferencial, mensura o quanto, em comparação com torcedores de outros times, o torcedor se sente mais bem tratado pelo seu time. É um construto que busca refletir uma comparação no sentido de como um torcedor se sente em relação ao seu time, em comparação ao que ele acha que os outros se sentem com o time que torcem.

\footnotetext{
${ }^{80}$ Escala de Benefícios Sociais no Esporte - nome dado para a escala desenvolvida pelo autor para este
} trabalho 
Avaliação dos outros, busca medir o grau com que o torcedor avalia o que os outros pensam do seu time. Por fim, a satisfação mede o grau de satisfação do torcedor com seu time, mas além das quatro linhas. Não só os resultados em campo são medidos, mas também os resultados extracampo.

A identificação com o time é, claramente, o alicerce mais importante da relação time/torcedor. Ela é o nascedouro do processo de construção da lealdade e o patamar inicial para o surgimento do fanatismo. E é no fanatismo que os clubes devem ter uma atenção redobrada.

Numa primeira interpretação, ter torcedores fanáticos pode parecer excelente. Porém, conforme apresentamos na revisão da literatura, nem todo fanatismo é constituído de boas intenções. Ou melhor, para o fanático, a intenção sempre é boa ou positiva, mas aos olhos do que estão de fora pode constituir com um rompimento das normais sociais. Com isso, acarretar prejuízos para o próprio fanático ou para aqueles que estão perto dele.

Neste sentido, é importante que os times possam mensurar, por meio da SBSS, o grau de fanatismo de seus torcedores e verificar quais estão no nível da devoção patológica, porque esses podem trazer prejuízos ao time, que podem ser financeiros, de imagem, de reputação. Brigas de torcidas afastam torcedores identificados dos estádios. Pressão exagerada em atletas ou diretoria afastam do clube novos talentos.

Por fim, recomendamos aos times investimentos no processo de transformar a identificação do torcedor em fidelidade. Isso é importante, pois a identificação não necessariamente é uma relação que traz benefícios financeiros para os times. Por outro lado, a lealdade ao time está vinculada a processos que, indireta ou diretamente, beneficiam o clube financeiramente.

A lealdade ao time também se apresentou como um forte construto antecedente da lealdade ao patrocinador, inclusive quando compardo ao construto congruência, que é bastante estudado na academia. Os resultados deste trabalho permitem posicionar a lealdade ao time desta forma. Além disso, a lealdade ao time apresentou uma forte mediação na relação identificação com o time e lealdade ao patrocinador (Identificação com o Time $\rightarrow$ Lealdade ao time $\rightarrow$ Lealdade ao patrocinador), nas duas amostras. 
Esses resultados demostram, não apenas que os construtos identificação com o time e lealdade são dois separados (conforme proposição deste trabalho), mas que devem ser mensurados e trabalhados separadamente pelos times. As equipes necessitam saber antecipadamente o que buscam com seus torcedores e, mediante isso, traçar estratégias distintas para trabalhar na identificação ou na lealdade do torcedor.

Se a equipe busca aumentar sua base de torcedores, seu foco deve ser na construção da identificação. Trabalhar com os benefícios sociais/não financeiros propostos neste trabalho se apresenta como um bom caminho. Encorajar a autoestima do torcedor, de formar a fazer o torcedor se sentir mais do que um torcedor tornando-se único e especial.

Porém, se a ideia é construir uma relação mais forte, duradoura e que traga retornos financeiros, aí as estratégias devem estar ligadas à construção da lealdade. E é aqui, na construção dessa relação, que as equipes têm a possibilidade de criar uma vantagem competitiva de longo prazo: o torcedor.

Assim, como resultado desta pesquisa, propomos que os times vejam os torcedores não só como consumidores, mas como um ativo valioso da organização esportiva. Um ativo que, em linha com a Teoria Baseada em Recursos (RBT ${ }^{81}$ ), Barney (1991) é capaz de criar valor que não pode ser copiado pelos concorrentes.

Portanto, para nós, o torcedor não é apenas um coprodutor do valor a equipe. O torcedor é co-proprietário da equipe e um dos responsáveis pelo potencial sucesso.

\subsection{Contribuições gerenciais para organizações patrocinadoras}

Conforme exposto na revisão da literatura, o conceito da lealdade vem sendo muito trabalhado nos estudos de comportamento do consumidor. Desenvolver e manter consumidores leais é fundamental para a construção de uma relação de longo prazo entre

\footnotetext{
${ }^{81}$ Do inglês Resource-based Theory
} 
empresa/consumidor. Esses consumidores são mais comprometidos, não são facilmente atraídos por ofertas do concorrente, estão dispostos a pagar mais e a falar bem da marca.

Todavia a construção da lealdade tende a ser um processo longo e caro. Neste sentido, esse trabalho oferece aos patrocinadores uma alternativa às diversas práticas existente na construção deste caminho.

Os patrocinadores são hoje figuras onipresentes no esporte, é difícil imaginar grandes times ou grandes eventos esportivos sem o suporte financeiro de um patrocinador. $\mathrm{O}$ alto volume de dinheiro injetado pela atividade de patrocinar faz com que as empresas patrocinadoras busquem formas de mensurar os possíveis retornos destes investimentos.

Comumente usado, até pela simplicidade do cálculo, o retorno de mídia (a chamada mídia espontânea) pode ser suficiente para alguns. Mas no geral ela já vem demostrando que não atende às exigências daqueles que querem ir além da simples exposição, que pode ajudar a tornar a marca conhecida, fazer o consumidor ter atitudes positivas para a marca, tornar a marca mais familiar. Porém isso não garante necessariamente consumo. Embutir a possibilidade de ter para si parte da lealdade do torcedor ao time deve ser um dos objetivos das marcas nas ações de patrocínio.

Os últimos anos vêm apresentando uma série de mudanças no estilo de vida dos consumidores. Novos hábitos, novas demandas, novas necessidades. Estas mudanças vêm obrigando as organizações a modificar a forma como conduzem seus negócios. Sabemos que o patrocínio é uma das ferramentas que as empresas usam na tentativa alcançar os consumidores e despertar o interesse na compra dos produtos (Mason, 2005). Porém existe a dificuldade de analisar se a intenção de compra está sendo influenciada pelo patrocínio ou é efeito das outras atividades de marketing (promoção de vendas e propaganda) (Miles, 2000; Miyazaki \& Morgan, 2001).

Neste sentido, este trabalho oferece aos patrocinadores um caminho não só para mensurar o impacto do patrocínio na intenção de compra, mas também o efeito deste na construção da lealdade a marca patrocinadora, separando os efeitos relacionados a atitude, congruência e percepção.

Também propomos que as empresas analisem quanto um time pode ofertar da lealdade de seu torcedor para as marcas patrocinadoras. É nesse sentido que enxergamos o torcedor 
como vantagem competitiva para os times. Times que possuam maior capacidade de transferência desta lealdade poderão cobrar mais do patrocinador. Já os patrocinadores poderão atrelar seus patrocínios não só à venda de produtos, mas à transferência dessa lealdade.

Se para as equipes propomos que o torcedor seja visto como um coproprietário dos times que torcem, para as organizações patrocinadoras conseguir o engajamento do torcedor é o caminho recomendado. As empresas patrocinadoras devem usar a lealdade transferida para desenvolver estratégias que permitam ao torcedor se transformar num embaixador de sua marca.

\subsection{Contribuições acadêmicas}

No que se refere às contribuições acadêmicas, esta pesquisa buscou diversos caminhos para alcançar o objetivo principal. Isso nos permitiu navegar por diversas teorias, em diversas áreas. E, desta forma, contribuir com nossos achados não só para os estudos organizacionais, mas também para o marketing.

Primeiramente buscamos apresentar o torcedor como uma vantagem competitiva, dentro do paradigma da RBT. Os delineamentos de Barney (1991) resumiam em valor, raridade, imitabilidade e insubstituibilidade as características que podem transformar os recursos de uma organização em fonte de vantagem competitiva. Cada time possui sua cultura e sua própria identidade. Em nossa visão, cada time possui torcedores únicos.

Desta forma, os torcedores, vistos como recurso criam oportunidades ou neutralizam ameaças(valor) - principalmente quando vistos como consumidores ou, além, como coproprietários -, não estão amplamente disponíveis no mercado (raridade), pois são únicos em cada time, não podem ser copiados (imitabilidade) - a identificação é uma construção psicológica única e a lealdade é influenciada de forma significativa por ela - e não podem ser substituídos por recursos equivalentes (insubstituibilidade) - não existe recurso equivalente aos torcedores.

No âmbito da identificação do torcedor com o time, apesar de ser um assunto bastante explorados, apresentamos novos fatores que contribuem no processo de identificação: os chamados benefícios sociais/não financeiros. Estes fatores estão ancorados, assim como a 
identificação com o time, na teoria da identidade social. A busca da elevação da autoestima faz com que o torcedor se identifique mais com sua equipe quando recebem deles os benefícios sociais/não financeiros.

Buscamos aprofundar as questões relacionadas entre o torcedor, seu time e o patrocinador (ou patrocinadores) de sua equipe. Neste sentido, as definições apresentadas no que diz respeito aos conceitos que definem os construtos identificação com o time, fanatismo e lealdade também devem ser vistas como outro ponto de contribuição desta tese.

A revisão da literatura mostrou que as organizações estão cada vez mais buscando se aproximar dos consumidores. Ter clientes leais se faz cada vez mais necessário. Não à toa, os programas de fidelidade vêm ganhando espaço e relevância demonstrando a importância de estar cada vez mais perto do consumidor para as organizações. Nossa pesquisa contribui para essa área do conhecimento ao apresentar para aos patrocinadores um caminho para absorver uma lealdade que já foi construída por outra organização. Este processo, neste trabalho, foi chamado de transferência de lealdade.

Desta forma, também contribuímos para o conhecimento a respeito da teoria da lealdade. Acrescentamos a teoria de lealdade à ideia de que ela pode ser transferida. Para isso, utilizamos os preceitos da teoria da transferência e do equilíbrio. Por fim, buscamos acrescentar novos conhecimentos aos estudos a respeito dos patrocínios, principalmente os esportivos. Contribuímos com nossa pesquisa ao aprofundar os estudos na tríade torcedor/time/patrocinador. Ao analisar essa relação desde o seu começo (identificação) até seu fim (outputs da lealdade ao patrocinador), preenchemos uma lacuna na área de gestão e de gestão do esporte.

\subsection{Limitações da pesquisa e sugestões de pesquisas futuras}

Uma limitação deste trabalho, que deve ser claramente entendida por todos, é a constituição da amostra. Apesar de termos entrevistado pessoas de praticamente todos os estados (apenas dois estados não tiveram representantes), a amostra foi gerada não é probabilística. Além disso, o questionário foi aplicado online por meio de e-mails de um banco de dados particular e também por meio de snowball em redes sociais. Assim, é uma amostra por conveniência. Desta forma, não recomendamos a generalização dos resultados. 
Centramos o foco desta pesquisa na análise do torcedor brasileiro de futebol. Apesar de o futebol ser o esporte mais popular do mundo e ser bastante representativo no Brasil, não se podem generalizar os resultados aqui obtidos para outros esportes ou mesmo outros países. Por isso, parece-nos interessante a replicação deste trabalho em outros esportes e outros países.

Apesar da resposta positiva ao uso da teoria do equilíbrio, este trabalhou analisou apenas a relação do torcedor com os patrocinadores de suas equipes. Isso deve ser visto com o uma limitação do estudo. Desta forma, pesquisas que analisem a relação do torcedor com marcas patrocinadores de times concorrentes pode ser interessante para mensurar a ideia da transferência de lealdade e da própria teoria do equilíbrio.

O construto identificação com o time é um construto bastante trabalhado na área de esportes. Desta forma, usar outras variantes da identificação no lugar do modelo SBSS pode ser interessante para testar a escala de transferência da lealdade.

Apesar dos resultados atenderem às exigências mínimas estabelecidas, aprofundar os estudos no construto fanatismo também nos parece interessante. Os estudos relacionados à identificação trabalham sempre com a visão de que o fanático é o consumidor mais desejado por todas as organizações. Porém, quando analisada pela devoção patológica, essa adoração elevada pode ser negativa. Assim, estudos nessa área devem ser feitos para enriquecer o conhecimento a respeito do bom ou mau fanatismo.

Por fim, apesar de os resultados permitirem inferir que a transferência da lealdade é possível, novos estudos devem ser feitos para comprová-la. Algumas questões devem ser vistas como limitadoras neste estudo, neste sentido. Primeiramente, apesar de analisar patrocinador e fornecedor de uniforme de formas distintas, mensuramos preferências com marcas concorrentes apenas com os fornecedores de material esportivo. Essa decisão se deu devido à dificuldade de atingir um número mínimo de respondentes, de diversos clubes, se optássemos por analisar também os patrocinadores, que são muito diversos no futebol brasileiro.

Outro ponto é o fato de termos realizado uma pesquisa pré-experimental (utilização de variável independente que não varia) correlacional (objetivo empírico é analisar a extensão e caminho de relação entre as variáveis), o que também serve de limitação para generalizarmos os resultados. Assim, sugerimos que sejam realizados experimentos baseados na ideia da 
transferência da lealdade. Experimentos que permitam manipulação das variáveis e, desta forma, testar a transferência usando outros tipos de marcas, produtos e serviços.

Por fim, os estudos em esporte no Brasil ainda são novos, apesar da força econômica do setor na economia brasileira. Poucos são os autores da área das ciências administrativas e econômicas que buscam o esporte como objeto de estudo. Nota-se até um certo preconceito, talvez motivado pela desorganização ou corrupção d o esporte nacional ou mesmo pela falta de parâmetros para serem analisados. Porém acreditamos que é papel da academia apresentar propostas que permitam mostrar, inclusive, o impacto financeiro que uma desorganização pode trazer a determinados setores.

Cremos, pois, que existe um campo fértil a ser explorado pelas mais diversas áreas do conhecimento. Por isso, ratificamos nosso desejo de que este trabalho, fruto de um longo processo, desperte em outros pesquisadores nacionais motivação para se juntar a nós e adotar o esporte como objeto de estudo. 


\subsection{REFERÊNCIAS}

(NBA), C. s. (2003). Lachowetz, T; McDonald, M; Sutton, W. A; Hedrick, D. G. Sport Marketing Quarterly, 12(1), pp. 23-43.

Aaker, D. A., Kumar, V. L., \& Day, G. S. (2012). Marketing Research (11rd ed ed.). US: Wiley.

Abdel-Ghany, M. (2001). The Evolution of Research in Consumer Science: A 200-Year Perspective. Family and Consumer Sciences Research Journal, 30(2), pp. 223-239.

Abreu Novais, M. \&. (2013). Measuring the effects of event sponsorship: Theoretical frameworks and image transfer models. ournal of Travel \& Tourism Marketing, , 30(4), pp. 308-334.

Alwi, S. F., \& Kitchen, P. J. (2014). Projecting corporate brand image and behavioral response in business schools: Cognitive or affective brand attributes? Journal of Business Research, 67(11), pp. 2324-2336.

Anderson, E. W., Fornell, C., \& Lehmann, D. R. (1994). Customer satisfaction, market share, and profitability: Findings from Sweden. The Journal of Marketing, pp. 53-66.

Apostolopoulou, A., \& Papadimitriou, D. (2004). "Welcome Home": Motivations and Objectives of the 2004 Grand National Olympic Sponsors. Sport Marketing Quarterly, 13(4), pp. 180-192.

Ashforth, B. E., \& Mael, F. (1989). Social identity theory and the organization. Academy of management review, 14(1), pp. 20-39.

Assael, H., Pope, N., Brennan, L., \& Voges, K. (2007). Consumer Behaviour: First Asia Pacific Edition (1 a Edição ed.). Australia: John Wiley \& Sons.

Büchel, B., \& Raub, S. (2002). Building knowledge-creating value networks. European Management Journal, 58(7), pp. 587-596.

Baade, R. A., \& Tiehen, L. J. (1990). An analysis of major league baseball attendance 19691987. Journal of Sport and Social Issues, 14(1), pp. 14-32.

Backman, S. J., \& Crompton, J. L. (1991). The usefulness of selected variables for predicting activity loyalty. Leisure Sciences, 13(3), pp. 205-220.

Balaji, M. S., \& Chakraborti, R. (2015). Stadium atmosphere: scale development and validation in Indian context. Journal of Indian Business Research, 7(1), pp. 45-66.

Bandyopadhyay, S., \& Martell, M. (2007). Does attitudinal loyalty influence behavioral loyalty? A theoretical and empirical study. Journal of Retailing and Consumer Services, 14(1), pp. 35-44.

Barroso, C., \& Gabriel Cepeda Carri'on, a. J. (2010). Applying Maximum Likelihood and PLS on Different Sample Sizes: Studies on SERVQUAL Model and Employee Behavior Model. Em E. Vinzi, W. Chin, J. Henseler, \& H. Wang, Handbook of Partial Least Squares (p. 427). US: Springer.

Bauer, H. H., Stokburger-Sauer, N. E., \& Exler, S. (2008). Brand image and fan loyalty in professional team sport: A refined model and empirical assessment. Journal of sport Management, 22(2), pp. 205-226.

BDO Brasil. (2011). Valor das Marcas dos Clubes Brasileiros. São Paulo: BDO Brasil.

BDO Brasil, . (2012). Valor das marcas dos 17 clubes mais valiosos do Brasil. São Paulo: BDO Brasil.

BDO Brasil, . (2013). 6o Valor das Marcas dos Clubes Brasileiros. São Paulo: BDO Brasil. BDO Brasil, . (2014). 7 o Valor das Marcas dos Clubes Brasileiros. São paulo: BDO Brasil. 
Bearden, W. O., Netemeyer, R. G., \& Haws. (2011). Handbook of Marketing Scales: MultiItem Measures for Marketing and Consumer Behavior Research. South carolina: SAGE Publications.

Bennett, R., \& Rundle-Thiele, S. (2002). A comparison of attitudinal loyalty measurement approaches. Journal of Brand Management, 9(3), pp. 193-209.

Bernache-Assollant, I., Bouchet, P., \& Lacassagne, M. F. (2007). Spectators' identification with French sports teams: A French adaptation of the sport spectator identification scale. Perceptual and motor skills, 104(1), pp. 83-90.

Betting, E. (2011). Vai chover dinheiro: Entenda como o novo acordo para a transmissão teve impacto direto nas receitas dos clubes e deve turbinar seu time no meio do ano. Revsita Placar, 26.

Bido, D., Silva, S., Souza, C. A., \& Godoy, A. (2010). Mensuração com indicadores formativos nas pesquisas em administração de emrpesas. Administração: Ensino e Pesquisa, 11(2), pp. 245-269.

Bilgihan, A., Madanoglu, M., \& Ricci, P. (2016). Service attributes as drivers of behavioral loyalty in casinos: The mediating effect of attitudinal loyalty. Journal of Retailing and Consumer Services, 31, pp. 14-21.

Bodet, G. (2008). Customer satisfaction and loyalty in service: Two concepts, four constructs, several relationships. Journal of retailing and consumer services, 15(3), pp. 156-162.

Bodet, G., \& Bernache-Assollant, I. (2011). Consumer loyalty in sport spectatorship services: The relationships with consumer satisfaction and team identification. Psychology \& Marketing, 28(8), pp. 781-802.

Boss, M., \& Kleinert, J. (2015). Explaining social contagion in sport applying Heider's balance theory: First experimental results. Psychology of Sport and Exercise, 16, pp. $160-169$.

Boyle, R. (2009). Power Play: Sport, the Media and Popular Culture: Sport, the Media and Popular Culture. Edinburgh: Edinburgh University Press.

Brady, M. K., Voorhees, C. M., Cronin Jr, J. J., \& Bourdeau, B. L. (2006). The good guys don't always win: the effect of valence on service perceptions and consequences. Journal of Services Marketing, 20(2), pp. 83-91.

Branscombe, N. R., \& Wann, D. L. (1991). The positive social and self concept consequences of sports team identification. Journal of Sport \& Social Issues, 15(2), pp. 115-127.

Brashear-Alejandro, T., Kang, J., \& Groza, M. D. (2016). Leveraging loyalty programs to build customer-company identification. Journal of Business Research, 69(3), pp. 1190-1198.

Bristow, D., Schneider, K., \& Sebastian, R. (2010). Thirty games out and sold out for months! An empirical examination of fan loyalty to two Major League Baseball teams. Journal of Management Research, 2(1), pp. 1-14.

Burns, A. C., \& Bush, R. F. (2013). Marketing Research (7th ed. ed.). US: Prentice Hall.

Busby, R. (1997). Measuring successful sponsorship Evaluation strategies for justifying investment. Financial Times Telecoms \& Media Publishing.

Carlson, B. D., \& Donavan, D. T. (2013). Human brands in sport: Athlete brand personality and identification. Journal of Sport Management, 27(3), pp. 193-206.

Casado, L. (2 de Janeiro de 2012). valor.com.br. Acesso em 25 de Maio de 2016, disponível em Jornal Valor Economico: http://www.valor.com.br/empresas/1160318/paraproduto-esportivo-projecao-e-de-crescimento

Chang, M. L., \& Cheng, C. F. (2014). How balance theory explains high-tech professionals' solutions of enhancing job satisfaction. Journal of Business Research, 67(9), pp. 20082018. 
Chang, M. L., \& Cheng, C. F. (2014). How balance theory explains high-tech professionals' solutions of enhancing job satisfaction. Journal of Business Research, 67(9), pp. 20082018.

Chaudhuri, A., \& Holbrook, M. B. (2001). The chain of effects from brand trust and brand affect to brand performance: the role of brand loyalty. Journal of marketing, 65(2), pp. 81-93.

Churchill Jr, G. A. (1979). A paradigm for developing better measures of marketing constructs. Journal of marketing research, pp. 64-73.

Cialdini, R. B. (1976). Basking in reflected glory: Three (football) field studies. Journal of personality and social psychology, 34(3), pp. 350-366.

Compton, J. (2016). noculating against a Losing Season: Can Inoculation-Informed Public Relations Strategies Protect Fan Loyalty? International Journal of Sport Communication, 9(1), pp. 1-12.

Cooper, D. \&. (2010). Identification in organizations: The role of self-concept orientations and identification motives. Academy of Management Review, 35(4), pp. 516-538.

Cooper, D. R., \& Schindle, P. S. (2011). Métodos de pesquisa em administração (10th ed. ed.). Porto Alegre: Bookman.

Cornwell, T. B. (2005). The Relationship Between Major-League Sports' Official Sponsorship Announcements and the Stock Prices of Sponsoring Firms. Journal of the Academy of Marketing Science, 33(4), pp. 401-412.

Cornwell, T. B., Relyea, G. E., \& Irwin, R. I. (2000). Understanding long term effects of sports sponsorship: role of experience, involvement, enthusiasm and clutter. International Journal of Sports Marketing \& Sponsorship, 2(2), pp. 127-143.

Creswell, J. W. (2009). Projeto de Pesquisa: Método Qualitativo, Quantitativo e Misto (3th ed ed.). Bookman.

Davies, F. \&. (2008). Selection of leveraging strategies by national Olympic sponsors: A proposed model. International Journal of Sports Marketing and Sponsorship, 9(4), pp. 271-289.

Day, G. S. (1976). A two-dimensional concept of brand loyalty. Em G. S. Day, Mathematical models in marketing. Berlin: Springer Berlin Heidelberg.

Dechesne, M., Greenberg, J., Arndt, J., \& Schimel, J. (2000). Terror management and the vicissitudes of sports fan affiliation: The effects of mortality salience on optimism and fan identification. European Journal of Social Psychology, 30(6), pp. 813-835.

Delgado-Márquez, B. L.-T.-C. (2013). On the Measurement of Interpersonal Trust Transfer: Proposal of Indexes. Social Indicators Research, 113, pp. 433-449.

Delia, E. B. (2014). Subconscious ( Un ) Attachment to a Sponsor: An Irrational Effect of Facility Naming Rights. Journal of Sport Management, 28, pp. 551-564.

Deloitte, S. B. (2012). Fan power. Football Money League. Deloitte, Sports Business Group. London: Deloitte, S. B. G.

Deloitte, S. B. (2013). Captains of industry Football Money LeagueCaptains of industry Football Money League. Deloitte, Sports Business Group. London: Deloitte, S. B. G.

Deloitte, S. B. (2014). ll to play for Football Money League. Deloitte, Sports Business Group. London: Deloitte, S. B. G.

Deloitte, S. B. (2015). Commercial breaks Football Money League. Deloitte, Sports Business Group. London: Deloitte, S. B. G.

DeVellis, R. F. (2012). Scale Developtment: Theory and Applications. London: Sage.

Dick, A. S., \& Basu, K. (1994). Customer loyalty: toward an integrated conceptual framework. Journal of the academy of marketing science, 22(2), pp. 99-113. 
Dietl, H. M., Lang, M., \& Werner, S. (2009). Social Welfare in Sports Leagues with ProfitMaximizing and/or Win-Maximizing Clubs. Southern Economic Journal, 76(2), pp. 375-396.

Dietl, H., Franck, E., Hasan, T., \& Lang, M. (2009). Governance of professional sports leagues - Cooperatives versus contracts. International Review of Law and Economics, 29(2), pp. 127-137.

Dietl, H., Franck, E., Lang, M., \& Rathke, A. (2011). Organizational differences between US major leagues and European leagues: implications for salary caps. International Association of Sports Economist, 11(5), pp. 1-16.

Dietz-Uler, B., Harrick, E., End, C., \& Jacquemotte, L. (2000). Sex differences in sport fan behavior and reasons for being a sport fa. 23(3), pp. 219-232.

Dimmock, J. A., \& Grove, J. R. (2006). Identification with sport teams as a function of the search for certainty. Journal of sports sciences, 24(11), pp. 1203-1211.

Dimmock, J. A., \& Grove, J. R. (2006). Identification with sport teams as a function of the searchfor certainty. . Journal of sports sciences, 24(11), pp. 1203-1211.

Dimmock, J. A., Grove, J. R., \& Eklund, R. (2005). Reconceptualizing Team Identification: New Dimensions and Their Relationship to Intergroup Bias. Group Dynamics: Theory, Research, and Practice, 9(2), p. 75.

Dolphin, R. R. (2003). Sponsorship: perspectives on its strategic role. Corporate Communications: An International Journal, 8(3), pp. 173-186.

Donahay, B., \& Rosenberger, P. J. (2007). Using Brand Personality to Measure the Effectiveness of Image Transfer in Formula One Racing. Marketing Bulletin, 18(1), pp. $1-15$.

Doney, P. M., \& Cannon, J. P. (1997). An Examination of the Nature of Trust in Buyer-Seller Relationships. Journal of Marketing, 61(April), pp. 35-51.

Dooley, D. (2000). Social Research Methods (4th ed ed.). Pearson.

Doyle, J. P., Filo, K., McDonald, H., \& Funk, D. C. (2013). Exploring sport brand double jeopardy: The link between team market share and attitudinal loyalty. Sport Management Review, 16(3), pp. 285-297.

Drèze, X., \& Nunes, J. C. (2009). Feeling superior: The impact of loyalty program structure on consumers' perceptions of status. Journal of Consumer Research, 35(6), pp. 890905.

Dutton, J. E., Dukerich, J. M., \& Harquail, C. V. (1994). Organizational images and member identification. Administrative science quarterly, pp. 239-263.

Edwards, J. R., \& Bagozzi, R. P. (2000). On the nature and direction of relationships between constructs and measures. Psychological Methods, 5(2), pp. 155-174.

Epitropaki, O. (2013). A multi-level investigation of psychological contract breach and organizational identification through the lens of perceived organizational membership: Testing a moderated-mediated model. ournal of Organizational Behavior, 34(11), pp. 65-86.

Ernst \& Young. (2011). Brasil sustentável: Impactos Socioeconômicos da Copa do Mundo 2014. São Paulo: Ernst \& Young.

Farrelly, F., Quester, P., \& Burton, R. (2006). Changes in sponsorship value: Competencies and capabilities of successful sponsorship relationships. Industrial Marketing Management, 35(8), pp. 1016-1026.

Fink, J. S., Parker, H. M., B. M., \& Higgins, J. (2009). Off-field behavior of athletes and team identification: Using social identity theory and balance theory to explain fan reactions. Journal of Sport Management, 23(2), pp. 23(2), 142-155. 
Fink, J. S., Trail, G. T., \& Anderson, D. F. (2002). An examination of team identification: which motives are most salient to its existence? International Sports Journal, 6(2), pp. 195-212.

Fisher, R., \& Wakefield, K. (1998). Factors leading to group identification: A field study of winners and losers. Psychology and Marketing, 12(January), pp. 23-40.

Fleury, F. A., Alejandro, T. B., Isabella, G., \& Araujo, A. C. (2016). Consumer Identification: A Social Identity View of Loyalty Program Social and Psychological Benefits. $X L$ Encontro da Anpad, p. 12.

Fleury, F. A., Brashear-Alejandro, T., \& Feldmann, P. R. (2014). Theoretical considerations about the compound of sports marketing. Sport, Leisure and Tourism Review, 3(1), pp. $1-11$.

Fleury, F. A., Cardoso, M. V., Fouto, N. D., Vance, P., \& Marques, R. (2014). The Impact of the Stadium in the Supporter's Consumption: How Does the Frequency at The Stadium Boosts the Demand for the Clubs'. Future Studies Research Journal: Trends and Strategies, 6(2), pp. 126-156.

Franck, E. (2003). Beyond market power: Efficiency explanations for the basic structures of north American major league organizations. European Sport Management Quarterly, 3(4), pp. 221-239.

Fullerton, S., \& Merz, G. (2008). The Four Domains of Sports Marketing: A Conceptual Framework. Sport Marketing Quarterly, 17(2), pp. 90-108.

Funk, D. C., \& James, J. (2001). The psychological continuum model: A conceptual framework for understanding an individual's psychological connection to sport. Sport Management Review, 4(2), pp. 119-150.

Funk, D. C., \& James, J. D. (2004). Sport Management Review. The fan attitude network (FAN) model: Exploring attitude formation and change among sport consumers, 7(1), pp. 1-26.

Funk, D. C., \& James, J. D. (2006). Consumer loyalty: The meaning of attachment in the development of sport team allegiance. Journal of Sport Management, 20(2), pp. 189217.

Funk, D. C., \& Pastore, D. (2000). Equating attitudes to allegiance: The usefulness of selected attitudinal information in segmenting loyalty to professional sports teams. Sport Marketing Quarterly, 9, p. Sport Marketing Quarterly.

Funk, D. C., Mahony, D. F., \& Ridinger, L. L. (2002). Characterizing consumer motivation as individual difference factors: Augmenting the Sport Interest Inventory (SII) to explain level of spectator support. Sport Marketing Quarterly, 11(1), pp. 33-43.

Ganesan, S. (1994). Determinants of Long-Term in Buyer-Seller Orientation Relationships. Journal of Marketing, 58(2), pp. 1-19.

Gau, L. S., James, J. D., \& Kim, J. C. (2009). Effects of team identification on motives, behavior outcomes, and perceived service quality. Asian Journal of Management and Humanity Sciences, 4(2), pp. 76-90.

Geng, L., Burton, R., \& Blakemore, C. (2002). Sport Sponsorship in China: Transition and Evolution. Sport Marketing Quarterly, 11(1), pp. 20-32.

Gil, A. C. (2008). Métodos e técnicas de pesquisa social (6rd ed ed.). Atlas.

Gladden, J. M., \& Funk, D. C. (2002). Developing an understanding of brand associations in team sport: Empirical evidence from consumers of professional sport. Journal of Sport management, $16(1)$, pp. 54-81.

Greenwell, T. C., Fink, J. S., \& Pastore, D. L. (2002). Assessing the influence of the physical sports facility on customer satisfaction within the context of the service experienc2. Sport Management Review, 5(2), pp. 129-148. 
Grohs, R., \& Reisinger, H. (2005). Image transfer in sports sponsorships: an assessment of moderating effects. Image transfer in sports sponsorships: an assessment of moderating effects, 7(1), pp. 36-42.

Grohs, R., \& Reisinger, H. (2014). Sponsorship effects on brand image: The role of exposure and activity involvement. Journal of Business Research, 67(5), pp. 1018-1025.

Gwinner, K. (1997). A model of image creation and image transfer in event sponsorship. International marketing review, 14(3), pp. 145-158.

Gwinner, K. (1997). A model of image creation and image transfer in event sponsorship. International Marketing Review, 14(3), pp. 145-158.

Gwinner, K. P., \& Eaton, J. (1999). Building Brand Image Through Event Sponsorship: The Role of Image Transfer. Journal of Advertising, 28(4), pp. 47-57.

Gwinner, K. P., Gremler, D. D., \& Bitner, M. J. (1998). Relational benefits in services industries: the customer's perspective. Journal of the academy of marketing science, 26(2), pp. 101-114.

Gwinner, K. P., Larson, B. V., \& Swanson, S. R. (2009). Image transfer in corporate event sponsorship: assessing the impact of team identification and event-sponsor fit. International Journal of Management and Marketing Research, 2(1), pp. 1-15.

Gwinner, K., \& Bennett, G. (2008). The impact of brand cohesiveness and sport identification on brand fit in a sponsorship context. Journal of Sport Management, 22(4), pp. 410426.

Gwinner, K., \& Swanson, S. R. (2003). A model of fan identification: Antecedents and sponsorship outcomes. Journal of services marketing, 17(3), pp. 275-294.

Hair Jr, J. F., Hult, G. T., Ringle, C., \& Sarstedt, M. (2014). A primer on partial least squares structural equation modeling (PLS-SEM). London: Sage Publications.

Hair, J. F., Anderson, R. E., Tatham, R. L., \& Black, W. C. ((2009). ). Análise Multivariada de Dados (6th ed ed.). Brasil: Bookman.

Hallowell, R. (1996). The relationships of customer satisfaction, customer loyalty, and profitability: an empirical study. International journal of service industry management, 7(4), pp. 27-42.

Hambrecht, W., Hambrecht, E., Morrissey, P., \& Taylor, A. (2012). The US professional sports market \& franchise value report 2011. wrhambrecht. San Francisco: San Francisco. Acesso em 25 de Maio de 2016, disponível em wrhambrecht: https://www.wrhambrecht.com/wpcontent/uploads/2013/09/SportsMarketReport_2012.pdf

Han, J., Seo, Y., \& Ko, E. (2016). Staging luxury experiences for understanding sustainable fashion consumption: A balance theory application. Journal of Business Research.

Hansen, H., \& Gauthier, R. (1989). Factors affecting attendance at professional sport events. Journal of sport management, 3(1), pp. 15-32.

Harris, L. C., \& Goode, M. M. (2004). The four levels of loyalty and the pivotal role of trust: a study of online service dynamics. Journal of retailing, 80(2), pp. 139-158.

Heere, B., \& Dickson, G. (2008). Measuring attitudinal loyalty: Separating the terms of affective commitment and attitudinal loyalty. Journal of Sport Management, 22(2), pp. 227-239.

Heere, B., Walker, M., Yoshida, M., Ko, Y. J., Jordan, J. S., \& James, J. D. (2011). Brand community development through associated communities: Grounding community measurement within social identity theory. Journal of Marketing Theory and Practice, 19(4), pp. 407-422.

Heider, F. (1958). The psychology of interpersonal relations. New York: Wiley.

Hinkin, T. R. (1998). A brief tutorial on the development of measures for use in survey questionnaires. Organizational research methods, 1(1), pp. 104-121. 
Hogg, M. A., \& Mullin, B. A. (1999). Joining groups to reduce uncertainty: Subjective uncertainty reduction and group identification. Oxford: Blackwell.

Hogg, M. A., \& Terry, D. I. (2000). Social identity and self-categorization processes in organizational contexts. Academy of management review, 25(1), pp. 121-140.

Howard, D. R., \& Crompton, J. L. (1995). Financing sport. Fitness Information Technology. WV: Inc. Morgantown.

IEG. (2011). IEG Sponsorship Report. US: IEG.

IEG. (2012). IEG Sponsorship Report. US: IEG.

IEG. (2013). IEG Sponsorship Report. US: IEG.

IEG. (2014). Sponsorship Spending Report. Where the Dollars Are Going and Trends for 2014. US: IEG.

Irwin, R. L., \& Asimakopoulos, M. K. (1992). An approach to the evaluation and selection of sport sponsorship proposals. Sport Marketing Quarterly, 1(2), pp. 43-51.

Irwin, R. L., Sutton, W. A., \& McCarthy, L. M. (2008). Sport promotion and sales management (2nd ed. ed.). US: Human Kinetics.

Ito, N. C., Hayashi Junior, P., Gimenez, F. A., \& Fensterseifer, J. E. (2012). Value and competitive advantage: searching for definitions, relationships, and repercussions. Revista de Administração Contemporânea, 16(2), pp. 290-307.

Jacoby, J., \& Kyner, D. B. (1973). Brand loyalty vs. repeat purchasing behavior. Journal of Marketing research, pp. 1-9.

Johar, G. V., \& Pham, M. T. (1999). Relatedness, prominence and constructive sponsor identification. Journal of Marketing Research, 36(August), pp. 299-312.

$\mathrm{Ju}$ Rebecca Yen, H. \&. (2003). Internet retail customer loyalty: the mediating role of relational benefits. International Journal of Service Industry Management, 14(5), pp. 483-500.

Kandampully, J., Zhang, T., \& Bilgihan, A. (2015). Customer loyalty: a review and future directions with a special focus on the hospitality industry. International Journal of Contemporary Hospitality Management, , 27(3), pp. 379-414.

Kang, J., Alejandro, T. B., \& Groza, M. D. (2015). Customer-company identification and the effectiveness of loyalty programs. Journal of Business Research, 68(2), pp. 464-471.

Kapil, K., \& Kapil, S. (2009). Antecedents of brand loyalty: an empirical study in mobile telecom sector. International Journal of Indian Culture and Business Management, 3(1), pp. 1-22.

Katz, M., \& Heere, B. (2013). Leaders and followers: An exploration of the notion of scalefree networks within a new brand community. Journal of Sport Management, 27(4), pp. 271-287.

Kaynak, E., Salman, G. G., \& Tatoglu, E. (2008). An integrative framework linking brand associations and brand loyalty in professional sports. Journal of Brand Management, 15(5), pp. 336-357.

Keller, K. L. (1993). Conceptualizing, measuring, and managing customer-based brand equity. Journal of Marketing, pp. 1-22.

Kelman, H. C. (1961). Processes of opinion change. Public opinion quarterly, 25(1), pp. 5778.

Kim, A. C., Chelladuria, P., \& Kim, Y. K. (2015). Scholarly trusts in the Journal of Sport Management: Citation analyis . Global Sport Management Journal,, 2(1), pp. 1-20.

Kim, J., Morris, J. D., \& Swait, J. (2008). Antecedents of true brand loyalty. Journal of Advertising, 37(2), pp. 99-117.

Kim, M., Vogt, C. A., \& Knutson, B. J. (2015). Relationships among customer satisfaction, delight, and loyalty in the hospitality industry. Journal of Hospitality \& Tourism Research, 39(2), pp. 170-197. 
Kline, R. B. (2011). Principles and Practice of structural equation modeling. New York: The Guilford Press.

Knox, S., \& Walker, D. (2001). Measuring and managing brand loyalty. Journal of Strategic Marketing, 9(2), pp. 111-128.

Kohli, A. K., \& Jaworski, B. J. (1990). Market orientation: the construct, research propositions, and managerial implications. Journal of Marketin, pp. 1-18.

Kolbe, R. H., \& James, J. D. (2003). The internalization process among team followers: Implications for team loyalty. International Journal of Sport Management, 4(1), pp. 25-43.

Koo, G., Quarterman, J., \& Flynn, L. (2006). Effect of Perceived Sport Event and Sponsor Image Fit on Consumers: Cognition, Affect, and Behavioral Intentions. Sport Marketing Quarterly, 15(2), pp. 80-90.

Kressmann, F., Sirgy, M. J., Herrmann, A., Huber, F., Huber, S., \& Lee, D. J. (2006). Direct and indirect effects of self-image congruence on brand loyalty. Journal of Business Research, 59(9), pp. 955-964.

Kumar, V. I., \& Shah, D. (2004). Building and sustaining profitable customer loyalty for the 21 st century. Journal of retailing, 90(4), pp. 317-329.

Kunkel, T., Doyle, J. P., \& Funk, D. C. (2014). Exploring sport brand development strategies to strengthen consumer involvement with the product-The case of the Australian ALeague. Sport Management Review, 17(4), pp. 470-483.

Kuzma, J. R., Shanklin, W. L., \& McCally Jr, J. F. (1993). Number one principle for sporting events seeking corporate sponsors: meet benefactor's objectives. Sport Marketing Quarterly, 2(3), pp. 27-32.

Kwon, H. H., \& Armstrong, K. L. (2004). An Exploration of the Construct of Psychological Attachment to a Sport Team Among College Students: A Multidimensional Approach. Sport Marketing Quarterly, 13(2), pp. 29-45.

Kwon, H. H., Trail, G., \& James, J. D. (2007). The mediating role of perceived value: Team identification and purchase intention of team-licensed apparel. Journal of Sport Management, 21(4), pp. 540-554.

Kwon, Y., \& Kwak, D. H. (2014). Revisiting the team identification-value-purchase relationship in the team-licensed merchandise consumption context: a multidimensional consumer value approach. Sport Marketing Quarterly, 23(2), pp. 100-111.

Kyoum Kim, Y., Jae Ko, Y., \& James, J. (2011). The impact of relationship quality on attitude toward a sponsor. Journal of Business \& Industrial Marketing, 26(8), pp. 566576.

Lacey, R. (2007). Relationship drivers of customer commitment. Journal of Marketing Theory and practice, 15(4), pp. 315-333.

Landau, E. (2012). Governança no mundo do futebol. In 13o Congresso Internacional de Governança Corporativa. São Paulo: Instituto Brasileiro de Governança Corporativa (IBGC) .

Larán, J. A., \& Espinoza, F. D. (2004). Consumidores satisfeitos, e então? Analisando a satisfação como antecedente da lealdade. Revista de Administração Contemporânea, $8(2)$, pp. 51-70.

Lee, D., Trail, G. T., Lee, C., \& Schoenstedt, L. J. (2013). Exploring factors that affect purchase intention of athletic team merchandise. Journal of Research in Health \& Physical Education, Recreation, Sport \& Dance, 8(1), pp. 40-51.

Lee, J. S., \& Kang, J. H. (2015). Effects of sport event satisfaction on team identification and revisit intent. Effects of sport event satisfaction on team identification and revisit intent, 24(4), p. 225. 
Lee, S., Lee, H. J., Seo, W. J., \& Green, C. (2012). A new approach to stadium experience: The dynamics of the sensoryscape, social interaction, and sense of home. Journal of Sport Management, 26(6), pp. 490-505.

Leedy, P. D., \& Ormrod, J. E. (2012). Practical research: Planning and design (10th ed ed.). Pearson.

Levin, A. M., Joiner, C., \& Cameron, G. (2001). The Impact of Sports Sponsorship on Consumers' Brand Attitudes and Recall: The Case of NASCAR Fans. Journal of Current Issues \& Research in Advertising, 23(2), pp. 23-31.

Lock, D., Funk, D. C., Doyle, J. P., \& McDonald, H. (2014). Examining the longitudinal structure, stability, and dimensional interrelationships of team identification. Journal of Sport Management, 28(2), pp. 119-135.

Lough, N. L., \& Irwin, R. L. (259-272). A compara- tive analysis of Sponsorship objectives. For U.S. Women's Sport and traditional Sport Sponsorship. Em A. Gillentine, Handbook of Sport Marketing Research. US: Fitness Information Technology.

Lu, Y., Yang, S., Chau, P. Y., \& Cao, Y. (2011). Dynamics between the trust transfer process and intention to use mobile payment services: A cross-environment perspective. Information and Management, 48(8), pp. 393-403.

Macdougall, H. K., Nguyen, S. N., \& Karg, A. J. (2014). 'Game, Set, Match': An exploration of congruence in Australian disability sport sponsorship. Sport Management Review, 17(1), pp. 78-89.

Madrigal, R. (1995). Cognitive and affective determinants of fan satisfaction. Journal of leisure research, 27(5), p. 205.

Madrigal, R. (2001). Social Identity Effects in a Belief - Attitude - Intentions Hierarchy: Implications for. Psychology \& Marketing, 18(2), pp. 145-165.

Mael, F. A., \& Ashforth, B. E. (2001). Identification in work, war, sports, and religion: Contrasting the benefits and risks. Journal for the Theory of Social Behaviour, 31(2), pp. 197-222.

Mahony, D. F., Madrigal, R., \& Howard, D. A. (2000). Using the psychological commitment to team (PCT) scale to segment sport consumers based on loyalty. Sport Marketing Quarterly, 9(1), pp. 15-25.

Malhotra, N. K. (2012). Pesquisa de marketing: uma orientação aplicada (3.ed ed ed.). Porto Alegre:: Bookman. .

Marques, R. D., Fleury, F. A., \& Gonçalves, E. B. (2015). É Ouro! A Percepção do Consumidor em Relação aos Patrocinadores dos Comitês Olímpico e Paralímpico BrasileiroÉ Ouro! A Percepção do Consumidor em Relação aos Patrocinadores dos Comitês Olímpico e Paralímpico Brasileiro. XXXIV EnANAPD , pp. 1-12.

Mason, K. (2005). How corporate sport sponsorship impacts consumer behavior. Journal of American Academy of Business, 7(September), pp. 32-35.

Matsuoka, H., Chelladurai, P., \& Harada, M. (2003). Direct and Interaction Effects of Team Identification and Satisfaction on Intention to Attend Games. Sport Marketing Quarterly, 12(4), pp. 34-49.

Maxwell, H. \&. (2009). Signage vs. no signage: An analysis of sponsorship recognition in women's college basketball. Sport Marketing Quarterly, 18(4), p. 188.

Mazodier, M. \&. (2014). The role of sponsorship fit for changing brand affect: A latent growth modeling approach. International Journal of Research in Marketing, 31(1), pp. 16-29.

McCracken, G. (1989). Who is the Celebrity Endorser? Cultural Foundations of the Endorsement Process. Journal of Consumer Research,, 16(3), pp. 310-321.

McCutcheon, L. E., Lange, R., \& Houran, J. (2002). Conceptualization and measurement of celebrity worship. British journal of psychology, 93(1), pp. 67-87. 
McKnight, D. H., Choudhury, V., \& Kacmar, C. (2002). Developing and validating trust measures for e-commerce: An integrative typology. Information Systems Research, 13(3), pp. 334-359.

Meenaghan, T. (1991). Sponsorship - Legitimising the Medium. European Journal of Marketing, 25(11), pp. 5-10.

Meenaghan, T. (2001). Understanding sponsorship effects. Psychology \& Marketing, 18(2), pp. 95-122.

Meenaghan, T., Mcloughlin, D., \& McCormarck, A. (2013). New Challenges in Sponsorship Evaluation Actors, New Media, and the Context of Praxis. Psychology \& Marketing, 30(5), pp. 444-460.

Melnick, M. J., \& Wann, D. L. (2004). Sport fandom influences, interests, and behaviors among Norwegian university students. International sports journal, 8(1), pp. 1-13.

Melnyk, V., \& Bijmolt, T. (2015). The effects of introducing and terminating loyalty programs. European Journal of Marketing, 493, pp. 398-419.

Melnyk, V., \& Bijmolt, T. (205). The effects of introducing and terminating loyalty programs. European Journal of Marketing, 49(3), pp. 398-419.

Menon, K., \& Dubé, L. (2000). Ensuring greater satisfaction by engineering salesperson response to customer emotions. Journal of Retailing, 76(3), pp. 285-307.

Miles, L. (2000). Successful Sport Sponsorship: Lessons from Association Football--the Role of Research.(Analysis). International Journal of Sports Marketing \& Sponsorship, 2(4), pp. 357-369.

Miloch, K., \& Lambrecht, K. (2006). Consumer awareness of sponsorship at grassroots sport events. Sport Marketing Quarterly, 15(3), pp. 147-154.

Mimouni-Chaabane, A., \& Volle, P. (2010). Perceived benefits of loyalty programs: Scale development and implications for relational strategies. Journal of Business Research, 15(3), pp. 32-37.

Miyazaki, A. D., \& Morgan, A. G. (2001). Assessing market value of event sponsoring: Corporate olympic sponsorships. Journal of Advertising Research, 4(1), pp. 9-15.

Moreno, F. C., Prado-Gascó, V., Hervás, J. C., Núñez-Pomar, J., \& Sanz, V. A. (2015). Spectator emotions: Effects on quality, satisfaction, value, and future intentions. Journal of Business Research, 68(7).

Murrell, A. J., \& Dietz, B. (1992). Fan support of sport teams: The effect of a common group identity. Journal of Sport and Exercise Psychology, 14(1), pp. 28-39.

Neale, W. C. (1964). The peculiar economics of professional sports. The quarterly journal of economics, 78(1), pp. 1-14.

Netemeyer, R. G., Heilman, C. M., \& Maxham, J. G. (2012). Identification with the retail organization and customer-perceived employee similarity: effects on customer spending. Journal of Applied Psychology, 97(5), pp. 10-49.

Neuman, W. L. (2011). Basics of Social Research: Qualitative and Quantitative Approaches ((3rd ed.) ed.). US: Pearson. .

Newcomb, T. (1968). Interpersonal balance. Em R. P. H. Abelson, E. Aronson, W. McGuire, T. Newcomb, \& M. Rosenberg, Theories of Cognitive Consistency: A Sourcebook. Chicago: Tannenbaum.

Nufer, G., \& Bühler, A. (2010). How effective is the sponsorship of global sports events? A comparison of the FIFA World Cups in 2006 and 1998. International Journal of Sports Marketing and Sponsorship, 11(4), pp. 33-49.

Odekerken-Schröder, G., De Wulf, K., \& Schumacher, P. (2003). Strengthening outcomes of retailer-consumer relationships: The dual impact of relationship marketing tactics and consumer personality. Journal of business research, 56(3), pp. 177-190. 
O’Reilly, N. J., \& Madill, J. J. (2007). Evaluating Social Marketing Elements in Sponsorship. Social Marketing Quarterly, 13(4), pp. 1-25.

Oliver. (1999). Whence consumer loyalty?. Journal of Marketing, pp. 33-44.

Oliver, L. (2014). Satisfaction: A behavioral perspective on the consumer. US: Routledge.

Olson, E. L. (2010). Does sponsorship work in the same way in different sponsorship contexts? . European Journal of Marketing, 44(1), pp. 180-199.

Pan, Y., Sheng, S., \& Xie, F. T. (2012). Antecedents of customer loyalty: An empirical synthesis and reexamination. Journal of Retailing and Consumer Services, 19(1), pp. $150-158$.

Papadimitriou, D., Apostolopoulou, A., \& Dounis, T. (2008). Event sponsorship as a value creating strategy for brands. Journal of Product ; Brand Management, 17(4), pp. 212222.

Pappu, R., \& Cornwell, T. B. (2014). Corporate sponsorship as an image platform: understanding the roles of relationship fit and sponsor-sponsee similarity. Journal of the Academy of Marketing Science, 42(5), pp. 490-510.

Park, J. Y., \& Jang, S. S. (2015). You got a free upgrade? What about me? The consequences of unearned preferential treatment. Tourism Management, 50, pp. 59-68.

Parker, H. M., \& Fink, J. S. (2010). Negative sponsor behaviour, team response and how this impacts fan attitudes. International journal of sports marketing and sponsorship, 11(3), pp. 17-28.

Pedersen, P. E., \& Nysveen, H. (2001). Shopbot banking: An exploratory study of customer loyalty effects. International Journal of Bank Marketing, 19(4), pp. 146-155.

Pesrsonneault, A., \& Kraemer, K. L. (1993). Survey Research Methodology Information Systems: Management An Assessment. Journal of Management Information Systems, , 10(2), pp. 75-105.

Pichler, E. A., \& Hemetsberger, A. (2008). Driven by devotion-how consumers interact with their objects of devotion. Advances in Consumer Research, 35.

Pichot, L., Tribou, G., \& O'Reilly, N. J. (2008). Sport Sponsorship , Internal Communications, and Human Resource Management: An Exploratory Assessment of Potential Future Research. International Journal of Sport Communication, 1(4), pp. $=413-423$.

Pluri \& Stochos. (2013). Ia Pesquisa PLURI STOCHOS Tamanho de Torcidas. São Paulo: Pluri \& Stochos.

Pluri Consultoria. (2012). O PIB do Esporte Brasileiro. Curitiba: Pluri Consultoria.

Pope, N. (1998). Consumption values, sponsorship awareness, brand and product use. Journal of Product and Brand Management, 7(2), pp. 124-136.

Pope, N. K., \& Voges, K. E. (1999). Sponsorship and image: a replication and extension. Journal of Marketing Communications, 9(2), pp. 17-28.

Pope, N., \& Vogues, K. (2000). The impact of Sport Sponsorship Activities, Corporate Image and prior use on consumer purchase intention. Sport Marketing Quarterl, 9(2), pp. 96102.

Porter, M. E. (1990). The competitive advantage of nations. Harvard business review, 68(2), pp. 73-93.

Porter, M. E. (1991). Towards a dynamic theory of strategy. Strategic management journal, 12(2), pp. 95-117.

Porter, M. E., \& Kramer, M. R. (2011). The big idea: Creating shared value. 89(1), pp. 1-3.

Radford, S. K., \& Bloch, P. H. (2012). Grief, commiseration, and consumption following the death of a celebrity. Journal of Consumer Culture, 12(2), pp. 137-155. 
Rambaran, J. A., Dijkstra, J. K., Munniksma, A., \& Cillessen, A. H. (2015). The development of adolescents' friendships and antipathies: A longitudinal multivariate network test of balance theory. Social Networks, 43, pp. 162-176.

Reczek, R. W., Haws, K. L., \& Summers, C. A. (2014)). Lucky loyalty: the effect of consumer effort on predictions of randomly determined marketing outcomes. Journal of Consumer Research, 41(4), pp. 1065-1077.

Redden, J., \& Steiner, C. J. (2000). Fanatical consumers: towards a framework for research. Journal of Consumer Marketing, 17(4), pp. 322-337.

Reichheld, F. F. (2003). The one number you need to grow. Harvard business review, 81(12), pp. 46-55.

Reinold, T., \& Tropp, J. (2012). Integrated marketing communications: How can we measure its effectiveness? Journal of Marketing Communications, 18(2), pp. 113-132.

Ringle, C. M., Da Silva, D., \& Bido, D. D. (2014). Modelagem de equações estruturais com utilização do SmartPLS. REMark, 13(2), p. 54.

Rosenberg, L. J., \& Czepiel, J. A. (1984). A marketing approach for customer retention. Journal of consumer marketing, 1(2), pp. 45-51.

Rosner, S., \& Shropshire, K. L. (2004). The business of sports. US: Jones \& Bartlett Learning.

Rundle-Thiele, S. (2005). Exploring loyal qualities: assessing survey-based loyalty measures. Journal of Services Marketing, 19(7), pp. 492-500.

Rust, R. T., \& Zahorik, A. (1993). Customer satisfaction, customer retention, and market share. Journal of retailing, 69(2), pp. 193-215.

Söderlund, M., Liljander, V., Gummerus, J., Hellman, P. L., Oikarinen, E. L., \& T. Liljedal, K. (2014). Preferential treatment in the service encounter. Journal of Service Management, 25(4), pp. 51-530.

Scarapicchia, T. M., Sabiston, C. M., A. R., \& Bengoechea, E. G. (2013). The motivational effects of social contagion on exercise participation in young female adults. Journal of Sport and Exercise Psychology, 35(6), pp. 563-575.

Scully, G. W. (1995). The Market Structure of Sports. Chicago: University of Chicago Press.

Seguin, B., Teed, K., \& O'Reilly, N. J. (2005). National sports organisations and sponsorship: an identification of best practices. International Journal of Sport Management and Marketing, 1(2), p. 69.

Seigneur, J., Gray, A., \& Jensen, C. D. (s.d.). Trust Transfer: Encouraging SelfRecommendations without Sybil Attack. Em J. Seigneur, A. Gray, \& C. D. Jensen, Trust Management . Berlin : Springer Berlin Heidelberg.

Shank, M. D., \& Lyberge, M. R. (2015). Sports marketing; A strategic perspect (5 Edição ed.). US: Routledge.

Shannon, J. R. (1999). Sports marketing: an examination of academic marketing publication. ournal of Services Marketing, 13(6), pp. 517-535.

Shapiro, B. P. (1988). What the Hell Is 'Market Oriented? Harvard Business Review, 66(6), pp. 119-125.

Sirdeshmukh, D., Singh, J., \& Sabol, B. (2002). Consumer trust, value, and loyalty in relational exchanges. Journal of marketing, 66(1), pp. 15-37.

Skaalvik, E. M., \& Skaalvik, S. (2011). Teacher job satisfaction and motivation to leave the teaching profession: Relations with school context, feeling of belonging, and emotional exhaustion. Teaching and teacher education, 27(6), pp. 1029-1038.

Sloan, L. R. (1989). The motives of sports fan. Em J. H. Goldstein, ports, games, and play: Social and psychological viewpoints. Hillsdale: Lawrence Erlbaum Associates.

Smith, A. C., \& Westerbeek, H. M. (2007). Sport as a vehicle for deploying corporate social responsibility. The Journal of Corporate Citizenship, 1(24), p. 43. 
Smith, A., Graetz, B., \& Westerbeek, H. (2008). Sport sponsorship, team support and purchase intentions. Journal of Marketing Communications, 14(5), pp. 387-404.

Smith, G. (2004). Brand Image Transfer Through Sponsorship: A Consumer Learning Perspective. Journal of Marketing Management, 20(3), pp. 457-474.

Smith, G. J., Patterson, B., Williams, T., \& Hogg, J. (1981). A profile of the deeply committed male sports fan. Arena Review, 5(2), pp. 26-44.

Snyder, C. R., Lassegard, M., \& Ford, C. E. (1986). Distancing after group success and failure: Basking in reflected glory and cutting off reflected failure. Journal of Personality and Social Psychology, 51(2), p. 382.

So, J. T., Danaher, T., \& Gupta, S. (2015). What do customers get and give in return for loyalty program membership? Australasian Marketing Journal , 23(3), pp. 196-206.

Sobral, E. (2011). Editora 3. Acesso em 25 de Maio de 2016, disponível em IstoÉ: http://editora3-idin.agilecontents.com/noticias/negocios/20110902/netshoes-abrejogo/2854.shtml

Speed, R., \& Thompson, P. (2000). Determinants of Sports Sponsorship Response. Journal of the Academy of Marketing Science, 28(2), pp. 226-238.

Srinivasan, S. S., Anderson, R., \& Ponnavolu, K. (2002). Customer loyalty in e-commerce: an exploration of its antecedents and consequences. Journal of retailing, 78(1), pp. 41-50.

Stewart, B., Smith, A., \& Nicholson, M. (2003). Sport consumer typologies: A critical review. Sport Marketing Quarterly, 12(4).

Stewart, K. J. (2003). Trust Transfer on the World Wide Web. Organization Science, 14(February), pp. 5-17.

Stotlar, D. K. (2004). Sponsorship Evolution: Moving from Theory to Practice. Sport Marketing Quarterly, 13(61), pp. 206-216.

Strub, P. J., \& Priest, T. B. (1976). Two Patterns of Establishing Trust: The Marijuana User. Socialogical Focus, 9(4), pp. 399-411.

Sutton, W. A., McDonald, M. A., Milne, G. R., \& Cimperman, J. (1997). Creating and fostering fan identification in professional sports. Sport Marketing Quarterly, 1(6), pp. $15-22$.

Tajfel, H. (1972). La catégorisation sociale [Social categorization]. in s. moscovici (ed.) Introduction à la psychologie sociale. Paris: Larousse.

Tajfel, H., \& Turner, J. C. (1979). An integrative theory of intergroup conflict. The social psychology of intergroup relations, 33(47), p. 74.

Tajfel, H., \& Turner, J. C. (1986). The social identity theory of intergroup behavior. Em S. Worchel, \& W. Austin, Psychology of intergroup relations (pp. 7-24). Chicago: S. Worc.

Tapp, A., \& Clowes, J. (2002). From "carefree casuals" to "professional wanderers" Segmentation possibilities for football supporters. European Journal of Marketing, 36(11), pp. 1248-1269.

Theodorakis, N. D., \& Alexandris, K. (2008). Can service quality predict spectators' behavioral intentions in professional soccer? Managing Leisure, 13(3), pp. 162-178.

Theodorakis, N. D., Alexandris, K., \& Ko, Y. J. (2011). A service quality framework in the context of professional football in Greece. International Journal of Sports Marketing and Sponsorship, 12(4), pp. 57-71.

Theodorakis, N. D., Alexandris, K., Tsigilis, N., \& Karvounis, S. (2013). Predicting spectators' behavioural intentions in professional football: The role of satisfaction and service quality. Sport management review, 16(1), pp. 85-96.

Theodorakis, N. D., Koustelios, A., Robinson, L., \& Barlas, A. (2009). Moderating role of team identification on the relationship between service quality and repurchase 
intentions among spectators of professional sports. Managing Service Quality: An International Journal, 19(4), pp. 456-473.

Theodorakis, N. D., Wann, D. L., \& Weaver, S. (2012). An antecedent model of team identification in the context of professional soccer. Sport Marketing Quarterly, 21(2), p. 80.

Thorne, S., \& Bruner, G. C. (2006). An exploratory investigation of the characteristics of consumer fanaticism. Qualitative Market Research: An International Journal, , 9(1), pp. 51-72.

Tokuyama, S., \& Greenwell, T. C. (2011). Examining similarities and differences in consumer motivation for playing and watching soccer. Sport Marketing Quarterly,, 2(3), p. 148.

Trail, G. T., Anderson, D. F., \& Fink, J. S. (2005). Consumer satisfaction and identity theory: A model of sport spectator conative loyalty. Sport Marketing Quarterly, 14(2).

Trail, G. T., Robinson, M. J., Dick, R. J., \& Gillentine, A. J. (2003). Motives and points of attachment: Fans versus spectators in intercollegiate athletics. Sport Marketing Quarterly, 12(4).

Tsiotsou, R. (2011). A stakeholder approach to international and national sport sponsorship. Journal of Business \& Industrial Marketing, 26(8), pp. 557-565.

Tsiotsou, R. H. (2013). Sport team loyalty: integrating relationship marketing and a hierarchy of effects. Journal of Services Marketing, 27(6), pp. 458-471.

Tsiotsou, R., \& Lalountas, D. (2005). Applying event study analysis to assess the impact of marketing communication strategies: the case of sponsorship. Applied Financial Economics Letters, 1(4), pp. 259-262.

Tucker, W. T. (1964). The development of brand loyalty. Journal of Marketing research, 27(6), pp. 32-35.

Turner, J. C. (1975). Social comparison and social identity: Some prospects for intergroup behaviour. European journal of social psychology, 5(1), pp. 1-34.

Uhrich, S., \& Benkenstein, M. (2010). Sport stadium atmosphere: formative and reflective indicators for operationalizing the construct. Journal of Sport Management, 24(2), pp. 211-237.

Ukman, L. (1995). The lEG 's Complete Guide to Sponsorship: Everything You Need to Know About Sports, Arts, Events, Entertainment, and Cause Marketing. Chicago: IEG.

Underwood, R., Bond, E., \& Baer, R. (2001). Building service brands via social identity: Lessons from the sports marketplace. Journal of Marketing Theory and Practice, 9(1), pp. 1-13.

Vieira, V. A. (2002). As tipologias, variações e características da pesquisa de marketing. Revista Da FAE, 5 (1), pp. 61-70.

Vinzi, V. E., Trinchera, L., \& Amato, S. (2011). PLS Path Modeling: From Foundations to Recent Developments and Open Issues for Model Assessment and Improvement. Em Esposito, \& W. Chin Henseler, Handbook of Partial Least Square. US: Springer.

Wakefield, K. L. (1995). The pervasive effects of social influence on sporting event attendance. Journal of sport and social issues, 19(4), pp. 335-351.

Wakefield, K. L. (2012). How sponsorships work: The sponsorship engagement model. Event Management, 16(2), pp. 143-155.

Wakefield, K. L., \& Bennett, G. (2010). Affective Intensity and Sponsor Identification. Journal of Advertising, 39(3), pp. 99-111.

Wakefield, K. L., \& Sloan, H. J. (s.d.). The effects of team loyalty and selected stadium factors on spectator attendance. Journal of sport management, 9(2), pp. 153-172.

Walliser, B. (2003). An international review of sponsorship research : extension and update. International Journal of Advertising, 22(1), pp. 5-40. 
Wang, N., Shen, X. L., \& Sun, Y. (2013). Transition of electronic word-of-mouth services from web to mobile context: A trust transfer perspective. Decision Support SystemS, 54(3), pp. 1394-1403.

Wann, D. L. (2006). Understanding the positive social psychological benefits of sport team identification: The team identification-social psychological health model. Group Dynamics: Theory, Research, and Practice,, 10(4), p. 272.

Wann, D. L., \& Branscombe, N. R. (1990). Die-hard and fair-weather fans: Effects of identification on BIRGing and CORFing tendencies. Journal of Sport and Social issues, 14(2), pp. 103-117.

Wann, D. L., \& Branscombe, N. R. (1993). Sports fans: Measuring degree of identification with their team. International Journal of Sport Psychology, 23(3).

Wann, D. L., \& Schrader, M. P. (1996). An analysis of the stability of sport team identification. Perceptual and Motor Skills, 2(4).

Wann, D. L., \& Schrader, M. P. (1997). Team identification and the enjoyment of watching a sporting event. Perceptual and Motor Skills, 84(3), pp. 954-954.

Wann, D. L., Hunter, J. L., Ryan, J. A., \& Wright, L. A. (2001). The relationship between team identification and willingness of sport fans to consider illegally assisting their team. Social behavior and personality: an international journal, 29(6), pp. 531-536.

Wann, D. L., Royalty, J. L., \& Rochelle, A. R. (2002). Using motivation and team identfication to predict sport fans' emotional responses to team performance. Journal of Sport Behavior, 25(2), p. 207.

Williams, C. (2007). Research Methods. Journal of Business \& Economic Research, 5(3), pp. $65-72$.

Wolfers, J. (2002). The Business of Sports: Where 's the Money? US: Stanford GSB.

Woodruff, R. B. (1997). Customer value: the next source for competitive advantage. Journal of the academy of marketing science, 25(2), p. 139.

Wulf, K. D., Odekerken-Schröder, G., \& Iacobucci, D. (2001). Investments in consumer relationships: A cross-country and cross-industry exploration. Journal of marketing, 65(4), pp. 33-50.

Xia, L., \& Kukar-Kinney, M. (2014). For our valued customers only: Examining consumer responses to preferential treatment practices. Journal of Business Research, 67(11), pp. 2368-2375.

Yoon, D., Choi, S. M., \& Sohn, D. (2008). Building customer relationships in an electronic age: The role of interactivity of E-commerce Web sites. Psychology \& Marketing,, 25(7), pp. 602-618.

Yoshida, M., \& James, J. D. ((2010)). Customer satisfaction with game and service experiences: Antecedents and consequences. Journal of sport managemenyt, 24(3), pp. 38-361.

Yoshida, M., Heere, B., \& Gordon, B. (2015). Predicting behavioral loyalty through community: Why other fans are more important than our own intentions, our satisfaction, and the team itself. Journal of Sport Management, 29(3), pp. 318-333.

Yuksel, A., Yuksel, F., \& Bilim, Y. (2010). Destination attachment: Effects on customer satisfaction and cognitive, affective and conative loyalty. Tourism management, 31(2), pp. 274-284.

Zeithaml, V. A., Parasuraman, A., \& Berry, L. L. (1985). Problems and strategies in services marketing. Journal of Marketing, pp. 33-46.

Zhang, T., Kandampully, J., \& Bilgihan, A. (2015). Motivations for customer engagement in online co-innovation communities (OCCs) A conceptual framework. Journal of Hospitality and Tourism Technology, 6(3), pp. 311-328. 


\section{APÊNDICE B - ESCALA PRÉ - TESTE}

\begin{tabular}{|c|c|c|}
\hline CONSTRUTO & INDICADOR AVALIADO & INDICADOR PRÉ-TESTE \\
\hline $\begin{array}{l}\text { Tratamento } \\
\text { Preferencial }\end{array}$ & $\begin{array}{l}\text { 1. Sinto que sou melhor tratado do que } \\
\text { torcedores de outros times. } \\
\text { 2. Sinto que sou tratado com mais } \\
\text { respeito do que torcedores de outros } \\
\text { times. } \\
\text { 3. Sinto que eu sou especial com relação } \\
\text { a torcedores de outros times. }\end{array}$ & $\begin{array}{l}\text { 1. Sinto que as pessoas (não apenas } \\
\text { torcedores) me tratam melhor do que } \\
\text { tratam torcedores de outros times. } \\
\text { 2. Sinto que as pessoas (não apenas } \\
\text { torcedores) me tratam com mais } \\
\text { respeito do que tratam torcedores de } \\
\text { outros times. } \\
\text { 3. Sinto que as pessoas em geral (não } \\
\text { apenas torcedores) me tratam de } \\
\text { forma diferenciada (distinta) do que } \\
\text { tratam torcedores de outros times. }\end{array}$ \\
\hline $\begin{array}{l}\text { Reconhecimento } \\
\text { Pessoal }\end{array}$ & $\begin{array}{l}\text { 1. Eu sou reconhecido positivamente pela } \\
\text { sociedade por ser torcedor do [Time]. } \\
\text { 2. Ser torcedor do [Time] facilita } \\
\text { conhecer novas pessoas. } \\
\text { 3. Ser torcedor do [Time] facilita fazer } \\
\text { amizades. } \\
\text { 4. Ser torcedor do [Time] faz com que as } \\
\text { pessoas pensem coisas boas de mim. }\end{array}$ & $\begin{array}{l}\text { 1. Eu sou reconhecido positivamente } \\
\text { pela sociedade por ser torcedor do } \\
\text { [Time] } \\
\text { 2. Ser torcedor do [Time] facilita } \\
\text { conhecer novas pessoas. } \\
\text { 3. Ser torcedor do [Time] facilita fazer } \\
\text { novas amizades. } \\
\text { 4. Ser torcedor do [Time] faz com que as } \\
\text { pessoas tenham uma boa imagem de } \\
\text { mim. }\end{array}$ \\
\hline $\begin{array}{l}\text { Sentimento de } \\
\text { Status }\end{array}$ & $\begin{array}{l}\text { 1. Ser torcedor do [Time] me faz me } \\
\text { sentir especial. } \\
\text { 2. Eu sou respeitado por ser torcedor do } \\
\text { [Time]. } \\
\text { 3. É difícil torcedores de outros times } \\
\text { terem o mesmo status que eu tenho } \\
\text { sendo torcedor do [Time]. }\end{array}$ & $\begin{array}{l}\text { 1. Ser torcedor do [Time] me faz me } \\
\text { sentir especial. } \\
\text { 2. Eu sou respeitado pelas pessoas (não } \\
\text { apenas torcedores), por ser torcedor do } \\
\text { [Time]. } \\
\text { 3. É difícil para os torcedores de outros } \\
\text { times alcançarem o mesmo status que } \\
\text { eu tenho por eu ser torcedor do } \\
\text { [Time]. }\end{array}$ \\
\hline Pertencimento & $\begin{array}{l}\text { 1. Eu pertenço a uma comunidade de } \\
\text { pessoas que compartilham os mesmos } \\
\text { valores que eu sendo torcedor do } \\
\text { [Time]. } \\
\text { 2. Eu me sinto próximo do [Time]. } \\
\text { 3. Sinto que o [Time] compartilha os } \\
\text { mesmos valores que eu. }\end{array}$ & $\begin{array}{l}\text { 1. Eu pertenço a uma comunidade de } \\
\text { pessoas que compartilham os mesmos } \\
\text { valores que eu, pelo fato de sermos } \\
\text { torcedores do [Time]. } \\
\text { 2. Eu me sinto parte (importante) do } \\
\text { [Time]. } \\
\text { 3. Sinto que o [Time] compartilha os } \\
\text { mesmos valores que eu. }\end{array}$ \\
\hline $\begin{array}{l}\text { Avaliação } \\
\text { Pessoal }\end{array}$ & $\begin{array}{l}\text { 1. O [Time] tem muito do que se } \\
\text { orgulhar. } \\
\text { 2. Eu sou orgulhoso de ser um torcedor } \\
\text { do [Time]. } \\
\text { 3. Vale a pena torcer para o [Time]. }\end{array}$ & $\begin{array}{l}\text { 1. Como torcedor do [Time] eu tenho } \\
\text { muito do que me orgulhar do meu } \\
\text { time. } \\
\text { 2. Eu tenho orgulho de ser torcedor do } \\
\text { [Time]. } \\
\text { 3. O tempo que eu gasto com o [Time] } \\
\text { vale a pena. } \\
\text { 4. O dinheiro que eu gasto com o [Time] } \\
\text { vale a pena. } \\
\text { 5. Eu desenvolvo conversas agradáveis } \\
\text { sobre o [Time] que valem a pena. }\end{array}$ \\
\hline
\end{tabular}




\begin{tabular}{|c|c|c|}
\hline $\begin{array}{l}\text { Avaliação dos } \\
\text { Outros }\end{array}$ & $\begin{array}{l}\text { 1. Em geral as pessoas têm uma visão } \\
\text { positiva do [Time]. } \\
\text { 2. Em geral as pessoas respeitam o } \\
\text { [Time]. } \\
\text { 3. No geral a maioria das pessoas } \\
\text { consideram o [Time] melhor do que os } \\
\text { times rivais. }\end{array}$ & $\begin{array}{l}\text { 1. As pessoas (não apenas torcedores) } \\
\text { têm uma visão positiva do [Time]. } \\
\text { 2. As pessoas (não apenas torcedores) } \\
\text { respeitam o [Time]. } \\
\text { 3. No geral a maioria das pessoas } \\
\text { consideram o [Time] melhor do que } \\
\text { os times rivais. }\end{array}$ \\
\hline Satisfação & $\begin{array}{l}\text { 1. Eu estou satisfeito com as decisões da } \\
\text { atual diretoria do โTime]. } \\
\text { 2. Eu estou satisfeito com as últimas } \\
\text { contratações do [Time]. } \\
\text { 3. Eu estou satisfeito com os resultados } \\
\text { do [Time】. } \\
\text { 4. Eu estou satisfeito com desempenho } \\
\text { do [Time】. }\end{array}$ & $\begin{array}{l}\text { 1. Eu estou satisfeito com as últimas } \\
\text { contratações do [Time]. } \\
\text { 2. Eu estou satisfeito com os resultados } \\
\text { do [Time]. } \\
\text { 3. Eu estou satisfeito com desempenho } \\
\text { do [Time] nas partidas indiferente dos } \\
\text { resultados alcançados. } \\
\text { 4u estou satisfeito com o estádio onde } \\
\text { o [Time] manda seus jogos. } \\
\text { 5. Eu estou satisfeito com a postura dos } \\
\text { jogadores do [Time]. }\end{array}$ \\
\hline $\begin{array}{l}\text { Envolvimento } \\
\text { com o Futebol }\end{array}$ & $\begin{array}{l}\text { 1. Futebol é muito importante para mim. } \\
\text { 2. Eu penso sobre futebol a todo } \\
\text { momento. } \\
\text { 3. Eu assisto futebol sempre que eu } \\
\text { posso. } \\
\text { 4. O futebol é meu esporte favorito. } \\
\text { 5. As pessoas pensam que o futebol é } \\
\text { muito importante para mim. }\end{array}$ & $\begin{array}{l}\text { 1. Futebol é muito importante para mim. } \\
\text { 2. Eu penso sobre futebol a todo } \\
\text { momento. } \\
\text { 3. Eu assisto futebol sempre que eu } \\
\text { posso. } \\
\text { 4. O futebol é meu esporte favorito. } \\
\text { 5. As pessoas pensam que o futebol é } \\
\text { muito importante para mim. }\end{array}$ \\
\hline $\begin{array}{l}\text { Identificação com } \\
\text { o Time }\end{array}$ & $\begin{array}{l}\text { 1. Amigos e familiares me identificam } \\
\text { como torcedor apaixonado do [Time]. } \\
\text { 2. É importante para mim que meus } \\
\text { amigos me vejam como um torcedor } \\
\text { apaixonado pelo [Time]. } \\
\text { 3. Eu me considero um torcedor } \\
\text { apaixonado do [Time]. } \\
\text { 4. Ser torcedor do [Time] é parte } \\
\text { importante de quem sou. } \\
\text { 5. Eu me sentiria muito mal se tivesse } \\
\text { que parar de torcer para o [Time]. } \\
\text { 6. Torcer para o [Time] é importante } \\
\text { para mim. }\end{array}$ & $\begin{array}{l}\text { 1. Amigos e familiares me identificam } \\
\text { como torcedor apaixonado do [Time]. } \\
\text { 2. É importante para mim que meus } \\
\text { amigos me vejam como um torcedor } \\
\text { apaixonado pelo [Time]. } \\
\text { 3. Eu me considero um torcedor } \\
\text { apaixonado do [Time] } \\
\text { 4. Ser torcedor do [Time] é parte } \\
\text { importante de quem sou. } \\
\text { 5. Eu me sentiria muito mal se tivesse } \\
\text { que parar de torcer para o [Time]. } \\
\text { 6. Torcer para o [Time] é importante } \\
\text { para mim. }\end{array}$ \\
\hline Fanatismo & 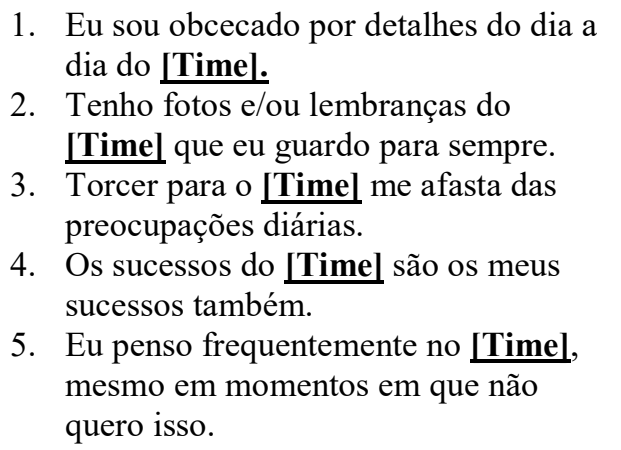 & $\begin{array}{l}\text { 1. Eu sou obcecado por detalhes do dia a } \\
\text { dia do [Time]. } \\
\text { 2. Tenho fotos e/ou lembranças do } \\
\text { [Time] que eu guardo para sempre. } \\
\text { 3. Torcer para o [Time] me afasta das } \\
\text { preocupações diárias. } \\
\text { 4. Os sucessos do [Time] são os meus } \\
\text { sucessos também. } \\
\text { 5. Eu penso frequentemente no [Time], } \\
\text { mesmo em momentos em que não } \\
\text { quero isso. }\end{array}$ \\
\hline $\begin{array}{l}\text { Lealdade } \\
\text { Atitudinal }\end{array}$ & $\begin{array}{l}\text { 1. Se eu tenho um convite para um outro } \\
\text { programa (cinema, teatro, festa de um } \\
\text { amigo, etc.) eu me sinto mal por não } \\
\text { assistir o jogo do [Time]. }\end{array}$ & $\begin{array}{l}\text { 1. Se eu tenho um convite para um outro } \\
\text { programa (cinema, teatro, festa de um } \\
\text { amigo, etc.) eu me sinto mal por não } \\
\text { assistir o jogo do [Time]. }\end{array}$ \\
\hline
\end{tabular}




\begin{tabular}{|c|c|c|}
\hline & 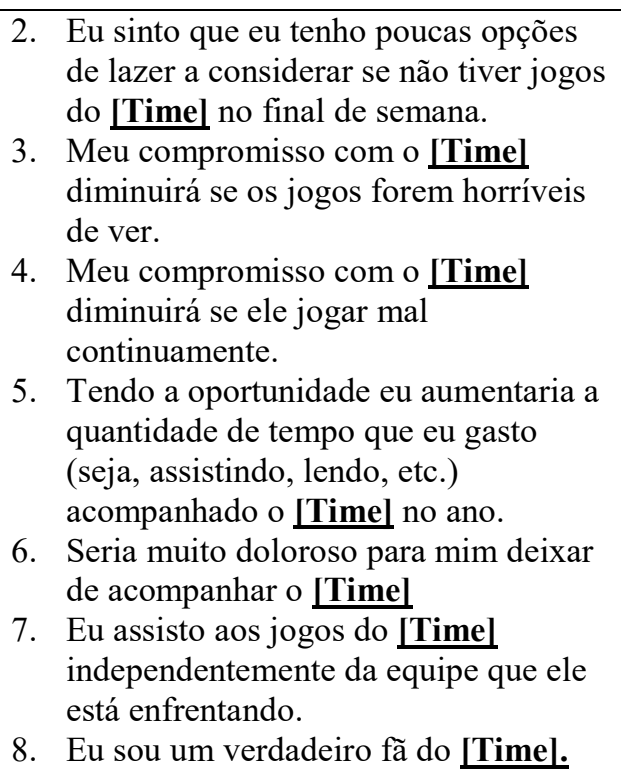 & 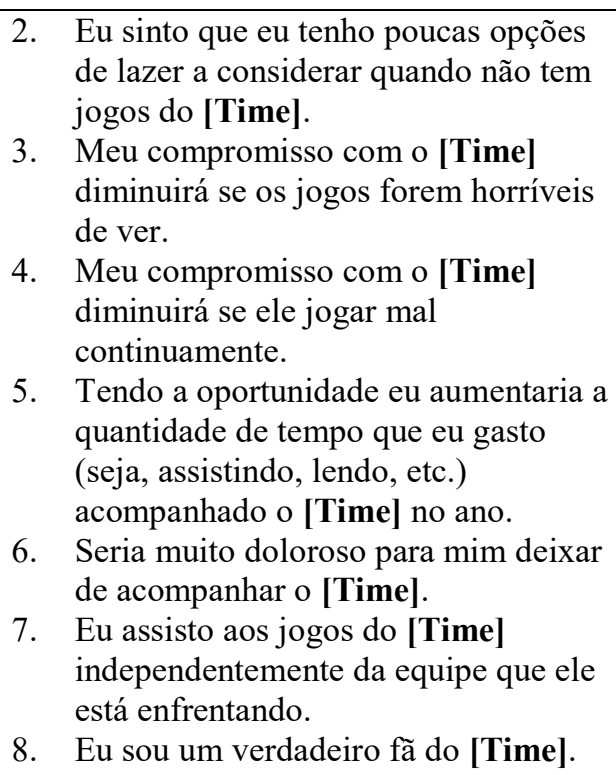 \\
\hline $\begin{array}{l}\text { Lealdade } \\
\text { Conativa }\end{array}$ & $\begin{array}{l}\text { 1. Mesmo que outras opções de lazer } \\
\text { (cinema, teatro, etc.) ofereçam } \\
\text { entradas mais baratas eu prefiro ir aos } \\
\text { jogos do [Time]. } \\
\text { 2. Mesmo que o [Time】 aumentasse os } \\
\text { preços dos ingressos eu continuaria } \\
\text { indo aos jogos. } \\
\text { 3. Eu tenho intenção de ir aos futuros } \\
\text { jogos do [Time]. } \\
\text { 4. Eu tenho intenção de comprar } \\
\text { produtos do [Time】 no futuro. } \\
\text { 5. Eu tenho intenção de comprar a camisa } \\
\text { oficial do [Time】 no futuro. }\end{array}$ & $\begin{array}{l}\text { 1. Mesmo que outras opções de lazer } \\
\text { (cinema, teatro, etc.) ofereçam } \\
\text { entradas mais baratas eu prefiro ir aos } \\
\text { jogos do [Time]. } \\
\text { 2. Mesmo que o [Time] aumentasse os } \\
\text { preços dos ingressos eu continuaria } \\
\text { indo aos jogos. } \\
\text { 3. Eu tenho intenção de ir aos futuros } \\
\text { jogos do [Time]. } \\
\text { 4. Eu tenho intenção de comprar } \\
\text { produtos do [Time] (exemplo: } \\
\text { produtos infantis, bonés, bolas, } \\
\text { chaveiros e etc) no futuro. } \\
\text { Eu tenho intenção de comprar a } \\
\text { camisa oficial do [Time] no futuro. }\end{array}$ \\
\hline $\begin{array}{l}\text { Lealdade } \\
\text { Comportamental }\end{array}$ & $\begin{array}{l}\text { 1. Eu acompanho o [Time] por meio de } \\
\text { programas de televisão, internet ou } \\
\text { rádio todos os dias. } \\
\text { 2. Eu assisto a muitos jogos no ano do } \\
\text { [Timel pela TV. } \\
\text { 3. Eu evito usar as cores dos maiores } \\
\text { rivais do [Time]. } \\
\text { 4. Acompanhar o [Time】 (pela TV ou no } \\
\text { estádio) é uma das minhas principais } \\
\text { atividades de lazer. } \\
\text { 5. Eu assistiria mais jogos do [Time】 se } \\
\text { eu tivesse tempo e dinheiro. }\end{array}$ & $\begin{array}{l}\text { 1. Eu acompanho o [Time] por meio de } \\
\text { programas de televisão todos os dias. } \\
\text { 2. Eu acompanho o [Time] por meio de } \\
\text { programas de internet todos os dias. } \\
\text { 3. Eu acompanho o [Time] por meio de } \\
\text { programas de rádio todos os dias. } \\
\text { 4. Eu assisto a muitos jogos do [Time] } \\
\text { pela TV. } \\
\text { 5. Eu assisto a muitos jogos do [Time] } \\
\text { no estádio. } \\
\text { 6. Eu evito usar as cores dos maiores } \\
\text { rivais do [Time]. } \\
\text { 7. Acompanhar o [Time] pela TV é uma } \\
\text { das minhas principais atividades de } \\
\text { lazer. } \\
\text { 8. Acompanhar o [Time] no estádio é } \\
\text { uma das minhas principais atividades } \\
\text { de lazer. } \\
\text { 9u assistiria mais jogos do [Time] se } \\
\text { eu tivesse tempo. } \\
\text { 10. Eu assistiria mais jogos do [Time] se } \\
\text { eu tivesse dinheiro. }\end{array}$ \\
\hline
\end{tabular}




\begin{tabular}{|c|c|c|}
\hline Percepção & $\begin{array}{l}\text { 1. A marca [Nome do Patrocinado], } \\
\text { ajuda o \Time] a ser bem-sucedido. } \\
\text { 2. A marca [Nome do Patrocinado] } \\
\text { melhora a imagem do [Time]. } \\
\text { 3. A marca [Nome do Patrocinado] do } \\
\text { [nome do time] tem grande reputação. } \\
\text { 4. Os torcedores do [Time] pensam bem } \\
\text { do patrocinador. } \\
\text { 5. O patrocínio é necessário para a } \\
\text { sobrevivência do [Time]. }\end{array}$ & $\begin{array}{l}\text { 1. A marca [Nome do } \\
\text { Patrocinador]ajuda o [Time] a ser } \\
\text { bem-sucedido. } \\
\text { 2. A marca [Nome do Patrocinador] } \\
\text { ajuda a melhorar a imagem do [Time] } \\
\text { 3. A marca [Nome do } \\
\text { Patrocinador]patrocinadora do } \\
\text { [Time] tem grande reputação. } \\
\text { 4. Os torcedores do [Time] pensam bem } \\
\text { da marca [Nome do Patrocinador]. } \\
\text { 5. A marca [Nome do Patrocinador]é } \\
\text { necessária para a sobrevivência do } \\
\text { [Time]. }\end{array}$ \\
\hline Congruência & $\begin{array}{l}\text { 1. Existe uma perfeita conexão entre o } \\
\text { [Time] e a marca [Nome do } \\
\text { Patrocinado]. } \\
\text { 2. O patrocinador e o [Time] } \\
\text { representam coisas parecidas. } \\
\text { 3. A principal razão pela qual o } \\
\text { patrocinador está envolvido com meu } \\
\text { time é porque eles acreditam no meu } \\
\text { time. } \\
\text { 4. É estranho para mim ver este } \\
\text { patrocinador ligado ao meu time (R). } \\
\text { 5. No geral, o [Time] e o patrocinador } \\
\text { formam uma boa combinação. }\end{array}$ & $\begin{array}{l}\text { 1. Existe uma forte conexão entre o } \\
\text { [Time] e a marca [Nome do } \\
\text { Patrocinador]. } \\
\text { 2. A marca [Nome do Patrocinador]e o } \\
\text { [Time] representam os mesmos } \\
\text { valores. } \\
\text { 3. A imagem que eu tenho da marca } \\
\text { [Nome do Patrocinador]e do [Time] } \\
\text { é bastante parecida. } \\
\text { 4. É estranho para mim ver a marca } \\
\text { [Nome do Patrocinador] } \\
\text { patrocinando o [Time]. (R) } \\
\text { 5. No geral, o [Time] e a marca [Nome } \\
\text { do Patrocinador]formam uma forte } \\
\text { combinação. }\end{array}$ \\
\hline Atitude & 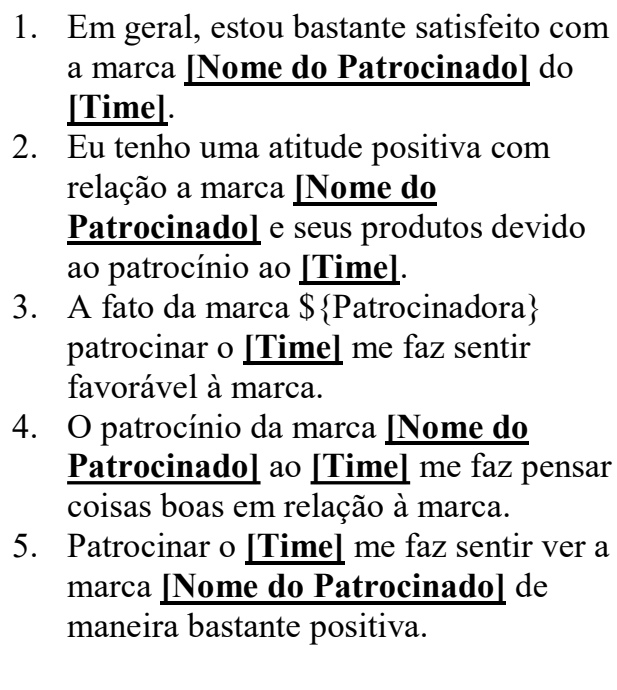 & $\begin{array}{l}\text { 1. Em geral, estou bastante satisfeito } \\
\text { com a marca [Nome do } \\
\text { Patrocinador]. } \\
\text { 2. Eu tenho uma atitude positiva com } \\
\text { relação a marca [Nome do } \\
\text { Patrocinador]e seus produtos devido } \\
\text { ao patrocínio ao [Time]. } \\
\text { 3. A fato da marca [Nome do } \\
\text { Patrocinador]patrocinar o [Time] me } \\
\text { faz sentir favorável à marca. } \\
\text { 4. O patrocínio da marca [Nome do } \\
\text { Patrocinador]ao [Time] me faz } \\
\text { pensar coisas boas em relação à } \\
\text { marca. } \\
\text { 5. Patrocinar o [Time] me faz ver a } \\
\text { marca [Nome do Patrocinador]de } \\
\text { maneira bastante positiva. }\end{array}$ \\
\hline $\begin{array}{ll}\text { Lealdade } & \text { ao } \\
\text { Patrocinador } & \end{array}$ & $\begin{array}{l}\text { 1. Enquanto o patrocínio ao [Time] } \\
\text { continuar eu duvido que eu troque de } \\
\text { produtos. } \\
\text { 2. Eu gosto de usar produtos da marca } \\
\text { [Nome do Patrocinado], } \\
\text { patrocinadora do [Time]. } \\
\text { 3. Eu acho que os produtos da marca } \\
\text { [Nome do Patrocinado], } \\
\text { patrocinadora do [Time] são os } \\
\text { melhores que existem. } \\
\text { 4. Eu tenho um sentimento de lealdade } \\
\text { para com a marca [Nome do }\end{array}$ & $\begin{array}{l}\text { 1. Enquanto a marca [Nome do } \\
\text { Patrocinador] continuar a patrocinar } \\
\text { o [Time] eu não irei trocar de marca. } \\
\text { 2. Eu gosto de usar produtos da marca } \\
\text { [Nome do Patrocinador] } \\
\text { patrocinadora do [Time]. } \\
\text { 3. Eu acho que os produtos da marca } \\
\text { [Nome do Patrocinador] } \\
\text { patrocinadora do [Time] são os } \\
\text { melhores que existem. } \\
\text { 4. Eu tenho um sentimento de lealdade } \\
\text { com a marca [Nome do }\end{array}$ \\
\hline
\end{tabular}




\begin{tabular}{|c|c|c|}
\hline & $\begin{array}{l}\text { Patrocinado], patrocinadora do } \\
\text { 5. } \\
\text { Eumel. } \\
\text { com a marca [Nome do Patrocinado], } \\
\text { patrocinadora do [Time]. }\end{array}$ & $\begin{array}{l}\text { Patrocinador]. } \\
\text { 5. Eu sou um comprador comprometido } \\
\text { com a marca [Nome do } \\
\text { Patrocinador] por ela ser } \\
\text { patrocinadora do [Time]. }\end{array}$ \\
\hline Boca a Boca & 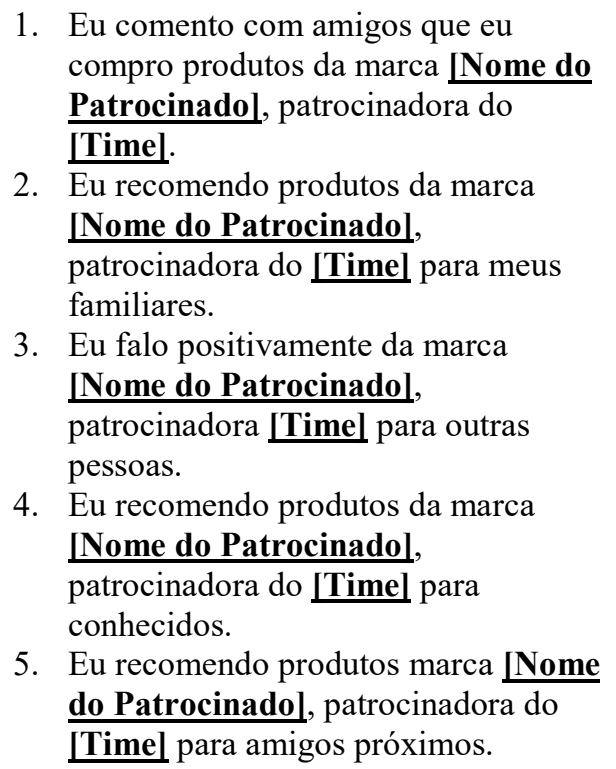 & $\begin{array}{l}\text { 1. Eu comento com amigos que eu } \\
\text { compro produtos da marca [Nome do } \\
\text { Patrocinador] devido a ela ser } \\
\text { patrocinadora do [Time]. } \\
\text { 2. Eu recomendo produtos da marca } \\
\text { [Nome do Patrocinador] para meus } \\
\text { familiares por ela patrocinar o [Time]. } \\
\text { 3. Eu falo positivamente da marca } \\
\text { [Nome do Patrocinador] para outras } \\
\text { pessoas devido a ela ser patrocinadora } \\
\text { do [Time]. } \\
\text { Eu recomendo produtos da marca } \\
\text { [Nome do Patrocinador] para } \\
\text { conhecidos pelo fato dela patrocinar o } \\
\text { [Time]. } \\
\text { Eu recomendo produtos da marca } \\
\text { [Nome do Patrocinador]para amigos } \\
\text { próximos por ela patrocinar o [Time]. }\end{array}$ \\
\hline $\begin{array}{l}\text { Intenção } \\
\text { compra }\end{array}$ & 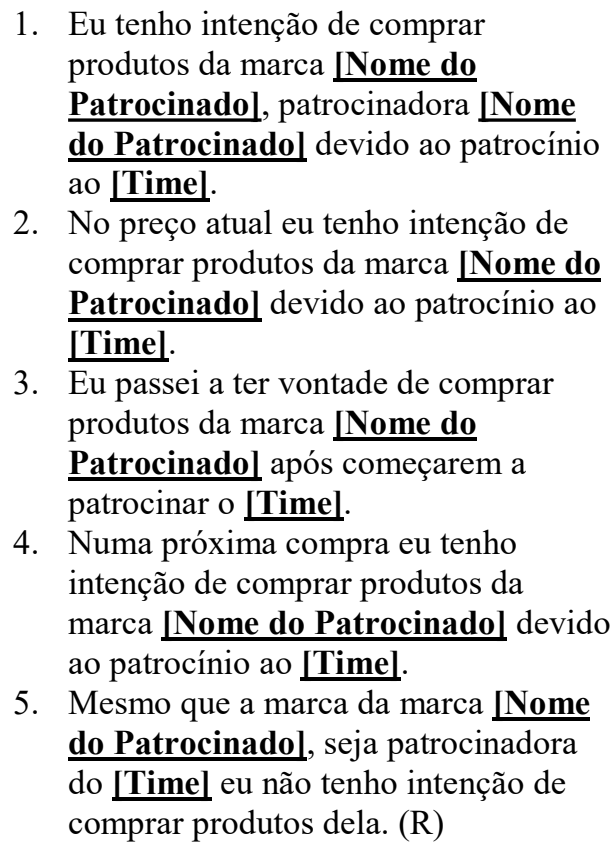 & $\begin{array}{l}\text { 1. Eu tenho intenção de comprar } \\
\text { produtos do [Nome do Patrocinador] } \\
\text { devido ao patrocínio ao [Time]. } \\
\text { No preço atual eu tenho intenção de } \\
\text { comprar produtos da marca [Nome do } \\
\text { Patrocinador]devido ao patrocínio ao } \\
\text { [Time]. } \\
\text { 3. Eu passei a ter vontade de comprar } \\
\text { produtos da marca [Nome do } \\
\text { Patrocinador]após começarem a } \\
\text { patrocinar o [Time]. } \\
\text { Numa próxima compra eu tenho } \\
\text { intenção de comprar produtos da } \\
\text { marca [Nome do } \\
\text { Patrocinador]devido ao patrocínio ao } \\
\text { [Time]. } \\
\text { Mesmo que a marca [Nome do } \\
\text { Patrocinador]seja patrocinadora do } \\
\text { [Time] eu não tenho intenção de } \\
\text { comprar produtos dela. (R) }\end{array}$ \\
\hline $\begin{array}{l}\text { Disposição } \\
\text { pagar mais }\end{array}$ & $\begin{array}{l}\text { 1. Estou disposto a pagar mais por } \\
\text { produtos da marca [Nome do } \\
\text { Patrocinado], patrocinadora do } \\
\text { [Time] em relação a outras marcas. } \\
\text { 2. Eu compraria produtos de } \\
\text { patrocinadores dos times rivais do } \\
\text { [Time] que oferecem preços melhores } \\
\text { que da marca [Nome do } \\
\text { Patrocinado]. (R) } \\
\text { 3. } \begin{array}{l}\text { Eu continuarei comprando produtos da } \\
\text { marca [Nome do Patrocinado], } \\
\text { patrocinadora mesmo que ele aumente }\end{array}\end{array}$ & $\begin{array}{l}\text { 1. Estou disposto a pagar mais por } \\
\text { produtos da marca [Nome do } \\
\text { Patrocinador]em relação a outras } \\
\text { marcas devido ao patrocínio [Time]. } \\
\text { 2. Eu compraria produtos de } \\
\text { patrocinadores dos times rivais do } \\
\text { [Nome do Patrocinador]que } \\
\text { oferecem preços melhores que os da } \\
\text { marca [Nome do Patrocinador]. } \\
\text { 3. Eu comprarei produtos da marca } \\
\text { [Nome do Patrocinador]mesmo que } \\
\text { ela aumente levemente os preços }\end{array}$ \\
\hline
\end{tabular}




\begin{tabular}{|c|c|c|}
\hline & $\begin{array}{l}\text { levemente os preços. } \\
\text { 4. Eu pagaria um preço mais elevado por } \\
\text { produtos da marca [Nome do } \\
\text { Patrocinado] em relação a marcas } \\
\text { patrocinadoras dos times rivais. } \\
\text { 5. Eu pararia de comprar produtos da } \\
\text { marca [Nome do Patrocinado], se os } \\
\text { preços dos produtos dos } \\
\text { patrocinadores dos times rivais do } \\
\text { [Time】diminuírem um pouco. }\end{array}$ & $\begin{array}{l}\text { 4. } \begin{array}{l}\text { Eu pagaria um preço mais elevado por } \\
\text { produtos da marca [Nome do }\end{array} \\
\text { Patrocinador]em relação a marcas de } \\
\text { patrocinadores dos times rivais do } \\
\text { [Time]. } \\
\text { 5. Eu pararia de comprar produtos da } \\
\text { marca [Nome do Patrocinador]se os } \\
\text { preços dos produtos dos } \\
\text { patrocinadores dos times rivais do } \\
\text { [Time] diminuíssem um pouco. }\end{array}$ \\
\hline Uso & $\begin{array}{l}\text { 1. Este patrocínio me faria mais } \\
\text { propensos a usar o produto do } \\
\text { patrocinador. } \\
\text { 2. Este patrocínio me faria mais } \\
\text { propensos a considerar produtos da } \\
\text { empresa a próxima vez que eu } \\
\text { comprar. } \\
\text { 3. Eu seria mais propenso a comprar de o } \\
\text { patrocinador, como resultado deste } \\
\text { patrocínio }\end{array}$ & $\begin{array}{l}\text { 1. O patrocínio ao [Time] me faz mais } \\
\text { propenso a usar produtos da marca } \\
\text { [Nome do Patrocinador]. } \\
\text { 2. O patrocínio ao [Time] me faz mais } \\
\text { propenso a considerar produtos da } \\
\text { marca [Nome do Patrocinador]a } \\
\text { próxima vez que eu for as compras. } \\
\text { 3. O patrocínio ao [Time] me faz mais } \\
\text { propenso a comprar produtos da } \\
\text { marca [Nome do Patrocinador]. }\end{array}$ \\
\hline Favorabilidade & $\begin{array}{l}\text { 1. Este patrocínio me faz sentir mais } \\
\text { favorável com o patrocinador } \\
\text { 2. Este patrocínio melhora minha } \\
\text { percepção do patrocinador } \\
\text { 3. Este patrocínio me faz gostar mais do } \\
\text { patrocinador }\end{array}$ & $\begin{array}{l}\text { 1. O patrocínio ao [Time] me faz sentir } \\
\text { mais favorável com a marca [Nome } \\
\text { do Patrocinador]. } \\
\text { 2. O patrocínio ao [Time] melhora } \\
\text { minha percepção em relação à marca } \\
\text { [Nome do Patrocinador]. } \\
\text { 3. O patrocínio ao [Time] me faz gostar } \\
\text { mais da marca [Nome do } \\
\text { Patrocinador]. }\end{array}$ \\
\hline Interesse & $\begin{array}{l}\text { 1. Este patrocínio me faz mais propenso a } \\
\text { perceber o nome do patrocinador em } \\
\text { outras ocasiões } \\
\text { 2. Este patrocínio me faria mais } \\
\text { propensos a lembrar promoção do } \\
\text { patrocinador. } \\
\text { 3. Este patrocínio me faz mais propenso a } \\
\text { prestar atenção as propagandas do } \\
\text { patrocinador }\end{array}$ & $\begin{array}{l}\text { 1. O patrocínio ao [Time] me faz mais } \\
\text { propenso a perceber a marca [Nome } \\
\text { do Patrocinador]em outras ocasiões. } \\
\text { 2. O patrocínio ao [Time] me faz mais } \\
\text { propenso a perceber (ou notar) } \\
\text { promoções da marca [Nome do } \\
\text { Patrocinador]. } \\
\text { 3. O patrocínio ao [Time] me faz mais } \\
\text { propenso prestar atenção nos anúncios } \\
\text { da marca [Nome do Patrocinador]. } \\
\text { 4. O patrocínio ao [Time] me faz mais } \\
\text { consciente a respeito da marca [Nome } \\
\text { do Patrocinador]. }\end{array}$ \\
\hline
\end{tabular}


APÊNDICE C - Teste de normalidade da amostra pré-teste

\begin{tabular}{|c|c|c|c|c|c|c|c|c|}
\hline \multirow{2}{*}{ Indicadores } & \multirow{2}{*}{ Média } & \multirow{2}{*}{ DP } & \multicolumn{2}{|c|}{ Kolmogorov-Smirnov* } & \multicolumn{2}{|c|}{ Shapiro-Wilk } & \multirow{2}{*}{ Skewness } & \multirow{2}{*}{ Kurtosis } \\
\hline & & & Estatística & Sig & Estatística & Sig & & \\
\hline IDF1 & 6,038 & 1,448 & 0,313 & 0 & 0,705 & 0 & 2,558 & $-1,728$ \\
\hline IDF2 & 5,316 & 1,786 & 0,212 & 0 & 0,834 & 0 & $-0,033$ & $-0,999$ \\
\hline IDF3 & 6,373 & 1,307 & 0,399 & 0 & 0,546 & 0 & 6,585 & $-2,595$ \\
\hline IDF4 & 6,464 & 1,384 & 0,457 & 0 & 0,441 & 0 & 7,528 & $-2,901$ \\
\hline IDF5 & 5,833 & 1,669 & 0,297 & 0 & 0,724 & 0 & 1,49 & $-1,524$ \\
\hline TRP1 & 3,361 & 1,687 & 0,21 & 0 & 0,909 & 0 & $-0,767$ & 0,132 \\
\hline TRP2 & 3,452 & 1,795 & 0,179 & 0 & 0,914 & 0 & $-0,855$ & 0,207 \\
\hline TRP3 & 3,608 & 1,853 & 0,169 & 0 & 0,918 & 0 & $-1,013$ & 0,116 \\
\hline $\mathrm{RCP} 1$ & 4,034 & 1,899 & 0,181 & 0 & 0,916 & 0 & $-0,973$ & $-0,116$ \\
\hline $\mathrm{RCP} 2$ & 4,715 & 1,86 & 0,158 & 0 & 0,896 & 0 & $-0,642$ & $-0,588$ \\
\hline RCP3 & 4,859 & 1,804 & 0,158 & 0 & 0,895 & 0 & $-0,458$ & $-0,648$ \\
\hline $\mathrm{RCP} 4$ & 3,962 & 1,704 & 0,209 & 0 & 0,926 & 0 & $-0,714$ & $-0,144$ \\
\hline SST1 & 5,529 & 1,851 & 0,262 & 0 & 0,771 & 0 & 0,46 & $-1,249$ \\
\hline SST2 & 3,954 & 1,872 & 0,164 & 0 & 0,924 & 0 & $-0,963$ & $-0,045$ \\
\hline SST3 & 3,989 & 2,085 & 0,134 & 0 & 0,901 & 0 & $-1,256$ & 0,038 \\
\hline PERTENC1 & 4,498 & 2,024 & 0,16 & 0 & 0,897 & 0 & $-1,114$ & $-0,376$ \\
\hline PERTENC2 & 4,977 & 1,91 & 0,171 & 0 & 0,872 & 0 & $-0,617$ & $-0,678$ \\
\hline PERTENC3 & 4,532 & 1,746 & 0,148 & 0 & 0,927 & 0 & $-0,662$ & $-0,365$ \\
\hline AVP1 & 6,186 & 1,17 & 0,304 & 0 & 0,714 & 0 & 3,673 & $-1,83$ \\
\hline AVP2 & 6,624 & 0,963 & 0,454 & 0 & 0,447 & 0 & 11,538 & $-3,299$ \\
\hline AVP3 & 5,837 & 1,417 & 0,257 & 0 & 0,779 & 0 & 2,298 & $-1,539$ \\
\hline AVP4 & 5,548 & 1,595 & 0,231 & 0 & 0,825 & 0 & 0,658 & $-1,167$ \\
\hline AVP5 & 5,696 & 1,269 & 0,252 & 0 & 0,835 & 0 & 2,126 & $-1,32$ \\
\hline SAT1 & 3,548 & 2,087 & 0,166 & 0 & 0,888 & 0 & $-1,351$ & 0,178 \\
\hline SAT2 & 4,023 & 1,938 & 0,153 & 0 & 0,923 & 0 & $-1,188$ & $-0,013$ \\
\hline SAT3 & 4,27 & 1,938 & 0,202 & 0 & 0,908 & 0 & $-1,11$ & $-0,332$ \\
\hline SAT4 & 3,711 & 1,85 & 0,148 & 0 & 0,929 & 0 & $-1,09$ & 0,085 \\
\hline SAT5 & 5,548 & 1,75 & 0,237 & 0 & 0,796 & 0 & 0,34 & $-1,151$ \\
\hline SAT6 & 4,563 & 1,723 & 0,186 & 0 & 0,924 & 0 & $-0,792$ & $-0,43$ \\
\hline PAO1 & 4,544 & 1,726 & 0,19 & 0 & 0,918 & 0 & $-0,555$ & $-0,541$ \\
\hline PAO2 & 5,133 & 1,594 & 0,189 & 0 & 0,886 & 0 & 0,243 & $-0,893$ \\
\hline PAO3 & 4,544 & 1,735 & 0,155 & 0 & 0,929 & 0 & $-0,618$ & $-0,424$ \\
\hline IDT1 & 6,004 & 1,512 & 0,292 & 0 & 0,694 & 0 & 2,72 & $-1,813$ \\
\hline IDT2 & 4,643 & 2,006 & 0,153 & 0 & 0,891 & 0 & $-1,025$ & $-0,411$ \\
\hline IDT3 & 6,186 & 1,339 & 0,344 & 0 & 0,662 & 0 & 3,911 & $-1,996$ \\
\hline IDT4 & 5,768 & 1,623 & 0,259 & 0 & 0,756 & 0 & 1,566 & $-1,477$ \\
\hline IDT5 & 6,316 & 1,413 & 0,389 & 0 & 0,547 & 0 & 5,929 & $-2,526$ \\
\hline IDT6 & 6,148 & 1,35 & 0,314 & 0 & 0,673 & 0 & 4,177 & $-2,035$ \\
\hline FAT1 & 4,776 & 2,036 & 0,221 & 0 & 0,861 & 0 & $-0,876$ & $-0,629$ \\
\hline FAT2 & 6,205 & 1,429 & 0,33 & 0 & 0,606 & 0 & 4,969 & $-2,317$ \\
\hline FAT3 & 4,392 & 2,033 & 0,146 & 0 & 0,901 & 0 & $-1,152$ & $-0,266$ \\
\hline FAT4 & 4,992 & 1,952 & 0,187 & 0 & 0,856 & 0 & $-0,613$ & $-0,761$ \\
\hline FAT5 & 4,81 & 2,016 & 0,178 & 0 & 0,872 & 0 & $-1,07$ & $-0,511$ \\
\hline LAT1 & 4,932 & 2,179 & 0,216 & 0 & 0,821 & 0 & $-0,968$ & $-0,706$ \\
\hline LAT2 & 3,304 & 1,992 & 0,184 & 0 & 0,888 & 0 & $-1,004$ & 0,492 \\
\hline LAT3 & 5,289 & 1,872 & 0,23 & 0 & 0,828 & 0 & $-0,753$ & $-0,75$ \\
\hline LAT4 & 5,529 & 1,776 & 0,27 & 0 & 0,791 & 0 & $-0,19$ & $-1,022$ \\
\hline LAT5 & 5,224 & 1,829 & 0,192 & 0 & 0,849 & 0 & $-0,183$ & $-0,894$ \\
\hline LAT6 & 5,973 & 1,646 & 0,323 & 0 & 0,671 & 0 & 2,038 & $-1,736$ \\
\hline LAT7 & 6,289 & 1,436 & 0,381 & 0 & 0,557 & 0 & 5,275 & $-2,425$ \\
\hline LAT8 & 6,243 & 1,306 & 0,35 & 0 & 0,637 & 0 & 4,824 & $-2,18$ \\
\hline LEC1 & 5,038 & 2,013 & 0,2 & 0 & 0,847 & 0 & $-0,792$ & $-0,691$ \\
\hline
\end{tabular}




\begin{tabular}{|c|c|c|c|c|c|c|c|c|}
\hline LEC2 & 3,981 & 2,001 & 0,139 & 0 & 0,916 & 0 & $-1,177$ & $-0,022$ \\
\hline LEC3 & 4,433 & 2,093 & 0,158 & 0 & 0,891 & 0 & $-1,218$ & $-0,326$ \\
\hline LEC4 & 3,821 & 2,059 & 0,126 & 0 & 0,907 & 0 & $-1,236$ & 0,11 \\
\hline LEC5 & 3,224 & 2,039 & 0,174 & 0 & 0,874 & 0 & $-1,028$ & 0,502 \\
\hline LEC6 & 6,293 & 1,206 & 0,341 & 0 & 0,636 & 0 & 6,061 & $-2,332$ \\
\hline LEC7 & 5,916 & 1,511 & 0,28 & 0 & 0,735 & 0 & 2,202 & $-1,621$ \\
\hline LEC8 & 6,232 & 1,324 & 0,331 & 0 & 0,631 & 0 & 5,088 & $-2,263$ \\
\hline LCM1 & 5,228 & 1,909 & 0,203 & 0 & 0,831 & 0 & $-0,316$ & $-0,897$ \\
\hline LCM2 & 5,878 & 1,657 & 0,29 & 0 & 0,705 & 0 & 1,814 & $-1,641$ \\
\hline LCM3 & 3,943 & 2,217 & 0,167 & 0 & 0,879 & 0 & $-1,451$ & 0,005 \\
\hline LCM4 & 6,11 & 1,454 & 0,342 & 0 & 0,663 & 0 & 3,264 & $-1,918$ \\
\hline LCM5 & 4,103 & 2,218 & 0,155 & 0 & 0,878 & 0 & $-1,453$ & $-0,036$ \\
\hline LCM6 & 3,97 & 2,413 & 0,18 & 0 & 0,836 & 0 & $-1,622$ & 0,018 \\
\hline LCM7 & 5,468 & 1,715 & 0,226 & 0 & 0,824 & 0 & 0,284 & $-1,078$ \\
\hline LCM8 & 4,517 & 2,204 & 0,178 & 0 & 0,865 & 0 & $-1,327$ & $-0,314$ \\
\hline LCM9 & 5,951 & 1,56 & 0,3 & 0 & 0,708 & 0 & 1,991 & $-1,651$ \\
\hline LCM10 & 5,867 & 1,666 & 0,318 & 0 & 0,715 & 0 & 1,299 & $-1,493$ \\
\hline PERCEP1 & 5,327 & 1,535 & 0,205 & 0 & 0,867 & 0 & 0,668 & $-1,043$ \\
\hline PERCEP2 & 5,213 & 1,55 & 0,192 & 0 & 0,891 & 0 & 0,103 & $-0,815$ \\
\hline PERCEP3 & 5,916 & 1,267 & 0,237 & 0 & 0,799 & 0 & 2,075 & $-1,399$ \\
\hline PERCEP4 & 5,441 & 1,374 & 0,236 & 0 & 0,871 & 0 & 0,962 & $-1,034$ \\
\hline PERCEP5 & 3,297 & 2,085 & 0,184 & 0 & 0,871 & 0 & $-1,266$ & 0,348 \\
\hline ATT1 & 5,365 & 1,388 & 0,235 & 0 & 0,879 & 0 & 0,657 & $-0,974$ \\
\hline ATT2 & 5,331 & 1,657 & 0,212 & 0 & 0,856 & 0 & 0,213 & $-0,966$ \\
\hline ATT3 & 5,536 & 1,574 & 0,239 & 0 & 0,829 & 0 & 0,798 & $-1,182$ \\
\hline ATT4 & 5,502 & 1,545 & 0,235 & 0 & 0,845 & 0 & 0,501 & $-1,052$ \\
\hline ATT5 & 5,643 & 1,483 & 0,26 & 0 & 0,819 & 0 & 1,163 & $-1,261$ \\
\hline CONG1 & 5,114 & 1,463 & 0,168 & 0 & 0,907 & 0 & 0,122 & $-0,647$ \\
\hline CONG2 & 4,392 & 1,642 & 0,197 & 0 & 0,922 & 0 & $-0,329$ & $-0,37$ \\
\hline CONG3 & 4,293 & 1,832 & 0,136 & 0 & 0,93 & 0 & $-0,856$ & $-0,248$ \\
\hline CONG4 & 5,776 & 1,596 & 0,263 & 0 & 0,762 & 0 & 1,167 & $-1,373$ \\
\hline CONG5 & 5,589 & 1,333 & 0,237 & 0 & 0,864 & 0 & 0,63 & $-0,948$ \\
\hline FAV1 & 5,388 & 1,625 & 0,232 & 0 & 0,844 & 0 & 0,492 & $-1,097$ \\
\hline FAV2 & 5,369 & 1,616 & 0,211 & 0 & 0,86 & 0 & 0,216 & $-0,966$ \\
\hline FAV3 & 5,285 & 1,706 & 0,225 & 0 & 0,855 & 0 & 0,104 & $-0,969$ \\
\hline FAV4 & 5,597 & 1,466 & 0,22 & 0 & 0,844 & 0 & 0,541 & $-1,048$ \\
\hline INTER1 & 5,414 & 1,636 & 0,221 & 0 & 0,843 & 0 & 0,439 & $-1,079$ \\
\hline INTER2 & 5,304 & 1,783 & 0,233 & 0 & 0,831 & 0 & 0,099 & $-1,049$ \\
\hline INTER3 & 5,35 & 1,713 & 0,241 & 0 & 0,829 & 0 & 0,474 & $-1,143$ \\
\hline INTER4 & 5,3 & 1,626 & 0,21 & 0 & 0,867 & 0 & 0,189 & $-0,942$ \\
\hline USO1 & 5,221 & 1,763 & 0,203 & 0 & 0,857 & 0 & $-0,151$ & $-0,896$ \\
\hline USO2 & 5,171 & 1,818 & 0,2 & 0 & 0,854 & 0 & $-0,199$ & $-0,901$ \\
\hline USO3 & 5,167 & 1,775 & 0,177 & 0 & 0,862 & 0 & $-0,15$ & $-0,866$ \\
\hline LPAT1 & 3,388 & 1,987 & 0,191 & 0 & 0,893 & 0 & $-1,021$ & 0,401 \\
\hline LPAT2 & 4,886 & 1,798 & 0,184 & 0 & 0,89 & 0 & $-0,487$ & $-0,684$ \\
\hline LPAT3 & 3,608 & 1,815 & 0,154 & 0 & 0,928 & 0 & $-1,026$ & 0,12 \\
\hline LPAT4 & 3,361 & 1,927 & 0,193 & 0 & 0,902 & 0 & $-0,994$ & 0,396 \\
\hline LPAT5 & 3,357 & 1,944 & 0,209 & 0 & 0,896 & 0 & $-1,015$ & 0,427 \\
\hline BaB1 & 3,43 & 2,066 & 0,208 & 0 & 0,883 & 0 & $-1,201$ & 0,388 \\
\hline BaB2 & 3,719 & 1,997 & 0,174 & 0 & 0,911 & 0 & $-1,238$ & 0,15 \\
\hline BaB3 & 4,015 & 2,038 & 0,161 & 0 & 0,908 & 0 & $-1,277$ & $-0,048$ \\
\hline BaB4 & 3,715 & 2,056 & 0,17 & 0 & 0,903 & 0 & $-1,282$ & 0,177 \\
\hline BaB5 & 3,722 & 2,07 & 0,185 & 0 & 0,898 & 0 & $-1,332$ & 0,181 \\
\hline INT_COMP1 & 4,274 & 1,983 & 0,167 & 0 & 0,908 & 0 & $-1,102$ & $-0,304$ \\
\hline INT_COMP2 & 4,091 & 1,892 & 0,146 & 0 & 0,923 & 0 & $-1,046$ & $-0,196$ \\
\hline INT_COMP3 & 4,057 & 1,966 & 0,14 & 0 & 0,918 & 0 & $-1,152$ & $-0,113$ \\
\hline INT_COMP4 & 3,92 & 1,994 & 0,155 & 0 & 0,915 & 0 & $-1,227$ & 0,001 \\
\hline INT_COMP5 & 5,289 & 1,65 & 0,222 & 0 & 0,868 & 0 & $-0,028$ & $-0,873$ \\
\hline DISP_M1 & 3,095 & 1,949 & 0,192 & 0 & 0,876 & 0 & $-0,824$ & 0,594 \\
\hline DISP_M2 & 3,194 & 1,847 & 0,2 & 0 & 0,883 & 0 & $-0,429$ & 0,74 \\
\hline
\end{tabular}




\begin{tabular}{lllllclrl} 
DISP_M3 & 3,152 & 1,772 & 0,171 & 0 & 0,909 & 0 & $-0,712$ & 0,477 \\
DISP_M4 & 3,042 & 1,889 & 0,173 & 0 & 0,88 & 0 & $-0,637$ & 0,644 \\
DISP_M5 & 4,171 & 1,713 & 0,171 & 0 & 0,935 & 0 & $-0,859$ & 0,084 \\
\hline \hline
\end{tabular}

* incluindo correção Liliefors 


\section{APÊNDICE D - Cargas Cruzado}

Tabela 68: Matriz de carga cruzada - Amostra pré-teste Modelo Ajustado

\begin{tabular}{|c|c|c|c|c|c|c|c|c|c|c|c|c|c|c|c|c|c|c|c|c|c|c|}
\hline Indicador & 1 & 2 & 3 & 4 & 5 & 6 & 7 & 8 & 9 & 10 & 11 & 12 & 13 & 14 & 15 & 16 & 17 & 18 & 19 & 20 & 21 & 22 \\
\hline AVP1 & 0,131 & 0,680 & 0,352 & 0,116 & 0,127 & 0,141 & 0,414 & 0,239 & 0,495 & 0,149 & 0,136 & 0,370 & 0,409 & 0,137 & 0,466 & 0,168 & 0,476 & 0,397 & 0,306 & 0,447 & 0,274 & 0,137 \\
\hline AVP3 & 0,288 & 0,880 & 0,360 & 0,231 & 0,203 & 0,205 & 0,604 & 0,470 & 0,637 & 0,266 & 0,306 & 0,585 & 0,599 & 0,209 & 0,672 & 0,210 & 0,495 & 0,421 & 0,348 & 0,461 & 0,255 & 0,281 \\
\hline AVP4 & 0,310 & 0,836 & 0,387 & 0,251 & 0,233 & 0,272 & 0,515 & 0,397 & 0,509 & 0,276 & 0,342 & 0,485 & 0,569 & 0,233 & 0,525 & 0,230 & 0,525 & 0,431 & 0,410 & 0,458 & 0,311 & 0,308 \\
\hline AVP5 & 0,207 & 0,774 & 0,312 & 0,227 & 0,141 & 0,213 & 0,474 & 0,413 & 0,506 & 0,197 & 0,249 & 0,474 & 0,394 & 0,171 & 0,525 & 0,172 & 0,475 & 0,481 & 0,266 & 0,458 & 0,320 & 0,193 \\
\hline PAO1 & 0,217 & 0,348 & 0,839 & 0,183 & 0,178 & 0,150 & 0,247 & 0,152 & 0,265 & 0,208 & 0,235 & 0,295 & 0,311 & 0,190 & 0,225 & 0,168 & 0,322 & 0,308 & 0,392 & 0,325 & 0,269 & 0,191 \\
\hline $\mathrm{PAO} 2$ & 0,174 & 0,372 & 0,808 & 0,165 & 0,174 & 0,154 & 0,183 & 0,176 & 0,190 & 0,192 & 0,176 & 0,256 & 0,278 & 0,161 & 0,212 & 0,104 & 0,255 & 0,283 & 0,271 & 0,335 & 0,224 & 0,172 \\
\hline PAO3 & 0,219 & 0,375 & 0,826 & 0,211 & 0,207 & 0,213 & 0,286 & 0,148 & 0,259 & 0,253 & 0,201 & 0,323 & 0,293 & 0,229 & 0,257 & 0,178 & 0,406 & 0,364 & 0,377 & 0,436 & 0,367 & 0,193 \\
\hline PERTENC1 & 0,190 & 0,419 & 0,295 & 0,292 & 0,155 & 0,295 & 0,536 & 0,333 & 0,486 & 0,275 & 0,234 & 0,462 & 0,437 & 0,256 & 0,420 & 0,146 & 0,787 & 0,678 & 0,213 & 0,622 & 0,562 & 0,236 \\
\hline PERTENC2 & 0,249 & 0,603 & 0,353 & 0,286 & 0,171 & 0,287 & 0,632 & 0,457 & 0,632 & 0,303 & 0,274 & 0,533 & 0,589 & 0,265 & 0,576 & 0,159 & 0,865 & 0,626 & 0,337 & 0,668 & 0,491 & 0,265 \\
\hline PERTENC3 & 0,253 & 0,487 & 0,348 & 0,304 & 0,225 & 0,294 & 0,488 & 0,320 & 0,472 & 0,319 & 0,274 & 0,418 & 0,445 & 0,311 & 0,422 & 0,177 & 0,811 & 0,574 & 0,370 & 0,580 & 0,451 & 0,273 \\
\hline $\mathrm{RCP} 1$ & 0,224 & 0,449 & 0,394 & 0,266 & 0,135 & 0,251 & 0,491 & 0,404 & 0,522 & 0,284 & 0,245 & 0,435 & 0,429 & 0,271 & 0,466 & 0,127 & 0,634 & 0,841 & 0,225 & 0,697 & 0,635 & 0,222 \\
\hline $\mathrm{RCP} 2$ & 0,183 & 0,509 & 0,272 & 0,235 & 0,153 & 0,256 & 0,502 & 0,371 & 0,495 & 0,242 & 0,209 & 0,435 & 0,433 & 0,206 & 0,447 & 0,118 & 0,664 & 0,879 & 0,260 & 0,646 & 0,537 & 0,216 \\
\hline $\mathrm{RCP} 3$ & 0,211 & 0,485 & 0,290 & 0,272 & 0,157 & 0,259 & 0,511 & 0,386 & 0,490 & 0,261 & 0,225 & 0,431 & 0,402 & 0,236 & 0,443 & 0,116 & 0,660 & 0,879 & 0,251 & 0,652 & 0,570 & 0,214 \\
\hline $\mathrm{RCP} 4$ & 0,214 & 0,385 & 0,360 & 0,282 & 0,152 & 0,321 & 0,414 & 0,283 & 0,427 & 0,285 & 0,252 & 0,381 & 0,387 & 0,282 & 0,338 & 0,145 & 0,616 & $\mathbf{0 , 7 8 3}$ & 0,244 & 0,680 & 0,696 & 0,251 \\
\hline SAT1 & 0,109 & 0,247 & 0,333 & 0,111 & 0,166 & 0,139 & 0,173 & 0,035 & 0,129 & 0,128 & 0,152 & 0,162 & 0,184 & 0,121 & 0,095 & 0,167 & 0,262 & 0,151 & 0,792 & 0,188 & 0,166 & 0,105 \\
\hline SAT2 & 0,146 & 0,328 & 0,374 & 0,125 & 0,169 & 0,151 & 0,226 & 0,133 & 0,205 & 0,158 & 0,208 & 0,226 & 0,267 & 0,140 & 0,178 & 0,189 & 0,281 & 0,227 & 0,836 & 0,220 & 0,190 & 0,157 \\
\hline SAT3 & 0,103 & 0,385 & 0,356 & 0,078 & 0,136 & 0,152 & 0,243 & 0,078 & 0,248 & 0,126 & 0,125 & 0,221 & 0,248 & 0,146 & 0,219 & 0,171 & 0,359 & 0,268 & $\mathbf{0 , 8 8 1}$ & 0,278 & 0,227 & 0,093 \\
\hline SAT4 & 0,114 & 0,342 & 0,355 & 0,151 & 0,115 & 0,225 & 0,205 & 0,099 & 0,185 & 0,179 & 0,126 & 0,213 & 0,248 & 0,171 & 0,177 & 0,106 & 0,337 & 0,265 & 0,825 & 0,271 & 0,251 & 0,109 \\
\hline SAT6 & 0,147 & 0,429 & 0,363 & 0,131 & 0,167 & 0,155 & 0,228 & 0,150 & 0,232 & 0,150 & 0,171 & 0,292 & 0,296 & 0,131 & 0,242 & 0,220 & 0,319 & 0,281 & 0,856 & 0,293 & 0,213 & 0,129 \\
\hline SST1 & 0,328 & 0,584 & 0,390 & 0,286 & 0,248 & 0,270 & 0,615 & 0,392 & 0,664 & 0,329 & 0,342 & 0,551 & 0,569 & 0,258 & 0,590 & 0,233 & 0,707 & 0,663 & 0,286 & $\mathbf{0 , 8 5 3}$ & 0,513 & 0,319 \\
\hline SST2 & 0,198 & 0,406 & 0,402 & 0,247 & 0,155 & 0,259 & 0,381 & 0,238 & 0,378 & 0,230 & 0,215 & 0,366 & 0,344 & 0,227 & 0,313 & 0,159 & 0,595 & 0,688 & 0,283 & $\mathbf{0 , 8 0 8}$ & 0,690 & 0,180 \\
\hline SST3 & 0,191 & 0,371 & 0,296 & 0,249 & 0,178 & 0,276 & 0,419 & 0,213 & 0,351 & 0,247 & 0,168 & 0,335 & 0,312 & 0,248 & 0,308 & 0,143 & 0,536 & 0,584 & 0,155 & 0,785 & 0,628 & 0,181 \\
\hline TRP1 & 0,116 & 0,290 & 0,376 & 0,259 & 0,106 & 0,227 & 0,361 & 0,216 & 0,337 & 0,217 & 0,147 & 0,321 & 0,298 & 0,213 & 0,270 & 0,088 & 0,518 & 0,649 & 0,241 & 0,631 & $\mathbf{0 , 9 0 2}$ & 0,127 \\
\hline
\end{tabular}




\begin{tabular}{|c|c|c|c|c|c|c|c|c|c|c|c|c|c|c|c|c|c|c|c|c|c|c|}
\hline TRP2 & 0,155 & 0,298 & 0,364 & 0,249 & 0,130 & 0,228 & 0,345 & 0,177 & 0,323 & 0,219 & 0,176 & 0,292 & 0,295 & 0,192 & 0,249 & 0,148 & 0,551 & 0,661 & 0,229 & 0,679 & 0,912 & 0,152 \\
\hline TRP3 & 0,145 & 0,383 & 0,219 & 0,256 & 0,113 & 0,236 & 0,379 & 0,262 & 0,389 & 0,232 & 0,188 & 0,354 & 0,288 & 0,226 & 0,352 & 0,145 & 0,567 & 0,630 & 0,207 & 0,666 & 0,878 & 0,161 \\
\hline FAT1 & 0,261 & 0,600 & 0,268 & 0,270 & 0,143 & 0,251 & 0,898 & 0,626 & 0,727 & 0,283 & 0,305 & 0,684 & 0,632 & 0,240 & 0,695 & 0,147 & 0,607 & 0,484 & 0,247 & 0,525 & 0,337 & 0,302 \\
\hline FAT3 & 0,224 & 0,494 & 0,230 & 0,271 & 0,121 & 0,213 & 0,787 & 0,413 & 0,563 & 0,270 & 0,263 & 0,517 & 0,444 & 0,246 & 0,545 & 0,070 & 0,537 & 0,477 & 0,200 & 0,472 & 0,344 & 0,293 \\
\hline FAT4 & 0,337 & 0,543 & 0,250 & 0,328 & 0,192 & 0,295 & 0,835 & 0,460 & 0,696 & 0,360 & 0,367 & 0,546 & 0,582 & 0,289 & 0,602 & 0,172 & 0,599 & 0,530 & 0,236 & 0,537 & 0,376 & 0,350 \\
\hline FAT5 & 0,229 & 0,503 & 0,246 & 0,302 & 0,101 & 0,235 & 0,858 & 0,556 & 0,645 & 0,293 & 0,247 & 0,615 & 0,578 & 0,248 & 0,609 & 0,107 & 0,535 & 0,427 & 0,187 & 0,463 & 0,307 & 0,250 \\
\hline IDF1 & 0,175 & 0,425 & 0,141 & 0,167 & 0,098 & 0,090 & 0,545 & 0,902 & 0,541 & 0,147 & 0,198 & 0,570 & 0,460 & 0,092 & 0,540 & 0,089 & 0,417 & 0,380 & 0,105 & 0,311 & 0,197 & 0,188 \\
\hline IDF2 & 0,169 & 0,395 & 0,219 & 0,171 & 0,088 & 0,114 & 0,615 & 0,853 & 0,489 & 0,134 & 0,204 & 0,577 & 0,444 & 0,110 & 0,483 & 0,073 & 0,413 & 0,383 & 0,144 & 0,342 & 0,256 & 0,170 \\
\hline IDF3 & 0,180 & 0,423 & 0,143 & 0,198 & 0,139 & 0,151 & 0,441 & 0,837 & 0,474 & 0,162 & 0,200 & 0,591 & 0,462 & 0,163 & 0,522 & 0,089 & 0,363 & 0,356 & 0,113 & 0,274 & 0,181 & 0,186 \\
\hline IDF4 & 0,193 & 0,413 & 0,133 & 0,193 & 0,127 & 0,111 & 0,443 & $\mathbf{0 , 8 0 3}$ & 0,482 & 0,162 & 0,206 & 0,512 & 0,401 & 0,128 & 0,520 & 0,154 & 0,354 & 0,314 & 0,095 & 0,283 & 0,181 & 0,203 \\
\hline IDF5 & 0,138 & 0,402 & 0,171 & 0,133 & 0,003 & 0,069 & 0,546 & 0,847 & 0,508 & 0,120 & 0,161 & 0,505 & 0,390 & 0,063 & 0,507 & 0,024 & 0,382 & 0,379 & 0,059 & 0,303 & 0,219 & 0,142 \\
\hline IDT1 & 0,224 & 0,506 & 0,191 & 0,238 & 0,076 & 0,161 & 0,603 & 0,477 & 0,818 & 0,259 & 0,241 & 0,539 & 0,590 & 0,224 & 0,646 & 0,121 & 0,508 & 0,440 & 0,191 & 0,448 & 0,335 & 0,228 \\
\hline IDT2 & 0,300 & 0,508 & 0,348 & 0,301 & 0,194 & 0,249 & 0,667 & 0,431 & 0,789 & 0,316 & 0,324 & 0,554 & 0,559 & 0,285 & 0,537 & 0,190 & 0,592 & 0,565 & 0,273 & 0,576 & 0,443 & 0,327 \\
\hline IDT3 & 0,275 & 0,651 & 0,265 & 0,228 & 0,155 & 0,170 & 0,674 & 0,579 & 0,888 & 0,256 & 0,282 & 0,651 & 0,618 & 0,201 & 0,748 & 0,195 & 0,546 & 0,465 & 0,211 & 0,474 & 0,282 & 0,275 \\
\hline IDT4 & 0,297 & 0,592 & 0,224 & 0,233 & 0,133 & 0,174 & 0,683 & 0,495 & 0,856 & 0,285 & 0,297 & 0,560 & 0,624 & 0,195 & 0,679 & 0,210 & 0,566 & 0,505 & 0,197 & 0,529 & 0,328 & 0,316 \\
\hline IDT6 & 0,247 & 0,590 & 0,194 & 0,207 & 0,145 & 0,170 & 0,666 & 0,494 & 0,866 & 0,242 & 0,270 & 0,577 & 0,605 & 0,168 & 0,701 & 0,153 & 0,525 & 0,434 & 0,147 & 0,459 & 0,257 & 0,259 \\
\hline LAT5 & 0,246 & 0,582 & 0,255 & 0,323 & 0,125 & 0,273 & 0,619 & 0,463 & 0,593 & 0,326 & 0,268 & 0,590 & 0,603 & 0,278 & 75 & 0,163 & 0,561 & 0,480 & 0,228 & 0,461 & 0,355 & 0,245 \\
\hline LAT6 & 0,261 & 0,564 & 0,229 & 0,268 & 0,129 & 0,217 & 0,597 & 0,470 & 0,671 & 0,304 & 0,286 & 0,599 & 0,625 & 0,227 & 0,855 & 0,146 & 0,458 & 0,400 & 0,161 & 0,429 & 0,258 & 0,275 \\
\hline LAT7 & 0,189 & 0,495 & 0,190 & 0,203 & 0,119 & 0,138 & 0,484 & 0,499 & 0,483 & 0,212 & 0,182 & 0,542 & 0,466 & 0,171 & 0,745 & 0,163 & 0,349 & 0,294 & 0,122 & 0,296 & 0,141 & 0,171 \\
\hline LAT8 & 0,289 & 0,597 & 0,239 & 0,251 & 0,153 & 0,197 & 0,645 & 0,541 & 0,771 & 0,295 & 0,305 & 0,611 & 0,632 & 0,229 & 0,867 & 0,189 & 0,493 & 0,433 & 0,201 & 0,461 & 0,274 & 0,291 \\
\hline LCM1 & 0,287 & 0,546 & 0,296 & 0,281 & 0,287 & 0,240 & 0,610 & 0,537 & 0,542 & 0,270 & 0,338 & 0,785 & 0,517 & 0,239 & 0,553 & 0,201 & 0,513 & 0,449 & 0,272 & 0,473 & 0,316 & 0,319 \\
\hline LCM10 & 0,216 & 0,320 & 0,186 & 0,194 & 0,147 & 0,102 & 0,377 & 0,375 & 0,442 & 0,201 & 0,193 & 0,645 & 0,435 & 0,191 & 0,436 & 0,234 & 0,339 & 0,307 & 0,102 & 0,318 & 0,234 & 0,178 \\
\hline LCM2 & 0,314 & 0,465 & 0,276 & 0,284 & 0,243 & 0,261 & 0,585 & 0,541 & 0,540 & 0,296 & 0,325 & $\mathbf{0 , 7 8 9}$ & 0,508 & 0,274 & 0,585 & 0,251 & 0,465 & 0,395 & 0,183 & 0,413 & 0,279 & 0,304 \\
\hline LCM7 & 0,244 & 0,484 & 0,296 & 0,233 & 0,161 & 0,159 & 0,594 & 0,521 & 0,571 & 0,259 & 0,260 & 0,801 & 0,485 & 0,229 & 0,612 & 0,177 & 0,438 & 0,363 & 0,203 & 0,373 & 0,226 & 0,250 \\
\hline LCM9 & 0,207 & 0,383 & 0,243 & 0,248 & 0,146 & 0,181 & 0,359 & 0,384 & 0,403 & 0,238 & 0,206 & 0,641 & 0,495 & 0,220 & 0,447 & 0,159 & 0,333 & 0,294 & 0,215 & 0,337 & 0,267 & 0,212 \\
\hline LEC1 & 0,293 & 0,543 & 0,305 & 0,352 & 0,155 & 0,317 & 0,649 & 0,510 & 0,614 & 0,349 & 0,284 & 0,563 & 0,821 & 0,298 & 0,640 & 0,137 & 0,547 & 0,447 & 0,236 & 0,449 & 0,309 & 0,293 \\
\hline LEC2 & 0,277 & 0,494 & 0,287 & 0,309 & 0,127 & 0,370 & 0,462 & 0,347 & 0,410 & 0,331 & 0,327 & 0,392 & 0,689 & 0,251 & 0,492 & 0,104 & 0,361 & 0,306 & 0,260 & 0,309 & 0,191 & 0,322 \\
\hline LEC6 & 0,271 & 0,474 & 0,239 & 0,233 & 0,187 & 0,177 & 0,470 & 0,414 & 0,524 & 0,257 & 0,279 & 0,578 & $\mathbf{0 , 7 3 1}$ & 0,242 & 0,513 & 0,149 & 0,436 & 0,368 & 0,212 & 0,383 & 0,232 & 0,281 \\
\hline LEC7 & 0,318 & 0,476 & 0,259 & 0,316 & 0,197 & 0,254 & 0,485 & 0,302 & 0,600 & 0,339 & 0,328 & 0,511 & 0,778 & 0,315 & 0,560 & 0,233 & 0,484 & 0,365 & 0,238 & 0,450 & 0,277 & 0,339 \\
\hline
\end{tabular}




\begin{tabular}{|c|c|c|c|c|c|c|c|c|c|c|c|c|c|c|c|c|c|c|c|c|c|c|}
\hline LEC8 & 0,375 & 0,385 & 0,263 & 0,334 & 0,228 & 0,249 & 0,435 & 0,341 & 0,525 & 0,369 & 0,316 & 0,453 & 0,763 & 0,322 & 0,517 & 0,225 & 0,434 & 0,352 & 0,195 & 0,358 & 0,219 & 0,375 \\
\hline ATT2 & 0,889 & 0,257 & 0,202 & 0,598 & 0,666 & 0,465 & 0,257 & 0,129 & 0,278 & 0,642 & 0,714 & 0,301 & 0,365 & 0,637 & 0,257 & 0,636 & 0,212 & 0,199 & 0,150 & 0,261 & 0,113 & 0,718 \\
\hline ATT3 & 0,926 & 0,276 & 0,244 & 0,587 & 0,659 & 0,453 & 0,296 & 0,206 & 0,281 & 0,638 & 0,759 & 0,335 & 0,357 & 0,591 & 0,280 & 0,608 & 0,271 & 0,245 & 0,108 & 0,294 & 0,150 & 0,785 \\
\hline ATT4 & 0,925 & 0,243 & 0,216 & 0,583 & 0,749 & 0,456 & 0,270 & 0,171 & 0,270 & 0,627 & 0,757 & 0,285 & 0,357 & 0,590 & 0,248 & 0,665 & 0,277 & 0,209 & 0,148 & 0,265 & 0,131 & 0,757 \\
\hline ATT5 & 0,928 & 0,328 & 0,250 & 0,608 & 0,706 & 0,458 & 0,322 & 0,230 & 0,341 & 0,645 & 0,778 & 0,357 & 0,400 & 0,601 & 0,338 & 0,677 & 0,271 & 0,248 & 0,138 & 0,290 & 0,172 & 0,764 \\
\hline PERCEP1 & 0,583 & 0,228 & 0,164 & 0,400 & 0,597 & 0,337 & 0,157 & 0,104 & 0,224 & 0,435 & 0,555 & 0,243 & 0,227 & 0,428 & 0,213 & 0,817 & 0,204 & 0,133 & 0,223 & 0,201 & 0,115 & 0,518 \\
\hline PERCEP2 & 0,624 & 0,189 & 0,187 & 0,386 & 0,693 & 0,314 & 0,114 & 0,092 & 0,150 & 0,408 & 0,509 & 0,229 & 0,201 & 0,434 & 0,156 & 0,861 & 0,180 & 0,154 & 0,178 & 0,178 & 0,137 & 0,482 \\
\hline PERCEP3 & 0,495 & 0,226 & 0,128 & 0,299 & 0,607 & 0,234 & 0,131 & 0,076 & 0,176 & 0,315 & 0,396 & 0,240 & 0,157 & 0,382 & 0,171 & 0,802 & 0,134 & 0,102 & 0,146 & 0,196 & 0,111 & 0,378 \\
\hline PERCEP4 & 0,637 & 0,183 & 0,136 & 0,421 & 0,710 & 0,318 & 0,098 & 0,063 & 0,144 & 0,438 & 0,502 & 0,213 & 0,158 & 0,467 & 0,139 & 0,855 & 0,129 & 0,107 & 0,131 & 0,176 & 0,109 & 0,492 \\
\hline CONG1 & 0,672 & 0,238 & 0,196 & 0,424 & 0,877 & 0,331 & 0,179 & 0,142 & 0,214 & 0,446 & 0,582 & 0,274 & 0,237 & 0,494 & 0,165 & 0,683 & 0,222 & 0,182 & 0,147 & 0,270 & 0,147 & 0,567 \\
\hline CONG2 & 0,582 & 0,142 & 0,194 & 0,447 & 0,803 & 0,381 & 0,128 & 0,062 & 0,106 & 0,463 & 0,505 & 0,189 & 0,157 & 0,471 & 0,124 & 0,556 & 0,188 & 0,153 & 0,141 & 0,161 & 0,096 & 0,510 \\
\hline CONG3 & 0,625 & 0,150 & 0,173 & 0,468 & 0,862 & 0,410 & 0,125 & 0,044 & 0,070 & 0,451 & 0,509 & 0,183 & 0,139 & 0,511 & 0,082 & 0,650 & 0,160 & 0,140 & 0,155 & 0,177 & 0,122 & 0,515 \\
\hline $\mathrm{BaB} 1$ & 0,557 & 0,219 & 0,220 & 0,913 & 0,432 & 0,654 & 0,315 & 0,210 & 0,272 & 0,768 & 0,573 & 0,334 & 0,374 & 0,760 & 0,300 & 0,382 & 0,328 & 0,321 & 0,162 & 0,304 & 0,278 & 0,636 \\
\hline BaB2 & 0,607 & 0,280 & 0,231 & 0,952 & 0,490 & 0,720 & 0,324 & 0,198 & 0,261 & 0,767 & 0,608 & 0,326 & 0,393 & 0,814 & 0,306 & 0,430 & 0,339 & 0,285 & 0,130 & 0,317 & 0,271 & 0,667 \\
\hline $\mathrm{BaB} 3$ & 0,657 & 0,251 & 0,216 & 0,939 & 0,525 & 0,696 & 0,332 & 0,185 & 0,265 & 0,823 & 0,647 & 0,310 & 0,390 & 0,808 & 0,318 & 0,470 & 0,334 & 0,278 & 0,121 & 0,291 & 0,249 & 0,701 \\
\hline BaB5 & 0,611 & 0,240 & 0,192 & 0,955 & 0,493 & 0,722 & 0,330 & 0,172 & 0,280 & 0,805 & 0,611 & 0,307 & 0,378 & 0,830 & 0,298 & 0,426 & 0,340 & 0,290 & 0,126 & 0,296 & 0,270 & 0,675 \\
\hline DISP_M1 & 0,484 & 0,258 & 0,195 & 0,730 & 0,396 & 0,921 & 0,319 & 0,128 & 0,253 & 0,744 & 0,497 & 0,276 & 0,348 & 0,703 & 0,266 & 0,338 & 0,348 & 0,323 & 0,172 & 0,326 & 0,272 & 0,556 \\
\hline DISP_M3 & 0,456 & 0,196 & 0,183 & 0,642 & 0,392 & $\mathbf{0 , 8 8 8}$ & 0,206 & 0,092 & 0,145 & 0,661 & 0,456 & 0,184 & 0,294 & 0,639 & 0,195 & 0,336 & 0,278 & 0,246 & 0,188 & 0,253 & 0,201 & 0,513 \\
\hline DISP_M4 & 0,430 & 0,268 & 0,203 & 0,665 & 0,375 & 0,937 & 0,279 & 0,124 & 0,198 & 0,675 & 0,452 & 0,257 & 0,343 & 0,661 & 0,244 & 0,326 & 0,345 & 0,307 & 0,181 & 0,318 & 0,229 & 0,519 \\
\hline INTER1 & 0,787 & 0,293 & 0,250 & 0,598 & 0,604 & 0,474 & 0,300 & 0,175 & 0,294 & 0,647 & 0,948 & 0,318 & 0,371 & 0,590 & 0,297 & 0,559 & 0,277 & 0,239 & 0,159 & 0,272 & 0,154 & 0,829 \\
\hline INTER2 & 0,766 & 0,336 & 0,238 & 0,611 & 0,599 & 0,488 & 0,336 & 0,217 & 0,329 & 0,653 & 0,948 & 0,366 & 0,406 & 0,617 & 0,323 & 0,552 & 0,319 & 0,248 & 0,195 & 0,289 & 0,168 & 0,857 \\
\hline INTER3 & 0,762 & 0,310 & 0,239 & 0,614 & 0,580 & 0,483 & 0,349 & 0,229 & 0,325 & 0,654 & 0,946 & 0,353 & 0,382 & 0,613 & 0,305 & 0,549 & 0,304 & 0,272 & 0,190 & 0,311 & 0,190 & 0,830 \\
\hline INTER4 & 0,777 & 0,314 & 0,209 & 0,624 & 0,619 & 0,485 & 0,339 & 0,240 & 0,319 & 0,652 & 0,928 & 0,347 & 0,359 & 0,619 & 0,302 & 0,574 & 0,297 & 0,276 & 0,159 & 0,289 & 0,205 & 0,817 \\
\hline INT_COMP1 & 0,682 & 0,281 & 0,255 & 0,785 & 0,536 & 0,690 & 0,342 & 0,170 & 0,329 & 0,955 & 0,695 & 0,342 & 0,427 & 0,768 & 0,341 & 0,473 & 0,335 & 0,287 & 0,172 & 0,305 & 0,217 & 0,775 \\
\hline INT_COMP2 & 0,638 & 0,264 & 0,220 & 0,779 & 0,475 & 0,739 & 0,324 & 0,155 & 0,305 & 0,918 & 0,610 & 0,305 & 0,393 & 0,747 & 0,314 & 0,455 & 0,343 & 0,315 & 0,170 & 0,334 & 0,241 & 0,702 \\
\hline INT_COMP3 & 0,653 & 0,244 & 0,267 & 0,782 & 0,496 & 0,696 & 0,335 & 0,166 & 0,277 & 0,938 & 0,646 & 0,334 & 0,400 & 0,787 & 0,335 & 0,454 & 0,315 & 0,276 & 0,139 & 0,292 & 0,227 & 0,715 \\
\hline INT_COMP4 & 0,633 & 0,274 & 0,258 & 0,807 & 0,511 & 0,721 & 0,338 & 0,147 & 0,297 & 0,936 & 0,638 & 0,316 & 0,406 & 0,780 & 0,338 & 0,426 & 0,370 & 0,310 & 0,183 & 0,323 & 0,247 & 0,710 \\
\hline LPAT1 & 0,497 & 0,207 & 0,235 & 0,757 & 0,362 & 0,637 & 0,266 & 0,132 & 0,234 & 0,726 & 0,540 & 0,263 & 0,354 & 0,846 & 0,278 & 0,293 & 0,274 & 0,255 & 0,132 & 0,234 & 0,230 & 0,576 \\
\hline LPAT2 & 0,680 & 0,191 & 0,188 & 0,684 & 0,615 & 0,529 & 0,224 & 0,107 & 0,196 & 0,720 & 0,636 & 0,253 & 0,339 & 0,825 & 0,200 & 0,543 & 0,220 & 0,161 & 0,112 & 0,187 & 0,093 & 0,707 \\
\hline
\end{tabular}




\begin{tabular}{|c|c|c|c|c|c|c|c|c|c|c|c|c|c|c|c|c|c|c|c|c|c|c|}
\hline LPAT3 & 0,537 & 0,192 & 0,201 & 0,671 & 0,534 & 0,595 & 0,241 & 0,085 & 0,192 & 0,637 & 0,504 & 0,286 & 0,263 & 0,862 & 0,199 & 0,490 & 0,276 & 0,239 & 0,202 & 0,261 & 0,185 & 0,550 \\
\hline LPAT4 & 0,559 & 0,187 & 0,156 & 0,750 & 0,529 & 0,707 & 0,250 & 0,084 & 0,190 & 0,688 & 0,523 & 0,240 & 0,296 & 0,865 & 0,220 & 0,470 & 0,301 & 0,254 & 0,166 & 0,268 & 0,205 & 0,575 \\
\hline LPAT5 & 0,560 & 0,246 & 0,242 & 0,814 & 0,446 & 0,675 & 0,317 & 0,153 & 0,281 & 0,763 & 0,577 & 0,313 & 0,368 & 0,907 & 0,312 & 0,419 & 0,372 & 0,352 & 0,124 & 0,334 & 0,293 & 0,629 \\
\hline USO1 & 0,810 & 0,284 & 0,228 & 0,688 & 0,612 & 0,554 & 0,322 & 0,184 & 0,321 & 0,749 & 0,856 & 0,321 & 0,408 & 0,680 & 0,290 & 0,562 & 0,294 & 0,256 & 0,132 & 0,269 & 0,153 & 0,975 \\
\hline USO2 & 0,798 & 0,277 & 0,211 & 0,696 & 0,605 & 0,563 & 0,344 & 0,211 & 0,320 & 0,758 & 0,857 & 0,344 & 0,408 & 0,697 & 0,295 & 0,542 & 0,310 & 0,262 & 0,148 & 0,272 & 0,161 & 0,966 \\
\hline USO3 & 0,795 & 0,301 & 0,218 & 0,693 & 0,625 & 0,570 & 0,367 & 0,215 & 0,335 & 0,750 & 0,863 & 0,355 & 0,416 & 0,682 & 0,310 & 0,543 & 0,311 & 0,259 & 0,133 & 0,297 & 0,164 & 0,973 \\
\hline
\end{tabular}

Nota1: Em destaque $=$ cargas fatoriais

Nota2: As nomenclaturas das colunas foram suprimidas para facilitar a montagem da tabela. Assim: (1) atitude; (2) avaliação pessoal; (3) avaliação dos outros; (4) boca a boca; (5) congruência; (6) disposição a pagar mais; (7) fanatismo; (8) envolvimento com o futebol; (9) identificação time; (10) intenção de compra; (11) interesse; (12) lealdade comportamental; (13) lealdade conativa; (14) lealdade ao patrocinador; (15) lealdade atitudinal; (16) percepção; (17) pertencimento; (18) reconhecimento pessoal; (19) satisfação; (20) sentimento de status; (21) tratamento pessoal; e (22) uso. 
APÊNDICE E - Teste de normalidade da amostra teste

\begin{tabular}{|c|c|c|c|c|c|c|c|c|}
\hline \multirow{2}{*}{ Indicadores } & \multirow{2}{*}{ Média } & \multirow{2}{*}{ DP } & \multicolumn{2}{|c|}{ Kolmogorov-Smirnov* } & \multicolumn{2}{|c|}{ Shapiro-Wilk } & \multirow{2}{*}{ Skewness } & \multirow{2}{*}{ Kurtosis } \\
\hline & & & Estatística & Sig & Estatística & Sig & & \\
\hline IDF1 & 5,534 & 1,763 & 0,245 & 0 & 0,766 & 0 & 0,461 & $-1,198$ \\
\hline IDF2 & 4,67 & 2,008 & 0,208 & 0 & 0,872 & 0 & $-0,937$ & $-0,559$ \\
\hline IDF3 & 5,942 & 1,58 & 0,324 & 0 & 0,669 & 0 & 1,922 & $-1,648$ \\
\hline IDF4 & 5,979 & 1,728 & 0,385 & 0 & 0,596 & 0 & 1,863 & $-1,735$ \\
\hline IDF5 & 5,355 & 1,889 & 0,245 & 0 & 0,788 & 0 & 0,048 & $-1,096$ \\
\hline TRP1 & 3,326 & 1,702 & 0,214 & 0 & 0,906 & 0 & $-0,826$ & 0,197 \\
\hline TRP2 & 3,36 & 1,774 & 0,191 & 0 & 0,914 & 0 & $-0,904$ & 0,215 \\
\hline TRP3 & 3,461 & 1,841 & 0,187 & 0 & 0,912 & 0 & $-1,025$ & 0,18 \\
\hline $\mathrm{RCP} 1$ & 3,922 & 1,86 & 0,189 & 0 & 0,919 & 0 & $-0,947$ & $-0,088$ \\
\hline $\mathrm{RCP} 2$ & 4,358 & 1,862 & 0,167 & 0 & 0,916 & 0 & $-0,857$ & $-0,349$ \\
\hline $\mathrm{RCP} 3$ & 4,512 & 1,826 & 0,176 & 0 & 0,908 & 0 & $-0,637$ & $-0,464$ \\
\hline $\mathrm{RCP} 4$ & 3,807 & 1,725 & 0,221 & 0 & 0,921 & 0 & $-0,761$ & $-0,075$ \\
\hline SST1 & 5,149 & 1,964 & 0,226 & 0 & 0,823 & 0 & $-0,432$ & $-0,885$ \\
\hline SST2 & 3,682 & 1,863 & 0,188 & 0 & 0,917 & 0 & $-0,996$ & 0,062 \\
\hline SST3 & 3,623 & 2,041 & 0,152 & 0 & 0,903 & 0 & $-1,166$ & 0,223 \\
\hline PERTENC1 & 4,126 & 2,04 & 0,139 & 0 & 0,906 & 0 & $-1,214$ & $-0,182$ \\
\hline PERTENC2 & 4,55 & 2,017 & 0,162 & 0 & 0,885 & 0 & $-1,018$ & $-0,45$ \\
\hline PERTENC3 & 4,236 & 1,835 & 0,148 & 0 & 0,923 & 0 & $-0,881$ & $-0,31$ \\
\hline AVP1 & 6,018 & 1,339 & 0,293 & 0 & 0,721 & 0 & 2,705 & $-1,654$ \\
\hline AVP3 & 5,494 & 1,537 & 0,238 & 0 & 0,837 & 0 & 0,543 & $-1,052$ \\
\hline AVP4 & 5,203 & 1,719 & 0,209 & 0 & 0,859 & 0 & $-0,061$ & $-0,864$ \\
\hline AVP5 & 5,465 & 1,428 & 0,229 & 0 & 0,856 & 0 & 1,165 & $-1,143$ \\
\hline SAT1 & 3,613 & 1,985 & 0,159 & 0 & 0,906 & 0 & $-1,241$ & 0,132 \\
\hline SAT2 & 4,079 & 1,897 & 0,162 & 0 & 0,926 & 0 & $-1,12$ & $-0,139$ \\
\hline SAT3 & 4,145 & 1,974 & 0,194 & 0 & 0,907 & 0 & $-1,202$ & $-0,24$ \\
\hline SAT4 & 3,859 & 1,844 & 0,174 & 0 & 0,928 & 0 & $-1,145$ & $-0,051$ \\
\hline SAT6 & 4,455 & 1,749 & 0,192 & 0 & 0,92 & 0 & $-0,783$ & $-0,441$ \\
\hline PAO1 & 4,611 & 1,607 & 0,185 & 0 & 0,924 & 0 & $-0,417$ & $-0,525$ \\
\hline PAO2 & 5,1 & 1,55 & 0,19 & 0 & 0,89 & 0 & 0,253 & $-0,851$ \\
\hline PAO3 & 4,315 & 1,728 & 0,147 & 0 & 0,936 & 0 & $-0,757$ & $-0,295$ \\
\hline IDT1 & 5,542 & 1,87 & 0,26 & 0 & 0,736 & 0 & 0,318 & $-1,222$ \\
\hline IDT2 & 4,312 & 2,051 & 0,145 & 0 & 0,9 & 0 & $-1,201$ & $-0,24$ \\
\hline IDT3 & 5,709 & 1,729 & 0,294 & 0 & 0,724 & 0 & 0,863 & $-1,354$ \\
\hline IDT4 & 5,306 & 1,954 & 0,233 & 0 & 0,789 & 0 & $-0,245$ & $-0,998$ \\
\hline IDT6 & 5,84 & 1,555 & 0,27 & 0 & 0,724 & 0 & 1,776 & $-1,541$ \\
\hline FAT1 & 4,223 & 2,13 & 0,182 & 0 & 0,885 & 0 & $-1,339$ & $-0,216$ \\
\hline FAT3 & 3,916 & 2,064 & 0,154 & 0 & 0,906 & 0 & $-1,295$ & $-0,008$ \\
\hline FAT4 & 4,414 & 2,113 & 0,171 & 0 & 0,881 & 0 & $-1,215$ & $-0,345$ \\
\hline FAT5 & 4,279 & 2,124 & 0,156 & 0 & 0,89 & 0 & $-1,342$ & $-0,207$ \\
\hline LAT5 & 4,843 & 1,919 & 0,174 & 0 & 0,877 & 0 & $-0,744$ & $-0,61$ \\
\hline LAT6 & 5,522 & 1,893 & 0,279 & 0 & 0,745 & 0 & $-0,002$ & $-1,127$ \\
\hline LAT7 & 6,03 & 1,58 & 0,334 & 0 & 0,633 & 0 & 2,826 & $-1,896$ \\
\hline LAT8 & 5,922 & 1,537 & 0,304 & 0 & 0,704 & 0 & 1,718 & $-1,567$ \\
\hline LEC1 & 4,617 & 2,147 & 0,183 & 0 & 0,861 & 0 & $-1,24$ & $-0,393$ \\
\hline LEC2 & 3,894 & 2,057 & 0,146 & 0 & 0,91 & 0 & $-1,28$ & 0,014 \\
\hline LEC6 & 5,817 & 1,521 & 0,27 & 0 & 0,747 & 0 & 1,514 & $-1,434$ \\
\hline LEC7 & 5,437 & 1,78 & 0,23 & 0 & 0,789 & 0 & 0,368 & $-1,14$ \\
\hline LEC8 & 5,766 & 1,711 & 0,274 & 0 & 0,706 & 0 & 1,394 & $-1,523$ \\
\hline LCM1 & 4,727 & 2,018 & 0,188 & 0 & 0,869 & 0 & $-0,931$ & $-0,551$ \\
\hline LCM2 & 5,376 & 1,965 & 0,241 & 0 & 0,771 & 0 & $-0,163$ & $-1,06$ \\
\hline
\end{tabular}




\begin{tabular}{|c|c|c|c|c|c|c|c|c|}
\hline LCM7 & 5,021 & 1,979 & 0,195 & 0 & 0,841 & 0 & $-0,619$ & $-0,783$ \\
\hline LCM9 & 5,519 & 1,774 & 0,244 & 0 & 0,783 & 0 & 0,331 & $-1,154$ \\
\hline LCM10 & 5,121 & 2,11 & 0,237 & 0 & 0,8 & 0 & $-0,787$ & $-0,793$ \\
\hline PERCEP1 & 4,825 & 1,75 & 0,188 & 0 & 0,897 & 0 & $-0,332$ & $-0,708$ \\
\hline PERCEP2 & 4,611 & 1,729 & 0,143 & 0 & 0,922 & 0 & $-0,591$ & $-0,465$ \\
\hline PERCEP3 & 5,436 & 1,563 & 0,217 & 0 & 0,847 & 0 & 0,833 & $-1,113$ \\
\hline PERCEP4 & 4,968 & 1,554 & 0,183 & 0 & 0,899 & 0 & 0,171 & $-0,753$ \\
\hline Att2 & 4,871 & 1,823 & 0,176 & 0 & 0,891 & 0 & $-0,528$ & $-0,662$ \\
\hline Att3 & 5,085 & 1,76 & 0,191 & 0 & 0,873 & 0 & $-0,121$ & $-0,849$ \\
\hline Att4 & 5,033 & 1,741 & 0,195 & 0 & 0,877 & 0 & $-0,091$ & $-0,845$ \\
\hline Att5 & 5,144 & 1,744 & 0,207 & 0 & 0,868 & 0 & $-0,073$ & $-0,872$ \\
\hline Cong1 & 4,422 & 1,764 & 0,158 & 0 & 0,925 & 0 & $-0,738$ & $-0,378$ \\
\hline Cong2 & 3,959 & 1,683 & 0,22 & 0 & 0,921 & 0 & $-0,631$ & $-0,217$ \\
\hline Cong3 & 3,796 & 1,866 & 0,141 & 0 & 0,928 & 0 & $-1,055$ & 0,013 \\
\hline Cong5 & 4,925 & 1,688 & 0,179 & 0 & 0,898 & 0 & $-0,228$ & $-0,703$ \\
\hline INTER1 & 5,046 & 1,763 & 0,192 & 0 & 0,872 & 0 & $-0,092$ & $-0,88$ \\
\hline INTER2 & 4,887 & 1,836 & 0,181 & 0 & 0,886 & 0 & $-0,504$ & $-0,707$ \\
\hline INTER3 & 4,946 & 1,814 & 0,191 & 0 & 0,875 & 0 & $-0,289$ & $-0,817$ \\
\hline INTER4 & 4,881 & 1,769 & 0,177 & 0 & 0,89 & 0 & $-0,332$ & $-0,744$ \\
\hline Uso1 & 4,688 & 1,896 & 0,161 & 0 & 0,898 & 0 & $-0,759$ & $-0,552$ \\
\hline Uso2 & 4,721 & 1,919 & 0,167 & 0 & 0,892 & 0 & $-0,755$ & $-0,582$ \\
\hline Uso3 & 4,679 & 1,905 & 0,162 & 0 & 0,895 & 0 & $-0,747$ & $-0,562$ \\
\hline LPAT1 & 3,57 & 2,082 & 0,161 & 0 & 0,913 & 0 & $-1,227$ & 0,118 \\
\hline LPAT2 & 4,354 & 2,066 & 0,154 & 0 & 0,903 & 0 & $-0,97$ & $-0,475$ \\
\hline LPAT3 & 3,315 & 1,854 & 0,17 & 0 & 0,925 & 0 & $-0,967$ & 0,175 \\
\hline LPAT4 & 3,239 & 1,978 & 0,183 & 0 & 0,909 & 0 & $-1,04$ & 0,333 \\
\hline LPAT5 & 3,372 & 2,035 & 0,183 & 0 & 0,911 & 0 & $-1,133$ & 0,281 \\
\hline $\mathrm{BaB} 1$ & 3,27 & 2,053 & 0,194 & 0 & 0,897 & 0 & $-1,173$ & 0,328 \\
\hline $\mathrm{BaB} 2$ & 3,479 & 2,03 & 0,164 & 0 & 0,917 & 0 & $-1,161$ & 0,173 \\
\hline $\mathrm{BaB} 3$ & 3,861 & 2,058 & 0,191 & 0 & 0,919 & 0 & $-1,233$ & 0,022 \\
\hline BaB5 & 3,48 & 2,059 & 0,178 & 0 & 0,911 & 0 & $-1,214$ & 0,188 \\
\hline INT_COMP1 & 3,863 & 2,106 & 0,149 & 0 & 0,92 & 0 & $-1,197$ & $-0,182$ \\
\hline INT_COMP2 & 3,624 & 2,008 & 0,167 & 0 & 0,929 & 0 & $-1,109$ & $-0,059$ \\
\hline INT_COMP3 & 3,725 & 2,089 & 0,157 & 0 & 0,924 & 0 & $-1,193$ & $-0,052$ \\
\hline INT_COMP4 & 3,578 & 2,065 & 0,165 & 0 & 0,926 & 0 & $-1,201$ & 0,042 \\
\hline DispM1 & 2,893 & 1,934 & 0,198 & 0 & 0,897 & 0 & $-0,721$ & 0,58 \\
\hline DispM3 & 2,953 & 1,823 & 0,171 & 0 & 0,922 & 0 & $-0,783$ & 0,411 \\
\hline DispM4 & 2,838 & 1,902 & 0,189 & 0 & 0,897 & 0 & $-0,701$ & 0,579 \\
\hline
\end{tabular}

* incluindo correção Liliefors 